\title{
Die Bedeutung des ÖPNV für die nachhaltige Sicherung der Mobilität in der Region Frankfurt Rhein-Main
}

\author{
unter besonderer Berücksichtigung \\ der Einführung eines Electronic Ticketing-Systems im ÖPNV
}

\author{
Dissertation \\ zur Erlangung des Doktorgrades \\ der Mathematisch-Naturwissenschaftlichen Fakultäten \\ der Georg-August-Universität Göttingen
}

vorgelegt von

Christian Ordon

aus Großburgwedel (Landkreis Hannover)

Göttingen 04.06.2007 
D 7

Referent

Koreferent

Tag der mündlichen Prüfung: $\quad$ 03.07.2007
Prof. Dr. Werner Kreisel

Prof. Dr. Karl-Heinz Pörtge 
Für meine Familie 


\section{Vorwort}

Feinstaubbelastung und $\mathrm{CO}_{2}$-Ausstoß, Pkw-Maut und Klimapass, Ölpreis und Pendlerpauschale sind nur einige aktuelle Schlagworte, die uns täglich daran erinnern, dass unsere individuelle Mobilität - und damit unser Alltag - von zahlreichen verkehrsbezogenen Faktoren abhängig ist. Unsere tägliche Mobilität ist aber nicht nur Ausdruck unseres Lebensstils, sondern beeinflusst auch die wirtschaftliche Entwicklung und den Wohlstand der Region, in der wir leben. Die von uns umgesetzte Mobilität - in Form von Verkehr kann auch negative Auswirkungen haben; dann nämlich, wenn von ihr schädigende Einflüsse auf Menschen und Umwelt ausgehen. Die Folge kann dann der Verlust von Lebensqualität und Wirtschaftskraft sein. Von daher bedarf es gleichzeitig der Sicherung einer uneingeschränkten Mobilität und des Schutzes der Umwelt. Der Wissenschaftstheologe Dr. Daecke sieht hierin gar eine "ethische“ Herausforderung, wobei nicht die Mobilität das „Böse“ bzw. die "Sünde“ ist, sondern deren Missbrauch - insbesondere in Form von zu viel Verkehr. Daecke hinterfragt daher, ob „wir wirklich so mobil sein, so viel herumfahren und herumreisen" müssen. ${ }^{1} \mathrm{Zu}$ hinterfragen ist aber auch, ob wir gerade in der Art und Weise mobil sein müssen, in der wir es heute sind: also vor allem mit dem Pkw. Welchen Beitrag können hier die anderen Verkehrsmittel liefern?

In diesem Kontext analysiert die vorliegende Arbeit die Bedeutung, die der ÖPNV für die Sicherung der Mobilität in der Region Frankfurt Rhein-Main hat und beschreibt Möglichkeiten, wie Effizienzpotenziale entfaltet werden können, damit der ÖPNV dieser Bedeutung dauerhaft gerecht werden kann.

An dieser Stelle danke ich allen, die mich bei der Erarbeitung der Dissertation unterstützt haben. Großer Dank gebührt hier insbesondere Herrn Prof. Dr. Werner Kreisel, der mich in der Idee zur Arbeit bestärkte und mir mit seinem Wissen stets zur Seite stand. Ebenfalls danke ich Herrn Prof. Dr. Karl-Heinz Pörtge für die Erstellung des Zweitgutachtens.

Darüber hinaus möchte ich mich bei allen Freunden und Kollegen bedanken, die sich unermüdlich mit der Durchsicht des Maunskripts befasst haben. Schließlich danke ich vor allem meiner Frau für die grenzenlose Geduld während der Erstellung der Dissertation und den fortwährenden Zuspruch.

\footnotetext{
${ }^{1}$ Henning 1996, S.24ff
} 


\section{INHALTSÜBERSICHT}

\section{Teil A: Fachliche Und Thematische AbgRenZung}

1 DIE VERKEHRSPLANUNG AN DER SCHNITTSTELLE ZWISCHEN VERKEHRSGEOGRAPHIE UND VERKEHRSWISSENSCHAFTEN ….......................... 1

2 DER ÖPNV VOR - NEUEN - HERAUSFORDERUNGEN ………………………………..... 5

\section{TEIL B: NACHHALTige MOBILITÄTSSICHERUNG} IN DER REGION FRANKFURT RHEIN-MAIN

3 NACHHALTIGE MOBILITÄT ALS STANDORTFAKTOR ............................................... 9

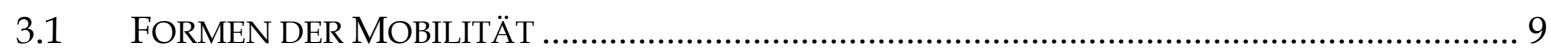

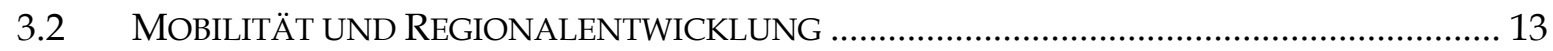

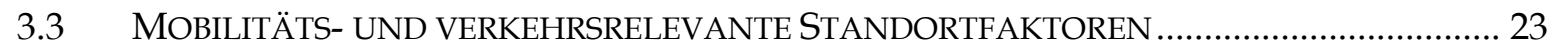

3.4 BEDEUTUNG DER LEISTUNGSFÄHIGKEIT DER VERKEHRSINFRASTRUKTUR ....................... 32

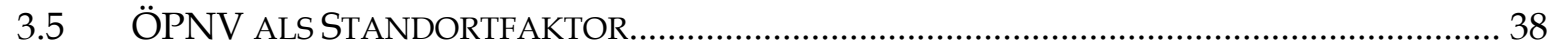

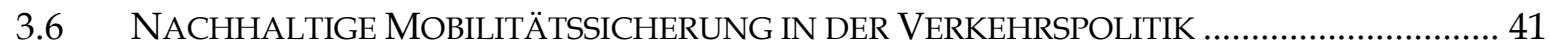

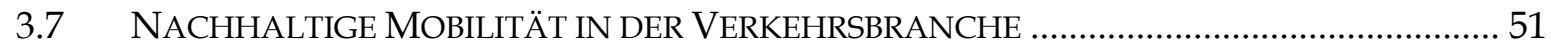

3.8 VERÄNDERTE ANFORDERUNGEN AN DIE MOBILITÄTSPLANUNG ..................................... 53

3.9 ZUNEHMENDE BEDEUTUNG REGIONALER KOOPERATIONSNETZWERKE.......................... 67

4 ANALYSE DER MOBILITÄT IN DER REGION FRANKFURT RHEIN-MAIN ........ 70

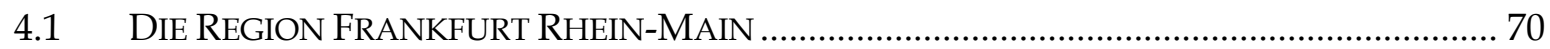

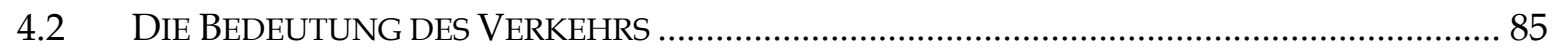

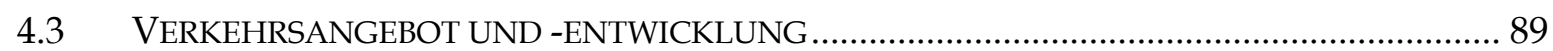

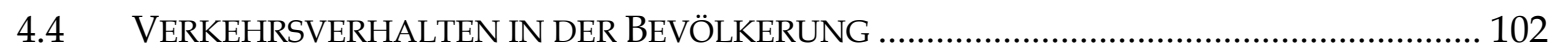

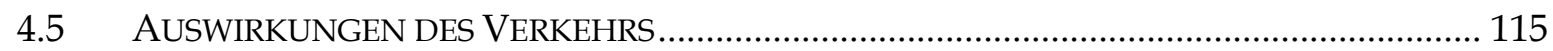

4.6 GEGENWÄRTIGE ANSÄTZE ZUR SICHERUNG DER MOBILITÄT.......................................... 134

4.7 KONSEQUENZEN: ÖPNV STÄRKEN, MOBILITÄT SICHERN .............................................. 168

\section{TEIL C: ERSChLIEßUNG VON EFFIZIENZPOTENZIALEN IM ÖPNV}

5 RAHMENBEDINGUNGEN FÜR VERÄNDERUNGSPROZESSE IM ÖPNV ........... 190

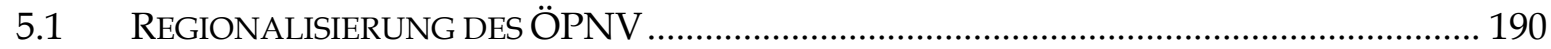

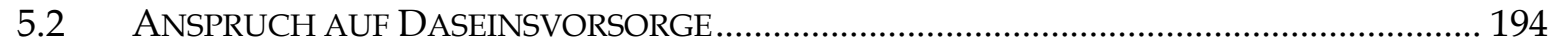

5.3 DER „HESSISCHE WEG“ DER VERGABE VON ÖPNV-LEISTUNG...................................... 199

5.4 ORGANISATION DES ÖPNV IN DER REGION FRANKFURT RHEIN-MAIN....................... 216

5.5 MARKTPOSITIONIERUNG DER ÖPNV-UNTERNEHMEN ALS

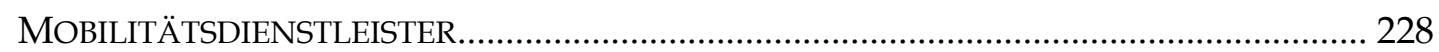

6 MÖGLICHKEITEN DER EFFIZIENZSTEIGERUNG IM ÖPNV .................................. 232

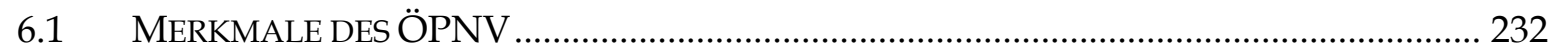

6.2 EFFIZIENZSTEIGERUNG IM ÖPNV ZWISCHEN GEWINNMAXIMIERUNG UND

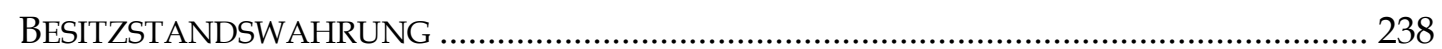

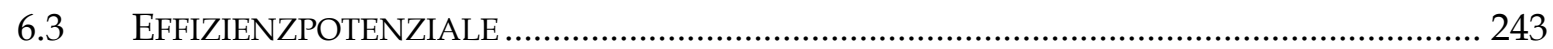

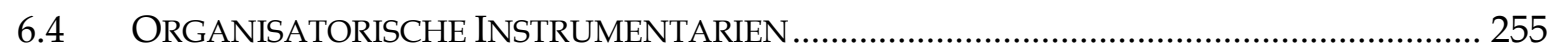

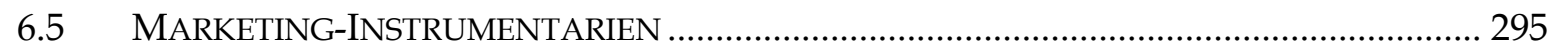


6.6 TECHNISCHE INSTRUMENTARIEN

6.7 FAZIT: SCHAFFUNG EINER TECHNISCH-ORGANISATORISCHEN PLATTFORM FÜR DIE VERMARKTUNG VON MOBILITÄTSDIENSTLEISTUNGEN ………...................................... 331

7 ERSCHLIEßUNG DER EFFIZIENZPOTENZIALE ÜBER E-TICKETING ................... 335

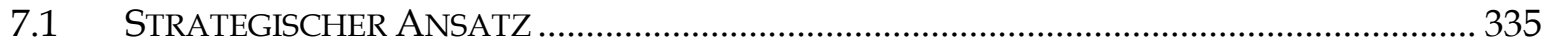

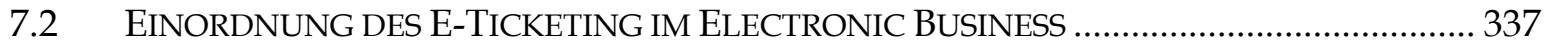

7.3 ENTWICKLUNG UND STANDARDISIERUNG VON E-TICKETING-SYSTEMEN.................... 341

7.4 VORAUSSETZUNGEN FÜR EINE ZIELGERICHTETE UMSETZUNG DES E-TICKETING ......... 356

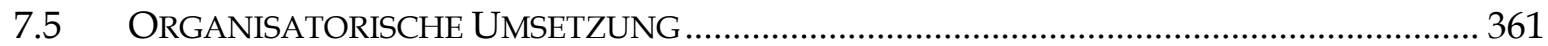

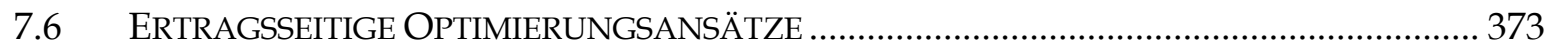

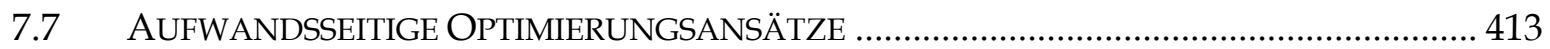

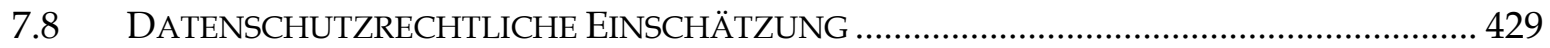

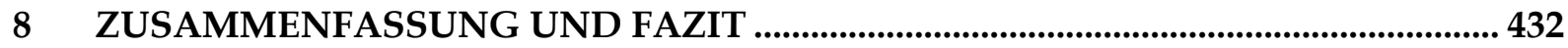

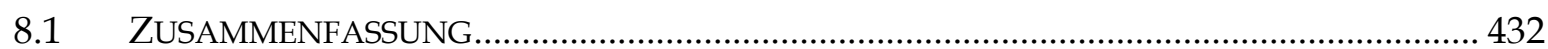

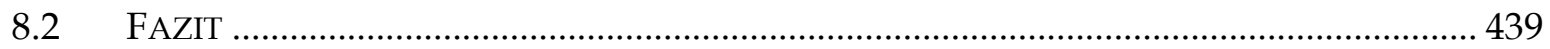

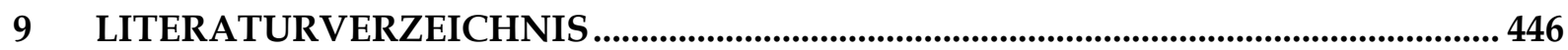




\section{INHALTSVERZEICHNIS}

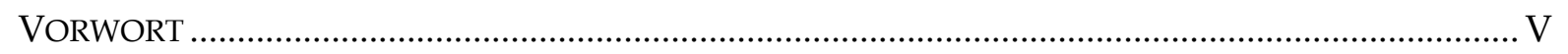

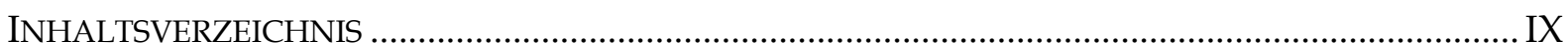

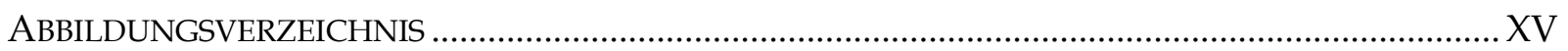

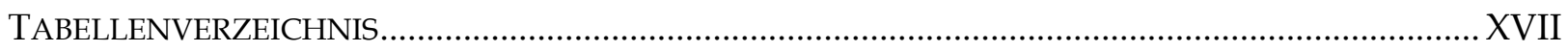

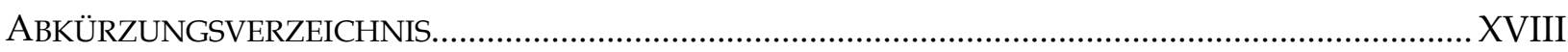

\section{Teil A: Fachliche und Thematische Abgrenzung}

1 DIE VERKEHRSPLANUNG AN DER SCHNITTSTELLE ZWISCHEN VERKEHRSGEOGRAPHIE UND VERKEHRSWISSENSCHAFTEN ......................1

2 DER ÖPNV VOR - NEUEN - HERAUSFORDERUNGEN ..........................................5

\section{Teil B: NaChHAltige MobilitätssicherUng} IN DER REGION FRANKFURT RHEIN-MAIN

3 NACHHALTIGE MOBILITÄT ALS STANDORTFAKTOR......................................9

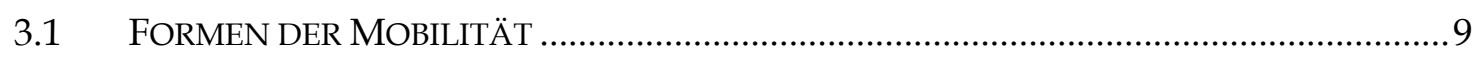

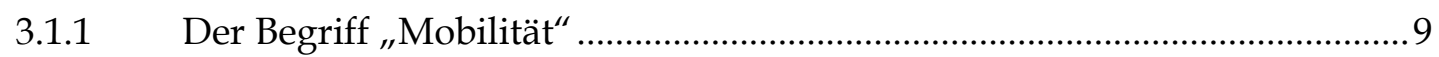

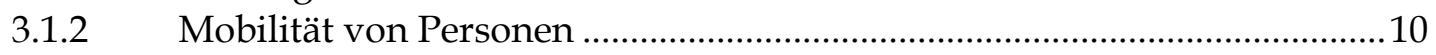

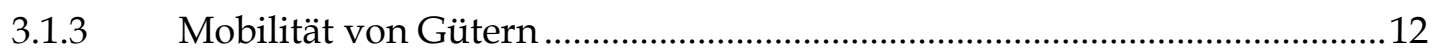

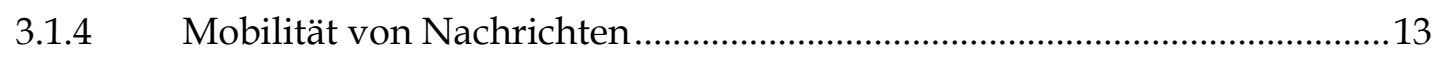

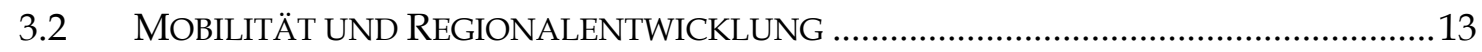

3.2.1 Die Abhängigkeit von Verkehrs- und Regionalentwicklung .....................13

3.2.2 Mobilitätswiderstände..........................................................................16

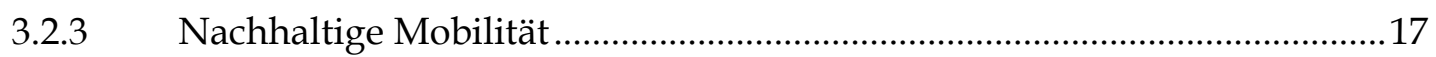

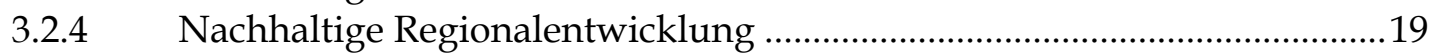

3.3 MOBILITÄTS- UND VERKEHRSRELEVANTE STANDORTFAKTOREN ................................2

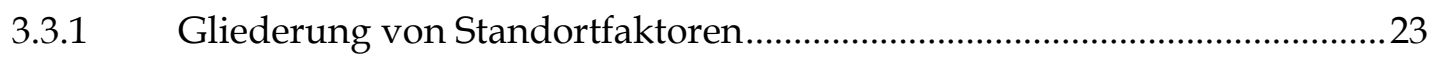

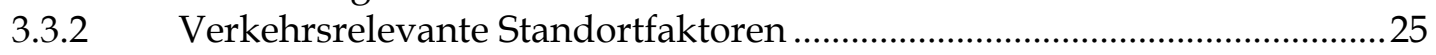

3.3.3 Einfluss von IuK-Technologien auf den Verkehr ...........................................2

3.4 BEDEUTUNG DER LEISTUNGSFÄHIGKEIT DER VERKEHRSINFRASTRUKTUR ..................32

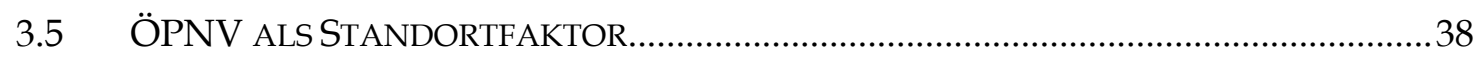

3.6 NACHHALTIGE MOBILITÄTSSICHERUNG IN DER VERKEHRSPOLITIK .........................4

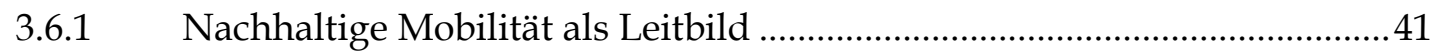

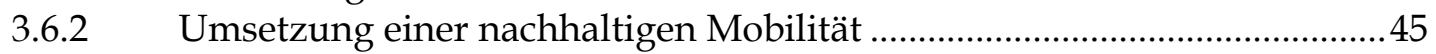

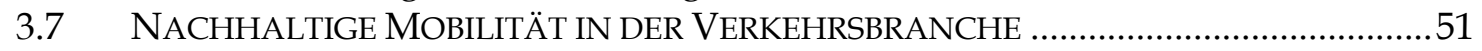

3.8 VERÄNDERTE ANFORDERUNGEN AN DIE MOBILITÄTSPLANUNG ..............................53

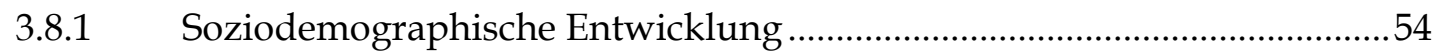

3.8.2 Flexibilisierung und Individualisierung ..................................................59

3.8.3 Konsequenzen für die Mobilitätsplanung ..................................................63

3.9 ZUNEHMENDE BEDEUTUNG REGIONALER KOOPERATIONSNETZWERKE....................67 


\section{ANALYSE DER MOBILITÄT IN DER REGION}

FRANKFURT RHEIN-MAIN .70

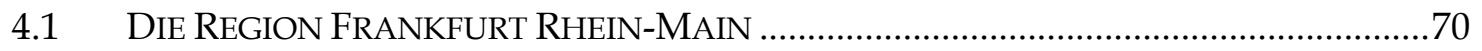

4.1.1 Naturräumliche Einordnung des Rhein-Main-Gebietes.............................70

4.1.2 Die Stadt Frankfurt am Main als Kern der Region ......................................70

4.1.3 Abgrenzung der Region Frankfurt Rhein-Main ...........................................73

4.1.3.1 Metropolregion Frankfurt Rhein-Main...................................................73

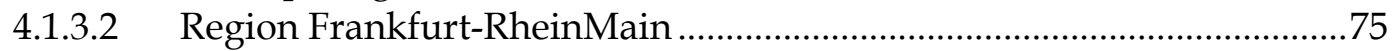

4.1.3.3 Ballungsraum Frankfurt/Rhein-Main ........................................................76

4.1.4 Die Region im nationalen und internationalen Wettbewerb .......................77

4.1.4.1 Die Region im nationalen Vergleich.........................................................77

4.1.4.2 Die Bedeutung der Region auf internationaler Ebene ..............................80

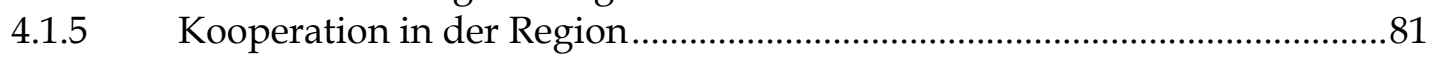

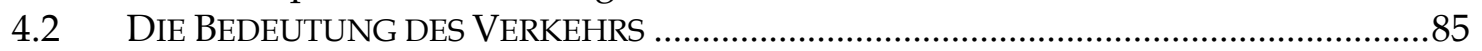

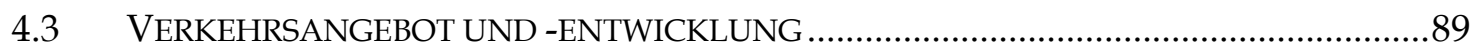

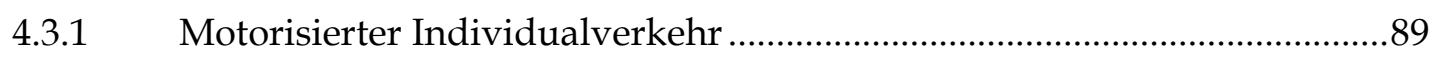

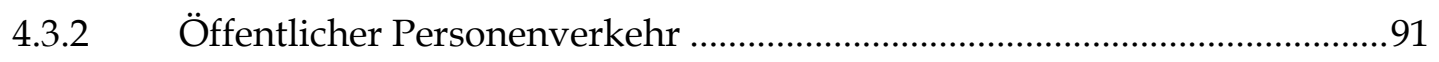

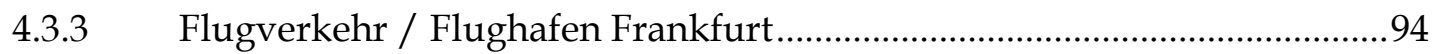

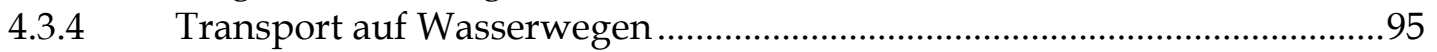

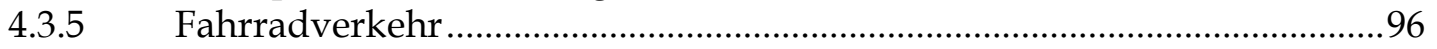

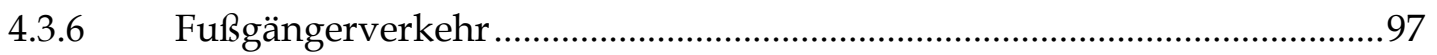

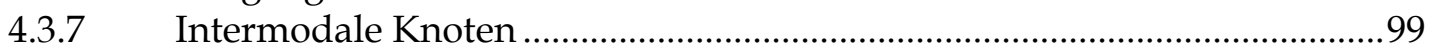

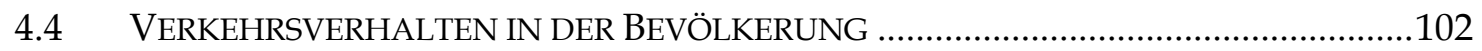

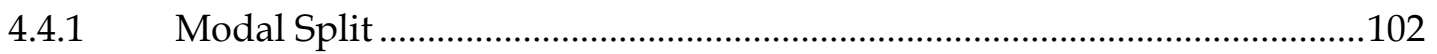

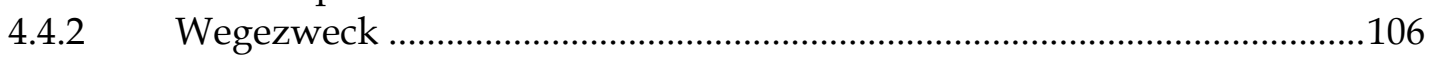

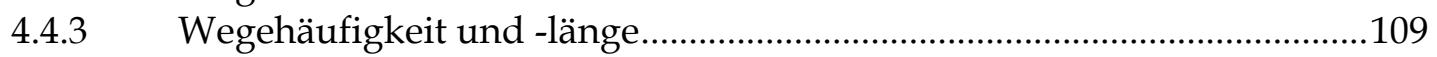

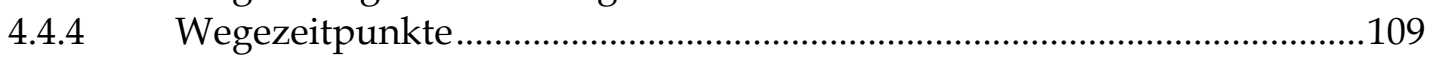

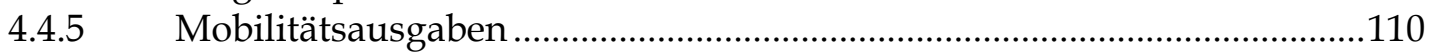

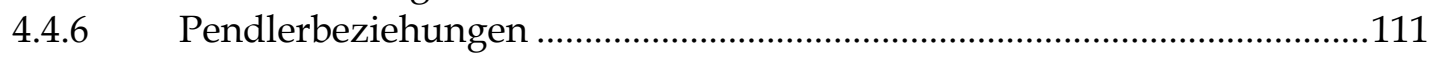

4.4.7 Die Entwicklung des Verkehrs in der Zukunft...........................................114

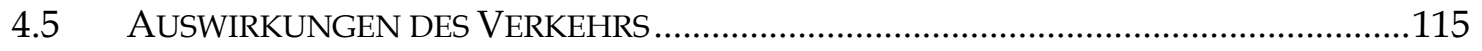

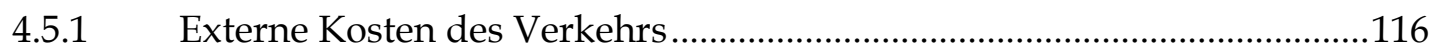

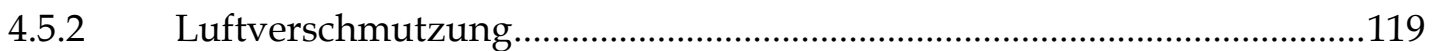

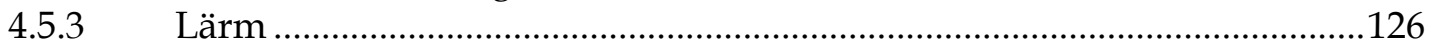

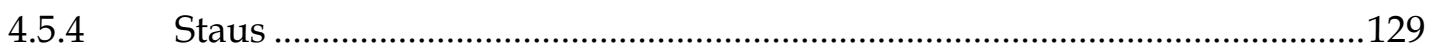

4.5.5 Unfälle und Unfallfolgekosten .............................................................132

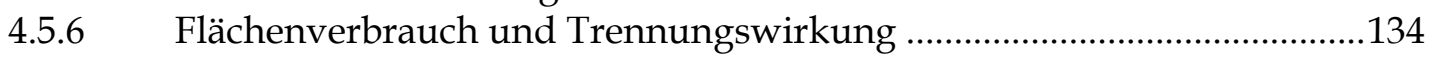

4.6 GEGENWÄRTIGE ANSÄTZE ZUR SICHERUNG DER MOBILITÄT.................................134

4.6.1 Ordnungspolitik und Verkehrsplanung ................................................134

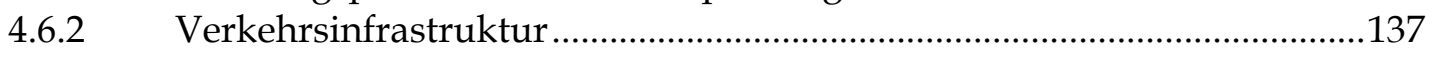

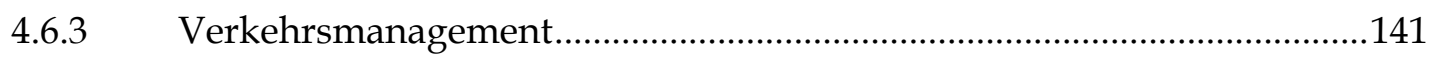

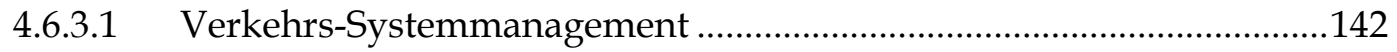

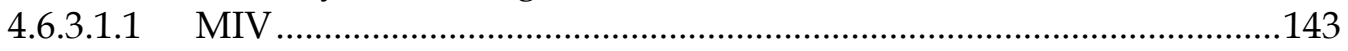

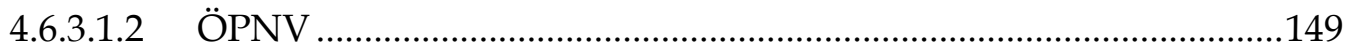

4.6.3.2 Kooperatives Verkehrsmanagement ........................................................153

4.6.3.3 Verkehrs-Nachfragemanagement............................................................157

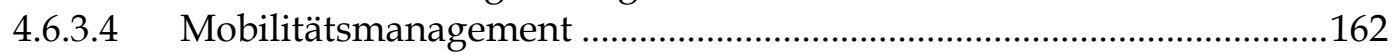

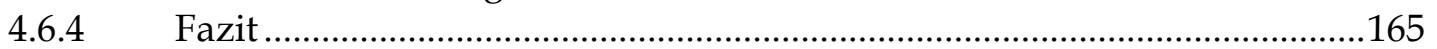


4.7 KONSEQUENZEN: ÖPNV STÄRKEN, MOBILITÄT SICHERN …………......................168

4.7.1 Motivation zur Sicherung der Mobilität ...............................................168

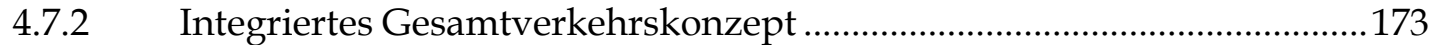

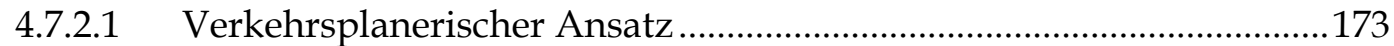

4.7.2.2 Nutzung der spezifischen Stärken der Verkehrsträger..........................176

4.7.2.3 Definition und Messung von Qualitätsansprüchen und -zielen...........179

4.7.2.4 Zielgerichtete und verbindliche Umsetzung .....................................183

4.7.2.5 Übergreifende Kooperation und Organisation .......................................184

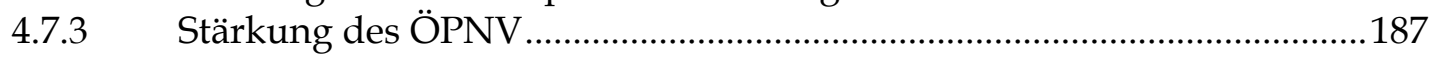

\section{TeIL C: ERSCHLIEßUNG VON EFFIZIENZPOTENZIALEN IM ÖPNV}

5 RAHMENBEDINGUNGEN FÜR VERÄNDERUNGSPROZESSE IM ÖPNV ...190

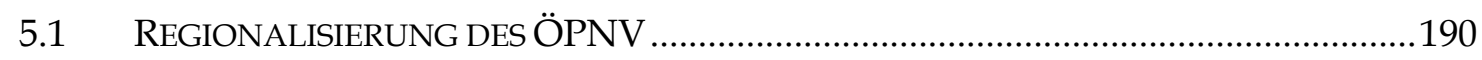

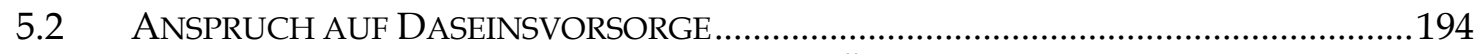

5.3 DER „HESSISCHE WEG“ DER VERGABE VON ÖPNV-LEISTUNG..............................199

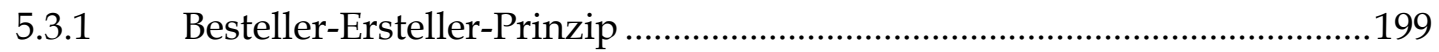

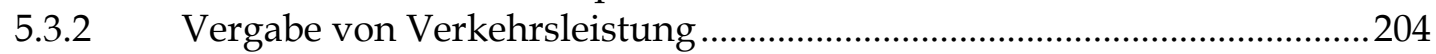

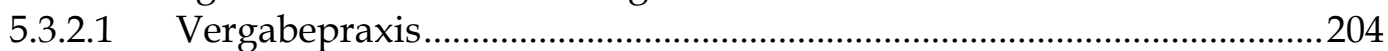

5.3.2.2 Positionierung der Verkehrsunternehmen im Wettbewerb ..................207

5.3.2.3 Wettbewerbsverzerrungen durch kommunale Aktivitäten ..................2.210

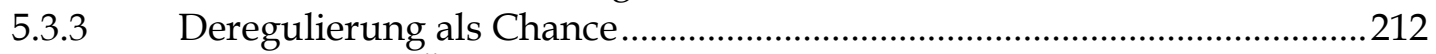

5.4 ORGANISATION DES ÖPNV IN DER REGION FRANKFURT RHEIN-MAIN.................216

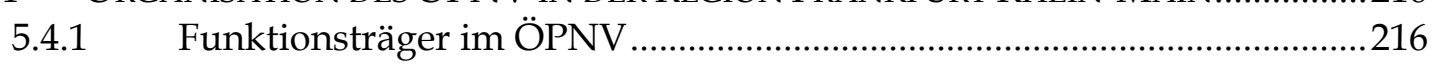

5.4.1.1 Hessisches Ministerium für Wirtschaft, Verkehr und

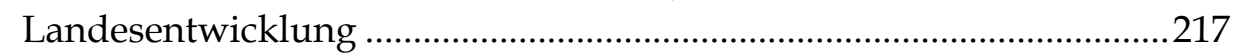

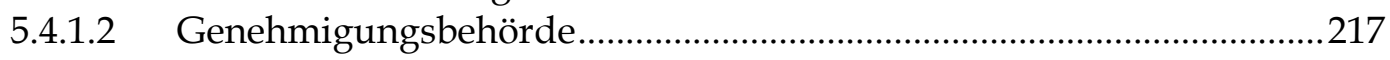

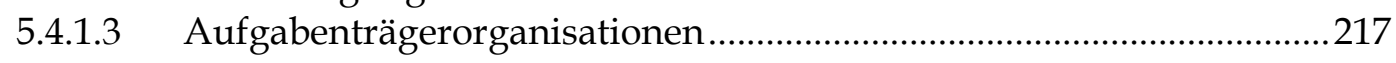

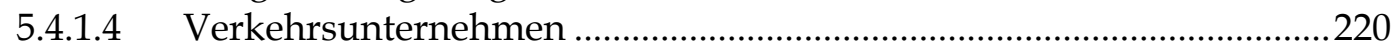

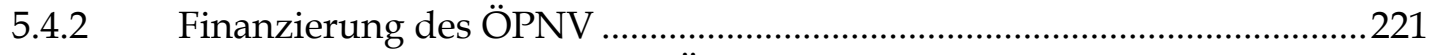

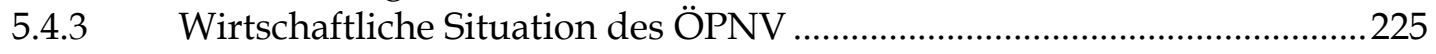

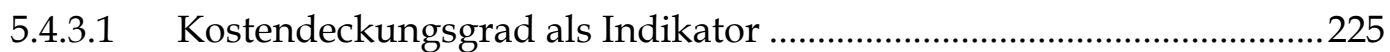

5.4.3.2 Entwicklung vom Verkäufer- zum Käufermarkt...................................227

5.5 MARKTPOSITIONIERUNG DER ÖPNV-UNTERNEHMEN ALS

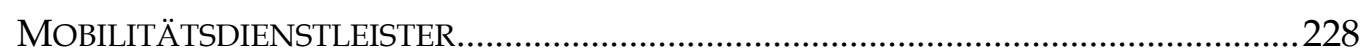

6 MÖGLICHKEITEN DER EFFIZIENZSTEIGERUNG IM ÖPNV ............................2232

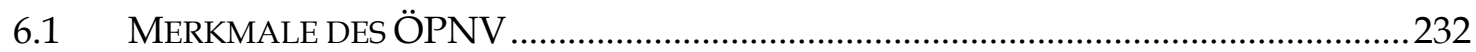

6.1.1 ÖPNV als Dienstleistung von „Mensch zu Mensch“................................2232

6.1.2 Fehlende Lagerfähigkeit und Vorhaltung von Reservekapazitäten.........233

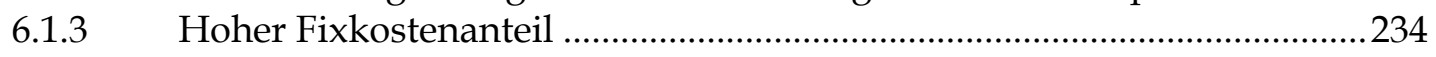

6.1.4 Natürliche Monopolstellung und ruinöser Wettbewerb ..........................2234

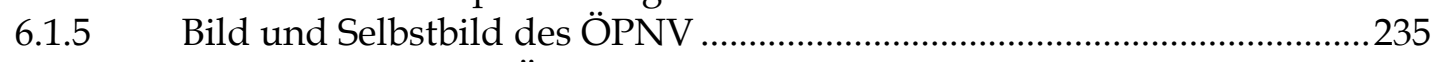

6.2 EFFIZIENZSTEIGERUNG IM ÖPNV ZWISCHEN GEWINNMAXIMIERUNG UND

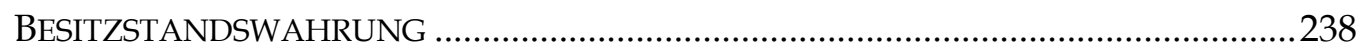

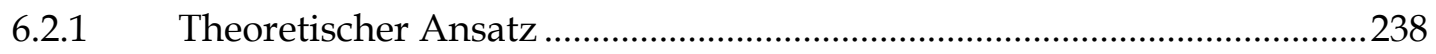

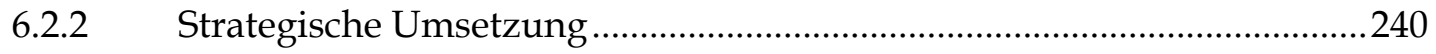

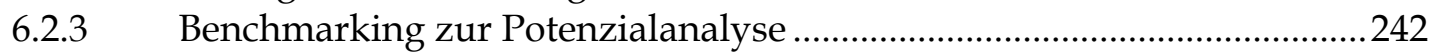

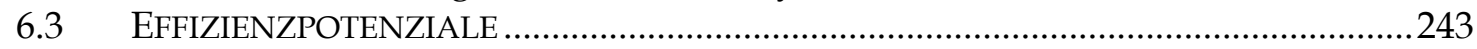




\begin{tabular}{|c|c|c|}
\hline 6.3. & & Mehreinnahmen ...... \\
\hline 6.3 . & & 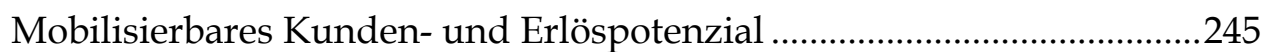 \\
\hline 6.3 . & & 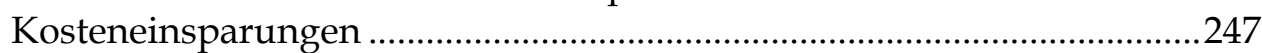 \\
\hline 6.3. & & Erreichbare Kosteneinsparungen................... \\
\hline & ORGA & ANISATORISCHE INSTRUMENTARIEN .................. \\
\hline 6.4 & & Organisationsentwicklung ................. \\
\hline & 6.4.1.1 & 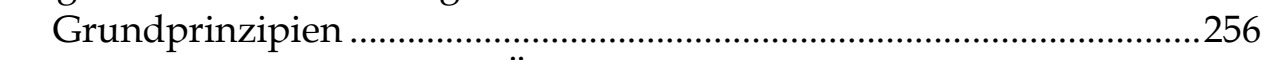 \\
\hline & 6.4.1.2 & 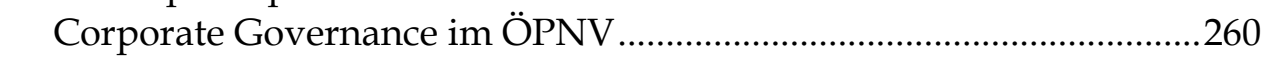 \\
\hline 6.4. & & Neue Kompetenzen zur nachhaltigen Mobilitätssicherung......................263 \\
\hline 6.4. & & Kundenorientierung in der strategischen Unternehmensausrichtung....268 \\
\hline 6.4 . & & Umsetzung einer kundenorientierten Unternehmensstrategie ................273 \\
\hline & 6.4.4.1 & 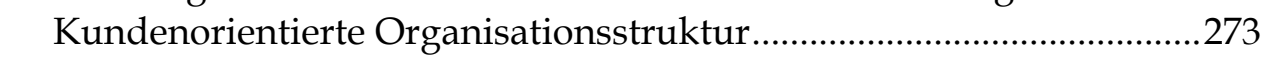 \\
\hline & 6.4.4.2 & Kundenorientierte Unternehmensführung ........ \\
\hline & 6.4.4.3 & ing der Kundenerwartung......................... \\
\hline & 6.4.4.4 & enbeziehungsmanagement..... \\
\hline & 6.4.4.5 & Messung der Kundenorientierung .... \\
\hline & 6.4.4.6 & olling und Berichterstattung ..... \\
\hline 6.5 & MARI & 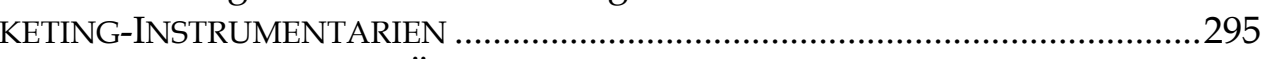 \\
\hline 6.5 .1 & & Der Marketing-Mix im ÖPNV ..... \\
\hline 6.5 .2 & & 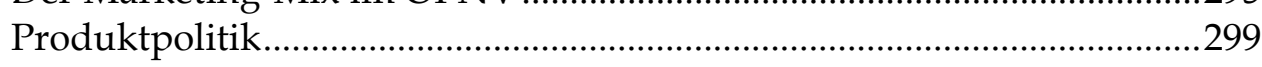 \\
\hline & 6.5.2.1 & Verbindungsqualität............ \\
\hline & 6.5 .2 & .1.1 Bedienungshäufigkeit.... \\
\hline & 6.5 .2 & Beförderungsgeschwindigkeit..... \\
\hline & 6.5 .2 & 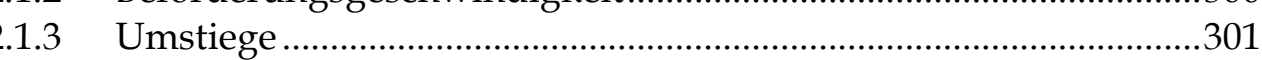 \\
\hline & 6.5 .2 .2 & Erschließungsqualität....... \\
\hline & 6.5 .2 .3 & 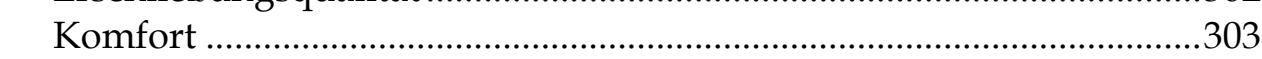 \\
\hline & 6.5 .2 & 3.1 Bahnhöfe und Haltestellen.... \\
\hline & 6.5 .2 & 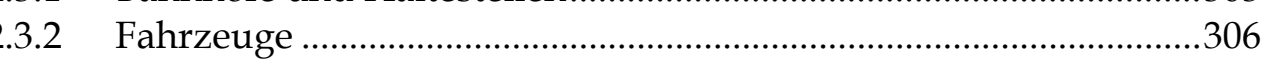 \\
\hline & 6.5.2.4 & 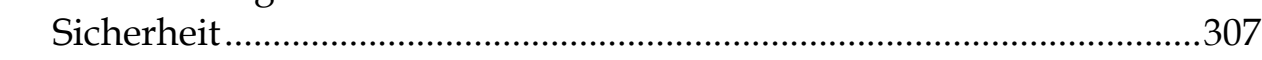 \\
\hline 6.5 .3 & & 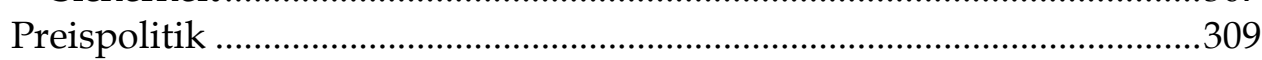 \\
\hline & 6.5.3.1 & Preisbildung und Tarifsystematik.. \\
\hline & 6.5.3.2 & Preisdifferenzierung ............ \\
\hline 6.5.4 & & Kommunikationspolitik ........... \\
\hline & 6.5.4.1 & 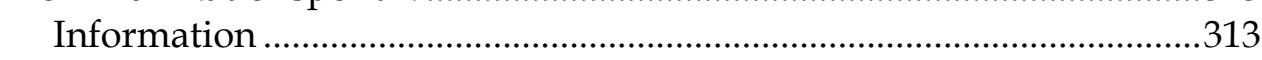 \\
\hline & 6.5 .4 & .1.1 Informationsnotwendigkeit ........ \\
\hline & 6.5.4 & 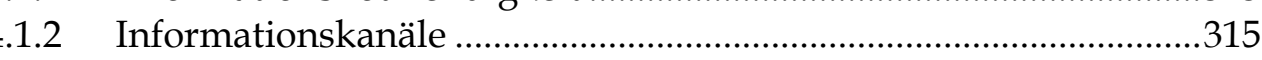 \\
\hline & 6.5 .4 .2 & Werbung und Marktauftritt .... \\
\hline & 6.5.4.3 & 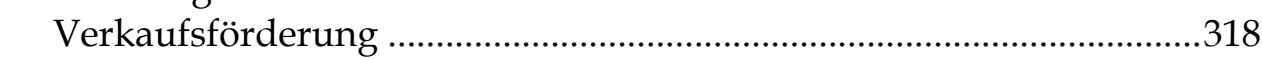 \\
\hline & 6.5.4.4 & Öffentlichkeitsarbeit ............................. \\
\hline & 6.5.4.5 & Direktkommunikation... \\
\hline 6.5 .5 & & 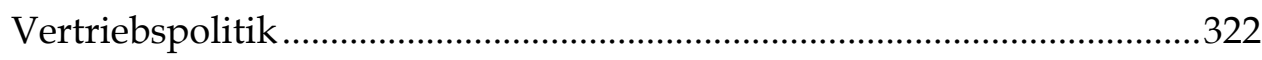 \\
\hline & 6.5.5.1 & Vertriebsorganisation ........ \\
\hline & 6.5.5.2 & 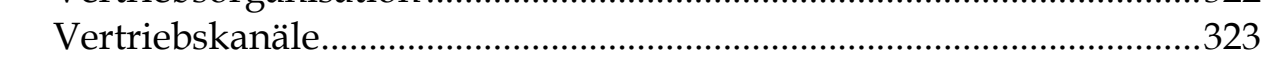 \\
\hline & 6.5.5.3 & Fahrausweiskontrollen.............................. \\
\hline 6.6 & TECH & 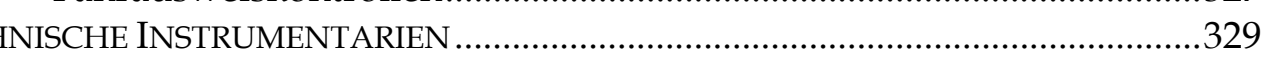 \\
\hline 6.6 .1 & & Technische Innovationen im Verkehr..... \\
\hline 6.6 .2 & & Entwicklung der Telematik im ÖPNV \\
\hline 6.7 & FAZIT & 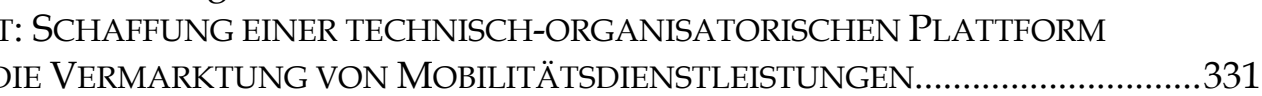 \\
\hline
\end{tabular}




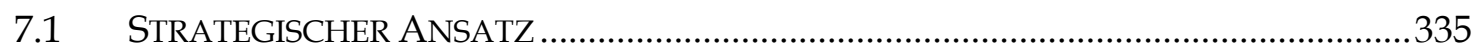

7.2 EINORDNUNG DES E-TICKETING IM ELECTRONIC BUSINESS ...................................337

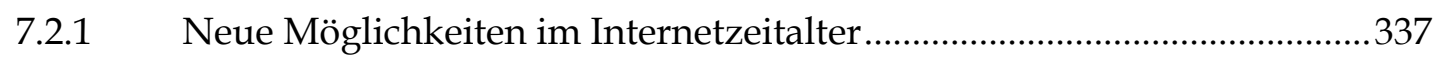

7.2.2 Bargeldlose Bezahlung als Basis für E-Ticketing.......................................338

7.2.3 Zusammenführung der Prozesse Informieren, Bezahlen und Buchen ...339

7.3 ENTWICKLUNG UND STANDARDISIERUNG VON E-TICKETING-SYSTEMEN...............341

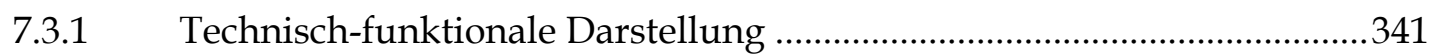

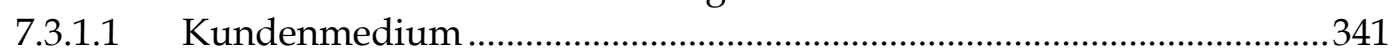

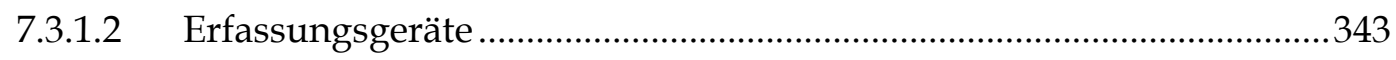

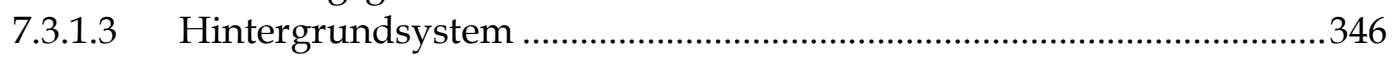

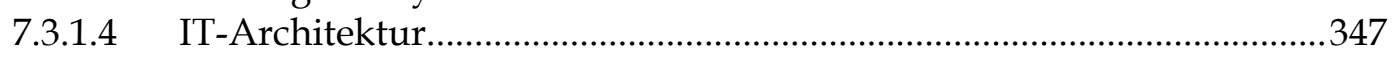

7.3.2 Übertragbarkeit bestehender Lösungen und Standards ............................349

7.3.3 Standard für E-Ticketing in Deutschland ..................................................350

7.3.4 Bisherige Erfahrungen mit E-Ticketing im RMV ........................................354

7.4 VORAUSSETZUNGEN FÜR EINE ZIELGERICHTETE UMSETZUNG DES

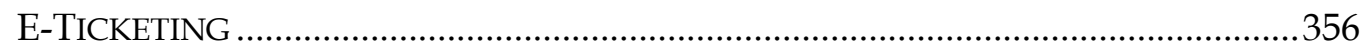

7.4.1 Von der Notwendigkeit der Zieldefinition.................................................356

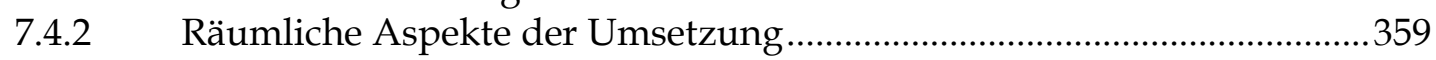

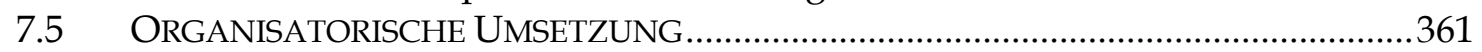

7.5.1 Vernetzung als Leitgedanke der intermodalen Zusammenarbeit ............361

7.5.2 Intramodale Kooperation und Koordination im Mobilitätsverbund .......363

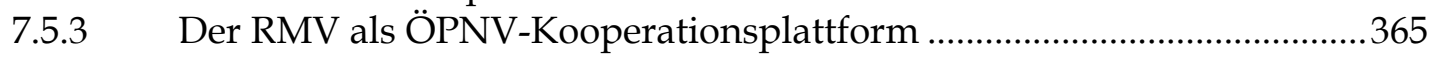

7.5.4 Voraussetzungen für eine kommunale Marketinggesellschaft .................371

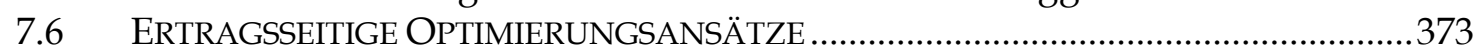

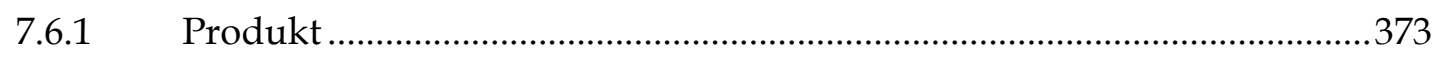

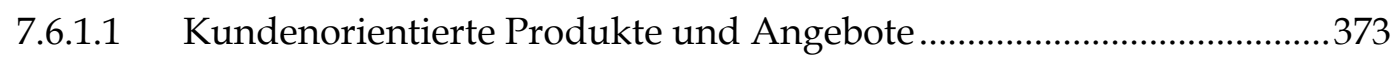

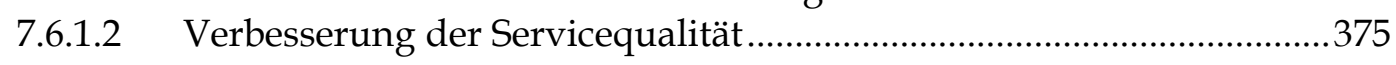

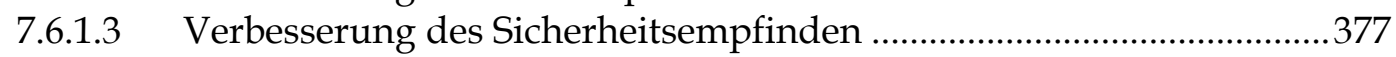

7.6.1.4 Multifunktionalität und Integration Zusatzleistungen ..........................378

7.6.1.5 Angebot von Wegeketten / Produktintegration ......................................380

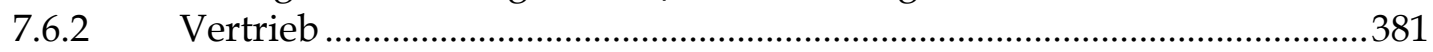

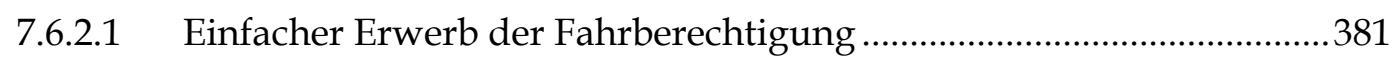

7.6.2.2 Nachträgliche Bezahlung und Best-Preis-Option ...................................382

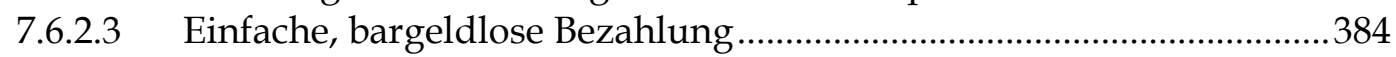

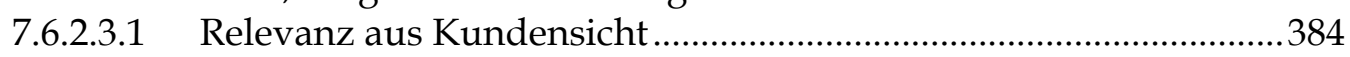

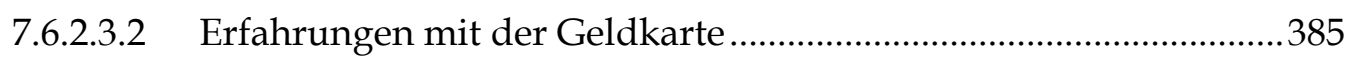

7.6.2.3.3 Sonstige bargeldlose Bezahlverfahren ...........................................387

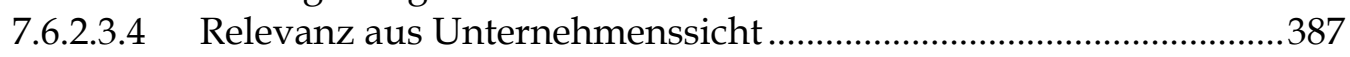

7.6.2.4 Nutzung neuer, attraktiver Vertriebskanäle.........................................388

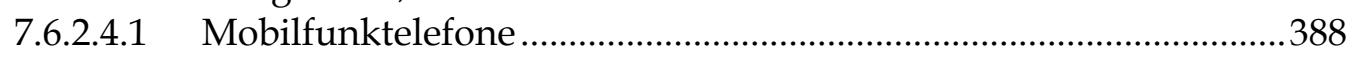

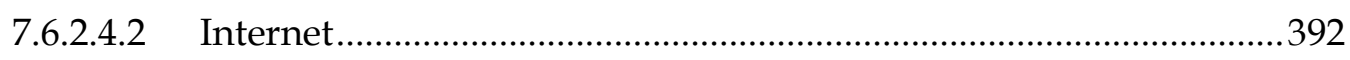

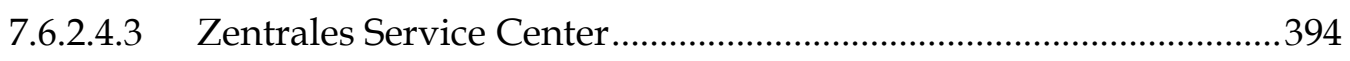

7.6.2.5 Fälschungssichere elektronische Kundenmedien ...................................395

7.6.2.6 Effektive und effiziente Fahrausweiskontrolle.......................................396

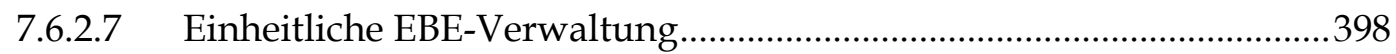

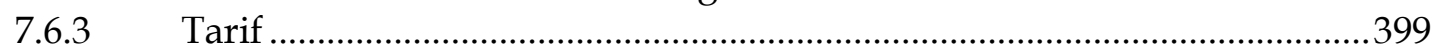

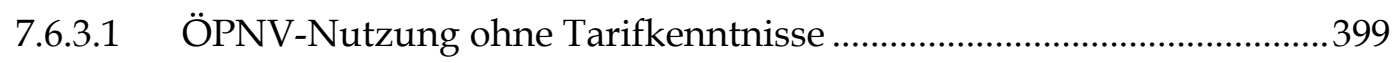

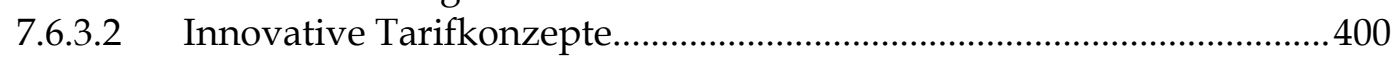




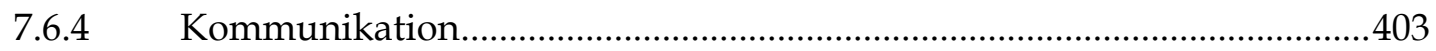

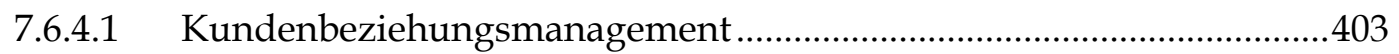

7.6.4.2 Direkte und individualisierte Kundenkommunikation ..........................405

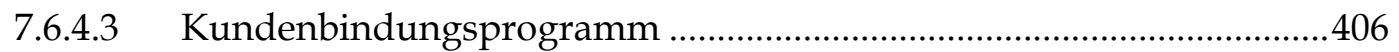

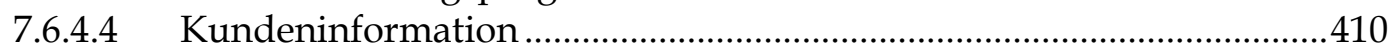

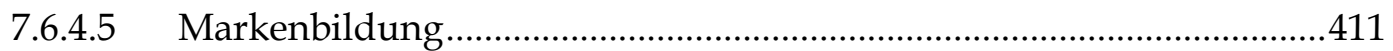

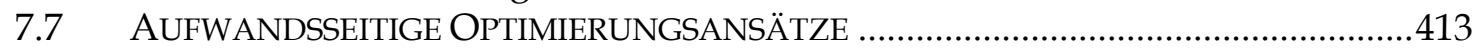

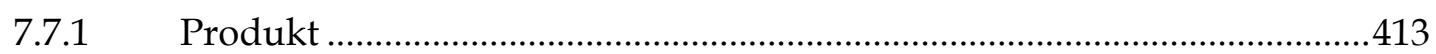

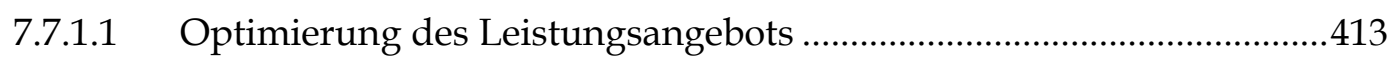

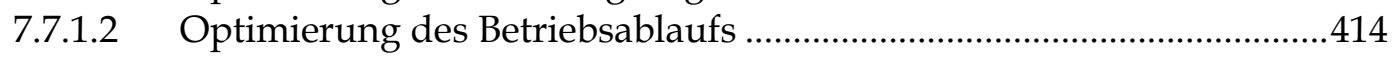

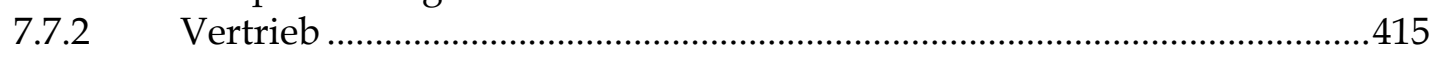

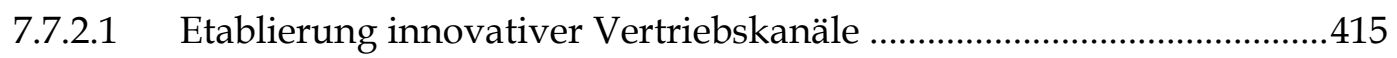

7.7.2.2 Bargeldlose Bezahlverfahren................................................................419

7.7.2.3 Einsatz elektronischer Kundenmedien ....................................................421

7.7.2.4 Verringerung der Kosten pro Kundenkontakt ....................................422

7.7.2.5 Bündelung von Vertriebsprozessen .......................................................423

7.7.2.6 Optimierung des Vertriebskanalmixes ...................................................424

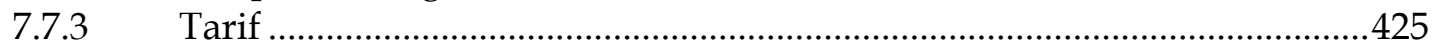

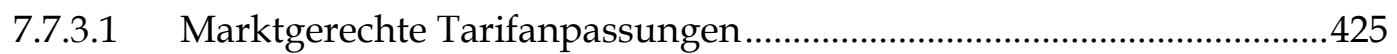

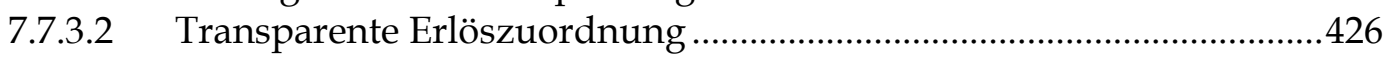

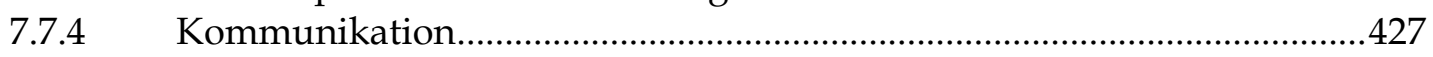

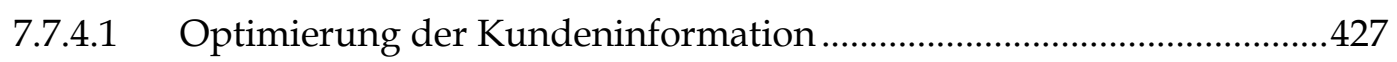

7.7.4.2 Effizienter Werbemitteleinsatz und gemeinsamer Marktauftritt.........428

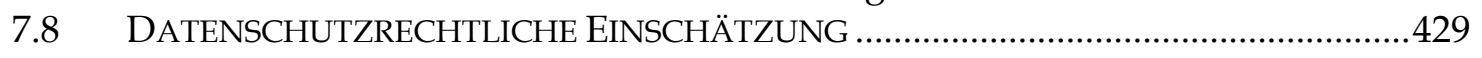

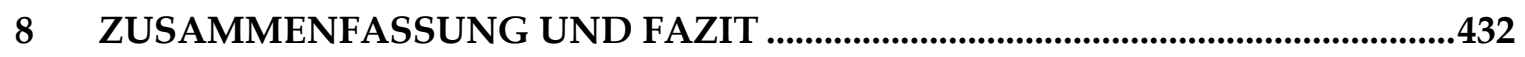

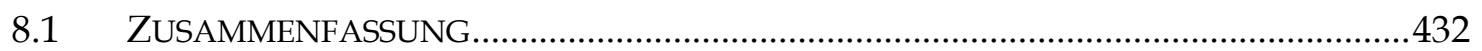

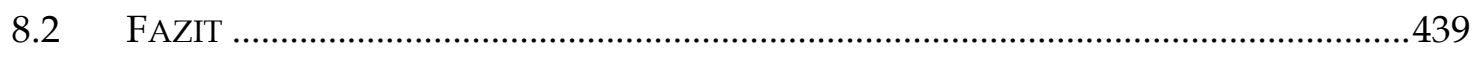

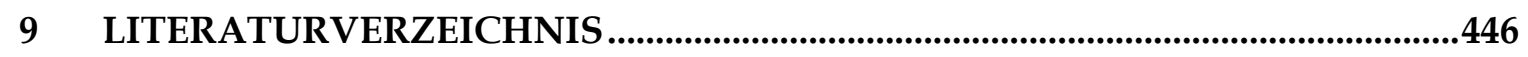




\section{ABBILDUNGSVERZEICHNIS}

ABBILDUNG 1: BEZIEHUNGSGEFLECHT VON MOBILITÄTS- UND VERKEHRSRELEVANTEN SOWIE ANDEREN STANDORTFAKTOREN

ABBILDUNG 2: VERKEHRSINFRASTRUKTUR UND WIRTSCHAFTSKRAFT IN HESSISCHEN

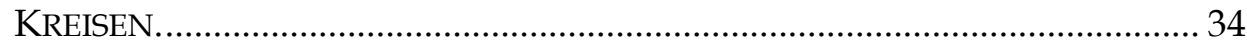

ABBILDUNG 3: ASPEKTE DES ÖPNV ALS STANDORTFAKTOR AUS UNTERNEHMENSSICHT. 39

ABBILDUNG 4: BEVÖLKERUNGSENTWICKLUNG 2003 BIS 2020 IN DEN LANDKREISEN

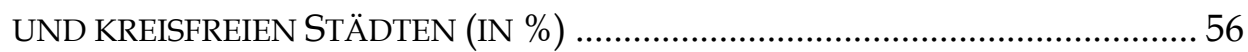

ABBILDUNG 5: ANTEIL DER ÜBER 80-JÄHRIGEN 2020 IN STÄDTEN UND GEMEINDEN ÜBER 5000 EINWOHNER (IN \%) ................................................................... 58

ABBILDUNG 6: ERWEITERTE ANFORDERUNGEN EINER NACHHALTIGEN

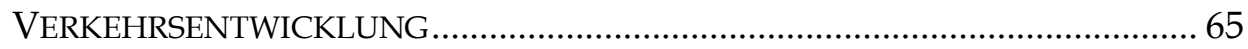

ABBILDUNG 7: RÄUMLICHER ZUSCHNITT DER METROPOLREGION FRANKFURT RHEIN-MAIN SOWIE DES BALLUNGSRAUMES FRANKFURT RHEIN-MAIN............................ 74

ABBILDUNG 8: DIE REGION FRANKFURT-RHEINMAIN NACH EINTEILUNG DES

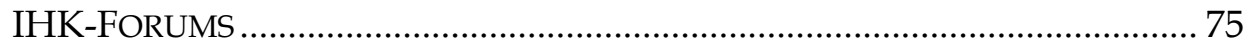

ABBILDUNG 9: SIEDLUNGS- UND VERKEHRSKORRIDORE SOWIE

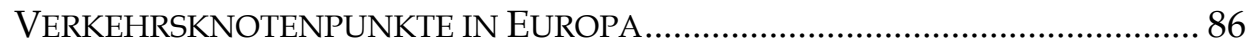

ABBILDUNG 10: SIEDLUNGS- UND VERKEHRSKORRIDORE SOWIE VERKEHRSKNOTENPUNKTE IN DEUTSCHLAND ............................................. 87

ABBILDUNG 11: VERKEHRSENTWICKLUNG DER TÄGLICHEN VERKEHRSSTÄRKEN AUF BAB VON 1963 BIS 1995 IM RHEIN-MAIN-NECKAR-RAUM....................89

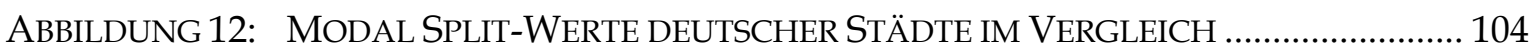

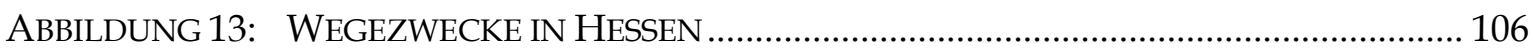

ABBILDUNG 14: VERKEHRSMITTELWAHL NACH WEGEZWECK, HESSEN (IN \%) ..................... 107

ABBILDUNG 15: VERKEHRSMITTELWAHL NACH WEGEZWECK, FRANKFURT UND OFFENBACH (IN \%) ....................................................................................... 108

ABBILDUNG 16: ENTWICKLUNG VON LEBENSHALTUNGS- UND MOBILITÄTSKOSTEN 2000-2005

ABBILDUNG 17: ENTWICKLUNG VON LEBENSHALTUNGS- UND MOBILITÄTSKOSTEN 2005-2007.

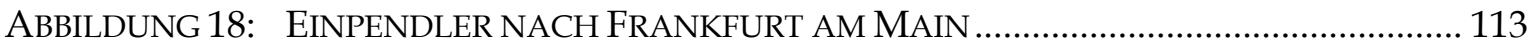

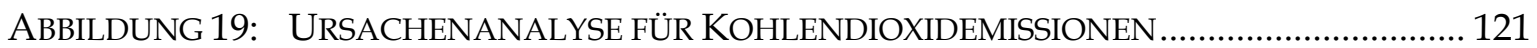

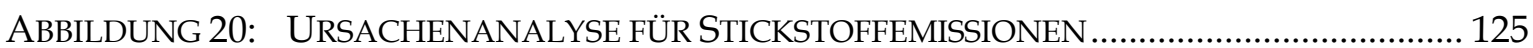

ABBILDUNG 21: URSACHENANALYSE FÜR FEINSTAUBEMISSIONEN (PM10) ........................... 125

ABBILDUNG 22: VERURSACHTER FLUGLÄRM DURCH DEN FLUGHAFEN FRANKFURT ............ 128

ABBILDUNG 23: TYPISCHE STAUSITUATION AUF BAB IM RHEIN-MAIN-GEBIET ........................ 130

ABBILDUNG 24: STÖRUNGSAUFKOMMEN AUF BAB IM RHEIN-MAIN-GEBIET

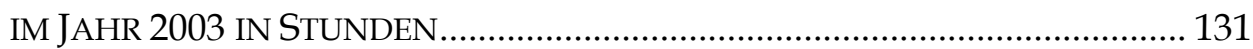

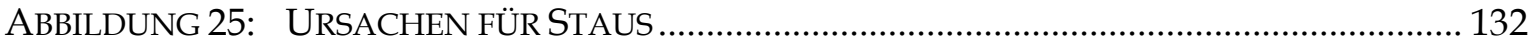

ABBILDUNG 26: UNTERGLIEDERUNG DES VERKEHRSMANAGEMENTS................................... 142

ABBILDUNG 27: ERGÄNZUNG VON VERKEHRS-SYSTEMMANAGEMENT UND MOBILITÄTSMANAGEMENT 
ABBILDUNG 28: EINSATZBEREICH DER VERSCHIEDENEN VERKEHRSMITTEL IM

PERSONENVERKEHR

ABBILDUNG 29: DILEMMA DES GETEILTEN MARKTS UND DER GETEILTEN

VERANTWORTLICHKEITEN IM ÖPNV 215

ABBILDUNG 30: ENTWICKLUNG VON KENNZIFFERN IM RMV 2000-2005 (INDEX-WERTE) .. 226

ABBILDUNG 31: ERREICHBARKEIT „ÜBLICHER ALLTAGS-ZIELE“ MIT DEM ÖPNV (IN \%) .... 246

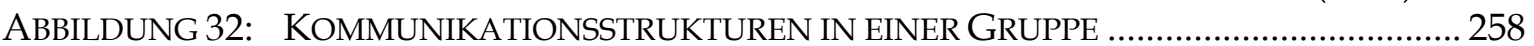

ABBILDUNG 33: KOMPETENZSPEKTRUM DER ÖPNV-AKTEURE IN EINEM SICH

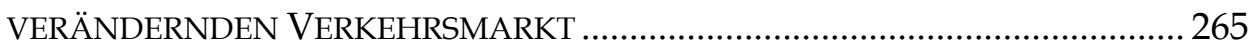

ABBILDUNG 34: PERSPEKTIVEN DER STRATEGISCHEN UNTERNEHMENSAUSRICHTUNG UND URSACHE-WIRKUNGS-BEZIEHUNG …............................................ 272

ABBILDUNG 35: WERTSCHÖPFUNG DURCH KUNDENORIENTIERUNG IM ÖPNV ..................... 283

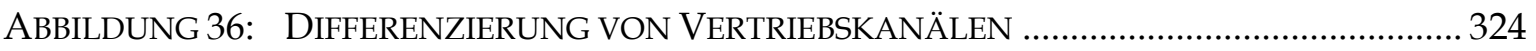

ABBILDUNG 37: INFORMATIONSBLATT ZUR EINFÜHRUNG DER „EINMANNBUSSE“ VON OKTOBER 1965.

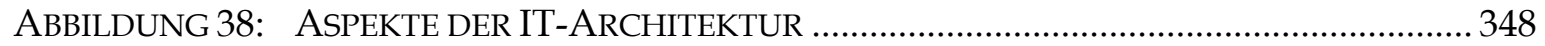

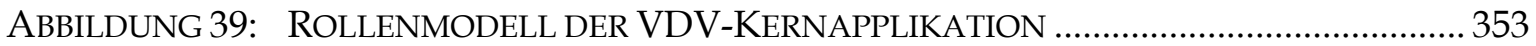

ABBILDUNG 40: WIRKUNGSBEREICHE DES E-TICKETING IM MARKETINGBEREICH................. 358

ABBILDUNG 41: MÖGLICHE DIMENSION EINES KUNDENBINDUNGSPROGRAMMS.................. 409

ABBILDUNG 42: RISIKO VON ZAHLUNGSAUSFÄLLEN IN AUSGEWÄHLTEN BRANCHEN ......... 421

ABBILDUNG 43: DER KUNDENBEZIEHUNGSPROZESS IM CRM …............................................. 422 


\section{TABELLENVERZEICHNIS}

TABELLE 1:

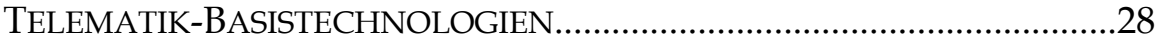

TABELLE 2:

IUK-TECHNOLOGIEN UND VERKEHR......................................................30

TABELLE 3:

DYNAMIK UND STÄRKE DER 20 BESTEN WIRTSCHAFTSSTANDORTE IN DEUTSCHLAND..............................................................78

TABELLE 4: JAHRESFAHRLEISTUNG IM BALLUNGSRAUM

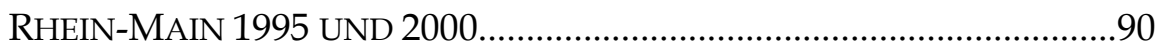

TABELLE 5: ÖPNV-LEISTUNGSANGEBOT UND ÖPNV-FAHRTEN NACH ÖFFENTLICHEN VERKEHRSMITTELN IM RMV IM JAHR 2005..............................92

TABELLE 6:

TABELLE 7:

DATEN ZUM SCHIENEN UND BUSNETZ................................................94

TABELLE 8:

MOBILITÄTSAUSGABEN IN DEUTSCHLAND UND HESSEN 2003.............110

ZIELBEREICHE UND QUALITÄTSZIELE NACHHALTIGER

MOBILITÄTSENTWICKLUNG.

TABELLE 9:

VERTRIEBSKOSTENINTENSITÄT FÜR EINZELNE

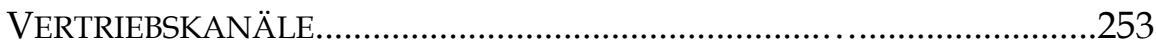

TABELLE 10:

KENNZAHLEN ZUM VERTRIEB IM RMV 


\section{ABKÜRZUNGSVERZEICHNIS}

\begin{tabular}{|c|c|}
\hline a & Jahr \\
\hline A & Autobahn \\
\hline Abb. & Abbildung \\
\hline Abo & Abonnement \\
\hline ADAC & Allgemeiner Deutscher Automobilclub \\
\hline $\mathrm{ADFC}$ & Allgemeiner Deutscher Fahrradclub \\
\hline AG & Aktiengesellschaft \\
\hline ATM & Air Traffic Management \\
\hline B & Bundesstraße \\
\hline BAB & Bundesautobahn \\
\hline BDI & Bundesverband der Deutschen Industrie \\
\hline $\mathrm{BIBO}$ & Be-in / Be-Out \\
\hline BMVBW & Bundesministerium für Verkehr, Bau- und Wohnungswesen \\
\hline BMW & Bayrische Motorenwerke \\
\hline BSC & Balanced Scorecard \\
\hline bspw. & beispielsweise \\
\hline BUND & Bund für Umwelt- und Naturschutz Deutschland \\
\hline B2B & Business to Business \\
\hline B2C & Business to Customer \\
\hline $\mathrm{CIBO}$ & Check-In / Be-Out \\
\hline $\mathrm{CICO}$ & Check-In / Check-Out \\
\hline $\mathrm{cm}$ & Zentimeter \\
\hline $\mathrm{CO}_{2}$ & Kohlendioxid \\
\hline COX & Communication and Orientation eXpert \\
\hline CRM & Customer Relationship Management \\
\hline $\mathrm{DAB}$ & Digital Audio Broadcasting \\
\hline $\mathrm{DB}$ & Deutsche Bahn \\
\hline $\mathrm{dB}(\mathrm{A})$ & Dezibel (Schallpegel) \\
\hline DCGK & Deutscher Corporate Governance Kodex \\
\hline DIAMANT & $\begin{array}{l}\text { Dynamische Informationen und Anwendungen zur Mobilitäts- } \\
\text { sicherung mit Adaptiven Netzwerken und Telematik-Infrastruktur }\end{array}$ \\
\hline DIANA & Dynamic Information And Navigation Assistance \\
\hline DIN & Deutsches Institut für Normung \\
\hline DIW & Deutsches Institut für Wirtschaftsforschung \\
\hline DVB & Digital Video Broadcasting (Kapitel 3) \\
\hline DVB & Dresdner Verkehrsbetriebe (Kapitel 6) \\
\hline dWiSta & dynamische Wegweiser mit integrierten Stauinformationen \\
\hline EBE & Erhöhtes Beförderungsentgelt \\
\hline ebd. & ebenda \\
\hline EDV & elektronische Datenverarbeitung \\
\hline EPC & Electronic Product Code \\
\hline E & Electronic \\
\hline $\begin{array}{l}\text { EN } \\
\text { etc }\end{array}$ & Europäische Norm \\
\hline
\end{tabular}




\begin{tabular}{|c|c|}
\hline $\mathrm{EuGH}$ & Europäischer Gerichtshof \\
\hline $\mathrm{EU}$ & Europäische Union \\
\hline EWG & Europäische Wirtschaftsgemeinschaft \\
\hline f & folgende Seite \\
\hline $\mathrm{F}$ & Frankfurt am Main, Stadt \\
\hline FAZ & Frankfurter Allgemeine Zeitung \\
\hline FCD & Floating Car Data \\
\hline $\mathrm{ff}$ & folgende Seiten \\
\hline $\mathrm{GmbH}$ & Gesellschaft mit beschränkter Haftung \\
\hline GOE & Gesellschaft für Organisationsentwicklung \\
\hline GPRS & General Packet Radio Service \\
\hline GSM & Global System for Mobile Communications \\
\hline GVFG & Gemeindeverkehrsfinanzierungsgesetz \\
\hline GVPIG & Gemeindeverkehrsplanungsgesetz \\
\hline HLSV & Hessisches Landesamt für Straßen- und Verkehrswesen \\
\hline HMWVL & $\begin{array}{l}\text { Hessisches Ministerium für Wirtschaft, Verkehr und Landes- } \\
\text { entwicklung }\end{array}$ \\
\hline HSVV & Hessische Straßen- und Verkehrsverwaltung \\
\hline IATA & International Air Transport Association \\
\hline IBIS & Integriertes Bord-Informations-System \\
\hline ICE & Intercity Express \\
\hline i.d.F. & in der Fassung \\
\hline i.d.R. & in der Regel \\
\hline IGLZ & Integrierte Gesamtverkehrs-Leitzentrale \\
\hline IFMO & Institut für Mobilitätsforschung \\
\hline IHK & Industrie- und Handelskammer \\
\hline insb. & insbesondere \\
\hline ISO & Internationale Organisation für Normung \\
\hline IT & Informationstechnologien \\
\hline ITCS & Intermodal Transport Control System \\
\hline ITF & Integrierter Taktfahrplan \\
\hline IuK & Information und Kommunikation \\
\hline IVM & (Gesellschaft für) Integriertes Verkehrsmanagement \\
\hline $\mathrm{kcm}$ & Kompetenzcenter Mobilität \\
\hline KA & Kernapplikation \\
\hline KIN & Kundenberater im Nahverkehr (der Deutschen Bahn AG) \\
\hline $\mathrm{km}$ & Kilometer \\
\hline $\mathrm{km} 2$ & Quadratkilometer \\
\hline $\mathrm{km} / \mathrm{h}$ & Kilometer pro Stunde \\
\hline LAN & Local Administration Network \\
\hline LCTP & Least Cost Transportation Planning \\
\hline LEP & Landesentwicklungsplan \\
\hline LNO & Lokale Nahverkehrsorganisation \\
\hline Lkw & Lastkraftwagen \\
\hline $\mathrm{m}$ & Meter \\
\hline $\mathrm{m}^{2}$ & Quadratmeter \\
\hline Mhz & Megahertz \\
\hline $\mathrm{MiD}$ & Mobilität in Deutschland \\
\hline Mio. & Millionen \\
\hline
\end{tabular}




\begin{tabular}{|c|c|}
\hline MIV & Motorisierter Individualverkehr \\
\hline MMS & Multimedia Messaging Service \\
\hline Mrd. & Milliarden \\
\hline $\mathrm{ms}$ & Millisekunde \\
\hline MTV & Main-Taunus-Verkehrsgesellschaft \\
\hline MVG & Münchener Verkehrsgesellschaft \\
\hline NBA & Netzbeeinflussungsanlage \\
\hline NFC & Near Field Communication \\
\hline $\mathrm{NO}$ & Stickstoffmonoxid \\
\hline $\mathrm{NO}_{x}$ & Stickstoffoxide \\
\hline $\mathrm{NO}_{2}$ & Stickstoffdioxid \\
\hline $\mathrm{N}_{2} \mathrm{O}$ & Distickstoffoxid (Lachgas) \\
\hline NRVP & Nationaler Radverkehrsplan \\
\hline NVV & Nordhessischer Verkehrsverbund \\
\hline $\mathrm{O}_{3}$ & Ozon \\
\hline OF & Offenbach am Main, Stadt \\
\hline ÖPNV & Öffentlicher Personennahverkehr \\
\hline ÖPNVG & Öffentliches Personennahverkehrsgesetz \\
\hline ÖPV & Öffentlicher Personenverkehr \\
\hline ÖV & Öffentlicher Verkehr \\
\hline OVB & Offenbacher-Verkehrs-Betriebe \\
\hline PBefG & Personenbeförderungsgesetz \\
\hline PEP & Preis- und Erlösmanagement Personenverkehr \\
\hline PIN & Persönliche Identifikationsnummer \\
\hline Pkm & Personenkilometer \\
\hline Pkw & Personenkraftwagen \\
\hline $\mathrm{PM}_{10}$ & Particulate Matter $10 \mu \mathrm{m}$ \\
\hline PPP & Public Private Partnership \\
\hline RBL & Rechnergesteuertes Betriebsleistsystem \\
\hline RDS-TMC & Radio Data System - Traffic Message Channel \\
\hline RFID & Radio Frequency identification \\
\hline RMV & Rhein-Main-Verkehrsverbund \\
\hline S. & Seite \\
\hline s.o. & siehe oben \\
\hline s.u. & siehe unten \\
\hline SAM & Secure Application Module \\
\hline SchWAbG & Schienenwegeausbaugesetz \\
\hline SMS & Short Message Service \\
\hline $\mathrm{SO}_{2}$ & Schwefeldioxid \\
\hline sog. & sogenannt \\
\hline SPNV & Schienenpersonennahverkehr \\
\hline STEP & Stationsentwicklungs-Programm \\
\hline TAN & Transaktionsnummer \\
\hline TU & Technische Universität \\
\hline u.a. & unter anderem \\
\hline UITP & $\begin{array}{l}\text { Union Internationale des Transports Publics } \\
\text { (Internationaler Verband für öffentliches Verkehrswesen) }\end{array}$ \\
\hline UMTS & Universal Mobile Telecommunications System \\
\hline UN & United Nations \\
\hline
\end{tabular}




$\begin{array}{ll}\text { UPI } & \text { Umwelt- und Prognose-Institut } \\ \text { UV-Strahlung } & \text { Ultraviolettstrahlung } \\ \text { VBB } & \text { Verkehrsverbund Berlin-Brandenburg } \\ \text { VDV } & \text { Verband Deutscher Verkehrsunternehmen } \\ \text { VGF } & \text { Verkehrsgesellschaft Frankfurt am Main } \\ \text { vgl. } & \text { vergleiche } \\ \text { VO } & \text { Verordnung } \\ \text { VRN } & \text { Verkehrsverbund Rhein-Neckar } \\ \text { VRR } & \text { Verkehrsverbund Rhein-Ruhr } \\ \text { VZH } & \text { Verkehrszentrale Hessen } \\ \text { WAP } & \text { Wireless Application Protocol } \\ \text { WCED } & \text { World Commission on Environment and Development } \\ \text { WIWO } & \text { Walk-In / Walk-Out } \\ \text { WLAN } & \text { Wireless Local Administration Network } \\ \text { wWw } & \text { world wide web (Internet) } \\ \text { WZB } & \text { Wissenschaftszentrum für Sozialforschung Berlin } \\ \text { z.B. } & \text { zum Beispiel } \\ \text { ZDF } & \text { Zweites Deutsches Fernsehen } \\ \text { ZSC } & \text { Zentrales Service Center }\end{array}$




\section{Teil A : Fachliche und thematische Abgrenzung}

\section{Die Verkehrsplanung an der Schnittstelle zwischen Verkehrsgeographie und Verkehrswissenschaften}

Während der Betrachtungsgegenstand der Wirtschaftswissenschaften in der Vergangenheit die Einheit von Wirtschaft und Gesellschaft war, beschäftigte sich die Wirtschaftsgeographie zunächst vor allem mit der Einheit von Natur und Mensch. Aus dem Verständnis heraus, dass der Ausgangspunkt wirtschaftsgeographischer Forschung nicht das Sichtbare an der Erdoberfläche sei, sondern vielmehr der wirtschaftende Mensch, näherte sich die Wirtschaftsgeographie den Wirtschafts- und Sozialwissenschaften an bzw. versteht sich die Wirtschaftsgeographie heute selbst als Wirtschafts- und Sozialwissenschaft. Die Wirtschaftsgeographie wurde so zu einer Wissenschaft, die sich konkreten Planungsproblemen der Wirtschaftsentwicklung zuwendet. Sowohl die Wirtschafts- und die Sozialwissenschaften wie auch die Geographie entwickelten beispielsweise Lösungsansätze zu den räumlichen Disparitäten, wie sie durch die Trennung von Wohn- und Arbeitsort entstehen. Gleichzeitig wurde in den Wirtschafts- und Sozialwissenschaften der räumliche Aspekt in den wissenschaftlichen Betrachtungen verstärkt aufgenommen und mit empirischen Arbeiten unterlegt. Dabei orientieren sich die Wirtschaftswissenschaften verstärkt auf die ökonomische Regionalpolitik, hingegen sich die Geographie auf die Regionalplanung konzentriert. Zusammen können so Beiträge zur künftigen Gestaltung der räumlichen Ordnung von Wirtschaft und Gesellschaft entwickelt werden, die sowohl auf theoretischen, empirischen wie auch regionalpolitischen Untersuchungen basieren.

Schätzl2 weist darauf hin, dass das für den Wohlstand wichtige wirtschaftliche Wachstum einer Region, welches primär durch Rationalisierung und technischem Fortschritt geprägt ist, unterschiedliche Determinanten von Bedeutung sind. So sind das vorhandene Produktionspotenzial und die reale Nachfrage wesentlich für das reale Einkommen. Das Wachstum einer Region hängt davon ab, inwieweit die reale (private und öffentliche) Nachfrage nach Konsum- und Investitionsgütern mobilisiert werden kann. ${ }^{3}$ Darüber hin-

\footnotetext{
2 vgl. Schätzl 2003, S.99ff

${ }^{3}$ Insbesondere der technologische Fortschritt und die damit einhergehenden Rationalisierungspotenziale ermöglichen das zunehmende Tempo des Wirtschaftswachstums. Die Chancen der
} 
aus spielen weitere Faktoren eine Rolle, so die Raumstruktur, die Sektoralstruktur (z.B. Anteil von Dienstleistungsunternehmen), die vorhandene Infrastruktur, das politische und soziale System und die Bereitschaft zum technischen Fortschritt. Letzteres betrifft aber nicht nur die Verbesserung der technischen Ausgangslage und die Innovationsbereitschaft, sondern auch die Bereitschaft zu organisatorischen Veränderungen. Jede Veränderung einer dieser Determinanten kann sich positiv auf das wirtschaftliche Wachstum einer Region auswirken. Außerdem hat der Staat unterschiedliche Einflussmöglichkeiten durch entsprechende Gesetzgebung wachstumshemmende Einflüsse (z.B. bei Steuerabgaben) zu beseitigen. ${ }^{4}$

Diese Auffassung macht das breite Spektrum notwendiger Wissenschaftsdisziplinen deutlich, die erforderlich sind, um das Entwicklungspotenzial einer Region in seiner Gesamtheit zu erfassen und zu bewerten. Die Verkehrswissenschaft, als Teildisziplin der Wirtschaftswissenschaften, liefert hier u.a. Erkenntnisse aus der betriebs- und volkswirtschaftlichen Analyse des Verkehrswesens. Dabei spielen auch rechtliche, politische, soziale und soziologische Aspekte eine Rolle. Der Beitrag der Wirtschaftsgeographie bezieht sich insbesondere auf „die Aufgabe, räumliche Strukturen und ihre Veränderungen aufgrund interner Entwicklungsdeterminanten und räumlicher Interaktionen - zu erklären, zu beschreiben und zu bewerten“. Neben der Theoriebildung zur räumlichen Ordnung der Wirtschaft sowie der empirischen Regionalanalyse kommt der Wirtschaftsgeographie damit die konkrete Aufgabe zu, „einen Beitrag zur Lenkung des räumlichen Prozeßablaufs in Richtung auf eine Optimierung wirtschafts- und gesellschaftspolitischer Zielsetzung zu leisten". ${ }^{5}$ Die Wirtschaftsgeographie liefert dabei theoretische Erklärungen zu den ökonomischen Raumsystemen, wie sie beispielsweise im Rahmen einer ökono-

\footnotetext{
Wissens- und Dienstleistungsgesellschaft, immer mehr Informationen und Leistungen immer schneller abzurufen und zu nutzen, führen dazu, dass Märkte immer schneller gesättigt werden können (dauerte es noch 50 Jahre bis das Festnetz-Telefon vom Luxusartikel zum Standard in den meisten Haushalten der Industrieländer wurde, verlief diese Entwicklung beim GSM-Handy in nur 10 Jahren). Allerdings ist es fraglich, ob sich hohes Wachstum von Wissen, Produktion und Dienstleistungen unbedingt in hohem Wirtschaftswachstum niederschlagen muss, da neue Märkte oft von sehr wenigen Menschen bedient werden können, alte Märkte der Rationalisierung unterliegen und entsprechender Fortschritt demzufolge mit relativ konstanten Umsätzen einhergehen kann. Zur Vertiefung siehe hierzu: Dennis Meadows u.a.: „Die Grenzen des Wachstums. Club of Rome. Bericht des Club of Rome zur Lage der Menschheit", München 1972; Dennis Meadows u.a.: "Grenzen des Wachstums - Das 30-Jahre-Update“, Stuttgart 2006; oder Herman E. Daly,: „Wirtschaft jenseits von Wachstum - Die Volkswirtschaftslehre nachhaltiger Entwicklung“", Salzburg 1999.

${ }^{4}$ vgl. Schätzl 2003, S. 99ff

${ }^{5}$ Schätzl 2003, S.21
} 
misch - aber eben auch ökologisch und sozial - nachhaltigen Raum- und Regionalentwicklung disziplinübergreifend notwendig sind ${ }^{6}$ (siehe Kapitel 3.6). Hierzu gehören u.a.: ${ }^{7}$

- die Standorttheorien, die die räumliche Struktur als Voraussetzung wirtschaftlicher Entwicklung berücksichtigen und im wesentlichen auf die Ansätze von Thünen und Christaller zurückgreifen,

- die räumlichen Mobilitätstheorien, die den Einfluss der räumlichen Mobilität auf einzelne Produktionsfaktoren untersuchen sowie

- die regionalen Wachstums- und Entwicklungstheorien, im Rahmen derer integrierte Erklärungsansätze der räumlich differenzierten Wirtschaftsentwicklung betrachtet werden.

Verkehr - als Prozess räumlicher Distanzüberwindung von Personen, Waren und Dienstleistungen - ist integraler Bestandteil dieses ökonomischen Gesamtsystems.

Dies rechtfertigt letztlich auch die Verkehrsgeographie als eigenständige Disziplin, wenngleich der Verkehr aufgrund der engen Beziehung zu Wirtschaftsthemen in der Vergangenheit als Teil der Wirtschaftsgeographie betrachtet wurde. ${ }^{8}$ In der frühen Phase der Verkehrsgeographie stand vor allem der morphogenetische Ansatz ${ }^{9}$ im Mittelpunkt, der den Verkehr in seiner deterministischen Abhängigkeit von den naturräumlichen Gegebenheiten beschrieb und die Verkehrsgeographie damit einen starken Bezug zur Physischen Geographie aufwies. Erst mit der Verknüpfung zu wirtschaftlichen Themen, beispielsweise über Entfernungsfragen, entwickelte sich die funktionale Verkehrsgeographie ${ }^{10}$ und näherte sich damit der Wirtschaftsgeographie an. Nuhn und Hesse formulieren den Gegenstand der Verkehrsgeographie im Vorwort ihrer 2006 erschienenden "Verkehrsgeographie“ folgendermaßen:

"Aus der Perspektive der Geographie geht es dabei um die räumliche Differenzierung von Verkehrsnachfrage und -angebot. Es geht auch um die Erreichbarkeit und Verkehrsfunktionalität insgesamt und ihre traditionell große Bedeutung für die Raumentwicklung". ${ }^{11}$

\footnotetext{
${ }^{6}$ vgl. Hübler/Kaether 1999, S.101

${ }^{7}$ vgl. Schätzl 2003, S.23

${ }^{8}$ vgl. Nuhn und Hesse 2006, S.14

9 Die Hauptvertreter dieses Ansatzes sind Schlüter (u.a. 1930) und Hettner

10 Die Hauptvertreter dieses Ansatzes sind Zimpel, Sander, Fochler-Hauke

${ }^{11}$ Nuhn und Hesse 2006, S.9
} 
Nuhn und Hesse ordnen die Verkehrsgeographie dem Bereich der Anthropo- bzw. Humangeographie zu. Sie steht damit gleichberechtigt, wenn auch weniger beachtet, zur Disziplin Wirtschaftsgeographie. Sie verweisen gleichzeitig auf ältere Ansätze, die die Verkehrsgeographie aufgrund der engen Verknüpfungen zwischen Handel und Verkehr noch als Teil der Wirtschaftsgeographie betrachteten. ${ }^{12}$ Beachtet man den absoluten Anstieg des Verkehrsaufkommens im Individualverkehr sowie dessen Folgen für die Umwelt oder die wachsende Bedeutung des Güterverkehrs im Rahmen der zunehmenden internationalen Wirtschaftsverflechtungen, scheint die separate Bezugnahme gerechtfertigt.

Bezogen auf die Verkehrsplanung liefert die funktionale Verkehrsgeographie, die die räumlichen Wirkungen des Verkehrs sowie den Verkehr selber als „räumliches System“ begreift, auf einer untergeordneten Ebene wichtige Grundlagen. Die Verkehrsplanung wiederum hat einen starken Bezug zu den geographischen Bereichen der Wirtschaftsund Sozialgeographie sowie zu den Verkehrswissenschaften als wirtschafts- und ingenieurswissenschaftliche Disziplin. Aus der Sicht der Verkehrsplanung wird damit der stark interdisziplinäre Charakter der „Verkehrsbranche“ deutlich.

Die vorliegende Arbeit versteht sich als Beitrag zur angewandten Geographie, die unter Berücksichtigung der erforderlichen theoretischen Grundlagen und Rahmenbedingungen Planungsmöglichkeiten aufzeigen möchte, mit deren Hilfe eine Optimierung der positiven Aspekte des Öffentlichen Personennahverkehrs (ÖPNV) und eine Minimierung negativer Faktoren und Einflüsse erfolgen kann.

12 vgl. Nuhn und Hesse 2006, S.14 


\title{
2 Der ÖPNV vor - neuen - Herausforderungen
}

\begin{abstract}
„Unterschiedliche Zugänge zu den ÖPNV-Verkehrsmitteln, unterschiedliche Bedienungsvorschriften für Fahrkarten- und Informationsautomaten und ähnliche Unterschiede erschweren die Nutzung des ÖPNV und damit die Bereitschaft des Einzelnen, sich für den ÖPNV zu entscheiden. Einheitliche Standards, eine einheitliche ,Benutzeroberfläche' sind daher unter Einsatz wirtschaftlich effizienter Technologien mindestens verbundweit festzulegen."

Begründung zu den im Gesetz über den öffentlichen Personennahverkehr in Hessen (Hess. ÖPNVG) verankerten allgemeinen Anforderungen ${ }^{13}$
\end{abstract}

Diese Fußnote findet sich als Begründung zum Paragraphen 4 der Gesetzesnovelle zum Hess. ÖPNVG, in dem der "Zugang und die Angebotsnutzung“ zum ÖPNV mittels einheitlicher "Normen mindestens verbundweit festzulegen“ sind. Die fehlende Einheitlichkeit, die dem potenziellen „Benutzer“ die Nutzung bereits an der „Oberfläche“ erschwert, ist ein Indiz dafür, dass dies nicht nur ein Problem technischer Natur ist, sondern auch auf organisatorische Versäumnisse zurückzuführen ist.

Die Fußnote verweist damit indirekt auf die komplexe Situation, durch die die Vermarktung des Nahverkehrs - nicht nur in Hessen - gekennzeichnet ist. Diese Situation hat ihren Ursprung in der unabgestimmten Entwicklung der Verkehrsunternehmen - insbesondere der Busunternehmen ${ }^{14}$ - nach dem Ende des 2. Weltkrieges. Damals erfolgte der Wiederaufbau der Verkehrsunternehmen vor allem in Eigenregie der Kommunen. ${ }^{15}$ In der Folge entwickelten sich insbesondere in den Ballungsräumen und Großstädten leistungsfähige Nahverkehrssysteme, die, der zunehmenden Motorisierung zum Trotz, die Mobilität der Städte weithin bewahrten. ${ }^{16}$ Allerdings hatten sich die kommunalen wirtschaftlichen Aktivitäten, wozu auch die Vorhaltung des öffentlichen Personennahver-

\footnotetext{
${ }^{13}$ Hessischer Landtag 2005, S.14

${ }^{14}$ Der Schienenpersonenverkehr befand sich durch die Deutsche Bundesbahn ehedem in staatlicher Hand.

15 So befanden sich 1957 76\% aller Nahverkehrsbetriebe in kommunaler Hand. 18\% waren gemischtwirtschaftlich und nur 6\% privat; vgl. Dienel und Schmucki 1997, S.7ff

${ }^{16}$ vgl. Kossak und Pällmann, S.25
} 
kehrs (ÖPNV) gehört, innerhalb der kommunalen Grenzen abzuspielen (vgl. Kapitel 5.3.2.3). Dies führte letztlich zu heterogenen ÖPNV-Landschaften und dazu, dass die verkehrsmittel- und gebietsübergreifende Nutzung von Bussen und Bahnen erschwert wurde. Dies mag neben städtebaulichen Verfehlungen mit ein Grund dafür sein, dass der ÖPNV gegenüber dem sich rasant entwickelnden motorisierten Individualverkehr $(\mathrm{MIV})^{17}$ kontinuierlich Anteile verloren hat. Nur mit „immensen Anstrengungen und Investitionen wird der rasante Rückgang des Modal Split-Anteils des öffentlichen Personenverkehrs in den 1970er Jahren abgebremst“. ${ }^{18}$ Trotz Förderprogrammen, der Gründung von Verkehrsverbünden, Liberalisierung und Regionalisierung (siehe Kapitel 5.1) sinkt der ÖPNV-Anteil jedoch bis heute weiter. Kossak und Pällmann schlussfolgern, dass neben der Herausforderung der konsequenten Umsetzung der Liberalisierungs- und Regionalisierungsbemühungen

„beträchtliche Herausforderungen aufgrund der knapper werdenden Mittel der öffentlichen Haushalte sowie drastischer Veränderungen der sozioökonomischen Struktur der Bevölkerung [auf den ÖPNV zukommen]. Um ihnen gewachsen zu sein, ist nicht zuletzt auch zu prüfen, ob sich die organisatorischen Strukturen der Gestaltung des ÖPNV überall richtig entwickelt haben". ${ }^{19}$

Unter den organisatorischen Strukturen können einerseits die administrativen Verwaltungsstrukturen verstanden werden (siehe Kapitel 5.4), andererseits aber auch die Organisation der Prozesse und Abläufe im Betrieb. Der organisatorische Anspruch hinter der Forderung nach einer „einheitlichen Benutzeroberfläche“, der mit großer Mehrheit auch von ÖPNV-Experten geteilt wird, ${ }^{20}$ bedeutet, dass die Kunden generell an allen Zugängen zum ÖPNV einheitliche Informations- und Verkaufsmöglichkeiten vorfinden sollten. Der Endbericht zu einer vom Deutschen Verkehrsforum in Auftrag gegebenen Studie zum „ÖPNV-Markt der Zukunft“21 kommt zur Erkenntnis, dass

"Angebote, Systeme und Aufgaben des ÖPNV entsprechend den Anforderungen regionaler Märkte und Akteure unterschiedlich ausgestaltet werden. Die Benutzeroberfläche des ÖPNV wird daher auf regionaler Ebene zukünftig jedoch stärker vereinheitlicht. Damit

\footnotetext{
17 hierunter werden Pkw, Motorräder und Mopeds gezählt; vgl. Nuhn und Hesse 2006, S.35

${ }^{18}$ Kossak und Pällmann, S.25

19 ebd., S.26

${ }^{20} \mathrm{vgl}$. Deutsches Verkehrsforum 2005, S.119

${ }^{21} \mathrm{ebd}$.
} 
wächst die Notwendigkeit von überregionalen Abstimmungen der Akteure und der Festlegung sinnvoller Standards für die Gestaltung der vielfältigen Kundenschnittstellen“. ${ }^{22}$

Diese Einheitlichkeit soll ihre Ausprägung nicht alleine in der grafischen Gestaltungen finden, sondern vor allem in den Prozessen, die vom Kunden zu durchlaufen sind, bis dieser eine gültige Fahrtberechtigung erhält. Diese Prozesse sind so zu gestalten, dass sie vom Fahrgast möglichst einfach und intuitiv zu erfassen sind. Kossak und Pällmann beschreiben diesen Zielzustand folgendermaßen:

„Am Ende der Entwicklung steht der dann ,vollwertige Bürger', der jederzeit an jedem Ort alle erforderlichen Informationen über den ÖPNV und seine Einbindung in den Mobilitätsverbund verfügbar hat, der die für ihn günstigste und bequemste Beförderungsart problemlos buchen, bezahlen und in Anspruch nehmen kann". ${ }^{23}$

Vor dieser Herausforderung steht auch der für die Region Frankfurt Rhein-Main in großen Teilen verantwortliche, im Jahre 1995 gegründete Rhein-Main-Verkehrsverbund (RMV). Dieser gibt zwar Grundsätze für die Gestaltung der Fahrgast-Information und der Vertriebsstellen heraus. Doch mehr als 150 Verkehrsunternehmen, 23 Lokale Nahverkehrsorganisationen (die lokale öffentliche Verkehrsaufgaben wahrnehmen) und mehrere hundert private Verkaufsstellen machen das organisatorische Problem am Beispiel des RMV besonders deutlich, den ÖPNV bzw. dessen Dienstleistungen einheitlich zu vermarkten.

In der oben genannten Fußnote wird diesbezüglich der Hoffnung Ausdruck verliehen, über „effiziente Technologien“ zu einer Einheitlichkeit zu finden, mit dem dieses - auch wirtschaftliche - Defizit begegnet werden kann. Das kann dahingehend interpretiert werden, dass man über den Einsatz standardisierter Technologien zu einer Vereinfachung bis hin zur vereinfachten grafischen Darstellung - bei der Auswahl von komplexen Preisbzw. Tarifkonstellationen und Fahrplanangeboten gelangt. Dieses stellt schließlich die grundlegende Voraussetzung dar, damit eine Fahrkarte vom Kunden erworben wird.

Im Kontext dieser Darlegung wird in der vorliegenden Arbeit beschrieben, wie auf Basis von Informations- und Kommunikationstechnologien (IuK-Technologien) neue Chancen

22 vgl. Deutsches Verkehrsforum 2005, S.119

${ }^{23}$ Kossak und Pällmann 2006, S.27 
im Bereich der Vermarktung von ÖPNV-Leistung erschlossen werden bzw. die Zugangsbarrieren bei der Nutzung von Bussen und Bahnen reduziert werden können und der ÖPNV auf eine wirtschaftlichere Basis gestellt werden kann. Denn nicht zuletzt versprechen sich die ÖPNV-Experten von der Nutzung dieser Technologien einen großen wirtschaftlichen Nutzen. ${ }^{24}$ Ohne eine Verbesserung der wirtschaftlichen Ausgangslage wird der ÖPNV letztlich nur einen unwesentlichen Beitrag zur - immer notwendiger werdenden - nachhaltigen Mobilitätssicherung im Rahmen eines von der hessischen Landesregierung geforderten Integrierten Gesamtverkehrskonzeptes liefern können. Dieser Beitrag unterstützt die für die Region Frankfurt Rhein-Main notwendige Sicherung der Mobilität, die wesentlich zur Wirtschaftskraft und zum Wohlstand beiträgt.

${ }^{24}$ vgl. Deutsches Verkehrsforum 2005, S.49f 


\title{
Teil B: Nachhaltige Mobilitätssicherung in der Region Frankfurt Rhein-Main
}

\section{$3 \quad$ Nachhaltige Mobilität als Standortfaktor}

\begin{abstract}
"I I want to wake up in a city that never sleeps': Noch Frank Sinatras New-York-Hymne an die Stadt, die niemals schläft, setzte für Handel und Wandel zweierlei voraus: unendliche Kommunikation und grenzenlose Osmose der Stadtbewohner. Also geistige und räumliche Mobilität. Sowie ein entspanntes Verhältnis zum Auto, das - als Analogie zur Stadt - vor allem auch die Images von Individualität und Freiheit von A nach B transportiert". ${ }^{25}$

Gerhard Matzig, Journalist und Redakteur der "Süddeutschen Zeitung“
\end{abstract}

\subsection{Formen der Mobilität}

\subsubsection{Der Begriff „Mobilität“}

Mobilität wird allgemein mit „Beweglichkeit“ verbunden. Hierzu gehört einerseits die räumliche, distanzüberwindende Mobilität, andererseits die soziale Mobilität, die mit gesellschaftlichem Auf- oder Abstieg verknüpft ist. In Verbindung mit räumlicher Distanzüberwindung spielt die Erreichbarkeit von Orten eine Rolle, die wiederum von der Verfügbarkeit von Verkehrsmitteln und Infrastrukturen abhängt. "Geistige Mobilität" dagegen wird als Möglichkeit zur Teilhabe am gesellschaftlichen Leben verstanden, die ihrerseits stark von der individuellen Bereitschaft zur Bewegung abhängt. ${ }^{26}$ „Mobilitätsräume sind daher auch immer Möglichkeitsräume für eine moderne Lebensgestaltung“ ${ }^{27}$ Verkehr dagegen ist der konkrete Ausdruck der Nachfrage der Menschen nach Verkehrsleistungen, also die tatsächlich erfolgte Umsetzung der Ortsveränderung. „Ortsveränderungen erfolgen, weil jemand ein Ziel erreichen will, weil ein Mobilitätsbedürfnis vor-

\footnotetext{
25 In: Süddeutsche Zeitung vom 11.01.2007: „Alle Räder stehen still“. S.13.

${ }^{26}$ vgl. Hesse und Nuhn 2006, S.19

${ }^{27}$ vgl. Canzler und Knie 2005, S.9
} 
liegt“ ${ }^{28}$, ganz gleich, ob es sich um einen Berufspendler oder Freizeitakteure handelt: „Da zur Raumüberwindung Aufwand und Kosten nötig sind, ist Verkehr [also] nie Selbstzweck, sondern Ausdruck des Menschen nach Ortsveränderung“. ${ }^{29}$ Mobilität und Verkehr hängen also unmittelbar miteinander zusammen: Mobilität beschreibt das Bedürfnis nach Ortsveränderung, Verkehr die Umsetzung. ${ }^{30}$

\subsubsection{Mobilität von Personen}

Der Begriff „Person“ meint hier sowohl natürliche Personen (Individuen, die private Haushalte bilden) wie auch juristische Personen (also Wirtschaftsunternehmen, Vereine, Stiftungen oder juristische Personen des öffentlichen Rechts). Beide Gruppen haben unterschiedliche Anforderungen an die Verkehrssysteme. ${ }^{31}$ Für natürliche Personen steht die konkrete Überwindung der Raumdistanz im Vordergrund (Raumerschließung), während für Wirtschaftsunternehmen die Qualität der Raumerschließung von Bedeutung ist (Raumwirksamkeit).

Die Mobilität von natürlichen Personen ${ }^{32}$ war immer schon eng mit der Nutzung technischer Innovationen verknüpft. So wurde die Industrialisierung maßgeblich von der Entwicklung der Eisenbahn beeinflusst, da über sie erst die notwendigen Arbeitskräfte und Ressourcen bereit gestellt wurden. ${ }^{33}$ Bezogen auf die Arbeitskräfte drückt sich diese Mobilität in Pendlerbewegungen aus, die wiederum in den unterschiedlichen Verhältnissen der Quell- und Zielregionen bzw. -orte begründet lagen. Schließlich führten technischen Innovationen und damit einhergehend die Vergünstigung der Produktionsbedingungen in der Automobilindustrie dazu, dass nach dem 2. Weltkrieg eine Massenmotorisierung bzw. -mobilisierung stattfand. Sowohl der Bau der Eisenbahnen im 19. Jahrhundert wie auch im 20. Jahrhundert die Massenmotorisierung sowie „der Aufstieg der modernen Hochgeschwindigkeitssysteme von Eisenbahn und Luftverkehr“, wären allerdings ohne

\footnotetext{
${ }^{28}$ vgl. Becker, U. 2002, S.13

${ }^{29}$ Schliephake 1982, S.44

${ }^{30}$ vgl. Becker, U. 2002, S.13

${ }^{31}$ Verkehrssysteme setzen sich zusammen aus Verkehrsmitteln und Verkehrswegen.

32 Im Gegensatz hierzu wird „Migration“ als räumliche Mobilität mit gleichzeitigem Wechsel des Wohnsitzes verstanden.

${ }^{33}$ vgl. Nuhn und Hesse 2006, S.21
} 
die zu Grunde liegenden Vorgaben der Infrastruktur- und Ordnungspolitik nicht denkbar gewesen. ${ }^{34}$

Ob ein individueller Vorteil in einer Ortsveränderung erkannt wird, hängt vom jeweiligen Informationsstand der Akteure ab. Dieser wiederum wird beeinflusst vom bestehenden Kommunikationssystem, von der Leistungsfähigkeit der Kommunikationskanäle und von der Intensität der Informationsimpulse sowie von der individuellen Bereitschaft, mobilitätsrelevante Informationen aufzunehmen. ${ }^{35}$ Je größer also beispielsweise die Unterschiede zwischen den Bedingungen am Wohnort und den Bedingungen an einem möglichen Arbeitsort, desto größer ist die Wahrscheinlichkeit für räumliche Mobilität bzw. die Wahrscheinlichkeit, dass das Bedürfnis von A nach B zu kommen befriedigt werden muss. Die Unterschiede ergeben sich u.a. durch das zu erzielende Einkommen, dem Lohnniveau, den Lebenshaltungskosten, der Beschäftigungsstruktur, den Wohnverhältnissen, dem Freizeitwert, der Infrastruktur (Verkehr, Bildung, Kultur etc.). ${ }^{36}$ So gibt es neben den erwerbs- und berufsorientierten Fahrtanlässen auch versorgungsorientierte, ausbildungsorientierte oder freizeitorientierte Fahrtanlässe. Das Vorhandensein sowie die Qualität der Standortfaktoren einer Region sowie das Wissen über diese Faktoren beeinflussen also die inter- und intraregionale Mobilität einer Region ganz wesentlich.

Die Studie „Mobilität in Deutschland 2002“37 (MiD) unterstreicht in ihren Ergebnissen, dass die Mobilität von Personen einem Wandel unterliegt, auch wenn dieser Wandel em-

34 Nuhn und Hesse 2006, S.22

${ }^{35} \mathrm{vgl}$. Siebert 1970, S.44ff

36 vgl. Schätzl 2003, S.105

37 vgl. DIW und infas 2003; Das Deutsche Institut für Wirtschaftsforschung (DIW) hat gemeinsam mit dem infas-Institut für angewandte Sozialwissenschaft im Jahre 2002 im Auftrag des Bundesministeriums für Verkehr, Bau und Wohnungswesen die KONTIV Nachfolgestudie „Mobilität in Deutschland“ durchgeführt. Die Erhebung liefert u.a. Aussagen zu den Nutzungsmöglichkeiten von Verkehrsmitteln sowie den Bedürfnissen und Anforderungen von Mobilitätkunden (Zielorte, -aktivitäten, Zeit- und Finanzbudgets etc.). Die Kombination aus Stichtagsbefragung und generellen Fragen zur Inanspruchnahme unterschiedlicher Verkehrsmittel auf der einen Seite und hohen methodischen Standards auf der anderen Seite liefert gleichzeitig eine solide Grundlage für Hochrechnungen des Verkehrsgeschehens und Ansätze zum Marketing für Bus oder Bahn (siehe Kapitel 6.3.2). Die Erhebung liefert u.a. Erkenntnisse über die Verkehrsmittelwahl, Wegehäufigkeiten und -längen sowie die Verteilung und Art der Nutzung einzelner Verkehrsmittel. Durch eine Aufstockungsstichprobe besteht die Datengrundlage für Hessen aus 8.761 Haushalten, 21.229 befragten Personen und 57.159 erfassten Wegen (vgl. Planungsverband Ballungsraum Frankfurt/Rhein-Main u.a. 2005, S.4). Der Planungsverband Ballungsraum Frankfurt/Rhein-Main, die Lokale Nahverkehrsgesellschaft Frankfurt am Main und der Nordhessische Verkehrsverbund haben aus dieser aufgestockten Stichprobe repräsentative Aussagen für die Grundgesamtheit der in Hessen lebenden Bevölkerung und Haus- 
pirisch erst schrittweise erschlossen wird. ${ }^{38}$ Dieser Wandel drückt sich in fünf zentralen Trends aus: eine zunehmende Motorisierung der privaten Haushalte, steigende Anteile des Pkw-Verkehrs am gesamten Verkehrsaufkommen, ein stagnierendes absolutes Aufkommen im ÖPNV, hohe Wachstumsraten im Erledigungs-, Einkaufs- und Freizeitverkehr sowie höhere Zeitbudgets für die tägliche Mobilität bei wachsenden Wegelängen (siehe Kapitel 4.4.7). ${ }^{39}$ Dieser Wandel führt soweit, dass die Mobilität anderen Bedürfnissen als nur der Raumüberwindung dient, Mobilität und Verkehr also zum Beispiel Mittel der Freizeitbeschäftigung und der Selbstverwirklichung werden. 40 „Die ,Fahrt ins Blaue' mit dem eigenen Pkw findet statt, weil der Autofahrer den erhofften ,Lustgewinn' hoch einschätzt und bereit ist, dafür eine bestimmte Geldsumme auszugeben“ ${ }^{41}$

\subsubsection{Mobilität von Gütern}

Die Mobilität von Gütern ist vor allem ökonomisch bestimmt und wird daher stets im engen Bezug zu den Transportkosten gesehen. Dabei ist zu berücksichtigen, dass auch standortunabhängige Unternehmen von bestimmten lokalen und regionalen Komponenten abhängig sind, denn auch sie benötigen Arbeitskräfte und produzieren für einen $\mathrm{Ab}$ satzmarkt. ${ }^{42}$ Die jeweilige Lagerfähigkeit der Güter ist dabei ausschlaggebend für den Verkehrsbedarf und beeinflusst auch die Wahl des Verkehrsmittels für den Transport. Ansonsten gibt es über die Gütermobilität nur wenige Informationen, insbesondere „unterhalb der hochaggregierten Werte von Transportaufkommen, Tonnen- und Fahrzeugkilometern", die im Bereich der Logistik eine Rolle spielen. ${ }^{43}$ Da diese Arbeit schwerpunktmäßig den Bereich des Personenverkehrs behandelt, wird der Güterverkehr nur insoweit behandelt, als dass ihm eine ökonomisch-raumwirksame Funktion zukommt, die im Rahmen eines verkehrsbezogenen Gesamtsystems unbedingt berücksichtigt werden muss.

halte abgeleitet. Es liegen Ergebnisse für Teilgebietstypen mit besonderer Bedeutung (Bundesland, Region, Ballungsraum, Stadt, Umland) vor, die auch in zeitlicher Hinsicht (Jahreswerte) repräsentativ sind. Die Analyse des Verkehrsverhaltens in Hessen bzw. in der Region Frankfurt Rhein-Main stützt sich zu wesentlichen Teilen auf diese Erhebung.

${ }^{38}$ vgl. Nuhn und Hesse 2006, S.27

39 vgl. Planungsverband Ballungsraum Frankfurt/Rhein-Main u.a. 2005, S.74f

${ }^{40}$ vgl. Nuhn und Hesse 2006, S.27

${ }^{41}$ Schliephake 1982, S.44

42 vgl. Schliephake 1982, S.56

${ }^{43}$ vgl. Aberle 2003, S.5 
Der Nachrichtenverkehr umfasst den Transport von Waren im weitesten Sinne, gegliedert nach materieller (z.B. Briefe) und elektronischer Beförderung. ${ }^{44}$ Zunächst verstand man unter der Mobilität von Nachrichten den Transport von Briefen per Postkutsche. Mit der Erfindung des Telegrafen und des Telefons im 19. Jh. kam es dann zu einer grundlegenden Veränderung des Kommunikationswesens. In der ersten Hälfte des 20. Jh. entwickelte sich das Radio zu einer wichtigen Informationsquelle. Mit der Verbreitung von Telefon und Fernsehen in der 2. Hälfte des 20. Jh. wurden Information und Kommunikation endgültig zu Massenphänomenen. Die Digitalisierung der Datenübertragung - aber auch die Aufhebung von staatlichen Monopolen bei der Nachrichtenübermittlung - führte zu weitreichenden gesellschaftlichen Transformationen, so dass man heute von einer Informationsgesellschaft spricht. Wesentlichen Anteil hieran haben das Internet und die Entwicklung der Mobilfunktechnologie, die dazu beitragen, dass Nachrichten schneller (quasi online), in besserer Qualität, fast in beliebiger Menge, zu günstigeren Preisen und - vor allem auch - nahezu ortsunabhängig bereit gestellt werden können. Die Entwicklung der IuK-Technologien hat daher direkte Auswirkungen auf das Mobilitätsverhalten von Personen, insbesondere in raum-zeitlicher Hinsicht. 45

\subsection{Mobilität und Regionalentwicklung}

3.2.1 Die Abhängigkeit von Verkehrs- und Regionalentwicklung

Schon Thünen hat in seinem 1826 veröffentlichten Hauptwerk „Der isolirte Staat in Beziehung auf Landwirthschaft und National-Oekonomie“ 46 darauf hingewiesen, dass die Art und Weise der Verkehrserschließung Einfluss auf die räumliche Differenzierung in der Intensität der Landnutzung hat. Ausschlaggebend für diese Differenzierung sind im Modell Thünens vor allem die entstehenden Transportkosten, die direkt proportional von der Entfernung des Produktionsstandortes zum Konsumort betrachtet wurden. Eine Aufhebung der vereinfachten Annahmen führt im Modell dazu, dass die konzentrischen Kreise

\footnotetext{
${ }^{44}$ vgl. Schliephake 1982, S.61f

${ }^{45}$ vgl. Nuhn und Hesse 2006, S.160ff

46 Thünen, Johann Heinrich von: „Der isolirte Staat in Beziehung auf Landwirthschaft und National-Oekonomie“. Hamburg 1826.
} 
(„Thünschen Ringe“) der Intensität der Bodennutzung um einen Konsumort herum eine Abweichung aufzeigen. ${ }^{47}$

Ein Jahrhundert später hat Christaller 481933 in der „Theorie der zentralen Orte“ den Einfluss ökonomischer Faktoren auf die hierarchische Ordnung von Siedlungen dargelegt. Im „Verkehrsprinzip“ wird ergänzt, dass die Verkehrsanbindung wesentlichen Einfluss auf die Anordnung der hierarchischen Stufenfolge der Orte hat. Dies wird daran deutlich, dass sich zentrale Orte insbesondere entlang von bedeutenden Verkehrswegen entwickeln. Seit der Veröffentlichung der Theorie gab es etliche empirische, theoretische und regionalpolitische Untersuchungen, von denen die meisten die wesentlichen Eigenschaften des Modells Christallers bestätigten. In den Zeiten der Globalisierung49, in denen Lebensmittel weit entfernt von den Konsumorten erzeugt werden, muss allerdings auch eingeräumt werden, dass - auch aufgrund der Individualität der Räume - noch zahlreiche andere Faktoren Einfluss auf die Entwicklung von Orten und Städten ausüben.50 Hierzu zählen insbesondere siedlungsstrukturelle Einflüsse sowie soziale Aspekte. „Erst das Zusammenwirken von (Verkehrs-)Infrastruktur, Sozialstruktur und Raumstruktur erklärt die jeweilige Eigenschaft eines Teilraums mit Blick auf das spezifische Aufkommen von Mobilität und Verkehr“. ${ }^{51}$

Die Art und Weise der verkehrlichen Erreichbarkeit eines Ortes, einer Stadt und einer Region ist entscheidend für deren Entwicklung und Prosperität. Historisch betrachtet entstanden wohlhabende Siedlungen vor allem an Kreuzungspunkten von wichtigen Verkehrsadern. Bis zum Einsatz der Eisenbahn spielten hierbei vor allem Häfen und Wasserstraßen eine bedeutende Rolle, da die Landwege schlecht ausgebaut und gefährlich(er) waren. Erst mit der räumlichen Erschließung durch die Eisenbahn im Zuge der industriellen Revolution - insbesondere im 19. Jahrhundert - kam die Wende zur Entwicklung des modernern Verkehrswesens und des modernen Handels. Die Eisenbahn ermöglichte eine

\footnotetext{
${ }^{47}$ vgl. Schätzl 2003, S.63ff

${ }^{48}$ Christaller, W.: „Die zentralen Orte in Süddeutschland. Eine ökonomisch-geographische Untersuchung über die Gesetzmäßigkeit der Verbreitung und Entwicklung der Siedlungen mit städtischen Funktionen". Jena 1933.

${ }^{49}$ Unter Globalisierung wird ein „Prozeß zur Etablierung und Intensivierung weltweiter Wirtschaftsbeziehungen verstanden“. Hierzu gehören u.a. die Internationalisierung der Finanzmärkte (siehe Frankfurt am Main), die internationale Verflechtung von Wirtschaftsunternehmen sowie der internationale Austausch von Wissen und Technologie; vgl. Lucas, S.6.

${ }^{50} \mathrm{vgl}$. Schätzl 2003, S.72ff

${ }^{51}$ Nuhn und Hesse 2006, S.187-189
} 
drastische Reduzierung der Transportkosten, wodurch sich die ökonomische Bedeutung der räumlichen Distanz verringerte. Dies führte in der Folge zu einer Intensivierung des Handels. Diese Tendenz setzte sich im 20. Jahrhundert durch den massenhaften Einsatz von Lastkraftwagen weiter fort. ${ }^{52}$ Erst im 20.Jahrhundert, das auch als „Zeitalter der Mobilität“ bezeichnet werden kann, „kamen die Bilder der Bahnhöfe, der Straßenschluchten und der bewegten Massen in der Vorstellung der modernen Stadt zur Deckung“. ${ }^{53}$

In dem Maße wie sich die städtische, regionale und globale Arbeitsteilung entwickelte und sich die Konsum- und Wohnorte von den Arbeits- und Produktionsorten lösten, erhielt das Transportwesen auch zunehmend Bedeutung für die Personenbeförderung. Niedrige Transport- und Beförderungskosten und eine entsprechend hohe Qualität bei der Personenbeförderung sind Indikatoren für eine gute Verkehrsanbindung. Sie begünstigen eine über weite Räume ausgedehnte Arbeitsteilung mit entsprechender Spezialisierung. „Arbeitsteilung [wiederum] ist Grundlage moderner Wirtschaft, Verkehr Grundlage der Arbeitsteilung. Somit bewirkt Arbeitsteilung, dass Verkehr zum essentiellen Bestandteil der Produktion wird“ ${ }^{54}$ Eine qualitativ hochwertige Verkehrsanbindung trägt dazu bei, dass die Verteilung der Produktionsfaktoren in einer für die Volkswirtschaft günstigen Weise vollzogen werden kann und sich der größte ökonomische - aber auch soziale - Nutzen für die Wirtschaftsakteure ergibt. ${ }^{55}$

Die gute verkehrliche Erreichbarkeit eines Produktionsstandortes ist also nicht nur aus Sicht des Arbeitnehmers von großer Bedeutung, sondern auch für das arbeitgebende Unternehmen. Dieses fällt seine Entscheidung über die Standortwahl in der Regel nach dem Rationalprinzip, d.h., dass es das Ziel ist, mit möglichst geringem Mitteleinsatz einen größtmöglichen Gewinn zu erzielen. Bei der Standortwahl zählen Argumente wie Zeitersparnis, Kostenreduktion und die einfache Erreichbarkeit leistungsfähiger Verkehrssysteme. Deren Bedeutung nimmt in den Zeiten der Globalisierung zu, wobei die verstärkte internationale Arbeitsteilung einerseits zu großräumigen Strukturen bei den Transportund Warenströmen führt, andererseits aber die Spezialisierung der Regionen forciert. So

\footnotetext{
52 vgl. Kahl 2005, S.15f

53 Matzig 2007, S.13

${ }^{54}$ Kahl 2005, S.17; siehe auch Schliephake 1982, S.40

${ }^{55}$ vgl. Wagner 1998, S.10
} 
besteht zwar zwischen der Regionalentwicklung und der Globalisierung ein Spannungsverhältnis, doch schließen sie sich als Entwicklungsziele gegenseitig nicht aus. ${ }^{56}$

Die Abhängigkeit von Verkehr und Wirtschaft ist eine wechselseitige Beziehung. So ist die Wirtschaftsstruktur eine ganz wesentliche Determinante für den Verkehr in einer Region. In Abhängigkeit von der Art, Funktion und Bedeutung sowie der räumlichen Verteilung und Vernetzung der Wirtschaftsbereiche richten sich die Verkehrsströme in ihrer Intensität hierauf aus. Die Verkehrsströme spiegeln den Austausch von Personen und Gütern, aber auch von Dienstleistungen, Kaufkraft, Kapital und technischem Wissen wider. Sie bilden damit eine wesentliche Basis der regionalen Wirtschaftskraft und für die Wirtschaftsentwicklung. ${ }^{57}$ Beispielsweise erhöht die Zuwanderung der Produktionsfaktoren Arbeit, Kapital und technisches Wissen die regionale Produktionskapazität oder wirkt sich eine Intensivierung des interregionalen Güteraustauschs über die Angebots- und Nachfrageseite positiv auf die Wirtschaftsentwicklung aus. Von daher kommt der räumlichen Mobilität von Personen und Gütern eine wesentliche Funktion bei der Regionalentwicklung zu.

Eine gute Verkehrsqualität 58 wirkt sich also günstig auf die Wettbewerbssituation eines einzelnen Unternehmens aus - und damit auf die Regionalentwicklung insgesamt. Aberle kommt zum Schluss, dass die Qualität der Verkehrsinfrastruktur die „Voraussetzung positiver regionaler Entwicklung im überregionalen (nationalen, europaweiten, weltweiten) Standortwettbewerb" ist. 59

\subsubsection{Mobilitätswiderstände}

Neben mobilitätsfördernden Faktoren gibt es solche, die Mobilität behindern können. Hierzu gehören beispielsweise die lokalen Verhältnisse auf den Arbeits- und Wohnungsmärkten sowie persönliche und finanzielle Faktoren. Außerdem gehört die räumliche Distanz selbst dazu und die damit verbundenen Kosten und Zeitaufwände, die zu Über-

\footnotetext{
${ }^{56}$ vgl. Lucas 2000, S.6

${ }^{57}$ vgl. Wagner 1998, S.21

${ }^{58}$ Die Verkehrsqualität ist durch zahlreiche Aspekte gekennzeichnet, so bspw. durch die Verkehrsbedienung, Verkehrsinfrastruktur, Nahverkehrsangebot, Fahrt- und Wartezeiten, Fahrtkosten, Sicherheit, Bequemlichkeit etc.

${ }^{59}$ Aberle 2006, S.4
} 
windung der Distanz notwendig sind. ${ }^{60}$ Kosten und Zeit nehmen in der Regel mit steigender Entfernung zwischen Ausgangs- und Zielpunkt (z.B. zwischen Wohn- und Arbeitsort) zu und sind von Verkehrsmittel zu Verkehrsmittel in der Höhe und auch in der Transparenz unterschiedlich. Dagegen spielt die Distanz bei der Informationsbeschaffung (z.B. über einen Zielort) durch die Verbreitung der neuen Medien kaum mehr eine Rolle. Einzig alleine können bei - vor allem grenzüberschreitender Mobilität - Unterschiede in Kultur, Sprache und Lebensgewohnheiten und die damit verbundenen Anpassungsschwierigkeiten am Zielort als Mobilitätswiderstände wirken. Die Bedeutung mobilitätsbehindernder Faktoren kann sich also verändern. So stellen Nuhn und Hesse, aufgrund des steigenden Anteils von sogenannten Freizeitverkehren, die - zumindest relative - Bedeutung der Faktoren Reisezeiten und Transportkosten in Frage. ${ }^{61}$

Siebert führt aus, dass der Entschluss zur Ortsveränderung keine statische Entscheidung, sondern ein dynamischer, von Unsicherheit geprägter Prozess ist. ${ }^{62}$ Dieses lässt sich etwa vom Vorhandensein einer verlässlichen Wegeführung (über Schilder oder Navigationsgerät) oder auch am Beispiel von Verkaufsautomaten im ÖPNV nachvollziehen. So spiegeln sich die unterschiedlichen Tarifstrukturen der Verkehrsverbünde in der Benutzeroberfläche des Verkaufsautomaten wider (unterschiedliche Altersklassen, Mitnahmeregelungen, Gültigkeitsdauer, Zeiteinteilungen63, Entwertung etc). Ein vom Kunden einmal gelerntes Vorgehen im "eigenen“ Verbund kann also nicht einfach auf einen "fremden“ Verbund übertragen werden. Die Verunsicherung, die hieraus für den Kunden erwächst, muss zwar nicht unbedingt dazu führen, dass eine Reise gar nicht angetreten wird. Aber es kann dazu führen, dass diese Reise mit dem privaten Pkw durchgeführt wird, bei dem der erlernte Gebrauch des Fahrzeuges ortsunabhängig ist und die Regeln (in Form der Straßenverkehrsordnung) bundesweit standardisiert sind.

\subsubsection{Nachhaltige Mobilität}

Die Qualität der Verkehrssysteme einer Region lässt keine Aussage zu, ob die nachgefragte Mobilität zu einer nachhaltigen Regionalentwicklung beiträgt. Denn damit der Verkehrssektor die Regionalentwicklung nachhaltig unterstützt, muss der Verkehr selber

\footnotetext{
${ }^{60} \mathrm{vgl}$. Bundesamt für Bauwesen und Raumordnung 2001, S.91

${ }^{61}$ vgl. Nuhn und Hesse 2006, S.27

62 vgl. Siebert 1995, S.405ff

${ }^{63}$ Als Beispiel sei hier die „9-Uhr-Karte“ des Rhein-Main-Verkehrsverbundes erwähnt.
} 
nachhaltig sein. Was allerdings unter „nachhaltigem Verkehr“ oder „nachhaltiger Mobilität“ zu verstehen ist, ist nicht immer klar. Das Begriffspaar „Nachhaltige Mobilität“ wird gelegentlich (insbesondere in Österreich) auch mit „Sanfter Mobilität“ synonym verwendet. ${ }^{64}$ Nachhaltige Mobilität zielt darauf ab, umweltschonende und sozial verträgliche Verkehrsmittel zu fördern. Zu diesen Verkehrsmitteln werden das zu Fuß gehen, Fahrradfahren und der ÖPNV gezählt, die zusammengefasst auch als „Umweltverbund“ bezeichnet werden. Kennzeichen dieser Verkehrsmittel ist ihre im Unterschied zum MIV höhere Effizienz ${ }^{65}$ und die von ihnen ausgehenden geringeren Umwelteinflüsse. Beispielsweise verbrauchen Busse und Bahnen bei entsprechender Auslastung weniger Energie pro beförderter Person, stoßen weniger Schadstoffe aus, verursachen weniger Lärm, nehmen weniger Fläche in Anspruch (auch im ruhenden Verkehr) und gehen von ihnen eine geringere Gefährdung anderer Verkehrsteilnehmer aus.

„Man kann Mobilität mit einem sehr teuren und aufwändigen Verkehrsmittel und über sehr große Entfernungen mit hohen Energie- und Abgaskosten erreichen, und man kann Mobilität mit wenig Verkehr, wenig Geld, wenigen Umweltbelastungen, wenig Ressourcenverbrauch und wenig Lärm und Abgasen ermöglichen". 66

Problematisch hierbei ist, dass ein attraktiver (also schneller, billiger, bequemer) Verkehr in der Regel jedoch mit negativen Folgewirkungen für Umwelt, Menschen und Wirtschaft behaftet ist. Damit sich der Verkehr nachhaltig entwickelt, müssen diese negativen Folgen minimiert und gleichzeitig die Mobilitätsbedürfnisse eines jeden Einzelnen befriedigt werden. Dieses hat mit möglichst wenig Aufwand zu erfolgen, was in der Konsequenz eine Reduzierung der Verkehrsnachfrage bedeutet.

Eine Verkehrsreduzierung bedeutet jedoch einen tiefen Einschnitt in die heutigen Verhaltensmuster im Verkehr. Die hierfür notwendigen Änderungen im Mobilitäts- und Verkehrsverhalten können kaum erzwungen werden. Insbesondere dann nicht, wenn den Menschen möglichst viele Mobilitätsoptionen angeboten werden sollen, es also nicht zu einem dirigistischen und restriktiven ordnungspolitischen Eingriff in das Verkehrsangebot und den -ablauf kommen soll. Denn auch die unterschiedlichen Optionen auf Mobili-

\footnotetext{
${ }^{64} \mathrm{vgl}$. www.bund.de

65 Unter Effizienz wird im Rahmen dieser Arbeit die Wirksamkeit von Maßnahmen im Verhältnis zu den angestrebten Zielen verstanden.

${ }^{66}$ Becker, U. 2002, S.13
} 
tät sind Teil der Nachhaltigkeitsstrategie, zumal niemand voraussagen kann, wie sich die Rahmenbedingungen für einzelne Verkehrsträger in Zukunft entwickeln werden. Dieses trifft insbesondere auf den MIV zu, dessen Attraktivität heute u.a. von (immer noch relativ) niedrigen Ölpreisen abhängt. Sollte also die Mobilität zukünftig vornehmlich über den MIV gesichert werden, könnten Mobilitätseinschränkungen unabwendbar sein, wenn es zu einem Engpass in der Ölversorgung käme - mit allen nachteiligen Auswirkungen auf die Regionalentwicklung. ${ }^{67}$ Darüber hinaus könnten sich der weitere Schadstoffanstieg in der Erdatmosphäre und die weiterhin ungebremste Zunahme der Pkw-Nutzung als kritische Faktoren für die Mobilitätssicherung durch den MIV herausstellen. Mobilität kann also nur dann als nachhaltig bezeichnet werden, wenn der Verkehr bedürfnisgerecht und mit minimalem Aufwand erbracht wird sowie alle Teile der Bevölkerung einschließt, sie also die ökologische, ökonomische und soziale Nachhaltigkeit als generelle Zielperspektive hat.

\subsubsection{Nachhaltige Regionalentwicklung}

Wachstumskritiker zweifeln an, ob in einer postindustriellen Wissens- und Dienstleistungsgesellschaft vergleichbare Wachstumsraten wie in einer Industriegesellschaft erreicht werden können. Sie fordern eine Entwicklung, die nicht notwendigerweise auf Wirtschaftswachstum abzielt, also auf die kontinuierliche Steigerung des Bruttoinlandsproduktes. „Das Wort ,Wachstum' steht für quantitative Steigerung im physischen Ausmaß durch Angleichung und Zuwachs von Materialien. ,Entwicklung' bezieht sich auf qualitative Veränderungen, von Potentialen in einen besseren Zustand". ${ }^{68}$ Forderte der "Club of Rome“ am Anfang der 1970 Jahre aufgrund der begrenzten Ressourcen noch ein nachhaltiges Wirtschaftswachstum ${ }^{69}$, ist in dem 2004 veröffentlichten Bericht „Limits To Growth - The 30-Year Update ${ }^{\prime 70}$ gar von der Notwendigkeit einer nachhaltigen Wachstumsrücknahme die Rede. Durch sie soll eine Überbeanspruchung der Ressourcen und ein Kollaps vermieden werden. Unterschieden wird zwischen einer nachhaltigen Wirtschaftsentwicklung und einer nachhaltigen gesellschaftlichen Entwicklung, da eine Gesellschaft zusammenbrechen könne, „,schon bevor ihre Wirtschaft die Grenzen der ökolo-

\footnotetext{
${ }^{67}$ vgl. Becker, U. 2002, S.14f

68 Bärnthaler 2004, S.35f

69 Siehe hierzu: Dennis L. Meadows u.a.: "The Limits To Growth". 1972

70 Siehe hierzu: Dennis L. Meadows u.a.: "Limits To Growth - The 30-Year Update". 2004
} 
gischen und ressourcenbezogenen Nachhaltigkeit überschritten hat" ${ }^{\prime 1}$ Die Notwendigkeit für diese Rücknahme wird u.a. in zwei Prinzipien deutlich: Der „ökologische Rucksack“ verdeutlicht, dass für die Herstellung von Produkten und Dienstleistungen große Mengen an Rohstoffen umgewandelt werden müssen, deren Gewicht um ein Vielfaches größer ist als das Endprodukt. Das Prinzip berücksichtigt alle notwendigen Ressourcen, die für das Produkt und die Dienstleistung aufgewendet werden müssen, bis es konsumiert und entsorgt ist. Hierzu gehören beispielsweise auch die Transportkosten. Diese Energie- und Materialflüsse bewirken Umweltveränderungen, deren Auswirkungen bislang nur abgeschätzt werden können, deren Folgen aber bereits jetzt anhand des Klimawandels spürbar sind. Das Prinzip des „Ökologischen Fußabdrucks“ beschreibt, wie viel produktive Land- und Wasserfläche benötigt wird, damit die Bedürfnisse einer Wirtschaftseinheit unverändert aufrecht erhalten werden können. Indikator ist die Fläche, die benötigt wird, damit ein Gut oder eine Dienstleistung hergestellt werden kann bzw. die Fläche, die eine einzelne Person „verbraucht". Global betrachtet ergibt sich so die Fläche von 1,45 ha pro Person. Tatsächlich liegt der Flächenverbrauch in den Industrieländern weit darüber (4-8 ha), so dass die auf der Erde verfügbaren Flächen zur menschlichen Bedürfnisbefriedigung stark überstrapaziert sind. Durch Effizienzsteigerung, Verbesserung der Produktionsprozesse und technologischen Fortschritt könnte der Flächenverbrauch aber reduziert werden. ${ }^{72}$

Im Rahmen einer regional nachhaltigen Entwicklung geht es konkret um den Potenzialerhalt und die bestmögliche Nutzung der regionalen und regionsexternen Ressourcen. Dabei sollen die Bedürfnisse der „Gegenwart befriedigt [werden], ohne zu riskieren, daß künftige Generationen ihre eigenen Bedürfnisse nicht befriedigen können“. ${ }^{73}$ Dühr definiert nachhaltige Regionalentwicklung folgendermaßen:

„Das Konzept der Nachhaltigen Regionalentwicklung kombiniert [hierbei] die globale Debatte um eine nachhaltige Entwicklung mit den Ansätzen einer eigenständigen Regionalentwicklung und verfolgt die Umsetzung der beiden Diskussionslinien auf regionaler Ebene durch Integration ökologischer, ökonomischer und sozialer Aspekte". ${ }^{74}$

\footnotetext{
71 Bärnthaler 2004, S.34

72 vgl. Bärnthaler 2004, S.18ff

73 vgl. WECD 1987, S.46

${ }^{74}$ Dühr 1998, S.21
} 
Da der Umgang mit diesen Ressourcen sukzessive verbessert werden kann, ist nachhaltige Regionalentwicklung als zielorientierter Lernprozess zu verstehen, bei dem jeweils unterschiedliche strategische Ziele im Vordergrund stehen können:

- „Vorsorgen: Qualitäten schützen, Qualitäten und Potentiale entwickeln,

- Belastungen vermeiden, Belastungspotentiale gering halten und

- Belastungen und Beeinträchtigungen beheben bzw. sanieren“. ${ }^{25}$

Diese Ziele müssen sich in den raumordnerischen Vorgaben (z.B. Raumentwicklungsplan, Flächennutzungsplan) wiederfinden und entsprechende Maßnahmen zeitbezogen abgeleitet werden. Dabei kommt dem Nachhaltigkeitsprinzip eher auf langfristiger Sicht Bedeutung zu, wohingegen kurzfristige Maßnahmen eher die Funktion haben, Belastungen zu vermeiden und Kapazitäten zu optimieren. ${ }^{76}$ In diesem Zusammenhang stellt sich die zunehmende Globalisierung, mit der Tendenz der internationalen Arbeitsteilung und der damit einhergehenden Intensivierung der Güter- und Verkehrsströme, als große Herausforderung für die nachhaltige Regionalentwicklung dar. Hier gilt es also, einen Ausgleich zwischen der Innenentwicklung einerseits und der Außenentwicklung andererseits herbeizuführen.

Für die nachhaltige Innenentwicklung sind die Größe und die Struktur einer Region wichtige Determinanten: Ist der administrative räumliche Zuschnitt beispielsweise zu klein und fehlt es dadurch an Substanz oder ist das Potenzialgefüge nicht ausreichend, kann ein Bereich auch nicht "regionalisiert" werden. Liegen hingegen ausreichend großräumige Versorgungs- und Produktionsstrukturen mit hoher Fertigungstiefe in einer Region vor, können beispielsweise bestimmte Produkt- und Stoffkreisläufe in Form regionaler Materialverbünde oder Wertschöpfungsketten auch transporttechnisch optimiert werden. Dazu gehört auch, dass die Produkte regional vermarktet und konsumiert werden. Die Transportkosten haben also einen wesentlichen Einfluss auf nachhaltige Konzepte. ${ }^{77}$ In diesem Zusammenhang wurde bereits oben auf die enge Verbindung von Verkehr und Raumstruktur hingewiesen, bei der beispielsweise die Zersiedlung und die Arbeitsteilung über große Entfernungen hinweg zu einem erhöhten Verkehrsaufkommen beitragen, was

\footnotetext{
75 Hübler und Kaether 1999, S.25

${ }^{76}$ vgl. Hübler und Kaether 1999, S.26

77 vgl. Lucas 2000, S.17f sowie Umweltbundesamt 2003(b), S.3
} 
vom Prinzip her einer nachhaltigen Entwicklung entgegensteht. ${ }^{78}$ Je disperser also beispielsweise die Raumstruktur ist, desto schwieriger ist es für den im Vergleich zum MIV als „nachhaltiger“ geltenden ÖPNV - mit seinen starren Fahrplänen und unflexiblen Linienführungen - die sich hieraus ergebenden Bedürfnisse an Mobilität zu befriedigen. Das Ergebnis ist dann ein hoher Anteil MIV.

Generell ist der Bereich Mobilität - als Grundbedürfnis - einer der Bereiche (neben z.B. der Energiegewinnung, der Nahrungsmittelproduktion und dem Konsumverhalten), den es im Rahmen einer nachhaltigen Regionalentwicklung zu optimieren gilt. Dies hat vor allem mit der negativen Umweltwirksamkeit des Verkehrs zu tun. Diese ist bedingt durch Emissionen ${ }^{79}$ (Schadstoffe, u.a. $\mathrm{CO}^{2}$ ), raumwirksame ökologische Wirkungen, Unfallschäden, psychischen und sonstigen Auswirkungen. ${ }^{80}$ Im Bereich des Personenverkehrs bedeutet nachhaltige Regionalentwicklung konkret, die nachgefragte Verkehrsleistung ökonomisch, ökologisch und sozial effizient zu befriedigen. Dieses wird nur dann geschehen, wenn ,,jeder Verkehrsträger seine Systemvorteile optimal ausspielen kann“. ${ }^{81}$ Es geht also um einen effizienten Einsatz und bewussten Umgang mit den Verkehrsträgern. Effizienz bedeutet hierbei, „dass mit geringerem Zuwachs an Fahrleistung höhere Verkehrsleistungen bei geringerem Energieverbrauch und geringerer Emission möglich werden“ ${ }^{82}$ Hierfür ist es notwendig, technische Innovationspotenziale zur Optimierung der Effizienz, zur Erhöhung der Sicherheit, der Verringerung der Umweltbelastungen und zur Verbesserung von Komfort und Planbarkeit zu nutzen. 83 Für die Umsetzung derartiger Ansätze bedarf es eines regional abgestimmten Vorgehens zwischen allen Verkehrsakteuren ${ }^{84}$ und zwar unter Einbeziehung der Mobilitätskonsumenten, denen ein leistungsfähiges Gesamtverkehrsangebot bereit gestellt werden soll; Im Idealfall bedeutet dies die Gewährleistung intermodaler Mobilität durch interkommunale Kooperation.

\footnotetext{
${ }^{78}$ vgl. Hübler und Kaether 1999, S.25

${ }^{79}$ Unter „Emission“ wird der Prozess der Freisetzung von Stoffen verstanden, hingegen „Immission" den Eintrag, bspw. die einwirkende Verunreinigung der Luft bezeichnet. Jeder Immission geht daher eine Emission voraus; vgl. Hessisches Landesamt für Umwelt und Geologie 2006, http:/ /atlas.umwelt.hessen.de/atlas/index-ie.html: Luftreinhaltung (Zugriff am 4.2.2007).

${ }^{80}$ vgl. Hertel 2000, S.132

81 Tiefensee 2006, S.2

82 Hertel 2000, S.134

83 vgl. Wissenschaftlicher Beirat beim Bundesminister für Verkehr, Bau- und Wohnungswesen 2003, S.599

${ }^{84}$ Dieses sind verkehrspolitische Entscheidungs- und Aufgabenträger wie auch öffentliche und private Unternehmen.
} 
Die beteiligten Akteure (Politik, Verwaltung, Wirtschaft, Individualpersonen) selbst stellen allerdings oft eine Schwachstelle der nachhaltigen Regionalentwicklung dar, zumal das tatsächliche Verhalten der Akteure und die damit verbundenen Wirkungen den größten Einfluss auf die erfolgreiche Umsetzung haben. So widerspricht gerade ihr Wirken allzu oft den raumordnerischen Zielen und Vorgaben, was u.a. daran liegt, dass gesellschaftliche Leitbilder und Ziele einer nachhaltigen Regionalentwicklung allzu oft widersprechen. Selbst wenn zum Beispiel die geforderten räumlichen Wege zwischen Arbeitsplatz, Wohn- und Erholungsort sowie Versorgungseinrichtung kurz sind, muss dies noch lange nicht heißen, dass die am Ort Wohnenden auch dort arbeiten oder sich wohnortnah erholen und versorgen. Um dem Prinzip der Nachhaltigkeit in diesem Beispiel zum Erfolg zu verhelfen, bedarf es der Förderung einer kleinräumigen Funktionsmischung, der Stärkung von Stadtteilzentren sowie einer Reduzierung des MIV.

Überträgt man die allgemeinen Prinzipien der Nachhaltigkeit auf den Mobilitätsbereich, muss die Effizienz- und Qualitätssteigerung des Verkehrsbereichs Vorrang vor einer quantitativen Ausweitung haben. Beispielsweise wird nachhaltige Mobilität nicht ohne eine Verbesserung der subjektiv und objektiv empfundenen Sicherheit im Verkehr erreicht werden können. Ein Konzept nachhaltiger Mobilitätssicherung muss auch den Menschen in seinen unterschiedlichen Mobilitätsrollen begreifen und akzeptieren: Der Mensch in der mobilen Freizeit, im Berufs- oder Wirtschaftsverkehr, bei der Besorgung, auf der Urlaubsreise, auf dem Weg, jemanden zu holen oder zu bringen, als Fahrer oder Begleiter, als Auto-Fan oder Öko-Befürworter. 85

\subsection{Mobilitäts- und verkehrsrelevante Standortfaktoren}

\subsubsection{Gliederung von Standortfaktoren}

Unter Standortfaktoren werden alle jene Faktoren verstanden, die Unternehmen und Personen bei der Wahl eines Standortes beeinflussen können. Dies betrifft zum einen neue Niederlassungen, zum anderen aber auch Wohnortumzüge, die häufig auch auf eine Region begrenzt sind. Trotz internationaler Arbeitsteilung und Globalisierung gibt es allerdings nach wie vor Wirtschaftsbereiche und -aktivitäten, die teilweise oder sogar vollständig an die spezifischen, räumlichen Faktoren gebunden sind. Auch wenn die tatsäch-

${ }^{85}$ vgl. Hertel 2000, S.134 
liche Standortwahl in der Realität noch von einigen anderen Faktoren beeinflusst wird ${ }^{86}$, stellt sich die Frage nach der "richtigen“ Örtlichkeit auf unterschiedlichen räumlichen Ebenen. Hier sind internationale, interregionale, intraregionale, lokale und schließlich innerbetriebliche (betriebliche Aufteilung der unterschiedlichen Abteilungen) Standortfragen zu klären. Neben Standortfaktoren, die bestimmend sind für die Leistungserstellung (Input) und die Leistungsverwertung (Output), sind dies zum Beispiel Faktoren der räumlichen Nähe zu Konkurrenten und Absatzmärkten (Agglomerationsfaktor) sowie infrastrukturelle Faktoren. Zu den letzteren zählen die Versorgung mit Energie und Wasser, die Abwasserentsorgung, die Bildungs- und Forschungseinrichtungen, die Gesundheitsversorgung, die Verwaltung, die Freizeiteinrichtungen, das Wohnumfeld und eben auch der Verkehr. Im Bereich des Verkehrs sind dies harte, also objektiv messbare Standortfaktoren, die Auskunft über die Leistungsfähigkeit des Verkehrssystems geben. Hierzu gehören vor allem die vorhandenen Verkehrswege, die verfügbaren Transportmittel, die Transportkapazitäten und die damit verbundenen Transportkosten.

Die Gliederung dieser Faktoren geschieht teils nach räumlichen Aspekten, z.B. in global, regional und lokal, teils nach Aspekten der „Greifbarkeit“, d.h. nach „harten“ und „weichen“ Kriterien und teils nach Aspekten ihrer Raumwirksamkeit, d.h. in ortsunabhängige „mobile“ und ortsgebundene „starre“ Faktoren.

\section{Globale, regionale und lokale Faktoren}

Im Rahmen der räumlichen Differenzierung beschreiben globale Standortfaktoren die nationale Situation eines Staates hinsichtlich der politischen, wirtschaftlichen und sozialen Verhältnisse. Berücksichtigung finden hierbei die Außen-, Wirtschafts- und Steuerpolitik sowie die Gesetzgebung im Land. Regionale Faktoren kennzeichnen die Wirtschaftsräume eines Landes mit ihren spezifischen Situationen im Arbeits- und Beschaffungsmarkt sowie bei der Verkehrsinfrastruktur. Lokale Faktoren definieren die Situation am konkreten Standort. Hier geht es um Auflagen, die Ver- und Entsorgung sowie die lokale Verkehrsanbindung vor Ort.

\footnotetext{
${ }^{86}$ Der „richtige“ Standort kann bspw. auch von der zu erzielenden maximalen gesellschaftlichen Anerkennung beeinflusst sein.
} 
Harte Standortfaktoren können direkten Einfluss auf die Bilanz eines Unternehmens haben. Dies gilt insbesondere für Steuern und Subventionen, aber auch in bezug auf Mietund Bodenpreise, Energieversorgung und den Anschluss an eine leistungsfähige Verkehrsinfrastruktur. Daneben wirken sich Faktoren wie etwa Naturschutz, Landwirtschaft (auch als Kulturraum wahrgenommen), Wohnen und Erholen sowie Gewässerschutz (auch Trinkwasserschutz) unmittelbar auf die Attraktivität eines Standortes aus. Insbesondere seit den 1990er Jahren wird in der Regionalpolitik daher nicht mehr alleine auf die Entwicklung der harten Standortfaktoren gesetzt, sondern zunehmend auch auf weiche Faktoren, so u.a. auf Freizeit- und Erholungseinrichtungen, aber auch auf das Wirtschaftsklima sowie die lokale Vernetzung. ${ }^{87}$

\section{Mobile und starre Faktoren}

Mit der verbreiteten Nutzung moderner IuK-Technologien in den Produktions- und Alltagsprozessen gewinnt zunehmend eine Unterteilung in mobile und starre Standortfaktoren an Bedeutung. Dabei wird berücksichtigt, dass der Einfluss bestimmter Produktionsfaktoren für die Standortwahl abnimmt, weil sie über die neuen Technologien standortunabhängig werden. Dies trifft im besonderen Maße auf die Faktoren Information und Kapital zu. Es ist davon auszugehen, dass sich dieser Trend durch die anhaltende Globalisierung der Wirtschaftsbeziehungen zwischen Regionen und Ländern weiter verstärken wird. 88 „Je nachdem, wie stark die mobilen und nicht mobilen [starren] Faktoren der Leistungserstellung das Wirtschaftsgeschehen der Regionen prägen, stellt sich eine unterschiedliche ,Globalisierungsbetroffenheit' ein“. ${ }^{89}$

\subsubsection{Verkehrsrelevante Standortfaktoren}

Die verkehrsrelevanten Standortfaktoren lassen sich untergliedern nach der verkehrlichen Anbindung bzw. dem Verkehrsangebot sowie der Verkehrsinfrastruktur. Hierzu gehören im Einzelnen: ${ }^{90}$

- Lokales Straßennetz

\footnotetext{
${ }^{87}$ vgl. Nuhn und Hesse 2006, S.307

88 vgl. Maier und Beck 2001, S.96

${ }^{89}$ Lucas 2000, S.6

${ }^{90}$ vgl. Schad, Riedle, Höffken u. Bihn 2000, S.22
} 
- Autobahnanschluss

- $\quad$ Bedienung durch den ÖPNV

- Verfügbarer Parkraum

- Erreichbarkeit zu Fuß und mit dem Fahrrad

- Flughafennähe

- Anbindung an den Schienenfernverkehr

- Gleisanschluss (für Güterverkehr)

- Güterverkehrszentrum

- Hafennähe (See- oder Binnenhafen)

Abbildung 1 zeigt, dass sich „Mobilität" nur im harten Kern als ein von verkehrsabhängigen Faktoren dominiertes Thema darstellt. Mobilität als Standortfaktor wird ganz wesentlich von anderen, weichen Faktoren mit gestaltet. Mobilität wiederum beeinflusst aber auch die wahrgenommene Qualität dieser weichen Standortfaktoren. So verliert beispielsweise eine Freizeiteinrichtung oder das Wohnumfeld an Qualität, wenn sie verkehrlich nur schlecht erreichbar sind. Die lokale und regionale Verkehrsanbindung bzw. das Verkehrsangebot sowie die Verkehrsinfrastruktur stellen einerseits zwar die Grundlage für die positive quantitative (harte) und qualitative Ausgestaltung der Mobilität in einer Region dar, dennoch kommt es insgesamt betrachtet auf die Ausgewogenheit aller Standortfaktoren an. Denn so wenig wie sich ein Standortfaktor alleine kaum gewinnbringend auf die wirtschaftliche Entwicklung einer Region auswirkt, so nachteilig wirkt sich dieser Faktor bei einer Überbetonung auf andere Bereiche aus. Ferner darf auch nicht unberücksichtigt bleiben, dass das Vorhandensein von ausreichendem Kapital sowie hinreichender Information wesentlichen Einfluss auf die Wirkung und Wahrnehmung von einzelnen Standortfaktoren haben. So führen die IuK-Technologien im Mobilitätsbereich im Allgemeinen und im Verkehrsbereich im Besonderen zu nachhaltigen Veränderungen. 


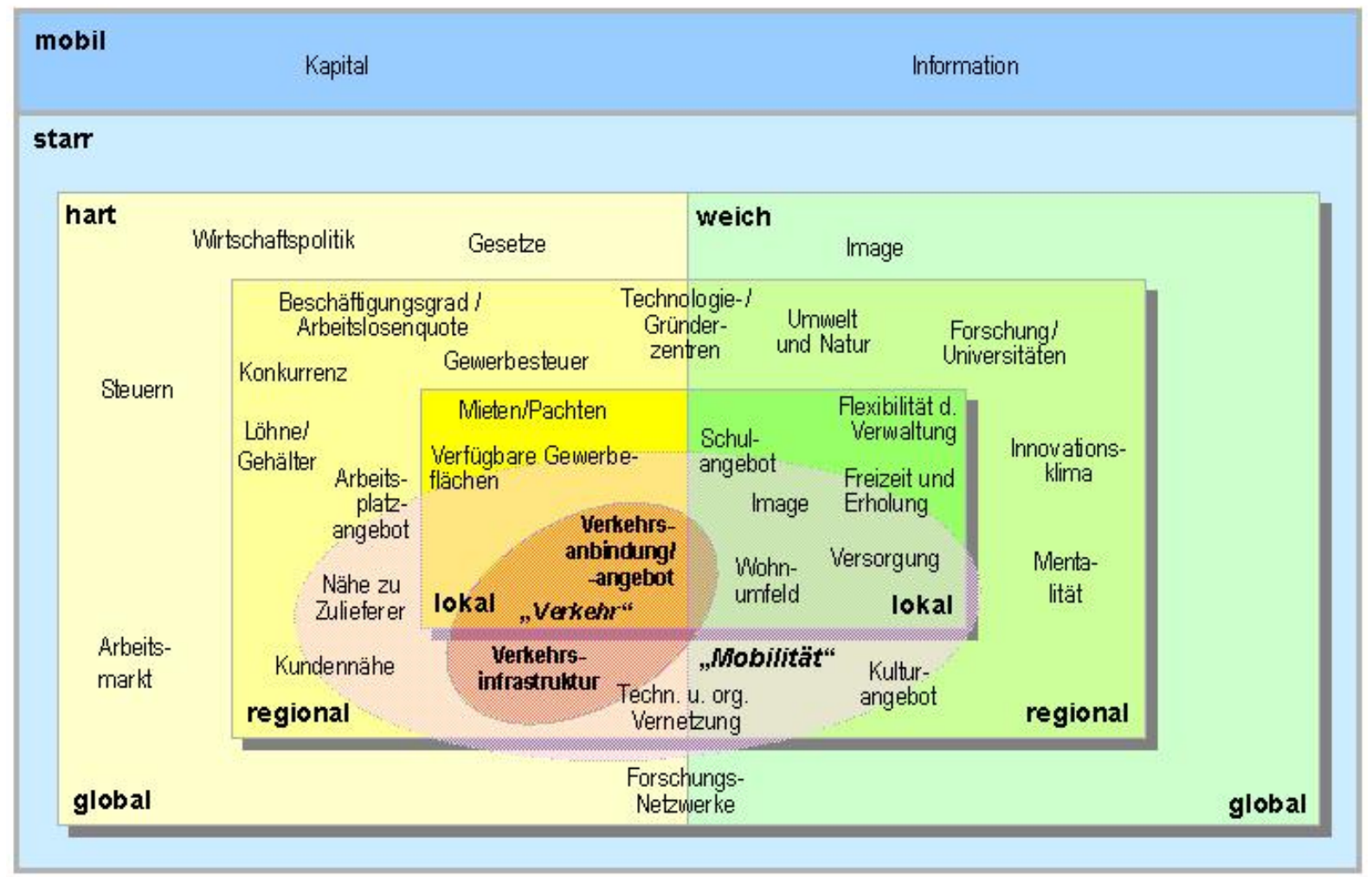

Abbildung 1:Beziehungsgeflecht von mobilitäts- und verkehrsrelevanten sowie anderen Standortfaktoren Quelle: Eigene Darstellung

\subsubsection{Einfluss von IuK-Technologien auf den Verkehr}

Die Entwicklungen der Informations- und Kommunikationstechnologien in den letzten Jahren haben insbesondere im Verkehrs- und Fahrzeugbereich zu einer sprichwörtlichen Euphorie hinsichtlich der Möglichkeiten der Lösung von Verkehrsproblemen in der nahen Zukunft geführt. Teilweise wurde gar die Erwartung geschürt, dass hierüber der (Ausbau-)Bedarf an Infrastruktur zurückgehen könnte. ${ }^{91}$ Auch wenn sich diese Hoffnung nicht erfüllt hat, so ist doch unumstritten, dass technische Innovationen einen wesentlichen Beitrag für die Lösung von Verkehrsproblemen liefern können. ${ }^{92}$ Neben Verbesserungen in der Fahrzeug- und Antriebstechnik und der Betriebsoptimierung sind dies technologische Entwicklungen, die unter dem Oberbegriff "Telematik“ zusammengefasst werden und ein Teilgebiet der Informatik meinen, welches „sich mit der Kommunikation von Daten unter Nutzung technischer Mittel über („größere“) räumliche Entfernung be-

\footnotetext{
${ }^{91}$ vgl. Wissenschaftlicher Beirat beim Bundesminister für Verkehr, Bau- und Wohnungswesen 2003, S.599

92 vgl. Halbritter u.a. 2005, S.27
} 
fasst" ${ }^{\prime \prime}{ }^{93}$ Tabelle 1 gibt einen Überblick über die wichtigsten Basistechnologien, die im Verkehr Anwendung finden.

\begin{tabular}{|l|c|c|}
\hline Datenerfassung & Datenübermittlung & Datenaufbereitung \\
\hline - Induktionsschleifen & - Einwegekommunikation & • Kollektive Information \\
- Radartechnik (Mikrowellen) & o RDS-TMC & o Digitale Karten \\
- Drucksensoren & o DAB, DVB & (Navigation) \\
- Laserdetektoren & o GPS & O Wechselverkehrszeichen \\
- Fahrzeugsensoren & o Elektronische Anzeigen \\
- Wetter- und Umfeld- & o Mobilfunk & im Pkw \\
sensoren & - GSM, GPRS, UMTS & o (Dynamische) Anzeigen \\
- Terrestrische Funkortung & o Datenfunknetze & im ÖPV \\
o GALILEO & - Bündel-/Betriebsfunk & - Infosäulen/ \\
& o Nahbereichs- & Infobildschirme \\
& kommunikation & o Internet \\
& - elektronische Bake & O Persönlicher Digitaler As- \\
& - Infrarot & sistent \\
& - Mikrowellen & Mobilfunkgerät \\
\hline
\end{tabular}

Tabelle 1:Telematik-Basistechnologien

Quelle: nach Halbritter u.a. 2005, S. 47ff, eigene Bearbeitung

Der Einsatz der Verkehrstelematik in Deutschland zielte bislang vor allem darauf ab, den physischen Verkehr auf Basis der vorhandenen Verkehrsinfrastruktur effizienter zu gestalten. Hauptanwendungen stellten Wechselverkehrszeichenanlagen vor Ort dar sowie die Informationsbereitstellung über Radio und Mobilfunk. Im Zuge der Verbesserung des Verkehrsmanagements und der Verkehrsüberwachung nimmt außerdem die Ortung von Fahrzeugen beispielsweise über GPS - und zukünftig wahrscheinlich über GALILEO94 an Bedeutung zu, zumal sich aus den individuellen Fahrzeugdaten Informationen über die Straßenbelastung ableiten lassen, die dann beispielsweise über die Wechselzeichenanlagen an die Autofahrer in Form von Fahrtrichtungsempfehlungen weitergegeben werden. ${ }^{95}$ Fahrzeugautonome Telematikanwendungen sollen ebenfalls den Verkehrsfluss optimieren helfen, beispielsweise in Form von Navigationshilfen, die den aktuellen Ver-

\footnotetext{
${ }_{93}$ vgl. Henning und Olbertz 1997, S.70

${ }^{94}$ Mit GALILEO entsteht Europas eigenes Satellitennavigationssystem. Es steht unter ziviler Kontrolle und soll einen hochpräzisen und garantierten globalen Ortungsdienst bereitstellen. Es soll mit dem US-amerikanischen GPS und dem russischen globalen Navigationssatellitensystem (GLONASS) kompatibel sein. Für Galileo sind zahlreiche Anwendungen vorgesehen, darunter Ortungs- und daraus entstehende Mehrwertdienste, u.a. auch für den Verkehr; vgl. www.esa.int/esaCP/SEMBHN8A9HE_Germany_0.html (Zugriff am 4.3.2007)

${ }^{95}$ vgl. Deutsche Bank Research 2002, S.4ff
} 
kehrszustand berücksichtigen und Ausweichrouten vorschlagen. In der Diskussion stehen aber noch zahlreiche andere Anwendungen, die den Betriebsablauf insgesamt auf den Straßen verbessern helfen sollen (siehe Kapitel 4.6.3.1) oder die Nutzung beeinflussen. Hierzu gehört auch die Einführung von Maut-Systemen (siehe Kapitel 4.6.3.3) sowie innovativer Logistik (siehe Kapitel 7.2.3). Die Nutzbarmachung dieser Technologien konnte auch durch die - anfänglichen - Rückschläge bei der Einführung der Lkw-Maut nicht beeinträchtigt werden.

Gerade das Beispiel der Lkw-Maut verdeutlicht die immense wirtschaftliche Dimension, die hinter dem Einsatz telematikgestützter Verkehrslösungen steht. Über die Entwicklung des e-commerce (siehe Kapitel 7.2.1) und der damit verbundenen Entwicklung neuer, internetbasierter Geschäftsfelder und dezentraler Prozessstrukturen, kann die Verkehrsentwicklung aber auch indirekt beeinflusst werden. ${ }^{96}$ Mit den damit in Zusammenhang stehenden neuen Arbeitsformen (z.B. Telearbeit) wird gelegentlich argumentiert, dass auch der Faktor Verkehrsanbindung bzw. Erreichbarkeit des Standortes in seiner Bedeutung abnimmt, bzw. „mobil“ wird. Dies trifft allerdings nur für solche Aktivitäten zu, für die ein persönlicher Kontakt als nicht wichtig gilt und lediglich ein Informationstransfer notwendig ist. An wissenschaftlicher Stelle kommt man zu der Erkenntnis, dass es im wesentlichen zu keiner Reduzierung des Verkehrsaufkommens infolge der verstärkten Nutzung der IuK-Technologien kommen wird. Vielmehr wird von einer Verlagerung der Kommunikationsabläufe ausgegangen, bei der die eingesparten Wege nur zeitlich und an andere Stelle verlagert werden. Als stellvertretendes Beispiel sei hier auf den verstärkten Trend von Warenbestellungen über das Internet (B2C-e-commerce) hingewiesen. Der „Besorgungsweg“ wird hierdurch zwar substituiert, im Gegenzug wird aber ein „Versorgungsweg“ ausgelöst. Vor dem Hintergrund steigender Nutzungszahlen des „Teleshoppings" hängt es somit letztlich von innovativen Raum- und Logistikstrukturen ab, ob sich hieraus eine Netto-Verkehrsentlastung ergeben wird. ${ }^{97}$

Im Rahmen der Diskussion um die Substitution von Verkehrswegen durch die Anwendung von IuK-Technologien muss auch berücksichtigt werden, dass diese Technologien dem Einzelnen nun den Raum in einer Art und Weise zu beherrschen helfen, der vormals nicht möglich war. An die Stelle des Vertrauens in den persönlichen, bekannten Raum

\footnotetext{
96 ebd., S.2

97 vgl. Henning und Schmid 1998, S.158 sowie Deutsche Bank Research 2002, S.11
} 
tritt nun das Vertrauen in bekannte Technologien und Anwendungen. Mit der Zuhilfenahme von zum Beispiel Navigationssystemen trauen sich die Menschen nun dorthin, wo sie sich vormals nicht hin bewegten. ${ }^{98}$ Auch hierin zeigt sich die bereits oben angesprochene Dynamik des Entscheidungsprozesses.

\begin{tabular}{|c|c|}
\hline $\begin{array}{l}\text { Direkter, originärer Einfluss der Technik auf } \\
\text { den Verkehr }\end{array}$ & $\begin{array}{l}\text { Indirekter Einfluss der Technik auf den Ver- } \\
\text { kehr }\end{array}$ \\
\hline - Maut-Systeme & $\bullet \quad$ B2B-e-commerce; B2C-e-commerce \\
$\bullet \quad$ Logistik & Telearbeit \\
$\bullet \quad$ Telematik via & \\
o Straßenseitig fixe Anlagen & \\
$0 \quad$ Fahrzeugseitige Anwendungen \\
$0 \quad$ Radio \\
$0 \quad$ Internet (mobil und stationär) \\
$0 \quad$ Mobilfunk
\end{tabular}

Tabelle 2: IuK-Technologien und Verkehr

Quelle: Deutsche Bank Research 2002; Economics Nr.34, S.56, eigene Bearbeitung

Der Einsatz von IuK-Technologien im Rahmen eines nachhaltigen Mobilitätskonzeptes sollte hinsichtlich des Potenzials bewertet werden, die Sicherheit und Umweltverträglichkeit der Verkehrssituation zu verbessern. Da dieses häufig nicht ohne flankierende (z.B. verkehrspolitische) Maßnahmen geht, haben isolierte technische Maßnahmen häufig nur den Charakter, dass "dauerhaft wirksame Problemlösungen hinausgeschoben werden“ ${ }^{99}$ „Das größte Umweltentlastungspotenzial liegt in der Nutzung der Verkehrstelematik zur Unterstützung anderer, insbesondere ökonomischer Maßnahmen, deren Leistungswirkung durch Telematikeinsatz gezielt verstärkt werden kann“. ${ }^{100}$ So konnten bislang weder durch den Einsatz fahrzeugautonomer noch infrastrukturbezogener Systeme alleine nachhaltige Auswirkungen auf die automobilen Umweltfolgen verzeichnet werden. Denn eine Verbesserung der Verkehrsprobleme kann durch die Verbesserung der Autos selbst kaum erwartet werden. ${ }^{101}$ Dies trifft auch auf den ÖPNV zu, wo fahrzeugseitige Verbesserungen zwar zu einer verbesserten Umweltverträglichkeit führen, aber dieses nichts am Gesamtverkehrsaufkommen ändert. Beyer argumentiert hierzu:

\footnotetext{
98 vgl. Henning und Olbertz 1997, S.106

${ }^{99}$ vgl. Henning und Schmid 1998, S.23

100 Sachverständigenrat für Umweltfragen 2005, S.9

101 vgl. Henning und Schmid 1998, S.23
} 
"Das Problem des weiteren Anstiegs im Verkehrsaufkommen kann nur gelöst werden, wenn der Einsatz moderner Technologien einem übergeordnetem Konzept unterworfen wird; einem Konzept, aus dem Anforderungen an Technologien und Infrastruktur aus verkehrstechnischer Sicht entwickelt und formuliert werden". 102

Beispielhaft lässt sich dieser Ansatz an der Entwicklung der Pkw-Fahrzeugsicherheit nachvollziehen. „Viele Jahre war das Bemühen, die Sicherheit im Straßenverkehr zu erhöhen, sehr stark auf das Fahrzeug selbst fokussiert" . ${ }^{103}$ Standen zunächst passive Sicherheitssysteme (Drei-Punkt-Gurte, sichere Fahrgastzelle, Airbags etc.) im Vordergrund, wurden seit den 1990er Jahren verstärkt aktive Sicherheitssysteme (Fahrwerk-, Antriebsund Bremssysteme, Wahrnehmungssicherheit etc.), entwickelt, deren Ziel es war, Unfälle überhaupt zu vermeiden. Aus der Erkenntnis heraus, dass die Vorverlegung der Fahrerreaktion um nur eine Sekunde zu einer Reduzierung der Unfälle um 90\% führt, wurde die Fahrzeugsicherheit in einem ganzheitlichen Kontext von Fahrzeug, Fahrer und Umfeld und Infrastruktur betrachtet. Beyer äussert sich zu den Vorzügen eines abgestimmten Gesamtsystems folgendermaßen:

"Die Optimierung des Gesamtsystems, so wurde deutlich, versprach größere Zugewinne an Sicherheit als die Optimierung der einzelnen Elemente, wobei natürlich auf Letzteres nicht verzichtet werden sollte. So entstanden die ersten Überlegungen, die Steigerung der Fahrzeugsicherheit in umfassende Verkehrsmanagement-Konzepte einzubinden, deren Ziel neben einer Erhöhung der Verkehrssicherheit gleichzeitig auch eine Verbesserung des Verkehrsflusses und eine Steigerung der Umweltverträglichkeit war". ${ }^{104}$

Eine Studie der Technischen Universität München aus dem Jahr 2001 rechnete vor, dass unter "sehr günstigen Bedingungen“ durch den intensiven Einsatz von Telematikanwendungen Verkehrsengpässe um 15\%, Verkehrsunfälle um 20\% und Umweltbelastungen um 19\% vermindert werden könnten. ${ }^{105}$ Der Einfluss der allgemeinen Wirtschaftsentwicklung auf das Verkehrsaufkommen übertrifft den Einfluss der IuK-Technologien [allerdings] deutlich“. Von daher wird es größerer Anstrengungen bedürfen, die Wirtschaftsentwicklung von der Verkehrsentwicklung zu entkoppeln, als dies durch die einfa-

\footnotetext{
102 Beyer 2005, S.108

103 Diez 2005, S.88

104 Diez 2005, S.88f

${ }^{105}$ vgl. Pauli und Schindler 2001, S.15
} 
che Bereitstellung der IuK-Technologien zu erwarten ist. „Die Technik ist ein ergänzendes verkehrsrelevantes Instrument, aber kein Allheilmittel gegen den Verkehrsinfarkt" 106 und die negativen Folgen des Verkehrs. Auch der Internationale Verband für öffentliches Verkehrswesen (Union Internationale des Transports Publics, UITP) warnt vor einer Überschätzung des Einsatzes isolierter technischer Maßnahmen:

„Das Versprechen, die Technik sei dazu in der Lage, viele der Nachteile, die mit der gestiegenen Mobilität der Menschen einhergehen, zu lösen, wurde schlichtweg in den vergangenen Jahren nicht eingelöst, und schlimmer noch - es ist unwahrscheinlich, dass sich dies in absehbarer Zeit ändert". ${ }^{107}$

Vielmehr bedarf es intelligenter Organisationsformen und Strategien, die es ermöglichen, die durch die IuK-Technologien geschaffenen Freiräume im Sinne einer nachhaltigen und qualitativen Verkehrsentwicklung zu nutzen. Erst dann wird ein nachhaltig gestalteter Verkehr auch einen Beitrag zu einer nachhaltigen Regionalentwicklung beisteuern. ${ }^{108}$

\subsection{Bedeutung der Leistungsfähigkeit der Verkehrsinfrastruktur}

Zur Verkehrsinfrastruktur zählen alle ortsfesten Anlagen, die der Beförderung von Gütern und/oder Personen dienen bzw. diese ermöglichen. Hierbei werden Fahrwege und Knotenpunkte differenziert. Die Fahrwege unterscheiden sich hinsichtlich der Verkehrsträger, die von ihnen genutzt werden in Schienenwege, Straßen, Wasser- und Luftstraßen sowie Rohrleitungen. ${ }^{109}$ Die Knotenpunkte vernetzen die Verkehrsträger an ihren Schnittstellen, wodurch überhaupt erst Verkehrsnetze entstehen. Je nachdem, ob sich identische oder nicht identische Verkehrsträger berühren, spricht man von intra- oder intermodalen Verkehrsknoten. Letztlich sind diese Knoten notwendig, um die notwendige Mobilität von Personen und Gütern in einem Verkehrsnetz zu gewährleisten.

Der Entscheidungsspielraum in der individuellen Alltagsmobilität wird maßgeblich durch die Siedlungsstruktur und dem vorhandenen Verkehrsangebot beeinflusst. ${ }^{110}$ Die Qualität der Verkehrsinfrastruktur steht dabei in direkter Abhängigkeit zu diesen beiden

\footnotetext{
106 Deutsche Bank Research 2002, S.11

107 UITP 2005, S.7

108 vgl. Halbritter u.a. 2005, S.32

109 vgl. Aberle 2003, S.18f

${ }^{110}$ vgl. Hunecke und Schweer 2006, S.148
} 
Kriterien. Die Abwägung der Anforderungen an die Erreichbarkeit beispielsweise des Wohnstandortes, des Arbeitsplatzes, einer Schule oder eines Kindergartens, von Erholungseinrichtungen etc. aus einer spezifischen Lebenssituation heraus ist als Optimierungsprozess zu verstehen und kann sich beispielsweise in einem Umzug an einen verkehrlich besser angebundenen Standort niederschlagen. ${ }^{111}$ Für das individuelle Mobilitätsverhalten von Personen ist neben gesellschaftlichen und ökonomischen Rahmenbedingungen auch die jeweils spezifische Mobilitätseinstellung sowie Lebenssituation von hoher Relevanz, aus der sich ganz bestimmte individuelle Mobilitätsanforderungen an die Verkehrsinfrastruktur ableiten. So sind u.a. die Ansprüche an die Freizeit- und Urlaubsmobilität in den letzten Jahren stark gestiegen. ${ }^{112}$

Die verkehrliche Erreichbarkeit eines Unternehmensstandortes ist essentieller Natur und definiert sich über eine leistungs- und funktionsfähige Verkehrsinfrastruktur. Deren Bedeutung nimmt in dem Maße zu, wie die Produktions-, Arbeits- und Konsummärkte räumlich von einander getrennt liegen, beispielsweise im Rahmen der Globalisierung wirtschaftlicher Austauschprozesse. Werden beispielsweise die Fertigungstiefe an einem Unternehmensstandort reduziert oder Produktionsabläufe und -prozesse "outgesourct", führt dies zu einem Bedeutungszuwachs der verkehrlichen Anbindung und damit der Verkehrsinfrastruktur. ${ }^{113}$ Diese muss daher bedarfsorientiert dimensioniert und gestaltet sein, damit Menschen und Güter über diese mobil sein können. ${ }^{114}$

Die Verkehrsinfrastruktur ist damit sowohl für Individualpersonen wie auch für Unternehmen von Bedeutung. Sie ist eine grundsätzliche Voraussetzung für individuelle und wirtschaftliche Aktivitäten und letztlich für Wachstum und Wohlstand. Ohne einen reibungsarmen Transport von Personen, Gütern und Dienstleistungen auf Basis einer leistungsfähigen Verkehrsinfrastruktur ist eine arbeitsteilige Wirtschaft nicht möglich. Arbeitsteilung wiederum nimmt in Zeiten der Globalisierung - insbesondere für eine international eng verflochtene Region wie Frankfurt Rhein-Main - für Industrie- und Dienstleistungsgesellschaften einen immer größer werdenden Stellenwert ein. Abbildung 2 zeigt, wie die Verkehrsinfrastruktur - hier am Beispiel der Bundesautobahnen und mehr-

\footnotetext{
111 vgl. Schiener 2006, S.67

112 vgl. Aberle 2006, S.4

113 vgl. Aberle 2006, S.4

${ }^{114}$ vgl. Umlandverband 2000, S.103
} 
spurig ausgebauten Bundesstraßen („Fernstraßen“) - und die Wirtschaftskraft in hessischen Städten und Kreisen in einem abhängigen Verhältnis zueinander stehen.

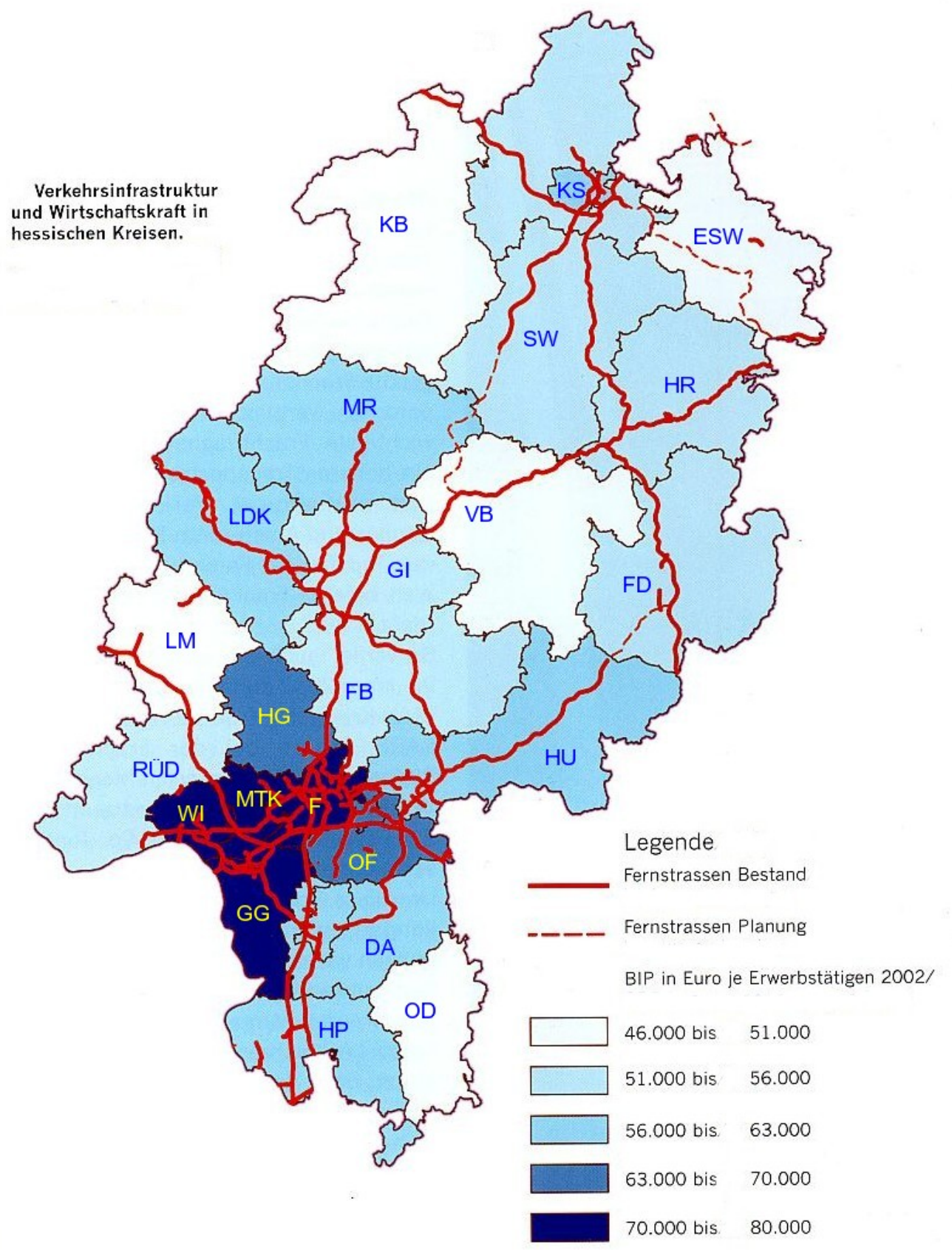

Abbildung 2: Verkehrsinfrastruktur und Wirtschaftskraft in hessischen Kreisen.

Quelle: Adam Opel AG und Hessische Staatskanzlei (Hrsg.) 2006, S.4, eigene Bearbeitung

Durch den wirtschaftlichen Integrationsprozess (Europäische Union, Öffnung der osteuropäischen Märkte, Liberalisierung des Welthandels) sehen viele Wirtschaftsunternehmen neue Chancen und Möglichkeiten der Entwicklung. Im internationalen Wettbewerb führt 
der zunehmende Kostendruck, die wachsende Produktvielfalt und die Forderung nach ständiger Verfügbarkeit dazu, dass die Unternehmen neue Produktions- und Distributionsstrategien einführen, über die sie schnell und flexibel reagieren können. So sind produzierende Unternehmen auf pünktliche und zuverlässige Transporte angewiesen (justin-time-delivery). Aber auch Dienstleistungsunternehmen sind auf die Einhaltung von Lieferfristen und -terminen angewiesen, um wettbewerbsfähig zu sein. Insbesondere aufgrund der Nutzung moderner Kommunikationsmittel ist es den Kunden möglich, ihre Waren weltweit zu bestellen. Die Konsumenten erwarten aber weiterhin, dass ihnen die Ware schnellstmöglich geliefert wird. Ein ausgebautes Verkehrssystem auf Basis umfassender Verkehrsinfrastruktur ist für eine funktionierende Logistik daher eine wichtige Voraussetzung und führt $\mathrm{zu}$ einer stärkeren Betonung der verkehrsinfrastrukturellen Standortfaktoren. ${ }^{115}$ Umgekehrt bedeuten mangelnde Erreichbarkeit und langsame Wege einen klaren Standortnachteil.

Zwar führt der wirtschaftliche Integrationsprozess auch dazu, dass andere Faktoren an Einfluss gewinnen, die ebenfalls Auswirkungen auf die regionale Entwicklung haben. Hier sind vor allem interne Unternehmensstrategien, lokale institutionelle Netzwerke und Rahmenbedingungen einer jeweiligen Region von Bedeutung. ${ }^{116}$ Das ändert aber nichts an dem Umstand, „dass Mobilität und Verkehr sowie Handel und Warenaustausch auf eine materielle Infrastruktur angewiesen sind, erst recht im Zeitalter wachsender weltwirtschaftlicher Verflechtungen“. ${ }^{117}$

Dies sieht auch die hessische Landesregierung so und betont in ihrer Internetpräsens:

„Hessens wirtschaftliche Stärke korrespondiert eng mit dem hohen Grad an Mobilität. Die Mobilitätssicherung ist daher Grundvoraussetzung für Wohlstand und wirtschaftliche Prosperität. Über 80 Prozent des Personenverkehrs und über 60 Prozent des Güterverkehrs werden auf dem Hessischen Straßennetz abgewickelt". 118

Auch der Präsident der Industrie- und Handelskammer Frankfurt am Main, von Harbou, verweist auf die Bedeutung der Verkehrsinfrastruktur nicht nur für den Wirtschaftsstandort Frankfurt, sondern für ganz Hessen:

\footnotetext{
115 vgl. IHK-Arbeitsgemeinschaft Hessen 2004, S.4

116 vgl. Nuhn und Hesse 2006, S.305f

117 ebd. S.299

118 www.hessen.de/irj/zentral_Internet (Zugriff am 14.4.2006)
} 
„Für die hohe Attraktivität des Wirtschaftsstandortes Hessen gibt es vor allem drei Gründe: die exzellente Telekommunikations- und Verkehrsinfrastruktur, der vielseitige Branchenmix von Unternehmen [...] sowie die, weichen' Standortfaktoren, die sich immer stärker als harte Wettbewerbsfaktoren herauskristallisieren". 119

Allerdings wird gleichzeitig von der IHK Kritik am ihrer Meinung nach schleppenden Ausbau und der „Unterfinanzierung“ der Verkehrsinfrastruktur in Hessen geübt. Die IHK warnt davor, dass eine Vernachlässigung des Verkehrsträgers „Straße“ nicht zu einer Verlagerung auf andere Verkehrsträger führt, sondern dass in der Konsequenz die Unternehmen auf andere Standorte mit besseren verkehrlichen Bedingungen ausweichen könnten. Gleichzeitig wird plädiert, dass der Staat in seiner Verantwortung für die Daseinsvorsorge die notwendige Verkehrsinfrastruktur bereit stellt und diese auch aus öffentlichen Mitteln finanziert. 120

Die Forderungen nach zusätzlichen Infrastrukturinvestitionen kommen dabei keineswegs nur von Autobefürwortern, sondern auch von Umweltverbänden oder umweltnahen Organisationen. Ihnen geht es allerdings vornehmlich um die Bestandserhaltung und den Ausbau des Schienenverkehrsnetzes zum Zwecke des Gütertransports. So ist der Gütertransport im Zeitraum von 1991 bis 2001 auf der Straße bundesweit um 42\% gestiegen, auf der Schiene aber um 5\% zurückgegangen. ${ }^{121}$ Vor dem Hintergrund, dass von einem weiteren Anstieg des Güterverkehrs von 2001 bis 2015 um 45\% ausgegangen wird, ist ersichtlich, mit welchen Folgewirkungen (siehe Kapitel 4.5) - auch für den Personenverkehr - zu rechnen ist, wenn keine gegensteuernden Maßnahmen ergriffen werden. ${ }^{122}$

Doch aufgrund finanzieller und zum Teil auch räumlicher Ressourcenknappheit verlangsamt sich der Ausbau der Verkehrsinfrastruktur vor allem in den Ballungsräumen, bei weiterhin stetiger Zunahme des Verkehrsaufkommens (siehe Kapitel 4.3). Hinzu kommt, dass durch die hohe Beanspruchung der bestehenden Verkehrsinfrastruktur ein immer größerer Anteil für die Erhaltung verwendet werden muss. So sieht der Bundesverkehrswegeplan vor, dass mehr als die Hälfte des Finanzvolumens der rund 150 Mrd. Euro, die

\footnotetext{
${ }^{119}$ von Harbou 2006, S.12

${ }^{120}$ vgl. IHK-Arbeitsgemeinschaft Hessen 2004, S.9

${ }^{121}$ Mittlerweile zeichnet sich ein Trend ab, dass auch auf der Schiene der Gütertransport zunimmt. So stieg die Transportleistung im Jahre 2006 um gut 10\% auf fast 100 Mrd. Tonnenkilometer; vgl. Frankfurter Rundschau v. 15.2.2007

122 vgl. IHK-Arbeitsgemeinschaft Hessen 2004, S.5
} 
für die Verkehrsinfrastruktur im Zeitraum von 2001 bis 2015 vorgesehen sind, in den Erhalt der vorhandenen Verkehrsinfrastruktur fließen sollen. ${ }^{123}$

Bei einem Ausbau der Verkehrsinfrastruktur ist außerdem zu berücksichtigen, dass neue Verkehrswege auch neuen Verkehr mit sich bringen. So wird geschätzt, dass etwa 15-20\% des Verkehrs auf „induzierten Verkehr“ zurückzuführen ist. ${ }^{124}$ Da bis zum Jahr 2025 noch mit einem weiteren starken Anstieg der Verkehrsleistung gerechnet wird, gleicht die Anpassung der Verkehrsinfrastruktur an die weiter wachsende Verkehrsnachfrage einem nur schwer zu gewinnenden Wettlauf, der schon aus finanzieller Sicht kaum bewältigt werden kann. Bereits Anfang der 1990er Jahre wies eine Studie des Umwelt- und Prognose Instituts (UPI) darauf hin, dass die Anzahl der Autos etwa 9 Mal schneller expandiert, als das Straßennetz und bezeichnet die verkehrspolitische Priorisierung von Verkehrsinfrastrukturmaßnahmen als "Scheinlösungen im Verkehrsbereich“. ${ }^{125}$ Von daher bedarf es anderer verkehrsplanerischer Maßnahmen, die Verkehrsinfrastruktur effizient zu halten.

Daher hatte bereits 1999 die damalige Bundesregierung eine Regierungskommission eingesetzt, die nach ihrem Vorsitzenden Wilhelm Pällmann benannte „PällmannKommission“, die neue Finanzierungsmöglichkeiten für öffentliche Verkehrsinfrastrukturen prüfen sollte. Das 2000 vorgelegte Ergebnis schlägt im Kern eine Verlagerung der haushaltsbasierten hin zu einer nutzerbasierten Finanzierung der Verkehrsinfrastruktur vor. Darüber hinaus wurde aber auch eine Neustrukturierung der föderalen Verkehrspolitik angeregt sowie die verstärkte Einbeziehung privaten Kapitals. ${ }^{126}$ Umgesetzt wurde bislang die Gründung der Verkehrsinfrastrukturfinanzierungsgesellschaft (VIFG), die, gespeist aus Einnahmen der Lkw-Maut und Nutzungsgebühren für Wasserstraßen, Verkehrswege auf der Basis von PPP-Modellen (Public-Private-Partnership) finanziert. ${ }^{127}$

Zusammenfassend betrachtet ist eine gut ausgebaute und leistungsfähige Verkehrsinfrastruktur quasi der Rohstoff, aus dem Mobilität entsteht. „Mobilität wird zu einem immer entscheidenderen Faktor für den Wirtschaftsstandort Deutschland“ ${ }^{128}$ Wachsende Mobilität ist aber nicht mehr nur noch sichtbares Zeichen prosperierender Wirtschaftskraft einer

\footnotetext{
${ }^{123}$ vgl. Statistisches Bundesamt 2006, S.22

124 ebd., S.28

${ }^{125}$ vgl. Umwelt- und Prognose-Institut 1993

126 vgl. Hauff 2003, S.180f

127 vgl. Verkehrsinfrastrukturfinanzierungsgesellschaft 2006, S.4ff

${ }^{128}$ vgl. Hauff 2003, S.181
} 
Region, sondern stellt sich als kritischer Standortfaktor für die Region selbst dar, den es zu bewahren gilt.

\section{5 ÖPNV als Standortfaktor}

Im Rahmen der - insbesondere nachhaltigen - Regionalentwicklung wurde der ÖPNV zwar stets thematisiert, jedoch die Bedeutung als Standortfaktor für einen Wirtschaftsstandort sowie dessen Vermarktung bislang nicht gebührend berücksichtigt. Dies gilt auch für wissenschaftliche Betrachtungen, in denen im wesentlichen der allgemeine kommunale Nutzen im Vordergrund stand oder aber auf volkswirtschaftliche Effekte, insbesondere des Fernverkehrs, verwiesen wurde. ${ }^{129}$ Dagegen machte der Oberbürgermeister von München Ude in der Zeitschrift „Der Nahverkehr“ darauf aufmerksam, dass die ÖPNV-Bedienung „in vielen Fällen eine „unabdingbare Vorleistung“ für die Prosperität einer Region darstellt. ${ }^{130}$ Diese Vorleistung wird in ganz besonderem Maße bei der nachhaltigen Entwicklung von Städten und verdichteten Ballungsräumen deutlich. Hier besitzt der ÖPNV sowohl hohe Transportkapazitäten wie auch gegenüber dem MIV eine relative höhere Umweltfreundlichkeit und günstigere Produktionskosten bei der Transportleistung. ${ }^{131}$ Außerdem liegt der Flächenanspruch pro beförderter Person - sowohl was den fließenden, als auch den ruhenden Verkehr anbelangt - deutlich unter dem des MIV. Der ÖPNV ist also ein ausgesprochen stadtverträgliches Transportsystem. ${ }^{132}$

Der Einfluss einer ÖPNV-Anbindung auf einen Standort zeigt sich beispielsweise an den Preisen für Immobilien. Diese fallen in der Nähe von Haltestellen/Bahnhöfen höher aus als ohne eine entsprechende Anbindung. Unterschätzt wurde bislang auch die Bedeutung des ÖPNV für das einzelne Wirtschaftsunternehmen. So ergab eine Umfrage der Prognos AG unter mehr als 600 Unternehmen in deutschen Städten im April 2000, dass der ÖPNV für mittelgroße und große Unternehmen von hoher Relevanz bei der Standortwahl ist (siehe Abbildung 3). Nach der Verfügbarkeit von qualifizierten Arbeitskräften wird bereits die verkehrliche Anbindung als zweitwichtigster Standortfaktor eingeschätzt. Im speziellen wird eine ÖPNV-Anbindung sogar - nach der Bedeutung des örtlichen Stra-

\footnotetext{
${ }^{129}$ vgl. Ring 2004, S.21

${ }^{130}$ vgl. Ude 2002, S.8

${ }^{131}$ Die im Vergleich zum MIV relative Umweltfreundlichkeit und höhere Effizienz des ÖPNV werden im weiteren Verlauf auch als "komparative Vorteile“ bezeichnet.

132 vgl. Nuhn und Hesse 2006, S.190f
} 
ßennetzes und einer Autobahnanbindung - wichtiger eingestuft als eine Flughafenanbindung oder die Anbindung an den Schienenfernverkehr. ${ }^{133}$ Hierin spiegelt sich die Bedeutung einer verlässlichen (pünktlichen) Erreichbarkeit des Unternehmens für Mitarbeiter und Kunden wider. Darüber hinaus bewerten viele Unternehmen positiv, insbesondere mit Sitz in Stadtzentren, dass der ÖPNV dazu beiträgt, den eigenen Bedarf an Parkraum zu begrenzen. ${ }^{134}$

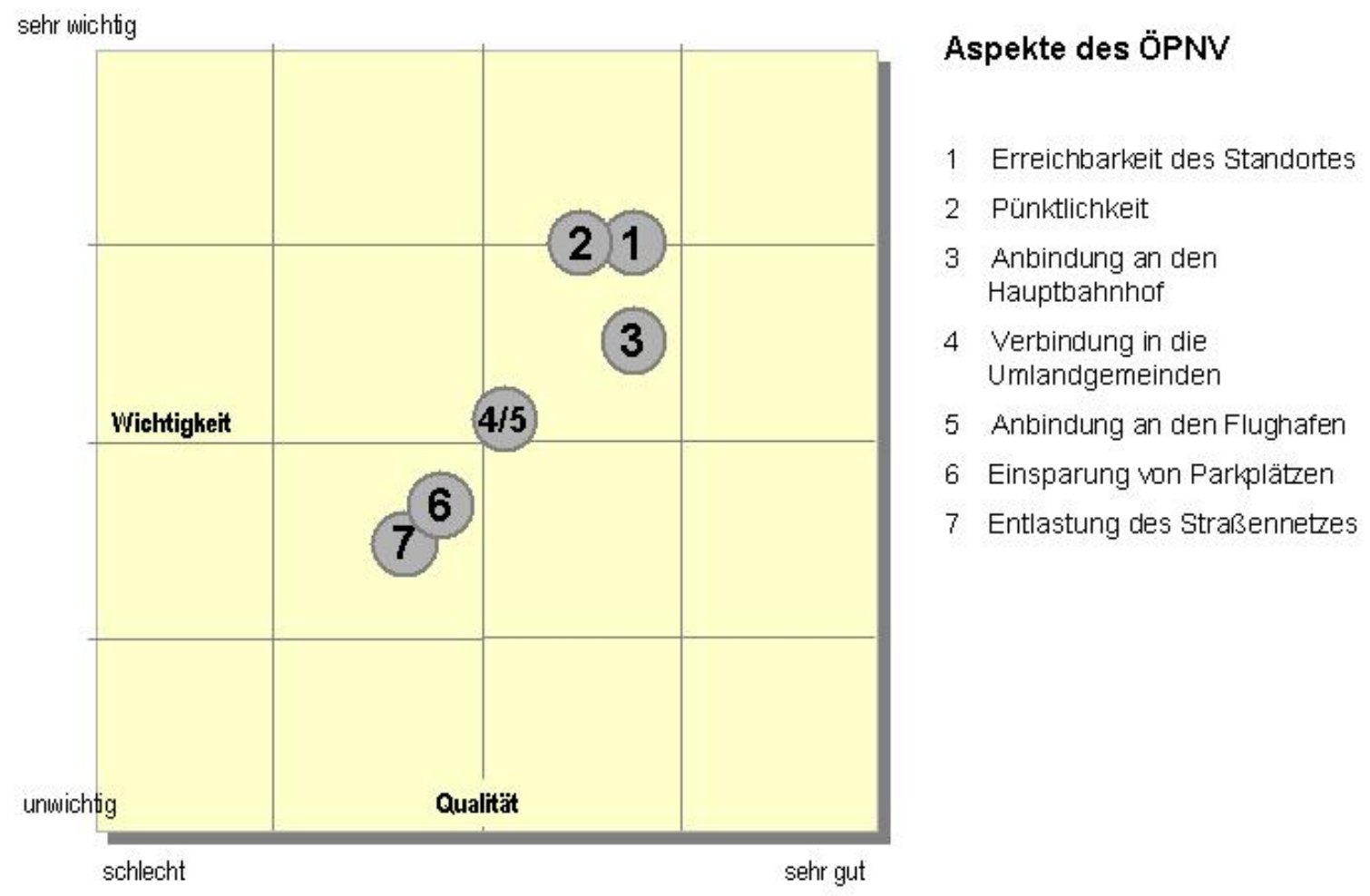

Abbildung 3:Aspekte des ÖPNV als Standortfaktor aus Unternehmenssicht

Quelle: Schad u.a. 2002, S.23, eigene Bearbeitung

Eine attraktive ÖPNV-Anbindung hat also positiv zu bewertende Effekte für ein Unternehmen, da hierüber die direkten und indirekten Mobilitätskosten gesenkt werden können. Zu den direkten Effekten gehören die Einsparung von eigenem Parkraum und reduzierte Kosten bei Geschäftsfahrten und Dienstwagen. Letzteres wird allerdings durch den stetig steigenden Anteil von Dienstwagen an Neuzulassungen eingeschränkt, der zuletzt sogar über dem Anteil von privaten Neuzulassungen lag. Zu den indirekten Effekten gehören u.a. die sichere und stressfreie Anreise der Mitarbeiter zum Arbeitsort, deren Nut-

133 vgl. Ude 2002, S.8 ; Schad u.a. 2000, S.22; ProgTrans/HSW 2005, S.13

134 vgl. Schad u.a. 2000, S.22 
zung der Reisezeit im Sinne des Unternehmens oder die Verlagerung von Fahrten auf den ÖPNV, wovon wiederum die betriebliche Logistik profitiert.

In bezug auf die Zufriedenheit mit der verkehrlichen Anbindung zeigt die Befragung ferner, dass die Anforderungen an das städtische Straßennetz und die Anbindung an Bundesautobahnen sehr gut erfüllt werden. Die ÖPNV-Anbindung wird immerhin als gut bewertet, Verbesserungsbedarf besteht eher an den peripheren Standorten. Außerdem zeigte sich, dass die Wirtschaftsunternehmen einen verbesserten Beratungsservice sowie maßgeschneiderte Mobilitätsangebote erwarten, die über das heutige Maß hinausgehen. 135

Umso erstaunlicher ist es, dass der ÖPNV bei der Vermarktung von Wirtschaftsstandorten kaum Erwähnung findet. Dieser wird offensichtlich als Dienstleistung vorausgesetzt und in der Diskussion um Standortfaktoren nicht gesondert thematisiert oder hervorgehoben. Es scheint gar, dass „wesentliche Synergiepotenziale einer Kooperation von Wirtschaftsförderung und ÖPNV heute nicht ausgeschöpft sind“. ${ }^{136}$ Ein leistungsfähiger ÖPNV kann bei der Differenzierung und Abgrenzung zu anderen Standorten aber durchaus eine Rolle spielen. Die Tatsache, dass dies bislang kaum geschieht, liegt teilweise in der Ansicht der Wirtschaftsförderer, dass das ÖPNV-Angebot in Ballungsräumen als durchweg "gut" vorausgesetzt werden kann. Ein gutes Leistungsniveau ist gerade die Voraussetzung dafür, dass der ÖPNV dazu beitragen kann, andere Standortfaktoren, die durch das stetig wachsende Verkehrsaufkommen bedroht sind, zu stärken. Hierzu zählen insbesondere verkehrsbezogene Standortfaktoren, also die Verkehrsanbindung und die Verkehrsinfrastruktur. Ein leistungsstarker und effizienter ÖPNV stärkt aber auch umweltbezogene und haushaltsnahe Standortfaktoren ${ }^{137}$, wovon nicht nur Wirtschaftsunternehmen profitieren, sondern auch direkt die Menschen. Diese gesellschaftliche Bedeutung des ÖPNV wird u.a. daran deutlich, dass rund acht 8 der fast 39 Mio. deutschen Haushalte ohne Auto auskommen und täglich etwa 26 Mio. Fahrten im ÖPNV unternommen werden. Aber nicht nur für diese Menschen ist der ÖPNV bereits Bestandteil der alltäglichen „Erfahrungswelt". So wird die Wertigkeit des Wohnumfeldes durch einen guten ÖPNV-Anschluss aufgewertet, die Attraktivität der Innenstädte verbessert, der Flächen-

\footnotetext{
135 ebd.

136 vgl. Topp 2006 (a), S.25

137 Also Standortfaktoren, von denen Unternehmen in indirekter Weise profitieren.
} 
bedarf für den gesamten Verkehr reduziert, lassen sich Freizeit- und Erholungseinrichtungen sicher und stressfrei erreichen, werden die schädlichen Umwelteinflüsse des Individualverkehrs auf die Umwelt minimiert und die Sicherheit im Verkehr verbessert. Eine optimierte Nutzung der bestehenden ÖPNV-Infrastruktur bzw. ein hoher Anteil des ÖPNV am Verkehr trägt daher auf vielfältige Weise zur Lebensqualität der Menschen bei. ${ }^{138}$ Ein leistungsfähiger und qualitativ hochwertiger ÖPNV ist daher ein wichtiger regionaler Standortfaktor.

\subsection{Nachhaltige Mobilitätssicherung in der Verkehrspolitik}

\subsubsection{Nachhaltige Mobilität als Leitbild}

Spätestens seit der Massenproduktion von Autos in der Mitte der 1950er Jahre und der „stürmischen Entwicklung der privaten Motorisierung“ wurden verkehrspolitische Entscheidungen in Deutschland in der Regel zugunsten der autogerechten Stadt und somit des Straßenbaus gefällt. ${ }^{139}$ Das Ergebnis dieser monodimensionierten Siedlungs- und Infrastrukturpolitik waren vom Autoverkehr geprägte Städte und die Trennung von gesellschaftlichen Funktionen. So entstand ein Mobilitätssystem, dass in seiner Dynamik selbstverstärkend ist, sich kaum mehr auflösen lässt und dessen Folgen noch heute zu spüren sind. Erst in den 1990er Jahren erfolgte vor dem Hintergrund der negativen Auswirkungen der Massenmotorisierung ein Wechsel in den Leitbildern der Verkehrspolitik in Richtung einer konzeptionellen Strategie der Integration unter Nachhaltigkeitsaspekten. Heute steht das Thema noch immer bzw. erneut auf den politischen Agenden. ${ }^{140}$

Dabei war die Idee einer nachhaltigen Verkehrspolitik keineswegs neu. Bereits auf dem „Weltkongreß für Kraftwagentransporte“ im Jahr 1930 wurde eine verbesserte Abstimmung zwischen Pkw und Eisenbahn im Interesse des Gemeinwohls gefordert. ${ }^{141}$ Und im Jahre 1964 legte eine vom Bundestag eingesetzte Sachverständigenkommission ein Gutachten vor, das dem Ausbau des ÖPNV einen Vorrang gegenüber dem MIV einräumte, da hierüber mit geringeren Kosten ein größerer Nutzen zu erzielen sei. ${ }^{142}$ Spätestens seit

\footnotetext{
138 vgl. Deutsches Institut für Urbanistik 2005, S.5 sowie Umweltbundesamt 2003 (a), S.5

139 vgl. Kossak und Pällmann 2006, S.23

140 vgl. Beckmann 2001, S.2

141 vgl. Schöller 2005, S.180

${ }^{142}$ vgl. Kossak und Pällmann 2006, S.24
} 
der Öl(preis)krise in den 1970er Jahren lagen dann die Probleme des zu hohen Energieverbrauchs und der damit in Verbindung stehende Klimawandel offen auf dem Tisch der Politik. ${ }^{143}$ Vergleichbare Entwicklungen und Ansätze gab es daher auch in anderen europäischen Ländern. So forderte das britische Verkehrsministerium ebenfalls 1964 eine „integrated policy“" im Rahmen dessen die Siedlungs- und Verkehrspolitik besser aufeinander abgestimmt werden sollte. ${ }^{144}$

Eine integrierte Verkehrspolitik strebt Integration auf drei Ebenen an: Erstens die Verknüpfung der unterschiedlichen Verkehrsträger mit Hilfe technischer Innovationen (technische Integration), zweitens die Einbindung anderer Politik- und Planungsbereiche in den originären Verkehrsplanungsprozess (politische Integration) sowie drittens die Beteiligung und Information von betroffenen Bevölkerungsgruppen und Interessenvereinigungen (soziale Integration). Durch die Ausrichtung der Planungen und Konzepte an ökonomischer Effizienz und der Orientierung an ökologischen und sozialen Standards soll gleichzeitig die Nachhaltigkeit der Verkehrsentwicklung gewährleistet werden. ${ }^{145}$

Bereits auf der UN-Konferenz in Rio de Janeiro im Jahr 1992 hatte sich die damalige Bundesregierung unter Kanzler Kohl zum Leitbild der nachhaltigen Entwicklung bekannt. Kernergebnis der Konferenz war, dass der Schutz der natürlichen Lebensgrundlagen, die soziale Verantwortung und die wirtschaftliche Leistungsfähigkeit zusammen die Eckpfeiler für eine lebenswerte Zukunft darstellen. Nur eine Entwicklung, die diese drei Bereiche gleichermaßen berücksichtigt, kann als „nachhaltig“ gelten. Seit 1997 ist die „nachhaltige Raumentwicklung“ in Deutschland gar Gesetzesvorschrift. ${ }^{146}$ Das Umweltbundesamt hat aus diesem Anlass im selben Jahr in einer Zukunftsstudie "Nachhaltiges Deutschland“ aufgezeigt, wie das Ziel der Nachhaltigkeit in Deutschland umgesetzt werden kann. Der Bereich Mobilität ist hierbei einer von vier zentralen Handlungsbereichen. Die Studie stellt klar, dass es eines „tiefgreifenden Wandels der Werterhaltung und Einstellungen zum Verkehr“ bedarf, um die negativen Verkehrseinflüsse zu mindern, was den „Ausbau des Personenverkehrs“ einschließt. Darüber hinaus spielt aber auch die Nutzung der Po-

\footnotetext{
143 vgl. UITP 2005, S.8

144 vgl. Schöller 2005, S.187

145 ebd., S.171

${ }^{146}$ vgl. Hübler und Kaether 1999, S.1
} 
tenziale des technischen Fortschritts eine Schlüsselrolle für eine "dauerhafte umweltgerechte Entwicklung“. ${ }^{147}$

Unter der rot-grünen Bundesregierung unter Bundeskanzler Schröder wurden zwar die Investitionen für den Schienenverkehr in der ersten Legislaturperiode um ca. 50\% auf 4,5 Mrd. Euro erhöht, doch erreichte auch der Etat für den Straßenbau mit 5 Mrd. Euro ein neues Rekordniveau. ${ }^{148}$ Dennoch setzte sich auch diese Bundesregierung zum Ziel, im Rahmen einer nachhaltigen Verkehrspolitik, das Wirtschafts- vom Verkehrswachstum voneinander $\mathrm{zu}$ entkoppeln. ${ }^{149}$ Dieses sollte insbesondere über Verkehrsverminderung und -verlagerung sowie effizientere Verkehrsgestaltung geschehen. Dabei sah sich die damalige Bundesregierung drei großen Herausforderungen gegenüber:

- Eine hohe Mobilität zu erhalten und gleichzeitig die Verkehrsintensität von Wirtschaft und Gesellschaft zu verringern, um so das dynamische Wachstum des Verkehrs zu verlangsamen,

- das verbleibende Verkehrswachstum effizient und umweltverträglich zu bewältigen sowie

- die durch den Verkehr bedingten Belastungen für Umwelt und Natur, die menschliche Gesundheit und Lebensqualität weiter zu verringern. ${ }^{150}$

Die negative Entwicklung im Bereich des Güter- und Personenverkehrs sollte so zugunsten umweltfreundlicher Verkehrsträger umgedreht werden, d.h. eine Wende in der Verkehrsentwicklung herbeigeführt werden. „Eine erfolgreiche wirtschaftliche Entwicklung“ wurde dabei als „integraler Bestandteil einer nachhaltigen Entwicklung“ verstanden, dessen Leistungspotenzial nicht zuletzt in der Fähigkeit gesehen wurde, Innovationen - beispielsweise in der Wirtschaft und im Umweltschutz - hervorzubringen und erfolgreich anzuwenden. 151

Diesem Ansatz folgt prinzipiell auch die aktuelle Bundesregierung unter Bundeskanzlerin Merkel: „Unsere Verkehrspolitik folgt dem Gebot der Nachhaltigkeit. Wir sichern Mobilität und bewältigen zugleich ihre negativen Auswirkungen“. Der Verkehrsinfrastruktur

${ }^{147}$ vgl. Umweltbundesamt v.18.6.1997

148 vgl. BUND o.J., S.1ff

149 vgl. Bundesregierung 2002, S.112

150 ebd., S.181

151 ebd., S.276 
wird dabei nach wie vor eine zentrale Rolle eingeräumt: „Nur eine moderne, leistungsstarke und effiziente Verkehrsinfrastruktur ist in der Lage, Mobilität heute und in $\mathrm{Zu}$ kunft zu gewährleisten. Die Sicherung der Mobilität als Grundlage des wirtschaftlichen Erfolges Deutschlands ist deshalb das zentrale verkehrspolitische Ziel der Bundesregierung. Das stärkt die wachstumsorientierte Wirtschaft, schafft und sichert Arbeitsplätze und sorgt für Freiheit und Flexibilität des Einzelnen“. ${ }^{152}$ Die Diskrepanz zwischen der Fokussierung auf die Infrastruktur einerseits, hier insbesondere dem Straßenbau, sowie dem Ziel der Mobilitätssicherung, soll im Rahmen einer „Mobilitätsoffensive“ aufgelöst werden, die noch unter Bundeskanzler Schröder initiiert wurde. In den dazugehörenden „Handlungsempfehlungen für die Mobilität der Zukunft“ versteht man unter dem Einsatz von technischen Innovationen die „Nutzung neuer Informations-, Kommunikationsund Leittechnologien im Verkehr" (Verkehrstelematik) und verspricht sich davon die Erschließung von Potenzialen, „um Mobilität in ihren vielfältigen Ausprägungen für die Wirtschaft wie für den Einzelnen dauerhaft, effizient und möglichst umweltschonend zu gestalten“. ${ }^{153}$ Es wird davon ausgegangen, dass „die Gewährleistung von Mobilität zu einem immer entscheidenderen Faktor für die Stärke des Wirtschaftsstandortes Deutschland" wird. ${ }^{154}$

Das Bundesamt für Bauwesen und Raumordnung formulierte 2002 den Anspruch an eine nachhaltige Mobilität aus Sicht der Politik folgendermaßen:

„Zielsetzung einer an Nachhaltigkeit orientierten Verkehrspolitik und -planung ist es, die Teilhabe der Menschen am sozialen, gesellschaftlichen und kulturellen Leben zu verbessern. In gleicher Weise müssen die wirtschaftlichen Austauschprozesse der Produktion, Verteilung, Konsumption etc. durch eine geeignete Verkehrsversorgung gesichert werden. Zentrales Anliegen einer Politik nachhaltiger Mobilität ist es jedoch, und hier liegt die entscheidende Anforderung, dass diese Austausch- und Vermittlungsprozesse und die daraus entstehenden Verkehrsvorgänge unter tragfähigem Einsatz der Ressourcennutzung sowie unter reduzierten Belastungen und Beeinträchtigungen für Mensch, Umwelt, d.h. insgesamt mit reduziertem Verkehrsaufwand ablaufen müssen. "155

\footnotetext{
${ }^{152}$ vgl. www.bmvbs.de/Verkehr-,1405.22720/Verkehrspolitik.htm (Zugriff am 26.8.2006)

${ }^{153}$ vgl. www.bmvbs.de/Verkehr/Integrierte-Verkehrspolitik-,1414/Telematik.htm (Zugriff am 26.8.2006)

154 Bundesministerium für Verkehr, Bau und Stadtentwicklung 2005, S.2

155 Kanzlerski und Würdemann 2002, S.47
} 
Mittlerweile trifft das Leitbild der integrierten Verkehrspolitik auf eine breite gesellschaftliche Anerkennung. So wird eine Vernetzung der unterschiedlichen Verkehrsträger gegenüber der heute noch zumeist unverbundenen Nutzung allgemein als vorteilhaft anerkannt. „Zudem wird eine einheitliche Verkehrskonzeption, die politische und soziale Problemstellungen einbezieht, der Wahrnehmung und Bearbeitung vielfältiger gesellschaftspolitischer Interessenkonflikte vorgezogen“.156 Auch die hessische Landesregierung hat im „Landesentwicklungsplan Hessen 2000“ (LEP) das Ziel einer nachhaltigen Verkehrsentwicklung - rechtsverbindlich - verankert: „Dem Mobilitätsbedarf der Bevölkerung und dem Transportbedarf der Wirtschaft ist Rechnung zu tragen, soweit dies mit der nachhaltigen Entwicklung in Einklang zu bringen ist und für Mensch und Natur keine unverhältnismäßigen Beeinträchtigungen hervorruft" ${ }^{\text {“ }}{ }^{157}$

Dennoch muss konstatiert werden, dass sich die Verkehrsentwicklung weiterhin in konventionellen Bahnen vollzieht und es an der Umsetzung nachhaltig ausgerichteter Verkehrskonzepte mangelt. Beckmann kritisiert, dass

„die Bilanz der vor zehn, vor fünfzehn Jahren oder auch vor längerer Zeit erarbeiteten Verkehrsentwicklungspläne [...] hinsichtlich der Zielerreichung wie auch der Umsetzung der vorgesehenen Maßnahmen und Projekte teilweise ernüchternd“158

sei. Probleme der Verkehrsangebote und der Verkehrsabwicklung, insbesondere aber auch der Anforderungen an eine Verringerung von Verkehrsauswirkungen scheinen „weitgehend ungelöst bzw. unerfüllt, allenfalls graduell gedämpft“. ${ }^{159}$

\subsubsection{Umsetzung einer nachhaltigen Mobilität}

Der Sachverständigenrat für Umweltfragen betont in seinem im Jahre 2005 veröffentlichten Sondergutachten $\mathrm{zu}$ „Umwelt und Straßenverkehr“160, dass es für die Umsetzung einer umweltgerechten Mobilitätspolitik insbesondere der Festlegung verbindlicher und konkreter Ziele bedürfe. Die sich daraus ableitenden Strategien der Verkehrsvermeidung, der Verkehrsverlagerung und der Nutzung (fahrzeugbezogener) technischer Verbesserungen

\footnotetext{
156 Schöller 2005, S.172

${ }^{157}$ HMWVL 2000, S.8

158 Beckmann 2001, S.2

159 ebd.

${ }^{160}$ vgl. Sachverständigenrat für Umweltfragen 2005
} 
dürften wiederum nicht isoliert betrachtet werden. Darüber hinaus sollten aber auch die Raumordnung und die Verkehrswegeplanung kritisch überdacht werden. So sollte beispielsweise im Rahmen einer verkehrssparenden Siedlungspolitik, die der Zersiedlung und der zunehmenden Entmischung entgegenwirkt, „das raumordnerische Leitbild dezentraler Konzentration mit Achsenstrukturen und das Konzept der Zentralen Orte flankiert durch den Abbau verkehrserzeugender finanzieller Anreize konsequenter als bisher in der Praxis umgesetzt werden“. ${ }^{161}$ Konsequenter sollten auch Verkehrsauswirkungsprüfungen von baulichen Maßnahmen durchgeführt werden oder auf die strikte Einhaltung von „Sozialvorschriften im LKW-Verkehr“ gedrängt werden, damit der „ungerechtfertigte Wettbewerbsvorteil gegenüber dem Schienenverkehr" verringert wird. Darüber hinaus wird die Umsetzung verkehrssparender Regionalkonzepte angeraten. Hier gibt es unterschiedliche EU-Förderprogramme und Regionalfonds, die strukturpolitische Initiativen für die Umsetzung verkehrssparender Wirtschafts- und Raumstrukturen unterstützen und auf eine verbesserte ländliche Entwicklung abzielen, in denen u.a. die regionale Vermarktung und Weiterverarbeitung gestärkt wird. ${ }^{162}$

Aus diesem Anspruch wird ersichtlich, dass eine nachhaltige Mobilitätssicherung keineswegs nur über die Verbesserung der technischen Effizienz von beispielsweise Pkw erfolgen kann. Vielmehr geht es um Verkehrsvermeidung sowie -verlagerung auf umweltverträgliche(re) Verkehrsmittel und deren effiziente Auslastung. Unter der Annahme dieser Veränderungen hat das Umweltbundesamt im Jahre 2002 in einem „Nachhaltigkeitsszenario" konkrete Ziele für die Umsetzung einer nachhaltigen Mobilität aufgestellt. Demnach soll der Verkehrsaufwand bis 2030 auf das Niveau von 2000 zurückgeführt und gleichzeitig die Auslastung aller Verkehrsmittel um 20\% verbessert werden. So ließe sich der vom Verkehr verursachte Kohlendioxid-Ausstoß auf die Hälfte des Wertes von 1990 reduzieren, die Luftschadstoffemissionen um über 90\% verringern und der Lärmpegel nahezu flächendeckend unter $65 \mathrm{~dB}(\mathrm{~A})$ am Tage drücken. ${ }^{163}$ Das Umweltbundesamt stellt gleichzeitig klar, dass hierfür ganze Maßnahmenbündel und der Einsatz unterschiedlicher Instrumente notwendig seien.

161 Sachverständigenrat für Umweltfragen 2005, S.10

$162 \mathrm{vgl}$. Sachverständigenrat für Umweltfragen 2005, S.10

163 vgl. Umweltbundesamt 2002, S.3 
Bereits 1995 hatte das Umweltbundesamt im "Maßnahmenkatalog Umwelt und Verkehr“ 164 empfohlen, dass die Bestrebungen zur Umsetzung einer nachhaltigen Mobilität von ordnungsrechtlichen Maßnahmen flankiert werden sollten. Zu den kurzfristig wirksamsten Maßnahmen werden in diesem Katalog die Erhöhung der Kosten der Pkw-Nutzung gezählt, vor allem über die Erhöhung der Mineralölsteuer. ${ }^{165}$ Außerdem empfahl das Umweltbundesamt in diesem Maßnahmenkatalog die Kürzung der Pendlerpauschale, die „Reduzierung der allgemein zulässigen Höchstgeschwindigkeit auf Autobahnen, sonstigen Außerortsstraßen und auf Innerortsstraßen“, der „Verzicht auf Erweiterung des überörtlichen Straßennetzes" und die "Parkraumverknappung und -verteuerung". Dauerhafte Emissionsminderung seien aber nur dann zu erzielen, wenn neben diesen restriktiven Maßnahmen („push-Maßnahmen“) „auch Maßnahmen ergriffen werden, die der Verbesserung des Angebots an Alternativen zum Straßen- und Luftverkehr dienen (sog. „pullMaßnahmen“) [...] Verkehrssparende Raumstrukturen und eine verkehrsminimierende Nutzung bilden das Polster, auf dem höhere Transportkosten und Restriktionen für den motorisierten Verkehr abgefedert werden können“. Zu diesen dauerhaft wirksamen pullMaßnahmen gehört insbesondere auch die Verlagerung von Fahrten auf den ÖPNV, die mit einer „Förderung des Umweltverbundes im Nahverkehr" und einer "Angebotsverbesserung bei ÖPNV und Bahn“ einhergeht. Das Umweltbundesamt betont, dass der Erfolg nachhaltiger Mobilität zuallererst von der Effizienz eines attraktiven ÖPNV abhänge. Als „zweite Wahl“ werden dagegen u.a. Maßnahmen wie „elektronische Verkehrsbeeinflussungsanlagen“ (siehe Kapitel 4.6.3.1) sowie die City-Maut, aber auch „Tarifsenkungen bei ÖPNV und Bahn" eingestuft (siehe auch Kapitel 4.6.3.3). ${ }^{166}$

Die potenziellen positiven Wirkungen des ÖPNV auf die Nachhaltigkeit des Gesamtverkehrssystems betreffen alle drei Dimensionen der Nachhaltigkeit: Ökonomisch betrachtet kann über die verstärkte Abwicklung eines hohen Gesamtverkehrsaufkommens in Form kollektiver Verkehre die volkswirtschaftliche Effizienz gesteigert werden, vorausgesetzt die ÖPNV-Leistung wird selber effizient erstellt. Der ÖPNV trägt dann zu einer verbes-

\footnotetext{
164 vgl. Umweltbundesamt 1995

165 Kritiker befürchten hingegen, dass eine Erhöhung der Mineralölsteuer vor allem zu einem Umstieg von Berufspendlern auf den ÖPNV führen würde, also zu den ÖPNV-Stoßzeiten, in denen die Reservekapazitäten weitgehend ausgenutzt sind. Dies hätte zur Folge, dass die Kapazitäten als wesentlicher Kostentreiber des ÖPNV weiter vergrößert werden müssten; vgl. Storchmann 1999.

166 ebd., S.10ff
} 
serten ökologischen Effizienz bei, wenn es zu Verkehrsverlagerungen vom MIV kommt und dadurch die Umweltbelastungen reduziert werden können. Die Voraussetzung hierfür ist, dass der durch technische und organisatorische Vorteile erreichte ökologische Vorsprung erhalten bleibt. Zur sozialen Nachhaltigkeit trägt der ÖPNV bei, indem er prinzipiell allen Bevölkerungsgruppen offen steht. Damit dies gewährleistet bleibt, ist nicht nur ein flächendeckendes und insgesamt attraktives ÖPNV-Angebot notwendig (z.B. Bedienungshäufigkeit, Komfort etc.), es bedarf auch eines barrierefreien Zugangs sowohl zu den Beförderungsmitteln, als auch zu den relevanten Informationen. ${ }^{167}$

Da die pull-Maßnahmen auf die Überzeugung und Kooperation der Mobilitätskonsumenten abzielen, kommt der Integration der Bevölkerung sowie der Förderung der Austauschprozesse zwischen den Verkehrsakteuren und den Bürgern - und zwar über die reine Ortsveränderung hinaus - eine große Bedeutung zu. Dieses setzt die gesellschaftliche Akzeptanz für die nachhaltigen verkehrspolitischen Ziele voraus. In Abhängigkeit ihrer demokratischen Legitimierung können diese Ziele durchaus auch lokalen oder regionalen Bezug haben. ${ }^{168}$ Voraussetzung ist also, dass die Bürger für die verkehrspolitischen Maßnahmen aktiv „geworben“ werden. Gefördert wird dies durch eine Kommunikation zwischen Bürgern und Verkehrsakteuren, deren Ergebnis die Reflektion von Kundenbedürfnissen und Übertragung in nachhaltige Mobilitätsangebote ist. Von daher kann Kommunikation als Voraussetzung betrachtet werden, eine „breite Kultur der Nachhaltigkeit" in der Gesellschaft zu etablieren. ${ }^{169}$

Im Idealfall führt die Kommunikation und Kooperation zwischen den Verkehrsakteuren zu einer lokal oder regional institutionalisierten Vernetzung und zur Entwicklung von abgestimmten nachhaltigen Lösungsansätzen, wie sie insbesondere im Rahmen von „Agenda $21^{\prime \prime}$-Aktionsplänen angestrebt werden. Nicht umsonst ist die Vernetzung seit über 30 Jahren eines der wichtigsten Prinzipien nachhaltiger Entwicklung. Allerdings kann gleichzeitig festgestellt werden, dass die Zersplitterung von Planungsentscheidungen in vielen Sektoren zunimmt, so dass eine ganzheitliche Problemlösung zunehmend erschwert wird. ${ }^{170}$ Auch muss resümiert werden, dass für keine deutsche Großstadt eine auf der Konferenz in Rio geforderte - „Agenda 21“ vorliegt, in der ein langfristiger Akti-

\footnotetext{
167 vgl. Schäfer-Sparenberg, Bongardt und Dalkmann 2006, S.14

168 vgl. Bratzel 2000, S.93

169 vgl. Rat für Nachhaltige Entwicklung 2006, S.8

170 vgl. Hübler und Kaethler 1999, S.97
} 
onsplan für die nachhaltige kommunale Entwicklung zugrunde gelegt wird. ${ }^{171}$ Dies gilt auch für Hessen bzw. für Frankfurt, wo lediglich, in der Regel durch Bürgerinitiative, Einzelprojekte zu verzeichnen sind, von denen einige vom Land Hessen gefördert werden:

"Rund 270 hessische Städte und Gemeinden - das sind etwa 60 \% - arbeiten an einer Lokalen Agenda 21. Nahezu 150 Kommunen haben bereits ein erstes "Lokales Handlungsprogramm" vorgelegt. Rund 15.000 Menschen engagieren sich ehrenamtlich in den kommunalen Agenda 21Prozessen. Hessen hat hier im Vergleich mit den anderen Flächen-Bundesländern eine Spitzenposition eingenommen. Dazu haben insbesondere die Kommunen beigetragen.

Das Land Hessen hat seit 1997 mit finanziellen und personellen Mitteln Fortbildungsveranstaltungen und zentrale Projekte mit Schwerpunkt im kommunalen Bereich intensiv unterstützt. Im Rahmen eines Wettbewerbs im Jahr 2001, den das Land mit rund 500.000 Euro ausstattete, wurden Projekte in 15 Kommunen und zwei Regionen gefördert. Im Jahr 2002 konnten 16 weitere innovative Projekte zur Nachhaltigkeit aus hessischen Kommunen und Regionen mit Fördermitteln in Höhe von rund 280.000 Euro unterstützt werden. Im Jahr 2003 wurden weitere 10 Kommunen für ihre Projekte mit insgesamt 85.000 Euro ausgezeichnet" ${ }^{172}$

Der Anspruch einer nachhaltig orientierten Verkehrspolitik verweist auf die enge Verknüpfung bzw. gegenseitige Beeinflussung von Verkehr und Wirtschaft, woraus sich das Oberziel ableitet, das Wirtschafts- vom Verkehrswachstum zu trennen. Diese Trennung, die als „Verkehrswende“ bezeichnet wird und die eine Verschiebung der Verkehrsmittelwahl zugunsten des Umweltverbundes vorsieht, ist bis heute mit den bislang umgesetzten Maßnahmen- und Aktionsplänen nicht eingetreten. Der Vorsitzende des Rates für Nachhaltige Entwicklung und u.a. ehemalige Bundesverkehrsminister sowie Oberbürgermeister der Stadt Frankfurt am Main, Volker Hauff, schätzte 2003 die Umsetzung einer nachhaltig-zukunftsverträglichen Mobilität folgendermaßen ein:

"Ich setze ein großes Fragezeichen dahinter, weil ich eine sehr große Ratlosigkeit aller Beteiligten wahrnehme. Ich sehe im Grunde die Ratlosigkeit auch dort, wo man sie heute nicht zugibt und fleißig weiter die alten Konzepte fortschreibt"173

\footnotetext{
171 vgl. Klühspies 1999, S. 8 f

172 Hessisches Ministerium für Umwelt, ländlichen Raum und Verbraucherschutz: Lokale Agenda 21 - Umsetzung in Hessen (Internetpräsens).

${ }^{173}$ Hauff 2003, S.181
} 
und kommt in bezug auf die Realisierung der Verkehrswende zu folgender Erkenntnis: „Die Verkehrswende ist stark in den Ansprüchen und schwach in der Ausgestaltung und Umsetzung". ${ }^{174}$ Wenig verwunderlich ist es dann auch, dass sich der Modal Split weiter zu Gunsten des MIV verschoben hat - und dies bei einem erheblichen Anstieg des Gesamtverkehrsaufkommens (siehe Kapitel 4.4.1). ${ }^{175}$ Auch die Reformbestrebungen der Bundesregierung(en), das Wirtschaftswachstum vom Verkehrswachstum zu entkoppeln, stellen sich im Ergebnis nur bescheiden dar. Diesbezügliche restriktive Maßnahmen wie die Erhöhung der Mineralölsteuer, die Kürzung bzw. Streichung der Pendlerpauschale sowie der Eigenheimzulage, wurden weniger aus verkehrspolitischen Erwägungen getroffen, sondern eher aus haushaltspolitischem Kalkül.

Letztendlich bedarf es für die erfolgreiche Umsetzung von nachhaltig ausgerichteten Mobilitätskonzepten eines mehrdimensionalen Ansatzes, der unterschiedliche „Handlungsfelder und Instrumente" nutzt und "diese ortspezifisch anwendet". Nuhn und Hesse kommen daher zum Schluss, dass ein solches Konzept nicht als „Verwaltungsakt verordnet werden darf, sondern die Menschen hierfür aktiv gewonnen werden müssen. ${ }^{176}$ Es geht also nicht um die Umsetzung unpopulärer, weil restriktiver verkehrspolitischer Maßnahmen, sondern um die Entwicklung sozial ausgewogener Problemlösungen, die ressortübergreifend wirksam sind und um die überzeugende Vermittlung - auch im Sinne von Vermarktung - dieser Lösungen. Nachhaltigkeit darf nicht länger nur „eine Variante staatlicher Ordnungspolitik“ sein und „auch kein Thema allein wissenschaftlicher Experten“. 177

Tatsächlich zeichnet sich auch in der Verkehrsbranche selbst, die sich jahrzehntelang über alle Bundesregierungen der letzten Jahre hinweg - als außerordentlich veränderungsresistent im Hinblick auf die Erreichung von Nachhaltigkeitszielen präsentiert hat, ein Bewusstseinswandel ab. Dieser Wandel kann zuallererst in der Verwendung des Begriffs „Nachhaltige Mobilität“ wahrgenommen werden.

\footnotetext{
174 ebd. S.183

175 vgl. Canzler und Knie 2000; Kossak und Pällmann 2006, S.23ff; Halbritter u.a. 2005, S.39

176 vgl. Nuhn und Hessen 2006, S.323

177 Hauff 2003, S.179
} 


\subsection{Nachhaltige Mobilität in der Verkehrsbranche}

In der Verkehrsbranche wird der Begriff „Mobilität" häufig genutzt, um Produkte und Angebote aber auch das eigene Unternehmensimage aufzuwerten. Dieses ist vor allem in der Automobilbranche der Fall, wo das Auto in ausgeprägt emotionaler Weise zum Inbegriff der individuellen Mobilität stilisiert wird. Diesbezüglich bestehen seitens der Automobilhersteller auch keine Berührungsängste, den Begriff „nachhaltige Mobilität“ in ihrem Unternehmensleitbild zu verwenden, also mit der Vermeidung negativer ökologischer, ökonomischer und sozialer Folgen zu werben. So wirbt der größte europäische Autobauer, der Volkswagen-Konzern, auf seiner Internetseite mit folgender Unternehmensstrategie:

"Mobilität ist ein Grundbedürfnis des Menschen und Triebkraft wirtschaftlicher Entwicklung. Als einer der weltweit größten Automobilhersteller ist der Volkswagen-Konzern fest überzeugt, dass eine nachhaltige Mobilität möglich ist - eine Mobilität, die Auswirkungen auf Umwelt und Gesellschaft ebenso berücksichtigt wie die steigenden Mobilitätsbedürfnisse der Menschen weltweit. Wir arbeiten daran, diese Vision mit unseren Produkten und Leistungen zu verwirklichen". 178

Der hessische Autobauer Adam Opel AG gibt gar einen eigenen "Nachhaltigkeitsbericht" heraus, indem das Unternehmen ankündigt,

"das Prinzip der Nachhaltigkeit in seine Unternehmensstrategie [zu integrieren] und identifiziert den unternehmerischen Nutzen (business case) von Nachhaltigkeit. Der Automobilhersteller macht sich damit die Erkenntnis zu eigen, dass nachhaltiges Wirtschaften eine Grundvoraussetzung der langfristigen Existenzsicherung ist - und zugleich ein bedeutender Wettbewerbsvorteil sein kann". ${ }^{179}$

Dieser Sichtweise schließt sich auch die Lufthansa AG als größte deutsche Luftfahrtgesellschaft an, indem sie in ihrer Konzernstrategie betont, dass Umweltschutz und Nachhaltigkeit durch Investitionen in Innovation feste Bestandteile sind und dass wirtschaftlicher

\footnotetext{
178 www.volkswagen-nachhaltigkeit.de/nhk/nhk_folder/de/strategie.html (Zugriff am 30.12.2006)

${ }^{179}$ www.opel.de/res/download/pdf/nachhaltigkeit_teil1.pdf (Zugriff am 30.12.2006)
} 
Erfolg und eine an dem Leitbild der Nachhaltigkeit orientierte Unternehmenspolitik sich nicht ausschließen. ${ }^{180}$

Der Begriff der „Nachhaltigkeit“ wird häufig als „unverbindliche Metapher für alles Gutgemeinte und Zukunftsträchtige“ ${ }^{181}$ verwandt. Die Verwendung des Begriffs in Kombination mit „Mobilität" bei Autoherstellern und Fluggesellschaften erscheint als Rechtfertigung für die Nutzung von Autos und Flugzeugen. ${ }^{182}$ Dennoch soll im Rahmen dieser Arbeit nicht untersucht werden, inwieweit die Umsetzung der Leitbilder in unternehmensinternen Bereichen und nach außen tatsächlich in nachhaltiger Weise erfolgt ist oder inwieweit der Begriff der nachhaltigen Mobilität nur genutzt wird, um beispielsweise die Kfz- oder Flugzeug-Nutzung emotional aufzuwerten. Bemerkenswert ist vielmehr, dass mit der Positionierung als Anbieter von Mobilität stets auch ein Anspruch auf - wie auch immer geartete - nachhaltige Umsetzung dieser Position verbunden ist. Damit dringt vor allem die Automobilbranche in einen „claim“ (im Marketingdeutsch gesprochen) ein, der bislang vom ÖPNV quasi als Alleinstellungsmerkmal beansprucht wurde und beispielsweise vom Verband Deutscher Verkehrsunternehmen (VDV) auch nicht in Frage gestellt wird: „Der öffentliche Personennahverkehr (ÖPNV) sichert die nachhaltige Mobilität in Städten und Regionen". ${ }^{183}$

Als „Umweltverband“ firmiert der ÖPNV mit Fahrradfahrern und Fußgängern zu einer Allianz der umweltschonenden Verkehrsträger. Diese Allianz stand bislang in Abgrenzung zum MIV, der als umweltbeeinträchtigend galt. Der VDV sieht diesen Unterschied nach wie vor und betrachtet das Auto als den größten Konkurrenten und Verursacher von Umweltproblemen:

„Der öffentliche Personennahverkehr in Ihrer Stadt und in Ihrer Gemeinde leistet tagtäglich einen wichtigen Beitrag zur Reduzierung von Schadstoffemissionen. Nicht der Verzicht auf das Auto steht dabei im Mittelpunkt, sondern die Vernunft, möglichst viele Fahrten mit Bus und Bahn zu machen und dabei festzustellen, dass der Nahverkehr insbesondere in den Ballungsräumen inzwischen eine äußerst attraktive Alternative geworden ist". ${ }^{184}$

\footnotetext{
${ }^{180}$ vgl. http:/ / konzern.lufthansa.com/de/html/ueber_uns/balance/

${ }^{181}$ Lucas 2000, S.17

182 vgl. Henning 1996, S.26

183 VDV 2004 (a), S.3

${ }^{184}$ VDV 2003 (a), S.3
} 
Vor dem Hintergrund stagnierender Fahrgastzahlen und rückläufiger Einnahmen muss jedoch kritisch hinterfragt werden (siehe Kapitel 6.1.5), ob ein auf rein rationalen Argumenten aufbauendes Konkurrenzdenken noch konform zu den gewachsenen Mobilitätsansprüchen läuft.

Dass ein Denken in anderen Bahnen möglich ist, beweist die Deutsche Bahn AG (DB AG), die - mittlerweile - einen offensiven Umgang mit sämtlichen Mobilitätsformen an den Tag legt. Zukünftig möchte sie ihren Kunden „Reiseketten komplett aus einer Hand anbieten und abrechnen, und zwar mit allen Verkehrsmitteln“. ${ }^{185}$ Die DB AG hat erkannt, dass sie über den zielgerichteten Ausbau ihres Leistungsportfolios im gesamten Mobilitätsumfeld eine deutlich höhere Wertschöpfung erreicht als durch die ausschließliche Konzentration auf ihr Kerngeschäft. So bietet die DB AG über ihre Tochter DB Rent mittlerweile Car-Sharing-Fahrzeuge und in vier deutschen Städten, darunter Frankfurt am Main, auch Mietfahrräder (Call-a-Bike) an. Dabei ist der Veränderungsprozess der Deutschen Bundesbahn als Verkehrsunternehmen hin zur Deutsche Bahn AG als „Mobilitätsdienstleister" aus wirtschaftlicher Motivation heraus zu verstehen. Die sich verändernden Mobilitätsmuster und -anforderungen sind die Ausgangslage für die Entwicklung eines Alleinstellungsmerkmals in einem Verkehrsmarkt, in dem die einzelnen Verkehrsmittel weitgehend unabgestimmt voneinander operieren. Das Thema „Nachhaltigkeit", welches die $D B A G$ auch in ihr Unternehmensleitbild übernommen hat, wird von dem verkehrsträgerübergreifenden „integrierten“ Umgang mit Mobilität untermauert und macht die Marktpositionierung glaubhaft.

Obwohl der Begriff der „Mobilität“ also definiert ist, verändert sich der Umgang mit diesem. Dies wiederum hängt mit den veränderten Bedürfnissen und Erwartungen der Mobilitätskunden zusammen, auf die sich die ÖPNV-Unternehmen einstellen müssen.

\subsection{Veränderte Anforderungen an die Mobilitätsplanung}

Die heutige Gesellschaft ${ }^{186}$ durchläuft einen tiefgreifenden Wandel, der einerseits demographischen Ursprungs ist, andererseits durch soziale Veränderungsprozesse gekennzeichnet wird. Dieser Wandel kann mit den Begriffen „Individualisierung“, Flexibilisie-

\footnotetext{
185 Mehdorn 2006, S.3

186 Der Übergang von der industriellen Massenproduktion hin zu einer flexiblen Produktion kennzeichnet die Entwicklung der Industriegesellschaft hin zu einer Wissensgesellschaft.
} 
rung“ und „Pluralisierung“ umschrieben werden. Individualisierung meint die Veränderung der Verlaufsmuster von Handlungen; Flexibilisierung die abnehmende Bindung des Einzelnen in ein festes soziales Gefüge und Pluralisierung die soziale Diversifikation in neue soziale Milieus und Gruppen. ${ }^{187}$ Die damit im Zusammenhang stehenden gesellschaftlichen Veränderungsprozesse wirken sich auch auf die Mobilitätsbedürfnisse und erwartungen der Menschen aus, mit dem Ergebnis, dass sich das Mobilitätsverhalten allmählich wandelt. Auf die geänderten Anforderungen der Kunden nach individueller und flexibler Mobilität muss sich auch der ÖPNV einstellen. So passt beispielsweise das aus dem 19. Jahrhundert stammende Konzept, mit großen „Transportgefäßen“ auf festgelegten Linien nach getakteten Fahrplänen unterwegs zu sein, nicht mehr zur geforderten Mobilität des 21. Jahrhunderts. ${ }^{188}$

\subsubsection{Soziodemographische Entwicklung}

Bereits seit den 1970er Jahren liegen die Geburtenraten in Deutschland um rund einem Drittel unter dem Niveau, welches für die Bestandserhaltung der Bevölkerung notwendig wäre. Daraus resultieren demographische Veränderungen in der Bevölkerungsstruktur, die es u.a. mit sich bringen, dass die Bevölkerungszahl zurückgeht und es einen größeren Anteil älterer Menschen geben wird. ${ }^{189}$ Dieser Wandel stellt eine immense Herausforderung für Gesellschaft, Politik und Wirtschaft dar190, der letztlich auch Auswirkungen auf das Mobilitätsverhalten und die Mobilitätsnachfrage hat. So gehen auch die ÖPNVExperten (eine gute und aktuelle Übersicht bietet die im Sommer 2005 vorgestellte DELPHI-Studie ${ }^{191}$ ) davon aus, dass sich die Rahmenbedingungen der Mobilität in der Zukunft auch im ÖPNV teils dramatisch ändern werden.

Ein wesentlicher Unterschied zwischen zukünftigen „Älteren“ und heutigen „Alten“ wird sein, dass die zukünftig "Älteren“ fast alle über einen Führerschein und (mindestens) einen Pkw verfügen, dessen Gebrauch sich über Jahrzehnte habitualisiert haben wird. Zudem lassen sich nachlassende Körperkraft oder verringertes Reaktionsvermögen über defensive Fahrweisen und Assistenzsysteme im Pkw immer besser kompensieren. Auch

\footnotetext{
${ }^{187}$ vgl. WZB / Projektgruppe Mobilität 2001, S.29

188 ebd., S.8f

189 vgl. IFMO 2005, S.25; Bundesministerium für Verkehr, Bauwesen und Raumordnung 2005, S.7

190 vgl. Deutscher Bundestag 2003, S.44

191 vgl. Deutsches Verkehrsforum 2005
} 
körperliche Behinderungen werden dann häufig eher für die Nutzung des Pkw als für Busse und Bahnen sprechen. ${ }^{192}$ Das heißt, dass die objektive Affinität zum MIV in der Gruppe der zukünftigen Alten im Vergleich zu heute weiter ansteigen wird. Im Gegensatz zu gestern und heute werden die Älteren von Morgen außerdem eine aktive Bevölkerungsgruppe sein, mit reger Beteiligung am Alltagsleben und den damit verbundenen Mobilitätsansprüchen. Ein solcher Anspruch ist, so lange wie möglich selber Auto zu fahren und "sehr viel unterwegs“ zu sein. Die in der ÖPNV-Nachfrage heute noch dominierenden Wegezwecke Arbeit und Ausbildung werden in dieser Bevölkerungsgruppe keine Rolle mehr spielen; dafür gewinnen Wege zum Einkaufen, für Besorgungs- und Freizeitaktivitäten aller Art und begleitete bzw. gemeinsam zurückgelegte Wege an Bedeutung. ${ }^{193}$

Gleichzeitig nimmt aufgrund sinkender Geburtenzahlen der Anteil junger Menschen an der Gesamtbevölkerung ab. ${ }^{194}$ Dieser Trend ist bereits heute durch die zurückgehenden Zahlen bei Schülern und Auszubildenden zu erkennen. Hierdurch wird zwar die gesamte Verkehrsnachfrage durch Kinder und Jugendliche zurückgehen, der ÖPNV wird hiervon aber im besonderen Maße betroffen sein. ${ }^{195}$ Die Bevölkerungsprognose des Bundesamtes für Verkehr, Bauwesen und Raumordnung geht allerdings davon aus, dass die Auswirkungen des demographischen Wandels regional sehr unterschiedlich sind.196 Dieser „Schrumpfungsprozess" wird sich vor allem in ländlichen Gebieten negativ auswirken und dort insbesondere durch eine zurückgehende ÖPNV-Nachfrage bemerkbar machen. Also gerade dort, wo der Anteil von Schülern und Auszubildenden am gesamten Fahrgastaufkommen heute teilweise über 90\% beträgt, also das „Rückgrat des ÖPNV“ 197 im ländlichen Raum ist. In Hessen werden hierdurch besonders stark die Gebiete in Nordhessen betroffen sein. ${ }^{198}$ Aber auch ländliche Gebiete Mittelhessens, wie der Vogelsbergkreis, werden den Rückgang der Schülerzahlen drastisch zu spüren bekommen. Fehlen zudem noch Arbeitsplätze in diesen Gebieten oder eine spezifische Widmung - beispielsweise als Naherholungs- oder Wohnstandort - wird es zu einem unumkehrbaren

\footnotetext{
192 vgl. Topp 2006 (a), S.21

193 vgl. Huber 2005, S.14

194 vgl. Lehr 2003, S.3

195 vgl. Sommer 2005, S.10

196 vgl. Bundesministerium für Verkehr, Bauwesen und Raumordnung 2005,

197 Topp 2006 (a), S.21

${ }^{198}$ vgl. Tutt 2006, S.20
} 
Schrumpfungsprozess kommen, 199 bzw. wird mit einer teilweisen „Entleerung“ der Bevölkerung gerechnet, die sich mit hohem Tempo vollzieht. 200

Die negative Geburtenrate und der damit verbundene Bevölkerungsrückgang ${ }^{201}$ wird durch die Zuwanderung von Menschen aus dem Ausland - die gegenwärtig zwar noch größer ist als die Sterberate ${ }^{202}$, jedoch ebenfalls rückläufig ist 203 - allenfalls gemildert, aber nicht aufgehalten werden können. 204

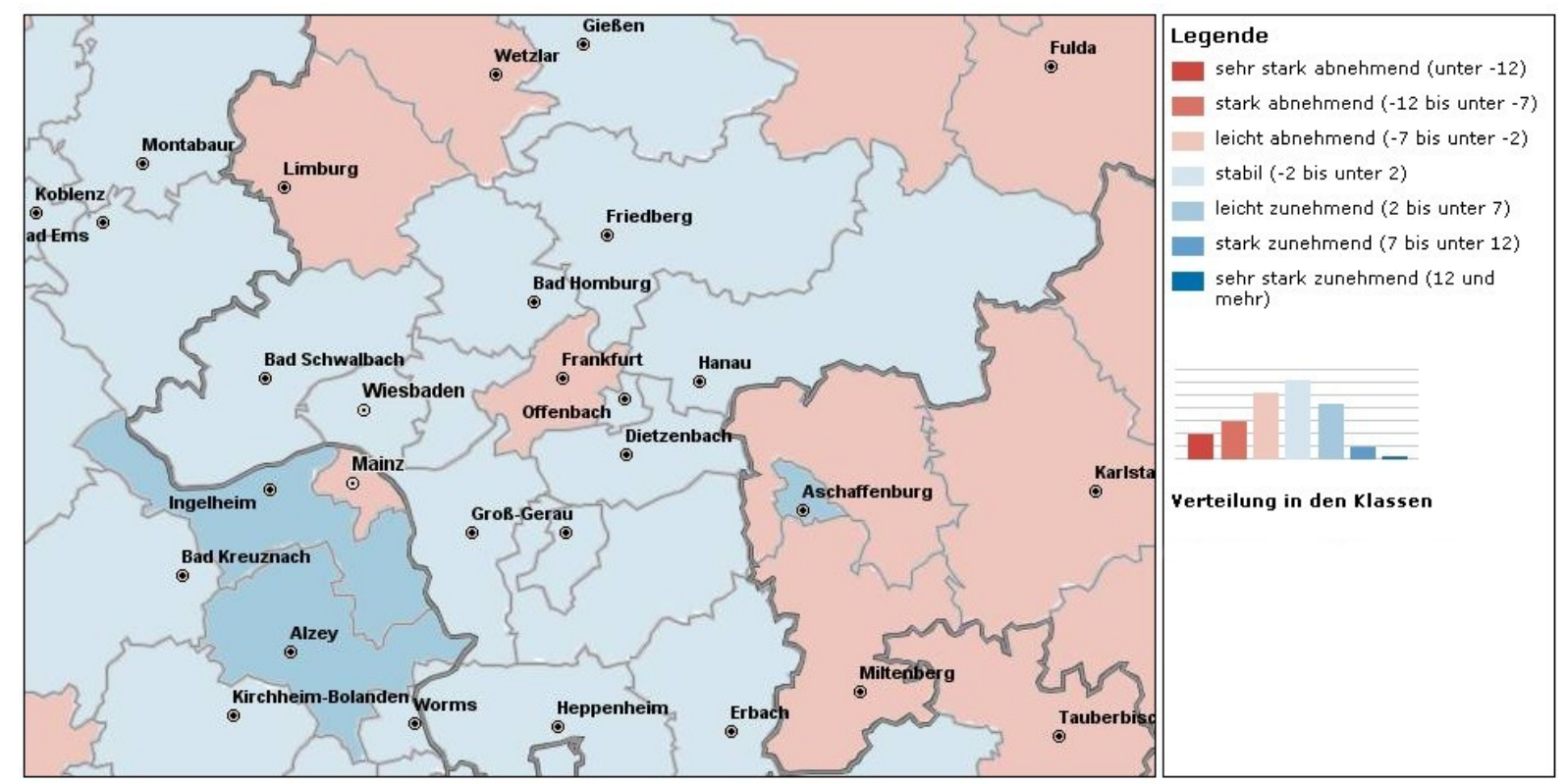

Abbildung 4:Bevölkerungsentwicklung 2003 bis 2020 in den Landkreisen und kreisfreien Städten (in \%)

Quelle: Bertelsmann Stiftung: Wegweiser Demographischer Wandel, 2006

Der Hessische Landtag ging noch Ende 2005 davon aus, dass die wirtschaftsstarken Regionen wie die Region Frankfurt Rhein-Main mindestens bis 2020205, evtl. auch darüber hinaus, eine positive Bevölkerungsbilanz aufweisen werden. Der demographische Bericht der Bertelsmann Stiftung sieht dagegen für die Region allenfalls noch eine stabile Bevölkerungsentwicklung. ${ }^{206}$ Bevölkerungswachstum ist vor allem auf Wanderungsgewinne ${ }^{207}$

\footnotetext{
${ }^{199}$ vgl. Hessischer Landtag 2005 (b), S.8

200 vgl. IFMO 2005, S.37 sowie Tutt 2006, S.21

201 laut Abschlussbericht der Enquete-Kommission des Deutschen Bundestages zum „Demographischen Wandel“" sinkt die Zahl der Einwohner von heute rund 82 Mio. Menschen auf rund 60 Mio. in 2050.

202 vgl. Bundesamt für Bauwesen und Raumordnung 2001, S.170

${ }^{203}$ vgl. IFMO 2005, S.25

204 vgl. Deutscher Bundestag 2003, S.43

205 vgl. Hessischer Landtag 2005 (b), S.8

206 vgl. Bertelsmann Stiftung 2006
} 
zurückzuführen, so etwa in der Stadt Offenbach (siehe Abbildung 4). Dies geht generell mit einer starken Alterung der Bevölkerung in der Region einher, wobei aber auch hier alterspezifische Unterschiede existieren. So spielen je nach Altersgruppe ausbildungsoder arbeitsplatzrelevante Kriterien eine Rolle. Daraus ergibt sich, dass der Kern des Ballungsraumes, also die Städte Frankfurt und Offenbach, offenbar keine Alterung kennt, hingegen Landkreise in der Peripherie - so zum Beispiel der Hochtaunuskreis, der MainKinzig-Kreis und der Kreis Darmstadt-Dieburg - eine besonders starke Alterung zu verzeichnen haben 208 (siehe Abbildung 5). Dies liegt u.a. darin begründet, dass die zukünftigen Senioren - realistischerweise - davon ausgehen, auch noch im Alter mit dem Auto sehr mobil zu sein und keine Notwendigkeit sehen, ihren Wohnsitz zwecks Verbesserung der Mobilität zu verlegen. ${ }^{209}$ Es wird ferner davon ausgegangen, dass sich die Wanderungsgewinne nicht wesentlich auf das Wachstum der Siedlungsfläche auswirken werden, zumal der Anteil der Siedlungs- und Verkehrsfläche an der Gesamtfläche bereits sehr hoch ist. 210

Insgesamt gesehen führen die soziodemographischen Veränderungen in allen Räumen zu neuen Herausforderungen. Sie erfordern, dass (auch) aus verkehrlicher Sicht in den ländlichen Regionen die Kooperation, Vernetzung und kosteneffiziente Bestandsentwicklung notwendig sein wird, soll die Qualität der Nahverkehrsbedienung gewahrt bleiben. Hier heißt es also Ressourcen bündeln, statt in „Konkurrenz von jedem gegen jeden zu treten“.211 In den städtischen Gebieten geht es dagegen eher um eine wachstumsorientierte Planung. ${ }^{212}$

\footnotetext{
${ }^{207}$ Dies bedeutet gleichzeitig einen hohen Integrationsbedarf von Zuwanderern und Ausländern; vgl. Bundesamt für Bauwesen und Raumordnung 2001, S.173

${ }^{208}$ vgl. Hessischer Landtag 2005 (b), S.86

${ }^{209}$ vgl. DIW 2005, S.772

${ }^{210}$ vgl. Bundesamt für Bauwesen und Raumordnung 2001, S.179

211 vgl. Tutt 2006, S.21

${ }^{212}$ vgl. Hessischer Landtag 2005 (b), S.86
} 


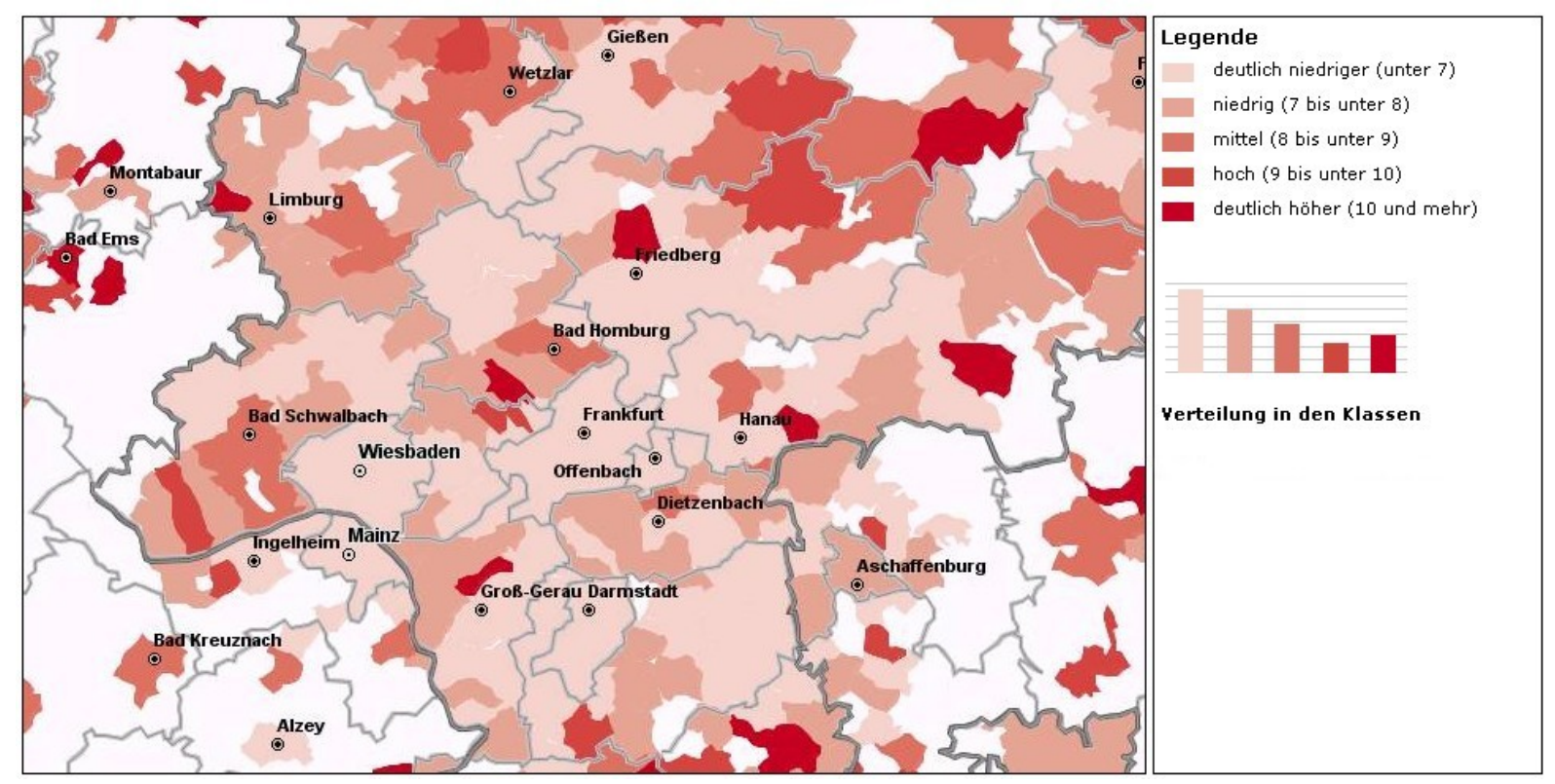

Abbildung 5: Anteil der über 80-jährigen 2020 in Städten und Gemeinden über 5000 Einwohner (in \%) Quelle: Bertelsmann Stiftung: Wegweiser Demographischer Wandel, 2006

Es ist davon auszugehen, dass aufgrund der (zunächst) fortdauernden Bevölkerungszunahme - zumindest im Verdichtungsraum - der Umfang des ÖPNV-Leistungsangebotes in der Region Frankfurt Rhein-Main grundsätzlich aufrechterhalten werden sollte. Die soziodemographischen Veränderungen führen aber zu einer veränderten Nachfragestruktur im ÖPNV, die vor allem in ländlichen Bereichen dazu führen wird, dass sich die Bedienung mit Bussen auf eine Grundversorgung beschränkt. Vor dem Hintergrund sinkender Schülerzahlen und eines steigenden Anteils älterer Bürger mit einer geringen Wanderungsbereitschaft ${ }^{213}$ wurden bereits die Finanzierungsmittel nach §45a PBefG für die Ausgleichszahlungen im Schülerverkehr landesseitig in Hessen eingefroren. Denn fehlen dem ÖPNV in den ländlichen Gebieten erst einmal die Kunden, könnte dies eine „nach unten gerichtete Qualitätsspirale auslösen und für einen noch größeren Vorsprung des Individualverkehrs sorgen". ${ }^{214}$

Vielmehr bedarf es der Umwidmung der Mittel in Richtung „seniorengerechter“ Angebote. Dies sehen auch die im Rahmen der „Delphi-Studie“ befragten ÖPNV-Experten so: Die Zielgruppe der Senioren wurde mit 79\% als die Zielgruppe mit den größten Erfolgschancen für ein zielgruppenorientiertes Marketing eingestuft. Mit 57\% folgte mit Abstand die

213 vgl. DIW 2005, S.773

${ }^{214}$ DIW 2005, S.774 
Gruppe der bisherigen Nichtnutzer. ${ }^{215}$ Dabei darf nicht der Fehler begangen werden, die Gruppe der Senioren in entweder "krank“ oder "alt" einzustufen. Mindestens bedarf es einer Einteilung in "Junge Alte“ („,best agers“) und „Hochbetagte“.216 So ist die Gruppe der „Jungen Alten“ durch eine hohe Mobilität gekennzeichnet, hingegen die „Hochbetagten" ab einer bestimmten physischen Einschränkung - und sich einer damit einstellenden Verunsicherung - das Auto, auch wenn sie mit diesem alt geworden sind, nur noch im Nahbereich nutzen bzw. irgendwann ganz stehen lassen (trotz aller Assistenzsysteme). Vor diesem Hintergrund scheint einerseits das rechtzeitige Vertrautmachen älterer Menschen mit dem ÖPNV besonders wichtig. Andererseits müssen die erhöhten Anforderungen älterer Menschen in bezug auf Service, Komfort, Sicherheit und Zuverlässigkeit Berücksichtigung finden.217 Darüber hinaus gilt es, die Information über das Angebot zu verbessern, damit auch die Zielgruppe der „Freiwilligen“, d.h. wahlfreien Stammkunden besser an den ÖPNV gebunden werden. ${ }^{218}$

Insgesamt muss der ÖPNV also in viel stärkerem Maß über neue Angebote, technische Lösungen, aber auch mit sozialer Kompetenz, den spezifischen Mobilitätsanforderungen aller Altersklassen gerecht werden. ${ }^{219}$

\subsubsection{Flexibilisierung und Individualisierung}

Die Flexibilisierung und Individualisierung der Gesellschaft haben direkte Auswirkungen auf die Mobilität der Menschen. Das Institut für Mobilitätsforschung geht in seiner Studie "Zukunft der Mobilität - Szenarien für das Jahr 2025“ davon aus, dass die gegenwärtigen gesellschaftlichen Entwicklungen 220 dazu führen könnten, dass sich die Situation auf dem Verkehrsmarkt erheblich verschlechtert, sofern keine aktive Gegensteuerung stattfindet. Demnach käme es im Bereich der Mobilität zu einer Polarisierung: Einerseits verursachen

\footnotetext{
215 vgl. Deutsches Verkehrsforum 2005, S.118

216 vgl. Huber 2005, S.8

217 vgl. Huber 2005, S.10; Topp 2006 (a), S.25

${ }^{218} \mathrm{vgl}$. Topp 2006 (a), S.25

${ }^{219}$ vgl. Huber 2005, S.22

${ }^{220}$ Die Entwicklung der auf Massenproduktion ausgerichteten Industriegesellschaft („Fordismus“) hin zu einer Wissens- und Dienstleistungsgesellschaft ist von einer Ausdifferenzierung der erst städtischen, dann regionalen und schließlich globalen Arbeitsteilung geprägt. Dies führt zu tiefgreifenden Veränderungen in der Beschäftigungsstruktur, die zu einer stärkeren Trennung von Wohn-, Lebens- und Arbeitsorten führt.
} 
die gestiegenen Kosten für Mobilität ${ }^{221}$ Einschränkungen im Mobilitätsverhalten, andererseits führen die veränderten Lebensstile und Veränderungen in der Arbeitswelt dazu, dass die Ausgaben für Mobilität weiter steigen (siehe Abbildung 16 und 17 in Kapitel 4.4.5).222 Der individuellen Mobilität kommt daher zukünftig eine viel höhere Aufmerksamkeit zu. ${ }^{223}$ Auch wenn die Auswirkungen der soziodemographischen Veränderungen erst ab 2020, dann allerdings massiv, einsetzen werden, bedeutet dies eine Herausforderung für den ÖPNV, der er sich rechtzeitig mit räumlich differenzierten Lösungsansätzen stellen muss. 224

Ihre Ausprägung findet die Flexibilisierung der Arbeitswelt u.a. im anteiligen Rückgang klassischer Beschäftigungsverhältnisse im produzierenden Gewerbe (sowie in der öffentlichen Verwaltung), wo an fünf Arbeitstagen an festen Arbeitsplätzen gearbeitet wird. Dagegen nimmt der Anteil der Beschäftigten im Dienstleistungssektor mit flexiblen Arbeitszeiten und -orten zu. "Sowohl befristete, projektbezogene Aufgaben als auch Teilzeitjobs gehören zum Alltag der Zukunft“. ${ }^{225}$ Institutionelle Zeitvorgaben werden mehr und mehr durch individuelle Zeiteinteilungen ersetzt, wie sie durch Gleit-, Teil- oder Schichtarbeitszeiten zum Ausdruck kommen. Eine „Normalarbeitszeit“ bei vielen Arbeitnehmern gibt es nicht mehr. ${ }^{226}$ In den letzten Jahrzehnten ist auch die durchschnittliche Arbeitszeit stetig zurückgegangen, so dass die Menschen ihre Zeit nicht nur individueller gestalten können, sondern auch mehr Zeit für andere Tätigkeiten haben (Freizeit, ehrenamtliche Tätigkeiten etc). Teilzeitbeschäftigung, gleitende Arbeitszeiten und geänderte Ladenöffnungszeiten führen schon heute dazu, dass die ehemals bekannten „Verkehrsspitzen“ weniger ausgeprägt sind als früher. ${ }^{227}$ Insgesamt betrachtet verwischen die Grenzen zwischen Arbeits- und Freizeitwelt zunehmend. Die Konsequenz daraus ist, dass die Menschen nicht nur weitere Wegstrecken zurück legen, sondern vor allem auch in viel

\footnotetext{
${ }^{221}$ Gestiegene Kosten für Mobilität resultieren bspw. durch gestiegene Benzinpreise in Form höherer Steuerabgaben oder tatsächlich gestiegener Rohölpreise sowie die wahrscheinliche Einführung einer Autobahnmaut für private Pkw; im ÖPNV wird es durch die zurückgehenden Regionalisierungsmittel des Bundes zu einer Verknappung des Angebotes oder einer Steigerung der Fahrpreise kommen.

222 Schon heute stehen die Ausgaben für „Mobilität" nach den Ausgaben für „Wohnen“ bereits an zweiter Stelle der Haushaltsausgaben. Noch vor einigen Jahren war „Versorgung“ wichtiger als „Mobilität".

${ }^{223}$ vgl. IFMO 2005, S.27

${ }^{224}$ vgl. Huber 2005, S.6

225 WZB / Projektgruppe Mobilität 2001, S.38

226 ebd., S.32

${ }^{227}$ vgl. Umlandverband 2000, S.29f
} 
flexiblerer Weise mobil unterwegs sein möchten und müssen. Diese Flexibilisierung der Arbeitswelt betrifft vor allem die wirtschaftlich aktive Bevölkerungsgruppe der 2060jährigen, die heute über 50\% der Gesamtbevölkerung repräsentieren.

Bezogen auf die Individualisierung der Gesellschaft wird die Familie als das von vielen favorisierte Lebensmodell auch in der Zukunft Bestand haben. Dennoch gibt es eine Entwicklung hin zu einer „höheren Vielfalt der Lebensformen“.228 Damit verknüpft ist, dass die durchschnittliche Familiengröße abnimmt und die Anzahl von nichtehelichen Lebensgemeinschaften und Alleinerziehenden steigt. So stieg beispielsweise der Anteil alleinerziehender Frauen mit Kind(ern) in der Stadt Frankfurt am Main in den Jahren 2001 bis 2004 von 13,7\% auf 17,0\%.229 Die Ursachen für diesen Trend, der auch als „Pluralisierung der Gesellschaft" bezeichnet wird, werden zum Teil mit einem allgemeinen Wertewandel (z.B. Änderungen im Geschlechterverhältnis, Verlängerung der Adoleszenzpha$\mathrm{se}^{230}$ ) begründet, zum anderen mit gestiegenem Wohlstand und Bildung. Dies führt dazu, dass Individuen ihre Entscheidungen freier treffen können. ${ }^{231}$ Dieser Trend ist insbesondere in Ballungsräumen dadurch ausgeprägt, dass es immer mehr kleinere Haushalte gibt, d.h. mehr Einpersonenhaushalten, Haushalte von Alleinerziehenden und kinderlose Zweipersonenhaushalte. Außerdem steigt die Anzahl doppelter Haushaltsführungen ebenso wie die saisonale oder wöchentliche Aufteilung der Zeit auf unterschiedliche Orte. 232

Vornehmlich bei der Gestaltung der Arbeits- und Freizeit treten örtliche, regionale und Landesgrenzen in den Hintergrund. Räumliche Widerstände nehmen durch technische, fiskalische und politisch-rechtliche Entwicklungen kontinuierlich ab. Der geographische Raum für die potenzielle persönliche Entfaltung weitet sich dadurch aus. Gleichzeitig wächst der „Bedarf an eigenkontrollierten Räumen“ und macht sich im Raumkonsum bemerkbar. Der veränderte Anspruch an den privaten Raum ist beispielsweise an der Entwicklung der durchschnittlichen Wohnungsgröße erkennbar. Diese hat sich von $71 \mathrm{~m}^{2}$ im Jahre 1967 auf mittlerweile über $86 \mathrm{~m}^{2}$ verändert. Insbesondere durch die Belastung,

\footnotetext{
${ }^{228}$ vgl. Brüderl 2004, S.3

${ }^{229}$ vgl. Stadt Frankfurt am Main, Frankfurter Statistik aktuell 24/2005

230 vgl. Hammer und Scheiner 2006, S.15

231 vgl. Brüderl 2004, S.3ff

${ }^{232}$ vgl. WZB / Projektgruppe Mobilität 2001, S.34 sowie DIW 2005, S.770
} 
die individuelle Zeiteinteilungen auslösen, wächst die Bedeutung von privaten und sicheren Räumen, die gleichzeitig auch soziale Abgrenzung garantieren.233

Die neu entstehenden Lebensstile („Pluralisierung“) ersetzen dabei keineswegs die klassische Schichtenstruktur der Gesellschaftsanalyse, sondern ergänzen diese. Der Vollständigkeit halber sei hier erwähnt, dass der Einfluss dieser unterschiedlichen Lebensstile auf das Mobilitätsverhalten in der Wissenschaft noch unklar ist. ${ }^{234}$ So liefert beispielsweise der soziologische Milieuansatz von SINUS Sociovision'235, der eine Verknüpfung zwischen Gesellschaftsschicht und Werteorientierung herstellt, zwar einen Ansatz für die Segmentierung von Kundengruppen. Für die Bildung von Mobilitätszielgruppen muss jedoch das Mobilitätsverhalten im Kontext individueller und gesellschaftlicher Prozesse betrachtet werden, die wiederum in starkem Maße von persönlichen Einstellungen und Motiven abhängen. ${ }^{236}$

Diesem Trend der Individualisierung entspricht der private Pkw viel besser als es durch den ÖPNV der Fall ist. „Diese Vielfältigkeit individueller Einstellungen, Emotionen, Erwartungen und funktionaler Anforderungen stößt sichhart mit der Kollektivität und manchmal auch - Monotonie und Uniformität des ÖPNV“. ${ }^{237}$ So bietet der ÖPNV - als Massentransportmittel - nur sehr bedingt Antworten auf die Auflösung angestammter kollektiver Raum-Zeit-Cluster. Feste Zeittakte auf starren Linien und Strecken werden den Ansprüchen nach flexibler Mobilität immer weniger gerecht. ${ }^{238}$ Was sich für den einzelnen als Nachteil darstellt, mag vereinzelt für den ÖPNV sogar als wirtschaftlicher Vorteil angesehen werden, da sich hierdurch die Tagesganglinien der Nachfrage verstetigen. ${ }^{239}$ Die hierüber frei gesetzten Reservekapazitäten (siehe auch Kapitel 6.1.3), die vormals für die Hauptverkehrszeiten vorgehalten werden mussten, könnten dann das ÖPNV-Angebot zielführend ergänzen, beispielsweise in Form flexibler Angebotsformen, wie sie durch Rufbusse oder Anrufsammeltaxen geboten werden. ${ }^{240}$

\footnotetext{
${ }^{233}$ vgl. Canzler und Knie 2000, o. S.

${ }^{234}$ vgl. Hammer und Scheiner 2006, S.23

235 vgl. hierzu bspw. Sinus Sociovision 2006: „Zielgruppen, die es wirklich gibt".

${ }^{236}$ vgl. Hunecke, Schubert und Zinn 2005, S.26

237 Topp 2006 (a), S.24

238 vgl. Canzler und Knie 2005, S.8ff

239 vgl. Huber 2005, S.15

240 ebd., S.25
} 
Die Auffächerung der Gesellschaft in unterschiedliche Lebensstile wird durch die Vielzahl heterogener Produkte und Leistungen des alltäglichen Lebens gleichermaßen verursacht und gefördert. So lassen vor allem multimediale Angebote die unterschiedlichen persönlichen Präferenzen und Anforderungen zu - auch in bezug auf Mobilität und Information. ${ }^{241}$ Die Mobilisierung des Internets über WAP, UMTS oder WLAN-hotspots etc. bedeutet, dass Information immer einfacher und quasi ubiquitär zu erhalten ist. Der wachsende Umfang und die steigende Qualität von Informationsdiensten setzt bei den Kunden einen Gewöhnungsprozess in Gang, den diese letztlich - früher oder später auch auf den ÖPNV übertragen, zumal die Nutzung des ÖPNV die Information über Fahrpläne, Haltestellen und Tarife voraussetzt. Wenn die Verkehrsunternehmen und Verbünde ihrer strategischen Positionierung als „Mobilitätsdienstleister“ (hierauf wird in Kapitel 5.5 näher eingegangen) gerecht werden wollen, bedarf es mit der Nutzbarmachung der neuen Medien hier eines konkreten Beweises. Anderenfalls drohen sie an der Erwartungshaltung der Kunden zu scheitern. In diesem Zusammenhang fordert Topp gar eine "totale Durchdringung des Verkehrssektors mit Informationstechnik“, damit auf individuelle Anforderungen mit individueller Information und intermodalen Angeboten geantwortet werden kann. ${ }^{242}$

Für den Erfolg von Mobilitätsdienstleistungen ist es daher wesentlich, mit der Dynamik der sich verändernden sozialen Lebenswelten und den sich hieraus geänderten Anforderungen Schritt zu halten. Auf der Kundenseite sind diese Anforderungen gekennzeichnet von wachsender Konsumentensouveränität, Bedarf nach Produktvielfalt und immer kürzeren Produktlebenszyklen, aber auch von schnell wechselnden Kundenwünschen. Dies bezieht sich nicht alleine auf das Beförderungsangebot, sondern auch auf die Art und Weise der Kommunikation und Information, die sogar die kulturelle Identität des Einzelnen berücksichtigen kann. Hunecke weist hier auf den Einfluss der symbolisch-emotionalen Bewertung der Mobilität und deren Einfluss auf das individuelle Mobilitätsverhalten und die Verkehrsmittelwahl hin, die in die vier grundlegenden Dimensionen "Autonomie“, "Status“, Erlebnis" und "Privatheit" unterteilt wird. ${ }^{243}$ Demnach sollen Mobilitätsdienstleistungen die „Freiheit, Selbstbestimmung, Individualität und Flexibilität“ des

\footnotetext{
${ }^{241}$ vgl. Henning und Olbertz 1997, S.92f

242 Topp 2006 (a), S.24

243 vgl. Hunecke und Schweer 2006, S.150
} 
Einzelnen gewährleisten (Autonomie), sollen Spaß vermitteln und das Reisen selbst zum Erlebnis machen (Erlebnis). Dabei ist wichtig, dass die Wahl des Verkehrsmittels gesellschaftlich anerkannt ist und nicht als letzte Möglichkeit der Fortbewegung eingestuft wird (Status). Schließlich spielt auch der Grad der Bewahrung der persönlichen Privatsphäre eine Rolle, bzw. die individuelle Möglichkeit, soziale Kontakte beim Reisen zu steuern (Privatheit). ${ }^{244}$ All diese Anforderungen können bzw. müssen nicht nur produkt-, sondern auch produktionsseitig zu Konsequenzen führen, die technologische Veränderungen erfordern und letztlich auch Anpassungen in der Arbeitsorganisation nach sich ziehen.

Diesen veränderten Mobilitätsansprüchen wird der ÖPNV aber nicht dadurch gerecht, dass lediglich die quantitativen Leistungsparameter angepasst werden. Es müssen sich auch die qualitativen Merkmale ändern. Die Quantität der Verkehrsdienstleistung im ÖPNV orientiert sich unter anderem an Kriterien wie Netz- und Taktdichte sowie Fahrzeugklassen. Die Qualität der ÖPNV-Dienstleistung ist weniger scharf zu fassen, insbesondere dann, wenn an den ÖPNV der Anspruch gestellt wird, nicht bloß eine Grundversorgung sicher zu stellen, sondern eine Alternative zum privaten Pkw zu bieten. Insofern muss die Qualität der ÖPNV-Dienstleistung, beispielsweise gekennzeichnet durch Sauberkeit, Reisegeschwindigkeit oder Komfort, stets im Spiegel der spezifischen und sich kontinuierlich wandelnden Kundenerwartungen und -bedürfnisse gesehen werden. Vor dem Hintergrund der Bedeutung einer integrierten Gesamtverkehrsentwicklung weist Beckmann daher darauf hin, dass nachhaltige Mobilität nicht mehr nur den ökonomischen, ökologischen und sozialen Anforderungen gerecht werden muss, sondern auch die Erhaltung und Entwicklung kultureller Werte anstreben sowie eine psychisch-emotionale Komponente umfassen sollte (siehe Abbildung 6). ${ }^{245}$

\footnotetext{
${ }^{244} \mathrm{vgl}$. Hunecke, Schubert und Zinn 2005, S.27

${ }^{245}$ vgl. Beckmann 2001, S.4
} 


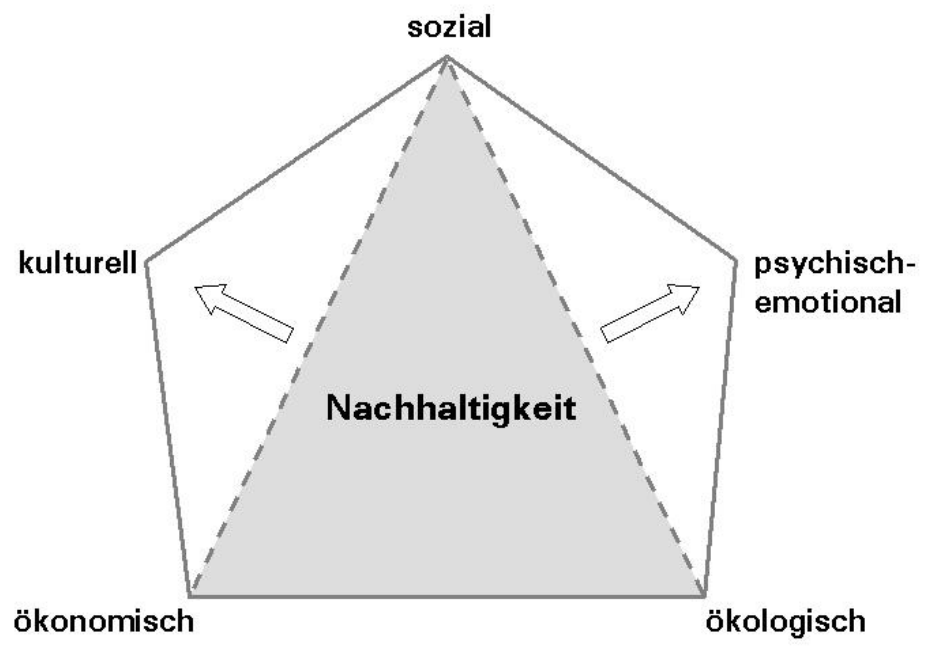

Abbildung 6: Erweiterte Anforderungen einer nachhaltigen Verkehrsentwicklung

Quelle: nach Beckmann 2001, S.4, eigene Bearbeitung

Für die Entwicklung eines zukunftsorientierten ÖPNV bedarf demnach des kundenorientierten Einsatzes zeitgemäßer Methoden und Instrumente der Angebotsentwicklung, optimierung und -vermarktung. Bislang fehlen dem ÖPNV aber die Konzepte hierfür oder hapert es an deren Umsetzung. Oftmals fehlen auch die Instrumentarien, um den spezifischen Erwartungen und Bedürfnissen auf Kundenseite zu entsprechen oder gar neue Felder in der Wertschöpfungskette strategisch und operativ zu besetzen. ${ }^{246}$ In der Konsequenz definiert sich die ÖPNV-Leistungskapazität alleine durch die Verkehrsinfrastruktur und durch Fahrpläne.

Die Voraussetzung für die Erschließung der Potenziale im ÖPNV ist eine Entwicklung, die auf eine stärkere wissensbasierte und kommunikative Verflechtung mit anderen Mobilitäts- und Dienstleistungsbereichen sowie mit dem Absatzmarkt abzielt. ${ }^{247}$ Nur so können im ÖPNV die Grundlagen gelegt werden, flexibel auf Markterfordernisse reagieren zu können und gleichzeitig ein wirtschaftlich tragfähiges Geschäft zu führen. Hilfreich hierfür wäre eine Aufhebung der strikten unternehmerischen Trennung in öffentliche und private sowie in individuelle und kollektive Verkehrsformen. Vielmehr sollte sich der

\footnotetext{
${ }^{246}$ vgl. Blümel 2004, S.11

247 Verflechtung heißt nicht, dass im Rahmen einer Diversifikation neue Produktions- und Dienstleistungsbereiche vom Unternehmen selbst übernommen werden. Auch in anderen Zukunftsmärkten (wie Umwelt, Gesundheit und Kommunikation) bündeln Unternehmen ihre Kernkompetenz und lagern für die Produktion und die Erbringung der Dienstleistung wichtige Aufgaben aus („Outsourcing“).
} 
ÖPNV dem Selbstverständnis nach als Teil einer ganzheitlichen Mobilitätsdienstleistung betrachten, deren Ziel es ist, dem Mobilitätskunden durchgängige Reisen („Wegeketten“) bis zum Ziel anzubieten - mit allem, was der Reisende in Verbindung hiermit benötigt. Schließlich wohnen die Kunden nicht an Haltestellen und Bahnhöfen, sondern haben Ziele, deren Erreichbarkeit durch den Pkw definiert wird. Das Auto gilt für den Mobilitätskunden daher als „benchmark“ seiner Erwartungen. ${ }^{248}$ Diesen Vergleich und die damit verbundene Herausforderung muss der ÖPNV annehmen, soll nicht in Zukunft der Mobilitätsmarkt von anderen Verkehrsträgern - vor allem dem privaten Pkw - zur Gänze dominiert werden ${ }^{249}$ und sich der „ÖPNV zu einem subventionierten Restverkehr für Zwangsbenutzer" entwickeln.250

Was für den ÖPNV gilt, trifft auch für das Gesamtverkehrssystem zu. Eine nachhaltige Mobilität wird nur umsetzbar sein, wenn die zunehmende Nachfrage nach Mobilität auf Dauer nicht über den Ausbau der Verkehrswege - insbesondere von Straßen - und damit zugunsten des MIV erfolgt. Eine Mobilitätsplanung, die sich ausschließlich an der MIVNachfrage orientiert, ist aus ökonomischer, ökologischer und sozialer, aber eben auch kultureller und psychisch-emotionaler Sicht nicht zielführend. Vielmehr bedarf es einer zielorientierten Mobilitätsplanung, die verstärkt auf qualifizierte Nachfragesteuerung sowie Vermeidungs- und Verlagerungsstrategien setzt. Wichtige Elemente dieser Strategie sind nutzerorientierte Mobilitätsdienste in einem auf Kooperation ausgelegten, verkehrsträgerübergreifenden Gesamtsystem. Über die Bereitstellung und ausdrücklich erfolgreiche Vermarktung dieser Dienste können für Umwelt, Gesellschaft und Wirtschaft verträgliche Verhaltensweisen gefördert, „aber auch die Vorteilhaftigkeit von Alternativangeboten für die Verkehrsteilnehmer selbst verdeutlicht werden“. ${ }^{251}$ Dabei muss die Freiheit der Verkehrsmittelwahl weder generell noch ideologisch in Frage gestellt werden. ${ }^{252}$ Denn jedes Verkehrsmittel hat seine spezifischen Transportvorteile, auf die es sich zu konzentrieren gilt (siehe Kapitel 4.7.2.2). Für die Ballungsräume ist es daher wichtig, alle Pkw-Verkehre zu gewährleisten, „die für das Funktionieren des Ballungsraumes unverzichtbar sind und dabei durch Öffentliche Verkehre nicht effektiv ersetzt werden kön-

\footnotetext{
${ }^{248}$ vgl. Schäfer-Sparenberg, Bongardt und Dalkmann 2006, S.52

${ }^{249}$ vgl. WZB / Projektgruppe Mobilität 2001, S.25f

250 Heinze 2001, S.62

251 Schnüll 2000, S.2

252 ebd.
} 
nen“. ${ }^{253}$ Auf der anderen Seite muss ein qualitativ gutes ÖPNV-Angebot aufrecht erhalten sowie offensiv kommuniziert und vermarktet werden. Im ländlichen Raum dagegen muss der ÖPNV bedarfsgerechter gestaltet werden. Hier gilt es, auf die lokalen Bedingungen zugeschnittene Konzepte zu entwickeln. ${ }^{254}$

\subsection{Zunehmende Bedeutung regionaler Kooperationsnetzwerke}

„Das Wechselspiel von regionalen und globalen Faktoren nimmt angesichts der Vielschichtigkeit, Komplexität und Dynamik der Wirtschaftsentwicklung zu“.255 Regionale Netzwerke helfen nicht nur, den Anschluss an die globalen Entwicklungen sicher zu stellen, über sie können auch regionale Kompetenzen vermarktet werden. Die Voraussetzung hierfür ist aber die Bündelung der regionalen Kompetenzen und die Netzwerkbildung. Grundlage für Netzwerke wiederum sind gemeinsame Interessen, Werte- und Zielvorstellungen der zusammengeschlossenen Akteure. ${ }^{256}$ Gerade weil nachhaltige Mobilität von allen Akteuren der Verkehrsbranche eingefordert bzw. proklamiert wird, bietet sich auf regionaler Ebene ein intermodales Netzwerk zwischen öffentlichen und privaten Akteuren an, das zum Ziel hat, das Gesamtverkehrssystem auf Sicherheit, Zeit- und Energieeffizienz hin fortdauernd zu optimieren. ${ }^{257}$

Neben den gemeinsamen Interessen, Werte- und Zielvorstellungen ist für das dauerhafte Bestehen von Netzwerken eine regional verankerte institutionelle Konsolidierung förderlich, die gemeinsame Aktivitäten steuert („managet“). Falls diese regionalen Steuerungskapazitäten nicht vorhanden sind, bietet sich für regionale Problemlösungen die Anknüpfung an bereits bestehende Ansätze einer Netzwerkbildung an. Wo es im Bereich der intermodalen Mobilität derartige Ansätze nicht gibt, empfiehlt der Sachverständigenrat für Umweltfragen, bezogen auf die intermodale Nutzung der Verkehrstelematik, den staatlichen Planungsträgern

„eine Vernetzung der Akteure aus Industrie, Forschung und Kommunen zu fördern, damit sich die Entwicklung und Anwendung verkehrstelematischer Dienste vorrangig auf solche Bereiche konzentriert, die nicht nur im Hinblick auf eine bessere Ausnutzung der

\footnotetext{
253 Klühspies 1999, S.11

${ }^{254}$ vgl. Heinze 2001, S.62

255 Lucas 2000, S.8

256 vgl. Lucas 2000, S.8

${ }^{257}$ vgl. Klumpp 2005, S.151
} 
Verkehrsinfrastruktur, sondern auch hinsichtlich einer Umweltentlastung sinnvoll $\sin d^{\prime \prime} .258$

Hierfür bedarf es aber wiederum „Basis-Infrastrukturen der Information und Kommunikation im Verkehrssektor [, die] ohne die erklärte Allokationsfunktion eines Ministeriums oder einer von diesem beauftragten Institution nicht in Gang gesetzt werden [können]“. ${ }^{259}$

Über den Einsatz von neuen Informations- und Kommunikationstechnologien kann auch der wachsenden Bedeutung von Information und Wissen für ökonomische Prozesse entsprochen werden. Denn über sie können die Kosten für Information, Kommunikation und Koordination gesenkt werden. Darüber hinaus beschleunigen sie die Information bzw. die Informationsbereitstellung und erweitern die geographische Reichweite von Information und ökonomischen Prozessen. ${ }^{260}$ Durch die Vernetzung unterschiedlicher Wissensbanken bzw. -netze können Mehrwerte generiert werden, die für die Verkehrsakteure neue Betätigungsfelder („Mobilitätsdienstleister“) und schließlich für die Kunden neue räumliche Möglichkeiten und Erfahrungen gestatten. Henning und Olbertz machen diese Erfahrung an einem Beispiel deutlich:

„Das eine Netz liefert die Information, das andere den Zufahrtsweg - das Citynetz informiert über den freien Tennisplatz im übernächsten Ort, die elektronische Fahrplanauskunft weist die nächste ÖV-Fahrt aus, oder der Scout führt direkt dorthin. An die Stelle der Informationskorridore tritt eine Raumbeherrschung, deren Intensität von der Güte und Zahl der zur Verfügung stehenden IEK-Systeme abhängt".261

Informations- und Kommunikationsnetze erweitern damit die potenziellen Bereiche der Wertschöpfung im Mobilitätsumfeld.

Für die Umsetzung eines nachhaltigen Mobilitätskonzepts bedarf es also der vernetzten Information über alle Verkehrsträger, die dann zu höherwertigem Wissen - und schließlich Angeboten - über das Gesamtverkehrssystem „veredelt" werden können. Sofern Informationen über die unterschiedlichen Verkehrsträger heute vorhanden sind, liegen diese aber in der Regel dezentral in lokalen Datenbanken vor, die miteinander nicht ver-

\footnotetext{
258 Sachverständigenrat für Umweltfragen 2005, S.9

259 Klumpp 2005, S.150

260 vgl. Caspar u.a. 2001, S.76

${ }^{261}$ Henning und Olbertz 1997, S.107
} 
knüpft sind. Dies trifft auch auf die intramodale Abstimmung zu, zumal es hier aus unterschiedlichen Gründen zu einem Wettbewerbsverhalten kommt. So werden beispielsweise Telematikanwendungen in der Automobilbranche als Verkaufsargumente gegenüber der Konkurrenz bemüht, obwohl doch jedem Käufer klar sein müsste, dass sich „Verkehrsflüsse (und Kommunikationsflüsse) partout nicht auf einzelne Marken beschränken lassen“.262 An solchen Beispielen wird deutlich, dass die inter- wie auch die intramodale Kooperation nicht an den technischen Möglichkeiten scheitert, sondern an der Bereitschaft der Verkehrsakteure zum Dialog und zur Zusammenarbeit. „Die Intermodalität steckt im Dilemma vieler Innovationen. Alle würden mitmachen, aber keiner will anfangen“. Es bedarf also auch einer organisatorischen Innovation, die eine Institution hervorbringt, die das intermodal generierte Wissen in umsetzbare Konzepte überführt. Was fehlt, ist die politische Beschlussfassung, die diesen arbeits- und kostenintensiven Prozess anstößt. „Institutionalisiert werden müssen dabei Zuständigkeiten und Verantwortlichkeiten, egal ob öffentlich oder privat organisiert“. ${ }^{263}$ Benötigt werden also neue Organisationsformen, die „eine zentrale Erfolgsbedingung für eine Nachhaltigkeitspolitik auf der regionalen Ebene sind“. ${ }^{264}$

\footnotetext{
262 Klumpp 2005, S.159

263 vgl. Klumpp 2005, S.159f

264 Lucas 2000, S.20
} 


\title{
$4 \quad$ Analyse der Mobilität in der Region Frankfurt Rhein-Main
}

\author{
"Mobilität ist Freiheit. Aber Verkehr ist die Hölle" \\ Weert Canzler, \\ Mobilitätsforscher am Wissenschaftszentrum Berlin für Sozialforschung
}

\subsection{Die Region Frankfurt Rhein-Main}

\subsubsection{Naturräumliche Einordnung des Rhein-Main-Gebietes}

Aus naturräumlicher Sicht gehört das Rhein-Main-Gebiet zum "Rhein-Main-Tiefland“, das sich im wesentlichen aus der Untermainebene, der hessischen Rheinebene und dem nördlichen Teil der Oberrheinniederung sowie der Wetterau und dem Büdinger Hügelland zusammensetzt. Der Begriff „Tiefland“ macht deutlich, dass es sich um ein Gebiet handelt, das ähnlich wie bei einer Kessel- oder Beckenlage - nur etwas weitläufiger ringsum von Höhenzügen abgeschirmt ist. Der Taunus im Norden, der Spessart im Osten und der Odenwald im Südosten bis Süden begrenzen die Rhein-Main-Ebene nach Norden und Osten; nach Westen erstreckt sich das Gebiet bis zum Rhein bzw. der Landesgrenze zwischen Rheinland-Pfalz und Hessen, wo das Rheinhessische Tafel- und Hügelland beginnt. Dieses tiefliegende und damit relativ warme Gebiet ist ein von Natur aus fruchtbarer und agrartechnisch leicht zu bearbeitender Raum, der daher schon in römischer und mittelalterlicher Zeit dicht besiedelt war. Nach Norden setzen sich diese landwirtschaftlich und verkehrlich günstigen Gegebenheiten nicht mehr fort. ${ }^{265}$

\subsubsection{Die Stadt Frankfurt am Main als Kern der Region}

Bis 1945 war Frankfurt eine von vielen deutschen Großstädten, umgeben von Dörfern und kleineren Städten. Erst nach dem 2. Weltkrieg entwickelte sich die Region über den inten-

${ }^{265} \mathrm{vgl}$. Freund 2002, S.44 
siven Ausbau der Verkehrswege zu einer Einheit. ${ }^{266}$ Heute stellt sich der Ballungsraum im Rhein-Main-Tiefland mit den Städten Frankfurt, Wiesbaden, Mainz ${ }^{267}$, Offenbach, Darmstadt und weiteren Subzentren als polyzentrischer und stark vernetzter Raum dar, der durch anhaltende Suburbanisierungsprozesse stark zersiedelt ist. Die Abgrenzung zwischen städtischen und ländlichen Strukturen ist allerdings wegen der starken Durchmischung urbaner und ländlicher Elemente mancherorts nur schwer möglich. ${ }^{268}$ In der Region besteht eine deutlich ausgeprägte hierarchische Zentrenstruktur, weshalb die Region im Forschungsprojekt zur „Mobilität im suburbanen Raum“ des Bundesministeriums für Verkehr, Bau- und Wohnungswesens auch als "polyzentrisch dominiert" bezeichnet wird. ${ }^{269}$ Nach den Gesichtspunkten der „alltagsweltlichen Interaktion“270 - und somit auch aus verkehrlicher Sicht - können zur Rhein-Main-Region alle Gemeinden gezählt werden, deren Pendlerbeziehungen auf die Kernstädte dieses Gebietes ausgerichtet sind (s.u.). Allerdings ergibt sich, begünstigt durch den ost-westlichen Mainverlauf und den Rhein als wichtige Verkehrsader im Westen sowie das vorherrschende Relief, ein großräumliches West-Ost-Gefälle in Bezug auf die Industrie- und Siedlungsentwicklung. ${ }^{271}$

Heute ist die Rhein-Main-Region nach Berlin und dem Ruhrgebiet die drittgrößte Agglomeration Deutschlands und ein bedeutender europäischer Wirtschaftsraum. Herausragendes Zentrum der Region und gleichzeitig größte Stadt ist Frankfurt am Main mit ca. 650.000 Einwohnern und ca. $600.000^{272}$ Erwerbstätigen. ${ }^{273}$ Die fast 350.000 täglichen Einpendler führen allerdings dazu, dass Frankfurt tagsüber zur Millionenstadt wird. Hier befinden sich alleine $40 \%$ der Arbeitsplätze im tertiären Sektor (Dienstleistungsbereich) der gesamten Region. ${ }^{274}$ Doch wenngleich in Frankfurt selbst eine Agglomeration von Industrie- und Dienstleistungsbetrieben besteht, liegen viele wirtschaftlich bedeutsame

\footnotetext{
266 vgl. Stein und Wolf 2005, S.260

${ }^{267}$ Mainz, die Landeshauptstadt von Rheinland-Pfalz, grenzt mit ihrem Stadtgebiet an das von Wiesbaden, so dass sie - zumindest aus verkehrlicher Sicht - integraler Bestandteil dieses Ballungsraumes ist; vgl. Freund 2002, S.222

$268 \mathrm{vgl}$. Stein und Wolf 2005, S.281

269 vgl. Stein und Wolf 2005, S.88: Ein ähnliche Struktur findet sich nur noch in der Region RheinNeckar. Das Ruhrgebiet sowie die Region Köln-Bonn haben dagegen eine polyzentrische Struktur mit ausgeglichenen Hierarchien.

${ }^{270}$ vgl. Freund 2002, S.92

271 ebd., S.222

272 Im Jahr 2005 waren hiervon ca. 460.000 Beschäftigte sozialversicherungspflichtig; vgl. Stadt Frankfurt am Main; Frankfurter Statistik aktuell 19/2005 sowie Stadt Frankfurt am Main 2006, S.205

${ }^{273}$ vgl. Stadt Frankfurt am Main, Frankfurter Statistik aktuell 14/2005

${ }^{274}$ vgl. Stein und Wolf 2005, S.263 und 267
} 
Aktivitäten schon heute an oder jenseits der Stadtgrenzen. Damit gehen von der Stadt Frankfurt auch Wachstumsimpulse auf Siedlungen niedrigerer hierarchischer Ordnung aus, deren Wachstumsraten die der Stadt Frankfurt häufig übersteigen.275 Gleichzeitig verschärft sich der intraregionale Standortwettbewerb mit der wachsenden wirtschaftlichen Bedeutung der umliegenden Städte. ${ }^{276}$

Alleine von der Größe des Stadtgebietes her gesehen, kann Frankfurt heute gar nicht alle Funktionen vorhalten, die für eine Metropole von Bedeutung sind, auch wenn Frankfurt viele zentralörtliche Funktionen für die Gemeinden im Umland vorhält. Dies trifft auch für den für Frankfurt bedeutenden Finanzsektor (siehe Kapitel 4.1.4.2) zu, der sich nicht auf das Stadtgebiet von Frankfurt begrenzen lässt. Lo betont hier:

"Die Stadt allein wäre gar nicht in der Lage, ein internationales Finanzzentrum zu tragen. Sie profitiert daher von der polyzentrischen Struktur der metropolitanen Region RheinMain, so z.B. von der Konzentration von Versicherern in Wiesbaden und von SoftwareFirmen in Darmstadt". 277

$\mathrm{Zu}$ den ausgelagerten Funktionen zählen aber auch flächenintensive Funktionen des Verkehrsbereichs oder weitere Funktionen der Daseinsvorsorge wie Erholung und attraktives Wohnen. Das Umland von Frankfurt und den anderen Großstädten weist mit einem sehr hohen Anteil an Wohnbevölkerung und Arbeitsplätzen eine starke Suburbanisierung auf, die wesentlich dazu beiträgt, dass die Bevölkerungszahl des gesamten Raumes erheblich größer ist, als es die alleinige Größe Frankfurts vermuten lässt. ${ }^{278}$ Während die Einwohnerzahl der Stadt Frankfurt in der 2. Hälfte des 20. Jahrhunderts sank (zwischen 1961 und 2000 von 690.000 auf 645.000) verdoppelten manche Städte im Umland - vor allem die mit günstigeren Bodenpreisen - ihre Wohnbevölkerung. 279 „Die metropolitane Region ist daher gekennzeichnet von einer (neuen) Einheit von Stadt und Umland“.280 „Frankfurt

\footnotetext{
275 Beispiele hierfür sind die Stadt Eschborn, die zum Main-Taunus-Kreis gehört und bei einer Einwohnerzahl von 18.000 über 25.000 Arbeitsplätze verfügt, sowie die Städte Bad Vilbel und Offenbach. Vgl. Stein und Wolf 2005, S.261

276 vgl. Stein und Wolf 2005, S.264

277 Lo 2001, S.140

$278 \mathrm{vgl}$. Freund 2002, S.232

279 vgl. Stein und Wolf 2005, S.261

280 Esser und Schamp 2001, S.13
} 
bleibt zwar bedeutendste Kommune in der Region, ihre internationale Wettbewerbsfähigkeit ist aber in zunehmendem Maße abhängig von der Region“ . ${ }^{281}$

\subsubsection{Abgrenzung der Region Frankfurt Rhein-Main}

Weit weniger klar als die wirtschaftliche Bedeutung ist die regional-räumliche Abgrenzung der Region Rhein-Main. ${ }^{282}$ Die polyzentrische Struktur der Region Rhein-Main wird durch die bestehende politisch-territoriale Administration noch verstärkt. ${ }^{283}$ So reichen die starken wirtschaftsräumlichen Interdependenzen weit über die hessischen Landesgrenzen hinaus bis nach Rheinland-Pfalz, Bayern und Baden-Württemberg. An diese Landesgrenzen sehen sich die Wirtschafts-, aber auch die Verkehrs- und Siedlungsentwicklung kaum gebunden. Diese fehlende Deckungsgleichheit der administrativpolitischen Strukturen mit den vorherrschenden Entwicklungsprozessen wirkt sich durchaus nachteilig auf die Entwicklung der Region aus. ${ }^{284}$

\subsubsection{Metropolregion Frankfurt Rhein-Main}

Mit Beschluss der Ministerkonferenz für Raumordnung vom 28.4.2005 wurde die Region Frankfurt Rhein-Main zu einer von 11 deutschen Metropolregionen benannt. Ausschlaggebend für diese Bezeichnung ist die Konzentrierung von politischen und wirtschaftlichen Entscheidungs- und Kontrollfunktionen, die Akkumulation technisch-wissenschaftlicher sowie soziokultureller Innovationen sowie der schnelle Zugang zu Märkten, Wissen und Menschen (sog. "gateway-Funktion“). Aufgrund der internationalen Bedeutung der hier versammelten zentralörtlichen Funktionen bescheinigt der Raumordnungsbericht 2005 der Region Frankfurt Rhein-Main eine „führende“ Rolle unter den deutschen Metropolregionen. ${ }^{285}$

Die Metropolregion reicht vom Landkreis Gießen im Norden bis zum Kreis Bergstraße (der Kreis Bergstraße gehört bereits zur Metropolregion Rhein-Neckar) im Süden. Von West nach Ost erstreckt sie sich vom Landkreis Bingen-Mainz bis zum Kreis Aschaffenburg. Damit dehnt sich die Region über drei Bundesländer aus, umfasst mit den Städten Frankfurt am Main, Wiesbaden, Mainz, Darmstadt, Offenbach, Worms und Aschaffenburg sie-

\footnotetext{
281 Stein und Wolf 2005, S.260

282 vgl. Freund 2002, S.92 sowie Stein und Wolf 2005, S.259

283 vgl. Stein und Wolf 2005, S.259

284 vgl. Ude 2002, S.9

${ }^{285}$ vgl. Planungsverband Frankfurt/Rhein-Main 2005(a), S.2
} 
ben kreisfreie Städte sowie 17 weitere Landkreise. Insgesamt liegen 445 Kommunen in dieser Metropolregion. Damit ist die Region weitgehend deckungsgleich mit der Region Frankfurt Rhein-Main des IHK-Forums Rhein-Main. ${ }^{286}$ Nach außen wird die Metropolregion Region Frankfurt Rhein-Main institutionell durch den Planungsverband Ballungsraum Frankfurt/Rhein-Main (s.u.) vertreten, so u.a. im Initiativkreis Europäische Metropolregionen in Deutschland. ${ }^{287}$

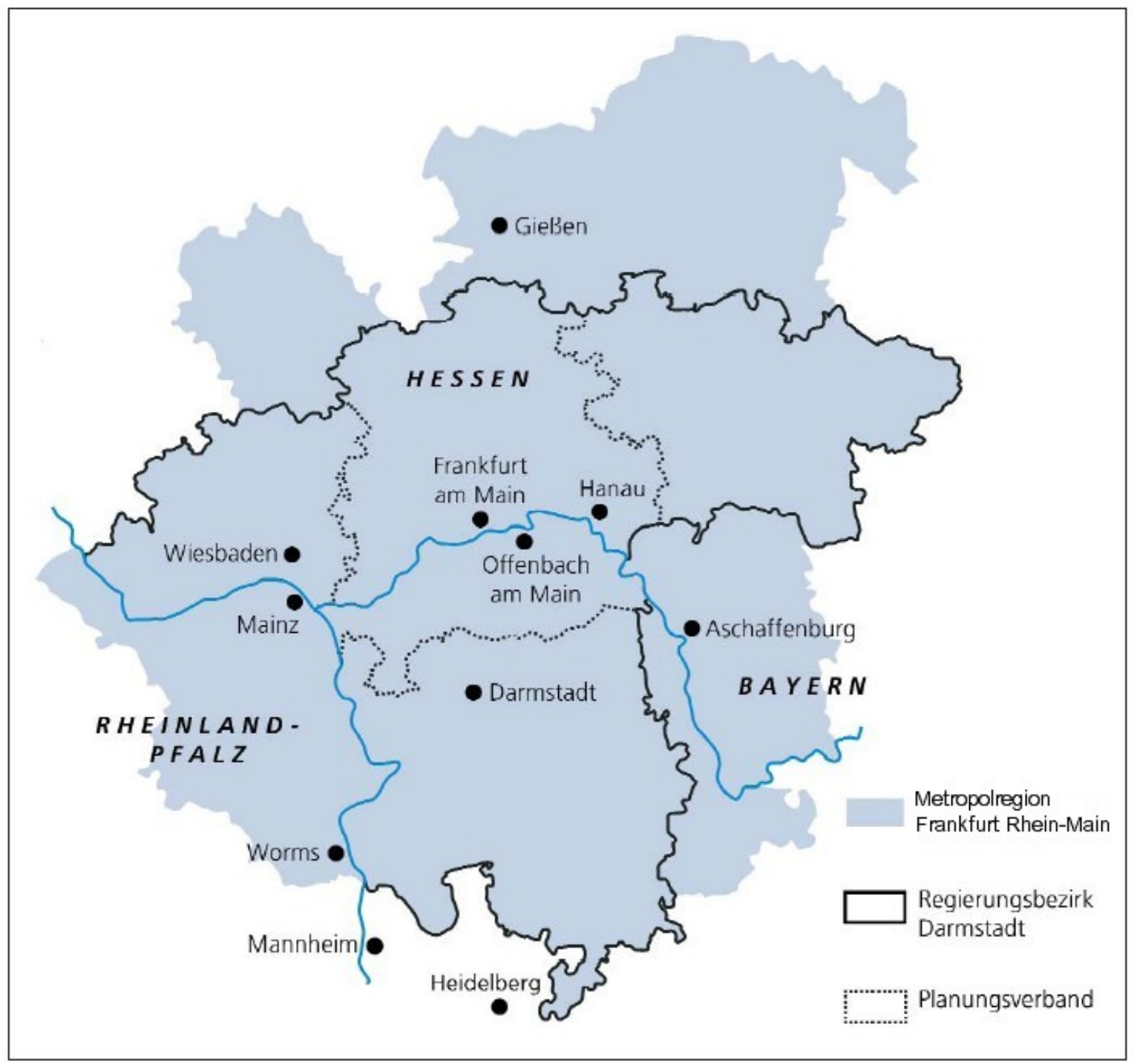

Abbildung 7:Räumlicher Zuschnitt der Metropolregion Frankfurt Rhein-Main sowie des Ballungsraumes Frankfurt Rhein-Main

Quelle: Planungsverband Ballungsraum Frankfurt/Rhein-Main: Regionales Monitoring 2005, S.3, eigene Bearbeitung

286 vgl. Planungsverband Ballungsraum Frankfurt/Rhein-Main 2005(a), S.3

287 vgl. www.deutsche-metropolregionen.org/html_de/frankfurt-rhein-main.html

(Zugriff am 7.1.2007) 


\subsubsection{Region Frankfurt-RheinMain}

In jüngerer Zeit gibt es verstärkt Bestrebungen, nicht nur die Stadt Frankfurt als global bedeutsamen Wirtschaftsstandort zu vermarkten, sondern die "gesamte" Region. In diesem Zusammenhang hat sich für die Stadt Frankfurt und den umgebenden Raum der Begriff und die Schreibweise Region Frankfurt-RheinMain herausgebildet. Die Abgrenzung umfasst das Gebiet von insgesamt neun Industrie- und Handelskammern, die sich 1992 zum IHK-Forum Rhein-Main ${ }^{288}$ zusammengeschlossen haben und auch Gebietskörperschaften der Bundesländer Rheinland-Pfalz und Bayern einbezieht. ${ }^{289}$ Das Gebiet setzt sich aus 22 Städten und Landkreisen zusammen, in dem ca. 5,5 Mio. Menschen leben und sich ca. 2 Mio. Arbeitsplätze befinden.

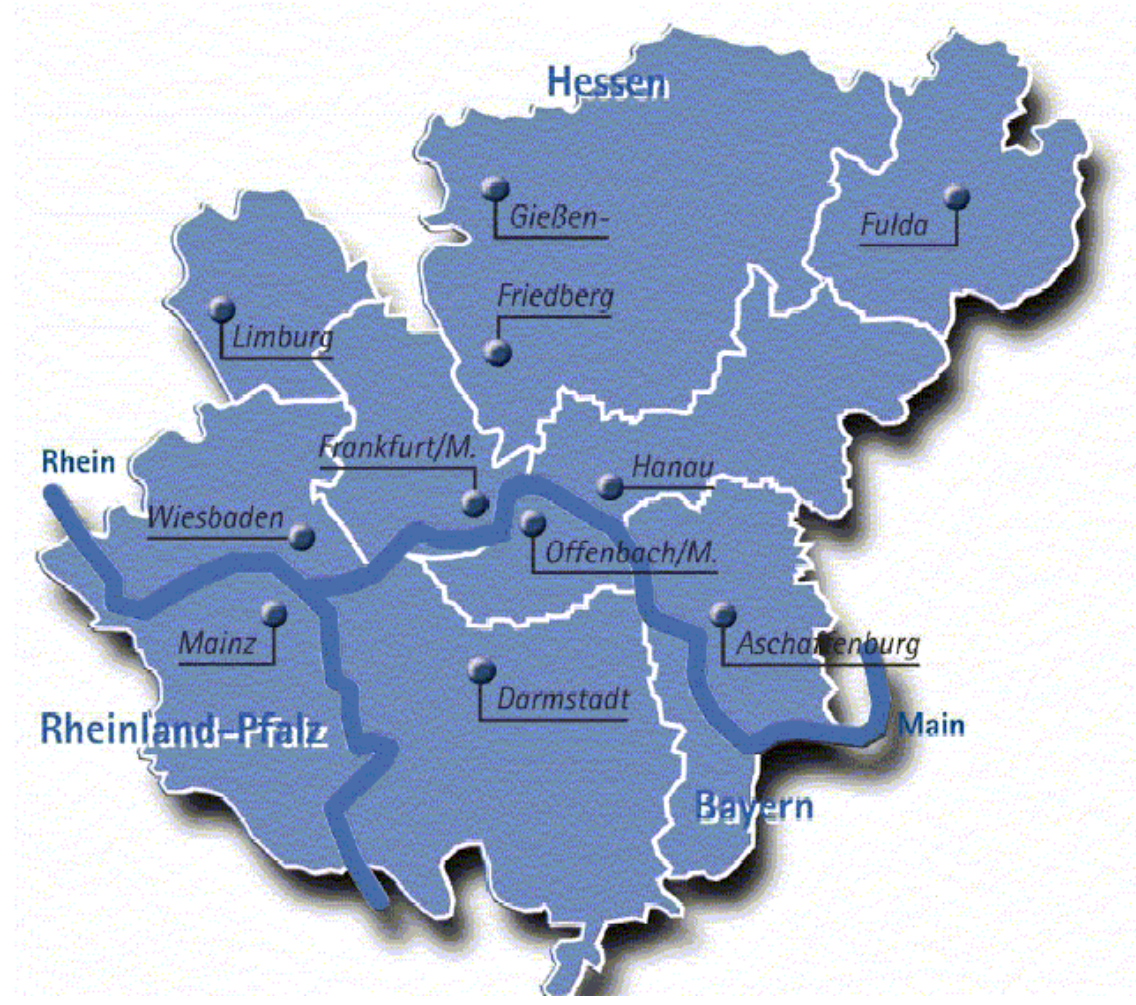

Abbildung 8: Die Region Frankfurt-RheinMain nach Einteilung des IHK-Forums

Quelle: http://hanau.ihk.de

Die Region ist fast $15.000 \mathrm{~km}^{2}$ groß, was ca. $4 \%$ der Fläche der Bundesrepublik Deutschland ausmacht. Auf dieser Fläche werden jedoch über 8\% der gesamten innerdeutschen

288 Das IHK-Forum Rhein-Main ist ein Zusammenschluss der neun Industrie- und Handelskammern Aschaffenburg, Darmstadt, Frankfurt, Friedberg, Hanau, Limburg, Mainz, Offenbach und Wiesbaden; vgl. Freund 2002, S.93

${ }^{289}$ vgl. Freund, S.92f 
Bruttowertschöpfung erwirtschaftet. ${ }^{290}$ Angebunden sind Städte, Gemeinden, Wirtschaftsförderungsgesellschaften und -verbände, öffentliche Einrichtungen sowie Fachhochschulen und Universitäten. Als Wirtschaftsinitiative hat sich dieser Zusammenschluss unter anderem zum Ziel gesetzt, bestehende Abgrenzungen zu überwinden, die Zusammenarbeit zu stärken und über eine verbesserte Außendarstellung die Region zu vermarkten. Hierfür hat die Wirtschaftsförderung Frankfurt Rhein-Main auch ein eigenes Markenzeichen entwickelt. ${ }^{291}$

\subsubsection{Ballungsraum Frankfurt/Rhein-Main}

Einen kleinräumigeren Ansatz liefert die Gebietsabgrenzung des Planungsverbands Ballungsraum Frankfurt/Rhein-Main, einer Körperschaft des öffentlichen Rechts. Der Planungsverband ist Rechtsnachfolger des Umlandverbandes Frankfurt und wurde durch das Ballungsraumgesetz zur „Stärkung der kommunalen Zusammenarbeit und Planung in der Region Rhein-Main“ am 1. April 2001 gegründet. Zugehörig sind die Städte Frankfurt und Offenbach sowie 73 weitere Kommunen in den Kreisen Groß-Gerau, Offenbach, Main-Kinzig, Hochtaunus und Wetterau mit im Jahre 2004 insgesamt 2,18 Mio. Einwohnern. Eine Verbandskammer mit Gemeindevertretern hat Mitwirkungsrecht und Beschließungsaufgaben. ${ }^{292}$ Das Zusammenwirken der Beteiligten beschränkt sich auf das Gebiet innerhalb der hessischen Landesgrenzen und dort wiederum auf ein Teilgebiet des Regierungsbezirks Darmstadt (siehe Abbildung 7). Hauptaufgabe des Planungsverbands ist die Erstellung eines erweiterten (regionalen) Flächennutzungs- und Landschaftsplanes, der auch die Verkehrsplanung berücksichtig. Er soll noch 2007 in Kraft treten und bis 2020 Gültigkeit besitzen. Damit besteht erstmals Gelegenheit, einen Regionalplan mit einem Flächennutzungsplan zusammenzulegen. 293

Damit ist der Ballungsraum Frankfurt/Rhein-Main - im weiteren Verlauf auch als „Planungsverband“ bezeichnet - enger gefasst als die Wirtschaftregion Frankfurt-RheinMain oder die Metropolregion Region Frankfurt Rhein-Main, zu der beispielsweise auch die Städte Wiesbaden, Darmstadt, Gießen, Mainz (Rheinland-Pfalz) und Aschaffenburg (Bayern) gehören.

\footnotetext{
${ }^{290}$ vgl. IHK-Forum Rhein-Main 2005, S.1

291 vgl. www.region-frankfurt.de

292 vgl. Planungsverband Ballungsraum Frankfurt/Rhein-Main 2005 (b)

${ }^{293}$ vgl. Stein und Wolf 2005, S.272
} 


\subsubsection{Die Region im nationalen Vergleich}

Im Regionalplan Südhessen sind die Städte Frankfurt und Offenbach als Oberzentren ausgewiesen. Insbesondere Frankfurt soll seine herausragende Position weiter ausbauen. Wie oben bereits ausgeführt, ist die Bruttowertschöpfung der Region gemessen an der Fläche und den Beschäftigten ausgesprochen hoch. Dies ist vor allem dem Dienstleistungssektor zuzuschreiben, der mit etwa 87\% den größten Anteil einnimmt. ${ }^{294}$ Den Bereichen Kredit- und Versicherungsgewerbe, Wirtschaftsprüfung, Rechts- und Steuerberatung sowie den Marketing- und Werbeagenturen kommt hierbei die größte Bedeutung zu. ${ }^{295}$ In jüngerer Zeit ist allerdings festzustellen, dass Unternehmen gerade aus diesen Bereichen verstärkt ins Umland abwandern, hingegen innovationsorientierte Industriebetriebe im Stadtgebiet expandieren. Dies ist einerseits ein Indikator für die „Mobilitätsfähigkeit“ von Dienstleistungsunternehmen, andererseits spiegelt dies die zunehmende Tertiärisierung des produzierenden Gewerbes wieder. ${ }^{296}$

Die Dynamik, mit der sich die Region wirtschaftlich entwickelt hat, hat sich in den letzten Jahren leicht verlangsamt. Anhand der Entwicklung der sozialversicherungspflichtig Beschäftigten zeigt sich, dass sich die Region Frankfurt Rhein-Main im Vergleich zum Durchschnitt der anderen deutschen Metropolregionen Hamburg, Köln/Düsseldorf, Stuttgart, Berlin-Brandenburg und München zwischen 1986 und 1995 zwar anfangs etwas günstiger, danach aber leicht ungünstiger entwickelt hat. So war der Beschäftigungsanteil in Frankfurt Rhein-Main im Jahr 2002 nur wenig höher als 15 Jahre zuvor. Mit 918 Arbeitsplätzen je 1000 Einwohnern ist Frankfurt allerdings immer noch einsame Spitze in Bezug auf die Arbeitsplatzdichte. ${ }^{297}$

Insbesondere die Region München entwickelte sich in den letzten Jahren dynamischer als die Region Frankfurt Rhein-Main. Stieg die Anzahl der Beschäftigten bis zur Mitte der 1990er Jahre in Frankfurt noch schneller als in München, so hat sich das Verhältnis danach

\footnotetext{
${ }^{294}$ Mit 87,2\% Anteil an den Betrieben und 86,4\% Anteil an den Beschäftigten; vgl. Stadt Frankfurt am Main, Frankfurter Statistik aktuell 20/2005

295 vgl. Freund 2002, S.113

${ }^{296}$ vgl. IHK Frankfurt 2004, S.10

297 Auf Platz 2 und 3 folgen Düsseldorf und München mit 795 bzw. 743 Arbeitsplätzen je 1000 Einwohnern; vgl. Stadt Frankfurt am Main, Frankfurter Statistik aktuell 14/2005
} 
umgekehrt. ${ }^{298}$ Die Zahl der am Standort Frankfurt sozialversicherungspflichtig Beschäftigten sank von März 2003 bis März 2004 um 3,2\%. Einen überdurchschnittlichen Rückgang von Beschäftigten verzeichnete dabei die Stadt in den bedeutsamen Bereichen des Baugewerbes, des Kredit- und Versicherungsgewerbe sowie im Dienstleistungsbereich für Unternehmen. ${ }^{299}$ Zum Vergleich: In der Stadt München ging die Anzahl der Beschäftigten im selben Zeitraum um 2,8\% zurück, in der Region um 1,8\%.300

\begin{tabular}{|c|c|c|c|c|c|c|c|c|c|}
\hline \multirow[t]{2}{*}{ Gebiet } & \multicolumn{2}{|c|}{ Gesarnt } & \multicolumn{2}{|c|}{ Teilindex Dynamik } & \multicolumn{2}{|c|}{ Teilindex Stäre } & \multirow{2}{*}{$\begin{array}{c}\begin{array}{c}\text { Produk- } \\
\text { tivität }\end{array} \\
\text { In Euro }\end{array}$} & \multirow{2}{*}{$\begin{array}{c}\text { Wachs- } \\
\text { tum } 1997 \\
-2001 \\
\text { In } \%\end{array}$} & \multirow{2}{*}{$\begin{array}{c}\begin{array}{c}\text { Arbeits- } \\
\text { losen- } \\
\text { quote }\end{array} \\
\ln \%\end{array}$} \\
\hline & Rang & Indexwert & Rang & Indexwert & Rang & Indexwert & & & \\
\hline München, Landkreis & 1 & 60,0 & 12 & 19,8 & 1 & 40,2 & 148,840 & 52,6 & 5,0 \\
\hline München, Stact & 2 & 59,7 & 6 & 20,6 & 2 & 39,1 & 94406 & 15,6 & 7,2 \\
\hline Freising, Landkreis & 5 & 54,9 & 10 & 19,9 & 6 & 35,0 & 89670 & 17,9 & 4,6 \\
\hline Heidelberg & 6 & 54,8 & 7 & 20,6 & 9 & 34,2 & 74557 & 17,3 & 7,0 \\
\hline Erlangen & 7 & 54,0 & 29 & 18,5 & 5 & 35,4 & 73376 & 14,1 & 7,7 \\
\hline Stuttgart & 8 & 53,8 & 35 & 18,4 & 4 & 35,4 & 86316 & 9,9 & 7,3 \\
\hline Frankfurt am Main & 11 & 53,0 & 15 & 19,3 & 12 & 33,7 & 94971 & 13,2 & 8,3 \\
\hline Böblingen, Landkreis & 12 & 52,7 & 14 & 19,7 & 15 & 33,0 & 86173 & 14,7 & 5,6 \\
\hline Mainz & 13 & 52,6 & 19 & 19,0 & 13 & 33,6 & 84667 & 14,8 & 7,7 \\
\hline Ingolstact & 14 & 52,3 & 4 & 20,8 & 23 & 31,5 & 76330 & 27,0 & 8,5 \\
\hline Groß-Gerau, Landkreis & 15 & 51,6 & 71 & 17,6 & 11 & 34,0 & 102116 & 12,1 & 6,9 \\
\hline Main-Taunus-Kreis & 16 & 51,3 & 146 & 16,6 & 7 & 34,7 & 99494 & 21,6 & 4,9 \\
\hline Ulm, Universitätsstadt & 17 & 51,1 & 69 & 17,7 & 14 & 33,4 & 74407 & 7,2 & 7,9 \\
\hline Düsseldorf & 18 & 51,1 & 22 & 18,9 & 17 & 32,2 & 102462 & 13,4 & 10,3 \\
\hline Hochtaunuskreis & 19 & 51,1 & 118 & 16,9 & 10 & 34,2 & 90949 & 10,9 & 5,4 \\
\hline
\end{tabular}

Tabelle 3: Dynamik und Stärke der 20 besten Wirtschaftsstandorte in Deutschland

Quelle: Prognos Zukunftsatlas 2004, eigene Bearbeitung

Insgesamt betrachtet hat München die Wachstumsführerschaft übernommen, so zum Beispiel in den strategisch wichtigen Funktionsbereichen Forschung und Entwicklung, Management und Beratung. 2002 waren in diesen Bereichen in München knapp 6\% aller Be-

\footnotetext{
298 vgl. IHK Frankfurt 2004, S.3

${ }^{299}$ vgl. Stadt Frankfurt am Main, Frankfurter Statistik aktuell 13/2005

300 vgl. IHK München 2004, S.11
} 
schäftigten mit Entwicklungsaufgaben betraut und 3,5\% im Management tätig. In Frankfurt Rhein-Main betrugen die entsprechenden Anteile 3,3\% bzw. 2,9\%.

Der Zukunftsatlas der Prognos AG, der Auskunft gibt über die Zukunftschancen der insgesamt 439 Kreise und Kreisfreien Städte in Deutschland, macht die Distanz der Region Frankfurt Rhein-Main bzw. der Stadt Frankfurt zu den Spitzenplätzen deutlich. Die Analyse der Prognos AG berücksichtigte 29 Indikatoren nach den zwei Dimensionen "Stärke" und "Dynamik". Daraus resultierte eine Differenzierung in der Platzierung bezogen auf die (momentane) Standortstärke einerseits und die Entwicklung der Regionen in den vergangenen fünf Jahren andererseits. Außerdem wurden themenorientierte Auswertungen in den Bereichen "Demografie“, "Arbeitsmarkt", "Soziale Lage \& Wohlstand" sowie „Wettbewerb \& Innovation“ bei der Platzierung berücksichtigt. Charakteristische Eigenschaften der Kommunen hinsichtlich ihrer Ausgangssituation (z.B. Einwohnerzahl) wurden dabei entsprechend beachtet.

Die Auswertung (siehe Tabelle 3) zeigt, dass die Region München mit dem Landkreis München (Platz 1), der Stadt München (2), dem Landkreis Starnberg (3) und der Stadt Freising (5) gleich viermal unter den Kommunen vertreten ist, deren Zukunftsaussichten mit "Top" bewertet werden. Der Planungsverband Frankfurt (also der Ballungsraum Frankfurt/Rhein-Main) ist dagegen mit keinem „Top“ vertreten. Betrachtet man die größere Region Frankfurt Rhein-Main, liegt auf Platz 4 die Stadt Darmstadt mit "Top“ Entwicklungsaussichten. Darüber hinaus werden die Städte Frankfurt (11) und Mainz (13), der Landkreis Groß-Gerau (15), der Main-Taunus-Kreis (16) sowie der Hochtaunuskreis (19) mit „sehr guten“ Entwicklungsaussichten bewertet, so dass die Region insgesamt "sehr gut" abschneidet. ${ }^{301}$

In bezug auf die Standortqualität ist festzuhalten, dass sich die polyzentrische Siedlungsstruktur und regionale Entwicklung der Region Frankfurt Rhein-Main hinsichtlich der verfügbaren Freiräume durchaus günstig darstellt. ${ }^{302}$ Dieser Freiraum kann sowohl als Entwicklungsreserve für Ansiedlungen wie auch für Erholung und Freizeit genutzt werden. Hier kann die These vertreten werden, dass sich „in Deutschland die durch den För-

\footnotetext{
301 vgl. Prognos 2004, S.15

302 vgl. HMWVL 2000, S.4
} 
deralismus gestützt, gleichberechtigte Entwicklung mehrerer leistungsfähiger Regionen auch im Sinne der Nachhaltigkeit und des Freiraumschutzes als günstig erwiesen hat”. 303

Diese Raumstruktur kann auch für das Verkehrssystem als vorteilhaft bewertet werden, da sich die Kapazitätsauslastung auf mehrere Standorte verteilt und es so zu einer besseren Nutzungsmischung kommt als in einer monozentrischen Region. Allerdings sollte aufgrund der regionalen Verflechtungen in der Region Frankfurt Rhein-Main eher von einer „Region der kurzen Wege“ als von einer „Stadt der kurzen Wege“ gesprochen werden. Im bundesdeutschen Vergleich verschiedener Ballungsräume macht sich diese vergleichsweise günstige Situation an der mittleren Wegstrecke fest, die ein Pendler täglich zur Arbeit zurücklegt. Hier schneiden Stuttgart und Frankfurt besser ab als die monozentrisch strukturierten Räume Hamburg und München, die allerdings über einen höheren ÖPNV-Anteil verfügen (siehe Kapitel 4.4.1). 304

Als günstig für die weiteren Entwicklungsperspektiven der Region Frankfurt Rhein-Main erweist sich die Lage im Knotenpunkt europäischer Verkehrsachsen. Deren Dynamik wiederum liegt im Bereich interregionaler und internationaler Transport- und Distributionsfunktionen, die in Zukunft durch den europäischen Einigungsprozess weiter stark wachsen werden (siehe Kapitel 4.2).

\subsubsection{Die Bedeutung der Region auf internationaler Ebene}

In bezug auf ihre ökonomischen Funktionen wird die Stadt Frankfurt auch als Weltstadt beziehungsweise "Metropole" bezeichnet. Diese Bezeichnung ist insbesondere auf die Funktion Frankfurts als europäisches Finanzzentrum zurückzuführen. Esser und Schamp verweisen darauf, dass „die Region bereits vergleichsweise überdurchschnittlich in die globalen Güter- und Kapitalmärkte eingebunden ist, die Intensität der interregionalen Vernetzung hängt aber immer noch stark von topographischen Entfernungen ab“, wobei die „interregionale Vernetzung immer noch einen starken europäischen Bezug hat". ${ }^{305}$ Insbesondere der Finanzdienstleistungsbereich sowie die chemische Industrie und der Fahrzeugbau weisen starke Züge einer internationalen Verflechtung auf. 306

\footnotetext{
303 Umlandverband 2000, S.31

304 ebd. S.33

305 vgl. Heinrich 2001, S.69

$306 \mathrm{ebd}$.
} 
Frankfurt übernimmt daher nicht nur als Kernstadt der Region Frankfurt Rhein-Main wichtige zentralörtliche Funktionen, ihr kommen auch bedeutende internationale Aufgaben $\mathrm{zu}$, die sich beispielsweise an der Bedeutung der Europäischen Zentralbank, des Flughafens oder der Messe ablesen lassen. Neben Frankfurt gehen aber auch Impulse für die Regionalentwicklung von Wiesbaden, Mainz und Darmstadt aus. ${ }^{307}$

Aber auch in den Bereichen Verkehr und Informationstechnologien zeigt sich die europäische Bedeutung Frankfurts. So ist die Stadt einer der wichtigsten Verkehrsknoten auf dem europäischen Kontinent (siehe Kapitel 4.2) und zweitwichtigster Knoten in der Telekommunikation: 85\% des deutschen Internetverkehrs laufen über Frankfurt und 11 der 13 in Deutschland tätigen Internet-Provider haben hier ihre Deutschlandzentrale. 308

Zur Sicherung bzw. Verbesserung der Standortfaktoren mit dem Ziel der Profilierung gegenüber konkurrierenden Regionen und damit der Standortsicherung bedarf es gezielter Maßnahmen, damit die Region Frankfurt Rhein-Main auch in Zukunft zu den überdurchschnittlich prosperierenden Regionen in Deutschland und Europa zählt.

\subsubsection{Kooperation in der Region}

„Zunehmende internationale Konkurrenz zwischen den Regionen, ungeordnetes Wachstum mit steigendem Flächenverbrauch und wachsende Verkehrsströme sowie ungleiche Lastenverteilung innerhalb der Region lassen eine geordnete regionale Entwicklung und Planung als zwingend erscheinen“. ${ }^{309}$ Die Verbesserung der kommunalen Zusammenarbeit mit dem Ziel der Stärkung der Region im Wettbewerb mit anderen Regionen ist daher ein Thema, welches bereits seit mehreren Jahren auf den Agenden der politischen Parteien steht. Im LEP wurde formuliert, dass die „überörtliche Zusammenarbeit zur Verständigung auf gemeinsame Aufgabenbewältigung und Entwicklungsziele [...] zu einer unabdingbaren Forderung unserer Zeit geworden“ ist. 310 So wurden bereits mehrfach Ansätze unternommen, Modelle einer engeren Kooperation zwischen den beteiligten Kommunen umzusetzen oder auch eine politisch-institutionelle Neuordnung zu initiieren. Die Notwendigkeit einer Neuordnung begründet sich vor allem darin, dass die Regi-

\footnotetext{
${ }^{307}$ vgl. Freund 2002, S.222

308 ebd., S.17

309 Stein und Wolf 2005, S.259

${ }^{310}$ LEP Hessen 2000, S.14
} 
on Frankfurt Rhein-Main aufgrund ihres länderübergreifenden Einzugsgebiets politisch nicht verfasst ist, also keine ihrem Territorialgebiet zugewiesene demokratisch legitimierte Verwaltung besitzt, aber „Viele funktionale Zusammenhänge [...] nur noch regional gesteuert werden [können] (z.B. Abfall-, Verkehrs- und Kulturpolitik)“..311 Da unterschiedliche funktionsbezogene Handlungsfelder demnach unterschiedliche Raumabgrenzungen verlangen, „entspricht ein prozessualer Regionsbegriff eher den Zielen und Problemstellungen nachhaltiger Entwicklung“. ${ }^{312}$ Eine veränderte administrative Regionalabgrenzung ist daher für die Lösung spezifischer Nachhaltigkeitsprobleme notwendig - aber dennoch keineswegs ausreichend. Denn erst durch die Kooperation und die Vernetzung der Akteure in einem spezifischen Handlungsfeld entstehen schließlich neue Aktionsräume, die Potenziale für nachhaltige Verbesserung bieten (siehe auch Kapitel 3.9). Je nach Zusammenspiel der Akteure entstehen so unterschiedliche funktionale Regionen. Berechtigterweise spricht der Planungsverband Ballungsraum Frankfurt/Rhein-Main in diesem Zusammenhang von einer anzustrebenden Profilierung der Region als - beispielsweise - „Region der starken Zentren“, „Region der Wissenschaft und Ausbildung“, Region der innovativen Branchen“ oder „Region der Mobilität und Logistik“. ${ }^{133}$ Das „Leitbild für den Regionalen Flächennutzungsplan und den Regionalplan Südhessen“, das zusammen vom Planungsverband und der Regionalversammlung Südhessen entwickelt wurde, beschreibt dabei die allgemeinen Entwicklungsziele der Region. „Von Seiten der Experten wird hinsichtlich des Leitbildes [aber] die mangelnde Konkretisierung der Ziele in Maßnahmen kritisiert". ${ }^{314}$

So kommt der Region Frankfurt Rhein-Main einerseits als Ebene zwischen bundes- und landesbehördlicher Kompetenzen zwar eine wachsende Bedeutung zu, andererseits wird man dieser Bedeutung im Rahmen der Wirtschafts- und Strukturpolitik - bislang - nicht gerecht. Die damit verbundene Herausforderung der Anpassung der regionalen Strukturen wird sowohl von der hessischen Landesregierung, den kommunalen politischen Vertretungen sowie den Wirtschaftsverbänden gesehen. Eine Regionalreform ist daher vor dem Hintergrund der Entwicklung der spezifischen Entwicklungsmuster der Region sowie der Stärkung der für die Region bedeutsamen Standortfaktoren und damit der Sicher-

\footnotetext{
311 Lucas 2000, S.15

312 ebd. S.18

313 vgl. Planungsverband Ballungsraum Frankfurt/Rhein-Main 2005(b), S.12

${ }^{314}$ vgl. Stein und Wolf 2005, S.275
} 
stellung der Wettbewerbsfähigkeit auf unterschiedlicher funktionaler Ebene bedeutsam. Die Notwendigkeit der Kooperation in der Region Frankfurt Rhein-Main ergibt sich darüber hinaus auch für eine zukünftige, einheitlichen Vermarktung des Standortes „Frankfurt Rhein-Main“. Dieses ist ebenfalls seit mehreren Jahren ein durchgängiges Thema. ${ }^{315}$ So wird vor allem von Seiten der Wirtschaft der Ausbau und die Sicherung von Standortqualitäten gefordert. Insbesondere soll über eine Stärkung der interkommunalen Kooperation unter Einbeziehung der Wirtschaft „eine größere Korrespondenz zwischen den staatlichen institutionellen Strukturen und den urban-industriellen Agglomerationen“ 316 herbeigeführt werden, die die spezifischen Standortqualitäten hervorhebt.

Bei den politischen und wirtschaftlichen Entscheidungsträgern in der Region Frankfurt Rhein-Main reift die Erkenntnis, dass nur in Kooperation der umliegenden Großstädte und Landkreise der „Metropolenzwerg“ Frankfurt sowohl im innerdeutschen Wettbewerb wie auch im internationalen Wettbewerb mit Metropolen wie Paris, London, Amsterdam oder Mailand bestehen kann. ${ }^{317}$ Ergebnis dieser Kooperation soll insbesondere eine gemeinsame Präsentation der Region nach außen sein sowie eine Stärkung des inneren Regionalbewusstseins. Protagonisten einer verstärkten Kooperation und Kommunikation zwischen den Gebietskörperschaften in der Region sind heute die Wirtschaftsförderung Region Frankfurt Rhein-Main, die Wirtschaftsinitiative Frankfurt Rhein-Main und das IHKForum Rhein-Main. Alle drei Organisationen sind formal unabhängig voneinander, jedoch personell und inhaltlich miteinander verwoben und zielen allesamt auf die Stärkung und Förderung der wirtschaftlichen Verhältnisse in der Region Frankfurt Rhein-Main ab. Ihr gemeinsames Anliegen ist zu verhindern, dass ein Wettbewerb zwischen den Gebietskörperschaften um Investoren und Steuereinnahmen zu negativen Effekten für die Region führt. ${ }^{318}$ Der positive Erfolg der von ihnen initiierten Kooperationsplattformen steht und fällt mit der Kooperationsbereitschaft der in ihnen zusammengeschlossenen Partner.

Problematisch bei fast allen regionalen Initiativen der Kooperation erweist sich stets das Misstrauen, welches die Umlandgemeinden der Zentralstadt Frankfurt gegenüber aufbringen. Dieses Misstrauen rührt unter anderem daher, dass die Stadt Frankfurt anstrebt,

\footnotetext{
315 vgl. Prognos 2004, S.13

316 vgl. Falger 2001, S.217, der sich orientiert an: Brenner, N./ Heeg, S.: „Leistungsfähige Länder, konkurrenzfähige Stadtregionen? Standortpolitik, Stadtregionen und die Neugliederungsdebatte in den 90er Jahren". In: Informationen zur Raumentwicklung. O.O. 1998. S.661-672.

317 vgl. Freund 2002, S.260

318 vgl. Falger 2001, S.218f
} 
ihr Stadtgebiet auf Kosten der Selbständigkeit der angrenzenden Gemeinden zu vergrößern. Über eine Erhöhung des Steueraufkommens soll so ein höherer Deckungsbeitrag für zentralörtliche Funktionen (Theater, Museen, Zoo etc.) erzielt werden, die insbesondere auch von der Bevölkerung der Umlandgemeinden genutzt werden. So sah bereits das Modell der Regionalstadt Frankfurt aus dem Jahr 1971 Eingemeindungen bis nach Hofheim, Friedrichsdorf, Mörfelden und Rodgau vor. ${ }^{319}$ In jüngerer Zeit wird im Zusammenhang einer möglichen Zusammenlegung des Hochtaunuskreises mit dem Main-TaunusKreis die Eingemeindung der Stadt Eschborn diskutiert. Die Stadt Eschborn ist seit dem Jahre 2000 nicht nur schuldenfrei, sondern ist auch die Kommune mit den höchsten Steuereinnahmen in ganz Hessen. Durch eine Eingemeindung würden also in erheblichem Umfang Gewerbesteuereinnahmen nach Frankfurt umgeleitet, die bislang zu 40\% zum Wohlstand im Main-Taunus-Kreis beitragen. ${ }^{320}$

Bezeichnend für fast alle bisherigen Kooperationsansätze ist, dass sie an den bestehenden Strukturen nicht wirklich rütteln und die Grenzen und Zuständigkeiten der Gebietskörperschaften nicht nachhaltig verändern. Vielmehr beruhen alle Ansätze darauf, die bestehende "Ordnung" aufrecht zu erhalten und Besitzstände zu wahren. In dieses Schema passt beispielsweise auch die „Regionalkonferenz", die im Hinblick auf die Verbesserung der Wettbewerbschancen der Region Frankfurt Rhein-Main im Mai 2000 ins Leben gerufen wurde. Die Regionalkonferenz sieht neben einer mindestens einmal jährlich stattfindenden Tagung die Bildung von Arbeitskreisen zu unterschiedlichen Fragestellungen, so auch Verkehr, vor. Der Erfolg der Zusammenarbeit steht und fällt daher mit der Bereitschaft der beteiligten Kommunen zur Kooperation. Da auch der Ansatz eines Regionalverbands mit umfassenden Aufgaben in der Vergangenheit gescheitert ist, beschränkt sich die kommunale Kooperation mittlerweile vor allem auf sektorale Zweckverbände. ${ }^{321}$ Hierzu gehört auch der Verkehrsbereich, in dem die Zusammenarbeit zur Gründung des RMV geführt hat (siehe Kapitel 5.4.1.3).

\footnotetext{
319 vgl. Freund 2002, S.260; Falger 2001, S.241.

${ }^{320}$ vgl. Wiesbadener Kurier vom 7.9.2006: „Eschborn ist Hessens Krösus“.

${ }^{321}$ vgl. Falger 2001, S.231
} 


\subsection{Die Bedeutung des Verkehrs}

Die „Furt der Franken“ über den Main, die der fränkischen Siedlung ihren Namen gab ${ }^{322,}$ war bereits im Mittelalter aus verkehrlicher Sicht von großer Bedeutung. Sie markierte das nördliche Ende der römischen und frühgeschichtlichen Bergstraße, einem bedeutenden Handelsweg von Süden nach Norden. Diese Handelsstraße führte dann später durch die Wetterau weiter nach Norden. Ihre Geltung wurde durch den Bau der Sachsenhäuser Brücke im Mittelalter manifestiert. In Sichtweite zur Brücke wurde schließlich der Kaiserdom errichtet, der als Krönungsort deutscher Kaiser europäische Bedeutung hatte.

Der in Kapitel 3.2.1 dargestellte Einfluss der Verkehrswege auf die historische Siedlungsentwicklung lässt sich auch am Beispiel der Rhein-Main-Region nachvollziehen. Insbesondere die Dörfer entlang der am Ende des 19. Jahrhunderts gebauten Bahnstrecken südlich von Frankfurt und Offenbach sowie nordwestlich nach Limburg entwickelten sich schon vor dem Automobilzeitalter zu Wohnvororten. In den 1960er Jahren, als man vielerorts alleine nach automobilen Ansprüchen plante, wurde im Rahmen der Regionalplanung gar angestrebt, die Siedlungsschwerpunkte alleine auf Standorte mit gutem Anschluss an den schienengebundenen Verkehr auszurichten. Die Planung wurde allerdings nie vollständig umgesetzt, da sich einerseits der Ausbau der S-Bahn verzögerte, andererseits bereits vor Festlegung viele Gemeinden im großen Maße Bauland abseits der SBahntrassen ausgewiesen hatten. ${ }^{323}$

Heute hat sich die Stadt Frankfurt eine Stellung als wichtiger Knotenpunkt für den Verkehr in Deutschland gesichert - und darüber hinaus. Ein Blick auf das Bundesverkehrswegenetz macht diese Position deutlich. Nirgendwo sonst in Deutschland und Europa bündeln sich die Fernverkehrskorridore derart dicht wie zwischen den Regionen Frankfurt Rhein-Main und Rhein-Neckar (Mannheim, Ludwigshafen und Heidelberg). ${ }^{324}$ Dieser Raum gehört zu einem sehr dynamischen Siedlungs- und Verkehrskorridor, der sich entlang der Rheinschiene anordnet und von Rotterdam bis nach Basel und weiter ans Mittelmeer reicht und stark wachsende Agglomerationsräume miteinander verbindet (siehe Abbildung 9 und 10). Entlang dieses Korridors befinden sich Knotenpunkte der europäischen Verkehrsachsen.

\footnotetext{
322 vgl. Berger 1993, S.101

${ }^{323}$ vgl. Freund 2002, S.233ff

324 vgl. Bundesamt für Bauwesen und Raumordnung 2001, S.27f
} 


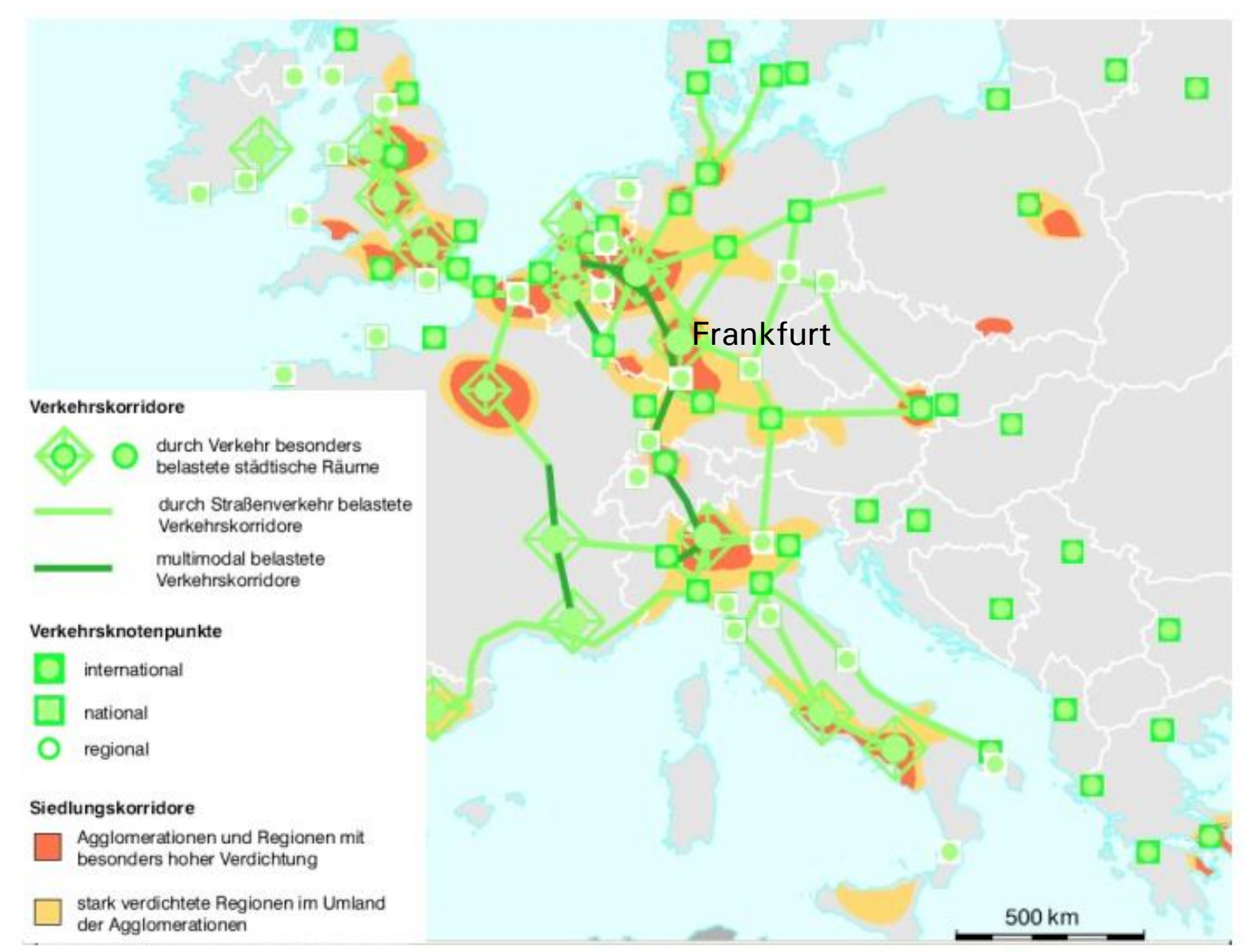

Abbildung 9: Siedlungs- und Verkehrskorridore sowie Verkehrsknotenpunkte in Europa

Quelle: Bundesamt für Bauwesen und Raumordnung: Raumordnungsbericht 2000, S.58, eigene Bearbeitung

Das Rhein-Main-Gebiet ist solch ein zentraler Knotenpunkt von internationaler Bedeutung, von dem „durch die verstärkte Wahrnehmung von deren Standortvorteilen Wachstumsimpulse ausgelöst werden“. ${ }^{325}$ Im LEP wird in diesem Zusammenhang gar von Hessen als „zentrales Transitland in Europa“ ${ }^{226}$ gesprochen, bei der die großräumigen Verkehrsachsen (Hauptverkehrsstrecken wie Schienenfernverkehr, Bundesautobahnen, Wasserwege und auch Luftverkehr) die Anbindung an andere „Verdichtungsräume im nationalen und internationalen Maßstab" sicherstellen. Dies trifft beispielsweise auf den Ausbau des europäischen Hochgeschwindigkeitsnetzes im Schienenfernverkehr zu. ${ }^{327}$ Den regionalen Verkehrssachsen (Nebenverkehrsstrecken auf der Schiene, Bundes- und Landesstraßen) kommt im LEP die Funktion der „intra- und innerregionale[n] Erschließung

\footnotetext{
325 ebd., S.57

${ }^{326}$ vgl. HMWVL 2000, S.34 sowie IHK Arbeitsgemeinschaft Hessen 2004, S.12

${ }^{327}$ vgl. Stein und Wolf 2005, S.265
} 
der Siedlungsstruktur für den Leistungsaustausch zwischen den Mittelzentren und zur Anbindung an die Oberzentren und das überregionale Fernverkehrsnetz" zu. 328

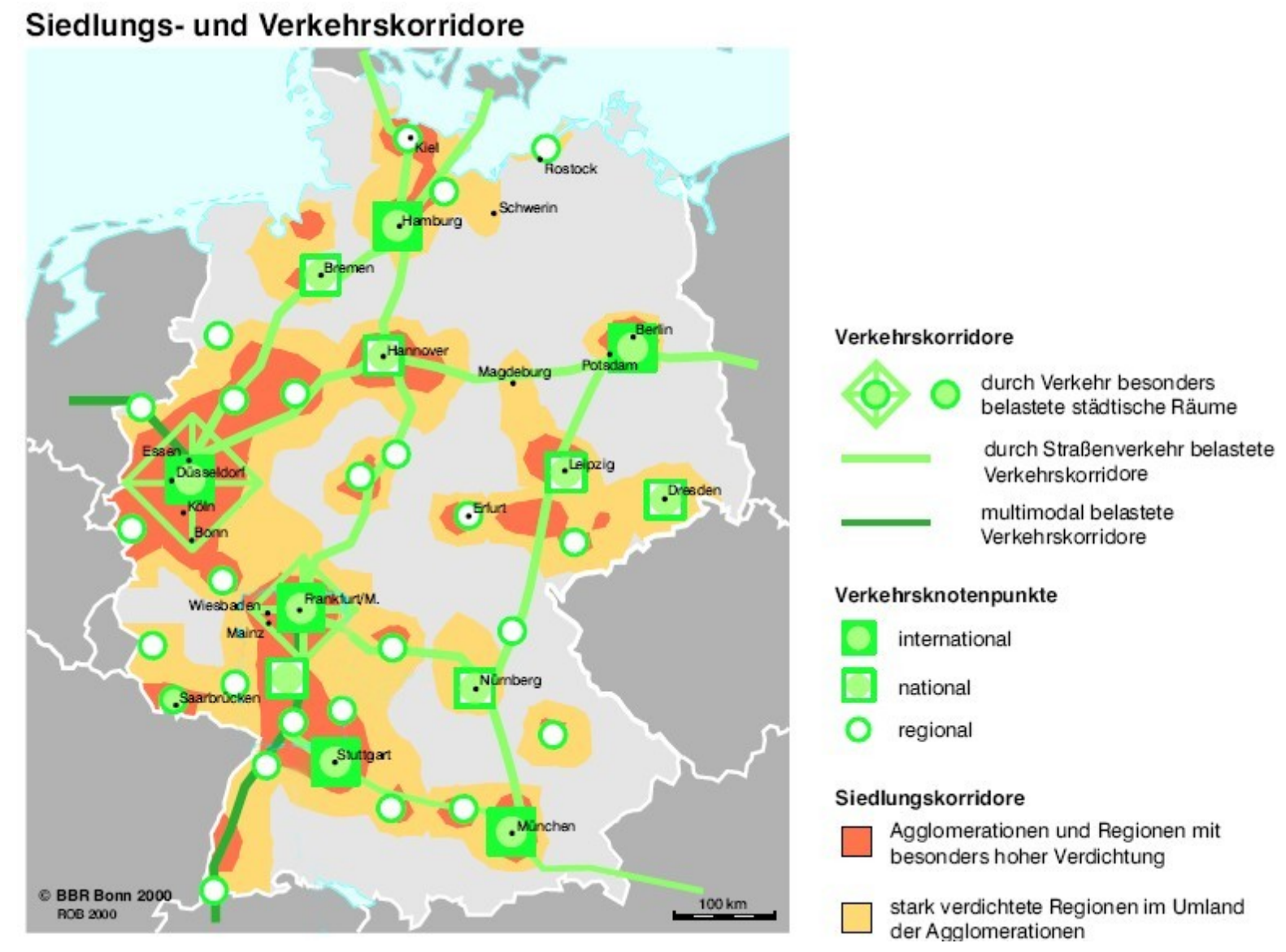

Abbildung 10: Siedlungs- und Verkehrskorridore sowie Verkehrsknotenpunkte in Deutschland

Quelle: Bundesamt für Bauwesen und Raumordnung: Raumordnungsbericht 2000, S.58, eigene Bearbeitung

Eine Überschrift in der Wirtschaftszeitung „Handelsblatt“ titelt im Jahr 2005 deshalb zu recht: "Die Mainmetropole ist die Verkehrsdrehscheibe Europas". ${ }^{329}$ Die Bedeutung des Verkehrs für die Rhein-Main-Region, die in der Überschrift zum Ausdruck kommt, spiegelt sich auch darin wider, dass fünf der zehn größten Unternehmen in Hessen dem Verkehrs- bzw. „Mobilitätssektor“ zuzuordnen sind. Von diesen fünf Unternehmen haben wiederum vier ihren Sitz in der Region Frankfurt Rhein-Main. An der Spitze stehen die Deutsche Lufthansa AG mit 34.500 Beschäftigten, deren Heimatflughafen Frankfurt am Main ist, und die Deutsche Bahn AG mit 25.000 Beschäftigten, deren Tochtergesellschaften Personenverkehr, Netz und Energie ihre Sitze in Frankfurt haben. Des weiteren gehören

328 ebd., S.8

${ }^{329}$ vgl. Handelsblatt v.16.6.2005 sowie Umlandverband 1999, S.2 
hierzu die Adam Opel AG (Rüsselsheim) mit 20.000, die Fraport AG (Frankfurt) mit 16.000 und die Volkswagen AG (Baunatal, Nordhessen) mit 15.000 Mitarbeitern. Mit der Deutschen Bank AG kommt das erste Finanzinstitut erst auf Platz 11 der größten Unternehmen in Hessen. ${ }^{330}$

In der Region Frankfurt Rhein-Main waren zum Stichtag 31.12.2003 ca. 140.000 sozialversicherungspflichtig Beschäftigte im Kredit- und Versicherungsgewerbe tätig. Demgegenüber gab es fast 100.000 Beschäftigte alleine in den oben genannten vier Unternehmen aus der Region Frankfurt Rhein-Main. ${ }^{331}$ Für das Jahr 2000 wird die in Deutschland im Verkehr erzielte Bruttowertschöpfung mit ca. 65 Mrd. Euro beziffert, d.h. 3,5\% der gesamten Bruttowertschöpfung. ${ }^{332}$ Da aber „wesentliche Bereiche wirtschaftlicher Aktivitäten, die unmittelbar verkehrsbezogen sind, anderen Wirtschaftsbereichen zugeordnet werden “ 333 (Automobilindustrie, Raffinerien etc.), wird die Bedeutung des Verkehrsbereichs als Arbeitgeber und Wirtschaftsfaktor systematisch unterschätzt. Dies trifft auch für die Region Frankfurt Rhein-Main zu, wo sich die öffentliche Aufmerksamkeit vor allem auf die herausgehobene Stellung Frankfurt als europäischer Bankenplatz konzentriert.

Von besonderer Wichtigkeit in bezug auf die Niederlassung und das Wachstum von Unternehmen ist der Flughafen Frankfurt. Am Standort finden mehr als 62.000 Menschen in 465 Betrieben Arbeit. Damit ist der Flughafen nicht nur größter Arbeitsplatzstandort Hessens, sondern auch Deutschlands. Die Bedeutung des Flughafens für die Wirtschaft wird nicht nur durch die 50 Mio. abgefertigten Passagiere deutlich, womit der Frankfurter Flughafen der größte kontinentaleuropäische Flughafen ${ }^{334}$ ist, sondern auch durch die Intensität des Linienverkehrs, die auf einen hohen Anteil von Geschäftsreisenden verweist. Der regional bedeutsame Einfluss des Flughafens lässt sich auch an den städtischen Entwicklungsbändern ablesen, wo an den flughafenorientierten Ausfallstraßen Frank-

\footnotetext{
${ }^{330}$ vgl. FAZ v. 4.3.2005. Für das Jahr 2006 gibt die Fraport AG die Zahl der Mitarbeiter im Durchschnitt mit über 17.500 an. Zum Jahresende 2006 lag die Anzahl der Mitarbeiter bei 18.400; vgl. Fraport AG 2007

${ }^{331}$ vgl. FAZ v. 4.3 .2005

332 vgl. Aberle 2003, S.40

333 Aberle 2003, S.42

334 Im Frachtverkehr nimmt der Frankfurter Flughafen auch europaweit die erste Position ein; vgl. Freund 2002, S.100
} 
furts, Wiesbadens, Offenbachs oder Darmstadts Büro- und Hotelkomplexe entstanden sind. 335

\subsection{Verkehrsangebot und -entwicklung}

\subsubsection{Motorisierter Individualverkehr}

Die auf den hessischen Straßen mit dem privaten Pkw zurückgelegte Fahrleistung sowie der Motorisierungsgrad sind zwei Parameter, an denen die rasante Entwicklung des MIV nachvollzogen werden kann.

\section{Verkehrsleistung}

In der Region Frankfurt Rhein-Main hat sich in den letzten zwanzig Jahren das Verkehrsaufkommen fast verdoppelt (siehe Abbildung 11). ${ }^{336}$
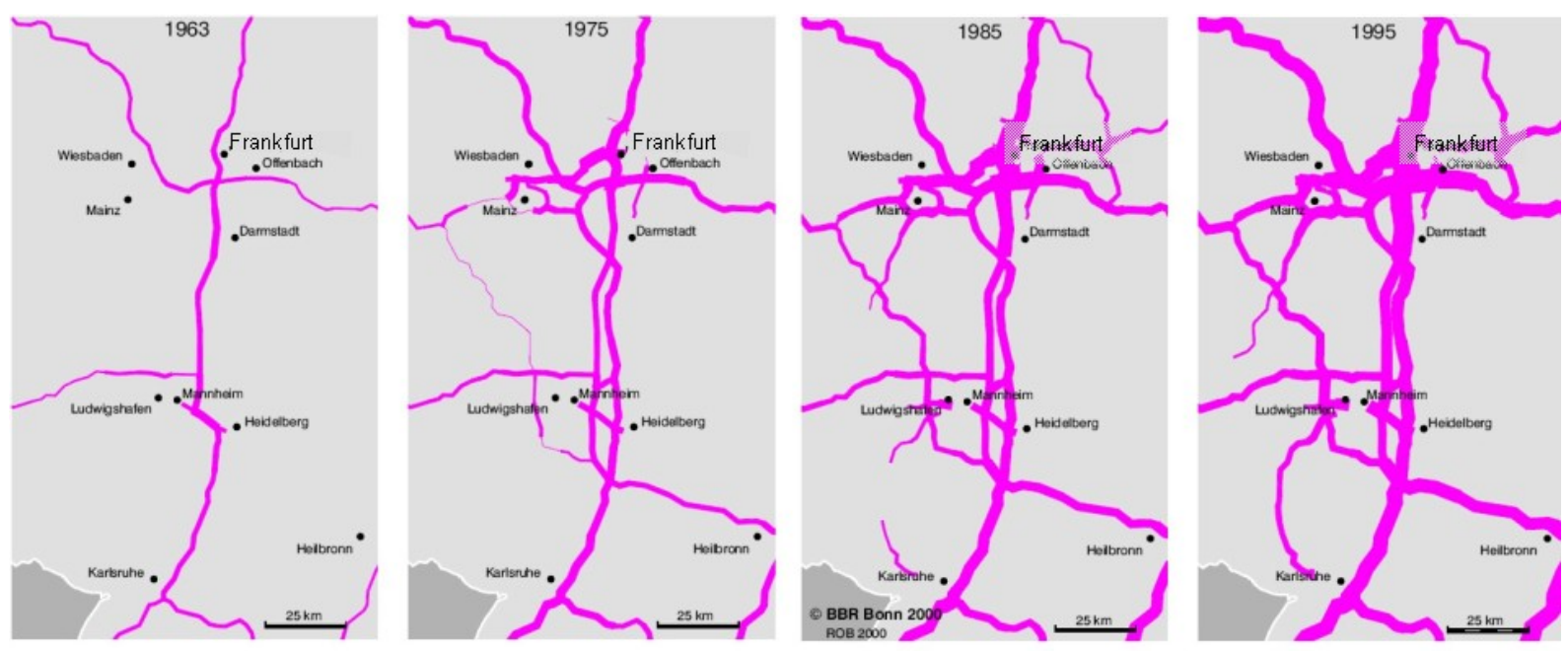

Durchschnittliche tăgliche Verkehrsstärke in Kłz/pro Tag auf Bundesautobahnen im Rhein-Main-Neckar-Raum

150000

80000

40000

Datenbasis: Bundesverkehrszählungen - Bundesanstalt fûr Straßenwesen

Abbildung 11: Verkehrsentwicklung der täglichen Verkehrsstärken auf BAB von 1963 bis 1995 im Rhein-MainNeckar-Raum

Quelle: Bundesamt für Bauwesen und Raumordnung: Raumordnungsbericht 2000, S.61, eigene Bearbeitung

335 ebd., S.97

336 vgl. Stein und Wolf 2005, S.267 
Dabei hat insbesondere die Fahrleistung auf den Autobahnen in den letzten Jahren zugenommen, hingegen die Fahrleistungen auf sonstigen Straßen eher gleich geblieben ist (siehe Tabelle 4). Die Bundesautobahnen im Raum Frankfurt (A3, A5, A60, A61, A66, A67 u.a.) sowie die Autobahnkreuze, an der sich Nord-Süd- und West-Ost-Verbindungen treffen, gehören zu den bedeutenden Verkehrsverbindungen in Deutschland. „Hieraus hat sich für die Stadt Frankfurt und sein Umland ein überwiegend radial ausgerichtetes Straßenverkehrsnetz entwickelt, das diesen Raum strahlenförmig mit dem Umland verbin$\operatorname{det}^{\prime \prime} .337$

27 Autobahnabschnitte im Rhein-Main-Gebiet sind heute mit Verkehrsmengen von über 100.000 Kraftfahrzeugen an einem durchschnittlichen Tag belastet. Vor allem der Abschnitt der A5 im Westen von Frankfurt ist mit durchschnittlich 147.000 Pkw am Tag auch im europäischen Verhältnis - besonders stark frequentiert. ${ }^{338}$ An Spitzentagen wird das Frankfurter Kreuz von mehr als 330.000 Fahrzeugen am Tag passiert. ${ }^{339}$

\begin{tabular}{|l|r|r|r|r|}
\hline & $\begin{array}{c}\text { Streckenlänge in } \\
\mathbf{~ k m ~ 1 9 9 5}\end{array}$ & $\begin{array}{l}\text { Jahresfahrleistung } \\
\text { in } \mathbf{1 0 ^ { 6 }} \mathbf{~ k m / a ~ 1 9 9 5}\end{array}$ & $\begin{array}{c}\text { Streckenlänge in } \\
\mathbf{~ k m ~ 2 0 0 0}\end{array}$ & $\begin{array}{l}\text { Jahresfahrleistung } \\
\text { in } \mathbf{1 0}^{\mathbf{6}} \mathbf{~ k m / a ~ 2 0 0 0}\end{array}$ \\
\hline Hessen Summe & 39.378 & 53.769 & 39.402 & 56.090 \\
\hline $\begin{array}{l}\text { Ballungsraum } \\
\text { Summe }\end{array}$ & 7.312 & 16.124 & 7.323 & 16.952 \\
\hline $\begin{array}{l}\text { Ballungsraum } \\
\text { Autobahn }\end{array}$ & 444 & 7.708 & 444 & 8.566 \\
\hline $\begin{array}{l}\text { Ballungsraum } \\
\text { Bundesstraßen }\end{array}$ & 581 & 2.886 & 594 & 2.949 \\
\hline $\begin{array}{l}\text { Ballungsraum } \\
\text { Gemeindestraßen }\end{array}$ & 5.265 & 3.118 & 5.265 & 3.117 \\
\hline $\begin{array}{l}\text { Ballungsraum } \\
\text { Kreisstraßen }\end{array}$ & 369 & 553 & 368 & 536 \\
\hline $\begin{array}{l}\text { Ballungsraum } \\
\text { Landesstraßen }\end{array}$ & 651 & 1.857 & 651 & 1.782 \\
\hline
\end{tabular}

Tabelle 4: Jahresfahrleistung im Ballungsraum Rhein-Main 1995 und 2000

Quelle: Hessisches Ministerium für Umwelt 2002, S.56

\section{Pkw-Verfügbarkeit}

Sowohl für Hessen wie auch für den Planungsverband geht der Trend zu einer hohen Autoverfügbarkeit je Haushalt mit 83\% bzw. 81\% konform mit der Entwicklung auf Bun-

\footnotetext{
337 Stein und Wolf 2005, S.266

338 vgl. HSVV 2006 (b), S.23

${ }^{339}$ vgl. Hessische Staatskanzlei 2005 (c), S.4
} 
desebene. Er liegt sogar noch leicht über dem Bundesdurchschnitt. Betrachtet man nur die Stadtgebiete von Frankfurt und Offenbach, zeigt sich, dass dort die Pkw-Verfügbarkeit je Haushalt bei $67 \%$ liegt. Im Vergleich dazu verfügen im umgebenden Ballungsraum $89 \%$ aller Haushalte über mindestens einen $\mathrm{Pkw}$. Bezogen auf die individuelle $\mathrm{Pkw}$ Verfügbarkeit ergibt sich, dass 72\% der Erwachsenen in Hessen jederzeit einen Pkw nutzen können. Im Planungsverband beträgt die Pkw-Verfügbarkeit 70\% und in Frankfurt und Offenbach 60\%. Etwas anders verhalten sich diese Zahlen, wenn nur die VollzeitErwerbstätigen betrachtet werden. Hier verfügen $86 \%$ der Vollzeit-Erwerbstätigen in Hessen über einen Pkw bzw. 82\% im Planungsverband und 72\% in den Städten Frankfurt und Offenbach. ${ }^{340}$ Räumlich betrachtet nimmt die Pkw-Verfügbarkeit also von der Stadt zum Land zu. Zeitlich gesehen ist sie über die Zeit gestiegen und liegt heute bei einem vergleichsweise hohen Wert.

\section{Führerscheinbesitz}

Einen Führerschein besitzen in Hessen 87\% aller Erwachsenen. In Frankfurt und Offenbach liegt der Wert bei $81 \%$. In allen Altersklassen überwiegt der Führerscheinbesitz bei Männern. Der Unterschied ist in den jüngeren Altersklassen allerdings nur noch schwach ausgeprägt. ${ }^{341}$

\subsection{2 Öffentlicher Personenverkehr}

Verkehrsangebot

Der ÖPNV in der Region Frankfurt Rhein-Main basiert auf einem "gestuften Verkehrsnetz“342, dessen Angebot im Kernnetz auf dem Schienenverkehr und einem integrierten regionalen Busverkehr beruht. Im Ballungsraum Frankfurt wird dieses Angebot auf der Schiene durch das S-Bahn-Netz verdichtet, durch welches das Umland der Stadt Frankfurt sowie Stadteile erschlossen werden. Außerhalb dieses Bereichs verkehren Regionalzüge, die auch die weiteren Zentren miteinander verbinden. Die Regionalbusse bedienen vor allem zentrale Einrichtungen (z.B. Schul- und Verwaltungszentren) und Gewerbegebiete mit überörtlichem Charakter. Die lokalen Busverkehre übernehmen vor allem die Erschließungsfunktion innerhalb der Städte und Gemeinden. Als Zubringerverkehre zum

\footnotetext{
340 vgl. Planungsverband Ballungsraum Frankfurt/Rhein-Main u.a. 2005, S.13ff

341 ebd. S.18

${ }^{342}$ vgl. RMV 2004 (a), S.8
} 
Schienenpersonennahverkehr (SPNV) sind sie zu einem wesentlichen Teil auf das Schienennetz ausgerichtet, sowohl von der Linienführung her als auch im Hinblick auf ihren Takt. Wichtige ÖPNV-Verknüpfungspunkte sind der Frankfurter Hauptbahnhof sowie die Bahnhöfe in Darmstadt, Mainz, Wiesbaden, Friedberg, Hanau, Offenbach und Aschaffenburg. 343

Da die Region Frankfurt Rhein-Main vom RMV als zuständigem Verkehrsverbund zu einem großen Teil abgedeckt wird, spiegelt das Leistungsangebot der im Verbund zusammengeschlossenen Unternehmen das ÖPNV-Angebot in der Region relativ gut wider. Der RMV deckt - neben den Kommunen, die zur Metropolregion gehören - auf hessischer Seite auch noch die Stadt Fulda sowie die Landkreise Fulda, Marburg-Biedenkopf und den Vogelbergkreis ab. Auf rheinland-pfälzischer Seite gehört nur die Stadt Mainz zum Verbundgebiet. Allerdings gibt es für die zur Metropolregion gehörenden rheinlandpfälzischen (Stadt Worms, Landkreis Alzey-Worms und der Landkreis Mainz-Bingen) und bayrischen Kommunen (Stadt und Kreis Aschaffenburg und der Kreis Miltenberg) Übergangstarife. Lediglich für den Landkreis Alzey-Worms besteht keine Tarifkooperation. ${ }^{344}$

\begin{tabular}{|l|c|c|}
\hline & $\begin{array}{c}\text { Leistungsangebot } \\
{[\%]}\end{array}$ & $\begin{array}{c}\text { Fahrten } \\
{[\%]}\end{array}$ \\
\hline U-Bahn & 4 & 15 \\
\hline Straßenbahn & 6 & 10 \\
\hline Regionalbahn ${ }^{346}$ & 14 & 9 \\
\hline S-Bahn & 7 & 17 \\
\hline Regionaler Busverkehr & 17 & $\mathbf{7 1}$ \\
\hline Lokaler Bus & 52 & $\mathbf{1 0 0}$ \\
\hline \multicolumn{1}{|c|}{ insgesamt } & $\mathbf{1 0 0}$ & $\begin{array}{c}\text { (Summe 640 Mio. } \\
\text { Fahrten) }\end{array}$
\end{tabular}

Tabelle 5: ÖPNV-Leistungsangebot und ÖPNV-Fahrten nach öffentlichen Verkehrsmitteln im RMV im Jahr 2005

Quelle: RMV 2006 (a), S. 47 und 50

Ein herausragender Verknüpfungspunkt ist auch der Flughafen (s.u.), der mit dem Fernbahnhof und dem Regionalbahnhof sowohl national wie auch regional sehr gut zu errei-

\footnotetext{
${ }^{343}$ vgl. Stein und Wolf 2005, S.265

${ }^{344}$ vgl. RMV 2006 (b), S.56ff

345 nach Kilometern

346 inklusive InterRegio
} 
chen ist. Eine Studie geht davon aus, dass im Jahr 2010 am Flughafen täglich etwa 225.000 Personenfahrten von Reisenden, Beschäftigten, Besuchern und Kunden stattfinden. Ca. 10\% dieser Fahrten sollen über die Fernzüge und ca. gut 20\% über Busse und Bahnen abgewickelt werden. ${ }^{347}$

Auch der Frankfurter Hauptbahnhof hat große regionale wie nationale Bedeutung.

„25 Gleise, fünf mächtige Hallendächer, ein 270 Meter breites Kopfgebäude, zwei unterirdische Etagen, darin sieben U- und S-Bahn-Gleise, 85 Gastronomie- und Handelsunternehmen auf 9000 Quadratmeter Verkaufsfläche, 1000 Schließfächer, rund 100 Servicemitarbeiter der Bahn, Arbeit für mehr als 6000 andere Menschen sowie jeden Tag rund 350.000 Reisende und Besucher - das ist der Frankfurter Hauptbahnhof" ${ }^{\prime 348}$

Damit ist der Frankfurter Hauptbahnhof nach Größe und Kapazität einer der bedeutendsten Bahnhöfe und die wichtigste Drehscheibe im Zugverkehr bundesweit. Der Hauptbahnhof verbindet Europa, Deutschland, die Region und Teile der Stadt. So gibt es beispielsweise eine direkte ICE-Verbindung über die Hochgeschwindigkeitstrasse nach Amsterdam. Insgesamt gibt es 1116 Anschlussverbindungen. Auch für den Nahverkehr ist der Frankfurter Hauptbahnhof die Station mit den am Abstand meisten Verbindungen und Fahrgästen, zumal das Bankenzentrum Frankfurts von hier fußläufig zu erreichen ist. 349

\section{Verkehrserschließung}

Die Qualität des ÖPNV wird wesentlich durch den Erschließungs- und Bedienungsgrad bestimmt. Vor allem die Anbindung zum schnellen und komfortablen Schienenverkehr beeinflusst die Bereitschaft potenzieller Kunden den ÖPNV zu nutzen ganz erheblich. Im Rahmen der Studie MiD 2002 gaben 69\% der Befragten (über 14 Jahre) in Frankfurt und Offenbach an, in weniger als $1 \mathrm{~km}$ zur nächsten Bahnstation zu leben. Im Planungsverband sind dies immerhin noch 52\% (Hessen 34\%). Dies ist insbesondere auf die gute räumliche Erschließung der Region Frankfurt Rhein-Main durch die S-Bahn zurückzuführen. ${ }^{350}$ Damit lebt ein großer Teil der Bevölkerung in fußläufiger Entfernung zum ÖPNV.

\footnotetext{
347 vgl. Deutsche Bahn u.a. 1998, S.12

348 Deutsche Bahn AG 2003, S.120f

${ }^{349}$ vgl. Deutsche Bahn AG 2003, S.118

350 vgl. Planungsverband Ballungsraum Frankfurt/Rhein-Main u.a. 2005, S.20
} 
Dies stellt für die Kundengewinnung eine wichtige Voraussetzung dar (siehe Kapitel 6.3.2), wenngleich zahlreiche weitere Faktoren hierfür von Relevanz sind.

\begin{tabular}{|l|l|}
\hline Gesamt-Schienenlänge Eisenbahn & 1450 Kilometer \\
Schienenlänge S-Bahn & 297 Kilometer, davon 13 Kilometer Tunnel \\
Regionalbahnlinien & 33 \\
S-Bahn im RMV & 9 \\
Schiene gesamt - Bahnhöfe und Stationen & 389 (inklusive Mainz) \\
S-Bahn-Bahnhöfe und Stationen & 109 (inklusive Mainz) \\
Zugkilometer S-Bahn & ca. 13,5 Mio. \\
Längste S-Bahn-Strecke & S1 (Wiesbaden - Ober-Roden) $73 \mathrm{~km}$ \\
\hline Regionale Buslinien & 145 \\
Lokale Buslinien & 798 \\
Bushaltestellen im Verbundgebiet & ca. 11.900 \\
Bushaltestellen im Verbundgebiet mit Über- & 13.500 \\
gangstarifgebieten & \\
\hline
\end{tabular}

Tabelle 6: Daten zum Schienen und Busnetz

Quelle: www.rmv.de/coremedia/generator/RMV/WirUeberUns/RMVinZahlen, Stand 12/2006

\subsubsection{Flugverkehr / Flughafen Frankfurt}

Der Frankfurter Flughafen (auch „Fraport”) ist Deutschlands wichtigster Flughafen und steht nach London Heathrow (67,3 Mio. beförderte Passagiere in 2006) und Paris (Charlesde-Gaulle, 56,8 Mio. in 2006351) mit 52,8 Mio. beförderten Passagieren im Jahre 2006 an dritter Stelle der größten europäischen Flughäfen. ${ }^{352}$ Mehr als 100 Fluggesellschaften fliegen 304 Ziele in 108 Ländern an. Es finden durchschnittlich 80 Flugbewegungen in der Stunde bzw. etwa 1300 Starts und Landungen pro Tag statt, wobei täglich etwa 140.000 Passagiere bedient werden. Etwa die Hälfte der Passagiere nutzt dabei den Flughafen zum Umstieg. Im Luftfrachtverkehr nimmt der Frankfurter Flughafen europaweit sogar den ersten Rang ein. 2006 wurden erstmals mehr als 2 Mio. Tonnen umgeschlagen. ${ }^{353} \mathrm{Au}-$ Berdem arbeiten am Standort Flughafen Frankfurt, wie in Kapitel bereits 4.2 dargestellt, mehr als 60.000 Menschen. Durch die Pendler-, Reise- und Besucherverkehre ergibt sich daher auch „am Boden“ für den ÖPNV und MIV eine intensive Verkehrsnachfrage.

\footnotetext{
351 vgl. www.aeroportsdeparis.fr (Zugriff am 4.2.2007)

352 vgl. Nuhn und Hesse 2006, S.151 sowie Fraport AG 2007

353 vgl. Fraport AG 2007
} 
Gegenwärtig laufen die Planungen zum weiteren Ausbau des Flughafens. Der Bau einer neuen Landebahn wird dabei von der Umsetzung eines Nachtflugverbots zwischen 23 und 5 Uhr abhängig gemacht (siehe Kapitel 4.5.3). Nach Meinung von Vertretern von Luftfahrtgesellschaften beeinträchtige ein absolutes Nachtflugverbot jedoch die Wettbewerbsfähigkeit des Flughafens. Außerdem sei insbesondere der Luftfrachtverkehr auf Nachtflüge angewiesen. ${ }^{354}$ Mit dem Ausbau soll die Anzahl der Starts und Landungen in der Stunde auf 120 steigen. ${ }^{355}$ Unumstritten ist dagegen der Bau eines dritten Terminals sowie die Errichtung von Wartungshallen für das neue Großraumflugzeug Airbus A380. Frankfurt ist damit neben London, Dubai, Singapur und New York einer der ersten Flughäfen weltweit, auf dem das neue Großraumflugzeug verkehren kann. ${ }^{356}$ Außerdem werden die von der US-Armee übergebenen Flächen für den Ausbau der Cargo City Süd genutzt. 357

Der Flughafen Frankfurt ist damit ein wichtiger Standortfaktor für die Regionalentwicklung der Region Frankfurt Rhein-Main. Die Ausbaumaßnahmen sollen maßgeblich dazu beitragen, die Wettbewerbsfähigkeit des Flughafens zu erhalten.

\subsubsection{Transport auf Wasserwegen}

Der Rhein, der die Region im Westen durchfließt, ist Europas wichtigste Wasserstraße für den Gütertransport. Über den Main, der bei Mainz in den Rhein mündet, ist die Region Frankfurt Rhein-Main direkt an diese bedeutende Wasserstraße angebunden. Von daher besitzt vor allem der Unterlauf des Mains für die Region als Transportweg eine gewisse Bedeutung. Größere Binnenhäfen gibt es in Frankfurt (Frankfurt-Höchst), Hanau, Offenbach und Aschaffenburg. Hier wird der größte Anteil der ca. 22 Mio. Tonnen Schiffsgüter jährlich auf dem Main umgeschlagen. Durch die Stauregelungen flussaufwärts sowie die Eröffnung des Main-Donau-Kanals 1992 ist der Main allerdings bis Hallstadt bei Bamberg bzw. bis zur Donau schiffbar. ${ }^{358}$ Bezogen auf den Personenverkehr sind die Wasserwege von nachrangiger Bedeutung.

\footnotetext{
${ }^{354} \mathrm{vgl}$. Wiesbadener Kurier v. 14.2.2007

355 vgl. Woitschützke 2002, S.206

356 vgl. Frankfurter Allgemeine Zeitung v. 16.6.05

357 vgl. Nuhn und Hesse 2006, S.154

358 ebd., S.106f
} 
Rein statistisch gesehen fahren 13\% der Hessen (fast) täglich mit dem Fahrrad. In der Region Frankfurt Rhein-Main sind es sogar 17\%. Allerdings entfallen bei der Fahrtenverteilung im Modal Split in Hessen auf das Fahrrad nur 6\% aller getätigten Fahrten. Betrachtet man die günstige topografische Situation in der Stadt Frankfurt, liegt der Modal SplitAnteil mit 7\% vergleichsweise niedrig - und dass, obwohl ca. 80\% der Haushalte im Bereich des Planungsverbands und ca. 70\% der Haushalte in Frankfurt und Offenbach über mindestens ein Fahrrad verfügen (im Durchschnitt 1,8 Fahrräder pro Haushalt im Planungsverband bzw. 1,4 in Frankfurt und Offenbach). ${ }^{359}$ Der Grund hierfür könnte das „subjektive Risiko-Empfinden durch [die] Gefährdung im innerstädtischen Straßenverkehr“ sein, die dazu führt, dass „das Fahrrad trotz seiner objektiv spezifischen Stärken im großstädtischen Raum - geringe Wegedistanzen verbunden mit hoher Flexibilität und schnellem Vorankommen“ eine vergleichsweise geringe Nutzung erfährt. 360 Im Jahr 2003 hat die Stadtverordnetenversammlung der Stadt Frankfurt am Main beschlossen, bis zum Jahr 2012 den Modal Split-Anteil im Fahrradverkehr auf 15\% zu steigern. Dieser Beschluss erfolgte im Zusammenhang mit der Beteiligung am Nationalen Radverkehrsplan, der die Senkung von Umweltbelastungen durch die Verlagerung von Fahrten des MIV auf das Fahrrad verfolgt. ${ }^{361}$

Der vom Allgemeinen Deutschen Fahrradclub (ADFC) und dem Bund für Umwelt- und Naturschutz (BUND) 2005 durchgeführte „Fahrradklimatest“ 362 gibt Auskunft über die Fahrradfreundlichkeit von insgesamt 148 deutschen Städten und Gemeinden. Die Auswertung 2005 führt die Stadt Frankfurt an Platz 14 der Städte mit mehr als 200.000 Einwohnern. Die Gesamtnote von 3,87 belegt, dass die Stadt Frankfurt noch weit davon entfernt ist, sehr gute Bedingungen für Radfahrer zu bieten. Wie in den meisten anderen Städten sind Probleme mit der allgemeinen Akzeptanz von Radfahrern vorhanden. „Besonders schlechte Noten wurden für die Situation an Baustellen, den Konflikten mit Autos und

${ }^{359}$ Zum Vergleich: In der fahrradfreundlichsten Stadt Deutschlands, Münster, liegt der Anteil des Fahrradverkehrs am Gesamtverkehr bei 32\%. Allerdings liegen dort die Modal Split-Anteile für den ÖPNV und MIV auch im Verhältnis niedriger als in Frankfurt; vgl. Abbildung 12.

360 vgl. Planungsverband Ballungsraum Frankfurt/Rhein-Main u.a. 2005, S.16f bzw. 58

361 vgl. o. V.: „Runder Tisch Fahrradverkehr" sowie Frankfurt Rundschau v. 24./25.3.2005

362 Die Beurteilung erfolgte anhand von Schulnoten; die Teilnahme am Test und das damit verbundene Ausfüllen eines Fragebogens erfolgte auf freiwilliger Basis. 
der Problematik der Falschparker gegeben“. ${ }^{363}$ Erfreulich ist alleine, dass im Vergleich zum „Fahrradklimatest“ 2003 die Situation des Fahrradverkehrs in der Stadt Frankfurt mittlerweile besser eingestuft wird. 2003 lag Frankfurt mit einem Durchschnittswert von 4,26 noch auf Platz 23.364

\section{Exkurs: Projekt bike + business}

Bislang gibt es für die Region Frankfurt Rhein-Main kein umgesetztes Radverkehrskonzept oder einen integrierten Gesamtverkehrsplan, der das Verkehrsmittel Fahrrad berücksichtigt. Allerdings gibt es auf Basis des Bundestagsbeschlusses zur Entwicklung eines Nationalen Radverkehrsplans (NRVP) eine Projektinitiative des ADFC Hessens diesen Plan auch für die Region Frankfurt Rhein-Main umzusetzen. Das Ziel ist letztlich die "Stärkung des beruflichen Radverkehrs im System lokaler und regionaler Verkehrspolitik und planung". Der Projektgruppe gehören der Landesverband Hessen e.V. des ADFC, der Planungsverband Ballungsraum Frankfurt Rhein-Main, der Rhein-Main-Verkehrsverbund, das Hessische Ministerium für Wirtschaft, Verkehr und Landesentwicklung, die Lokale Nahverkehrsgesellschaft Frankfurt am Main TraffiQ sowie das Klima-Bündnis an.

Zunächst gab es eine Pilotphase in Eschborn - also vor den Toren Frankfurts -, in der mittels Flyer und eigens angefertigter Fahrradkarten die für die aktive Teilnahme von Mitarbeitern zweier großer Firmen (zusammen 1.800 Mitarbeiter) geworben wurde. In einer zweiten Phase ab 2004 wurde das Projekt auf Firmen in Frankfurt ausgedehnt, so etwa die Deutsche Bank und die Fraport AG sowie auf Verwaltungen in der Region. Bislang wurden allerdings noch keinen infrastrukturellen Maßnahmen im Rahmen dieses Projektes durchgeführt. Es bleibt abzuwarten, mit welchem Erfolg sich das Projekt weiter entwickelt und ob gesetzte Ziele erreicht werden können, insbesondere den Umstieg zu fördern "vom PKW auf das Fahrrad zur Verbesserung der Leistungsfähigkeit des gesamten Verkehrssystems und zur Reduzierung der Verkehrsbelastungen". ${ }^{365}$

\subsubsection{Fußgängerverkehr}

Die Bedeutung des Fußgängerverkehrs wird häufig unterschätzt, obwohl fast jede Person täglich zu Fuß unterwegs ist. Insbesondere in der polyzentrischen Region Frankfurt

\footnotetext{
363 vgl. BUND/ADFC 2005

364 vgl. BUND/ADFC 2003

365 vgl. www.bikeandbusiness.de
} 
Rhein-Main - für die auch schon der Begriff der „Region der kurzen Wege“ 366 geprägt wurde - liegt der Fußgängeranteil vergleichsweise hoch (siehe Abbildung 12). Seine große Bedeutung für die Sicherung der nachhaltigen Mobilität hat der Fußgängerverkehr vor allem, weil er im Vergleich zu anderen Fortbewegungsarten besonders flexibel und umweltschonend ist und außerdem sehr wenig Platz benötigt. Darüber hinaus werden Fußwege auch häufig mit der Nutzung anderer Verkehrsmittel kombiniert, so beispielsweise im Vor- und Nachlauf einer ÖPNV-Fahrt. Die fußläufige Erreichbarkeit der nächsten ÖPNV-Haltestelle ist hierfür die Voraussetzung. In der Erhebung MiD 2002 wurde nach der Entfernung der Wohnung zum nächsten Bahnhaltepunkt gefragt. In Frankfurt und Offenbach gaben $38 \%$ an, dass sich dieser in weniger als $400 \mathrm{~m}$ von der Wohnung befindet. Weitere 31\% nannten eine Entfernung von 400 bis 1000 m. Damit wohnen zwei Drittel der Einwohner Frankfurts und Offenbachs in einer Entfernung zum nächsten Bahnhaltepunkt, die - zumindest von der Distanz her betrachtet - fußläufig gut zu bewerkstelligen ist. Für den gesamten Bereich des Planungsverbands liegt für 22\% die Entfernung unter $400 \mathrm{~m}$ und für weitere 30\% unter $1000 \mathrm{~m}$, so dass etwa die Hälfte der Bevölkerung im Planungsverband in fußläufiger Entfernung zum nächsten Bahnanschluss wohnt. Bei diesen Werten muss allerdings berücksichtigt werden, dass sie auf den Angaben der Befragten beruhen und von den realen Werten abweichen können. Dennoch hat die subjektiv wahrgenommene Entfernung großen Einfluss auf die Bereitschaft, den ÖPNV zu nutzen. ${ }^{367}$ Bei einer Entfernung über 1 km wird in der Regel auf das Fahrrad zurückgegriffen. ${ }^{368}$

Beeinträchtigt wird der Fußgängerverkehr durch den motorisierten Verkehr in Form erhöhter Unfallgefahr, Lärm, Abgase, Zuparken von Gehwegen und der Zerschneidung von Fußwegen. Um den Fußgängerverkehr attraktiver zu gestalten, sollten daher die Belange der Fußgänger in Verkehrskonzepten stärker berücksichtigt werden. Die Förderung der Sicherheit des Fußgängerverkehrs ist außerdem erforderlich, weil vor allem die „schwächeren Verkehrsteilnehmer“ (Kinder, ältere Menschen) zu Fuß unterwegs sind.

\footnotetext{
366 vgl. Stein und Wolf 2005, S.279

367 vgl. Planungsverband Ballungsraum Frankfurt/Rhein-Main u.a. 2005, S.20

368 vgl. RMV 2000, S.5
} 
Intermodale Knoten, als Übergangspunkte von einem Verkehrsträger auf einen anderen, sind die Voraussetzung, dass intermodale Wegeketten überhaupt erst entstehen können. Neben der Information über das vorhandene Verkehrsangebot an intermodalen Knotenpunkten, hat vor allem die Gestaltung der Übergangspunkte wesentlichen Einfluss auf die Attraktivität der Nutzung intermodaler Wegeketten. Die Bedeutung von Haltestellen und Bahnhöfen in diesem Zusammenhang wird in Kapitel 6.5.2.3.1 dargestellt. Aufgrund der Komplexität dieses Themas wird an dieser Stelle ausschließlich auf die Verknüpfung von MIV und ÖPNV, Fahrrad und ÖPNV sowie auf die intermodalen Knoten eingegangen, an denen mindestens drei Verkehrsträger miteinander koordiniert werden.

$M I V-\ddot{O P}(N) V$

Bezogen auf die physische Vernetzung von MIV und ÖPNV - hier insbesondere dem Schienenverkehr - haben vor allem Park-and-Ride-Plätze eine Bedeutung. Deren Nutzung hängt wiederum von unterschiedlichen „anziehenden“ (pull) und „zwingenden“ (push) Faktoren ab (vergleiche Kapitel 3.6.2). Attraktivitätssteigernde pull-Faktoren sind beispielsweise eine gute Erreichbarkeit, lange Öffnungszeiten, niedrige Parkgebühren, guter baulicher Zustand, Sicherheit und eine gute Qualität des vorhandenen ÖPNVAngebots. Restriktive und einschränkende push-Faktoren, wie beispielsweise der begrenzte Parkraum am Zielort, führen dazu, dass die Nutzenschwelle für die Wahrnehmung von Park-and-Ride-Angeboten heruntergesetzt wird. Voraussetzung für die Akzeptanz der Park-and-Ride-Plätze ist die Information der potenziellen Nutzer über das aktuell verfügbare Angebot. Diese Information ist gerade für diejenigen Nutzer von Interesse, die "sich nach einer pre-trip Abfrage der aktuellen Verkehrslage im ÖPNV und MIV für das gerade geeignetere Verkehrsmittel für die Fahrt" entscheiden. ${ }^{369}$

Für das Rhein-Main-Gebiet weist die Internetseite www.parkinfo.com, eine kostenlose Datenbank des Allgemeinen Deutschen Automobilclubs (ADAC) und der BMW AG über Park-and-Ride-Angebote, insgesamt 152 Park-and-Ride-Anlagen aus. ${ }^{370}$ Die Internetseite des RMV verzeichnet sogar 163 Anlagen im Verbundgebiet. ${ }^{371}$ Beide Auskunftsseiten geben aber rein statische Auskünfte. Nur von der Anzahl her betrachtet, erscheint das An-

\footnotetext{
${ }^{369}$ vgl. Beckers u.a. 2001, S.10

370 vgl. www.parkinfo.com/de/ (Zugriff am 5.11.2006)

${ }^{371}$ vgl. www.rmv.de/coremedia/generator/RMV/AutoCo/Auto/ParkRide (Zugriff am 5.11.2006)
} 
gebot zunächst umfangreich. Für die Stadt Frankfurt weist die Internetseite der Integrierten Gesamtverkehrs-Leitzentrale Frankfurt am Main (IGLZ) 16 Park-and-Ride-Anlagen aus. Allerdings gibt es auch hier keine aktuellen Daten über freie Stellplätze 372 (dafür aber über das Stellplatzangebot in den Parkhäusern). ${ }^{373}$

In einem Vergleich des Park-and-Ride-Angebots von sechs deutschen Großstädten, den das Wirtschaftsmagazin WISO des Senders ZDF im März 2006 veröffentlichte, schnitt Frankfurt am Main am schlechtesten ab. Bemängelt wurden u.a. die schlechte Beschilderung, die fehlende Sauberkeit, der schlechte bauliche Zustand und auch die zu geringe Größe der Anlagen. 374

Der Generalverkehrsplan 2000 geht davon aus, dass im Rhein-Main-Gebiet die Gruppe der Berufstätigen rund 80-90\% der Park-and-Ride-Nutzer ausmacht. 10\% entfallen auf den Ausbildungsverkehr. Nur ein sehr kleiner Anteil findet im Bereich des Einkaufs- und Gelegenheitsverkehrs statt. $\mathrm{Zu} \mathrm{70 \%} \mathrm{ist} \mathrm{der} \mathrm{Innenstadtbereich} \mathrm{von} \mathrm{Frankfurt} \mathrm{das} \mathrm{Ziel} \mathrm{von}$ Park-and-Ride-Nutzern. Ihr Anteil an allen ÖPNV-Fahrten wird auf etwa 2-6\% geschätzt. Gleichzeitig wird im Generalverkehrsplan festgestellt, dass es nur wenige Park-and-RideAnlagen gibt, die über freie Kapazitäten verfügen. Dagegen gibt es viele Plätze, deren Kapazitäten zu über 100\%, ja sogar 200\% ausgeschöpft sind, die Nachfrage also bedeutend höher als das Angebot ist. ${ }^{375}$

\section{Fahrrad und ÖPNV}

Es kann davon ausgegangen werden, dass in der Region Frankfurt Rhein-Main an fast allen Bahnstationen im regionalen Schienenverkehr ein Mindestangebot an Fahrradabstellanlagen (Bike-and-Ride-Anlagen) existiert. Der Generalverkehrsplan 2000 schätzt die Bedeutung der Bike-and-Ride-Nutzung ähnlich hoch ein, wie die Park-and-RideNutzung, d.h., dass etwa 80-90\% der Nutzungsfälle im Berufs- und Ausbildungsverkehr stattfinden. ${ }^{376}$ Neben individuellen push-Faktoren wie fehlender Pkw-Führerschein oder

\footnotetext{
372 Ein gutes Beispiel, wie über die Verfügbarkeit von Park-and-Ride-Plätzen informiert wird, bietet die Münchener Park\&Ride GmbH. Unter www.parkundride.de/de/03anlagen/ kann sowohl die aktuelle wie auch die prognostizierte Belegung (in Prozent) von Park-and-Ride-Plätzen und -Parkhäusern zu bestimmten Zeiten abgefragt werden.

373 vgl. www.iglz.de (Zugriff am 30.12.2006)

374 vgl. ZDF 2006; verglichen wurde das Angebot in den Städten Düsseldorf, Frankfurt am Main, Hamburg, Köln, Nürnberg und Stuttgart.

$375 \mathrm{vgl}$. Umlandverband 2000, S.88

376 ebd. S.89
} 
Pkw-Verfügbarkeit sowie der vorherrschenden Topographie und Witterungseinflüssen, ist die Nutzung von Bike-and-Ride-Angeboten abhängig von der infrastrukturellen Anbindung der Bahnstationen (Fahrradwege, verkehrsberuhigte Zonen) und der Art und Qualität der Abstellanlagen vor Ort, die als pull-Faktoren wirken. Hier werden nicht überdachte und überdachte Fahrradständer sowie abschließbare Fahrradboxen und Fahrradstationen bzw. automatische Fahrradparkhäuser unterschieden. ${ }^{377}$ Ferner wird die Kombination von Fahrradverkehr und ÖPNV-Nutzung durch die kostenlose Mitnahme von Fahrrädern zusätzlich unterstützt. Im RMV-Verbundgebiet ist diese Mitnahmemöglichkeit allerdings nicht einheitlich geregelt. ${ }^{378}$

$M I V-O ̈ P(N) V-L u f t$

Als intermodaler Knoten ist insbesondere der Flughafen Frankfurt von herausragender Bedeutung für die Region Frankfurt Rhein-Main. Der Flughafen liegt am Autobahnknoten Frankfurter Kreuz, der Kreuzung der zwei meist frequentierten Autobahnen in Deutschland und ist über diese auch an das europäische Fernstraßennetz angebunden. Hinzu kommen gute verkehrliche Anbindungen an regional bedeutsame Autobahnen (A60, A67) und Bundesstraßen (B43, B44 und B468).

Darüber hinaus ist der Flughafen Frankfurt einer der ersten intermodalen Fernverkehrsknoten Deutschlands, der an das ICE-Fernverkehrsnetz der Deutschen Bahn AG mit einem eigenen Bahnhof an der Hochgeschwindigkeits-Neubaustrecke Frankfurt-Köln angeschlossen wurde. Der 1999 in Betrieb genommene Fernbahnhof ermöglicht eine teilweise Kapazitätsentlastung des Flughafens. „So können Slots (Zeitfenster für Starts und Landungen) von Kurzstreckenflügen, die auf die Schiene verlegt werden, für dringend benötigte Europa- und Interkontinental-Flüge frei gemacht werden“.379 Täglich wird der Bahnhof von 167 ICE und IC angefahren. Zusätzlich kommen am unterirdischen Regionalbahnhof täglich 250 S-Bahnen und Regionalzüge an. Außerdem gibt es noch den Cargo-Bahnhof in der Cargo-City, über den ebenfalls eine Anbindung an den Schienengüterverkehr sichergestellt wird.

\footnotetext{
377 vgl. RMV 2000, S.8ff

378 vgl. RMV 2006 (b), S.42

${ }^{379}$ www.fraport.de/cms/kapazitaetsausbau/rubrik/2/2413.intermodalitaet.htm (Zugriff am 18.2.2007)
} 


\section{Intermodaler Güterverkehr}

Im Mai 2004 wurde im Industriepark Frankfurt-Höchst der „Trimodalport“ in Betrieb genommen, an dem die Verkehrträger von Straße, Schiene und Wasserweg zusammengeführt werden. Durch dieses Güterverkehrszentrum können nun „erhebliche Transportkapazitäten von der Straße auf umweltfreundliche Verkehrsträger verlagert werden“. ${ }^{380}$ Die Kapazität des Trimodalports beträgt ca. 1,2 Mio. Tonnen jährlich. Bei einer angenommenen durchschnittlichen Nutzlast eines Lkw von 27 Tonnen entspricht dies etwa 45.000 Lkw-Transporten pro Jahr. ${ }^{381}$ Einen vergleichbaren Ansatz gibt es im Frankfurter Osthafen, wo am Standort eines Container-Terminals ebenfalls ein Trimodalport entsteht. Der Ausbau zu einem vollwertigen Güterverkehrszentrum ist allerdings noch nicht beschlossen.

\subsection{Verkehrsverhalten in der Bevölkerung}

Aus der bereits angesprochenen bundesweiten Erhebung "Mobilität in Deutschland 2002“ (MiD 2002, siehe auch Kapitel 3.1.2) wurden bundesweit detaillierte Informationen über die Mobilitätsnachfrage bzw. das Verkehrsverhalten und die Einstellungen der Bevölkerung zum Verkehr abgeleitet. Die folgenden Darstellungen basieren in weiten Teilen auf Literaturstellen, die auf die Ergebnisse dieser Erhebung zurückgreifen.

\subsubsection{Modal Split}

Unter „Modal Split“ versteht man die Aufteilung des Verkehrsaufkommens auf die unterschiedlichen Verkehrsträger. Der Modal Split ist die Folge der Verkehrsmittelwahl der Bevölkerung bzw. der verkehrlichen Entscheidungen von Wirtschaftsunternehmen. ${ }^{382}$

Nur ca. jede vierte Bürgerin bzw. jeder vierte Bürger in Hessen greift heute zur Befriedigung ihrer/seiner Mobilitätsansprüche auf den ÖPNV als bevorzugtes Verkehrsmittel zurück. Fast drei Viertel (72\%) sind dagegen mit dem Pkw unterwegs. Im Bereich des

\footnotetext{
380 Infraserv 2004

381 vgl. Infraserv 2004

382 vgl. Nuhn und Hesse 2006, S.19
} 
Planungsverbands sind dies immerhin noch 70\%. Dagegen besitzen dort nur 22\% der Personen über 14 Jahre eine ÖPNV-Zeitkarte. ${ }^{383}$

Betrachtet man die Modal Split-Werte der Erhebung MiD 2002 für privat getätigte Wege ${ }^{384}$, werden im Gebiet des Planungsverbands 37\% aller Wege im Auto als Selbstfahrer zurückgelegt (in Frankfurt und Offenbach (F/OF) 31\%, Hessen 41\%). ${ }^{385}$ Als Mitfahrer im Pkw sind 17\% unterwegs (F/OF 14\%, Hessen 18\%). 9\% der Wege werden mit dem ÖPNV zurückgelegt (F/OF 14\%, Hessen 7\%). Der sogenannte Umweltverbund besitzt damit im Bereich des Planungsverbands einen Anteil von 46\% 386 (F/OF 54\%, Hessen 41\%). ${ }^{387}$

Im direkten Vergleich der Verkehrsmittelnutzung zwischen MIV und ÖPNV an Wochentagen ergibt sich im Planungsverband ein Verhältnis von 84\% (60\% Fahrer, 24\% Mitfahrer) zu 16\%. Auf Landesebene stellt sich dieses Verhältnis mit $88 \%$ zu 12\% sogar noch schlechter für den ÖPNV dar. Lediglich in den Kernstädten des Ballungsraumes Frankfurt und Offenbach existiert mit 63\% zu 27\% ein für den ÖPNV günstigeres Verhältnis. 388

Bei einem Vergleich der Modal Split-Werte mit anderen bundesdeutschen Städten zeigt sich, dass die Region Frankfurt Rhein-Main einen vergleichsweise niedrigen ÖPNV-Anteil aufweist (siehe Abbildung 12). Allerdings wird hierbei nicht berücksichtigt, dass ein Großteil des Verkehrs im Stadtgebiet von Frankfurt nicht von den Bewohnern der Stadt, sondern von den Einpendlern verursacht wird. Zwar dominiert bei diesem Wegezweck auch das Auto bei der Verkehrsmittelwahl, doch erreicht der Modal Split-Wert für den ÖPNV einen deutlich besseren Wert als bei der ausschließlichen Betrachtung der von der Bevölkerung der Stadt zurückgelegten Wege. ${ }^{389}$ Es ist daher davon auszugehen, dass der tatsächliche ÖPNV-Anteil zumindest für die Stadt Frankfurt über dem Wert von 14\% liegt. 390

\footnotetext{
383 vgl. Planungsverband Ballungsraum Frankfurt/Rhein-Main u.a. 2005, S.15 bzw. 19; als Zeitkarten gelten Jahrs-, Monats-, Wochenkarte, Jobticket, Semesterticket.

384 D.h. ohne die beruflichen Wege, die dem Personenwirtschaftsverkehr zugerechnet werden. Dieser beträgt in Hessen $8 \%$.

385 vgl. Planungsverband Ballungsraum Frankfurt/Rhein-Main u.a. 2005, S.30

$3861 \%$ entfallen auf sonstige: u.a. Schienenfernverkehr

387 vgl. Planungsverband Ballungsraum Frankfurt/Rhein-Main u.a. 2005, S.30

388 ebd., S.32

389 vgl. Planungsverband Ballungsraum Frankfurt/Rhein-Main u.a. 2005, S.35

390 Die Studie „Mobilität in Städten - SrV 2003“kommt für die Stadt Frankfurt für das Jahr 2003 auf Modal Split-Werte für den MIV von 38\%, ÖPNV 23\%, Fußwege 30\% und Fahrrad 9\%. Da sich das Befragungsdesign an der Studie „Mobilität in Deutschland - MiD” orientiert, lassen sich
} 


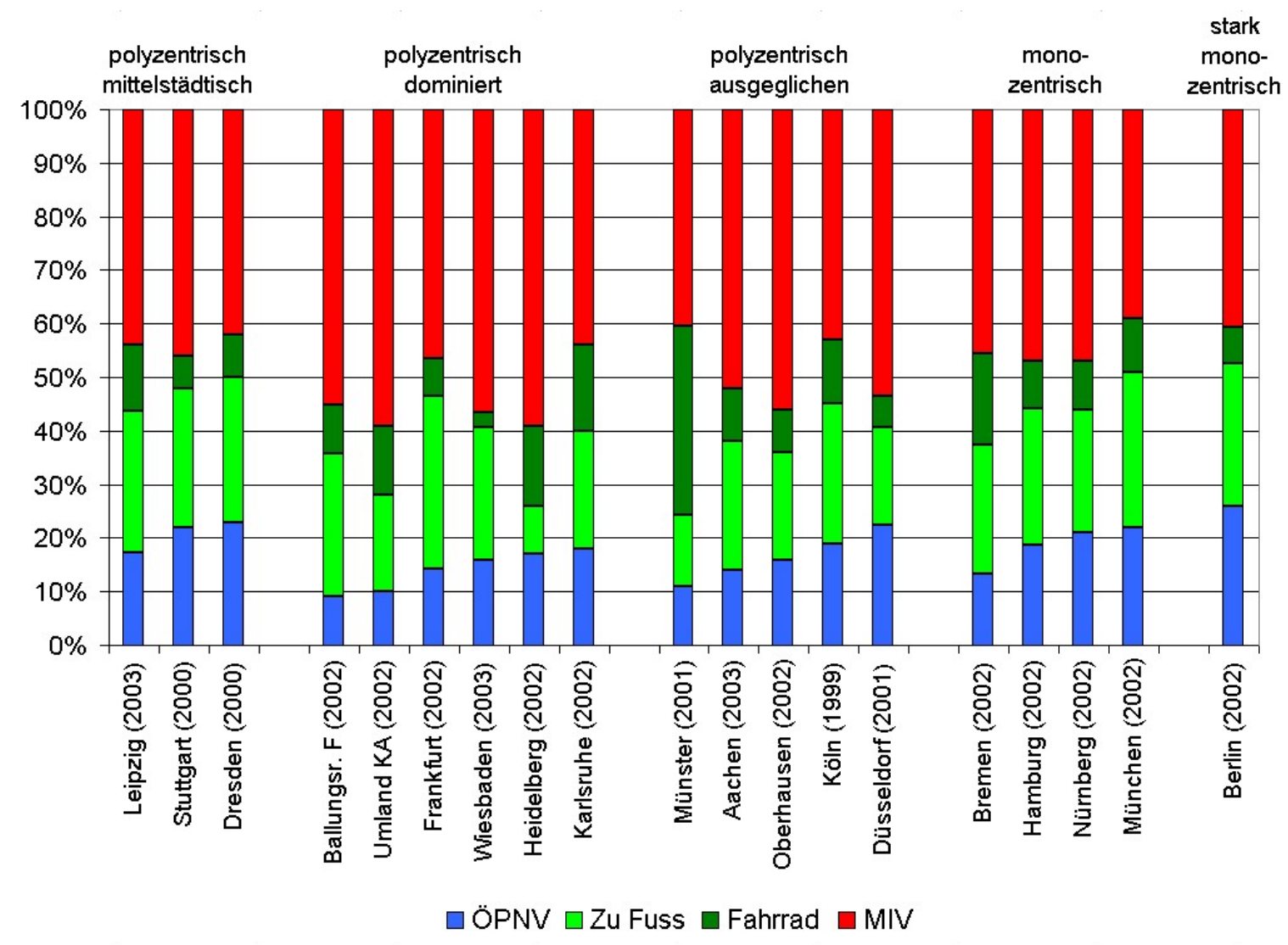

Abbildung 12: $\quad$ Modal Split-Werte deutscher Städte im Vergleich

Quelle: Eigene Bearbeitung; unterschiedliche Datenbasen ${ }^{391}$

Da die Siedlungsstrukturen einen wesentlichen Einfluss auf die Verkehrsverflechtungen haben, werden bei der vergleichenden Betrachtung auch die unterschiedlichen Raumstrukturen berücksichtigt. Entscheidende Indikatoren für die Einstufung in einen Raumtyp sind hierbei die intraregionalen Verflechtungsmuster, die in engem Zusammenhang

die Abweichungen nur mit der eingeschränkten zeitlichen Befragung erklären. So wurde ausschließlich im Zeitraum zwischen April und Juni 2003 an den Wochentagen von Dienstag bis Donnerstag befragt und die Ergebnisse auf das gesamte Jahr hochgerechnet. Der Detaillierungsgrad der MiD-Studie, zur der es außerdem noch eine Aufstockungsstichprobe für Hessen gab, scheint hier zuverlässiger; vgl. Frankfurt am Main 2004, S.3 bzw. Planungsverband Ballungsraum Frankfurt/ Rhein-Main u.a. 2005, S. 4f.

391 Quellennachweise: Frankfurt und Ballungsraum F: Planungsverband Ballungsraum Frankfurt/ Rhein-Main u.a. 2005 (ohne berufliche Wege), S.31; Wiesbaden, KA Umland, Stuttgart, Oberhausen, Köln: Socialdata - Verkehrsmittelwahl (ohne berufliche Wege), München 2007; Bremen, Hamburg und Berlin: DIW und infas (ohne berufliche Wege), Berlin 2003; Münster: Stadt Münster - Verkehrsbild Münster 2001, Münster 2003; Düsseldorf: Amt für Verkehrsmanagement der Stadt Düsseldorf, Düsseldorf 2001; München: Landeshauptstadt München, München 2002; Aachen: Bau- und Planungsdezernat - Nahverkehrsplan der Stadt Aachen 2003; Nürnberg: Verkehrsplanungsamt der Stadt Nürnberg - Nahverkehrsplan, Nürnberg 2006; Leipzig: Amt für Verkehrsplanung der Stadt Leipzig - Nahverkehrsplan der Stadt Leipzig, Leipzig 2005; Heidelberg: Stadt Heidelberg - Stadtblatt Nr.19/2002; Heidelberg 2002. 
mit den Verflechtungsmustern im Berufsverkehr stehen ${ }^{392}$ (also die Pendlerströme siehe Kapitel 4.4.6). Hier zeigt sich, dass in monozentrisch ausgeprägten Räumen der ÖPNVAnteil im Schnitt leicht erhöht ist. Im einzigen stark monozentrischen Raum (Berlin) ist der ÖPNV-Anteil sogar deutlich höher. Dagegen können in den polyzentrisch strukturierten Räumen keine ausgeprägten Unterschiede festgestellt werden. Typisch für die polyzentrisch geprägten Regionen ist, dass der Anteil der Bevölkerung in den Kernstädten geringer ist, als in den monozentrischen Regionen. Dies führt zu einem insgesamt diffuseren Verflechtungsniveau und zu der Situation, dass für etliche Relationen keine günstigen ÖPNV-Verbindungen angeboten werden können. ${ }^{393}$ Dies ist u.a. in der Region Frankfurt Rhein-Main daran zu erkennen, dass trotz vorwiegend radial ausgerichteter Verkehrsströme, die höchsten Belastungssteigerungen auf Bundesstraßen verzeichnet werden, die tangential zum Kernraum verlaufen. Ferner wirkt sich der hohe Anteil von einbrechenden Autoverkehren von Außen in die Kernstadt aus, der deutlich über dem Binnenverkehr liegt. 394

Günstig stellt sich dagegen der vergleichsweise hohe Anteil an Fußwegen in Frankfurt sowie im Planungsverband dar. Hier wirkt sich die polyzentrische Struktur der Region positiv aus, deren vergleichsweise kurzen Wege den Fußgängerverkehr begünstigen („Region der kurzen Wege“). Der Anteil des Fahrradverkehrs wiederum ist in Anbetracht der verhältnismäßig günstigen Topographie in der Stadt Frankfurt recht gering.

In der Region Frankfurt Rhein-Main ist die Anzahl zurückgelegter Fahrten im ÖPNV über die vergangenen Jahre kontinuierlich gestiegen. Dies hat vor allem mit dem verbesserten Leistungsangebot zu tun. Hier haben sich insbesondere die Ausbaumaßnahmen und das zusätzliche Angebot im S- und Regionalbahnbereich positiv bemerkbar gemacht. Insgesamt nutzt ca. ein Viertel der Bevölkerung in Hessen den ÖPNV mindestens einmal in der Woche. Von 15\% wird der ÖPNV fast täglich genutzt. In den Städten Frankfurt und Offenbach erreicht der Anteil einen Spitzenwert von 28\%. Weitere 22\% sind immerhin noch ein- bis dreimal in der Woche mit Bussen und Bahnen unterwegs, so dass ca. die Hälfte der Bevölkerung einmal pro Woche den ÖPNV nutzt. ${ }^{395}$

\footnotetext{
392 vgl. Stein und Wolf 2005, S.85

393 ebd., S.88

394 ebd., S.267

${ }^{395}$ vgl. Endemann u.a. 2006, S.42
} 
Die Anzahl der Gesamtfahrten im Rhein-Main-Verkehrsverbund stieg von ca. 530 Mio. in 1997396 auf ca. 640 Mio. in 2005.397 Da sich aber die Verkehrsanteile des ÖPNV wie auch des übrigen Umweltverbundes am Modal Split verringert haben, geht daraus hervor, dass der Zuwachs an Mobilität fast ausschließlich vom MIV abgedeckt wird.

\subsubsection{Wegezweck}

Von allen in Hessen zurückgelegten Wegen dienen etwa 20\% der Erreichung von Arbeitsoder Ausbildungsplatz - bisher "die Domäne“ des ÖPNV. Dabei entfallen 14\% auf Wege zum/vom Arbeitsplatz und 6\% zum/vom Ausbildungsplatz. Freizeit- und Einkaufs-/ Besorgungswege machen rund die Hälfte aller Wege aus; 30\% aller Wege finden im Freizeitverkehr statt und 19\% dienen Einkäufen. Auf Begleitwege (z.B. elterliche Bring- und Holfahrten) entfallen 9\% aller Wege. Für private Erledigungen werden 13\% aller Wege durchgeführt. 8\% der Wege sind Fahrten im Wirtschaftsverkehr, also sogenannte "nicht verzichtbare“ Wirtschaftsverkehre (siehe Kapitel 4.7.1). ${ }^{398}$

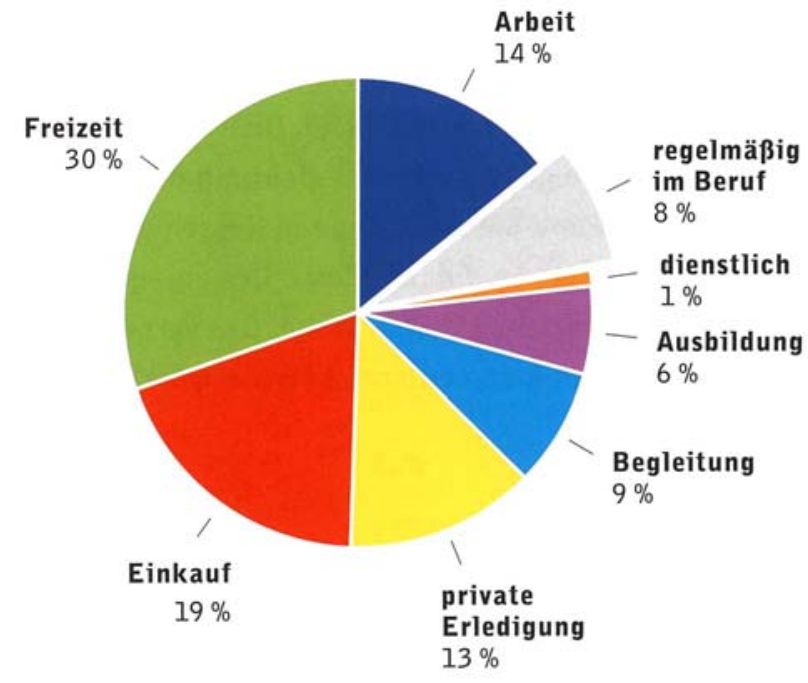

Basis: 72.492 Wege, Hessen

Quelle: MiD 2002, ausgewertet von Planungsverband Ballungsraum Frankfurt/Rhein-Main und traffiQ

Abbildung 13: Wegezwecke in Hessen

Quelle: Planungsverband Ballungsraum Frankfurt/Rhein-Main u.a. 2005, S.26

\footnotetext{
396 vgl. RMV 1998, S.58

397 vgl. RMV 2006 (a), S.14

398 vgl. Planungsverband Ballungsraum Frankfurt/ Rhein-Main u.a. 2005, S.26
} 
Der Wegeanlass beeinflusst in hohem Maße die Verkehrsmittelwahl. 71\% aller Wege zur Arbeit werden in Hessen mit dem Auto zurückgelegt. Der geringe Anteil von 6\% Mitfahrern belegt bei diesem Fahrtzweck den niedrigen Besetzungsgrad der Pkw. Mit dem ÖPNV gelangen 13\% der Beschäftigten zu ihrem Arbeitsort. 13\% nutzen das Fahrrad oder gehen zu Fuß (siehe Kapitel 4.3.5). 3\% gelangen mit sonstigen Verkehrsmitteln zur Arbeit (z.B. Schienenfernverkehr). ${ }^{399}$ Betrachtet man den Bereich des Planungsverbands ohne Frankfurt und Offenbach, stellen sich diese Werte ähnlich dar (70\% MIV; 15\% ÖPNV; 12\% Fahrrad und zu Fuß; 2 sonstige). Für Frankfurt und Offenbach alleine betrachtet liegen die Werte mit 31\% für den ÖPNV günstiger. Die Werte für die Nutzung des MIV betragen 50\%. 17\% kommen mit dem Fahrrad oder zu Fuß zu Arbeit, 3\% nutzen sonstige Verkehrsmittel. Am niedrigsten ist der ÖPNV-Anteil mit nur 7\% für Wege zur Arbeit in Nordhessen. Diese Werte verdeutlichen dass gute ÖPNV-Angebot in den Kernstädten des Ballungsraums. Daneben beeinflussen aber auch die insgesamt niedrigere PkwVerfügbarkeit und die Parkraumsituation in den Städten die Verkehrsmittelwahl.400

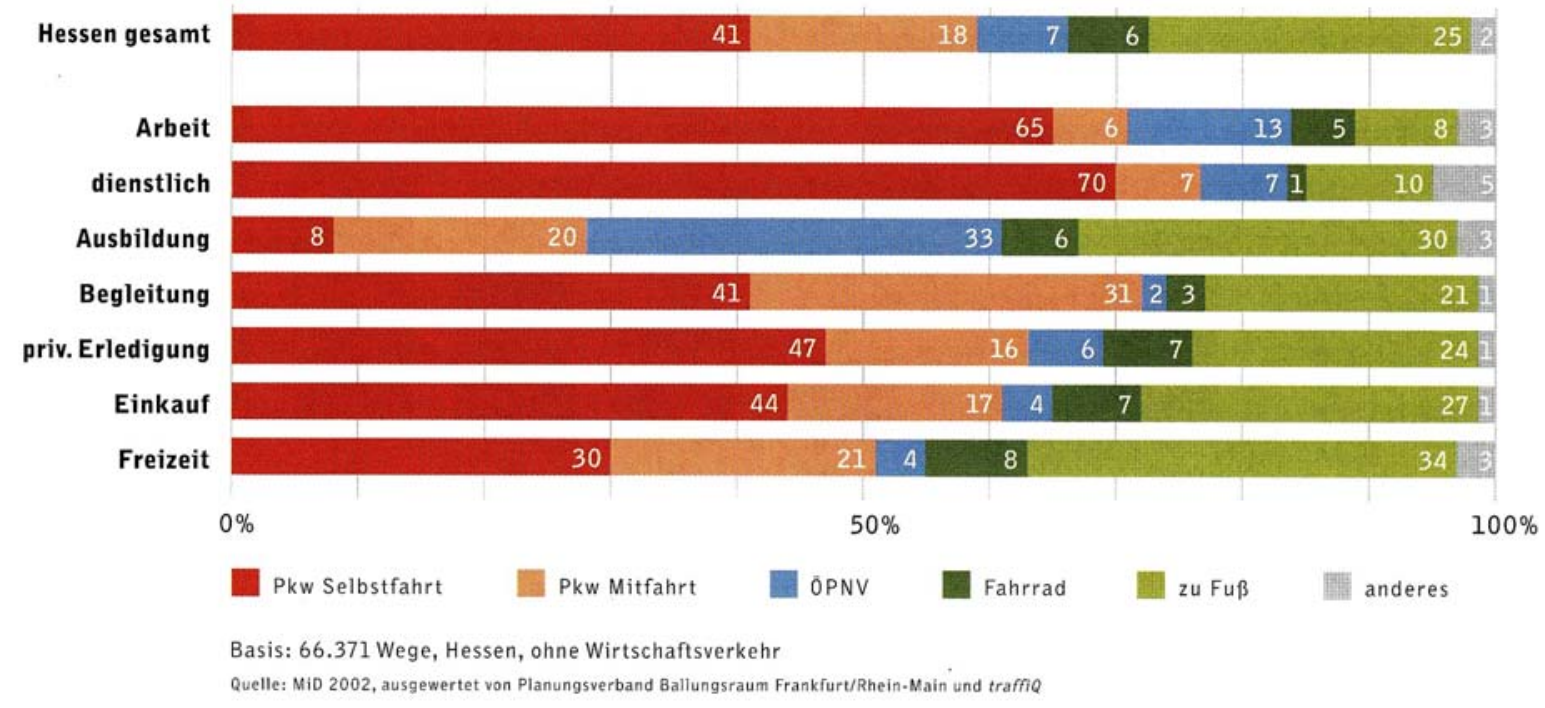

Abbildung 14: Verkehrsmittelwahl nach Wegezweck, Hessen (in \%)

Quelle: Planungsverband Ballungsraum Frankfurt/Rhein-Main u.a. 2005, S.33

399 ebd., S.33
400 ebd., S.35 


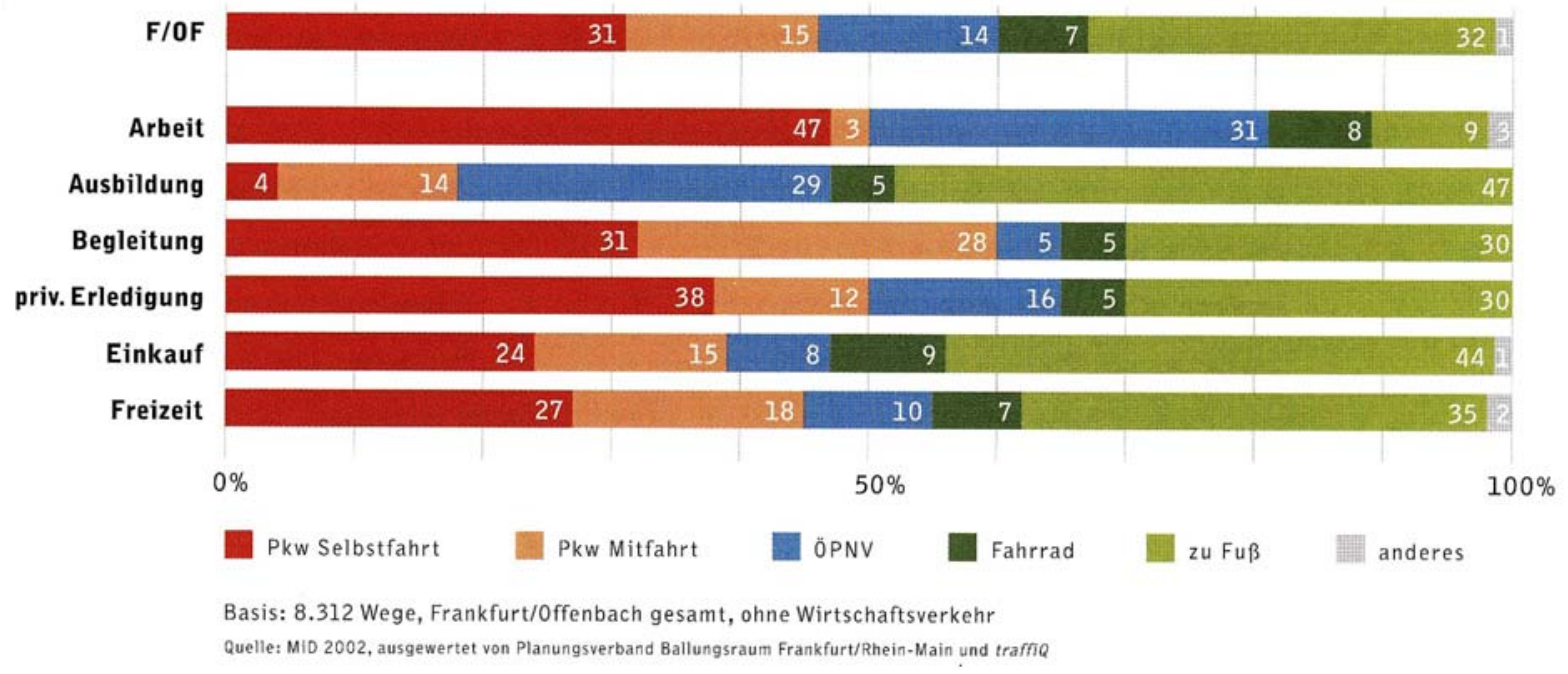

Abbildung 15: Verkehrsmittelwahl nach Wegezweck, Frankfurt und Offenbach (in \%)

Quelle: Planungsverband Ballungsraum Frankfurt/Rhein-Main u.a. 2005, S.35

Vor allem bei Wegen zur Ausbildungsstätte ist ein hoher ÖPNV-Anteil zu verzeichnen (Hessenweit 29\%; F/OF 33\%). Aufgrund des nicht vorhandenen Führerscheins sowie der häufigen Nähe zum Ausbildungsort spielt für Schüler und Auszubildende aber auch das Zufußgehen und das Fahren mit dem Fahrrad mithin die größte Rolle. Nur in den ausgeprägt ländlichen Gebieten in Nordhessen entfällt auf den ÖPNV der größte Anteil bei diesem Wegezweck. ${ }^{401}$ Den geringsten Anteil weist der ÖPNV dagegen in allen Teilgebietstypen in den Bereichen Freizeit, Einkauf, private Erledigungen und Begleitwege auf. Für diese Wegeanlässe scheint es keine attraktiven Angebote seitens Bus und Bahn zu geben.

Diese Zahlen verdeutlichen, welchen Stellenwert der Pkw in der heutigen Gesellschaft einnimmt. Verkehrsproblemen, Umweltschäden, hohen Spritpreisen und sonstigen Einflüssen zum Trotz ist das Auto nach wie vor der Inbegriff von Unabhängigkeit und Selbstbestimmtheit. Über das Auto lässt sich offensichtlich in viel besserem Maße eine räumliche und zeitliche Unabhängigkeit und Flexibilität realisieren, die einer lückenlosen Mobilität von Tür zu Tür am ehesten entspricht. 402

\footnotetext{
401 ebd., S.35f

402 vgl. Schöller 2005, S.41
} 
Statistisch gesehen legt jeder Bewohner Hessens im Durchschnitt am Tag 3,2 Wege zurück. Nur 14\% der Bewohner legen im Schnitt am Tag keinen Weg zurück. Auffällig ist, dass unter den mobilen Personen die Frauen mit 3,8 Wegen gegenüber den Männern mit 3,6 Wegen eine etwas höhere Mobilität aufweisen. Besonders ausgeprägt ist dieses Verhältnis in der Gruppe der Teilzeitbeschäftigten, die zu 90\% aus Frauen besteht. Dort werden im Durchschnitt täglich 4,2 Wege zurückgelegt. Eine ähnlich hohe Mobilität weist die Gruppe der Hausfrauen/-männer auf, die zu 98\% aus Frauen besteht. Dort fallen 4,1 Wege täglich an. Die im Verhältnis höhere Mobilität von Frauen kann auf ihre stärkere Einbindung in die tägliche Versorgung (Einkaufen) und das Begleiten von Personen (bspw. Bring- und Holfahrten zur Schule) zurückgeführt werden. Daraus resultiert auch, dass der Berücksichtigung von Mobilitätsbedürfnissen von Frauen ein hoher Stellenwert eingeräumt werden sollte. Außerdem wurde beobachtet, dass Personen mit ständiger PkwVerfügbarkeit eine höhere Wegehäufigkeit aufweisen. ${ }^{403}$ Die durchschnittliche Wegelänge im Planungsverband beträgt 7,7 km (F/OF 7,2, Hessen 8). Die durchschnittlich zurückgelegte Entfernung pro Tag bei mobilen Personen liegt bei 27,4 km (F/OF 24,6, Hessen $28,2) .404$

\subsubsection{Wegezeitpunkte}

Rund drei Viertel aller Wege werden Montags bis Freitags zurückgelegt. Etwa 15\% entfallen auf den Samstag und ca. 10\% auf Sonntage. Die Erhebung belegt, dass sich der Verkehr werktags relativ gleichmäßig auf die Tageszeit zwischen 7 und 19 Uhr verteilt. Innerhalb dieses Zeitraumes variiert das stündliche Verkehrsaufkommen nur zwischen 6 und $8 \%$. An Wochenenden ist Samstags eine Verkehrsspitze am späten Vormittag zu verzeichnen, am Sonntag am frühen Nachmittag. Ausgeprägte Verkehrsspitzen gibt es nur für den ÖPNV. Diese liegen werktags um 7 und 13 Uhr und sind auf den hohen Anteil beförderter Schüler zurückzuführen. Besonders ausgeprägt sind diese Spitzen im Umland des Ballungsraumes, da hier der Schüleranteil relativ gesehen am höchsten ist. Damit ent-

\footnotetext{
${ }^{403}$ vgl. Endemann u.a 2006, S.37

${ }^{404}$ vgl. Planungsverband Ballungsraum Frankfurt/ Rhein-Main u.a. 2005, S.23; Werte bereinigt um Wege über 3 Stunden Dauer und $100 \mathrm{~km}$ Entfernung
} 
stehen insbesondere dort Kosten für das Vorhalten von Reservekapazitäten (siehe Kapitel 6.1.2). .405

\subsubsection{Mobilitätsausgaben}

Die durchschnittlichen Ausgaben eines hessischen Haushalts pro Monat für den ÖPNV betragen nur rund 18,- Euro und damit 5\% aller Mobilitäts-/Verkehrsausgaben, die mit insgesamt 318,- Euro monatlich 13,6\% der Gesamtausgaben eines Haushalts ausmachen.

\begin{tabular}{|l|c|c|c|c|c|}
\hline & $\begin{array}{c}\text { Haushalts- } \\
\text { ausgaben } \\
\text { (in EURO/Jahr) }\end{array}$ & $\begin{array}{c}\text { Ausgaben für } \\
\text { Verkehr } \\
\text { (Euro) }\end{array}$ & $\begin{array}{c}\text { Anteil Ver- } \\
\text { kehrsausgaben } \\
\text { am Gesamt- } \\
\text { konsum }\end{array}$ & $\begin{array}{c}\text { Ausgaben für } \\
\text { ÖPNV } \\
\text { (EURO) }\end{array}$ & $\begin{array}{c}\text { Anteil der ÖPNV- } \\
\text { Ausgaben (an allen } \\
\text { Verkehrsausgaben) }\end{array}$ \\
\hline Deutschland & 2.126 & 306 & $14,4 \%$ & 18,50 & $5,2 \%$ \\
\hline Hessen & 2.338 & 318 & $13,6 \%$ & 18,10 & $4,9 \%$ \\
\hline
\end{tabular}

Tabelle 7: Mobilitätsausgaben in Deutschland und Hessen 2003

Quelle: Statistisches Bundesamt (Hrsg.): „Datenreport 2004". Bonn 2004 und Hessisches Landesamt für Statistik: Landesdaten zu Versorgung und Verbrauch (www.statistik-hessen.de/themenauswahl/einkommen-verbrauch/index.$h$ tml).

Insgesamt sind die individuellen Kosten für Mobilität in den letzten Jahren deutlicher gestiegen als die allgemeinen Lebenshaltungskosten. Laut Angaben des ADAC stiegen die Kosten im ÖPNV zwischen 2000 und 2005 stärker als die Kosten für die Pkw-Nutzung - trotz höherer Versicherungsbeiträge und Ökosteuer (siehe Abbildung 16). ${ }^{406}$ Zwischen 2005 und 2007 haben sich nach Angaben des Auto Club Europa (ACE) dann die durchschnittlichen Kosten für die Pkw-Nutzung stärker entwickelt als die Preise für die ÖPNVNutzung (siehe Abbildung 17). Für die Region Frankfurt Rhein-Main liegt die Preissteigerung für den ÖPNV im Zeitraum 2005 bis 2007 mit 9,3\% aber über den allgemeinen Preissteigerungen für den MIV mit 7,4\%. Allerdings ist der durchschnittliche Kilometerpreis im ÖPNV mit 14 Cent immer noch deutlich niedriger als der Kilometerpreis mit dem Auto, für den 81,5 Cent zugrundegelegt werden. ${ }^{407}$

\footnotetext{
405 vgl. Endemann u.a 2006, S.41

406 vgl. ADAC 2006, S.38

407 vgl. ACE 2007
} 


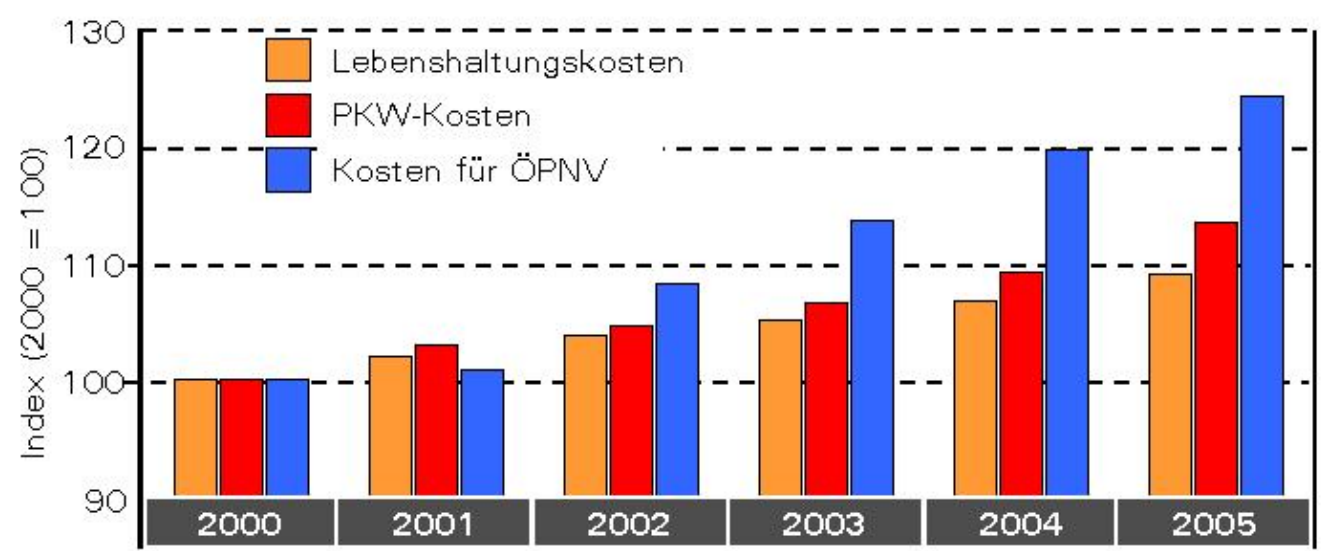

Abbildung 16: $\quad$ Entwicklung von Lebenshaltungs- und Mobilitätskosten 2000-2005

Quelle: ADAC-Motorwelt, Nr.34; eigene Bearbeitung

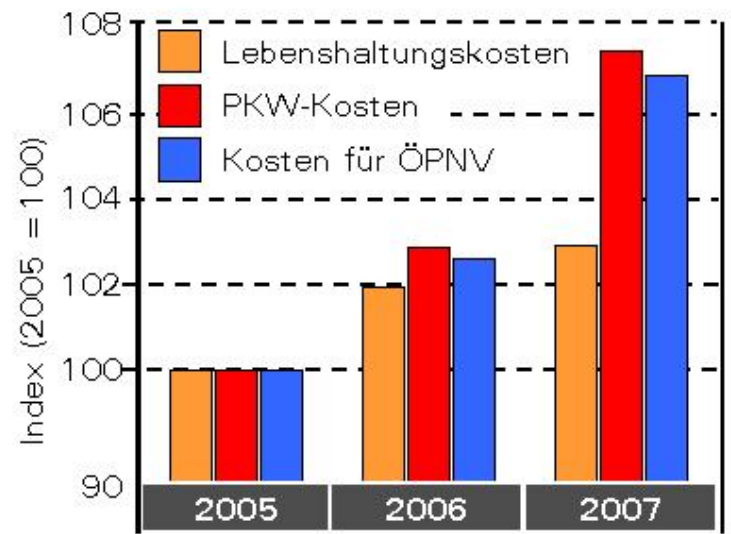

Abbildung 17: Entwicklung von Lebenshaltungs- und Mobilitätskosten 2005-2007

Quelle: ACE Auto Club Europa, Pressemitteilung vom 15.02.2007; eigene Bearbeitung

\subsubsection{Pendlerbeziehungen}

Die hohe Suburbanisierung der Region trägt maßgeblich zum Pendlerverhalten der Bevölkerung in der Region bei. ${ }^{408}$ Die stärksten Pendlerbeziehungen nicht nur Hessens, sondern der gesamten Bundesrepublik hat Frankfurt am Main. In allen vier Volkszählungen, die seit 1950 durchgeführt wurden, wies die Stadt jeweils die höchste Anzahl Einpendler auf, obwohl München und Hamburg doppelt bzw. dreimal so groß sind.409 Von den 460.000 Sozialversicherungspflichtigen am Arbeitsort Frankfurt am Main waren 2005 ins-

${ }^{408} \mathrm{vgl}$. Freund 2002, S.232ff

409 ebd., S.255 
gesamt 302.000 Einpendler zu verzeichnen (65,8\%). Von den 217.000 sozialversicherungspflichtig Beschäftigten am Wohnort Frankfurt am Main pendelten über 59.000 aus (27,4\%).410 Zum Vergleich: 1994 verzeichnete Frankfurt noch gut 34.000 Einpendler weniger. Da die Pendlerzahlen aus der Anzahl der sozialversicherungspflichtig Beschäftigten abgeleitet werden und nicht aus der Anzahl der Erwerbstätigen, die mit 590.000 noch erheblich höher ist ${ }^{411}$, liegt die Vermutung nahe, dass die tatsächliche Anzahl der Pendler nochmals um bis zu $20 \%$ höher liegt.

Einige Umlandgemeinden weisen allerdings ähnlich starke oder sogar noch höhere Pendlerverflechtungen auf. So liegen die Pendlerquoten für Eschborn und Liederbach bei über 90\%. Gleichzeitig pendeln in Liederbach 87\% der dort wohnenden Erwerbstätigen aus. ${ }^{412}$ Auch die anderen Mittel- und Oberzentren wie Wiesbaden, Mainz, Hanau, Darmstadt, Bad Homburg und Offenbach sind sowohl Ein- als auch Auspendlerzentren. Aufgrund der Funktionsteilungen und -ergänzungen zwischen diesen Zentren kommt es zu einem komplexen Verflechtungsmuster der Pendlerbeziehungen in der Region. Dennoch haben die zentralörtlichen Hierarchien in der Region bestand, d.h., es ist insgesamt immer noch eine klare Ausrichtung der Pendlerverflechtungen auf die Kernstadt Frankfurt am Main zu erkennen. ${ }^{413}$

Derartig deutlich ausgeprägte Pendlerbeziehungen gibt es im Vergleich in anderen deutschen Städten nicht. Dieses veranschaulicht auch die Arbeitsplatzdichte in der Stadt Frankfurt, die für das Jahr 2003 mit 918 Erwerbstätigen je 1000 Einwohner angegeben wird. Auf den Plätzen dahinter, schon mit deutlichem Abstand, liegen die Städte Düsseldorf (795), Stuttgart (775), München (743) und Nürnberg (693). ${ }^{414}$

Zur Jahresmitte 2002 kamen die meisten Einpendler aus dem nahen Umland; dies sind alle an Frankfurt am Main angrenzenden Landkreise einschließlich der kreisfreien Stadt Offenbach am Main. Zusammen waren dies insgesamt 181.668 sozialversicherungspflichtig Beschäftigte, die zu ihrem Arbeitsort nach Frankfurt am Main pendelten. Dabei kamen aus dem Main-Taunus-Kreis mit 33.026 die meisten Einpendler, gefolgt vom Landkreis Offenbach mit 32.348 Pendlern, dem Main-Kinzig-Kreis mit 31.149 und dem Wetterau-

\footnotetext{
${ }^{410}$ vgl. Stadt Frankfurt am Main 2006, S.205

411 vgl. Stadt Frankfurt am Main 2005, Frankfurter Statistik aktuell 14/2005

412 vgl. Freund 2002, S.257

413 vgl. Planungsverband Ballungsraum Frankfurt/Rhein-Main 2003, S.16f

${ }^{414}$ vgl. Stadt Frankfurt am Main 2005, Frankfurter Statistik aktuell 14/2005
} 
kreis mit 25.679 Beschäftigten. Knapp ein Viertel (76.080 Personen) aller Einpendler gab einen Wohnort außerhalb des Landes Hessen an. ${ }^{415}$

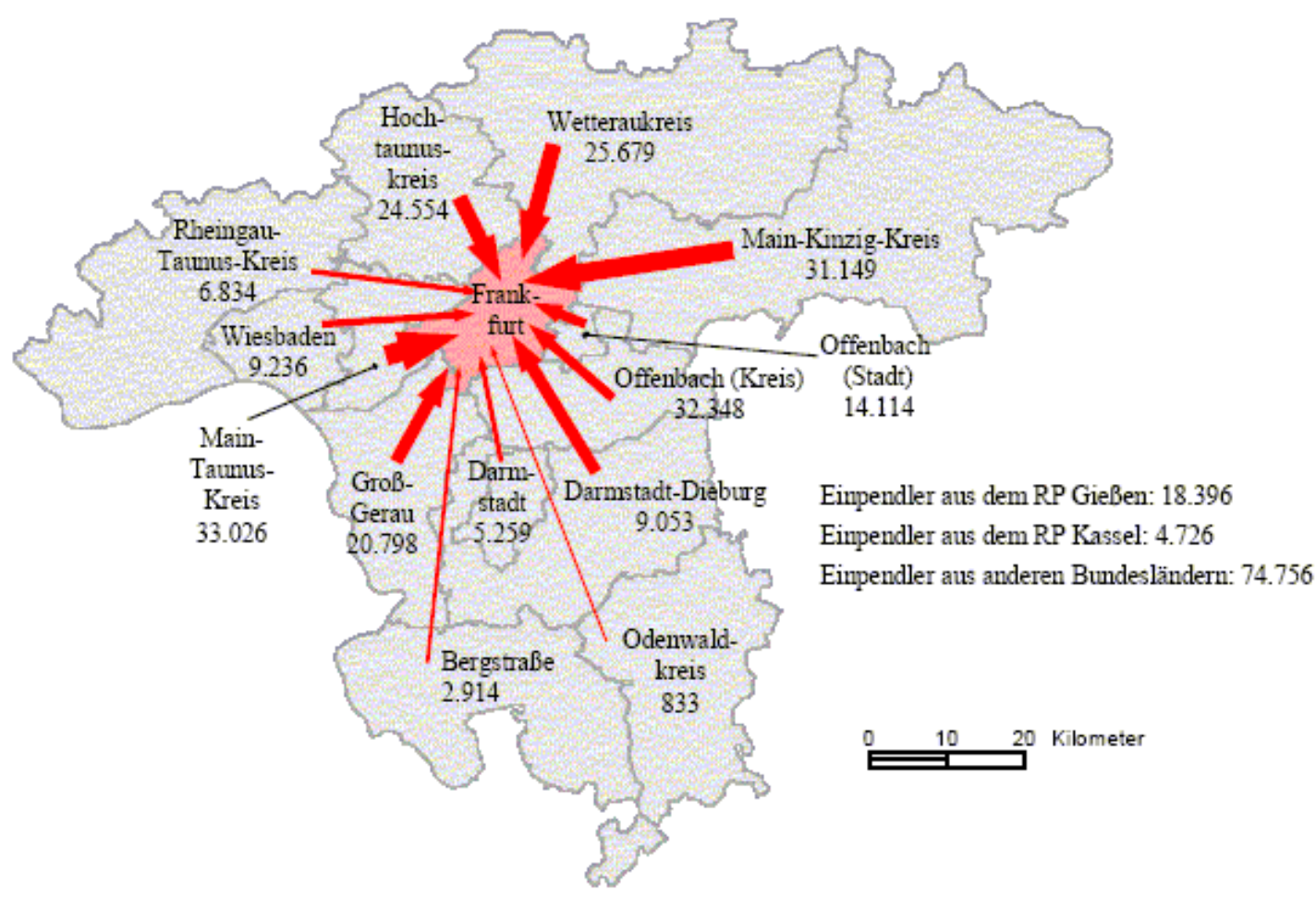

Abbildung 18: Einpendler nach Frankfurt am Main

Quelle: Hessisches Ministerium für Umwelt, ländlichen Raum und Verbraucherschutz 2002: „Luftreinhalteplan für den Ballungsraum Rhein-Main", S.17.

Die Region Frankfurt Rhein-Main weist aufgrund ihrer polyzentrischen Struktur im Vergleich zu den anderen deutschen Metropolregionen - ausgenommen Stuttgart - günstigere mittlere Pendlerdistanzen auf. ${ }^{416}$ Erwerbstätige außerhalb der Städte Frankfurt und Offenbach legen bei ihrem Weg zur Arbeit in Frankfurt im Durchschnitt eine Wegstrecke von 17,2 km zurück. Innerhalb der Städte Frankfurt und Offenbach verringert sich die Weglänge um ein Viertel auf 13,6 km. ${ }^{417}$

Obwohl der Anteil von Wegen zur Arbeit mit 14\% nur den drittgrößten Posten darstellt, fällt doch mit $71 \%$ die überragende Bedeutung des MIV in diesem Bereich auf. Nur 13\%

415 vgl. Schad u.a. 2000, S.1f

416 vgl. Umlandverband 2000, S.33 sowie Harbich u.a. 2005, S.115

${ }^{417}$ vgl. Planungsverband Ballungsraum Frankfurt/Rhein-Main u.a. 2005, S.40 
der Wege zur Arbeit werden dagegen mit dem ÖPNV zurückgelegt. ${ }^{418}$ Damit werden absolut mehr Pkw-Fahrten durch Wege zur Arbeit verursacht als in den Bereichen Freizeit und Einkaufen. Gefördert wird die hohe Pkw-Nutzung für Fahrten zum Arbeits- und Ausbildungsplatz durch hohe Einkommen, da mit steigendem Einkommen längere Wegstrecken zwischen Wohn- und Arbeitsort in Kauf genommen werden. ${ }^{419}$ Zudem ist der Auslastungsgrad der Pkw bei den Berufspendlern auf dem Weg zur Arbeit besonders gering bzw. in den Bereichen Freizeit und Einkaufen deutlich höher. Dies kann als Indiz für ein vorhandenes Optimierungspotenzial gewertet werden.

Der Einzugsbereich Frankfurts für Pendler reicht weit über die Region hinaus, wodurch die Bedeutung des Schienenfernverkehrs potenziell zunimmt. Im Verhältnis zum Pkw ist die Bedeutung des Fernverkehrs tatsächlich aber gering. So entfallen laut Studie „Mobilität in Stadt und Region“ nur 3\% aller Fahrten zur Arbeitsstätte auf den Bereich "anderes“, zu dem auch der Schienenfernverkehr zählt. ${ }^{420}$ Dennoch haben im Bereich des Fernverkehrs seit Inbetriebnahme der Neubaustrecke Frankfurt-Köln die ICE-Bahnhöfe an dieser Trasse an Bedeutung für die Pendlerbeziehungen gewonnen. So liegt beispielsweise der Flughafen Frankfurt nur 35 Minuten Fahrzeit vom ICE-Bahnhof Montabaur entfernt. Eine Studie der Wirtschaftsförderungsgesellschaft des Westerwald-Kreises sowie der Verbandsgemeinde Montabaur aus dem April 2004 hatte zum Ergebnis, dass mindestens ein Drittel aller 2000 täglichen Ein- und Aussteiger am Bahnhof Montabaur Berufspendler sind. Zwei Drittel der Berufspendler wiederum haben Frankfurt oder den Flughafen Frankfurt als Reiseziel. Insgesamt wird die Attraktivität dieser Verbindung derart positiv gesehen, dass mit einem Anstieg der täglichen Fahrgäste bis auf 3000 Kunden gerechnet wird. ${ }^{421}$

\subsubsection{Die Entwicklung des Verkehrs in der Zukunft}

Auch für die Zukunft muss davon ausgegangen werden, dass die Umkehr der Dynamik der weiterhin steigenden Verkehrsentwicklung, die sogenannte „Verkehrswende“, nicht stattfinden wird. „Die Nachfrage nach Personenverkehrsleistungen steigt ungebrochen. Es gibt keine Anzeichen, dass sich diese Entwicklung in den nächsten Jahren ändern

\footnotetext{
418 ebd., S.33

$419 \mathrm{vgl}$. Statistisches Bundesamt 2006, S.35

420 ebd., S.35

${ }^{421}$ vgl. Nassauische Neue Presse vom 17.02.2005
} 
wird“. ${ }^{422}$ So wird bis zum Jahre 2020 mit einem weiteren Anstieg der Personenverkehrsleistung um 7\% gerechnet. Damit einher geht die weitere Zunahme der Summe an privaten Pkw sowie die Pkw-Verfügbarkeit. ${ }^{423}$ Aus der Erhebung MiD 2002 ergeben sich fünf zentrale Trends im deutschen Alltagsverkehr:

- Weitere, zunehmende Motorisierung,

- steigende Anteile des Pkw-Verkehrs am Gesamtverkehrsaufkommen,

- stagnierendes, absolutes Aufkommen im ÖPNV,

- hohe Wachstumsraten im Erledigungs-, Einkaufs- und Freizeitverkehr sowie

- $\quad$ höhere Zeitbudgets für die tägliche Mobilität. 424

Bereits in den letzten Jahren ist der Bereich der Fahrten im Einkaufs- und Freizeitverkehr stärker gewachsen (von 65\% in 1976 auf 70\% in 2002) als der Anteil der Fahrten zur Arbeit (von $35 \%$ in 1976 auf $30 \%$ in 2002). ${ }^{425}$ Zukünftig werden die heute noch berufstätigen Pendler ihre hohe Pkw-Mobilität bis in die hohen Lebensjahre mitnehmen, wobei die Fahrleistung immer geringer wird. Vor allem wird sich die Stagnation in der ÖPNVNutzung in der Fläche als Nachfragerückgang ausprägen. Schätzungen gehen davon aus, dass der ÖPNV dort zwischen 2015 und 2050 zwei Drittel seiner Nutzer verlieren wird. ${ }^{426}$ Gleichzeitig muss aber auch davon ausgegangen werden, dass die Kosten für Mobilität weiter steigen werden, wovon der MIV im besonderen Maße betroffen sein könnte. ${ }^{427}$ In dem sich ergebenden Spannungsverhältnis von Mobilitätserfordernissen und Verkehrsverhalten muss sich auch der ÖPNV neu positionieren. ${ }^{428}$

\subsection{Auswirkungen des Verkehrs}

Der Verkehr in seiner heutigen, durch den MIV dominierten Form, droht in der Region Frankfurt Rhein-Main ein Ausmaß zu erreichen, das die Grenzen der Tolerierbarkeit überschreitet und damit die in der Region lebende Bevölkerung in ihren Chancen, ihrer

\footnotetext{
422 ProgTrans/HSW 2005, S.1

${ }^{423}$ vgl. ProgTrans/HSW 2005, S.1

${ }^{424}$ vgl. Planungsverband Ballungsraum Frankfurt/Rhein-Main u.a. 2005, S.74f

${ }^{425}$ vgl. ProgTrans/HSW 2005, S.5

${ }^{426}$ vgl. Mietsch 2005, S.19

427 bspw. durch die Pkw-Maut oder Mineralölpreise

${ }^{428}$ vgl. Topp 2006 (a), S.21
} 
Gesundheit oder ihrer Freiheit einschränkt sowie die Entwicklung und den Wohlstand der Region gefährdet. In einer Bürgerbefragung zu den größten Stadtproblemen in der Stadt Frankfurt aus dem Dezember 2005, wurde die "Verkehrssituation“ von jedem 5. Befragten (20\%) subjektiv am schlechtesten eingestuft und löste damit sogar das Dauerproblem „Kriminalität" ab (13\%), das bis 2001 noch an erster Stelle genannt wurde. ${ }^{429}$ Die Darstellung der negativen Auswirkungen des Verkehrs hat insofern vor allem den Zweck herauszustellen, dass es nicht regionalpolitisches Ziel sein kann und darf, die verkehrliche Entwicklung ungeplant - im Sinne von ungehemmt - vorantreiben zu wollen. Vielmehr gibt es limitierende Faktoren, die es zu berücksichtigen gilt, wenn „Mobilität als Standortfaktor" für die Region eine Bedeutung haben soll.

\subsubsection{Externe Kosten des Verkehrs}

Aus verkehrswissenschaftlicher Sicht ist ein Mehr an Verkehrsleistung nur dann gesamtwirtschaftlich sinnvoll, wenn die Erträge und der Nutzen (höhere Produktion, zusätzliches Einkommen etc.) höher sind als die dadurch verursachten Kosten. Während der aus Verkehrsleistungen entstehende Nutzen (im Sinne von Erträgen oder Nutzenwert) in der Marktwirtschaft den beteiligten Marktteilnehmern in der Regel bekannt ist, gehen die Kosten nur teilweise in die Kalkulation der Unternehmen und in die individuellen Entscheidungen der Verkehrsteilnehmer ein bzw. sind diese Kosten im Marktpreis nicht enthalten. ${ }^{430}$ Vor allem die vom Verkehr verursachten Umwelteinwirkungen erhöhen die Gesamtkosten des Verkehrs. Viele dieser Kosten werden jedoch von den Verursachern nicht selbst getragen, sondern von der Allgemeinheit, sei es von einer anderen Region oder aber auch erst von zukünftigen Generationen am selben Ort. Weil diese externalisierten Kosten nicht direkt oder selbst bezahlt werden müssen, führen sie bei den Verkehrsteilnehmern zu „suboptimalen Entscheidungen, zu Ineffizienzen und Vergeudung“ . ${ }^{431}$ So werden beispielsweise Ressourcen dort verbraucht, wo sie nicht den höchsten Nutzenwert haben. Von der Anlastung der externen Kosten an die Verursacher verspricht man sich daher eine Reduktion der externen Kosten insgesamt. Denn liegen die Kosten für eine Fahrt hoch, muss auch der Nutzen der Fahrt entsprechend hoch sein.

\footnotetext{
${ }^{429}$ vgl. Stadt Frankfurt am Main, Frankfurter Statistik aktuell 14/ 2006

${ }^{430}$ vgl. Ellwanger 2001, S.34

${ }^{431}$ Becker, U. und Gerike, R. 2007, S.2
} 
Die Internalisierung bezeichnet in diesem Zusammenhang die Anlastung der externen Kosten an die Verursacher. Der Grad der Internalisierung der externen Kosten ist heute im ÖPNV wesentlich höher als im MIV, d.h., dass Autofahren gemessen an den verursachten Kosten billiger ist als die Nutzung von Bussen und Bahnen. Bezogen auf die interne Wegekostenrechnung, bei der es um die Ermittlung von Ausgaben, Aufwänden und Erträgen bei der - fiktiven unternehmerischen - Vorhaltung und dem Betrieb der Verkehrsinfrastruktur geht, 432 wundert es daher nicht, dass man im Straßenverkehr in der Regel zu deutlichen Einnahmeüberschüssen kommt 433 und die persönliche Verkehrsmittelwahl zugunsten des MIV erfolgt, wo die Verkehrsteilnehmer einen geringeren Anteil der Gesamtkosten für jede Fahrt bezahlen müssen. 434

$U$. Becker betont, dass bei der Internalisierung der externen Kosten in den Preisen für die Verkehrsmittelnutzung eine Gleichberechtigung angestrebt werden sollte. Dabei seien von jedem Verkehrsträger die Kosten für Betrieb, Infrastruktur, Energie und Umweltbeeinträchtigungen und Folgekosten selbst zu tragen. Auch für den ÖPNV sollten diesbezüglich keine Ausnahmen gelten. Denn nur mit ehrlichen Preisen seien effiziente Allokationen möglich. Alles andere würde zur Vergeudung führen, die wiederum „unökonomisch, unsozial, unökologisch: Un-intelligent. Un-nachhaltig“ sei. ${ }^{435}$ Allerdings würden derartige Ansätze von ÖPNV-Vertretern abgelehnt, da durch die Internalisierung auch die Kosten für die ÖPNV-Benutzung steigen würden, was zu einer kundenseitigen Ablehnung des ÖPNV führen könnte. Laut $U$. Becker führt eine gleichberechtigte Internalisierung der externen Kosten allerdings nur bei statisch-kurzfristiger Betrachtungsweise in die Sackgasse für den ÖPNV. Bei einer dynamisch-langfristigen Sichtweise hingegen würden sich die Kosten für den ÖPNV weniger stark entwickeln als für den MIV. Dies würde schließlich dazu führen, dass die Verkehrsteilnehmer die höheren Preise vermeiden würden. Becker und Gerike zufolge ließe sich darüber nicht alleine die Verkehrsmittelwahl optimieren, sondern könnte der Einfluss auf die Standortwahl auch zu ÖV-affineren Raumstrukturen führen. ${ }^{436}$

\footnotetext{
${ }^{432}$ vgl. Aberle 2003, S.376

433 vgl. ProgTrans/HSW 2005, S.9

434 vgl. Becker, U. und Gerike, R. 2007, S.5

${ }^{435}$ vgl. Becker, U. 2007, S.5

${ }^{436}$ vgl. Becker, U. und Gerike, R. 2007, S.6
} 
Die Gesamthöhe der externen Kosten kann nur geschätzt werden. Laut einer Studie von INFRAS und der Universität Karlsruhe betrugen die externen Kosten im Jahr 2000 für 17 europäische Länder ${ }^{437}$ rund 650 Mrd. Euro ${ }^{438}$, was 7,3\% des BIP ausmacht. Klimaveränderungen tragen $30 \%$ bei, Luftverschmutzung 27\%, Unfallkosten $24 \%$, Lärm $7 \%$, Zersiedlung, Trennungswirkung und sonstige weitere Effekte betragen nochmals $12 \%$. Der Hauptverursacher dieser Kosten ist mit 83,7\% der Straßenverkehr, gefolgt vom Luftverkehr mit 14\%. Der Schienenverkehr mit 1,9\% und der Verkehr auf den Wasserstraßen mit 0,4\% tragen nur unwesentlich zu diesen Kosten bei. ${ }^{439}$ Ein Bericht des Internationalen Eisenbahnverbands (Union Internationale des Chemins de fer, UIC) kommt zu etwas anderen Werten: Demnach entfielen im Jahr 1995 - ebenfalls gemessen auf der Grundlage von 17 europäischen Ländern - auf den Luftverkehr nur rund 6\% der externen Kosten, hingegen der Anteil des Straßenverkehrs bei über 90\% liegt. ${ }^{440} U$. Becker kommt in einer Studie der TU Dresden über ungedeckte externe Kosten im Verkehr im Bundesland Sachsen zu einem Gesamtwert für Deutschland in Höhe von 120 Mrd. Euro. Dabei entfallen auf jeden Einwohner etwa 1.400 Euro im Bereich des Straßenverkehrs und 57 Euro im Bereich des Schienenverkehrs. Bei der Bezifferung der externen Kosten pro Fahrzeug liegen laut $U$. Becker die externen Kosten beim Fahrrad aufgrund der sehr hohen Folgekosten von Unfällen am höchsten, weshalb sich $U$. Becker zufolge eine Betrachtung der externen Kosten auf die gesamten verursachten Kosten der jeweiligen Verkehrsmittel beziehen sollte. ${ }^{441}$

Im Rahmen einer nachhaltigen Regionalentwicklung muss die Wirtschaftsfunktion einer Stadt in seiner Bedeutung über die betriebswirtschaftlichen Einzelinteressen hinausgehen. Insofern müssen Kapitalverwertungsinteressen (auch sogenannter freier Ressourcen wie Luft, aber auch Gesundheit) im Interesse des Allgemeinwohls dann zurückstehen, wenn diese die Entwicklungsmöglichkeiten einer Region einschränken. So erscheint es aus privatwirtschaftlicher Sicht oftmals einfacher, ",die Stagnation festzuschreiben als schnell das finanzielle Risiko eines umfassenden Weiterplanens einzugehen“. ${ }^{442}$ Solange eben, bis die Folgekosten nicht mehr länger externalisiert werden können. Was für Unternehmen auf betriebswirtschaftlicher Ebene zutrifft, ist auch für Privatpersonen von Relevanz, wenn

\footnotetext{
${ }^{437}$ EU-Mitgliedsstaaten in 2000 plus Schweiz und Norwegen

438 ohne Staukosten

439 vgl. INFRAS/IWW 2004, S.4f

${ }^{440}$ vgl. UIC 2000, S.9 (ohne Staukosten) sowie Aberle 2003, S.591

${ }^{441}$ vgl. Becker, U. und Gerike, R. 2007, S.3ff

${ }_{442}$ Klühspies 1999, S.16
} 
das etwa aus privaten Bequemlichkeitsvorlieben verursachte Verhalten jenseits der Grenzen der ökologischen Tragfähigkeit stattfindet. In diesem Zusammenhang muss rationalzweckmäßiges Handeln von Verkehrsteilnehmern keineswegs den ökologischen und sozialen Anforderungen widersprechen. Vielmehr müssen die Verkehrsteilnehmer über alternative Handlungsspielräume informiert werden und ihnen Angebote gemacht werden, die sich durchaus in ein sozial-marktwirtschaftliches Denken und Handeln integrieren lassen. ${ }^{443}$

\subsubsection{Luftverschmutzung}

Der Verkehr ist zu 95\% vom Erdöl als fossilen Energieträger abhängig. Da der zukünftig erwartete Anstieg des Erdölverbrauchs vorrangig vom Verkehrs getragen wird und sich die Einführung emissionsarmer Motoren und Kraftstoffe nicht vor 2030 bemerkbar machen wird, ist davon auszugehen, dass der Verkehrsbereich auch weiterhin einer der Hauptverursacher von Luftverschmutzung sein wird.444 $\mathrm{Zu}$ den luftverschmutzenden, sogenannten „Treibhausgasen“ gehören Kohlendioxid $\left(\mathrm{CO}_{2}\right)$, Stickstoffoxide (NOx) und Schwefeldioxid $\left(\mathrm{SO}_{2}\right)$.

Die Region Frankfurt Rhein-Main ist nicht nur aufgrund des hohen Verkehrsaufkommens, sondern auch durch ihre topgraphische Situation von den negativen Auswirkungen der Luftverschmutzung besonders bedroht. Durch die von starken Winden abgeschirmte Lage der Rhein-Main-Ebene herrscht dort nicht nur ein vergleichsweise mildes Klima, gleichzeitig existiert auch ein wenig effektiver Luftaustausch. Dieses führt in einem „belastenden Verdichtungsraum“, wie ihn der Ballungsraum Rhein-Main darstellt, häufig zu erhöhter Schadstoffanreicherung in der Luft. Laut Luftreinhalteplan des Hessischen Ministeriums für Umwelt, ländlichen Raum und Verbraucherschutz sind die Verursacher der Luftverschmutzung zu wesentlichen Anteilen beim Kfz-Verkehr zu suchen. ${ }^{445}$

\section{Kohlendioxid $\left(\mathrm{CO}_{2}\right)$}

$\mathrm{CO}_{2}$ ist für den Menschen unschädlich, es wird aber für den sich abzeichnenden Klimawandel verantwortlich gemacht. In 2003 wurden in Deutschland insgesamt 865 Mio. t

\footnotetext{
${ }^{443}$ vgl. Klühspies 1999, S.16f

444 vgl. UITP 2005, S.23

${ }^{445}$ vgl. Hessisches Ministerium für Umwelt, ländlichen Raum und Verbraucherschutz 2002, S.37ff
} 
$\mathrm{CO}_{2}$ ausgestoßen. ${ }^{446}$ Hiervon entfielen $20 \%$ auf den Verkehrsbereich, wobei $19,6 \%$ dem Straßenverkehr anzulasten sind. Der Personenverkehr hatte dabei einen Anteil von mehr als zwei Drittel. Zwar hat sich die ausgestoßene Menge seit 1993 um 15\% reduziert, der Verkehr hat an dieser Reduktion aber nicht beigetragen, sondern seinen Ausstoß noch um 5\% erhöht. ${ }^{447}$ Dies ist vor allem auf das gestiegene Verkehrsaufkommen im Straßengüterverkehr zurückzuführen, welches zwischen 1990 und 2000 um 41\% gewachsen ist. 448 In Hessen trug der Verkehr mit 27\% (13,5 Mio. t) vergleichsweise überdurchschnittlich am Ausstoß von $\mathrm{CO}_{2}$ bei. Davon entfielen 26\% auf den MIV und 1\% auf den Flugverkehr (siehe Abbildung 19).

Der $\mathrm{CO}_{2}$-Ausstoß korreliert mit dem Energie- und Kraftstoffverbrauch. In den letzten Jahren ist zwar die Energieeffizienz der Fahrzeugmotoren verbessert worden, doch wurde die Verbesserung des Wirkungsgrads von Automotoren vor allem in höhere Leistung investiert. Hier wirkte sich die Zunahme an privaten Dieselfahrzeugen mit relativ niedrigem Verbrauch günstig auf den $\mathrm{CO}_{2}$-Ausstoß (aber ungünstig auf den $\mathrm{NO}_{2}$-Ausstoß, s.u.) aus. Außerdem führen die gestiegenen Sicherheits- und Komfortausstattungen zu höherem Verbrauch der Fahrzeuge. Die so erreichten technischen Verbrauchsminderungen wurden jedoch vom gestiegenen Verkehrsaufkommen überkompensiert. ${ }^{449}$

Im Rahmen des - rechtsverbindlichen - Kyoto-Protokolls hat sich die deutsche Bundesregierug verpflichtet, die Emission von Treibhausgasen bis 2012 um 21\% gegenüber $1990 \mathrm{zu}$ reduzieren. ${ }^{450}$ Bislang ist allerdings noch weitgehend unklar, wie sich der Kyoto-Emissionshandel auf die $\mathrm{CO}_{2}$-Reduktion im Verkehrsbereich auswirkt. ${ }^{451}$ Das Umweltbundesamt geht davon aus, dass bei

„einem sektorübergreifenden System Emissionsreduktionen an den Stellen des Wirtschaftssystems erfolgen, an denen die zugehörigen Vermeidungskosten minimal sind - also

\footnotetext{
${ }_{446}$ Pro Kopf sind das ca. 10 t. „Wissenschaftler haben sich auf einen Grenzwert von 1,7 t geeinigt, von dem man glaubt, dass die Tier- und Pflanzenwelt ihn noch verkraften kann“. Bärnthaler 2004, S.26.

${ }^{447}$ vgl. Statistisches Bundesamt 2006, S.57

448 vgl. Umweltbundesamt 2003 (b), S.1

${ }_{449}$ vgl. Umweltbundesamt 2006, S.1

450 vgl. Statistisches Bundesamt 2006, S.57

${ }^{451}$ vgl. Hauff 2003, S.182
} 
gesamtwirtschaftlich ökonomisch gering. Denn klimapolitisch ist es unerheblich, in welchen Sektoren die gewünschten Einsparungen erbracht werden". ${ }^{452}$

Da ein Emissionshandelssystem angestrebt wird, dass direkt beim Emittenten ansetzt (also dem Verkehrsteilnehmer/Mobilitätskonsumenten), sind der administrative Aufwand und die Transaktionskosten für die Überwachung und Nachhaltung entsprechend hoch. 453

\section{Kohlendioxid-Emissionen nach Emittenten in Hessen (Erhebungsjahr 1994)}

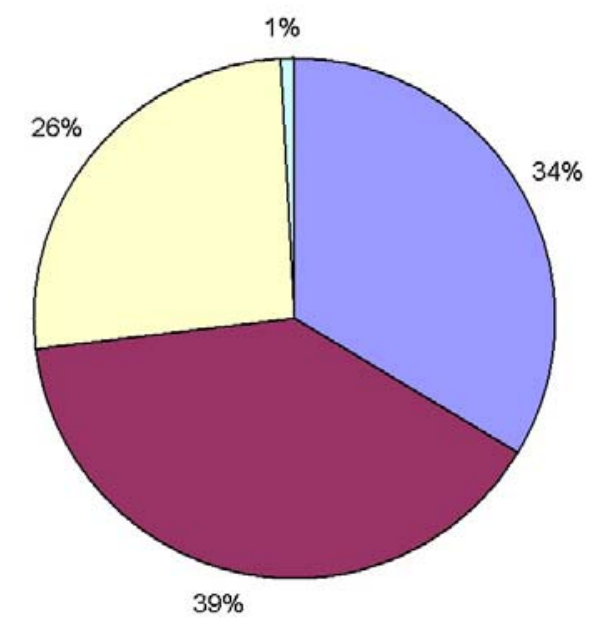

Abbildung 19: Ursachenanalyse für Kohlendioxidemissionen

Quelle: Hessisches Landesamt für Umwelt 1999, S.42, 44 u. 56; eigene Bearbeitung

Stickstoffoxide (NOx) und Feinstaub (PM10)

$\mathrm{Zu}$ den Stickstoffoxiden $\left(\mathrm{NO}_{\mathrm{x}}\right)$ zählen Stickstoffmonoxid (NO) und Stickstoffdioxid $\left(\mathrm{NO}_{2}\right) .{ }^{454} \mathrm{NO}$ reagiert mit Luftsauerstoff $\mathrm{zu} \mathrm{NO}$, welches wiederum mit Wasser und Sauerstoff zu Salpetersäure reagiert, die wesentliche zu Bodenversauerung und Pflanzenschädigung beiträgt („,Saurer Regen“). Darüber hinaus haben $\mathrm{NO}_{\times}$gesundheitsschädigenden Einfluss, insbesondere auf die Atemwege. Bodennah emittierte $\mathrm{NO}_{\mathrm{x}}$ tragen zur photochemischen Bildung von Ozon $\left(\mathrm{O}_{3}\right)$ bei („Sommersmog“), einem stark oxidativen und daher toxischen Reizgas, dass bei Menschen vor allem die Lunge schädigen kann. $\mathrm{NO}_{\mathrm{x}}$ hingegen, welches von hoch fliegenden Flugzeugen ausgestoßen wird, schädigt die vor

\footnotetext{
452 Umweltbundesamt 2003 (b), S.26

${ }^{453}$ vgl. Umweltbundesamt 2003 (b), S.27

${ }^{454}$ Gelegentlich wird noch Distickstoffoxid ( $\mathrm{N}_{2} \mathrm{O}=$ Lachgas) zur Gruppe der $\mathrm{NO}_{x}$ hinzugezählt.
} 
UV-Strahlung schützende Ozonschicht in der Stratosphäre. ${ }^{455}$ In jüngerer Zeit wird, ausgelöst durch die Verschärfung der Grenzwerte durch EU-Recht, außerdem die Belastung durch lungengängiges Feinstaub $\left(\mathrm{PM}_{10}\right)^{456}$ thematisiert. Feinstaub steht in Verdacht zahlreiche Gesundheitsrisiken zu erhöhen. Hierzu gehören vor allem Atemwegs- und Herzkranzerkrankungen, aber auch Krebs. ${ }^{457}$

Im Ballungsraum Frankfurt Rhein-Main wurden im Jahr 2000 insgesamt etwa 38.000 t $\mathrm{NO}_{2}$ emittiert. ${ }^{458}$ Bundesweit waren es im Jahr 2003 insgesamt 1,4 Mio. t. ${ }^{459}$ Die Anteile des Straßenverkehrs im Luftmessnetz „Rhein-Main“ 460 liegen für den $\mathrm{NO}_{2}$-Ausstoß bei ca. $55 \%$ der erfassten Immissionen ${ }^{461}$ (siehe Abbildung 20). ${ }^{462}$ Personen- und Güterverkehr haben deutschlandweit etwa gleiche Anteile am $\mathrm{NO}_{2}$-Ausstoß. ${ }^{463}$

Bezüglich der Feinstaubbelastung ist der Verkehrsbereich direkt nach der Industrie im Ballungsraum Frankfurt Rhein-Main ebenfalls ein bedeutender Verursacher von Feinstäuben (siehe Abbildung 21). Die Immissionsanteile des Straßenverkehrs im Luftmessnetz „Rhein-Main“ liegen für den Feinstaubausstoß bei 41\%.464 Der Immissionsanteil der Industrie bei $\mathrm{NO}_{2}$ und $\mathrm{PM}_{10}$ ist allerdings über die vergangenen Jahre deutlich zurückgegangen. ${ }^{465}$ Der Flughafen hat als Verursacher von Feinstäuben nur eine geringe Relevanz.

455 vgl. Hessisches Landesamt für Umwelt und Geologie 2006, http://atlas.umwelt.hessen.de/atlas/index-ie.html: Stickstoffdioxid (Zugriff am 4.2.2007).

456 Unter Feinstaub werden Partikel mit einer Größe bis $10 \mu \mathrm{m}$ gerechnet; Particulate Matter $10 \mu \mathrm{m}$ $\left(\mathrm{PM}_{10}\right)$. Aufgrund dieser Partikelgröße hat der Feinstaub eine vernachlässigbare Sedimentationsgeschwindigkeit und verhält sich in der Atmosphäre wie ein Gas; vgl. Hessisches Landesamt für Umwelt und Geologie 2006, http://atlas.umwelt.hessen.de/atlas/index-ie.html: Feinstaub PM10 (Zugriff am 4.2.2007).

457 vgl. Wiesbadener Kurier v. 7.3.2007

458 vgl. Hessisches Ministerium für Umwelt, ländlichen Raum und Verbraucherschutz 2002, S.33

${ }^{459}$ vgl. Statistisches Bundesamt 2006, S.57

460 Das Luftmessnetz Rhein-Main ist nicht deckungsgleich mit dem „Ballungsraum Rhein-Main“, den der Planungsverband definiert hat. So werden im Luftmessnetz Rhein-Main die für die Beeinflussung der luftklimatischen Verhältnisse wichtigen Städte Wiesbaden und Darmstadt mit berücksichtigt.

461 Unter „Emission“ wird der Prozess der Freisetzung von Stoffen verstanden, hingegen „Immission“ den Eintrag, bspw. die einwirkende Verunreinigung der Luft bezeichnet. Jeder Immission geht daher eine Emission voraus; vgl. Hessisches Landesamt für Umwelt und Geologie 2006, http://atlas.umwelt.hessen.de/atlas/index-ie.html: Luftreinhaltung (Zugriff am 4.2.2007).

${ }^{462}$ vgl. Stadt Frankfurt am Main, Umweltamt u.a. 2004, S.16

${ }^{463}$ vgl. Statistisches Bundesamt 2006, S.58

464 vgl. Stadt Frankfurt am Main, Umweltamt u.a. 2004, S.17

${ }^{465}$ vgl. Hessisches Ministerium für Umwelt, ländlichen Raum und Verbraucherschutz 2002, S.55ff 
Dagegen trägt der Flughafen Frankfurt immerhin zu 7\% an den Immissionen von $\mathrm{NO}_{2}$ im Luftmessnetz Rhein-Main bei (siehe Abbildung 20 und 21).

In der Frankfurter Innenstadt wird der Luftaustausch durch die geschlossene Straßenrandbebauung stark verschlechtert. Die Folge ist eine hohe Belastung mit Feinstaubpartikeln sowie mit Stickoxiden.

„Bereits im Jahre 2002 wurde im Gebiet des Ballungsraumes Rhein-Main der Immissionsgrenzwert für den Tag bei Stickstoffdioxid $\left(\mathrm{NO}_{2}\right)$ in Darmstadt, Frankfurt am Main und Wiesbaden sowie der Immissionsgrenzwert für den Tag für PM10 in Frankfurt am Main überschritten". ${ }^{466}$

Im Jahr 2006 wurde in Frankfurt an der vor allem mit Lkw stark befahrenen Friedberger Landstraße der EU-Grenzwert gar $55 \mathrm{Mal}$ überschritten - erlaubt sind $35 \mathrm{Mal}$. Dies macht Frankfurt zur Stadt in Hessen mit der höchsten Feinstaubbelastung. ${ }^{467}$ Vor dem Hintergrund der weiteren Verschärfung der EU-Grenzwerte für $\mathrm{NO}_{2}$ und Feinstaub ist davon auszugehen, dass es in Zukunft im Luftmessnetz Rhein-Main zu regelmäßigen Überschreitungen der Grenzwerte kommen wird. 468

In der Innenstadt von Frankfurt trägt der Verkehr zum Ausstoß von Schadstoffen etwa zur Hälfte bei. Daneben spielen der Ferneintrag, insbesondere der Industrie, zu 40\% eine Rolle. ${ }^{469}$ In bezug auf die durch Kfz-Verkehr verursachte Luftverschmutzung wird auch die Bedeutung des Autobahnknotens „Frankfurter Kreuz" ersichtlich. Die ca. 80 Autobahnkilometer rund um das Frankfurter Kreuz (A3 und A5) sind bereits für 18,1\% der $\mathrm{NO}_{2}$-Immissionen und 12,7\% der Feinstaub-Immissionen verantwortlich und tragen erheblich zur Hintergrundbelastung sowohl bei $\mathrm{NO}_{2}$ als auch bei Feinstaub bei. ${ }^{470}$

Dabei ist zu berücksichtigen, dass die Fahrzeuge mit Benzinmotoren, bei einem Anteil von ca. $80 \%$ an der Kfz-Dichte, einen Anteil bei $\mathrm{NO}_{2}$ von ca. $30 \%$ und bei Feinstaub von weniger als $0,1 \%$ an der Gesamtemissionsrate haben. Überproportional tragen dagegen private Diesel-Pkw zum $\mathrm{NO}_{2}$-Ausstoß bei, die etwa 10 Mal mehr $\mathrm{NO}_{2}$ emittieren als Pkw

\footnotetext{
466 Hessisches Ministerium für Umwelt, ländlichen Raum und Verbraucherschutz 2005, S.17

${ }^{467}$ vgl. Wiesbadener Kurier v. 7.3.2007

468 vgl. Stadt Frankfurt am Main, Umweltamt u.a. 2004, S.4

${ }^{469}$ vgl. Hessisches Ministerium für Umwelt, ländlichen Raum und Verbraucherschutz 2005, S.12

470 ebd., S.37
} 
mit Benzinmotoren. ${ }^{471}$ Schwere Lkw (Güterverkehr) und Busse (Personenverkehr) mit Dieselmotoren verursachen bei einem Anteil von ca. 4\% an der Zahl der Kfz-Bewegungen ca. 55\% der $\mathrm{NO}_{2}$-Immission und ca. 50\% der Immissionen von Feinstaub. Maßnahmen zur Minderung der Immissionsbelastung beim Kfz-Verkehr sind für $\mathrm{NO}_{2}$ und Feinstaub daher am effizientesten bei den schweren Lkw und Bussen mit Dieselmotor, soweit diese noch keinen leistungsfähigen Partikelfilter und keine funktionsfähige Vorrichtung zur $\mathrm{NO}_{2}$-Minderung haben. Allerdings gelten die verschärften Abgasnormen (Grenzwerte) zunächst nur für Neuwagen. Erste über das Ausscheiden von Altfahrzeugen erfolgt eine Senkung der mittleren Emissionswerte. Hier wirkt sich aber die erheblich gestiegene Verkehrsleistung in den letzten Jahren kontraproduktiv aus. ${ }^{472}$

Neben den Abgasen vor allem von Dieselfahrzeugen kommt auch dem Reifen-, Bremsund Straßenabrieb eine Bedeutung als Feinstaubquelle zu. Eine Studie im Auftrag des Umweltbundesamtes geht davon aus, dass der Reifenabrieb als wichtigste Quelle von "Abriebemissionen mobiler Quellen“ bis $\mathrm{zu} 4 \%$ an der gesamten Feinstaubbelastung ausmacht. 473

Luftreinhaltepläne sollen dazu beitragen, die EU-Grenzwerte vor allem von $\mathrm{NO}_{2}$ und Feinstaub langfristig und dauerhaft einzuhalten. ${ }^{474}$

\footnotetext{
${ }^{471} \mathrm{vgl}$. Umweltbundesamt 2006, S.1

472 vgl. Hessisches Ministerium für Umwelt, ländlichen Raum und Verbraucherschutz 2002, S.56

473 vgl. Umweltbundesamt 2002, S.116

474 ebd., S.13
} 
Emissionsbilanz für Stickstoffoxide (angegeben als $\mathrm{NO}_{2}$ ) im Ballungsraum Rhein-Main (Erhebungsjahr 2000)

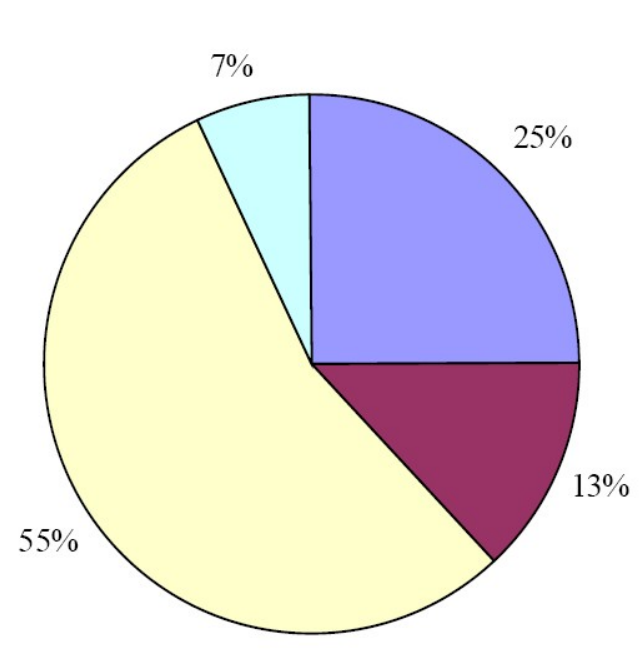

$\square$ Indus trie

$\square$ Gebäudeheizung

$\square$ Kfz-Verkehr

$\square$ Flughafen Ffm

Abbildung 20: Ursachenanalyse für Stickstoffemissionen

Quelle: Stadt Frankfurt am Main, Umweltamt u.a., S.34

Emissionsbilanz für PM10 im Ballungsraum Rhein-Main (Erhebungsjahr 2000)

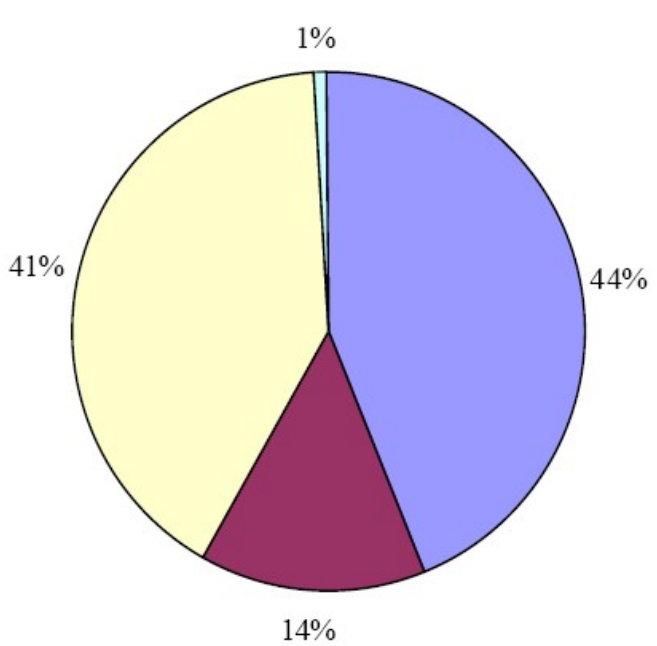

$\square$ Industrie

$\square$ Gebäudeheizung

$\square \mathrm{Kfz}$-Verkehr

$\square$ Flughafen Ffm

$14 \%$

Abbildung 21: Ursachenanalyse für Feinstaubemissionen (PM10)

Quelle: Stadt Frankfurt am Main, Umweltamt u.a., S.35 


\section{Schwefeldioxid $\left(\mathrm{SO}_{2}\right)$}

Beim $\mathrm{SO}_{2}$ konnte in den vergangenen Jahren ein deutlicher Rückgang der Immissionen um fast 90\% verzeichnet werden, wozu der Verkehrsbereich durch die Einführung schwefelarmer Treibstoffe überproportional beigetragen hat. ${ }^{475}$

In bezug auf Umweltverschmutzung sollte nicht unerwähnt bleiben, dass nicht nur die Luft, sondern auch die Gewässer und Böden durch den Verkehr belastet werden. Hauptverursacher sind hier der ständige Verlust von Treib- und Schmierstoffen sowie Streusalze. Im Bereich des Schienenverkehrs besteht außerdem eine Belastung durch den Einsatz von Pestiziden zur „Unkrautbekämpfung“. Die externen Kosten der Wasser- und Bodenbelastung lassen sich allerdings nur sehr ungenau quantifizieren. ${ }^{476}$

\subsubsection{Lärm}

Der Verkehrslärm ist eine der Hauptquellen für Belästigung und gesundheitliche Beeinträchtigungen. In Städten ist der Verkehr für etwa $80 \%$ des Lärms verantwortlich. ${ }^{477}$ Etwa die Hälfte der Bevölkerung in Deutschland wird von Straßenlärm belästigt, der das physische und psychische Wohlbefinden stört, etwa $20 \%$ von Schienenverkehrslärm. ${ }^{478} \mathrm{Im}$ Stadtverkehr wird er hauptsächlich von Motorengeräuschen verursacht. Mit zunehmender Fahrtgeschwindigkeit nehmen aber auch die Abrollgeräusche der Reifen sowie die Windgeräusche zu. ${ }^{479}$ Die Lärmausbreitung im Bereich des MIV (aber auch des schienengebundenen ÖPNV) ist von der Art der Bebauung bzw. Bepflanzung abhängig, aber auch von vorherrschenden Windrichtungen und klimatischen Verhältnissen (insbesondere Luftfeuchte).

Maßnahmen zur Lärmeindämmung sind daher vor allem bauliche Maßnahmen wie Lärmschutzwände, die aber aus finanziellen Gründen häufig nicht gebaut werden. So hat die DB AG im Rahmen ihres Lärmschutzprogramms in acht Jahren erst 360 km und damit erst ca. 10\% der beabsichtigten Strecken saniert, die bis 2020 mit Lärmschutzwänden ausgestattet werden sollten. Von daher plant die DB AG zukünftig verstärkt aktive Schutz-

\footnotetext{
475 vgl. Statistisches Bundesamt 2006, S.57ff

476 vgl. Rauschenberg 1999, Kap.2, S.11

477 vgl. Matzig 2007, S.13

478 vgl. Statistisches Bundesamt 2006, S.59

${ }^{479}$ vgl. Nuhn und Hesse 2006, S.313
} 
maßnahmen umzusetzen. So soll durch die Verwendung von Kunststoffbremsen ${ }^{480}$ im Güterverkehr die Lärmbelästigung flächendeckend um die Hälfte reduziert werden. ${ }^{481}$

Zur Eindämmung des Straßenverkehrslärms müssen entsprechend der EU-Umgebungslärmrichtlinie Städte über 250.000 Einwohner (das betrifft in der Region Frankfurt RheinMain die Städte Frankfurt mit ca. 650.000 und Wiesbaden mit 270.000 Einwohnern) bis zum 30.06.2007 „Lärmkarten“ erstellt haben. Diese sollen als Grundlage zukünftiger Zufahrtsbeschränkungen dienen. Ab 2012 gilt diese Regelung dann auch für Städte mit über 100.000 Einwohnern. ${ }^{482}$

In der Region Frankfurt Rhein-Main wird vor allem der Frankfurter Flughafen als Quelle von Lärm thematisiert. Eine Untersuchung im Auftrag des Regionalen Dialogforums 483 ergab, dass die Bewohner des Region Frankfurt Rhein-Main stärker unter Fluglärm leiden als der Durchschnitt der Bewohner Hessens und auch Deutschlands. Laut der Untersuchung werden $64 \%$ der Befragten im Rhein-Main-Gebiet durch Fluglärm gestört oder belästigt, davon $41 \%$ sogar stark bis äußerst stark. In diesem Zusammenhang wird vor allem die Beeinträchtigung der Wohnqualität bemängelt sowie die Angst vor gesundheitlichen Schädigungen geäußert. ${ }^{484}$ „Besonders die Störungen und Belästigungen in der Nacht tragen zu diesen hohen Störungswerten bei“. ${ }^{485}$ Die Studie schließt aber auch nicht aus, wenngleich sie es nicht belegen kann, dass

"die Personen mit mittlerer Fluglärmbelastung die erwartete Veränderung [zum Flughafenausbau] am stärksten als qualitative Veränderung insb. Verschlechterung ihrer Lebensumstände begreifen und daher schon jetzt (vor dem Ausbau) ein geringeres generelles Wohlbefinden in der Wohn- und Lebensqualität artikulieren als die Personen der übrigen Pegelklassen". 486

480 Gusseiserne Bremsen verursachen geriffelte Räder, die letztendlich für die Geräusche verantwortlich sind.

481 vgl. Frankfurter Rundschau vom 15.2.2007

482 vgl. Matzig 2007, S.13

${ }^{483} \mathrm{Im}$ Regionalen Dialogforum sind insgesamt 33 Verbände, Vereinigungen, Unternehmen und öffentliche Einrichtungen zusammengeschlossen, um über den Flughafenausbau gemeinsam zu beraten. Das Dialogforum hat keine Beschlussfunktion. Mitglieder sind u.a. der Fraport, Lufthansa, Kirchen, Gewerkschaften, der Hessische Städte- und Gemeindebund, der Hessische Städtetag sowie der BUND; vgl. www.dialogforum-flughafen.de

${ }^{484} \mathrm{vgl}$. Zeus 2006, S.5

485 ebd., S.26

486 ebd., S.28f 


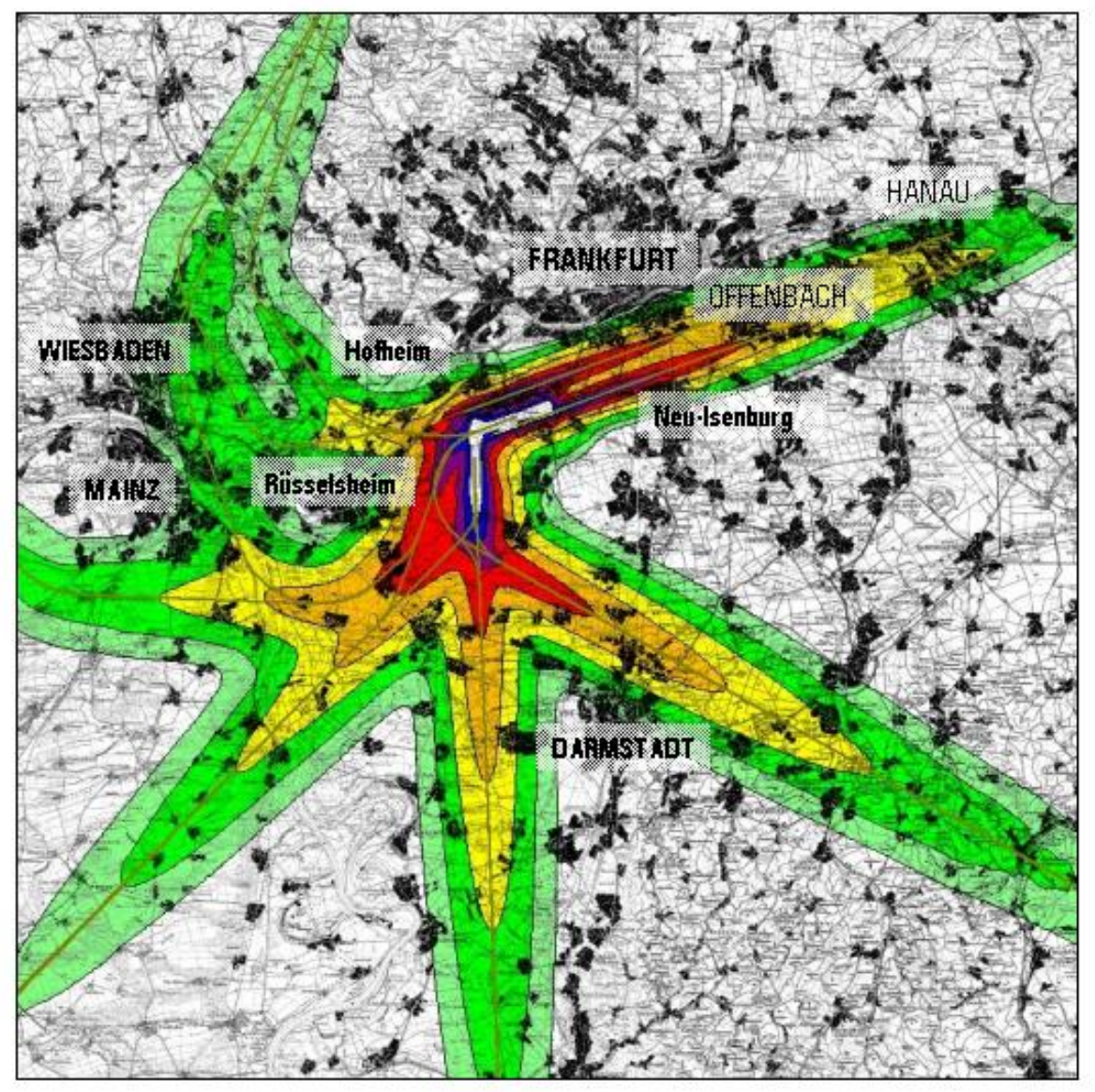

Fluglärmausbreitung am Boden durch den Flugbetrieb am Frankfurter Flughafen

bei Westbetriebsrichtung !an ca. $80 \%$ der Tage im Jahr) - tagsüber -

Karte basierend auf Flugrouten und $\mathrm{D}$ aten aus den Unterlagen des Raumordnungsverfahrens aus dem Jahr 2001.

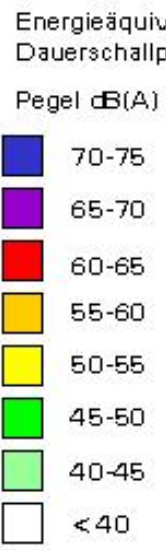

Abbildung 22: Verursachter Fluglärm durch den Flughafen Frankfurt Quelle: www.laermkarten.de/dialogforum, eigene Bearbeitung

Nach einer Studie des Umweltbundesamtes über Fluglärmwirkungen werden für die Bewertung von Fluglärmbelastungen bestimmte Qualitätsziele formuliert. So werden mit Fluglärmbelastungen (außen) von $55 \mathrm{~dB}(\mathrm{~A}) 487$ tags und $45 \mathrm{~dB}(\mathrm{~A})$ nachts die Grenzen zu erheblichen Belästigungen erreicht. Bei Fluglärmbelastungen deutlich unterhalb dieser Werte können nennenswerte Beeinträchtigungen weitgehend ausgeschlossen werden. Bei Fluglärmbelastungen (außen) oberhalb $65 \mathrm{~dB}(\mathrm{~A})$ tags und $55 \mathrm{~dB}(\mathrm{~A})$ nachts sind Gesundheitsbeeinträchtigungen in Form von Herz-Kreislauf-Erkrankungen zu erwarten. Gebiete mit diesen Belastungen sind grundsätzlich zum Wohnen ungeeignet. 488 Abbildung 22 stellt die Lärmbelastung des Umlands des Frankfurter Flughafens bei Westbetrieb am Tage dar. Ersichtlich ist, dass die An- und Abflugschneisen zwar nicht unmittelbar über

487 Die Lärmbelastung wird als „energieäquivalenter Dauerschallpegel (Leq(3)“ angegeben. Der Leq kombiniert den Schallpegel, die Dauer und die Häufigkeit von Lärmereignissen zu einer Maßzahl.

${ }^{488}$ vgl. Umweltbundesamt 2000, S.31 
die großen Städte und Siedlungen führen, es aber dennoch einige Bereiche gibt, die unmittelbarem Fluglärm ausgesetzt sind.

Insbesondere in den Ortschaften, die im Bereich der An- und Abflugkorridore liegen (z.B. Offenbach, Neu-Isenburg, Kelsterbach, Flörsheim, Raunheim), erreicht die Lärmbelastung tagsüber den kritischen Wert von $65 \mathrm{~dB}(\mathrm{~A})$.

Letztendlich muss der Flughafenausbau im Kontext der Sicherung des Wirtschaftsstandortes Frankfurt Rhein-Main betrachtet werden, zumal erhebliche volkswirtschaftliche Effekte vom Flughafen ausgehen. Die externen Kosten sind dabei soweit wie möglich zu reduzieren, beispielsweise durch aktive (z.B. Triebwerktechnik) wie auch passive Schallschutzmaßnahmen. Als Kompromiss scheint sich gegenwärtig die Empfehlung des Regionalen Dialogforums abzuzeichnen. Dieses macht die Zustimmung zum Bau einer weiteren Start- und Landebahn am Frankfurter Flughafen von der Durchsetzung eines Nachtflugverbots abhängig. ${ }^{489}$

\subsubsection{Staus}

Im Gegensatz zu den Infrastrukturkosten betreffen die Staukosten die Verkehrsteilnehmer selbst. Staukosten wirken als Zeitverlustkosten, die aus der Überbeanspruchung der Straßenverkehrswege resultieren, und führen zu höheren Fahrzeugbetriebskosten. ${ }^{490} \mathrm{Im}$ Rhein-Main-Gebiet kommt es insbesondere morgens und abends zu Zeiten des „Berufsverkehrs" dazu, dass sich die einzelnen Fahrzeuge wechselseitig blockieren und in der Konsequenz die Geschwindigkeit des Verkehrsflusses drastisch sinkt. Dies betrifft vor allem die Straßen unmittelbar um Frankfurt herum. Liegt die Pkw-Durchschnittsgeschwindigkeit im Bereich des Planungsverbands noch bei $31,1 \mathrm{~km} / \mathrm{h}$, sinkt sie in den Städten Frankfurt und Offenbach auf 29 km/h. ${ }^{491}$

Extern sind die Kosten insofern, als dass in einer stockenden Kolonne jedes Fahrzeug den Stau befördert und für alle Beteiligten den Zeitverlust vergrößert. Betroffene sind hier sowohl Pkw-Reisende als auch Bus- und Straßenbahnfahrende (sofern diese im Straßenraum verkehren). Die Staukosten bemessen sich in entgangener Arbeits- und Freizeit. Die

\footnotetext{
${ }^{489}$ vgl. Nuhn und Hesse 2006, S.314

490 vgl. Aberle 2003, S.583

491 vgl. Planungsverband Ballungsraum Frankfurt/Rhein-Main u.a. 2005, S.23
} 
Problematik verstärkt sich dadurch, dass ein Teil der (durch Unfälle verursachten) Staus nicht vorhersehbar ist. Einer Studie des Automobilkonzerns BMW AG zufolge verloren deutsche Unternehmen pro Arbeitnehmer ca. DM 6.000 jährlich aufgrund staubedingter Zeitverluste. ${ }^{492}$ Die UITP geht davon aus, dass durch Staus in der Europäischen Union „Arbeitsstunden und Produktivität im Wert von mehr als EUR 200 Mrd. verloren“ gehen. ${ }^{493}$ In besonderem Maße verschärft sich die Situation für bestimmte (Berufs-) Gruppen, die alternativlos auf den Autoverkehr angewiesen sind.

Die Auswirkung des hohen Pkw-Aufkommens sind, insbesondere zu Zeiten des Berufsverkehrs, zahllose Staus in der gesamten Region Frankfurt Rhein-Main. Die Abbildung 23 zeigt eine Karte der Verkehrszentrale Hessen, auf der eine typische Stausituation an einem Werktag rund um Frankfurt dargestellt ist. Als gestrichelte Linien sind die Staus zu erkennen, so rund um das Frankfurter Kreuz sowie auf der A5 vor dem Nordwest-Kreuz bzw. Bad Homburger Kreuz sowie auf der A66 aus Richtung Wiesbaden. Problematisch stellt sich außerdem die Verkehrslage rund um das Langenselbolder bzw. Hanauer Kreuz auf der A3 im Osten dar.

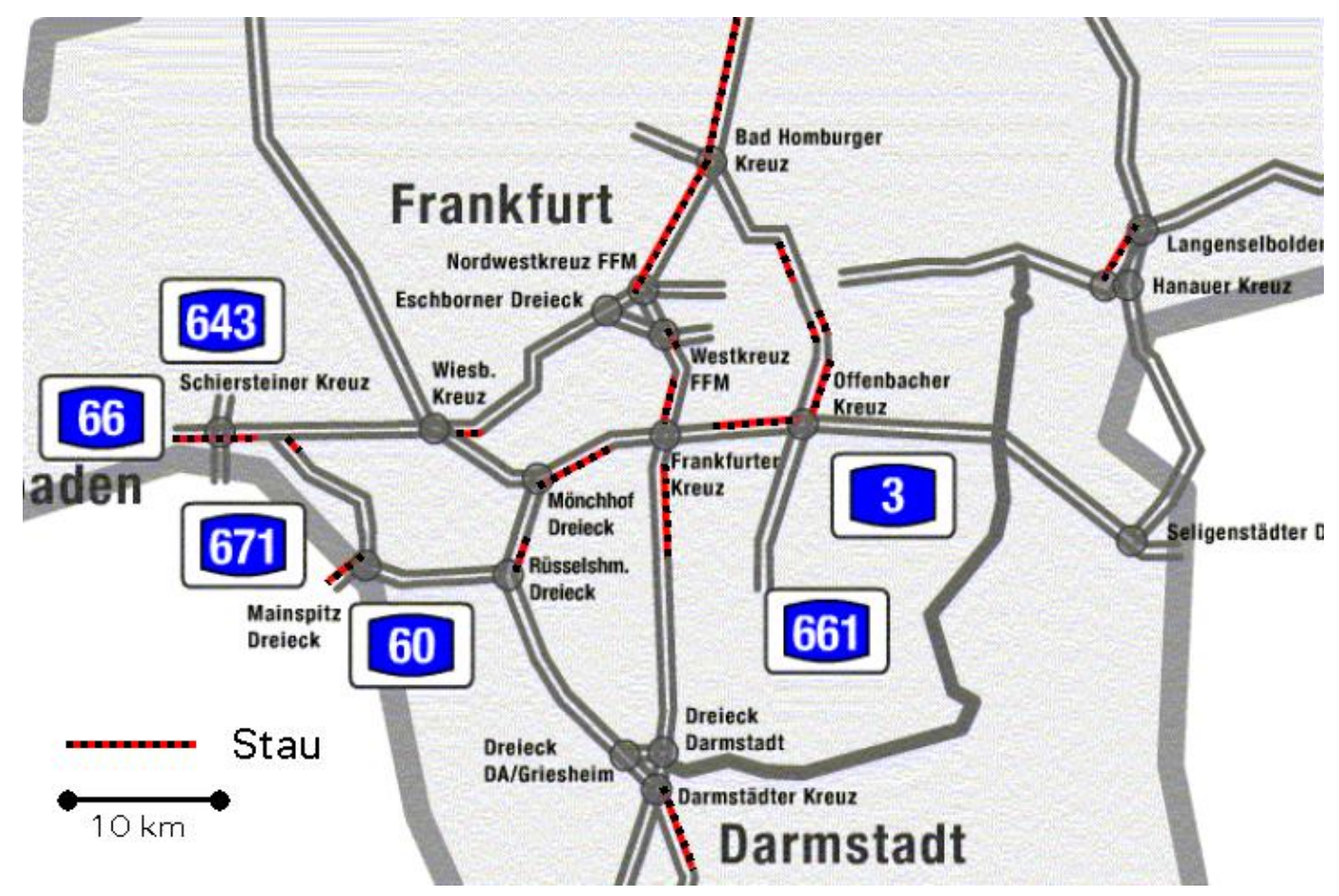

Abbildung 23: $\quad$ Typische Stausituation auf BAB im Rhein-Main-Gebiet Quelle: www.vz.hessen.de/flash/home.html

492 vgl. BMW 1997

${ }^{493}$ vgl. UITP 2005, S.19 
Das es sich bei der hier dargestellten Stausituation nicht um eine Ausnahmesituation handelt, sondern um die Regelsituation, verdeutlicht Abbildung 24. Dargestellt sind die Summenstunden auf den einzelnen Abschnitten der Bundesautobahnen für das Jahr 2003. $\mathrm{Zu}$ erkennen sind auch hier die Überbeanspruchungen der Kapazitäten auf der A5 vor dem Homburger Kreuz und Nord-West-Kreuz von Kassel kommend sowie auf der gesamten A3, insbesondere in der Nähe der Anschlussstellen rund um den Flughafen Frankfurt.

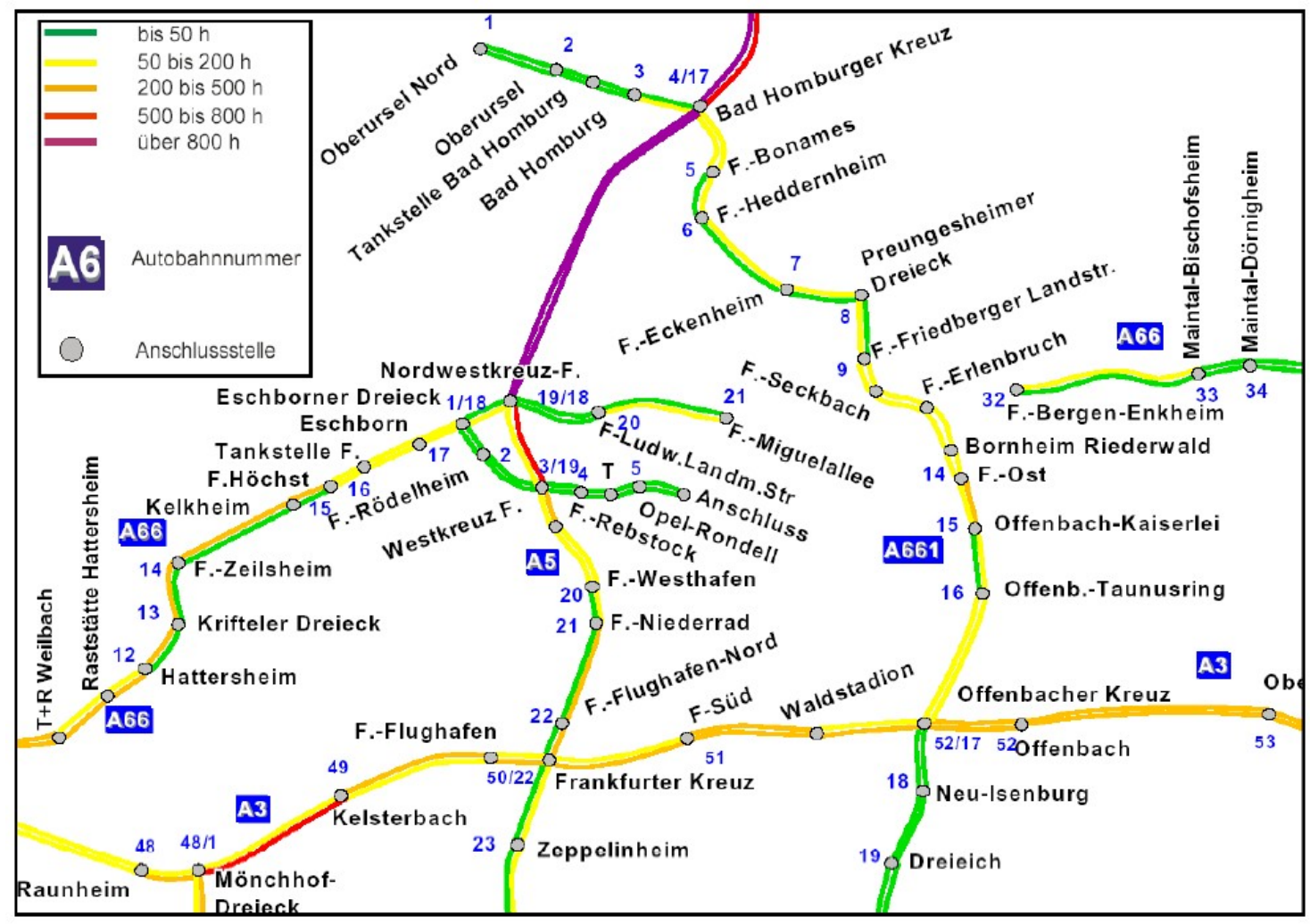

Abbildung 24: Störungsaufkommen auf BAB im Rhein-Main-Gebiet im Jahr 2003 in Stunden

Quelle: Sparmann, J. 2006, S.36

Die Ursachen für die Staus liegen vor allem im hohen Verkehrsaufkommen begründet. Zu einem Viertel führen Unfälle zu Staus (oft infolge des hohen Verkehrsaufkommens). 15\% werden durch Baustellen ausgelöst und 3\% durch Pannenfahrzeuge ${ }^{494}$ (siehe Abbildung 25).

${ }^{494}$ vgl. Sparmann, J. 2006, S.4 


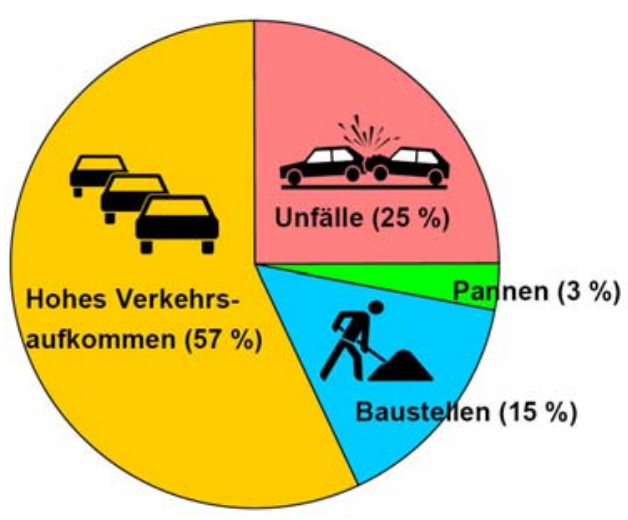

Abbildung 25: Ursachen für Staus

Quelle: Sparmann, J. 2006, S.4

$\mathrm{Zu}$ Stausituationen kommt es aber auch im Luftverkehr. „Warteschleifen wegen Verspätungen im Luftverkehr verursachen heute allein schon 6\% des Treibstoffverbrauchs im Luftverkehr" ${ }^{\text {“ }}{ }^{995}$

\subsubsection{Unfälle und Unfallfolgekosten}

Eine Vielzahl von Unfällen mit Personen- und Sachschäden zählt zu den Begleiterscheinungen intensiven Straßenverkehrs. Laut Statistischem Bundesamt gab es im Jahr 2005 bei ca. 350.000 Unfällen rund 5.300 Todesopfer und fast 440.000 Verletzte auf deutschen Straßen. ${ }^{496}$ Damit erreichen diese Zahlen ihren bislang niedrigsten Wert, denn in der Vergangenheit lagen sie noch deutlich höher: So kamen 1970 noch 17.000 Personen auf (west-) deutschen Straßen ums Leben, obwohl sich das Verkehrsaufkommen seit dem verdreifacht hat. ${ }^{497}$ In Hessen verunglückten 2005 statistisch betrachtet je 1 Million Einwohner ca. 5.500 Personen, davon 60 tödlich. Hessen liegt damit bei den Verunglückten leicht über und bei den Getöteten leicht unter dem Bundesdurchschnitt (ca. 5.300 bzw. 65). ${ }^{498}$ Dabei sind vor allem Kinder und junge Menschen besonders gefährdet: „Unfälle im Straßenverkehr sind [bei ihnen] in Europa die Haupttodesursache“. ${ }^{499} 57 \%$ der verletzten und getöteten Personen im deutschen Straßenverkehr verunglücken mit dem Pkw. 18\% mit dem Fahrrad, 12\% mit Motorrad/ Moped/ Mofa und 8\% waren als Fußgänger unterwegs. Nur

\footnotetext{
495 Statistisches Bundesamt 2006, S.48

496 vgl. Statistisches Bundesamt 2006, S.49f

497 vgl. Diez 2005, S.87

498 vgl. Statistisches Bundesamt 2006, S.53

${ }^{499}$ UITP 2005, S.18
} 
1\% der Verunglückten waren Insassen von Bussen. 500 Wer mit einem Auto unterwegs ist, trägt ein $10 \mathrm{Mal}$ höheres Risiko in einen Unfall verwickelt zu werden als ein Busbenutzer und sogar ein 20 Mal höheres Risiko als ein Bahnbenutzer. Zwei Drittel aller Unfälle geschehen in geschlossenen Ortschaften, wo der ÖPNV potenziell eine attraktive Alternative zum MIV ist. 501

$\mathrm{Zu}$ den externen Effekten des Unfallgeschehens sind die Schäden anderer Verkehrsteilnehmer und die darüber hinausgehenden Folgen für die Gesellschaft zu zählen. Die durch Unfälle verursachten volkswirtschaftlichen Folgekosten werden unterschiedlich hoch bewertet. Die Bundesanstalt für Straßenwesen bezifferte den Verlust, der sich aus Personen- und Sachschäden zusammensetzt, für das Jahr 2002 auf fast 36 Mrd. Euro. ${ }^{502}$ Dabei fließen in die Berechnung der volkswirtschaftlichen Kosten auch alle Unfallfolgekosten ein. Hierzu gehören die Reproduktionskosten (medizinische, handwerkliche, juristische, verwaltungstechnische und andere Maßnahmen, die notwendig sind, um eine "vergleichbare Situation wie vor dem Verkehrsunfall herzustellen“), Ressourcenausfallkosten (Minderung der Wertschöpfung durch den Ausfall verletzter oder getöteter Personen, Ausfall von Sachkapital) sowie humanitäre Kosten (Folgekrankheiten, physische und psychische Beeinträchtigungen der Unfallbeteiligten). ${ }^{503}$ Das Statistische Bundesamt in Wiesbaden veranschlagt die durch Straßenverkehrsunfälle verursachten volkswirtschaftlichen Kosten für das Jahr 2003 auf insgesamt 32 Mrd. Euro. ${ }^{504}$ Die jüngste Studie des EU-Weißbuches setzt den Verlust etwas niedriger an und geht europaweit von 0,5\% des Bruttoinlandsproduktes aus, was für Deutschland immer noch ca. $21 \mathrm{Mrd}$. Euro ausmachen würde.505

Ansatzpunkte der Verringerung von Unfällen sind vor allem der Ausbau der Verkehrsinfrastruktur, die Verkehrsvermeidung sowie die Verkehrsoptimierung. Insbesondere bei der Verkehrsoptimierung wird dem Einsatz von IuK-Technologien zukünftig eine große Bedeutung eingeräumt, zumal durch die Anwendung neuer Fahrzeugtechniken in Form von aktiven und passiven Sicherheitssystemen die Anzahl der Verkehrsopfer in der Vergangenheit deutlich minimiert werden konnte. Um eine weitere Reduzierung - bis hin zur Vermeidung - von Verkehrsunfällen zu erreichen, wird jedoch ein umfassendes Ver-

\footnotetext{
${ }^{500}$ vgl. Statistisches Bundesamt 2006, S.50

501 vgl. UITP 2005, S.18f

502 vgl. Aberle 2003, S.583

${ }^{503}$ vgl. Bundesanstalt für Straßenwesen 2003, S.46f

$504 \mathrm{vgl}$. Statistisches Bundesamt 2006, S.55

${ }^{505}$ vgl. Treiber 2005, S.77
} 
kehrsmanagementkonzept notwendig sein, das neben der Erhöhung der Verkehrssicherheit auch eine Verbesserung des Verkehrsflusses sowie die Steigerung der Umweltverträglichkeit verfolgt. ${ }^{506}$ Eine Verbesserung der Nutzenstiftung des ÖV für die Allgemeinheit liegt hier in einer Erhöhung der generellen Unfallsicherheit, da man mit öffentlichen Verkehrsmitteln deutlich sicherer unterwegs ist. 507

\subsubsection{Flächenverbrauch und Trennungswirkung}

Die wachsende Straßenverkehrsinfrastruktur beansprucht umfangreiche Flächen, letztere in Form von versiegelter Oberfläche für Fahrbahnen und Parkplätze. 508 Gleichzeitig zerschneiden diese Bauwerke Siedlungsstrukturen u.ä. So wird beispielsweise die Lebensqualität durch die Umwidmung von Naherholungsbereichen für Verkehrszwecke (bspw. durch den Bau einer Straße oder einer zusätzlichen Start- und Landebahn für den Frankfurter Flughafen) gemindert oder entstehen Zeitverluste für Fußgänger bei der Überquerung von Verkehrswegen. Außerdem resultieren aus der Bodenversieglung und der Trennungswirkung von Verkehrswegen negative Auswirkungen auf die Pflanzen- und Tierwelt (bspw. die Zerschneidung zusammenhängender Naturräume), die Klimaregulierung sowie das Grundwasser. Der sich hieraus ergebenden Ressourcenentwertung stehen zusätzliche Aufwendungen gegenüber. ${ }^{509}$ Hätten die 3,7 Mio. ÖPNV-Pendler, die es im Jahre 2004 in Deutschland gab, ihre Autos auf Parkplätzen abstellen wollen, hätten hierfür zusätzliche Parkplätze in der Größenordnung von 6.000 Fußballfeldern bereit gestellt werden müssen. 510

\subsection{Gegenwärtige Ansätze zur Sicherung der Mobilität}

\subsubsection{Ordnungspolitik und Verkehrsplanung}

Die Sicherung der Mobilität in der Region Frankfurt Rhein-Main kann nicht losgelöst von europäischen und bundespolitischen Vorgaben und Einflüssen betrachtet werden. Vor allem die Schaffung eines gemeinsamen europäischen Binnenmarktes 1993 und die damit einhergehende Deregulierung und Liberalisierung des Verkehrsmarktes hat zu einen um-

\footnotetext{
506 vgl. Diez 2005, S.89

507 vgl. Statistisches Bundesamt 2006, S.55

508 vgl. Umweltbundesamt 2003 (a), S.4

${ }^{509}$ vgl. Aberle 2003, S.582

${ }^{510}$ vgl. ProgTrans/HSW 2005, S.6
} 
fassenden Wandel im Verkehrsmarkt geführt. Auch zukünftig wird die Marktöffnung weiterhin großen Einfluss auf die Verkehrsentwicklung haben (die Auswirkungen auf den ÖPNV sind in Kapitel 5.1 ausführlich beschrieben). Darüber hinaus haben Beschlüsse der Steuer- und Abgabenpolitik auf Bundesebene, wie etwa die Kürzung der Pendlerpauschale, die Einführung der Maut auf Autobahnen oder die Erhöhung der Mineralölsteuer einen gewissen Einfluss auf das Verkehrsnachfrageverhalten. Auch Umweltstandards (z.B. die EU-Feinstaub-Richtlinie oder die Umgebungslärmrichtlinie) und damit im Zusammenhang stehende Fördermaßnahmen (z.B. die Bezuschussung des nachträglichen Einbaus von Rußpartikelfiltern) und ordnungspolitische Maßnahmen (z.B. Fahrzeugstandards, Tempolimits) können durchaus das Mobilitätsverhalten des Einzelnen beeinflussen. Letztendlich stellen die verkehrspolitischen Vorgaben auf europäischer Ebene und Bundesebene übergeordnete „Leitplanken für eine andere Verkehrsentwicklung“ dar, die es auf Landesebene und in den Regionen zu verwirklichen gilt.511

Diesem Planungs- und Koordinierungsauftrag entspricht die hessische Landesregierung im LEP, dem wichtigsten landespolitischen Steuerungsinstrument, in dem auch rechtsverbindliche Aussagen zur nachhaltigen Entwicklung gemacht werden. Verkehrspolitische Vorgaben ergeben sich aus der formulierten Anforderung, dass die „Siedlungsentwicklung [...] in Abstimmung mit der Verkehrsplanung dem Verlauf leistungsfähiger Einrichtungen vor allem des öffentlichen Nahverkehrs“512 zu folgen hat. Vor allem im Ballungsraum soll eine

"Reduzierung des motorisierten Individualverkehrs [...] durch Verkehrsvermeidung und verlagerung auf umweltfreundlichere Verkehrssysteme erreicht werden; Ausbau und verstärkte Inanspruchnahme des öffentlichen Personennahverkehrs sollen besonders beachtet werden", 513

mit dem Ziel, dass der ÖPNV „ein möglichst dichtes und attraktives Verkehrssystem“ bildet und seinen Anteil am Gesamtverkehrsaufkommen erhöht. ${ }^{514}$ Insbesondere die regionalen Schienenstrecken sollen das "Rückgrat des Öffentlichen Personennahverkehrs" bilden und zu einem „leistungsfähigen Netz unter Anwendung zeitgemäßer Technolo-

\footnotetext{
511 vgl. Nuhn und Hesse 2006, S.326

512 HMWVL 2000, S.9

$513 \mathrm{ebd}$.

$514 \mathrm{ebd}$.
} 
gien und optimaler Betriebsweisen ausgebaut werden“. Dies habe so zu geschehen, dass sich der ÖPNV zu einer "Alternative zum motorisierten Individualverkehr" entwickelt, sofern dies unter wirtschaftlichen Gesichtspunkten erfolgen kann, was insbesondere vom mobilisierbaren Kundenpotenzial abhängt. 515

Darüber hinaus liefert das Hess. ÖPNVG Rahmenvorgaben, wie die kommunalen Aufgabenträger die Ausgestaltung vorzunehmen haben. ${ }^{516}$ So sollen beispielsweise die ÖPNVAngebote "mit den Angeboten anderer Verkehrssysteme verknüpft werden“, ist die „Umweltverträglichkeit als besondere Stärke weiterzuentwickeln“ und der „Sozialen Bedeutung des öffentlichen Personennahverkehrs [...] besonders Rechnung zu tragen“. 517 Grundsätzlich soll es nur noch Finanzmittel für Investitionen in die Infrastruktur geben, wenn diese diskriminierungsfrei allen Verkehrunternehmen zugänglich ist. ${ }^{518}$

Verbindliche Ziele für die Verkehrsplanung für die Region sind im Generalverkehrsplan festgeschrieben, der noch vom Umlandverband Frankfurt erstellt wurde. Die dort aufgeführten Ziele sind bis 2015 festgeschrieben. Die Stadt Frankfurt erstellte parallel aber einen eigenen Gesamtverkehrsplan auf. Schwerpunkte der Verkehrsplanung dort sind infrastrukturelle Maßnahmen, wie der weitere Ausbau der zentralen Verkehrsachsen und der Bau von Ortsumgehungen. Wichtigstes Projekt zum Ausbau tangentialer Verkehrsverbindungen ist der Bau der Regionaltangente West (siehe Kapitel 4.6.2). Als „bedeutsame ,weiche' Maßnahme der Verkehrsorganisation [zählt] neben dem integrierten Taktfahrplan (ITF) die geplante Umsetzung eines regionalen Verkehrsmanagements“ (siehe Kapitel 4.6.3). Der Regionale Flächennutzungsplan des Planungsverbands Ballungsraum Frankfurt/Rhein-Main liefert hierfür die Grundlage. Zukünftig soll der regionale Gesamtverkehrsplan aber nicht vom Planungsverband - als Rechtsnachfolger des Umlandverbands - erstellt werden, sondern von der Gesellschaft für Integriertes Verkehrsmanagement (IVM, siehe 4.6.3.1). ${ }^{519}$

Zur Sicherung der Mobilität in Hessen und insbesondere in der Region Frankfurt RheinMain setzt die hessische Landesregierung vor allem auf die Optimierung der Verkehrsinfrastruktur und auf wirksame Maßnahmen des Verkehrsmanagements. So wird einerseits

\footnotetext{
515 ebd., S.33

516 ebd., S.34

517 Hessischer Landtag 2005, S.787

518 vgl. Frankfurter Rundschau v. 25.11.05

519 vgl. Stein und Wolf 2005, S.277
} 
der Schaffung guter Verkehrsanbindungen hohe Priorität eingeräumt und andererseits auf die Entwicklung und Anwendung von Lösungen aus dem Bereich der Telematik gesetzt. ${ }^{20}$ Der ehemalige Präsident des Hessischen Landesamtes für Straßen- und Verkehrswesen (HLSV), Jürg Sparmann, fasste diesen Ansatz folgendermaßen zusammen:

„Um die Standortqualität Hessens und insbesondere der Region Frankfurt RheinMain zu sichern ist es notwendig, die Erreichbarkeit des Ballungsraumes dauerhaft sicherzustellen. Darüber hinaus ist es erklärtes Ziel der Landesregierung, die Mobilität in dieser Region dauerhaft zu sichern. Um dieses Ziel zu erreichen, müssen regional wirksame Lösungen zum Ausbau der Verkehrsinfrastruktur und für das Verkehrsmanagement entwickelt werden. Gleichzeitig ist, allein schon aus Gründen der Zuständigkeit, aber auch zur Stärkung der Entwicklungsmöglichkeiten der Gestaltungsspielraum vor Ort zu erhalten“. 521

Im folgenden werden die Maßnahmen in den Bereichen Verkehrsinfrastruktur und Verkehrsmanagement näher betrachtet.

\subsubsection{Verkehrsinfrastruktur}

Seit den 1950er und 1960er Jahren, als der Motorisierungsgrad und damit die PkwNutzung drastisch anstiegen, war es ein weit verbreitetes verkehrsplanerisches Vorgehen, die Verkehrsinfrastruktur den Zuwächsen im MIV anzupassen. Vor dem Hintergrund, dass sich seit Beginn der 1970er Jahre die Verkehrsleistung des motorisierten Personenverkehrs jedoch mehr als verdoppelt hat, wird die ökonomische und ökologische Herausforderung deutlich, die Infrastruktur dem stetig wachsenden (Individual-) Verkehrsaufkommen anzugleichen. Zukünftig wird zwar mit geringeren Wachstumsraten gerechnet, aufgrund des hohen Niveaus wird das absolute Volumen zusätzlicher Verkehrsleistungen jedoch beträchtlich sein. ${ }^{522}$ Hinzu kommt, dass neben dem Verkehrswachstum insbesondere des Straßenverkehrs, die weiteren Wegelängen zunehmend zu Kapazitätsengpässen im Bereich der Infrastruktur führen. Da die heutigen Möglichkeiten für einen weiteren Ausbau der Verkehrsinfrastruktur - v.a. Verkehrsstraßen - jedoch begrenzt sind, wird es

\footnotetext{
${ }^{520} \mathrm{vgl}$. Hessische Staatskanzlei 2005 (c)

521 Sparmann, J. 2005, S.1

522 vgl. Henning und Schmid 1998, S.4
} 
gerade in den Ballungsräumen auch auf absehbare Zeit zu Problemen bei der Bewältigung des fließenden und ruhenden privaten Verkehrs kommen. ${ }^{523}$

Dies gilt auch für Hessen, wo es trotz bisheriger hoher Investitionen ${ }^{524}$ in die Verkehrsinfrastruktur infolge der Verkehrszunahme, weiterhin permanente, Stau auslösende Engpässe gibt, die zu erheblichen volkswirtschaftlichen Einbußen führen. Die Erhaltung der Leistungskapazität des Verkehrsnetzes als bedeutender Standortfaktor der Region ist daher eine entscheidende Komponente bei der Sicherung der Mobilität in der Region.525 Dem Ausbau der Verkehrsinfrastruktur wird seitens der hessischen Landesregierung und der Wirtschaftsverbände (vgl. Kapitel 3.4) daher hohe Priorität eingeräumt. Diese Position spiegelt sich auch im LEP wider, in dem die Bedeutung einer nachhaltigen Ausgestaltung der Verkehrsinfrastruktur betont wird:

„Maßgebend für die Gestaltung der Verkehrsinfrastruktur ist eine Befriedigung des Mobilitätsbedarfs der Bevölkerung sowie des Transportbedarfs der Wirtschaft in allen Regionen des Landes und ihren Teilräumen im Einklang mit ökologischen, ökonomischen und sozialen Erfordernissen". 526

Schon heute nimmt die Verkehrsinfrastruktur 7\% an der gesamten Landesfläche Hessens ein. Nur die bundesdeutschen Stadtstaaten verfügen über noch höhere Anteile.527 Von daher ist auch in Hessen eine Verlagerung der Prioritäten von Ausbaumaßnahmen hin zur Straßenerhaltung und der Sanierung von Straßenbauwerken zu erkennen sowie zu einer „intelligenteren Nutzung“ der Ressourcen. Der zuständige hessische Minister für Wirtschaft, Verkehr und Landesentwicklung, Rhiel, äußert sich diesbezüglich folgendermaßen:

\footnotetext{
${ }^{523}$ vgl. Nuhn und Hesse 2006, S.311

524 Mit allen dazugehörigen Anlagen beläuft sich der Zeitwert der Verkehrsinfrastruktur auf ca. 810 Mrd. Euro; vgl. HSVV 2005, S.12.

${ }^{525}$ Beispielhaft sei hier auf eine Erhebung unter wissensintensiven Dienstleistern aus dem Finanzbereich verwiesen, die, befragt nach der Bedeutung von Standortfaktoren für Mergers \& Acquisitions-Transaktionen (Abwicklung von Unternehmensübernahmen und Fusionen), die Verkehrsinfrastruktur mit 1,5 (nach Schulnoten) beurteilten; vgl. Lo 2001, S.144 (nach Lo, V. und Rentmeister, B.: „Wissensintensive Dienstleister: Die Stärke regionaler Cluster“. In: Industrie Management, Heft. 6/2000, Berlin 2000. S.37-41).

${ }^{526}$ HMWVL 2000, S.31

${ }^{527}$ vgl. Statistisches Bundesamt 2006, S.21
} 
"Hessens Verkehrsinfrastruktur intakt und leistungsfähig zu halten, wird nicht ausschließlich über den Neubau weiterer Verkehrswege zu leisten sein.[...] die Bestanderhaltung des vorhandenen Straßennetzes [wird] künftig in den Vordergrund unserer Aufgaben rücken". 528

Dennoch werden weitere infrastrukturelle Erschließungsmaßnahmen durch die Landesbauordnung gesetzlich gefordert und auch finanziert „und die Straßenbaulastträger [d.h. die Aufgabenträger] achten auf deren Einhaltung“. ${ }^{529}$ Im Bereich der Ausbaumaßnahmen im Straßenverkehr konzentriert sich das Land Hessen insbesondere auf Lückenschlüsse im bestehenden Verkehrsnetz, auf die Verlagerung des Verkehrs aus Ortskernen auf Umgehungsstraßen und auf die Optimierung des Verkehrs an „neuralgischen Stellen“. In der Rhein-Main-Region sind dies Ausbaumaßnahmen auf der A66 nach Fulda und zwischen Wiesbaden und Frankfurt sowie am Frankfurter Kreuz, an dem sich A3 und A5 treffen. 530

Selbst wenn die Dichte des Straßen- und Schienennetzes in Hessen als sehr gut bezeichnet werden kann, zeigt sich bei der Betrachtung des Zustandes der Bundesautobahnen sowie Bundesstraßen in Hessen, dass die physische Abnutzung der Straßen durch das hohe Verkehrsaufkommen enorm ist. Eine Untersuchung im Auftrag der Bundesregierung aus dem Jahr 2000 brachte hervor, dass nur 72,6\% der Bundesautobahnen sowie 72,7\% der Bundesstraßen in Hessen voll gebrauchsfähig sind. Mehr als ein Viertel der Straßen dieser Kategorien sind demnach nur eingeschränkt bzw. leicht eingeschränkt gebrauchsfähig. Damit liegt Hessen bei den Bundesautobahnen sogar unter dem Bundesdurchschnitt von $77,1 \%$. Das Schienennetz weist dagegen - auch bundesweit - eine vergleichsweise günstigere Modernität auf, zumal die meisten Gleisanlagen erst in den letzten 35 Jahren entstanden sind. ${ }^{531}$ Dennoch sah sich die DB AG im Frühjahr 2007 genötigt, Vorwürfe von Vertretern von Verkehrsverbänden, der Lokführergewerkschaft und Vertretern privater Eisenbahnbetreiber zurückgewiesen, sie würde das deutsche Schienennetz nicht ausreichend warten. Nach Aussagen der DB AG investiert sie jährlich etwa 1,6 Mrd. Euro, die

\footnotetext{
${ }^{528}$ vgl. HSVV 2005, S.4

${ }^{529}$ HSVV 2006 (a), S.19

$530 \mathrm{vgl}$. HSVV 2005, S.8ff

531 vgl. Puls 2004, S.8.ff
} 
für die Instandhaltung der 70.000 Kilometer Gleis, 80.000 Weichen und 25.000 Brücken notwendig sind. 532

„Im ÖPNV ist die Finanzierung von Erschließungsmaßnahmen wesentlich problematischer, weil sie anders als im MIV nicht gesetzlich gefordert wird“. ${ }^{533}$ Bauliche Maßnahmen wurden in der Vergangenheit über das Gemeindeverkehrsfinanzierungsgesetz (GVFG) finanziert, dessen Mittel aber in den letzten Jahren sukzessive abgeschmolzen wurden. ${ }^{534} \mathrm{Da}$ mit der Bereitstellung infrastruktureller Maßnahmen wie zusätzlicher Gleiskörper und Haltestellen/Bahnhöfe in der Folge auch umfangreiche Betriebskosten verbunden sind, deren Finanzierung gesondert über die Aufgabenträger sichergestellt werden muss, „unterbleiben oft sinnvolle Erschließungsmaßnahmen bzw. Angebotsverbesserungen oder finden in geringerem Umfang statt als es einem attraktiven Angebot entspricht ${ }^{\prime \prime} .535$

Im Bereich des Schienenverkehrs gehören hierzu Kapazitätserweiterungen im Bereich der S-Bahn (z.B. S-Bahn-Linie 7) oder Erweiterungen, die im Zusammenhang mit dem Bau von Fernverkehrsstrecken (v.a. Rhein-Main - Rhein-Neckar; Main-Kinzig - Fulda) stehen. Hierüber soll es zu einer Verlagerung von „wesentlichen Teilen“ des Fernverkehrs von der Riedbahn und Main-Neckar-Bahn hin zur Neubaustrecke kommen. Die freien Kapazitäten auf diesen Strecken kämen dann dem Nahverkehr zugute. „Die regionalen Schienenstrecken sollen als Rückgrat des Öffentlichen Personennahverkehrs (ÖPNV) zu einem leistungsfähigen Netz unter Verwendung zeitgemäßer Technologien und optimaler Betriebsweisen ausgebaut werden“. 536 Hierzu gehört auch das Programm „Frankfurt RheinMain plus“, das zum Ziel hat, die Leistung und Kapazität des Frankfurter Schienenverkehrsknoten durch eine Reihe unterschiedlicher Infrastrukturmaßnahmen zu erhöhen. ${ }^{537}$

Seit längerer Zeit geplant ist der Bau der Regionaltangente West, einer Tangentialverbindung, die über 68 km im Westen Frankfurts von Bad Homburg im Norden bis zum Flug-

\footnotetext{
532 vgl. www.bundestag.de/aktuell v. 21.3.2007: „Deutsche Bundesbahn: Schienennetz ist nicht , verlottert"“.

${ }^{533}$ HSVV 2006 (a), S.19

${ }^{534}$ Das GVFG, das ausschließlich die Förderung von Verkehrsmitteln (Objektfinanzierung) vorsah, wurde mittlerweile ganz abgeschafft. Damit wäre es möglich, die frei werdenden Mittel zur Förderung der Mobilitätskunden (Subjektfinanzierung) zu verwenden.

535 HSVV 2006 (a), S.20

536 LEP Hessen 2000, S.33

${ }^{537}$ vgl. Stein und Wolf 2005, S.278
} 
hafen im Süden führen soll. Dabei soll die Strecke zu zwei Dritteln auf vorhandenen Trassen geführt werden. Die hierdurch gesteigerte Attraktivität des Schienennetzes soll als zusätzlicher Entwicklungsimpuls für die gesamt Region dienen. Die Stadt Frankfurt sah in der Regionaltangente anfänglich keinen Nutzen für die Stadt und stand dem Bau zunächst ablehnend gegenüber. Da sowohl Planung als auch Prüfung nunmehr in einem fortgeschrittenen Stadium sind, ist eine Realisierung aber wahrscheinlich geworden. ${ }^{538}$ Ende Dezember 2005 hat schließlich auch die Stadtverordnetenversammlung der Stadt Frankfurt die Regionaltangente in ihren Gesamtverkehrsplan aufgenommen. ${ }^{339}$ Nun soll die etwa 360 Mio. Euro teure Verbindung bis spätesten 2019 fertig gestellt sein und täglich etwa 46.000 Fahrgäste bedienen - „davon ein Drittel als neue Kunden“. 540

Das Forschungsprojekt zur „Mobilität im suburbanen Raum“ des Bundesministeriums für Verkehr, Bau- und Wohnungswesens kritisiert, dass die Umsetzung von Infrastrukturvorhaben in der Region Frankfurt Rhein-Main „symptomatisch für eine rein reaktive Verkehrsplanung [ist], die weniger gestaltend wirkt, da sie der Siedlungsentwicklung und Verkehrsnachfrage erst mit zeitlicher Verzögerung folgt". Dies habe zum Teil damit zu tun, „dass die zunehmend dispersen Siedlungsstrukturen über Angebote des Schienenverkehrs nicht effizient bedient werden können“. ${ }^{541}$

\subsubsection{Verkehrsmanagement}

„Unter Verkehrsmanagement wird der zielgerichtete Einsatz von organisatorischen, ordnungspolitischen, betrieblichen und preispolitischen Steuerungsinstrumenten zur Optimierung des Verkehrssystems unter funktionalen und ökologischen Gesichtspunkten verstanden“. ${ }^{442}$ Wohingegen preispolitische Instrumente hauptsächlich zur Steuerung der Verkehrsnachfrage eingesetzt werden (Verkehrs-Nachfragemanagement), kommen organisatorische, ordnungspolitische und betriebliche Instrumente vor allem bei der Steuerung und Optimierung des Verkehrsablaufs zur Anwendung. Insbesondere die organisatorischen Instrumente dienen dem Ziel der intermodalen Kooperation und der Optimie-

\footnotetext{
538 ebd., S.276

539 vgl. www.planungsverband.de/index.phtml?NavID=1169.220\&La=1 (Zugriff am 10.3.2007)

540 RMV-Pressemitteilung vom 14.11.2006

541 Stein und Wolf 2005, S.281f

542 Götz 2002, S.326
} 
rung des Gesamtverkehrssystems. ${ }^{543}$ Es kann also in Instrumente unterschieden werden, die einerseits die Verkehrsnachfrage und andererseits den Verkehrsablauf steuern bzw. optimieren (siehe Abbildung 26).

Im nachfolgenden werden die Maßnahmen beschrieben, die gegenwärtig von der hessischen Landesregierung, den nachgeschalteten Verwaltungen sowie den Gebietskörperschaften teils in Kooperation mit privaten Unternehmen und Forschungseinrichtungen durchgeführt werden und den jeweiligen Bereichen des Verkehrsmanagements zugeordnet. Dabei ist zu beachten, dass sich die angewandten Instrumenten und Maßnahmen nicht immer trennscharf einem der in Abbildung 26 dargestellten Managementbereiche einordnen lassen.

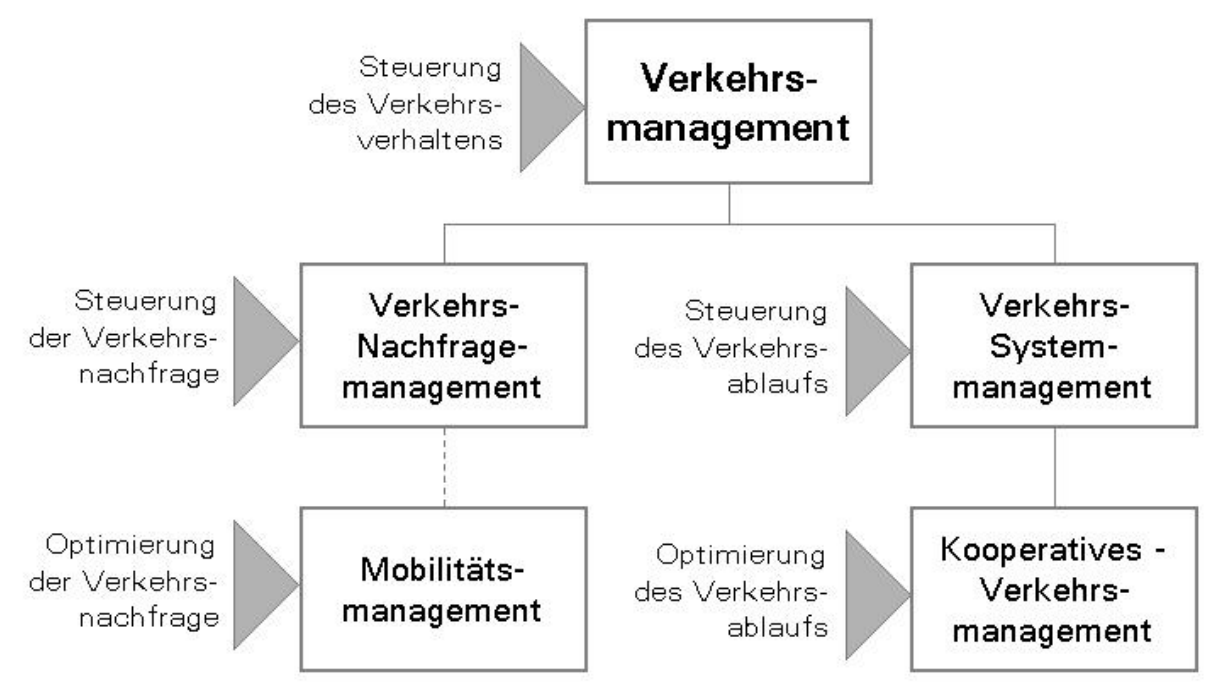

Abbildung 26: Untergliederung des Verkehrsmanagements

Quelle: nach Götz 2002, S.326; eigene Ergänzung und Bearbeitung

\subsubsection{Verkehrs-Systemmanagement}

Unter Verkehrs-Systemmanagement versteht man ein Konzept der durchgängigen Planung, Regelung und dynamischen Verkehrslenkung des Betriebsablaufs. Die hierfür eingesetzten Technologien sind u.a. Navigationssysteme, Verkehrsaktuatorik ${ }^{544}$ (z.B. infra-

${ }^{543}$ vgl. Götz 2002, S.327

${ }^{544}$ Der Begriff der „Aktuatorik“ kommt aus der Antriebstechnik. Dort setzen Aktuatoren elektronische Signale in mechanische Bewegung zur Herstellung eines Sollzustandes um und greifen so verbessernd in einen Regelkreis ein. Es wird unterschieden in fahrzeugseitige und infrastrukturelle Aktuatoren sowie in solche, die selbsttätig direkt regulieren oder eine entsprechende In- 
strukturelle Komponenten wie steuerbare Verkehrszeichen, Lichtsignalanlagen und Wechselwegweiser oder fahrzeugseitige Komponenten wie dynamische Routingsysteme), Telekommunikation, Datenbanken sowie Benutzeroberflächen. ${ }^{545}$ Die zum Einsatz kommenden Strategien unterscheiden sich dabei je nach Verkehrträger deutlich voneinander. Prinzipiell geht es um die Steuerung des Verkehrsflusses vor Ort und somit um einen Eingriff in den Verkehrsablauf, basierend auf einer übergeordneten Planung. Im MIV aber auch im Flugverkehr - kommen eher verkehrsspezifische technische Komponenten zum Einsatz (Planungsinstrumente, Navigation, Aktuatorik), hingegen im ÖPNV die Technologien (z.B. Dynamische Fahrgastinformation, elektronische Fahrplanauskünfte) eher unterstützenden Charakter haben sollen. ${ }^{546}$

\subsection{MIV}

Im Bereich des MIV kommen in Hessen vor allem Verkehrsmanagement-Maßnahmen aus dem Bereich der Verkehrstelematik zum Einsatz. Die Grundlage einer zielgerichteten Verkehrsbeeinflussung ist die automatische Erfassung der Verkehrslagen und kritischen Verkehrssituationen. Traditionell kommen zur Datenerfassung in der Fahrbahndecke eingelassene Induktionsschleifen zum Einsatz. Über diese Sensoren erfolgt im Stadtverkehr die Verkehrsbeeinflussung über die verkehrsabhängige Ampelsteuerung, teilweise auch mit Vorrangschaltung für den ÖPNV. ${ }^{547}$ Das Stadtgebiet von Frankfurt wird ringförmig von „Pförtnerlichtsignalanlagen“ umgeben, über die der Verkehrsfluss in das Stadtgebiet dosiert wird. Im Rahmen des "Aktionsplans Frankfurt am Main 2005“548 des Hessischen Ministerium für Umwelt, ländlichen Raum und Verbraucherschutz, der vorwiegend kurz- und mittelfristige Maßnahmen zur Reduzierung der Feinstaubbelastung beinhaltet, wird an der Abfahrt der A661 zur Friedberger Landstraße versucht, über eine weitere Reduzierung (bis 10\%) des Zuflusse eine großräumige Entlastung des nordöstlichen Innenstadtbereichs herbeizuführen. Inwieweit es hierdurch zu Verkehrsverlagerungen - und damit

formation - z.B. an einen Fahrer - weitergeben, der die Reglung indirekt ausführt; vgl. Beyer 2005, S.115.

545 ebd., S.108

546 ebd., S.112

547 vgl. Busch, Keller und Kessler 2004, S.458

548 Der „Aktionsplan Frankfurt am Main 2005“ sieht auch die Beteiligung der Öffentlichkeit vor, allerdings nur in der Form, als dass „interessierte Dritte Anregungen und Bedenken bei der zuständigen Behörde geltend machen“ können (vgl. Hessisches Ministerium für Umwelt, ländlichen Raum und Verbraucherschutz 2005, S.5). Von daher handelt es sich nicht um einen Ansatz des kooperativen Verkehrsmanagements, sondern aufgrund der restriktiven ordnungspolitischen Maßnahmen um einen des Verkehrs-Nachfragemanagements. 
verstärkt zu Störungen anderenorts - kommt, soll von der Straßenverkehrsbehörde genau verfolgt werden. Insgesamt sollen die Maßnahmen des Aktionsplanes zu einer Reduzierung der Feinstaubbelastung im Innenstadtbereich um ca. 17\% führen. Alleine das Fahrverbot für Lkw auf der Friedberger Landstraße soll hierzu mit 9\% beitragen. 549

Weit verbreitet auf hessischen Autobahnen sind Wechselverkehrszeichen, über die fahrstreifenbezogene, verkehrsregelnde Gebote (z.B. Geschwindigkeitsbeschränkungen, Überholverbote) vermittelt werden. Dabei werden die Verkehrs- und Umfelddaten (z.B. Verkehrsaufkommen, Witterungsverhältnisse) aus dem unmittelbaren Nahbereich herangezogen. Auf der A5 bei Friedberg wird beispielsweise die Zufahrt zur Autobahn über eine verkehrsabhängige Ampel geregelt, die nur dann Fahrzeuge auf die Autobahn auffahren lässt, wenn die Sensoren einen vorübergehend abgeschwächten Verkehrsfluss feststellen.

Gegenwärtig wird im Rahmen des Projektes „DIANA“ (Dynamic Information And Navigation Assistance) an der Erweiterung der Datenquellen gearbeitet. So sollen zukünftig Verkehrsinformationen aus unterschiedlichen Quellen zusammenfließen, beispielsweise aus der Verkehrszentrale Hessen (VZH), der Landesmeldestelle der Polizei, vom ADAC, oder auch aus dem fließenden Verkehr - als sogenannte Floating Car Data (FCD). Dabei werden die aktuellen Reisegeschwindigkeiten und die Positionen von Autos über Mobilfunktelefone in ein Hintergrundsystem weitergeleitet und dort zu einer Gesamtverkehrslage verdichtet. Auf Basis dieser „kollektiven Intelligenz“ kann dann einerseits über eine Verkehrszentrale über unterschiedliche Instrumente regelnd und steuernd in den Verkehr eingegriffen werden. Andererseits bieten sich durch FCD in der Zukunft Möglichkeiten der Umsetzung von lokalen Selbstregelungskonzepten. So kann beispielsweise eine adaptive und autonome Steuerung von Straßennetzen erfolgen, indem Verkehrsdaten, die über bordautonome Systeme ermittelt wurden, von Fahrzeug zu Fahrzeug weitergegeben werden. ${ }^{550}$ Dieser Ansatz wird im Projekt DIAMANT551 verfolgt, wo es zunächst einen bidirektionalen Informationsaustausch zwischen Fahrzeugen im Straßenverkehr gibt, beispielsweise zur Steuerungsempfehlung an Fahrerassistenzsysteme (z.B. elektronisches Stabilitätsprogramm). Über diese gezielte Verteilung von Informationen ist vor allem eine

\footnotetext{
549 vgl. Hessisches Ministerium für Umwelt, ländlichen Raum und Verbraucherschutz 2005, S.27ff

550 vgl. Treiber 2005, S.82f

${ }^{551}$ Dynamische Informationen und Anwendungen zur Mobilitätssicherung mit Adaptiven Netzwerken und Telematik-Infrastruktur
} 
zeitnahe Warnung der unmittelbar betroffenen Verkehrsteilnehmer möglich. Darüber hinaus können die Informationen auch an eine Verkehrszentrale zur allgemeinen Informationsvermittlung weitergeleitet werden. 552

Die Umlenkung von Verkehrsströmen geschieht an Autobahnen mit hoher Verkehrsbelastung über Wechselwegweiser, bei denen die Ziele der Wegweisung über Drehprismen dynamisch der Verkehrssituation angepasst werden können. Im Zuge der Austragung der Fußballweltmeisterschaft 2006 wurde eigens eine Netzbeeinflussungsanlage (NBA) im Frankfurter Süden in Betrieb genommen. Sie besteht aus 27 Wechselwegweisern, die zusätzlich zu den Drehprismen auch über variable Textanzeigen verfügen. Seit April 2005 sind erstmalig in Deutschland auch vier „dynamische Wegweiser mit integrierten Stauinformationen (dWiSta)" am Wiesbadener Autobahnkreuz (A3/A66) in Betrieb. Sie informieren die Autofahrer über die Verkehrlage in Form von Staulängen und damit verbundenen möglichen Reisezeitverlusten sowie Alternativrouten.

Eine weitere Maßnahme zur Verkehrsbeeinflussung ist die temporäre Freigabe des Seitenstreifens („Pannenstreifens“) auf der A3 und A5. Sie soll eine situationsgerechte Kapazitätssteigerung von Streckenabschnitten auf den Autobahnen gewährleisten. Die Steuerung erfolgt dabei durch eine Videoüberwachung, über die geprüft wird, ob die Seitenstreifen frei von Pannenfahrzeugen oder sonstigen Hindernissen sind. 553

Sowohl die Wechselwegweiser wie auch die dynamischen Informationstafeln und die temporäre Seitenstreifenfreigabe werden durch die Verkehrszentrale Hessen (VZH) betrieben bzw. organisiert, einer operativen Einheit der Hessischen Straßen- und Verkehrsverwaltung (HSVV). Die VZH ist für die Verkehrsbeeinflussung auf Autobahnen zuständig, mit dem Ziel der Bewältigung von Verkehrsstörungen im Rahmen von Unfällen, Baustellen, Veranstaltungen und periodischen Überlastungen. ${ }^{554}$

Einen der VZH vergleichbaren Ansatz auf lokaler Ebene gibt es in Frankfurt mit der Integrierten Gesamtverkehrs-Leitzentrale (IGLZ), deren Träger die Straßenverkehrsbehörde der Stadt Frankfurt am Main ist. Auch hier sollen verkehrsrelevante Daten des MIV und ÖPNV zusammengeführt werden, um auf der Basis von Verkehrsmanagementstrategien

\footnotetext{
552 vgl. Adam Opel GmbH und Hessische Staatskanzlei 2006, S.11

553 vgl. www.hsvv.hessen.de - Verkehrstelematik sowie HSVV 2005, S.18f

${ }^{554}$ vgl. HSVV o.J., S.2
} 
den Verkehrsfluss auf Frankfurter Straßen über die Steuerung von Ampeln, Wechselverkehrszeichen und Informationstafeln zu beeinflussen, u.a. bei Großveranstaltungen (z.B. Messen und Veranstaltungen in der "Commerzbank-Arena“, dem Frankfurter Sportstadion). Im Rahmen der Erstellung eines Gesamtverkehrslageberichts sowie der Durchführung unterschiedlicher geplanter Maßnahmen ist auch der Datenaustausch mit regional operierenden Organisationen vorgesehen, u.a. mit der RMV GmbH, der Verkehrsgesellschaft Frankfurt am Main (VGF) und der VZH. Alle Verkehrsinformationen sollen zukünftig über das Portal www.mainziel.de abrufbar sein. 555

Die hessische Landesregierung in Form des Hessischen Ministeriums für Wirtschaft, Verkehr und Landesentwicklung (HMWVL) ist der Ansicht, dass für eine nachhaltige Mobilitätssicherung eine deutliche Weiterentwicklung der VZH als „Telematikkeimzelle“ 556 notwendig ist:

„Um die Mobilität trotz der bestehenden Verkehrsprobleme und unter Berücksichtigung prognostizierter Verkehrszuwächse nachhaltig sichern zu können, [...] wird das Aufgabenund Leistungsspektrum der Verkehrszentrale Hessen inhaltlich, räumlich und organisatorisch deutlich erweitert werden müssen; integrierte Lösungen werden in den Vordergrund rücken". 557

So soll etwa ein „Intermodaler/Interregionaler Strategie Manager“ dabei helfen, die jeweils probate und aus Sicht der Beteiligten geeignete Strategie auszuwählen und lokal vor Ort umzusetzen. Dabei wird von einem „dezentralen Koordinierungsansatz“ ausgegangen, der

"gewährleistet, dass Zuständigkeiten weitestgehend erhalten bleiben, weil jeder beteiligte Partner für die Problemerkennung und Aktivierung von Strategien in seinem Verantwortungsbereich zuständig bleibt". 558

Bislang steht aber die Generierung von Daten ${ }^{559}$ aus dem MIV und somit eine Gesamtausrichtung auf das Verkehrssystem „Straße“ im Vordergrund, mit dem Ziel, den Verkehrsfluss auf den Autobahnen zu optimieren. 560

\footnotetext{
${ }^{555} \mathrm{vgl}$. Allekotte 2004, S.2ff

556 vgl. HSVV o.J., S.3

557 HSVV o.J., S.2f

558 ebd., S.6f
} 
Die hessische Landesregierung selbst sieht ihre vornehmliche Aufgabe beim Aufbau von Telematiksystemen in der „Wahrnehmung hoheitlicher Aufgaben und gesetzlicher Verpflichtungen“. ${ }^{561}$ In der öffentlich-privaten Zusammenarbeit im Bereich telematikgestützter Dienstleistungen wird daher der Schwerpunkt auf die Schaffung der notwendigen Rahmenbedingungen gelegt, die für die Entwicklung privater Dienstleistungen notwendig sind. Einen derartigen Rahmen stellt die Initiative "Staufreies Hessen 2015“ dar, welche von der Hessischen Staatskanzlei ins Leben gerufen wurde und für die die Landesregierung über 2 Mio. Euro in 3 Jahren bereit stellt. ${ }^{662}$ Bei der Vorstellung der Initiative am 21. April 2005 verwies der hessische Ministerpräsident Roland Koch nicht nur darauf, dass die vergeudete Zeit im Stau weder volkswirtschaftlich noch individuell hinnehmbar sei, sondern wies auch auf das wirtschaftliche Potenzial hin, dass in der technischen und organisatorischen Bewältigung dieser Problematiken stecke. Der wirtschaftliche Nutzen käme hierbei vor allem der Automobil-, IT- und Telekommunikationsbranche zugute. ${ }^{563}$ So soll in den kommenden Jahren all das realisiert werden, "was heute technisch möglich ist“. Die Initiative „Staufreies Hessen 2015“ orientiert sich somit vor allem am technisch Machbaren: „Ziel ist es, mit moderner Technik Lösungen gegen den Stau zu finden“. Das Verkehrsaufkommen wird dabei eher als Herausforderung für „einen Härtetest für moderne Technologie“ verstanden. ${ }^{564}$ Koordiniert wird die Initiative aus einer „Expertengruppe aus Ingenieuren, Wissenschaftlern und Verkehrsspezialisten“, die an Lösungsstrategien zur Harmonisierung des Verkehrsflusses auf den hessischen Straßen arbeiten, um die Infrastruktur leistungsfähig zu halten. ${ }^{565}$

Die Ansätze der Initiative „Staufreies Hessen 2015“ berücksichtigen sowohl übergeordnete Steuerungsmaßnahmen, wie auch Entwicklungen aus dem Bereich der Fahrzeugsicherheit. Letztere sollen vor allem zur Verbesserung der Sicherheit auf hessischen Straßen und zur Verringerung von Unfällen beitragen. Diesem Verständnis nach entsteht Sicherheit

\footnotetext{
${ }^{559}$ Hier stellt sich die Frage, ob alle Dienstleistungen, die auf diesen Daten basieren, von der VZH selbst angeboten werden müssen. Zumal diese Daten mit öffentlichen Mitteln erhoben wurden und die gleichberechtigte Weitergabe dieser Informationen an andere Institutionen - auch zur kommerziellen Nutzung - selbstverständlich sein sollte; vgl. Beckers u.a. 2001, S.12f, am Beispiel der Verkehrsmanagementzentrale Berlin.

560 ebd., S.13

561 vgl. Hessischer Landtag 2002, S.16

562 vgl. Hessische Staatskanzlei 2005 (c), S.8

563 vgl. Hessischer Landtag 2005, S.5f

564 vgl. www.staufreieshessen2015.de/3_1_0.html (Zugriff am 7.1.2007)

565 vgl. Hessischer Landtag 2005, S.5f
} 
aus dem optimierten Zusammenspiel von aktiven und passiven Maßnahmen, die zur besseren Abstimmung von Fahrzeug, Fahrer, Umfeld und Infrastruktur beitragen. Ziel sind sich selbst organisierende, lokal begrenzte Kommunikationsnetze, in denen sicherheitsrelevante Daten an unmittelbar betroffene Fahrzeuge weitergeleitet werden. Waren es bislang aktive Fahrerassistenzsysteme, wie zum Beispiel Antiblockiersysteme und elektronische Stabilisierungsprogramme, die dazu beitrugen, das Auto in kritischen Situationen besser beherrschbar zu machen, werden zukünftig beispielsweise „Blind Spot Detection“ (Fahrerinformation über Objekte im toten Winkel), „Lane Departure Warning“ (Warnung vor unbeabsichtigtem Spurwechsel), „Adaptive Cruise Control“ (automatische Abstandsregelung zum vorausfahrenden Fahrzeug) oder „Night Vision“ (Verbesserung der Nachtsicht) dazu führen, dass die Wahrnehmung - und Vorwarnung - des Fahrers verbessert wird. Grundlage hierfür ist eine verbesserte Informationsverarbeitung und Datenkommunikation zwischen Fahrzeug(en) und Infrastruktur (z.B. externe Sensoren oder Baken). Dieses setzt allerdings verbindliche und einheitliche Standards voraus. So sollen Unfälle reduziert und eine Verflüssigung des Verkehrs erreicht werden, wodurch die Gesamteffizienz bei gleichzeitiger Reduzierung der negativen Umwelteinflüsse erhöht werden soll. 566

Die kollektive Verkehrsbeeinflussung beruht dagegen im wesentlichen auf der Generierung von Information über die Verkehrszustände, der Verarbeitung dieser Information, dem Ableiten von Handlungsempfehlungen sowie die Übermittlung dieser Empfehlungen an die Verkehrsteilnehmer (zum Zeitpunkt der Nutzung, also vor Ort). Im Rahmen dieser Handlungsstrategien ist auch vorgesehen, dass bei Verkehrsengpässen ein Umstieg auf den ÖPNV vorgeschlagen wird, indem beispielsweise über Anzeigetafeln (später auch im Fahrzeug) Abfahrtszeiten und Fahrtdauer mit öffentlichen Verkehrsmitteln - beispielsweise in die Innenstadt - angezeigt und die Autofahrer auf Park-and-Ride-Plätze umgelenkt werden.

Bislang 567 liegen Konzepte bzw. Ideenskizzen für die dynamische Verkehrsführung im MIV vor, für die Verbesserung der Fahrzeug- und Straßensicherheit, für ein verbessertes Baustellenmanagement, für die verbesserte Fahrzeugauslastung und für die Regulierung über die Beeinflussung von Lichtsignalanlagen. Insofern versammelt die Initiative „Stau-

566 vgl. Diez 2005, S.93f

567 Dezember 2006 
freies Hessen 2015“ vor allem Maßnahmen aus dem Verkehrs-Systemmanagement im Bereich des MIV. Unpopuläre restriktive ordnungs- und preispolitische Maßnahmen des Verkehrs-Nachfragemanagements kommen nicht zum Einsatz. Auch spielen verkehrsträgerübergreifende Ansätze bisher kaum eine Rolle. Im Prinzip geht es um die Kapazitätsausweitung der vorhandenen Straßeninfrastruktur. Der erste verkehrsträgerübergreifende Ansatz ist die Entwicklung eines mobilen „Kommunikations- und OrientierungsExperten“ (COX), im Rahmen dessen ein Mobilfunkgerät zur Verkehrslageerfassung und als „Lotse für Fußgänger, Autofahrer oder ÖPNV-Benutzer“ 568 eingesetzt werden soll.

Hervorzuheben ist in dieser Initiative die direkte Einbeziehung von privaten Unternehmen, die den Charakter einer lose gekoppelten Netzwerkbeziehung aufweist. Das Land als Initiator und Schirmherr versteht sich dabei eher in der Moderatorenrolle. Ob allerdings die Rollen des Landes als Initiator und Schirmherr sowie der IVM (s.u.) als Moderator ausreichen, um zu einem verkehrsträger- und zuständigkeitsübergreifenden Schulterschluss zwischen Industrie und öffentlicher Verwaltung zu gelangen, der sich in gemeinsamen Beschlüssen und Maßnahmen niederschlägt, kann erst nach Abschluss der Initiative eingeschätzt werden. ${ }^{569}$

\subsubsection{2 ÖPNV}

Im ÖPNV wird technischen Maßnahmen zur Verbesserung der Antriebs- und Steuerungstechnik traditionell große Beachtung geschenkt. Insbesondere im Bereich der Antriebstechnik konnten in den letzten Jahren große Fortschritte bei der Verbreiterung der Energiebasis bei gleichzeitiger Reduzierung von Lärm und Schadstoffausstoß erzielt werden. Im Bereich des Straßenverkehrs ist hier vor allem die Ausrüstung von Bussen mit Rußpartikelfiltern erwähnenswert. Dadurch wird die Menge ausgestoßenen $\mathrm{NO}_{2}$ zwar nur um 10\% verringert, die Menge des freigesetzten Feinstaubs verringert sich aber um 90\%. In der Stadt Frankfurt wird mittlerweile bei allen ausgeschriebenen Buslinien die Standard Euro 3-Norm vorgeschrieben, die den Einsatz hochwertiger Rußpartikelfilter verlangt. 570 Der Einsatz von erdgasbetriebenen Fahrzeugen ist zur Zeit noch aufgrund der hohen Kosten für die eingebauten Gashochdrucktanks problematisch. ${ }^{571}$ Durch eine An-

\footnotetext{
568 Adam Opel GmbH und Hessische Staatskanzlei 2006, S.10

569 vgl. Klumpp 2005, S.150

570 vgl. Hessisches Ministerium für Umwelt, ländlichen Raum und Verbraucherschutz 2005, S.28f

${ }^{571}$ vgl. Hertel 2000, S.135
} 
schubfinanzierung durch das Bundesministerium für Umwelt, Naturschutz und Reaktorsicherheit soll die Anschaffung von erdgasbetriebenen Fahrzeugen zukünftig jedoch erleichtert werden. In diesem Zusammenhang wurden mit dem örtlichen Energieversorger in Frankfurt bereits Gespräche über die weitere Einrichtung von Erdgastankstellen im Stadtgebiet geführt. Schon heute gehört das Erdgastankstellennetz im Rhein-Main-Gebiet zu den dichtesten in ganz Deutschland. ${ }^{572}$ Andere Antriebstechniken, wie die Wasserstofftechnologie oder die Wasserstoff-Brennstoffzelle stecken noch in der Entwicklung. ${ }^{573}$ Bei der teilweise kostenintensiven Ausrüstung von Bussen mit neuen Antriebstechniken ist allerdings zu berücksichtigen, dass der Anteil von Bussen am Fahrzeuggesamtaufkommen und damit auch am Feinstaub- und Schadstoffausstoß - vergleichsweise gering ist. Insgesamt sind die neuen Antriebstechniken für die Zukunft zwar von großer Bedeutung, „doch ist es unwahrscheinlich, dass sie im Verkehrssektor kurz- und mittelfristig größere Veränderungen herbeiführen werden“. 574

Als kurzfristige ergänzende und kostengünstige Maßnahmen sind daher auch Fahrertrainings zur energiesparenden Fahrweise geeignet575, die auch für das Fahrpersonal von Schienenfahrzeugen von Interesse sind. So arbeitet auch die DB AG zur Zeit an der Verbesserung der energiesparenden Fahrweise. Dabei werden die Positionen der Züge mittels GPS bestimmt und gegen den Soll-Fahrplan abgeglichen. Über die so erfolgte Koordinierung von Betrieb und Fahrplan können Fahrzeitreserven besser ausgenutzt werden und der Energiebedarf der Züge durch frühzeitiges Ausrollen gesenkt werden. ${ }^{576}$

Vergleichbare Telematik-Maßnahmen zur Optimierung des ÖPNV-Betriebs kommen traditionellerweise in den Bereichen der Leit- und Sicherungstechnik, in der Fahrzeug- und Fahrerdisposition sowie im Betriebshofmanagement zum Einsatz. Jüngere Optimierungsansätze existieren im Bereich der Fahrgastinformation und bei der Beschaffung (von Fahrzeugen über Ersatzteile bis zum Büromaterial). Bei allen Lösungen spielt die Datenverarbeitung und -übertragung eine wesentliche Rolle. Neben den bekannten drahtgebundenen Lösungen (z.B. Integriertes Bord-Informations-System, IBIS) gewinnt die drahtlose

\footnotetext{
572 vgl. Hessisches Ministerium für Umwelt, ländlichen Raum und Verbraucherschutz 2005, S.29

573 vgl. Hertel 2000, S.135

574 UITP 2005, S.16

575 Fahrertrainings zur verbrauchsarmen Fahrweise sind grundsätzlich auch eine geeignete Maßnahme im MIV, doch lassen sich diese kaum verordnen, allenfalls finanzielle Anreize zur Teilnahmen schaffen.

${ }^{576}$ vgl. Beyer 2005, S.121
} 
Kommunikation mehr und mehr an Bedeutung, zumal über sie auch der Datenaustausch zwischen sich bewegenden Fahrzeugen und stationären Einrichtungen sichergestellt wird. Im Bereich von Betriebsanlagen ist dies die kostengünstige Wireless-LANAnbindung (WLAN), bei weiteren Entfernungen der (digitale) Bündelfunk und die Übertragung per GSM/GPRS. Aufbauend auf dieser drahtlosen Kommunikation kommen so eigene Telematiklösungen, wie beispielsweise ein „Intermodale Transport Control System" (ITCS; bisher rechnergestütztes Betriebsleitsystem, RBL) oder die Beeinflussung von Verkehrsampeln zugunsten des ÖPNV zur Anwendung, über die eine Beschleunigung von Fahrtzeiten erreicht werden kann. Das ITCS/RBL ist hier von besonderem Interesse, da es erst die Information für weiterführende Lösungen liefert. So ist etwa die Ortung von Fahrzeugen und der Vergleich von Soll- und Ist-Fahrplandaten sowie die Interpretation und Weiterleitung an entsprechende Informationssysteme die Grundlage für die dynamische Fahrgastinformation. Dabei können diese Informationen kollektiv über Informationstafeln/Internet oder individuell über Mobilfunktelefone bereitgestellt werden (z.B. IstFahrplan-Daten per SMS auf das Mobilfunkgerät). Überhaupt soll das Mobilfunkgerät zu einer grundsätzlichen Verbesserung der Kommunikation zwischen Kunde und Verkehrsunternehmen genutzt werden, wodurch vor allem flexible Bedienformen an Attraktivität gewinnen sollen (z.B. Anruf-Sammeltaxi oder Car-Sharing). 577

Für den ÖPNV muss betont werden, dass Betriebsleitsysteme bislang fast nur in Ballungsräumen zu finden sind (z.B. in Frankfurt, Offenbach und Wiesbaden) und auch dort die operativen Komponenten oftmals weiter entwickelt sind, als die Komponenten zur Informationsbereitstellung und Maßnahmenableitung (z.B. dynamische Fahrgastinformation und Anschlusssicherung). Dies wiederum mag weniger an der technischen Reife der Systeme liegen, als vielmehr an der fehlenden Kooperation zwischen den Verkehrsunternehmen - und erst recht zwischen den unterschiedlichen Verkehrsträgern. Eine zentrale Steuerung von lokalen Betriebsnetzen brächte hier enorme Vorteile, beispielsweise bei der Anschlusssicherung oder im Störfallmanagement. Gleichzeitig wäre sichergestellt, dass durch dezentral eingesetzte Telematik und lokaler Informationsbasen die Entscheidungskompetenz vor Ort gestärkt würde. 578 Insofern tragen Lösungsansätze aus dem Bereich der Telematik, die in der ÖPNV-Branche gerne als Beweis für vorhandenen Innovations-

\footnotetext{
577 vgl. VDV 2001, S.18ff

578 vgl. Wissenschaftlicher Beirat beim Bundesminister für Verkehr, Bau und Wohnungswesen 2003, S.602
} 
willen präsentiert werden, dann zur verbesserten Effizienz des ÖPNV bei, wenn sie in einem übergeordneten strategischen Ansatz eingebettet sind, der auch die organisatorischen, finanziellen und rechtlichen Möglichkeiten ausschöpft.

Im Hinblick auf eine verkehrsträgerübergreifende Zusammenarbeit im Bereich des Verkehrs-Systemmanagements lässt sich zusammenfassend sagen, dass bislang die Datenund Informationsgewinnung noch im Vordergrund steht. Sowohl die Datenbasen wie auch die Prozesskenntnisse sind noch nicht ausreichend für eine effektive Umsetzung von verkehrsträgerübergreifenden Maßnahen und Angeboten entwickelt. Auch fehlt es immer noch an Daten über die Akzeptanz und die Sensitivität von Maßnahmen zur Beeinflussung des Verkehrsverhaltens sowie an Interaktionsmöglichkeiten mit den Verkehrsteilnehmern respektive Kunden. Für einen integrativen bzw. intermodalen Ansatz sind hierzu enge organisatorische Abstimmungen zwischen den Beteiligten, z.B. mit privaten Dienstleistungsanbietern, notwendig. Beyer zieht hinsichtlich der Nutzung der Potenziale aus dem Verkehrsmanagement daher eine ernüchternde Bilanz:

"Generell lässt sich sagen, dass die Potenziale, die sich aus einem mehr oder weniger umfassenden Verkehrsmanagementsystem ergeben würden, bei keinem der Verkehrsträger zur Zeit voll ausgeschöpft werden. Eine Kooperation findet nicht nennensswert statt. Allenfalls über Schnittstellen zum Austausch von Daten wird gesprochen". 579

\section{Exkurs: Systemoptimierung im Bereich des Flugverkehrs}

Im Bereich des Flugverkehrs geht es im Bereich des Verkehrs-Systemmanagement u.a. um eine Optimierung der Kapazitäten am Frankfurter Flughafen, wo es aufgrund der Überlastungen zu Flugverspätungen, unwirtschaftlichen Flugwegeführungen und infolge dessen zu zusätzlichen Umweltbelastungen kommt. Um dieses Problem ohne den geplanten Neubau einer vierten Start- und Landebahn zu lösen, „arbeiten Luftfahrtgesellschaften, Flugsicherung, Industrie und Forschungseinrichtungen an einem innovativen Air Traffic Management (ATM) Konzept". Der Lösungsansatz sieht die genaue Planung und Regelung von Ankunftszeiten sowie die Optimierung der Mindestabstände beim Einfädeln im Landeanflug vor. Hierfür bedarf es jeweils eines Abgleichs der vorgeschriebenen Ankunftszeiten zwischen den Bordcomputern der Flugzeuge und der Lotsen. 580

\footnotetext{
579 ebd., S.122

${ }^{580}$ vgl. Beyer 2005, S.119f
} 


\subsubsection{2}

Kooperatives Verkehrsmanagement

Im kooperativen Verkehrsmanagement sollen Henning und Schmid zufolge,

"die spezifischen Stärken von Individual- und öffentlichem Verkehr in Abstimmung mit der öffentlichen Verwaltung und unter Nutzung moderner Verkehrs- und Informationstechnik optimal verknüpft und Effizienz, Sicherheit und Umweltverträglichkeit des Gesamtverkehrssystems erhöht werden". 581

Sowohl der Planungsverband Ballungsraum Frankfurt/Rhein-Main wie auch die in der Region Frankfurt RheinMain zusammengeschlossenen Gebietskörperschaften und Institutionen betonen in ihren Leitbildern und Zielen die Wichtigkeit des Erhalts bzw. die Sicherung der Mobilität in der Region. ${ }^{582}$ Bislang gibt es in der Region Frankfurt Rhein-Main jedoch keine etablierte oder institutionalisierte intermodale Kooperation im Bereich des Verkehrs. Einziger Ansatz ist bislang die Gründung der Gesellschaft „Integriertes Verkehrsmanagement Region Frankfurt RheinMain" (IVM) am 1. Juli 2005. Die IVM hat die Aufgabe, „Voraussetzungen für ein integriertes und intermodales Verkehrsmanagement in der Region Frankfurt RheinMain zu schaffen“ sowie die Maßnahmen im Bereich des Verkehrsmanagements zu koordinieren und aufeinander abzustimmen. „Sie koordiniert und integriert unterschiedlichste Ideen, Interessen und Informationen, als verkehrliche Plattform für die Region“. Schließlich soll ein integriertes und intermodales Verkehrsmanagement etabliert werden, in dem „in der Region gemeinsam getragene und aufeinander abgestimmte Ziele verfolgt werden“". ${ }^{583}$ Gesellschafter sind die Länder Hessen und Rheinland-Pfalz (mit der Beteiligung der Landeshauptstadt Mainz) sowie die Kommunen des Ballungsraums Rhein-Main. ${ }^{584}$

Die IVM sieht sich selber in der Rolle, das Zusammenwirken auf regionaler Ebene zu fördern sowie die Schnittstellen der regionalen und lokalen Verkehre besser zu entwickeln und „zumindest im Verkehrsbereich ein regionales Bewusstsein“ zu bilden. Die IVM adressiert bei der „Optimierung des regionalen Verkehrsangebotes die Interessen aller Zielgruppen und deren Mobilitätsbedürfnisse“ und versteht sich selbst als „Klammer zwi-

\footnotetext{
${ }^{581}$ vgl. Henning und Schmid 1998, S.25

582 vgl. hierfür beispielhaft Planungsverband Frankfurt/Rhein-Main 2005 (b), S.9 sowie IHKArbeitsgemeinschaft Hessen 2004, S.3f

583 vgl. www.ivm-rheinmain.de (Zugriff am 12.2.2006)

584 ebd.
} 
schen den verschiedenen Verkehrsträgern“. ${ }^{585}$ Die IVM strebt an, sämtliche Lösungsansätze in einem „Mobilitätsmasterplan“ zusammenzuführen und diese entsprechend ihrer Dringlichkeit zu priorisieren. Sie verspricht sich davon wesentliche Impulse für den weiteren Ausbau von Telematiksystemen. Gleichzeitig räumt die IVM selbst ein, dass es „aufgrund der Tatsache, dass es keine Zuständigkeitsverlagerungen gibt und Lösungen nur im Konsens durchgesetzt werden können“, vor „großen Herausforderungen“ bei der Umsetzung zu stehen. ${ }^{586}$

Damit weist die IVM - als eigenständige Maßnahme betrachtet - deutliche Züge eines kooperativen Verkehrsmanagements auf, zumal auch intermodalen Lösungen Platz eingeräumt wird. Die IVM wird aber auch selbst in der Projektarbeit tätig. So wurde etwa das „Pendlernetz RheinMain“, eine internetbasierte Mitfahrbörse, oder ein internetbasierter Fahrradroutenplaner entwickelt. ${ }^{587}$ Darüber hinaus strebt die IVM die Zusammenführung von unterschiedlichen Verkehrsinformationen und Datenpools an. Außerdem koordiniert die IVM das Projekt „Staufreies Hessen 2015“. Die IVM möchte so maßgeblich zur Schaffung der Grundlagen für ein integriertes Verkehrsmanagement beitragen, ohne dabei direkt für die Definition konkreter Ziele der regionalen Verkehrsentwicklung oder für die Aufstellung eines regionalen Gesamtverkehrsplanes verantwortlich zu sein. Vielmehr kümmert sich die IVM auf der Basis von konsensualen Entscheidungen „um die Belange der Region, ohne dass die Zuständigkeiten der jeweiligen Aufgabenträger verändert werden“. ${ }^{588}$

Für die Bündelung von intermodalen Verkehrsinteressen in der Region erweisen sich die uneinheitlichen übergeordneten administrativen Organisationsstrukturen als Hindernis. Als administrative Rückfallebene bleibt daher die Konzentration auf das kommunale verkehrliche Zusammenwirken innerhalb der hessischen Landesgrenzen. Hier sind die administrativen Zuständigkeiten zwar für die jeweiligen Verkehrsträger zugeordnet, doch eine verkehrsmittelübergreifende Zusammenarbeit besteht auch hier nicht, zumal es wie in anderen Bundesländern auch in Hessen niemanden gibt, der für das Intermodale pri-

\footnotetext{
585 ebd.

586 vgl. Sparmann, J. 2005, S.2

587 vgl. www.rheinmain.pendlernetz.de und www.fahrradroutenplaner.hessen.de

588 www.ivm-rheinmain.de (Zugriff am 14.1.2007)
} 
mär zuständig ist. ${ }^{589}$ Als oberste Verkehrsbehörde fungiert das HMWVL. Doch bereits die nachgeschalteten Behörden, wie das HSVV, sind verkehrsträgerspezifisch ausgerichtet und stark von den einzelnen handelnden Verantwortlichen geprägt oder abhängig.

Dies trifft auch auf den Planungsverband zu, der auf der Grundlage des Ballungsraumgesetzes $^{590}$ gegründet wurde. Der Planungsverband ist für die Erstellung eines Regionalen Flächennutzungsplanes (RFNP) zuständig, der auch die Idee eines „Regionalen Gesamtverkehrskonzeptes“ für den Ballungsraum Frankfurt Rhein-Main aufgreift. Diese Idee, alle für die Verkehrsplanung zuständigen Akteure zu vereinen, gibt es bereits seit den 1990er Jahren, als vom Umlandverband Frankfurt der „Generalverkehrsplan 2000“591 verabschiedet wurde. Die hierin entwickelten Leitbilder werden vom Ansatz her vom Planungsverband als Rechtsnachfolger bis heute weiter verfolgt. 592 Mit der Fertigstellung des RFNP wird nicht vor 2007 gerechnet. Der RFNP „wird Festlegungen treffen zum Schutz und zur Entwicklung zusammenhängender Freiräume, zur bedarfsgerechten Ausweisung der Siedlungsflächen für Wohnen, Gewerbe und Handel und zur Sicherung der umweltverträglichen Mobilität". ${ }^{593}$ Die Grundzüge der Verkehrsplanung im RFNP sehen eine

„zukunftsorientierte Weiterentwicklung des Flughafens Frankfurt/Main als internationales Drehkreuz, optimale Einbindung der Region in das europäische Hochgeschwindigkeitsnetz der Bahn, Ausbau des öffentlichen Nahverkehrsnetzes und Ergänzung des Straßennetzes [vor]". 594

589 Dieses ist keine spezifisch hessische Problematik, sondern ein bundesweites Phänomen; vgl. Klumpp 2005, S.150.

${ }^{590}$ Das Ballungsraumgesetz vom 1.4.2001, auf dessen rechtlichen Grundlagen der Planungsverband gegründet wurde, sieht die Zusammenarbeit auf Gebieten wie z.B. der Trinkwasserversorgung, des Standortmarketings und im Personennahverkehr vor. Es ist vor allem als Kooperations- und Steuerungsmechanismus zu verstehen und sieht vor, dass eine Zusammenarbeit in den oben genannten Bereichen durch die Hessische Landesregierung verordnet werden kann, bspw. in einem Pflichtverband, wenn die Regierung dies für notwendig hält. Zunächst haben jedoch die betroffenen Kommunen selbst Gelegenheit, geeignete Strukturen der Zusammenarbeit zu entwickeln. Zwar weist das Ballungsraumgesetz hierarchische Züge auf, dennoch ist die sich hieraus ergebende grundlegend netzwerkförmige Organisationsform relativ leicht zu beeinflussen, zumal Entscheidungsstrukturen dezentralen Charakter haben. Daher scheint diese Form der Zusammenarbeit von den Gebietskörperschaften durchaus favorisiert zu werden. In der Praxis hat sich vor allem „die Bildung von Verkehrsverbünden bisher als die real wirksamste Maßnahme zur regionalen Integration erwiesen, die selbst über Landesgrenzen (Mainz - Wiesbaden) reicht"; vgl. Falger 2001, S.235ff

${ }^{591}$ vgl. Umlandverband 2000

592 vgl. Planungsverband 2005 (b)

593 www.planungsverband.de/index.phtml?NavID=1169.25\&La=1 (Zugriff am 17.9.2006)

$594 \mathrm{ebd}$. 
Der RFNP trifft auch „Aussagen über die Verkehrsinfrastruktur, wie beispielsweise Straßen, überörtliche Fahrradrouten, Schienenwege, Flughäfen und wichtige Anlagen des ruhenden Verkehrs“. 595

Bereits vor Fertigstellung des RFNP kommen allerdings Zweifel in den Kommunen auf, ob sich mit dem Instrument wirklich verfahrensmäßige Optimierungen ergeben. Insbesondere wird kritisiert, dass die politischen Abstimmungsprozesse hierdurch keineswegs schlanker und flexibler würden und dass der RFNP ungeeignet für die erforderliche Kooperation zwischen den Kommunen im Rahmen der Regionalentwicklung sei. So herrsche nach wie vor eine Weisungsmentalität durch das Regierungspräsidium vor und bestehe weniger ein von Kommunikation und Verständnis geprägtes Klima. 596

Das Hess. ÖPNVG räumt dem ÖPNV bei der Befriedigung der Nachfrage nach Mobilität eine wichtige Bedeutung ein. Auch wird erkannt, dass ein „unkoordiniertes Nebeneinander der verschiedenen Systeme und Verkehrsmittel [...] dem künftigen weiteren Anstieg der Mobilitätsbedürfnisse nicht gerecht wird“ und es von daher integrierter Lösungen bedürfe. ${ }^{597}$ Doch eine über Gesetze und Verordnungen hinausgehende gelenkte Entwicklung in Form politischer Steuerungsmechanismus existiert nicht. "Aus dem jeweiligen wirtschaftlichen und technischen Selbstverständnis heraus optimiert jeder Verkehrsträger und jede Akteursgruppe sich selbst“. ${ }^{598}$ Die Erfolge des kooperativen Verkehrsmanagements nehmen sich daher bislang bescheiden aus, was nicht zuletzt damit zusammenhängt, dass vor allem verkehrsflussoptimierende - also betriebliche - Ansätze umgesetzt werden, die auf die verbesserte Kapazitätsauslastung der Straßeninfrastruktur abzielen. Kritiker sehen daher im Ansatz des kooperativen Verkehrsmanagements „vor allem eine Strategie zur Erschließung neuer Märkte für die Automobilindustrie und den mit ihr kooperierenden Großunternehmen aus dem Bereich der Kommunikations- und Nachrichtentechnik“. Die vorhandenen Strukturen des Verkehrssystems werden im Großen und Ganzen damit konserviert. ${ }^{599}$

Klühspies kritisiert am Beispiel des Konzeptes zum kooperativen Verkehrsmanagement in München, welches auf die „Optimierung des Verkehrsablaufs im Spannungsfeld zwi-

\footnotetext{
595 ebd.

596 vgl. www.vlk-hessen.de/archiv (Zugriff am 17.9.2006)

597 vgl. Hessischer Landtag 2005, S.13

598 Klumpp 2005, S.153

$599 \mathrm{vgl}$. Henning und Schmid 1998, S.25
} 
schen Verkehrsnachfrage und Verkehrsangebot" ausgerichtet ist, dass wichtige Fragen ausgeblendet bleiben. So etwa nach Aufwand und Nutzen der Maßnahmen, nach den ökologischen und sozialen Folgen, nach dem „Menschenbild der Urheber (Vorrang für Auto oder Mensch)“ sowie nach Grund und Ursache für steigende Verkehrsbelastung. ${ }^{600}$ Bezogen auf Kfz-Leitsysteme kommt Klühspies aufgrund der weiterhin bestehenden volkswirtschaftlich-ökologischen Schädigung sogar zur Schlussfolgerung, dass „Je erfolgreicher die einzelne Technologie [ist], um so negativer die insgesamten Konsequenzen für die Stadt" ${ }^{\prime 61}$ Insofern führt der Einsatz neuer Technologien nicht per se schon zu positiven Wirkungen für Verkehr und Umwelt. ${ }^{602} \mathrm{Im}$ Bereich des Verkehrs-Systemmanagements sind aufgrund der vornehmlich technisch-betrieblichen Ausrichtung der Instrumente die Probleme ähnlich gelagert.

Während die Maßnahmen des Verkehrs-Systemmanagements und des kooperativen Verkehrsmanagements in den Verkehrsablauf vor Ort eingreifen, adressieren das VerkehrsNachfrage-Management und das Mobilitätsmanagement die Verkehrsnachfrage, d.h. sie beeinflussen die Verkehrsmittelwahl.

\subsubsection{Verkehrs-Nachfragemanagement}

Unter Verkehrs-Nachfragemanagement wird der Einsatz von preispolitischen Maßnahmen (auch restriktive oder "push-Maßnahmen“) im Verkehr verstanden. Hierzu gehören u.a. Parkgebühren, Mautgebühren, ÖPNV-Tarife und steuerliche Maßnahmen (bspw. Mineralölsteuer). Konzepte zum Verkehrs-Nachfragemanagement integrieren in der Regel aber auch attraktivitätssteigernde Maßnahmen („pull-Maßnahmen“). Einerseits um die gewünschten Effekte zu unterstützen, andererseits um „Wahlmöglichkeiten zur Umstellung des eigenen Verhaltens“ überhaupt anzubieten. Die Verbesserung des ÖPNVAngebots oder die Bereitstellung von Park-and-Ride-Plätzen sind daher konsequente begleitende Maßnahmen. Zur weiteren Erhöhung der Akzeptanz von Maßnahmen des Verkehrs-Nachfragemanagements sollte die Verwendung der Einnahmen transparent sein und zu einer Verbesserung der Verkehrs-/Mobilitätsverhältnisse eingesetzt werden. ${ }^{603}$

\footnotetext{
${ }^{600}$ vgl. Klühspies 1999, S.76ff

${ }^{601}$ Klühspies 1999, S.78

602 vgl. Nassauische Neue Presse v. 17. 02.05

${ }^{603}$ Diese Idee ist keineswegs neu: Bereits Adam Smith (1723-1790), der als Begründer der klassischen Nationalökonomie gilt, machte den Vorschlag, die Verkehrsinfrastruktur über Benutzer-
} 
Ferner müssen die Maßnahmen sozial ausgewogen sein, d.h. bestimmte Bevölkerungsgruppen dürfen nicht benachteiligt werden, ohne dass ihnen alternative Angebote unterbreitet werden. ${ }^{604}$

Vor dem Hintergrund der nunmehr erfolgreichen Einführung der Autobahn-Maut für Lkw („Toll Collect") sowie der vorteilhaften Anwendung von Maut-Systemen unter europäischen Verhältnissen wird nun auch in verkehrspolitischen Kreisen in Deutschland die erweiterte Einführung eines Maut-Systems für private Pkw auf Basis einer elektronischen Wegeerfassung thematisiert. Von einer Erhebung von Straßenbenutzungsgebühren verspricht man sich einerseits eine Reduzierung der externen Kosten, andererseits die Anlastung der verbleibenden externen Kosten an die Verursacher.605 In den Ballungsräumen - und somit auch in der Region Frankfurt Rhein-Main - wird die Diskussion zusätzlich von den Finanzierungsengpässen für verkehrsinfrastrukturelle Maßnahmen sowie durch die Zuspitzung der Feinstaubproblematik vorangetrieben.606 Über die Ansätze und Ziele, vor allem auch die Verwendung der Mittel aus der Pkw-Maut, gibt es allerdings geteilte Auffassungen. So werden nicht nur in Frankfurt, sondern auch allgemein unterschiedliche Maut-Modelle thematisiert: 607

- Die Autofahrer zahlen für die (Ein-)Fahrt in die Innenstadt (,cordon pricing“)

- Die Autofahrer zahlen für eine zurückgelegte Distanz, v.a. auf Autobahnen (,road pricing $\left.{ }^{\prime \prime}\right)$

- Die Autofahrer zahlen nur zu Zeiten hoher Verkehrsbelastung (,congestion pricing“)

Ein weiteres Modell legt nicht die Fahrleistung zugrunde, sondern die Höhe der durch die Fahrt verursachten Umweltbelastung („ökologisches road pricing“).608 Demnach dürfen Autos nur noch zu Zeiten hoher Umweltbelastung in die Innenstadt einfahren, die dann als „Umweltzone“ deklariert wird, wenn sie vorgegebenen Umweltnormen entspre-

entgelte $\mathrm{zu}$ finanzieren und warnte vor anderweitiger Verwendung der eingenommenen Mautgebühren; vgl. Aberle 2006, S.5.

${ }^{604} \mathrm{vgl}$. Schade und Schlag 2001, S.72ff

${ }^{605}$ vgl. Halbritter u.a. 2005, S.42

${ }^{606}$ vgl. Frankfurt Rundschau v. 4.3.2004 sowie v. 27.9.2006

${ }^{607}$ vgl. Schade und Schlag 2001, S.72

${ }^{608}$ vgl. Lehmann 2000, S.51f 
chen. Der "Aktionsplan Frankfurt am Main 2005“ sieht zukünftig die Ausweisung einer solchen Umweltzone vor, in die im Fall einer Überschreitung der Feinstaubbelastung am Tag nur noch Fahrzeuge mit entsprechender Abgasnorm einfahren dürfen. Die Kennzeichnung abgasarmer Fahrzeuge soll über farbige „Abgasplaketten“ erfolgen. Die Verordnung hierfür soll nach erfolgtem Gesetzgebungsverfahren am 1. Januar 2008 in Kraft treten. ${ }^{609}$ Mit diesem Datum soll nach Vorstellung des Umweltdezernats der Stadt Frankfurt am Main auch die dortige Umweltzone eingerichtet werden. ${ }^{610}$ Die Städte Darmstadt, Wiesbaden und Mainz planen dagegen keine Einführung von Umweltzonen bzw. haben bereits ein Durchfahrtsverbot für Schwerlastverkehr eingeführt (Darmstadt) oder machen die Einführung einer Umweltzone von der weiteren Entwicklung der Feinstaubbelastung abhängig (Wiesbaden). ${ }^{611}$

Das Befahren dieser Umweltzone mit einer gültigen Plakette entspricht allerdings nicht der originären Idee einer Straßenbenutzungsgebühr nach dem Vorbild der Einrichtung einer "congestion zone“, die eine leistungsgerechte Abrechnung der Straßenbenutzung zum Ziel hat. ${ }^{612}$ Hierfür wären leistungsfähige Kontroll- und IT-Systeme die Voraussetzung. ${ }^{613}$ Beispiele für die Realisierung leistungsgerechter Maut-Systeme gibt es zahlreiche, das bekannteste in Deutschland ist das bereits erwähnte Projekt „Toll Collect“ für die Erhebung der Lkw-Maut auf Bundesautobahnen. Entsprechend ist auch das Votum der „Sachverständigen-Kommission zur Entwicklung neuer Modelle der VerkehrswegeFinanzierung“ (Pällmann-Kommission), demzufolge die Maut weniger ein Instrument sein soll, das ausschließlich auf eine Verteuerung der Pkw-Kosten abzielt, sondern vielmehr ein Mittel, auch im MIV die Finanzierung stärker nutzerfinanziert auszurichten. Allerdings berücksichtigen die Vorschläge der Kommission nur den Ausgleich der Infrastrukturkosten - und nicht auch die externen Kosten.614 Pkw-Maut und Ökosteuer, also die Anhebung der Mineralölsteuer, stehen demnach einer Pauschalbesteuerung im Rahmen der Kfz-Steuer gegenüber.

\footnotetext{
${ }^{609}$ vgl. Hessisches Ministerium für Umwelt, ländlichen Raum und Verbraucherschutz 2005, S.33f sowie Wiesbadener Kurier v. 7.3.2007

${ }^{610}$ vgl. FAZ v. 28.10 .2006

611 vgl. Wiesbadener Kurier v. 7.3.2007

612 vgl. Frankfurter Rundschau v. 24.4.2007

${ }^{613}$ vgl. Halbritter u.a. 2005, S.43

${ }^{614}$ vgl. Bundesministerium für Verkehr, Bau und Stadtentwicklung 2000, S.37
} 
Bei der Einführung eines Maut-Systems wird davon ausgegangen, dass sich durch die Erhebung eines Straßennutzungsentgelts der private Gebrauch eines Pkw verteuert und sich hierüber gewissermaßen die Intensität des MIV regulieren lässt. 615 Demnach würde eine Pkw-Maut zu einer Verringerung der Fahrtenanzahl insgesamt führen, etwa durch den Wegfall nicht unbedingt notwendiger Fahrten oder der Bildung von Fahrgemeinschaften sowie der Verlagerung von Fahrten auf andere Verkehrsmittel. ${ }^{616}$ So ist beispielsweise durch die Einführung einer City-Maut in Stockholm (Schweden) der Anteil der Autopendler um 22\% zurückgegangen.617 Eine derartige Verlagerung könnte auch dem ÖPNV zugute kommen. Gleichzeitig birgt diese Art der Regulierung jedoch die Gefahr, dass sich die Fahrten mit dem privaten Pkw auf andere, mautfreie Strecken verlagern, was insgesamt zu einer höheren Verkehrsbelastung auf Nebenstrecken führen könnte. 618 Darüber hinaus besteht das Problem, dass Mautgebühren "sozial selektiv“ wirken und Geringverdiener verhältnismäßig stark belastet werden. ${ }^{619}$ Zudem sind gerade Vielfahrer in besonderem Maße auf ihren privaten Pkw angewiesen und haben Pendler aus peripheren Gebieten oft keine Wahlmöglichkeit. Gerade diese Nutzergruppe, bei der die Preiselastizität ausgesprochen gering ist, würde durch die zusätzliche Einführung einer Straßenmaut - bei gleichzeitiger Reduktion der Pendlerpauschale - in ihren Mobilitätskosten besonders benachteiligt. In der Konsequenz würde dies vermutlich zu einer heftigen Gegenwehr von Interessenverbänden und politischen Gruppierungen führen. ${ }^{620}$

Auf der einen Seite unterläuft eine Maut für private Pkw also das Ausgleichs- und Verteilungsziel der Raumordnung, allen Menschen gleichwertige Lebensverhältnisse zu garantieren. Auf der anderen Seite kann die Maut zu einem gewissen Maß zur umweltverträglichen Abwicklung des Verkehrs beitragen. ${ }^{621}$ Insofern erfordert „die erfolgreiche Etablierung dieses potenziell hochwirksamen Verkehrs-Steuerungsinstrumentes [...] die Integration in ein Gesamtkonzept von Steuerungs- und Finanzierungsinstrumenten“. ${ }^{622}$ Die Pkw-

\footnotetext{
615 vgl. Baum 2005, S.1

616 vgl. Kossak 2004, S.10

${ }^{617}$ vgl. Frankfurter Rundschau v. 27.9.2006

618 vgl. Deutscher Industrie- und Handelskammertag 2005

${ }^{619}$ vgl. Nuhn und Hesse 2006, S.62

${ }^{620}$ Am Beispiel der Niederlande ist diese Diskussion nachzuvollziehen. Dort sollen die Einnahmen aus der Pkw-Maut - zumindest kurzfristig - für den Straßenausbau verwendet werden. Dieses Eingeständnis war notwendig, um einen politischen Konsens zwischen den verschiedenen Interessenverbänden und politischen Parteien herbeizuführen; vgl. de Jong 2006.

${ }^{621}$ vgl. Nuhn und Hesse 2006, S.62

${ }^{622}$ Kossak 2004, S.12
} 
Maut wäre also in erster Linie ein Instrument zur Lösung von Mobilitätsproblemen und nicht schon gleich die Lösung selbst.

Eine Nutzen-Kosten-Analyse für eine City-Maut für die Stadt Frankfurt erbrachte, dass den Einführungskosten in Höhe von 166 Mio. Euro (u.a. für 100 neue Busse, Park-andRide-Plätze und einem elektronischen Maut-System) jährlich Einnahmen (bei einer Mautgebühr von 2 Euro für die Fahrt in die Innenstadt) in Höhe von ca. 162 Mio. Euro entgegenstünden. ${ }^{623}$ Im September 2006 hat sich der grüne Verkehrsdezernent der Stadt Frankfurt Sikorski von einem City-Maut-Konzept für die Stadt Frankfurt mit dem Argument distanziert, dass Frankfurt vor allem an der „Hintergrundbelastung“ leide. Demnach entstünden die Belastungen für die Stadt vor allem durch die Autobahnen und Industrien, die außerhalb rund um der Stadt ansässig seien. Eine City-Maut würde außerdem vor allem den Handel gefährden und wenig bringen. Die Chancen der Einführung einer räumlich erweiterten City-Maut, die auch die größeren Städte der Region Offenbach, Wiesbaden und Darmstadt einschließen würde, werden vom Vorsitzenden der Frankfurter Grünen ebenfalls schlecht eingestuft. Dies liegt seiner Meinung nach vor allem an den administrativen organisatorischen Zuständigkeiten sowie den spezifischen politischen Verhältnissen in der Region: „Aber das ist, so wie die Region verfasst und von Egoismen der Kommunen geprägt, absolut unrealistisch“ ${ }^{624}$ Auch hierin zeigt sich die bereits unter Kapitel 4.6 diskutierte Notwendigkeit einer politisch-institutionellen Neuordnung bzw. die Problematik der regionalen Kooperation, die - nicht nur im Verkehrsbereich - von einem Misstrauen der Umlandkommunen gegenüber der Stadt Frankfurt gekennzeichnet ist. Darüber hinaus lehnt auch der „hessische Verkehrsminister [...] die City-Maut generell ab [und] setzt stattdessen auf ,kreatives Verkehrsmanagement'“ ${ }^{\prime \prime}{ }^{625}$

Im ÖPNV stellen vor allem die Höhe der Fahrpreise ein Instrument zur Beeinflussung der Nachfrage dar. Allerdings ist bislang über die Auswirkungen von Fahrpreiserhebungen abseits der Veränderung der kassentechnischen Einnahmen wenig bekannt. So kommt auch das Mittel der Preisdifferenzierung als Mittel zur Nachfragebeeinflussung nur ansatzweise zur Anwendung (siehe Kapitel 6.5.3.2.).

\footnotetext{
${ }^{623}$ vgl. Frankfurter Rundschau v. 27.9.2006

624 Frankfurter Rundschau v. 27.9.2006

${ }^{625}$ Frankfurter Rundschau v. 24.4.2007
} 


\section{Exkurs: New Yorks Pläne gegen den Klimawandel}

Der New Yorker Bürgermeister Bloomberg stellte Anfang 2007 einen Plan für eine ökologische Stadt vor, der "127 Vorhaben, Verordnungen und Vorschriften umfasst" und New York zur "ersten ökologischen Stadt des 21.Jahrhunderts" machen soll. Der Plan ist mehrdimensional angelegt und sieht u.a. die Einführung einer "congestion-fee" im südlichen Teil Manhattans vor, deren Einnahmen auch zur Verbesserung des Angebots im ÖPNV verwendet werden sollen, bspw. für die Einrichtung von Busspuren für "Super-ExpressBusse“. Zur Reduzierung des Austoßes von Treibhausgasen sollen u.a. 1 Million Bäume gepflanzt und umweltschädliche Kraftwerke geschlossen werden. Ferner soll es Anreize geben, den privaten Ressourcenverbrauch zu minimieren. Hierfür soll u.a. die Mehrwertsteuer für Pkw mit Hybrid-Antrieb entfallen und die Wiederverwendung von Brauchwasser gefördert werden. Außerdem sollen zur Verbesserung des Wohnklimas vermehrt Parkflächen angelegt werden. ${ }^{626}$

\subsubsection{Mobilitätsmanagement}

„Mobilitätsmanagement ist ein effizienter verkehrspolitischer Ansatz, der flexibel einsetzbar ist und auf Kooperation von Öffentlichen und Privaten basiert. [...] Mobilitätsmanagement umfasst Maßnahmen aus den Bereichen Information und Kommunikation sowie Organisation und Koordination. Diese Maßnahmen zielen darauf ab, die Verkehrsnachfrage in Richtung einer breiten und der Situation angepassten Nutzung von Verkehrsmitteloptionen zu beeinflussen. Leitbild ist ein multi- und intermodales Nutzerverhalten" ${ }^{627}$

Müller gibt mit dieser Begriffserklärung zu verstehen, dass im Mobilitätsmanagement eine frühestmögliche, durchgängige und zielgruppenspezifischen Ansprache bzw. Information bestehender und potenzieller Kunden wichtig ist, beispielsweise im Rahmen einer eingehenden verkehrsträgerübergreifenden Mobilitätsberatung oder über intermodal ausgelegte Auskunftssysteme.

So soll Mobilitätsmanagement Impulse auslösen, die auf einen höheren Integrationsgrad aller Verkehrssysteme abzielen. Aber auch hier ist die Voraussetzung, dass die vorhande-

${ }^{626}$ vgl. FAZ v. 24.4.2007

${ }^{627}$ Müller, G. 2004, S.371f 
nen Ressourcen der einzelnen Verkehrsträger durch bessere Abstimmung und Optimierung erschlossen werden. Dies berücksichtigt die Entwicklung und den Ausbau von Alternativen zum MIV mit niedrig(st)em Besetzungsgrad. Der Fokus der Verhaltensbeeinflussung ist dabei keineswegs als Kontrapunkt zu anderen Bereichen des Verkehrsmanagements zu verstehen, die sich bislang verstärkt mit der betrieblichen Beeinflussung der Verkehrsabläufe - insbesondere auf der Straße - beschäftigen (siehe Kapitel 4.6.3). Vielmehr geht es um eine Synthese beider Ansätze, bei der die IuK-Technologien die Basis für die Entwicklung und Vermarktung neuer Mobilitätsdienstleistungen liefern. Inhaltlich spielt beim Mobilitätsmanagement also die Erweiterung der Handlungsspielräume im Bereich der Verkehrsmanagement eine Rolle, ohne dabei von großen investitionsintensiven „harten“ Infrastrukturmaßnahmen Gebrauch machen zu müssen.

Dabei umfasst das Mobilitätsmanagement sowohl lokale (standortbezogene) wie auch regionale Ansätze. Zu den standortbezogenen Instrumenten zählen Mobilitätspläne oder die Einrichtung von Mobilitätsberatungsstellen in Unternehmen oder Verwaltungen. Die Einrichtung von Mobilitätszentralen (s.u.) in Städten oder der Einsatz von Mobilitätsberatern bei großen, „verkehrerzeugenden“ Einrichtungen haben dagegen eher regionalen Charakter. Alle Ansätze sind aber dahingehend gleich, dass sie eine enge Abstimmung und Koordination der Verkehrsakteure zugrunde legen und die Verkehrsplanung durch intensive Kommunikation und Kooperation ausgezeichnet sein muss. Auch sind die Maßnahmen des Mobilitätsmanagements eng verknüpft mit verkehrspolitischen Rahmenbedingungen, die auf die Förderung der allgemeinen Mobilität ausgerichtet sein sollten. ${ }^{628}$ Anderenfalls müssen Beratungsmaßnahmen in Mobilitätszentralen, das Aufstellen von Mobilitätsplänen oder die Ernennung von Mobilitätsberatern in Unternehmen und Institutionen ins Leere laufen. Die abgestimmte Organisation des komplexen Gesamtverkehrssystems und die Vermarktung neuer multi- und intermodaler Mobilitätsdienste stehen also im Mittelpunkt der Betrachtung des Mobilitätsmanagements. ${ }^{629}$

\footnotetext{
${ }^{628}$ So wirkt sich beispielsweise die Besteuerung von Zuschüssen des Arbeitgebers zu Jobticket, als geldwerter Vorteil, negativ auf die Akzeptanz aus; vgl. http://www.mobilitaetsmanagement.nrw.de. Auch kann sich die Bereitstellung kostenloser Parkplätze (evtl. sogar durch Bauvorschriften vorgegeben) oder allgemein hohe Investitionen in die Straßenverkehrsinfrastruktur kontraproduktiv auf Aktivitäten des Mobilitätsmanagements auswirken; vgl. Müller, G. 2004, S.377.

${ }^{629}$ vgl. Müller, G. 2004, S.372
} 
Innovative Ansätze des Mobilitätsmanagements wurden in Hessen im Projekt „WAYflow“ im Rahmen der Initiative des Bundesministeriums für Bildung und Forschung $(B M B F)^{630}$ „Mobilität in Ballungsräumen“ entwickelt. Das Projekt lief von Oktober 1998 bis September 2002. Der kooperative Ansatz des Projektes zeigte sich bereits darin, dass sowohl öffentliche als auch private Partner darin zusammen arbeiteten. Auf öffentlicher Seite waren dies allen voran die RMV GmbH sowie das HLSV, auf privater Seite u.a. TSystems und Philips. Wichtiges technisch-organisatorisches Element von WAYflow sollte die Entwicklung einer Informationsplattform sein, welche die Datenbasis für ein integriertes Verkehrsmanagement für die Region Rhein-Main bereit stellt. Dafür sollten unterschiedliche dezentral organisierte (Verkehrs-)Datenbanken mittels der sogenannten „Multiagententechnologie“ verknüpft werden. Als kundenorientierter Dienst war die Entwicklung eines „MobiChips“ vorgesehen, der als „wissensbasierter Reisebegleiter“ individualisierte Informationen für die verschiedenen Zielgruppen generiert und in Produkte, Systeme und Dienstleistungen umsetzt. Die Ergebnisse aus WAYflow mündeten u.a. in einem Pilotprojekt, in dem Chipkarten als Träger von elektronischen Fahrtberechtigungen eingesetzt wurden (siehe Kapitel 7.3.4). ${ }^{631}$ Letztlich blieb eine marktgerechte Verwertung der WAYflow-Projektergebnisse aber aus, was u.a. daran lag, dass die Beteiligten selbst das "starre unternehmerische Denken“ unterschätzten, wonach die beteiligten Unternehmen (selbstverständlich) zunächst einmal ihre eigenen Dienstleistungen und Produkte verkaufen wollten, sowie an dem „Umstand, dass Zugriffsrechte, Datenhoheit, Nutzungsund Verwertungsrechte meist nicht bis ins Detail geklärt“ waren. 632

Weitere Maßnahmen des Mobilitätsmanagements wurden in Hessen vor allem auf Initiative von ÖPNV-Unternehmen vorangetrieben, wobei auch hier die $R M V G m b H$ einer der frühen Initiatoren war. Hierbei spielt vor allem die Einrichtung und der Betrieb von Mobilitätszentralen eine Rolle. Mittlerweile gibt es im Bereich des RMV 18 Mobilitätszentralen, in denen sowohl Fahrplan- und Tarifauskünfte wie auch aktuelle Hinweise zur StraBenlage und zum Flughafen sowie zum Freizeitangebot in der Region gegeben werden. Darüber hinaus werden Informationen zu weiteren Mobilitätsangeboten wie Park-andRide-Möglichkeiten, Car-Sharing-Angeboten und Autovermietungen vermittelt. Die Bera-

\footnotetext{
630 mittlerweile Bundesministerium für Wirtschaft und Technologie

631 vgl. Internetpräsenz des TÜV Rheinlands als Projektträger: www.tuvpt.de/abgeschlosseneprojekte/mobilitaet-in-ballungsraeumen/wayflow.html (Zugriff am 30.12.2006)

632 Schuster 2001, S.19f
} 
tung und der Verkauf von Fahrkarten erfolgen dabei im persönlichen Gespräch, i.d.R. durch Mitarbeiter von Verkehrsunternehmen oder Nahverkehrsorganisationen. Daneben stehen zur persönlichen Beratung die telefonischen Auskünfte des RMV und der Lokalen Nahverkehrsgesellschaft Frankfurt am Main, TraffiQ zur Verfügung. Beide Hotlines geben über den ÖPNV hinaus Informationen, so beispielsweise auch zur Verkehrslage. 633

\subsubsection{Fazit}

Zusammenfassend lässt sich feststellen, dass die verkehrspolitisch Verantwortlichen in der Region Frankfurt Rhein-Main, allen voran die hessische Landesregierung, die Notwendigkeit für das aktive "Managen“ der Verkehrssysteme erkannt haben und unterschiedliche Initiativen angestoßen haben, über Instrumente des Verkehrsmanagements und gezielter Infrastrukturmaßnahmen („Lückenschlüsse“) den Verkehrsablauf zu verbessern. Das Ziel der hessischen Landesregierung ist schließlich die Umsetzung eines intermodalen Verkehrskonzeptes, in dem die jeweiligen Stärken der einzelnen Verkehrsträger optimal genutzt werden.634 Dabei konzentriert sich die hessische Landesregierung im Rahmen eines „Innovationsmanagements“635 auf hoheitliche Aufgaben, die von dazu legitimierten Behörden wahrgenommen werden. Das mit koordinierenden Aufgaben betraute Hessische Landesamt für Straßen- und Verkehrswesen (HLSV) hat hierfür den Begriff „Intelligentes Verkehrsmanagement“ gebildet und mit konzeptionellen Ansätzen unterfüttert. Hierzu gehören der „intelligente Infrastrukturausbau“ (Bewertung und Umsetzung infrastruktureller Maßnahmen nach Wirkung und Dringlichkeit) und die „intelligente Infrastrukturnutzung“ (Steuerung und Optimierung des Verkehrsablaufs). ${ }^{636}$

Auch wenn die dahinter stehenden Ziele auf die Steuerung und Optimierung des (Individual-)Verkehrs ausgerichtet sind und negative Folgen wie Staus und Unfälle reduziert werden sollen, ist der Erfolg der Maßnahmen in bezug auf eine Verbesserung der Intermodalität und damit die langfristige und nachhaltige Wirkung dieser Lösungen jedoch in Frage zu stellen. Es handelt sich zu einem großen Teil um „harte“ Maßnahmen mit vorwiegend technisch-betrieblichem Charakter. Die damit verbundenen verkehrsbeeinflussenden Maßnahmen führen allenfalls kurz- und mittelfristig zu einer Reduzierung des

\footnotetext{
${ }^{633} \mathrm{vgl}$. www.rmv.de sowie www.traffiq.de

${ }^{634}$ vgl. HMWVL 2000, S.31

${ }^{635}$ Hier verstanden als die Verwaltung der Technikentwicklung und Technikeinführung.

${ }^{636} \mathrm{vgl}$. Sparmann, J. 2006, S.5ff
} 
Gesamtverkehrsaufkommens, d.h. die Grundbelastung und die daraus resultierenden negativen Effekte werden - insbesondere vor dem Hintergrund eines weiter steigenden Verkehrsaufkommens - kaum bewältigt werden können. Die Erfahrung lehrt, dass es anscheinend auch nicht ausreicht, das Mobilitätsverhalten der Menschen ausschließlich über die Bereitstellung von Information zu verändern. Dies ist daran erkennbar, dass das Angebot und die Akzeptanz von Informationsdiensten mit Verkehrsinhalten weit hinter den prognostizierten Werten zurückliegt. So kommt eine Studie des Deutschen Zentrums für Luft- und Raumfahrt, Institut für Verkehrsforschung (DLR-IVF) zum Schluss, dass Verkehrsinformationsdienste „hauptsächlich auf die Optimierung des bestehenden Verhaltens ausgerichtet [sind], nicht aber auf eine Verhaltensänderung zugunsten einer vermehrten Nutzung von Verkehrsarten wie Öffentlicher Verkehr oder Fahrrad“.637 Erst recht „Im [weiter wachsenden] Bereich der Freizeitmobilität bieten telematische Anwendungen keine dauerhaften Verhaltensalternativen an". ${ }^{638}$

Folgerichtig resümierte der ausgeschiedene Präsident des HLSV und Geschäftsführer der IVM, Jürg Sparmann:

"Intelligentes Verkehrsmanagement", wie es vom HLSV verstanden wird, eignet sich insofern vor allem dafür, die Symptome des MIV kurzfristig zu mildern und bietet sektorale Begleitmaßnahmen im Rahmen eines verkehrsträgerübergreifenden Verkehrsmanagements für die Region. Auffällig ist, dass sich alle Ansätze in den bestehenden organisatorischen Strukturen abspielen, obwohl die umsetzungsbezogenen - und auch finanziellen - Unzulänglichkeiten dieser Zusammenarbeit erkannt werden: [...] da es jedoch keine institutionalisierte Zusammenarbeit gibt, optimiert jeder in seiner eigenen Zuständigkeit. Die Schnittstellen zwischen dem regionalen und lokalen Verkehr, sowie die übergreifende Zusammenarbeit der Verkehrsträger ist nicht sehr stark entwickelt. Hinzu kommt, dass durch Finanzierungsmängel und langfristige Realisierungszeiten für Infrastrukturmaßnahmen der Abbau von Kapazitätsengpässen behindert wird. Desgleichen fehlen netzbezogene Strategien für eine verbesserte Beeinflussung des Verkehrs, insbesondere in den Bereichen abseits der Autobahnen". 639

\footnotetext{
${ }^{637}$ Franken und Lenz 2004, S.16

638 Hunecke 1998, S.95

${ }^{639}$ Sparmann, J. 2005, S.1f
} 
Diese scheinbar unüberbrückbaren organisatorischen Schwierigkeiten zwischen den Verkehrsakteuren auf Verwaltungsebene, aber auch die unzureichende Kommunikation zwischen Verkehrsverwaltung und Verkehrswirtschaft, mögen ein Übriges dazu beitragen, dass die Verantwortlichen das Thema Verkehrsmanagement vornehmlich in den Dimensionen technik-orientierter Einzelprojekte betrachten. Für eine nachhaltige Verkehrsentwicklung bedarf es daher eines Paradigmenwechsels vom "technischen Management der Verkehrssysteme zum integrierten Mobilitätsmanagement" ${ }^{\prime}$, in dem die Mobilitätsbedürfnisse von Menschen und Unternehmen stärker in den Mittelpunkt einheitlicher und integrierter Konzepte gerückt werden und Maßnahmen verbindlich umgesetzt werden. ${ }^{640}$ Im Rahmen dieses integrierten Konzeptes müssen sich die in Hessen vornehmlich praktizierten Maßnahmen des Verkehrs-Systemmanagements sowie die Ansätze des Mobilitätsmanagements keineswegs gegenseitig ausschließen, sondern sich ergänzen (siehe Abbildung 27).

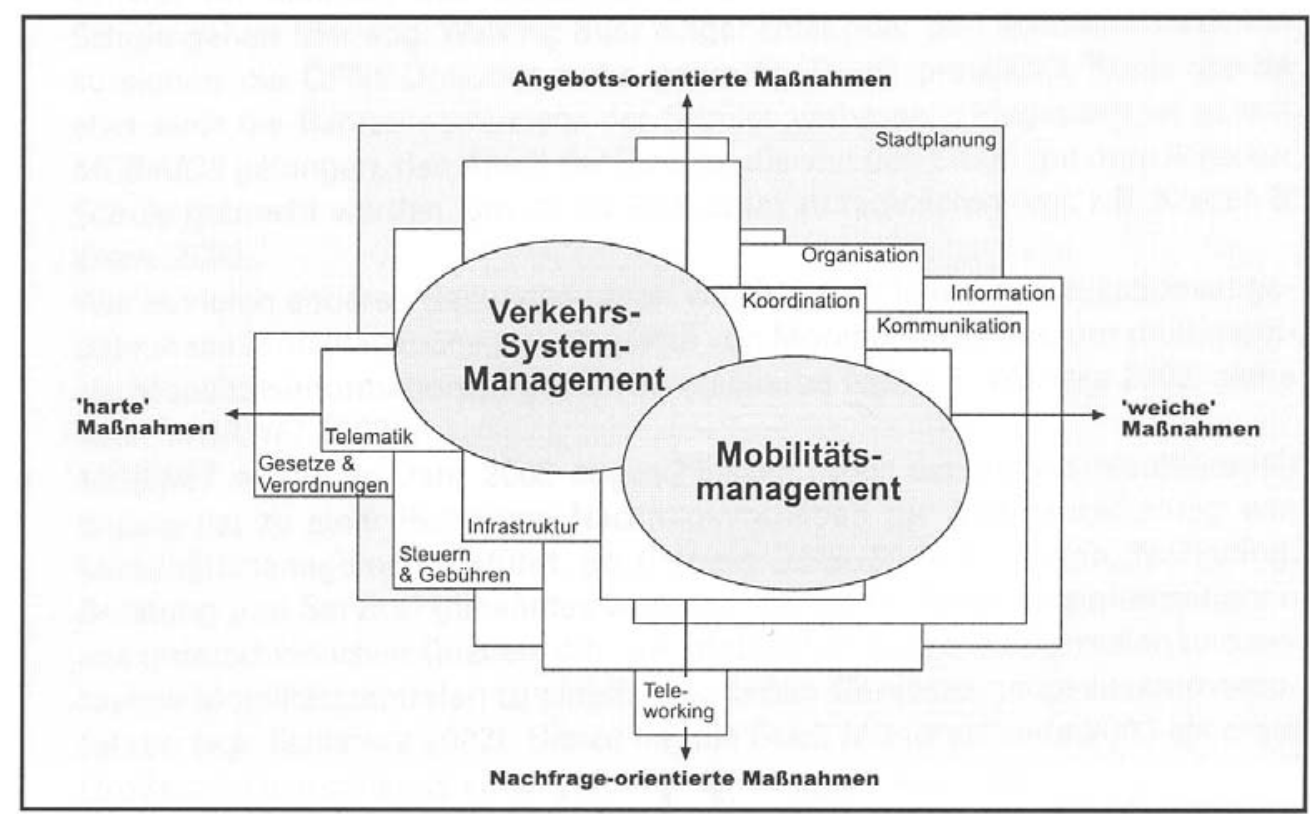

Abbildung 27: Ergänzung von Verkehrs-Systemmanagement und Mobilitätsmanagement Quelle: Kagermeier 2004, S.21

${ }^{640}$ vgl. Faltlhauser und Schreiner 2001, S.420 


\subsection{Konsequenzen: ÖPNV stärken, Mobilität sichern}

\subsubsection{Motivation zur Sicherung der Mobilität}

Am konkreten Beispiel der Region Frankfurt Rhein-Main lässt sich feststellen, dass die Leistungsfähigkeit der - wenn auch guten - (Straßen-)Verkehrsinfrastruktur durch die stetig steigende Nachfrage nach Verkehr an ihre Kapazitätsgrenzen kommt bzw. die Leistungsgrenzen erreicht und überschritten werden und die Mobilität dadurch letztendlich beeinträchtigt wird. Die damit im Zusammenhang stehenden Problematiken sind seit vielen Jahren bekannt und haben auf landespolitischer Ebene zu einem Umdenken geführt, das sich auch auf die Landesentwicklungsplanung auswirkt: „Die lokal und regional aus dem Verkehrsaufkommen resultierenden Belastungen sind durch Umsetzung eines zukunftsfähigen Verkehrskonzeptes auf der Grundlage einer integrierten Raumund Verkehrsplanung zu reduzieren“. ${ }^{641}$ Durch die bisherigen Anstrengungen der Optimierung der betrieblichen Abläufe und der Erhöhung der Effizienz der Verkehrssysteme sowie der Verbesserung der Umweltverträglichkeit im Rahmen des Verkehrssystemmanagements, wurden für die einzelnen Verkehrsträger in Hessen in den letzten Jahren beachtliche Fortschritte auf lokalörtlicher Ebene erzielt. Auch die Ansätze der Entwicklung eines kooperativen Verkehrsmanagements weisen konzeptionell in die richtige Richtung: Die Etablierung eines integrierten Verkehrssystems, in dem die unterschiedlichen Verkehrsträger und -netze verknüpft sind und intermodale Mobilität gewährleisten. Hingegen man beim Verkehrs-Nachfragemanagement und beim Mobilitätsmanagement wie auch beim kooperativen Verkehrsmanagement erst am Anfang der Entwicklung von auch integrierten - Lösungen steht, gibt es im Bereich des Verkehrs-Systemmanagements bereits umfängliche Erfahrungen. Diese Erfahrungen beruhen zu einem nicht unerheblichen Teil auf der Implementierung und Nutzung von Verkehrstelematik, die in etlichen Anwendungen das Stadium der Markterprobung überschritten haben und sich am Markt durchsetzen. ${ }^{642}$

Gleichzeitig muss festgestellt werden, dass sich an den grundsätzlichen Verkehrsproblematiken in der Region Frankfurt Rhein-Main nichts geändert hat. Die stark gestiegene Nachfrage nach Mobilität wird nach wie vor fast ausschließlich durch den MIV befriedigt,

\footnotetext{
${ }^{641}$ HMWVL 2000, S.8

${ }^{642}$ vgl. Reister 2001, S.537f
} 
was einhergeht mit negativen Auswirkungen auf die Umwelt und die Volkswirtschaft. Trotz eines guten ÖPNV-Angebots erfolgte nur teilweise eine Verlagerung der Verkehrsnachfrage auf den Umweltverbund. Hieran können auch die umfangreichen Maßnahmen des Verkehrs-Systemmanagements nichts ändern: „Die mit Telematik erzielten Fortschritte wurden inzwischen vielfach von der Verkehrszunahme überholt" oder führen dazu, dass die Nutzung des privaten $\mathrm{Pkw}$ „in vielen Fällen immer noch effizienter und kostengünstiger ist als öffentliche Verkehrsmittel zu nutzen“".643 Und diese Erkenntnis ist nicht neu: Bereits 1990 wurde im Rahmen eines Forschungsprojektes des Bundesministeriums für Wirtschaft darauf hingewiesen, dass vom rein technisch-betrieblichen Einsatz von Telematikanwendungen bei einzelnen Verkehrsträgern keine Verbesserungen im Gesamtverkehrssystem zu erwarten sind, da „dem Fehlen durchgängiger Konzepte und Systeme zur ganzheitlichen Verkehrsorganisation und zur Kooperation der Verkehrsmittel und Verkehrssysteme bisher zu wenig Aufmerksamkeit geschenkt wurde“. ${ }^{644}$

Reister führt den ausgebliebenen Erfolg von Telematikanwendungen allgemein darauf zurück, dass Verkehrstelematik vor allem zur „Aussteuerung von Störungen“ im Regelkreis Verkehr angewandt wurde, also als reiner Rückkopplungsprozess verstanden wurde. Er weist darauf hin, dass Telematik verstärkt auch zur Selbstorganisation beitragen sollte, um den nicht-linearen und dynamischen Prozessen im Verkehr, die vielfach nicht dem Rationalitätskalkül unterliegen, stärker gerecht zu werden. Dieses sei u.a. deshalb von Bedeutung, weil die Mobilitätskonsumenten die Verkehrssysteme nicht unter dem Aspekt der Systemstabilität nutzen würden und zur besseren Einschätzung von Mobilitätsalternativen technische Hilfe bräuchten. Die Voraussetzung hierfür sei aber eine „konsequente Gestaltung von Verkehrssystemen“, die dazu führt, dass die Verkehrsteilnehmer auch die öffentlichen Verkehrsmittel als „äquivalente Alternativen“ zum MIV begreifen, „die sich entsprechend ihren Stärken optimal zu Transportketten in einem Gesamtsystem vernetzen“. Diese Vernetzung betrifft nicht nur die betriebliche Abstimmung der Verkehrsträger aufeinander, sondern auch die kommunikative Vernetzung aller Verkehrsakteure und Verkehrsteilnehmer. Auch hier können Telematikanwendungen einen entscheidenden Beitrag liefern (vgl. Kapitel 3.9), wenngleich die Vernetzung nicht alleine als

${ }^{643}$ Reister 2001, S.538

${ }^{644}$ Reister 2001, S.537, der zitiert nach: Braess, H.H.; Frank, D. und Reister, D.: „Individualverkehr und Öffentlicher Verkehr - Konfrontation oder Kooperation?". In: Neue Konzepte für den flieBenden und ruhenden Verkehr - Tagung Wolfsburg, 27. u. 29.11.1990. VDI-Gesellschaft Fahrzeugtechnik (Hrsg.). VDI-Bericht Nr. 817. Düsseldorf 1990- S. 33-70. 
technisches Problem angesehen werden darf, sondern vor allem als organisatorischstrukturelle Herausforderung. Dennoch bildet die technische Vernetzung die Voraussetzung, um Synergien bei der gemeinsamen Nutzung von Ressourcen und Daten zu nutzen, die schließlich auch zu neuen organisatorischen Strukturen bei der Bewältigung von Verkehrsproblemen führen können.

Betrachtet man die Dominanz des MIV und den nachteiligen ÖPNV-Anteil am Modal Split, scheint die Konkurrenzfähigkeit des ÖPNV und damit die Gleichberechtigung der Verkehrsträger aber in Frage gestellt. Diese Konkurrenzfähigkeit stellt aber die Voraussetzung für die Vermeidung und Verlagerung von Verkehrsleistungen dar („Substitutionspotenzial“ ). 645 Dabei geht es vorrangig um die Verkehrsvermeidung und -verlagerung von als verzichtbar geltenden Pkw-Fahrten, die wiederum unverzichtbare Pkw-Verkehre behindern. $\mathrm{Zu}$ diesen unverzichtbaren $\mathrm{Pkw}$-Verkehren gehören alle Wirtschaftsverkehre, die nicht anderweitig getätigt werden können, wie „Lieferverkehre, Taxis, Notdienste sowie Wartungs- und Handwerkerverkehre, die nur schwer durch die Öffentlichen Verkehre abgewickelt werden können“. ${ }^{646}$

Eine Untersuchung des Forschungsinstituts SOCIALDATA für München aus dem Jahre 1993 ergab, dass der Anteil der notwendig erachteten „unverzichtbaren“ Verkehre nur bei $30 \%$ liegt. Demzufolge ergäbe sich ein Einsparungs- und Verlagerungspotenzial von 70\% aller mit dem Pkw getätigten Fahrten. Allerdings zählt die Studie auch sämtliche Fahrten zum Arbeitsplatz zu den verzichtbaren und auf den ÖPNV verlagerbaren Verkehren. ${ }^{647}$ In Kapitel 4.4.2 wurde dargestellt, dass der Anteil der in Hessen getätigten „unverzichtbaren“ Wege im Wirtschaftsverkehr 8\% beträgt. Addiert man hierzu noch die dienstlichen Fahrten, kommt man auf einen relativen Anteil von 9\% Wege, die - gemäß SOCIALDATA - unverzichtbar sind. ${ }^{648}$ Demzufolge wäre das Einsparpotenzial in Hessen weit größer. Blümel vom Wissenschaftszentrum Berlin für Sozialforschung kritisiert am Ansatz von SOCIALDATA allerdings, dass nicht hinterfragt wird, warum denn viele Kunden den ÖPNV nicht benutzen, auch wenn die nächste Haltestelle in günstiger Entfernung liegt.

\footnotetext{
${ }^{645}$ vgl. Umweltbundesamt 2005 (a) sowie S.5 sowie Halbritter u.a. 2005, S.40

${ }^{646}$ Klühspies 1999, S.11

${ }^{647} \mathrm{vgl}$. SOCIALDTA 1993, S.3

${ }^{648}$ vgl. Planungsverband Ballungsraum Frankfurt/Rhein-Main u.a. 2005, S.26
} 
Außerdem würde SOCIALDATA subjektive Gründe als falsch bewerten und „,andere Motive als die genannten rationalen" nicht zulassen. ${ }^{649}$

Die kategorische Betrachtungsweise von SOCIALDATA veranschaulicht deutlich die Diskrepanz zwischen stadt- oder mobilitätsplanerischer Sicht einerseits sowie individueller Einschätzung eines Pkw-Nutzers andererseits. Gleichzeitig macht die Untersuchung von SOCIALDATA aber deutlich, dass ein respektables Potenzial an Pkw-Verkehren existiert, die verlagert oder vermieden werden könnten, ohne dabei das „Recht der Bürger auf Mobilität“ einschränken zu müssen. ${ }^{650}$ Jedoch bedarf es für eine realistische Potenzialabschätzung auch der Berücksichtigung der Verlagerung von Fahrten, denen andere Wegezwecke zugrunde liegen (siehe hierzu Kapitel 6.3.2).

Die in Kapitel 4.4.2 dargestellten Modal Split-Anteile bei unterschiedlichen Wegezwecken zeigen, dass der ÖPNV allenfalls bei Wegen zur Ausbildung eine ansehnliche Position einnimmt (in Hessen 29\%, in Frankfurt und Offenbach 33\%). Hierbei handelt es sich aber vornehmlich um eine Gruppe „nicht-wahlfreier“ Kunden. Bei allen anderen Wegezwecken, bei denen die Wahlfreiheit zwischen den Verkehrsträgern größer ist, liegt der ÖPNV-Anteil niedriger. Bei Fahrten im Einkaufs- und Freizeitverkehr651, die einen immer größer werden Stellenwert einnehmen, werden nur jeweils $4 \%$ der Wege mit dem ÖPNV zurückgelegt. „Angesichts der Freiheit der Zielwahl und der Unabhängigkeit in der Gestaltung der Freizeit, dürfte die Neigung, sich an Fahrplan und Haltestelle zu ,binden', weniger ausgeprägt sein“. ${ }^{652}$ Der ÖPNV-Anteil bei Begleitwegen (Bring- und Holfahrten) fällt mit $2 \%$ noch niedriger aus. Hier dominiert ebenfalls der Pkw mit $72 \%$ als bevorzugtes Verkehrsmittel. Bei Fahrten im Berufsverkehr erreicht der ÖPNV einen Anteil von 13\% in Hessen. Auch hier dominiert die Nutzung des Pkw mit 71\% deutlich. Es scheint daher, dass der ÖPNV den Kundenwünschen nicht gerecht wird und/oder Hemmschwellen existieren, die die potenziellen Kunden davon abhalten den ÖPNV zu nutzen. ${ }^{653}$

Diese Hemmschwellen für eine vermehrte Nutzung des ÖPNV gilt es daher auf breiter Front abzubauen. Gleichzeitig muss der ÖPNV attraktiver und besser werden - und zwar in vielerlei Hinsicht. Der ÖPNV muss „kleinteiliger, flexibler, designorientierter, spaßiger,

\footnotetext{
${ }^{649}$ vgl. Blümel 2004, S.29

${ }^{650}$ vgl. Klühspies 1999, S.15

651 inklusive Fahrten für "private Erledigung“"

652 Planungsverband Ballungsraum Frankfurt/Rhein-Main u.a. 2005, S.66

653 vgl. Planungsverband Ballungsraum Frankfurt/Rhein-Main u.a. 2005, S.33
} 
emotionaler, kundenorientierter, städtebaulicher, altengerechter und barrierefreier, aber auch wirtschaftlicher werden“. ${ }^{654}$ Dies hat außerdem in Zeiten zu geschehen, in denen das wirtschaftliche und gesellschaftliche Umfeld für einen Wandel im ÖPNV zusehends schwieriger wird (siehe Kapitel 3.8) und es auch zu einer intramodalen Wettbewerbssituation zwischen den ÖPNV-Verkehrsunternehmen kommt (siehe Kapitel 5).

Das Ziel einer nachhaltigen Mobilitätssicherung wird keineswegs nur über eine, auf den ÖPNV ausgerichtete, eindimensionale sektorale Verkehrsplanung erreicht werden können. Wie dargestellt bedarf es zur Sicherung nachhaltiger Mobilität eines mehrdimensionalen und integrierten Vorgehens, im Rahmen dessen alle Verkehrsakteure in einem Gesamtverkehrskonzept einbezogen und vernetzt werden.655 Der hessische Wirtschaftsminister Riehl fasst die Herausforderung für den ÖPNV in einem Gesamtverkehrskonzept für Hessen wie folgt zusammen:

„Mobilitätsbewältigung der Zukunft erfordert ein integriertes Gesamtverkehrssystem. Der ÖPNV ist darin eine feste Größe - und das darf keine Randgröße sein. Die Menschen sollen ihn wegen seiner Attraktivität öfter nutzen". 656

Gleichermaßen lauten die Ziele im Hess. ÖPNVG:

„Der öffentliche Personenverkehr ist Teil des Gesamtverkehrssystems und trägt dazu bei, die Mobilitätsnachfrage zu befriedigen. Ziel ist es, den öffentlichen Personennahverkehr als wichtige Komponente zur Bewältigung des Gesamtverkehrsaufkommens zu stärken. Das Angebot des öffentlichen Personennahverkehrs ist leistungsfähig und effizient zu gestalten". .657

Aus diesem Anspruch ergeben sich für die nachhaltige Sicherung der Mobilität in der Region Frankfurt Rhein-Main zwei Konsequenzen:

1. die Entwicklung eines integrierten Gesamtverkehrskonzeptes und

2. die Stärkung des ÖPNV als wichtigen Bestandteil eines solchen Konzeptes.

${ }^{654}$ Topp 2006 (a), S.26

655 vgl. Topp 2006 (a), S.26

656 HMWVL 2003 (b)

${ }^{657}$ Hessischer Landtag 2005, S.787 
Auf die wesentlichen Aspekte des 1. Punktes, integriertes Gesamtverkehrskonzept, wird im folgenden allgemein eingegangen. Mit den Möglichkeiten der Attraktivitätssteigerung und dem Abbau von Zugangsbarrieren, Punkt 2, befasst sich die Arbeit im weiteren Verlauf detailliert.

\subsubsection{Integriertes Gesamtverkehrskonzept}

\subsubsection{Verkehrsplanerischer Ansatz}

Wesentliches Merkmal eines integrierten Gesamtverkehrskonzeptes 658 ist die Zusammenfassung aller kommunalen Verkehrsfragen in einem Management mit neuen Zuständigkeiten und Instrumenten. Erst so wird ein ganzheitliches Handeln in ökonomischen, ökologischen und sozialen Zusammenhängen möglich. Vor allem aber ist ein integriertes Gesamtverkehrskonzept durch die physische, informatorische und organisatorische Vernetzung der früher getrennten Verkehrssysteme charakterisiert. Diese Vernetzung ist die Voraussetzung für die Entstehung intermodaler Wegeketten, denn „nur integrierte Verkehrsmittel werden auf Dauer Bestandteil intermodaler Wegeketten sein“. ${ }^{659}$

"Integrativ" bezieht sich also nicht alleine auf die verkehrsmittelübergreifende Planung („,modale Integration“), sondern auch auf die Integration der verschiedenen Planungsebenen, die Berücksichtigung der unterschiedlichen Maßnahmenmöglichkeiten ${ }^{660}$ und die Einbindung aller Beteiligten („sektorale Integration“). Ein integriertes Gesamtverkehrskonzept bzw. ein integrierter Gesamtverkehrsplan tritt damit an die Stelle von vormals sektoralen Entwicklungsplänen (z.B. ÖPNV-Bedarfsplan). Er ist ausdrücklich kein Verkehrswegeplan, der nur die infrastrukturellen Vorhaben behandelt, sondern die Möglichkeiten, Erfordernisse und Wirkungen verkehrspolitischer, rechtlicher, organisatorischer, marketingseitiger und technischer Maßnahmen umfasst („Maßnahmenintegration“). Erst darüber wird sicher gestellt, dass verkehrliche Innovationen ihre größte Wirkung entfalten können. ${ }^{661}$ Darüber hinaus bietet es sich an, die Strategien und Maßnahmen des Gesamtverkehrskonzeptes mit benachbarten Regionen bzw. über- und untergeordneten Pla-

\footnotetext{
658 auch integrierte Stadt- und Verkehrsplanung; vgl. Nuhn und Hesse 2006, S.317

659 Topp 2002, S.219

${ }^{660}$ Schäfer-Sparenberg, Bongardt und Dalkmann regen bspw. an, die ÖPNV-Leistung zusammen mit der Parkraumbewirtschaftung auszuschreiben. So sei es möglich, dass die Vereinfachung der Tarife direkt über die Parkgebühren finanziert würde; vgl. Schäfer-Sparenberg, Bongardt und Dalkmann 2006, S.71.

${ }^{661} \mathrm{vgl}$. Halbritter u.a. 2005, S.40
} 
nungsebenen abzustimmen („räumliche Integration“). ${ }^{662}$ Nur so wird es möglich sein, die Verkehrsmittelwahl und das Mobilitätsverhalten in nachhaltige Bahnen zu lenken bzw. Mobilität ganzheitlich zu managen.

Übergeordnetes Ziel des integrierten Gesamtverkehrskonzeptes ist eine stadt- und umweltverträgliche Abwicklung des Verkehrs, wobei vor allem Akzente auf die Förderung des nichtmotorisierten Verkehrs und des ÖPNV gelegt werden. Daneben spielen vor allem die Bestandserhaltung, -erneuerung und -verbesserung der Verkehrsinfrastruktur „sowie die städtebauliche Integration des Verkehrs“ eine Rolle. Begleitend sollen Siedlungsschwerpunkte auf bereits durch den ÖPNV erschlossene Gebiete gesetzt werden (z.B. S-Bahn-Haltepunkte), die zusätzlich durch bedarfsorientierte Bedienformen oder Car-Sharing-Angebote ergänzt werden. Nachfrageorientierte, verkehrssteuernde Maßnahmen werden vor allem in Form der Begrenzung des Parkraumes sowie in der Parkraumbewirtschaftung gesehen. Ergänzenden Charakter haben die Steuerung und Optimierung des Güterverkehrs (z.B. durch die Einrichtung von Güterverkehrszentren) sowie die Nutzung fahrzeugtechnischer Maßnahmen zur Reduzierung von Lärm- und Schadstoffemissionen. 663

„Der Begriff ,Integrierte Verkehrsentwicklungsplanung' impliziert zudem zweifellos einen zielorientierten Anspruch der Gestaltung von Verkehrssystemen, Verkehrsnachfrage, Verkehrsabwicklung und Verkehrsauswirkungen“. ${ }^{664}$ Das kurz- und mittelfristige Ziel eines integrierten Gesamtverkehrskonzeptes ist die räumliche und zeitliche Verlagerung der Verkehrsnachfrage, indem die Kapazitäten der Verkehrsinfrastruktur effizienter ausgenutzt werden. Hierfür sind insbesondere auch die spezifischen Potenziale der einzelnen Verkehrsmittel sowie die Potenziale aus ihrer Vernetzung auszuschöpfen. Langfristig, und somit nachhaltig betrachtet, geht es um die Optimierung der verkehrlichen Einflüsse auf die Ökonomie, die Reduzierung der Verkehrsemissionen und die sozialverträgliche Gestaltung des Verkehrs. ${ }^{665}$ Die Umsetzung eines integrierten Gesamtverkehrskonzeptes erfordert also ein langfristiges Vorgehen, welches nach Hinricher und Schüller

\footnotetext{
${ }^{662}$ vgl. Landtag Nordrhein-Westfalen, S.11ff sowie Beckmann 2001, S.5

663 vgl. Nuhn und Hesse 2006, S.197

664 Beckmann 2001, S.5

${ }^{665}$ vgl. Busch, Keller und Kessler 2004, S.457
} 
"die unterschiedlichen Maßnahmen und Instrumente, deren Zusammenwirken auch auf verschiedenen räumlichen Ebenen, unterschiedlichen Zuständigkeiten und auch Zeithorizonte einbezieht. Ein solchermaßen integrierender und zugleich integrierter Ansatz [...] muss auf Dauer angelegt sein, also ein dauerhaft ausgewogenes Verhältnis von sozialen, ökonomischen und ökologischen Erfordernissen der Mobilität gewährleisten. [...] Gerade die langfristige Ausrichtung der Strategie erfordert es, den langfristigen Strukturwandel in Gesellschaft, Wirtschaft und Technik in seiner Bedeutung für die Verkehrspolitik zu erfassen und zu berücksichtigen". ${ }^{666}$

Gleichzeitig bedeutet dies, dass die Verkehrspolitik die Rahmenbedingungen für eine nachhaltige Mobilitätssicherung schaffen muss bzw. nicht erwartet werden kann, dass sich der Verkehrsbereich entgegen aller „Entwicklungen und Entscheidungen in anderen Wirtschafts-, Gesellschafts- und Politikbereichen“ - wie die fortschreitende Globalisierung oder die Öffnung des europäischen Binnenmarktes - aus sich selbst heraus optimieren wird. ${ }^{667}$ Hinricher und Schüller fordern hierzu:

"Jeder Politikbereich muss seinen Beitrag für die Gestaltung eines dauerhaft tragfähigen Verkehrssystems leisten. Diese Forderung ist nicht zuletzt deshalb berechtigt, weil die gesamtwirtschaftliche Bedeutung des Verkehrssektors nicht hoch genug eingeschätzt werden kann". 668

Obwohl dem Setzen von verkehrspolitischen Rahmenbedingungen durch die öffentliche Hand eine große Bedeutung zukommt, ist die erfolgreiche Umsetzung eines Gesamtverkehrskonzeptes nicht alleinige Aufgabe von öffentlichen Aufgabenträgern. Der Erfolg wird auch davon abhängen, inwieweit privatwirtschaftlichen Interessen an nachhaltiger Mobilität ein Platz eingeräumt wird. Schließlich sollen auch marktwirtschaftliche Prinzipien zu einer effizienteren Abwicklung von Verkehrsleistung, zu einer besseren Auslastung der Infrastruktur und zu einer Etablierung umweltverträglicher Fahrzeug- und Mobilitätskonzepte führen. Hinricher und Schüller vertreten die Auffassung, dass es Aufgabe des Staates sei,

"[...] seiner Gemeinwohlverpflichtung gerecht zu werden. Auch hier sollten jedoch Wege gesucht werden, die sich nicht am finanziellen Aufwand, sondern an dem erzielten Ergeb-

666 Hinricher und Schüller 2002, S.590f

$667 \mathrm{vgl}$. Hinricher und Schüller 2002, S.590f

668 ebd. S.591 
nis messen lassen. Dies gilt für die Vorhaltung der Verkehrsinfrastruktur ebenso wie für die Verkehrsbedienung, soweit diese nicht auf eigenwirtschaftlicher Basis - also ohne finanzielle Förderung - erbracht werden kann. Die Integrationsaufgabe besteht darin, beide Ordnungsprinzipien miteinander zu vereinbaren". 669

\subsubsection{Nutzung der spezifischen Stärken der Verkehrsträger}

Im Hinblick auf eine konkrete Ausgestaltung eines integrierten Gesamtverkehrskonzeptes und der darin enthaltenen verkehrlichen Maßnahmen, müssen die spezifischen Leistungsfähigkeiten der Verkehrsträger auf die örtlichen Gegebenheiten verträglichkeitsorientiert übertragen werden. Dabei gilt es die erforderlichen Maßnahmen problemorientiert dezentral zu entwickeln, zu entscheiden und umzusetzen. Hierbei kommt der engen Abstimmung zwischen Verkehrs- und Siedlungspolitik in Agglomerationsräumen eine besondere Bedeutung zu. So unterstützt in Agglomerationsräumen - so auch in der Region Frankfurt Rhein-Main - eine nach innen gerichtete Siedlungsentwicklung auf zentrale und vom ÖPNV gut erschlossene Zentren die Verlagerung von MIV-Fahrten auf den ÖPNV. In ländlichen Gebieten dagegen ist der ÖPNV dem MIV nicht grundsätzlich vorzuziehen. Vielmehr kommt es auf den zu erzielenden Auslastungsgrad und die zur Verfügung stehenden Alternativen an. ${ }^{670}$ Nur so wird unter der schwierigen Konkurrenzsituation zum Auto eine Bestandserhaltung oder auch Steigerung der Fahrgastzahlen möglich sein. Gleichzeitig muss eingeräumt werden, dass im „öffentlichen Verkehr die Zentrale-OrteHierarchie und das punkt-axiale Konzept nur noch auf hohem Maßstabsniveaus tragfähig“ ist. ${ }^{671}$ Topp äußert sich diesbezüglich folgendermaßen: „Weite Teile von Suburbia werden mehr oder weniger auf das Auto angewiesen sein; ÖPNV als Daseinsvorsorge wird im liberalisierten Verkehrsmarkt ausgedünnt" ${ }^{\prime 672}$

Heinze, aber auch andere zeigen auf, wie sich der ÖPNV weiterentwickeln kann, wenn neue Herausforderungen angenommen werden. Auch hier können Maßnahmen des Mobilitätsmanagements und IuK-Technologien wesentlich dazu beitragen,

„vorhandene Restmobilität zusammenzubinden, neue Wachstumsfelder (wie Freizeitverkehr und Paketdienste) zu erschließen, Verknüpfungen herzustellen (wie im Zubringer-

\footnotetext{
${ }^{669} \mathrm{ebd}$.

670 vgl. Nuhn und Hesse 2006, S.326

${ }^{671}$ Heinze 2001, S.61

672 Topp 2002, S.219
} 
und Verteilerverkehr zu den Verkehrsachsen) und sich an der Kundennähe privater Geschäftsleute zu orientieren". ${ }^{673}$

Das Umweltbundesamt verweist darauf, dass

"die Umweltvorteile des ÖPNV gegenüber dem MIV auch unter zunehmendem Wettbewerbsdruck zu sichern und auszubauen [sind]. Dies kann durch den Einsatz emissionsarmer Busse [...] und durch die Verbesserung ihres Auslastungsgrades bei gleichzeitiger Optimierung der Angebotsqualität (Pünktlichkeit, Sicherheit, Sauberkeit usw.) erreicht werden". 674

Es ist ersichtlich, dass vor allem den leistungsstarken Verkehrsmitteln auf der Schiene, also S- und Regionalbahnen, im Ballungsraum eine große Bedeutung für die zukünftige nachhaltige Verkehrsentwicklung zukommt. Darüber hinaus bedarf es aber auch eines leistungsfähigen und abgestimmten Verteilersystems auf lokaler (v.a. auch ländlicher) Ebene, über das die ÖPNV-Kunden ihre Bestimmungsorte erreichen können. Letztendlich sollen so die Verkehrsinfrastrukturen besser ausgelastet und der Ausbaubedarf in der Fläche reduziert werden. Da infolge der verbesserten Auslastung die Betriebs- und Unterhaltungskosten pro Fahrt sinken, ist eine nach innen gerichtete Siedlungsentwicklung auch betriebswirtschaftlich sinnvoll. 675 Ein integriertes Verkehrsmanagement (siehe 4.6.3), als betrieblicher Kern des Verkehrs, trägt zusätzlich zur Optimierung des Gesamtverkehrssystems bei. ${ }^{676}$

Allgemein werden den einzelnen Verkehrsträgern unterschiedliche spezifische Vorteile eingeräumt:

- Dem Fußgänger- und Radverkehr kommt vor allem bei - auch spontanen - Wegeanlässen auf kurzen Entfernungen, insbesondere in dicht besiedelten Gebieten, eine große Bedeutung zu. Das Fahrrad trägt als Bestandteil eines modernen, integrierten Verkehrssystems zur nachhaltigen und stadtverträglichen Mobilität wesentlich bei. Vor allem in verdichteten Räumen kann das Fahrrad zur Verbesserung der Leistungsfähigkeit des gesamten Verkehrssystems und zur Reduzierung

\footnotetext{
${ }^{673}$ Heinze 2001, S.62

674 Umweltbundesamt 2003 (a), S.5

$675 \mathrm{vgl}$. Kanton Zürich 2006, S.21

676 ebd., S.27
} 
der Verkehrsbelastungen beitragen. Bei Distanzen, die über $5 \mathrm{~km}$ liegen, spielt das Fahrrad als „Ergänzungsverkehrsmittel“ zum ÖPNV eine Rolle, „weil es den Einzugsbereich der Haltestellen und somit das Fahrgastpotenzial erheblich vergröBert“. ${ }^{\prime 77}$ Voraussetzung hierfür sind allerdings Abstellanlagen an den ÖPNVZugangspunkten (siehe Kapitel 4.3.7). Bei Distanzen unter $1 \mathrm{~km}$ spielt auch der Fußgängerverkehr im Vor- und Nachlauf bei der Nutzung des ÖPNV eine Rolle. Außerdem sind Radfahren und zu Fuß gehen (Fortbewegungs-)Mittel der aktiven Erholung. Aufgrund des geringen Platzbedarfs weisen Fußgänger- und Radverkehre im Ballungsraum sehr hohe Effizienzen auf, wenngleich an die Verkehrssicherheit besondere Anforderungen gestellt werden.

- Dem ÖV kommt im Nahverkehrsbereich in dicht besiedelten Gebieten und bei ausgeprägten Verkehrsbeziehungen eine zentrale Funktion zu. In der Fläche sichert er die Grundversorgung mit Mobilität. Voraussetzung ist ein abgestimmtes sowie konkurrenz- und leistungsfähiges Angebot. Vor allem im Ballungsraum (bei hoher Auslastung) weist der ÖPNV eine hohe Flächen-, Umwelt- und Energieeffizienz auf. Im Fernverkehr ist die Bahn unterhalb einer Reisezeit von ca. vier Stunden geeignet - vorausgesetzt es handelt sich um Direktverbindungen oder Verbindungen mit guten Anschlüssen, was aus betriebswirtschaftlichen Gründen vor allem zwischen Metropolregionen sowie Großstädten der Fall ist.

- Im MIV ist vor allem die hohe zeitliche und örtliche Verfügbarkeit hervorzuheben. Er besitzt große Vorteile bei der Erreichbarkeit von peripheren und nachfrageschwachen Räumen sowie der Erschließung von Tangentialverbindungen. Der MIV erfüllt außerdem vielfältige individuelle Anforderungen an den Personenund Warentransport. In Ballungsräumen und bei ausgeprägten Verkehrsbeziehungen erweist er sich aufgrund seiner niedrigen Flächen-, Umwelt- und Energieeffizienz als nachteilig. Mit der Verbreitung und Professionalisierung von CarSharing-Angeboten besteht allerdings die Chance, dass der Pkw durchaus einen Beitrag zur nachhaltigen Mobilitätssicherung leistet und „neben zu Fuß, Fahrrad und ÖPNV die vierte Säule des Umweltverbunds“ wird. Voraussetzung ist aller-

677 vgl. RMV 2000, S.4 
dings ein Service rund um die Uhr, die flächendeckende Verfügbarkeit sowie die Einhaltung von Umweltstandards (z.B. Abgasnormen). 678

- Der Flugverkehr ist für die Verbindung von weit auseinander gelegenen Wirtschaftsräumen von Bedeutung. Ihm kommt vor allem bei Reisezeiten über 4 Stunden sowie im interkontinentalem Verkehr eine tragende Funktion zu. Die örtlich hohen Lärmauswirkungen des Flugverkehrs wirken sich negativ aus. 679

Abbildung 28 verdeutlicht die spezifischen Einsatzbereiche der einzelnen Verkehrsträger in raum-zeitlicher Hinsicht.

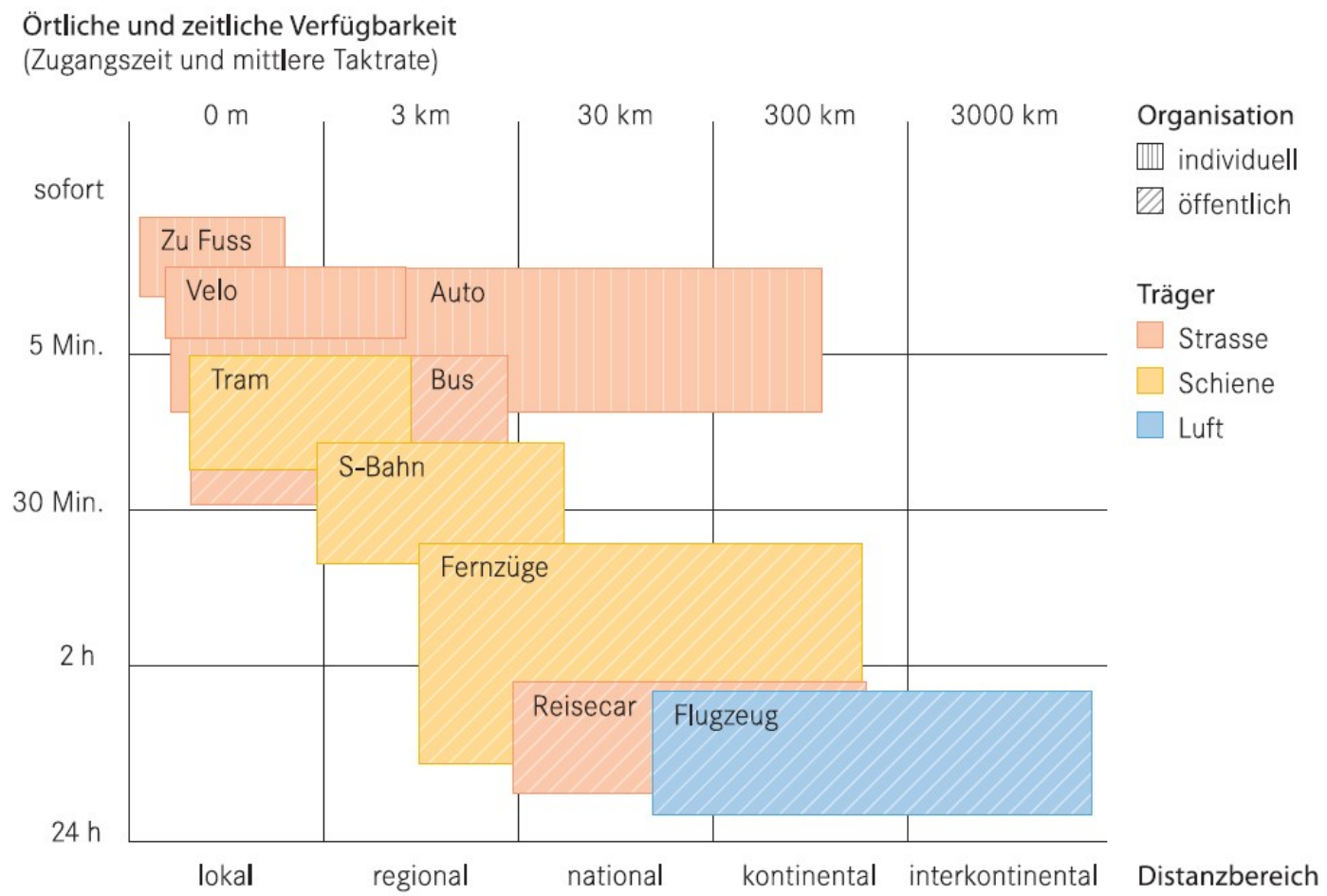

Abbildung 28: Einsatzbereich der verschiedenen Verkehrsmittel im Personenverkehr Quelle: Gesamtverkehrskonzept des Kantons Zürich; Kanton Zürich 2006, S.24

4.7.2.3 Definition und Messung von Qualitätsansprüchen und -zielen

Die Abhängigkeiten von Verkehrs-, Siedlungs- und Wirtschaftspolitik verdeutlichen die Notwendigkeit einer übergeordneten und integrierenden Managementverantwortung für die Gesamtverkehrsplanung. Um die Wirkungen und den Erfolg der einzelnen Maßnah-

678 vgl. Topp 2002, S.219

${ }^{679}$ vgl. Kanton Zürich 2006, S.24ff 
men abschätzen zu können, müssen ferner Beurteilungsbereiche und Qualitätsansprüche festgelegt werden. ${ }^{680}$

Der „Anwenderleitfaden für Qualitätsziele und Indikatoren für eine nachhaltige Mobilität" des Umweltbundesamtes aus dem Jahre 2005 gliedert die Ziele einer nachhaltigen Mobilität in sieben Zielbereiche und ordnet jedem Bereich Qualitätsziele zu (siehe Tabelle 8):

\section{Zielbereich}

Qualitätsziel

1. Umweltverträgliche 1.1 Möglichst hoher Anteil der täglichen Wege im Umweltverbund Verkehrsmittelwahl

2. Sicherung und För- 2.1 Dichtes und funktional ausreichendes Fußwegenetz \begin{tabular}{l|l} 
derung des Zufuß- & 2.2 Hohe Aufenthaltsqualität des öffentlichen Raums
\end{tabular} gehens 2.3 Fußgängerfreundliches Klima

3. Sicherung und Förderung des Radverkehrs

3.1 Dichtes und sicheres Radverkehrsnetz

3.2 Sicherung der Erreichbarkeit städtischer Ziele im Radverkehr

3.3 Fahrradfreundliches Klima

4. Förderung des ÖPNV

4.1 Gute räumliche und zeitliche Verfügbarkeit öffentlicher Verkehrsmittel in Stadt und Region

4.2 Konkurrenzfähigkeit des ÖPNV gegenüber dem MIV

4.3 Gute Erreichbarkeit und attraktive Gestaltung von Haltestellen des ÖPNV

5. Sicherung des not- 5.1 Flüssiger Verkehr auf Hauptverkehrsstraßen bei niedrigem Geschwindigwendigen MIV keitsniveau

5.2 Flächenhafte Verkehrsberuhigung in den Wohngebieten

5.3 Sicherung der Erreichbarkeit städtischer Ziele im MIV

6. Gesundheitsschutz 6.1 Keine Gesundheitsgefährdungen und Schlafstörungen durch Verkehrslärm und Ressourcenschonung

\section{2 Keine Gesundheitsgefährdungen durch verkehrsbedingte Luftschadstoffe}

6.3 Keine getöteten und schwer verletzten Personen im Straßenverkehr

6.4 Beschränkung der vorhandenen Verkehrsflächen auf ein notwendiges Maß

6.5 Sparsamer Energieverbrauch und verstärkte Nutzung regenerativer Energien im MIV

7. Nachhaltige Planung, Beteiligung und Information

7.1 Integrierte kommunale Planung unter Berücksichtigung der engen Zusammenhänge zw. Stadtentwicklung, Verkehrsentwicklung und Umweltqualität

7.2 Festschreibung von umweltverträglichen Bau- und Verkehrskonzepten in den Bebauungsplänen

7.3 Regelmäßige Überprüfung der umgesetzten Siedlungs- und Verkehrskonzepte hinsichtlich der Zielerreichung in bezug auf festgelegten Handlungsziele

7.4 Angemessene Beteiligung der Bevölkerung an den Planungen und bei der Entscheidungsfindung

7.5 Aktive Unterstützung und Förderung der Lokalen Agenda 21-Aktivitäten durch die Kommunalverwaltung

7.6 Eröffnung eines freien Zugangs zu wichtigen kommunalen Daten für alle interessierten Einwohner/innen

Tabelle 8: Zielbereiche und Qualitätsziele nachhaltiger Mobilitätsentwicklung

Quelle: Umweltbundesamt 2005 (a), S.10, eigene Bearbeitung

${ }^{680}$ vgl. Landtag Nordrhein-Westfalen 1998, S.17 
Aus den definierten Zielbereichen wird ersichtlich, dass eine Förderung des ÖPNV in direkter Weise zur Erreichung von Zielen nachhaltiger Mobilitätsentwicklung beiträgt (siehe Tabelle 8 , fettgedruckte Ziffern $1.1 ; 4.1 ; 4.2 ; 4.3$ ). Setzt man voraus, dass es durch die Förderung des ÖPNV zu einer Verlagerung von Fahrten des MIV auf den ÖPNV kommt und sich hierdurch die negativen Einflüsse des MIV reduzieren, unterstützt der ÖPNV indirekt auch die Erreichung weiterer Ziele (siehe Tabelle 8, kursive Ziffern). Hier ist vor allem der Bereich des Gesundheitsschutzes und der Ressourcenschonung zu nennen (6.16.4). Hier unterstützt eine Förderung des ÖPNV die eingegangenen Verpflichtungen der Bundesregierung zur Reduzierung des $\mathrm{CO}_{2}$-Austoßes. Daneben trägt der ÖPNV dazu bei, dass die notwendigen MIV-Fahrten störungsfrei abgewickelt werden können (5.1) und fördert durch die Reduzierung potenzieller Konfliktsituationen die Sicherheit im Fußgänger- und Radverkehr $(2.2 ; 3.2)$. Hierdurch wird die große Bedeutung des ÖPNV für die nachhaltige Mobilitätssicherung deutlich. Insofern ist die Steigerung des ÖPNV-Anteils Teil einer Nachhaltigkeitsstrategie, um die negativen Einflüsse des Verkehrs durch die immer noch steigende Nachfrage nach Mobilität zu minimieren. „Dies bezieht sich sowohl auf den sozialen Aspekt der Zugänglichkeit für alle Bevölkerungsgruppen als auch auf den Beitrag zur Reduzierung der Umweltbelastungen und der $\mathrm{CO}_{2}$-Emissionen“ ${ }^{6}{ }^{681}$

Im Anwenderleitfaden des Umweltbundesamtes wird ebenfalls die Wichtigkeit betont, dass die einzelnen Qualitätsziele mittels Indikatoren quantifizierbar sein müssen. Dabei sind die Qualitätsziele keineswegs als statische Determinanten zu verstehen, sondern müssen an die veränderten Rahmenbedingungen angepasst werden. Hierzu gehören beispielsweise rechtlich-organisatorische Veränderungen (z.B. EU-Vorgaben, Landesverkehrspolitik), die finanzielle Situation (z.B. kommunale Budgets) sowie prozessuale (z.B. Umsetzung und Dynamik der Verkehrsentwicklungsplanung) und strukturelle (z.B. Bevölkerungsentwicklung, Situation am Arbeitsmarkt) Einflüsse. ${ }^{682}$

Die Messbarkeit der Qualitätsziele ist auch vor dem Hintergrund von Zielkonflikten sinnvoll, die die Abwägung von Interessen notwendig machen kann. Diese Interessenkonflikte können auf unterschiedlichen behördlichen oder institutionellen Ebenen entstehen, beispielsweise, wenn problematische Planungsinhalte von den beteiligten Akteuren unterschiedlich gewichtet werden. So wird der Grad der integrativen Vernetzung der unter-

681 Schäfer-Sparenberg, Bongardt und Dalkmann 2006, S.13f

682 vgl. Umweltbundesamt 2005 (a), S.19 
schiedlichen Verkehrsträger von Verkehrsteilnehmern, Verkehrsplanern, Verkehrspolitikern, Geschäftsleuten oder Umweltschützern durchaus unterschiedlich interpretiert. Auch werden „Zielkonflikte einerseits zwischen der Verbesserung der Erreichbarkeit und der Siedlungsentwicklung nach innen und andererseits zwischen der Siedlungspolitik nach innen und der Verbesserung der Umweltqualität erkennbar“ ${ }^{683}$ Von daher bedarf es auch hier der engen Abstimmung im Planungs- und Umsetzungsprozess und der Beteiligung und Information aller Betroffenen. Insofern sieht der Anwenderleitfaden des Umweltbundesamtes auch hier einen eigenen Zielbereich (siehe Tabelle 8, Ziffern 7.1-7.6) vor. Das Spektrum möglicher Interessenkollisionen macht deutlich, dass die Messung der Nachhaltigkeit der Mobilität ausschließlich über den Modal Split - wie noch im Fortschrittsbericht der Bundesregierung zum Nachhaltigkeitsbericht im Oktober 2004 geschehen - nicht ausreicht bzw. nur eingeschränkt als Indikator für nachhaltige Mobilitätssicherung angesehen werden kann. 684

Im Hinblick auf die ökonomische, ökologische und soziale Bewertung eines integrierten Gesamtverkehrskonzeptes gibt es mit dem Ansatz des „Least Cost Transportation Planning“ (LCTP) einen verkehrsplanerischen Ansatz, der die bisherigen Verfahren, wie etwa das standardisierte Bewertungsverfahren, ergänzt. Voraussetzung für eine aufschlussreiche Anwendung ist aber eine ehrliche Zuordnung und ein transparenter Umgang mit Einnahmen und Ausgaben im Verkehrsbereich. Dies mag der Grund dafür sein, dass es bislang mit diesem Instrument bei den Kommunen noch wenig Erfahrung gibt. Das Umweltbundesamt sieht die Vorteile des LCTP folgendermaßen:

„Der Informationsgewinn durch LCTP besteht hauptsächlich darin, dass eine nicht nur am freien Markt, sondern zum Teil auch über die öffentliche Hand umgesetzte Bereitstellung von Mobilitätsdienstleistungen in ihrer Aufteilung und Größenordnung sichtbar gemacht wird. Diese Transparenz soll dazu beitragen, die Übereinstimmung von politischer Zielsetzung und Mittelverwendung überprüfbar zu machen und dadurch optimale Entscheidungen zu ermöglichen". ${ }^{685}$

\footnotetext{
683 Kanton Zürich 2006, S.22

${ }^{684}$ vgl. Schäfer-Sparenberg, Bongardt und Dalkmann 2006, S.13

685 Umweltbundesamt 2002 (b), S.13f
} 


\subsubsection{Zielgerichtete und verbindliche Umsetzung}

Mit der Gründung des Umlandverbands Frankfurt existierte in der Region Frankfurt RheinMain bereits eine institutionalisierte Plattform für die Entwicklung eines Gesamtverkehrsplans. Dem Planungsverband Ballungsraum Frankfurt/Rhein-Main als Rechtsnachfolger wurden diese Kompetenzen wieder entzogen und nun der IVM zugesprochen. „Die damit zersplitterte Aufgabenteilung im Bereich der Verkehrsplanung wird begleitet von unklaren Zuständigkeiten, Beschlussverfahren und Verbindlichkeiten, die mit den neuen Instrumenten und Organen des Planungsverbands kritisiert werden“".686 Eine verbindliche Umsetzung eines integrierten Gesamtverkehrsplans sowie die Handlungsspielräume scheinen unter diesen Rahmenbedingungen schwieriger geworden zu sein. Auch aufgrund der finanziellen Engpässe werden nunmehr „kleine“ Umsetzungsschritte angestrebt, die auf unterschiedlichen organisatorischen Ebenen erfolgen und deren verkehrsrelevanten Entscheidungen immer mit Blick auf das Gesamtverkehrskonzept getroffen werden sollten. Hierbei wird es wichtig sein, dass die Wirkungen der ausgeführten Maßnahmen entsprechend der übergeordneten Qualitätsziele erfasst und bewertet sowie gegebenenfalls nachgeregelt werden. Die Aufgabe der integrierten Verkehrsentwicklungsplanung steht der IVM erst noch bevor.

Nichtsdestotrotz müssen die spezifischen Stärken des ÖPNV entwickelt werden (siehe Kapitel 4.7.2.2). Für die konkrete Umsetzung von Maßnahmen im ÖPNV sind in Hessen die lokalen Aufgabenträgerorganisationen (sowie auf regionaler Ebene die $R M V G m b H$ ) verantwortlich, denen aufgrund der räumlichen Nähe eine angemessene Auswahl der Maßnahmen zugesprochen wird. ${ }^{687}$ Auf der anderen Seite ergibt sich durch den Grad der Dezentralität („dezentrales Prinzip“ siehe Kapitel 5.4.1.3) das Problem der Durchsetzung einheitlicher flächendeckender Qualitätsstandards bzw. der Verknüpfung mit übergeordneten Zielen. Das Hess. ÖPNVG schreibt hier vor, dass für „den Zugang und die Angebotsnutzung [...] einheitliche Normen mindestens verbundweit festzulegen" sind 688 und „Rahmenvorgaben und Gestaltungsziele der Verkehrsabwicklung“ in den Nahverkehrsplänen weiter auszuarbeiten sind. 689 Die Herausgabe von Grundsätzen (z.B. zu Marketing oder Vertrieb) kann durch die RMV GmbH erfolgen, unter dessen „Dach“ die lokalen

\footnotetext{
686 Stein und Wolf 2005, S.282

687 vgl. Schäfer-Sparenberg, Bongardt und Dalkmann 2006, S.58

688 Hessischer Landtag 2005, S.787

${ }^{689}$ ebd., S.790
} 
Aufgabenträgerorganisationen sogar „zur Zusammenarbeit verpflichtet sind um über ihre Zuständigkeitsgrenzen hinaus ein durchgängiges Angebot im Personennahverkehr zu gewährleisten“.690 Die Festlegung konkreter Qualitätsstandards und die Kontrolle der erbrachten Leistungen soll dann im Rahmen der Vereinbarungen zwischen lokalem Besteller und Ersteller erfolgen. ${ }^{691}$

Für eine notwendige rechtliche Bindungswirksamkeit der im Gesamtkonzept festgelegten Maßnahmen, wie sie beispielsweise aus Bauleitplänen bekannt sind, fehlt bislang allerdings die notwendige rechtliche Stringenz, bzw. liegen nur in rechtlichen Teilaspekten bezüglich bestimmter planerischer und ökologischer Gesichtspunkte rechtliche Vorschriften vor. Das Umweltbundesamt urteilt hierzu:

"Weitere sektorale und für ihren Bereich auch verdienstvolle Planungen wie die Nahverkehrs-, Luftreinhalte- und Lärmminderungsplanung sind zwar als Segmente einer medienübergreifenden, alle berührten Belange berücksichtigenden Planung einzusetzen, können aber eine rechtlich angeleitete kommunale Gesamtverkehrsplanung nicht ersetzen". ${ }^{692}$

Darüber hinaus ermöglicht eine Gesamtverkehrsplanung erst, dass frühzeitig Wechselwirkungen bzw. Auswirkungen auf andere Fachplanungsbereiche oder angrenzende Räume berücksichtigt werden. ${ }^{693}$ Das Umweltbundesamt schlägt daher im Rahmen eines Forschungsprojektes die Verabschiedung eines Gemeindeverkehrsplanungsgesetzes (GVPlG) vor, das die notwendigen Regelungen schafft, „die sowohl die Luftqualitätsziele mit rechtlicher Durchsetzungskraft versehen als auch den integrativen Ansatz des Gemeinschaftsrechts bezüglich aller Umweltbelastungen einschließlich des Lärms und der Eingriffe in Natur und Landschaft verwirklichen". ${ }^{694}$

\subsubsection{5 Übergreifende Kooperation und Organisation}

Organisatorische und strukturelle Neuerungen bzw. Veränderungen im Verkehrsbereich werden durch die komplexen Kompetenzverteilungen im ÖPNV häufig erschwert. Hier sind unter anderem die Trennung von Verantwortlichkeiten und institutionellen Zuständigkeiten nach Verkehrsmitteln, beispielsweise zwischen straßen- und schienengebunde-

\footnotetext{
690 ebd., S.788

${ }^{691} \mathrm{vgl}$. Hessischer Landtag 2005, S.789

692 Umweltbundesamt 2005 (b), S.3f

${ }^{693} \mathrm{vgl}$. Beckmann 2001, S.5

${ }^{694}$ Umweltbundesamt 2005 (b), S.4
} 
nen Verkehren, sowie räumlich begrenzte Zuständigkeitsgebiete zu nennen. Diese führen dazu, dass selbst prinzipiell geeignete Ansätze kaum Wirkung oder Synergieeffekte entfalten können. Darüber hinaus gibt es gerade in der kommunalen Verkehrspolitik eine große Zurückhaltung bei der Ausschöpfung der vielfältigen Handlungsmöglichkeiten im Verkehrsbereich, da gefürchtet wird, durch unpopuläre Entscheidungen Wählerstimmen einzubüßen. ${ }^{695}$ Beckmann sieht die Probleme bei der intermodalen Kooperation folgendermaßen:

„Die Risiken einer, Integrierten Verkehrsentwicklungsplanung' liegen vor allem im Aufwand und der Dauer der Prozesse. Insbesondere die Beteiligung verschiedenster Fachressorts, benachbarter Gebietskörperschaften sowie von Institutionen, Organisationen, Interessengruppen, politischen Gremien und der Bürgerschaft erfordern einen hohen Aufwand für Vorbereitung, Durchführung und Nachbereitung, der häufig kaum geleistet werden kann". ${ }^{696}$

Für die Optimierung des Gesamtverkehrssystems bedarf es daher nicht nur einer übergeordneten strategischen Sichtweise sowie der Vorgabe verkehrspolitischer Ziele, unter deren Maßgabe die Optimierung des Gesamtverkehrssystems zu erfolgen hat. Es bedarf auch einer neuen Qualität in der Kooperation der Zusammenarbeit mindestens der Verkehrsakteure in Form integrativer Organisationsformen, aus der sich neue Möglichkeiten ergeben, Mobilität in der Region in nachhaltiger Weise zu sichern. Ansonsten ist die Gefahr groß, dass Konflikte entstehen und/oder ein Verkehrsträger (allen voran der MIV) ohne die Berücksichtigung - oder gar auf Kosten - eines anderen (dann der ÖPNV) optimiert wird. Im Rahmen des Gesamtverkehrssystems geht es schließlich - auch - um die Verlagerung von Fahrten des MIV auf den ÖPNV. Das heißt nicht, dass Busse und Bahnen mit dem Automobil um Fahrten, respektive Verkehrsanteile konkurrieren sollen. Vielmehr geht es um integrative Vernetzung, wobei der ÖPNV eine tragende Funktion einnehmen sollte und nicht der Überlauf für zu volle Straßen wird. Die sichtbaren Auswirkungen einer fehlenden Verkehrsintegration, wie zum Beispiel der schwache Auslastungsgrad öffentlicher wie privater Verkehrsmittel, gilt es dabei zu reduzieren. ${ }^{697}$

\footnotetext{
${ }^{695}$ vgl. Beckmann 2001, S.6

${ }^{696}$ Beckmann 2001, S.6

$697 \mathrm{vgl}$. Henning und Schmidt 1998, S.24
} 
Die Lösung könnte die Entwicklung eines Organisationsmodells sein, das jenseits der traditionellen hierarchischen, vertikal integrierten Unternehmens- und Verwaltungsstrukturen liegt und das sich die kommunikationstechnische Vernetzung der Verkehrsakteure zunutze macht. Dabei kann bereits auf technisch-organisatorische Strukturen zurückgegriffen werden, die im Rahmen des Ausbaus der Kommunikationsinfrastrukturen in und zwischen den Unternehmen eingeführt wurden. Hierüber können Prozessabläufe optimiert und Einspareffekte generiert werden. Henning und Olbertz beschreiben, dass

„Wesentliche Merkmale dieser Strukturen [...] dezentrale Organisationseinheiten [sind], die auf der Grundlage der Telekommunikation miteinander vernetzt sind und Wettbewerbsvorteile bei der Bewältigung erhöhter Anforderungen an Flexibilität, Schnelligkeit und Qualität eröffnen“.698

Die erfolgreiche Funktion dieses Organisationsmodells ist von vielen Faktoren abhängig, so zum Beispiel von konkret definierten und zugewiesenen sowie allseits akzeptierten Rollen, die sich wiederum an überbetrieblichen Zielen und Leitbildern orientieren. Ferner müssen die technischen Voraussetzungen gegeben sein, zu denen ein leistungsfähiges Kommunikationsnetzwerk (Hard- und Software) gehört. Hierfür muss die Bereitschaft vorhanden sein, die eigenen technischen Schnittstellen offen zu legen. Gleichzeitig bieten sich über die Integration von IuK-Technologien neue Möglichkeiten, auf die Verkehrsnachfrage des einzelnen Verkehrsteilnehmers im Sinne einer Optimierung einzuwirken. Das bedeutet keine Abkehr von kollektiven Steuerungsformen, sondern eine stärkere Betonung von individuell ausgerichteten, kundenorientierten Dienstleistungen, die das gesamte Spektrum von Mobilität umfassen. Des weiteren ist wichtig, dass übergeordnete Handlungsvorgaben - beispielsweise auf der Basis verkehrspolitischer Leitbilder und Richtlinien - von den Beteiligten verbindlich umgesetzt werden müssen. Dies ist insbesondere dann von Bedeutung, wenn - wie in der Region Frankfurt Rhein-Main - unterschiedliche Interessenlagen vorliegen, die die Umsetzung von Innovationen verhindern können.

Zusammengefasst ist ein integriertes Gesamtverkehrskonzept ein Bündel lokal ausgeführter Maßnahmen im Verkehrsumfeld, die auf regionaler Ebene gemeinschaftlich getragen

${ }^{698}$ vgl. Henning und Olbertz 1997, S.11 
werden, deren Nutzen sich lokal auswirkt und deren Wirkungen regional zum tragen kommen. Topp fasst die Voraussetzungen und Wirkungen folgendermaßen zusammen:

„Modernes Mobilitätsmanagement, gute Verkehrsinfrastruktur und ein im Mobilitätsverbund integrierter ÖPNV als Alternative zum Auto stärken die Metropolregion; sie gewährleisten die Mobilität als Teilhabe am gesellschaftlichen Leben für Alle; sie halten Umland und Stadt zusammen, und sie sorgen für die Balance zwischen Urbanität und Verkehr der Metropole“. ${ }^{699}$

Allerdings muss hier resümiert werden, dass im ÖPNV die technischen Voraussetzungen kaum und die organisatorischen Voraussetzungen nur ansatzweise für eine intermodale Gesamtintegration vorhanden sind. Hier bedarf es zunächst der Konzentration auf die Entwicklung der intramodalen Voraussetzungen für verbesserte Kooperation als Grundlage für mehr Effizienz, die schließlich zu intermodaler Wettbewerbsfähigkeit führen soll.

\subsubsection{Stärkung des ÖPNV}

Soll der ÖPNV ein strategisches Instrument im Rahmen der nachhaltigen Regionalentwicklung sein und der Sicherung der Mobilität dienen, darf an diesen nicht alleine der Anspruch gestellt werden, nur die Grundversorgung an Mobilität zu sichern. Vielmehr sollte ein leistungsfähiger ÖPNV in Städten und Ballungsräumen ein wichtiges Element eines attraktiven und lebenswerten Umfeldes sein. Lediglich für die ländlichen Räume gilt, dass der ÖPNV im Rahmen der Daseinsvorsorge ein Mindestmaß an Mobilität für alle Bevölkerungsgruppen gewährleisten soll. Doch widerspricht dies nicht dem Ansatz, den ÖPNV mittels flexibler(er) und neuer Angebotsformen auch hier kundenorientiert weiterzuentwickeln. Diese Entwicklungsrichtung ist, ausgehend vom Rahmenwerk des Nahverkehrsgesetzes, in den Nahverkehrsplänen qualitativ vorzugeben und in den Ausschreibungen schließlich operativ und quantitativ umzusetzen. Denn nur über die eindeutige Definition der Leistungsparameter werden die Verkehrsunternehmen zielgerichtet gesteuert werden können. Dabei sind die ökonomischen, ökologischen und sozialen Nachhaltigkeitskriterien entsprechend zu berücksichtigen, wobei die komparativen Vorteile des ÖPNV gegenüber dem MIV unbedingt erhalten bleiben müssen. ${ }^{700}$

\footnotetext{
${ }^{699}$ Topp 2006 (a), S.26

700 vgl. Schäfer-Sparenberg, Bongardt und Dalkmann 2006, S.69 sowie Umweltbundesamt 2003 (a), S.5
} 
Damit der ÖPNV diese Funktionen in einem weiter wachsenden Mobilitätsmarkt auch zukünftig ausfüllen kann, muss er allerdings effizienter und attraktiver werden und müssen die Zugangsbarrieren, die einen Umstieg vom MIV auf den ÖPNV verhindern, abgebaut werden. Anderenfalls droht der ÖPNV teuer subventionierte Marktanteile zu verlieren - und damit auch die Fähigkeit mit anderen Verkehrsträgern in einem integrierten Gesamtverkehrskonzept zu kooperieren. Es wird nur zu einer nachhaltigen Verlagerung der MIV-Nachfrage auf den ÖPNV kommen, wenn die Qualität der ÖPNV-Verkehrsleistung den (sich verändernden) Kundenerwartungen entspricht und das Leistungsangebot flexibel und marktgerecht geplant wird. Vor allem vor dem Hintergrund der Finanzierbarkeit müssen die Konzepte den unterschiedlichen Bedingungen in Ballungsräumen und in ländlichen Gebieten Rechnung tragen (siehe Kapitel 3.8). Darüber hinaus ist aber auch eine einheitliche Marktpositionierung und ein gemeinsamer Marktauftritt aller ÖPNV-Unternehmen (verstanden als „Miteinander“) erforderlich, der nur über eine engere Kooperation der ÖPNV-Partner untereinander zu erreichen ist, die über den Zusammenschluss im Rahmen eines Verkehrsverbundes (als „Nebeneinander“ wahrgenommen) in der heutigen Form hinausreicht. ${ }^{701}$

Alleine aufgrund der Anzahl von Aufgabenträgerorganisationen und Verkehrsunternehmen im RMV-Gebiet, deren gemeinsames Unternehmensziel jeweils die verbesserte Kundenorientierung ist, wird der erhöhte Organisationsaufwand deutlich, die Kundenschnittstellen aufeinander abzustimmen, um einer Orientierungslosigkeit bei den Kunden entgegenzuwirken.702 Die Vergabe von Verkehrsleistung im Wettbewerb und die hiermit verbundene definitorische Macht der Kommunen soll zwar dazu führen, dass mit „verbessertem Service, höherer Qualität und mehr Kundeninformationen [...] eine höhere Kundenakzeptanz gewonnen und damit eine Steigerung der Fahrgastzahlen erreicht“703 wird (siehe Kapitel 5.3.2), doch lässt sich das Verkehrsverhalten der Menschen nicht alleine durch Produkte und Preise sowie die Information hierüber beeinflussen. ${ }^{704}$ Für die nachhaltige Mobilitätssicherung reicht es daher nicht aus, den ÖPNV als Dienstleistung einfach nur vorzuhalten. Vielmehr muss sich der ÖPNV vor dem Hintergrund der ordnungspolitischen, gesellschaftlichen, technischen und wirtschaftlichen Rahmenbedingun-

\footnotetext{
701 vgl. Kahl 2005, S.40

702 vgl. Blümel 2004, S.17

703 vgl. RMV 2005, S.65

${ }^{704}$ vgl. Canzler und Knie 2005, S.9
} 
gen weiterentwickeln. Die Vision der Entwicklung vom Transportunternehmen hin zum Mobilitätsdienstleister wurde bereits von vielen ÖPNV-Akteuren formuliert. Nun gilt es, im Sinne nachvollziehbarer Beweisführungen, den bislang inhalts- und wirkungslosen Absichtserklärungen konkretes Handeln folgen zu lassen.

Hierbei können die IuK-Technologien zu einem zentralen Faktor für erweiterte und koordinierte Vermarktungs- und Innovationsstrategien werden, um den ÖPNV in der Zukunft attraktiv und leistungsfähig zu gestalten. Neue Vertriebs-, Kommunikations- und Informationswege können einen wertvollen Beitrag leisten, wenn es darum geht, Kommunikationsnetze aufzubauen, Produktinnovationen einzuführen und über die marktorientierte Angebotsgestaltung und Vermarktung Effizienzvorteile zu erschließen. Dies beinhaltet auch organisatorische Potenziale in Form von schlanken Hierarchien, verstärkter Kooperation, dezentraler Koordination und Kontrolle.

Schließlich bedarf es im ÖPNV erst der Etablierung einer koordinierenden Instanz, die vorhandene Informationen aggregiert, Wissen generiert und verteilt. Die erfolgreiche Einführung und Nutzung dieser Technologien ist demnach an organisatorische Voraussetzungen geknüpft, die Innovationsbereitschaft und den Willen der Entscheidungsträger zur Veränderung voraussetzen. Nur hierüber wird sich der ÖPNV zu einem dem MIV ebenbürtigen Mobilitätsanbieter mit einer tragenden Rolle im Rahmen eines nachhaltigen Gesamtverkehrssystem entwickeln und einen Beitrag zur zukunftsorientierten Regionalentwicklung beisteuern.

Den Möglichkeiten der Erschließung dieser Effizienzpotenziale im ÖPNV widmen sich die anschließenden Teile der Arbeit. 


\title{
Teil C: Erschließung von Effizienzpotenzialen im ÖPNV
}

\section{Rahmenbedingungen für Veränderungsprozesse im ÖPNV}

\author{
"Wenn einer von einem Amt oder ein Beamter das Wort "verantwortlich" gebraucht, frage \\ man sogleich ,wem'".
}

Kurt Tucholsky, 1928

\subsection{Regionalisierung des ÖPNV}

Der Beginn des öffentlichen Transportwesens hat seine Wurzeln in der Entwicklung der Eisenbahn. Die frühen Eisenbahngesellschaften wurden alle unter Wettbewerbsbedingungen geführt und hatten das Ziel profitabel zu sein. Aus diesem Grunde heraus waren sie von der erfolgreichen Gewinnung von Fahrgästen abhängig. Als dann die Eisenbahngesellschaften verstaatlicht wurden und ein nationales Eisenbahnmonopol entstand, geschah dies mit der Maßgabe das Eisenbahnwesen zu vereinheitlichen und effizienter zu gestalten. Dieses war insbesondere vor dem Hintergrund der Industrialisierung und der Bedeutung des Güterverkehrs zu sehen, wobei auch machtpolitische Interessen jener Zeit eine Rolle spielten. Der gewerbliche Personenverkehr wurde aus praktischen Gründen gleich eingegliedert. Als 1934 das Personenbeförderungsgesetz (PBefG) und 1935 das Güterfernverkehrsgesetz erlassen wurden, entstand schließlich ein lückenloses Regelwerk über die Regulierung von Inbetriebnahmen von öffentlichen Liniendiensten, über die der Marktzugang und der Wettbewerb sowie das Angebot und die Preise kontrolliert werden konnten. Damit wurden die Ansätze zur Wettbewerbsbeschränkung, deren Grundlagen schon in der Weimarer Republik gelegt worden waren, weiter perfektioniert - auch zum Vorteil und Schutz der staatlichen Eisenbahn vor der Konkurrenz im Bereich des Straßenverkehrs. So wurde bereits früh von staatlicher Seite nicht nur in die intermodale Konkurrenz der Verkehrsträger regulierend eingegriffen, sondern auch die brancheninterne Konkurrenz beeinflusst. ${ }^{705}$

Dem PBefG zufolge können gemeinwirtschaftliche Verkehrsleistungen, die notwendig sind um eine „ausreichende Verkehrsbedienung“ (§ 13, PBefG) zu gewährleisten, vertrag-

${ }^{705}$ vgl. Püttner 2000, S.78f 
lich vereinbart oder den Verkehrsunternehmen auferlegt werden. Oberstes Gebot ist, dass jeweils die geringsten Kosten für die Allgemeinheit anfallen. Diese wiederum können müssen aber nicht - laut PBefG über eine Ausschreibung ermittelt werden. ${ }^{706}$ Bis zur ÖPNV-Deregulierung wurden aber faktisch keine Ausschreibungen vorgenommen. Für die Deregulierung des ÖPNV wurden mit der EWG-Verordnung Nr. 1191/69 (VO707 (EWG) 1191/69) im Jahre 1969 und ihrer Fortschreibung 1991 in der Verordnung Nr. 1893/91 die Grundlagen gelegt. Sie zielen unter anderem darauf ab, über die Marktöffnung im ÖP(N)V einen diskriminierungsfreien Marktzugang über die Pflicht zur Ausschreibung von gemeinwirtschaftlichen ÖPNV-Leistungen zu schaffen. ${ }^{708}$

Damit war zunächst einmal - zumindest vom Prinzip her - die Möglichkeit geschaffen, dass Verkehrsunternehmen im Kostenwettbewerb um zu vergebende ÖPNV-Leistungen konkurrieren. Mit der Vollendung des EU-Binnenmarktes am 31.12.1992 wurde gleichzeitig ein gemeinsamer Verkehrsmarkt geschaffen, in dem nun auch auf internationaler Ebene der Wettbewerb ausgetragen werden konnte. Die Leitidee der EU-Kommission war es, eine gemeinsame europäische Verkehrspolitik nicht nur unter marktwirtschaftlichen Aspekten weiter voranzutreiben, sondern auch die staatliche Einflussnahme weiter zu reduzieren. Ziel ist die Entwicklung eines effizienten und integrierten europäischen Gesamtverkehrssystems, welches den Verkehr in der EU zu sozialen und umweltgerechten Bedingungen ermöglicht. Verankert wurde dieses Ziel im 1992 erschienenen Weißbuch „Die künftige Entwicklung der Gemeinsamen Verkehrspolitik - Globalkonzept einer Gemein-

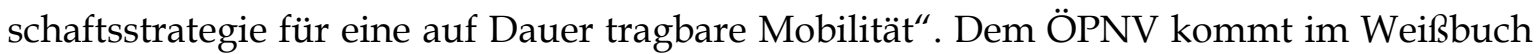
als umweltschonende Verkehrsart und umweltpolitisches Instrument eine besondere Aufmerksamkeit zu. Im Grünbuch, welches ebenfalls 1992 erschien, werden „Entwicklungsperspektiven für den öffentlichen Personennahverkehr als umweltschonende Alternative zum MIV“ dargestellt, bei der es zu einer „möglichst effiziente[n] Deckung des zunehmenden Verkehrsbedarfs [kommen soll], wobei gleichzeitig wirtschaftliche, soziale und ökologische Ziele erreicht werden sollen“. ${ }^{709}$

\footnotetext{
${ }^{706}$ vgl. Becker, T. 2004, S.23

707 Verordnung des Rates über das Vorgehen der Mitgliedsstaaten bei mit dem Begriff des öffentlichen Dienstes verbundenen Verpflichtungen auf dem Gebiet des Eisenbahn-, Straßen- und Binnenschiffsverkehrs

708 vgl. Aberle 2003, S.123

${ }^{709}$ vgl. Kahl 2005, S.274ff
} 
Ausgehend vom Deregulierungsdruck von Seiten der EU und den sich verschlechternden Ergebnissen der deutschen Eisenbahnen ${ }^{710}$ wurde dann 1993 die Bahnstrukturreform auf den Weg gebracht. ${ }^{711}$ Diese Strukturreform brachte eine Vielzahl von weiteren Gesetzen und Gesetzesänderungen mit sich, von denen insbesondere das Eisenbahnneuordnungsgesetz von Bedeutung ist, da dieses auch das Gesetz zur Regionalisierung des ÖPNV enthält. Im Rahmen dieser Reform wurden schließlich die ÖPNV-Gesetze der Länder erlassen ${ }^{712}$ und auch das PBefG 1996 überarbeitet. ${ }^{713}$

Mit Inkrafttreten des Regionalisierungsgesetzes am 1. Januar 1996 wurden die Verantwortlichkeiten im gesamten ÖPNV einschließlich des SPNV neu geregelt. Aufgabenträger für den ÖPNV sind demnach die Kreise und kreisfreien Städte. ${ }^{714}$ Damit wurde gleichzeitig die Aufgaben- und die Finanzverantwortung in eine Hand gelegt. Die Landkreise und kreisfreien Städte besitzen als Aufgabenträger demnach die unmittelbare Zuständigkeit für den ÖPNV. Die Wahrnehmung dieser lokalen Aufgaben wurde in Hessen weitestgehend in eigens dafür gegründete Lokale Nahverkehrsorganisationen (LNO) ausgelagert. Auf der regionalen Ebene übernehmen kommunal getragene Verkehrsverbünde die Verantwortung für die Planung, Organisation und Ausgestaltung des SPNV und des regionalen Busverkehrs sowie die Koordination der lokalen Nahverkehre. Ein wichtiges sektorales Steuerungsinstrument und Rahmenplan der kommunalen Aufgabenwahrnehmung ist der Nahverkehrsplan, der die Grundsätze des Bedienungsumfangs und der -qualität auf lokaler Ebene definiert. Außerdem beinhaltet der Nahverkehrsplan Rahmenvorgaben hinsichtlich der Investitionen bzw. der Bewilligung von Fördermitteln in den Bereichen der Infrastruktur- und Fahrzeugförderung. Der Nahverkehrsplan wird alle fünf Jahre

\footnotetext{
710 vgl. Kossak und Pällmann 2006, S.25

711 Die Bahnstrukturreform soll(te) sich in vier Schritten vollziehen. Die Zusammenlegung von Deutscher Bundesbahn und Deutscher Reichsbahn in eine Aktiengesellschaft sowie die Aufgliederung in verschiedene Geschäftsbereiche unter dem Dach einer Holding sind erfolgt. Der letzte Schritt, die Auflösung der Holding und die damit mögliche Trennung von Netz und Leistungserstellung ist noch offen bzw. ist eine politische Umsetzung bislang nicht erfolgt.

712 vgl. Becker, T. 2004, S.15f

${ }^{713}$ Hierbei wurden allerdings die planungs- und genehmigungsrechtlichen Zuständigkeiten der Aufgabenträger nicht entsprechend gestärkt. Dies hat in jüngerer Zeit regelmäßig zu Unsicherheiten bei den Aufgabenabgrenzungen geführt; vgl. Umweltbundesamt 2003 (a), S.23.

714 In Hessen liegen die „Aufgabenträgerschaften“ für den ÖPNV nach der Neuregelung bei den Landkreisen, Städten und so genannten Sonderstatusstädten (kreisangehörige Städte mit mehr als 50.000 Einwohner).
} 
angepasst und fortgeschrieben, wobei insbesondere die Rahmenvorgaben aus den Landes- und Gebietsentwicklungsplänen zu berücksichtigen sind.715

Mit der Deregulierung kam gleichzeitig die Debatte auf, in welchem Umfang der ÖPNVMarkt liberalisiert werden sollte. Diese Debatte rankt um die Frage, ob bestimmte Funktionen der Daseinsvorsorge (siehe Kapitel 5.2), die wesentlich für das Funktionieren eines Staates sind, eher von öffentlicher oder privater Seite wirtschaftlich effizient erbracht werden können. Zuletzt schien sich hier ein neoliberaler wirtschaftspolitischer Ansatz durchzusetzen, der die ausnahmslose Privatisierung von bislang staatlich kontrollierten Bereichen wie beispielsweise Post, Fernmeldewesen, Energieversorgung, Abfallwirtschaft und auch Öffentlicher Verkehr vorsah. Die neoliberale Seite sieht in der Privatisierung ehemals öffentlicher Bereiche die Interessen der Bürger stets gewahrt, da aufgrund der Profitorientierung die privaten Unternehmen ihr Handeln an den Interesse der Kunden orientieren würden - anderenfalls sei ein Scheitern am Markt unabdingbar. Diese Position steht im Widerstreit zur konservativen Argumentation, dass es im ÖPNV bei fehlender staatlicher Steuerung im Rahmen einer wettbewerbspolitischen Ordnung zu einem „Marktversagen“ 716 kommen könnte (siehe Kapitel 6.1.4). Nach neoliberaler Auffassung trägt der Staat jedoch selber zur Ineffizienz des ÖPNV bei („Staatsversagen“) und sollte sich von daher nur auf solche Funktionsbereiche beschränken, bei denen die wirtschaftliche Ineffizienz tatsächlich auf ein immanentes Marktversagen zurückzuführen sei. Auf der anderen Seite vertreten die (neo-) konservativen Kräfte die Auffassung, dass der Staat durchaus private Interessen wahrnehmen kann, vor allem und gerade weil er keine Rücksicht auf wirtschaftlichen Profit nehmen müsse. Die neo-konservativen Vertreter argumentieren außerdem, dass die Privatisierung zu einer Entdemokratisierung führe und eine langfristige nachhaltige Entwicklung privatwirtschaftlichen Interessen untergeordnet würde. ${ }^{717}$ Insbesondere gehe mit einer vollständigen Deregulierung eine „wesentliche

\footnotetext{
715 vgl. Kreiswerke Heinsberg 1997, S.13

716 Von einem normativ-theoretischen Ansatz her wird argumentiert, dass es durch fehlende staatliche Steuerung im Rahmen einer wettbewerbspolitischen Ordnung zu einem „Marktversagen“ kommen könnte. Dieses Marktversagen sei wiederum dadurch begründet, dass der ÖPNV durch natürliche Monopole gekennzeichnet ist, infolge es zwangsläufig zu einem Konzentrationsprozess auf der Anbieterseite kommt, da die nachgefragte Transportleistung günstiger durch ein einzelnes Verkehrsunternehmen erstellt werden kann als durch mehrere (kleinere) Anbieter; vgl. Aberle 2003, S.104.

${ }^{717}$ vgl. von Weizsäcker, Young und Finger 2004, S.6ff
} 
Verringerung der Systemintegration einher", was sich wiederum negativ auf die Effizienz vor allem des ÖPNV auswirken würde. ${ }^{718}$

Nach Ansicht der EU-Kommission muss eine Marktöffnung aber nicht völlige Privatisierung bedeuten. Hingegen die vollständige Privatisierung das freie Spiel der Marktkräfte im Wettbewerb und den Rückzug des Staates aus seiner (bisherigen) Verantwortung anstrebt, bedeutet Deregulierung - und auch Liberalisierung - die Stimulierung des Wettbewerbs unter bestimmten Rahmenbedingungen, die vom Staat vorzugeben sind. Dabei gibt es vielfältige Ausprägungen der Deregulierung. Diese reichen von der Streichung finanzieller Fördermittel und Unterstützung bis hin zur Vermittlung von Anreizen. Im Rahmen der Deregulierung muss also festgelegt werden, bis zu welchem Umfang Privatisierung „Sinn macht". Dabei gilt es die vorherrschenden Umstände und Rahmenbedingungen zu berücksichtigen, um sicher zu stellen, dass es weder zu einem Markt- noch zu einem Staatsversagen kommt. ${ }^{719}$ Vor allem die zeitlich befristete Vergabe von Verkehrsleistungen nach entsprechenden Qualitätsvorgaben scheint ein geeignetes Instrumentarium zu sein, sowohl Wettbewerb um den Markt zu generieren als auch den finanziellen Aufwand für die Erstellung zu senken und dabei eine nachhaltige Entwicklung sicherzustellen. ${ }^{720}$

\subsection{Anspruch auf Daseinsvorsorge}

\section{Begriffserklärung}

In bezug auf Mobilität bezeichnet der Begriff „Daseinsvorsorge“ die Aufgabe des Staates, gleiche Mobilitätsbedingungen für alle Bevölkerungsteile zu schaffen. Die Diskussion, was konkret darunter zu verstehen ist, gibt es bereits seit den 1930er Jahren, als allgemein zugängliche Mobilität nur über den ÖPNV zu realisieren war. Der Begriff selbst wurde bezeichnenderweise in einer Broschüre des Staatsrechtlers Ernst Forsthoff mit dem Titel „Die Verwaltung als Leistungsträger“ im Jahre 1938 eingeführt. ${ }^{721}$ Forsthoff argumentierte, dass durch die Industrialisierung und der damit einhergehenden Urbanisierung sowie Arbeitsteilung eine „soziale Bedürftigkeit“ erwachse. Dem einzelnen müssten daher die notwendigen Güter zum Leben durch den Staat zugänglich gemacht werden. Dies solle

\footnotetext{
${ }^{718}$ vgl. Kahl 2005, S.277

719 vgl. von Weizsäcker, Young und Finger 2004, S.10

${ }^{720}$ vgl. Kahl 2005, S.277

${ }^{721}$ vgl. Schöller 2005, S. 55
} 
unabhängig von seiner sozialen oder auch ökonomischen Lage geschehen, wodurch der Begriff der "sozialen Daseinsvorsorge“ deutlich vom Begriff der "sozialen Fürsorge“ zu trennen sei. ${ }^{722}$

Der Begriff der „Daseinsvorsorge“ wird als Rechtsbegriff auch im PBefG verwendet (welches seinen Ursprung ja ebenfalls in 1930er Jahren hat), wobei den öffentlichen Verkehrsmitteln eine Erschließungs- und Versorgungsfunktion zugewiesen wird. Das sozialstaatliche Prinzip, welches sich hieraus ableiten lässt, hat zum Ziel, allen Menschen eine annähernde soziale, wirtschaftliche und kulturelle Chancengleichheit zu gewährleisten. Voraussetzung hierfür ist insbesondere die Vorhaltung einer infrastrukturellen Grundvorsorgung mit Energie, Wasser und eben auch Verkehr. Bezogen auf den Verkehr bedeutet dies, die Sicherstellung einer ausreichenden bzw. angemessenen Verkehrsbedienung. „Öffentlicher Verkehr“ bedeutet, dass jede Person grundsätzlich einen Beförderungsanspruch genießt. „Öffentlich“ heißt also nicht, dass sich das eingesetzte Verkehrsmittel in kommunaler bzw. öffentlicher Hand befinden muss, sondern dass die Bereitstellung der Verkehrsleistung in den Bereich der staatlichen Daseinsvorsorge fällt. Darüber hinaus besteht weder ein Grundrecht auf Mobilität mit einem bestimmten Verkehrsmittel, noch ist die Daseinsvorsorge grundgesetzlich verankert, es kann lediglich ein Recht an der Teilhabe an der vorhandenen Infrastruktur abgeleitet werden. ${ }^{723}$

Im Artikel 1 der VO (EWG) 1191/69 ist festgehalten, dass eine ausreichende Verkehrsbedienung außerdem unter der Berücksichtigung nicht nur sozialer, sondern auch umweltpolitischer und landesplanerischer Faktoren sicherzustellen ist. Rechtlich legitimiert und formal präzisiert wird die ÖPNV-Daseinsvorsorge durch das Konzept der Bereitstellung einer ausreichenden Verkehrsbedienung u.a. im $§ 1$ des Regionalisierungsgesetzes sowie in den Landesnahverkehrsgesetzen. Aus der Schlussfolgerung heraus, dass der ÖPNV einem öffentlichen Zweck dient und die Förderung des ÖPNV in geeigneter Weise dazu beiträgt die Mobilität in sozialverträglicher Weise zu sichern sowie die Umwelt zu schützen, wird der Eingriff des Staates bzw. seiner Aufgabenträger in den ÖPNV gerechtfertigt.

\footnotetext{
$722 \mathrm{ebd}$.

${ }^{723}$ vgl. Barth 2000, S.87
} 
Daseinsvorsorge als öffentliche Aufgabe

Nur stellt sich die Frage, „welche Folgen daraus für eine normative Zielsetzung für das System ÖPNV abzuleiten sind“. ${ }^{724}$ Auch ist zu hinterfragen, ob der Staat diese ÖPNVLeistung finanzieren muss, zumal das PBefG vorgibt, dass die öffentliche Aufgabe der Daseinsvorsorge eigenwirtschaftlich zu erfolgen habe, also so wirtschaftlich wie möglich und Defizite so gering wie möglich gehalten werden sollen. ${ }^{725}$

Barth kommt in ihren Ausführungen zum „Nahverkehr zwischen kommunaler Daseinsvorsorge und Verkehrsgewerbe“ zu folgendem (Zwischen-)Ergebnis:

„Deutlich wird aber, daß die staatliche Daseinsvorsorge unter der Geltung des Grundgesetzes nicht aus sich selbst legitimiert ist, sondern in Beziehung zu anderen Verfassungsprinzipien und -normen zu setzen ist. [...] Daß sozialstaatliche Daseinsvorsorge im ÖPNV traditioneller und verfassungsrechtlich legitimer Zweck staatlichen Handelns anzusehen ist, begründet keine Notwendigkeit für ein auch in Zukunft fortdauerndes staatliches Engagement in diesem Bereich. Es legt den Staat weder auf ein bestimmtes Versorgungsniveau, wie etwa den status quo, noch auf bestimmte Maßnahmen zur Aufrechterhaltung der Verkehrsbedienung [...] fest". ${ }^{\prime 726}$

Schäfer-Sparenberg, Bongardt und Dalkmann konstatieren jedoch, dass „öffentliche Verkehrsangebote im Rahmen der Daseinsvorsorge in dem Maße sicherzustellen sind, dass alle Menschen eine nachhaltige Mobilität praktizieren können“. Sie erweitern damit den Aspekt der Daseinsvorsorge noch um die nachhaltigen umweltpolitischen und ökonomischen Dimensionen. Insofern sei ein dem MIV durchaus konkurrenzfähiges ÖPNVAngebot anzubieten. 727

Daraus folgert allerdings keineswegs, dass eine Kommune selbst mit dem Betrieb eines Verkehrsunternehmens dieser Pflicht nachkommen muss. ${ }^{728}$ Denn der Artikel 28 des Grundgesetzes gewährleistet den Kommunen bei der Wahrnehmung ihrer Aufgaben „Ei-

\footnotetext{
${ }^{724}$ Schäfer-Sparenberg, Bongardt und Dalkmann 2006, S.58

725 vgl. PBefG, $§ 8(4)$

726 Barth 2000, S.88.

${ }^{727}$ vgl. Schäfer-Sparenberg, Bongardt und Dalkmann 2006, S.49

${ }^{728}$ vgl. Barth 2000, S.89
} 
genverantwortlichkeit“, d.h. einen Ermessensspielraum, wie die Pflichtaufgaben zu erfüllen sind. Aus der Zuordnung des ÖPNV zur kommunalen Selbstverwaltung entsteht nur die Notwendigkeit, dieser Pflicht in geeigneter Weise nachzukommen. So ist im lokalen Nahverkehrsplan, der alle fünf Jahre aufgestellt werden muss, zu konkretisieren und zu definieren, wie und in welchem Umfang die ÖPNV-Leistungserbringung sicher gestellt werden soll. Die Durchführung des ÖPNV durch eine Kommune ist demnach als freiwillige Aufgabe $\mathrm{zu}$ interpretieren. ${ }^{729}$ Hinsichtlich einer sich daraus ableitenden Finanzierungsverantwortung kommt Nennen zu folgendem Schluss:

„Im Sinne der Daseinsvorsorge als Zweck bedarf er der öffentlichen Förderung so lange, bis nicht die Mittel selbst und damit auch die Systeme so arrangiert sind, dass Alimentierung nicht mehr erforderlich ist. Es käme also auf eine Verkehrspolitik an, die geschickt genug den Wettbewerb wie auch staatliche Regulierung und Infrastrukturverantwortung so arrangiert, dass ein System entsteht, das den Anforderungen gerecht zu werden verspricht. Dauerhaft aber bleibt es in jedem Fall die Aufgabe von Staat und Politik, die hierzu notwendigen Rahmenbedingungen zu schaffen, nicht nur für Markt und Wettbewerb, sondern auch für den Erhalt und die Modernisierung der Infrastruktur im magischen Dreieck zwischen Marktversagen, Politikversagen und Staatsversagen, von denen keines zu wünschen sein kann". ${ }^{730}$

Demnach könnte ein über das Grundangebot - im Sinne einer ausreichenden Verkehrsbedienung - hinausgehendes Angebot nur in dem Umfang bereit gestellt werden, wie es sich wirtschaftlich selber trägt und wären vom Staat lediglich die entsprechenden Rahmenbedingungen zu schaffen. ${ }^{731}$

Demgegenüber besteht die Auffassung bei vielen kommunalen Verkehrsakteuren, dass über einen freien bzw. liberalisierten Markt keine ausreichende Verkehrsbedienung zu erreichen sei und daher der Staat selbst operativ eingreifen müsse um ein Mindestmaß an Mobilität zu gewährleisten. Damit ist aber nichts über die Art und Weise gesagt, wie dies $\mathrm{zu}$ geschehen hat und ob der heutige Regulierungsumfang gerechtfertigt ist. Es liegt vielmehr die Vermutung nahe, dass Daseinsvorsorge und daraus resultierend die Sicherung einer allen Bürgern gerecht werdenden „Mobilität“ als Rechfertigung für Marktab-

\footnotetext{
${ }^{729}$ vgl. Götz 2002, S.156

730 Nennen 2001, S.52

${ }^{731}$ vgl. Schäfer-Sparenberg, Bongardt und Dalkmann 2006, S.49
} 
schottung und Wahrung der (lokalen) Monopolstellung herangezogen wird. Dabei wird gerne übersehen, dass „nicht mehr das Monopol schützenswert ist, sondern ausschließlich die jeweilige daseinsvorsorgende Dienstleistung selbst ${ }^{\prime \prime}{ }^{732}$ Die Erbringung einer gemeinwirtschaftlichen Leistung rechtfertigt also keineswegs die umfassende Monopolstellung eines kommunalen Verkehrsunternehmens. ${ }^{733}$

Der Anspruch auf Daseinsvorsorge widerspricht demnach auch nicht einer Zunahme von Wettbewerb im ÖPNV bzw. kann kein Anspruch abgeleitet werden, der einer marktgesteuerten und in der Folge wirtschaftlicheren ÖPNV-Bedienung widerspricht. Insbesondere der Weg der Ausschreibung von Linien, Linienbündeln oder Liniennetzen im Rahmen der Regionalisierung scheint hierbei ein geeigneter Weg zu sein, im ÖPNV zu mehr Effizienz und Kundenfreundlichkeit zu gelangen. Dabei soll es keineswegs zu einem freien Spiel der Kräfte im Markt kommen. So zielt der „Hessische Weg“ (siehe Kapitel 5.3) der Ausschreibung von ÖPNV-Verkehrsleistung ebenfalls auf die Steigerung der Effizienz ab, sprich auf die Steigerung des Kostendeckungsgrads des ÖPNV. Die öffentliche Aufgabe der Daseinsvorsorge als politische Vorgabe soll allerdings von der unternehmerischen Aufgabe und dem wirtschaftlichen Ergebnis aus der Leistungserstellung klar und transparent getrennt werden. 734

Die Vergabe von ÖPNV-Verkehrsleistung ruft jedoch bei Kommunen, die im Besitz von Verkehrsunternehmen sind, häufig Bedenken hervor. Mit dem Hinweis auf die Verpflichtung zur Daseinsvorsorge und die Gefahr der Vernachlässigung der sozialpolitischen Funktion des ÖPNV führen sie an, dass es im Rahmen einer Deregulierung insbesondere zu einem Wettbewerb um lukrative Strecken gehen könnte. Zum Schluss müssten dann die besonders unrentablen Strecken durch die kommunalen Unternehmen mit umso höherem Aufwand an öffentlichen Mitteln betrieben werden. Genau dies soll aber im RMV dadurch umgangen werden, dass nicht einzelne Linienkonzessionen vergeben werden, sondern Linienbündel und -netze mit starken Vorgaben durch die Aufgabenträger. ${ }^{735}$ „Im Endeffekt kommt es darauf an, den Wettbewerb, insbesondere in Ausschreibungen und

\footnotetext{
732 Kahl 2005, S.89

733 vgl. Kahl 2005, S.89

734 vgl. HMWVL 2003 (b)

735 vgl. Schöller 2005, S.65
} 
vertraglichen Vereinbarungen, so zu gestalten, dass tatsächlich die Daseinsvorsorge sichergestellt und die Dienstleistungsqualität gesteigert wird“ ${ }^{736}$

\subsection{Der "Hessische Weg“ der Vergabe von ÖPNV-Leistung}

\subsubsection{Besteller-Ersteller-Prinzip}

Der öffentliche Personenverkehr ist in Deutschland organisatorisch - aber auch rechtlich und institutionell - in die Bereiche Nah- und Fernverkehr gegliedert. ${ }^{737}$ Diese Trennung suggeriert unterschiedliche Wesenszüge in den Bedienungsformen, die schon aufgrund der engen Verflechtung der Verkehrsnetze in der Realität nicht gegeben sind, aber in den entsprechenden Regelwerken, Bestimmungen und Organisationsstrukturen zu voller Entfaltung kommen. So wird der Schienenfernverkehr nach privatwirtschaftlichen Vorgaben geführt und daran gemessen, ob ein Verkehrsunternehmen wie die DB AG börsenfähig ist oder nicht. Auf der anderen Seite wird der Nahverkehr als öffentliche Aufgabe im Rahmen der Daseinsvorsorge öffentlich subventioniert und verwaltet. ${ }^{738} \mathrm{Im}$ Nahverkehr wird die strategische Ebene für die Planung und die operative Ebene für die Leistungserstellung getrennt. Als staatliche Instanz erteilen die Genehmigungsbehörden die Bewilligungen im Schienenpersonennahverkehr (SPNV) sowie die Konzessionen im straßengebundenen Liniennahverkehr. In Hessen ist die Landesregierung in Form des Ministeriums für Wirtschaft, Verkehr und Landesentwicklung (HMWVL) oberste Genehmigungsbehörde, die unterschiedliche Aufgaben an die entsprechenden regionalen Verwaltungseinrichtungen delegiert hat, beispielsweise die Genehmigung von Tarifen an das Regierungspräsidium.

Mit Inkrafttreten des Regionalisierungsgesetzes am 1. Januar 1996 ist „die Sicherstellung einer ausreichenden Bedienung der Bevölkerung mit Verkehrsleistungen im öffentlichen Personennahverkehr" Aufgabe der Länder, die zuvor auch schon die Verantwortung für den SPNV übernommen hatten. Damit wurde die Verantwortung für Planung, Finanzierung und Organisation des gesamten ÖPNV auf Landesebene zusammengeführt. ${ }^{739}$ In Hessen übertrug das Land per Landesnahverkehrsgesetz diese Aufgabe an die Kommunen, die damit zu Aufgabenträgern des ÖPNV wurden. Ihnen kommt die politische Auf-

\footnotetext{
736 Schäfer-Sparenberg, Bongardt und Dalkmann 2006, S.68

737 Unterhalb von $50 \mathrm{~km}$ Entfernung spricht man von Nahverkehr, oberhalb von Fernverkehr.

738 vgl. Schöller 2005, S.82f

739 vgl. Barth 2000, S.27
} 
gabe zu Nahverkehrspläne aufzustellen, die Verkehrsleistung zu bestellen und „sich neben der Landesförderung angemessen mit originären kommunalen Mitteln an der Finanzierung zu beteiligen“ („,dezentrales Prinzip“, siehe auch Kapitel 5.4.1.3).740

Die so erreichte Trennung von Wirtschaftsbetrieb und öffentlichem Auftrag der Daseinsvorsorge ist als „Besteller-Ersteller-Prinzip“ im Hess. ÖPNVG verankert.741 Die damit verbundene Vergabe von Verkehrsleistung soll den Vorstellungen der hessischen Landesregierung gemäß einer wettbewerbskonformen Umsetzung des EU-Rechtsrahmen konsequent ausgeschrieben werden. Da dieser Ansatz in Deutschland (bislang) einmalig ist, wird dieses Vorgehen auch als "Hessischer Weg“ bezeichnet.742 So muss dem Hess. ÖPNVG nach der Aufgabenträger als Besteller die einzukaufende Leistung im Sinne einer im öffentlichen Interesse gewünschten Verkehrsbedienung genau definieren und hierfür einen angemessenen Preis zahlen. Hieraus erwachsen Anforderungen die Leistungs- und Zahlungsvereinbarungen mit dem Verkehrsunternehmen als Ersteller vertraglich klar zu regeln und zu überwachen. Ziel dieses Besteller-Ersteller-Prinzips ist insbesondere die Sicherstellung und Finanzierung einer ausreichenden Verkehrsbedienung unter effizientem Mitteleinsatz. Gleichzeitig wird erwartet, dass es durch die Vergabe von Verkehrsleistung im Wettbewerb zu einer Qualitätsverbesserung kommt und der Zuschussbedarf abnimmt. Das HMWVL stellt klar, dass „Wettbewerb kein ideologisch geprägter Selbstzweck ist, sondern ein notwendiger Anreiz, um die Effizienz zu erhöhen und die Interessen der Fahrgäste konsequent in den Mittelpunkt zu stellen“. ${ }^{743}$ Mit der Trennung nach dem Besteller-Ersteller-Prinzip wird gleichzeitig eine Kostentransparenz angestrebt, die Grundlage für die Vergabe von Verkehrsleistung im Wettbewerb ist.

Das Interesse der öffentlichen Hand und der ÖPNV-Aufgabenträger geht in Hessen nicht so weit, Veränderungen nur über ein freies Kräftespiel in einem völlig deregulierten Markt zu erreichen. Der hessische Minister für Wirtschaft, Verkehr und Landesentwicklung Riehl hob in einer Rede im Rahmen einer Veranstaltungsreihe zum Thema „Vorrang für Markt und Wettbewerb“ hervor, dass ÖPNV „eine wichtige und legitime staatliche Aufgabe" sei, dass der Staat jedoch die

\footnotetext{
${ }^{740}$ HMWVL 2002, S.3

${ }^{741}$ HMWVL 2003 (a), S.2

742 Das HMWVL betont, dass es sich hierbei keineswegs um einen „Sonderweg“ handelt, „sondern die Regel nach dem europäischen Recht" ist; vgl. HMWVL 2004, S.3 sowie RMV 2005, S.64.

${ }^{743} \mathrm{vgl}$. HMWVL 2003 (a), S.2
} 
„Leistung nicht selbst erbringen muss, sondern für die Leistungserstellung die dynamischen und innovativen Kräfte von Markt und Wettbewerb einspannt. Stichworte sind hier der Statt bestellt oder der Staat gewährleistet - er führt aber nicht selbst aus“. ${ }^{744}$

Die hessische Landesregierung sieht hier die Gefahr des Marktversagens und geht davon aus, „dass öffentliche Nahverkehrsleistungen im freien Spiel der Marktkräfte nicht effizient produziert und angeboten werden können“. ${ }^{745}$

Insofern sind also Regelungen und Standards notwendig, die die Entwicklung des Mobilitätsmarktes auf einen nachhaltigen Zielzustand hin steuern. Bei der Definierung dieses Ziels sind verbindliche Nahverkehrspläne hilfreich, die auf Basis von Bestands- und Mängelanalysen einerseits das zu entwickelnde ÖPNV-Angebot in Quantität und Qualität beschreiben, andererseits auch die Finanzierung des ÖPNV-Systems darlegen. Alleine aus der angespannten Haushaltslage der öffentlichen Hand lässt sich schon ableiten, dass ein entscheidendes Ziel in einem deregulierten Markt "Effizienzsteigerung“ heißen muss. ${ }^{746}$ Durch die stringente Trennung der Verantwortlichkeiten (siehe "3-Ebenen-Modell“ in Kapitel 5.4) soll die Vermischung von hoheitlichen und unternehmerischen Aufgaben vermieden und die fachlich-koordinierende Regieebene (Verbünde) gleichzeitig einen Interessensausgleich zwischen Aufgabenträgern und Verkehrsunternehmen herbeiführen. ${ }^{747}$ In Hessen sind demnach die Kommunen und das Land die Eigentümer der Verkehrsverbünde, die auch hoheitliche Aufgabenträger der Verkehrsleistung im SPNV sind.

Im Sinne einer weiteren institutionellen Trennung und Aufgabenverteilung nach dem Besteller-Ersteller-Prinzip wurde das Hess. ÖPNVG im Jahre 2005 novelliert. Es ergibt sich eine Aufgabenzuordnung, die die strategischen Planungsfunktionen (z.B. Fortschreibung Nahverkehrsplan, ÖPNV-Konzeption), die Bestellfunktionen (z.B. Vergabe von Verkehrsleistung, Vertragskontrolle, Budgetplanung) und die Regiefunktionen (z.B. Tarifpolitik, Einnahmeaufteilung, Übergeordnete Vertriebs- und Kommunikationsstrategie) bei den Aufgabenträgern sieht sowie die Betriebsfunktionen (Fahrzeuginstandhaltung, Dienst- und Einsatzplanung, Betriebsdurchführung und -überwachung) bei den Ver-

\footnotetext{
${ }^{744}$ HMWVL 2003 (b)

745 Riehl 2005, S.1

746 vgl. Götz 2002, S.322f

747 ebd. S.229
} 
kehrsunternehmen. ${ }^{748}$ Wenngleich auch die Zuständigkeit für die Infrastruktur vornehmlich bei den Verkehrsunternehmen gesehen wird, gibt es auch hier Tendenzen, ortsfeste Anlagen (z.B. Haltestellen, RBL-Systeme, Verkaufsgeräte) und Fahrzeuge den Aufgabenträgern zuzuordnen, um so insbesondere kleineren mittelständischen Verkehrsunternehmen einen diskriminierungsfreien Zugang zum Wettbewerb zu gewährleisten.

Unklarer sind dagegen die Zuständigkeiten für die Marketingaufgaben. Das Hess. ÖPNVG schreibt hier vor, dass die Verantwortung für die Vermarktung und den Vertrieb der ÖPNV-Verkehrsleistung vertraglich zwischen den Aufgabenträgern und den Verkehrsunternehmen zu regeln ist. ${ }^{749}$ Insofern sollen die Aufgabenträger Vorgaben für die unternehmerische Umsetzung des Vertriebs in bezug auf Vertriebswege und Vertriebsorgane formulieren. Darüber hinaus soll durch die Verpflichtung der Aufgabenträgerseite sicher gestellt werden, dass sich mögliche Konzessionswechsel nicht negativ auf der Kundenseite auswirken. Dies betrifft nicht nur die Qualitätsmerkmale der Beförderungsleistung selbst, sondern auch die Kundenschnittstelle. Hier sind insbesondere die durchgängige Verfügbarkeit von Verkaufs- und Beratungsstellen von Bedeutung sowie eine einheitliche Kundenansprache wichtig. Hierüber soll sicher gestellt werden, dass durch die Einführung von Wettbewerb dem Kunden keine Nachteile entstehen, sondern im Gegenteil ein einheitliches Erscheinungsbild des ÖPNV gefördert wird. 750

Der Wettbewerb eröffnet den Aufgabenträgern damit einen Gestaltungsspielraum wie die Vermarktung auszusehen hat, selbst wenn sie zukünftig nicht das operative Vertriebsgeschäft lokal vor Ort durchführen werden. Dieses verbleibt - vor allem im straßengebundenen ÖPNV aus betrieblichen Gründen - weiterhin bei den Verkehrsunternehmen. Auch der §3, Abs. 2 des PBefG, der beschreibt, dass die Erbringung der Verkehrsleistung „im eigenen Namen, unter eigener Verantwortung und für eigene Rechnung“751 erfolgen muss, wird allgemein dahingehend interpretiert, dass die Verantwortung für den operativen Vertrieb bei den Verkehrsunternehmen liegt.

Die Trennung in Besteller und Ersteller führt nicht zwangsläufig dazu, dass sich der „Staat“ aus der operativen Erstellerebene zurückziehen muss. Das Hess. ÖPNVG sieht

\footnotetext{
${ }^{748}$ vgl. Deutsches Institut für Urbanistik 2005, S.13f

749 vgl. Hessischer Landtag 2005, S.789

750 ebd. S.13

${ }^{751}$ PBefG §3 (2)
} 
hier unterschiedliche Betätigungsfelder, die nicht direkt von der ÖPNV-Deregulierung betroffen sind:

„Platz für öffentliche Unternehmen wäre aber bei allen Teilen der ÖPNV-Wertschöpfungskette, die entweder aufgrund ihrer Monopolstellung - wie etwa allgemein zugänglicher Infrastruktur - oder der Bedeutung für die Integration und Vernetzung des gesamten ÖPNV-Angebots - wie etwa Planung oder, je nach konkreter Organisations- und Vergabeform, auch Marketing und Kommunikation - nicht in den Wettbewerb überführt werden sollten". 752

Diese Regelung der Mitverantwortlichkeit für die ÖPNV-Vermarktung auf Aufgabenträgerseite ist konsequent, da die Aufgabenträger die Verkehrsleistung nicht nur zu einem erheblichen Teil finanzieren, sondern aufgrund der bestehenden Verkehrsverträge auch die Fahrgastinteressen vertreten sollen. Sie haben damit ein berechtigtes Interesse sowohl an einer effizienten Erbringung der Leistung wie auch an einem möglichst hohen Kostendeckungsgrad durch die eingenommenen Fahrgelder. Die Verkehrsunternehmen dagegen haben allerdings aufgrund ihrer bisherigen Beauftragung im Rahmen von Bruttoverträgen höchstens in bezug auf die Generierung von Liquiditätsvorteilen Interesse an vermehrten Fahrgeldeinnahmen. Ansonsten tragen die Verkehrsunternehmen das Produktionsrisiko, welches u.a. durch betriebswirtschaftliche Prozessoptimierungen und technische Verbesserungen vermindert werden kann. Allerdings ist auch die Vergabe von Verkehrsleistungen im Rahmen eines Nettovertrages - bei dem also das Einnahmenrisiko auf der Seite des Verkehrsunternehmens liegt - in Verkehrsverbünden problematisch, da die Verteilung der Einnahmen unter den Verkehrsunternehmen häufig umstritten ist. 753 Vor dem Hintergrund einer nachhaltigen Mobilitätssicherung ist es außerdem unerlässlich, umweltpolitische Ziele vertraglich zu verankern. Da aber Verkehrsunternehmen im Wettbewerb zukünftig kaum mehr zu leisten gewillt sind als vertraglich gefordert, scheidet der reine Nettovertrag als Vertragsform aus. ${ }^{754}$

Im zukünftigen Ausschreibungswettbewerb soll es daher verstärkt zur Vergabe von Verkehrsleistung im Rahmen von Mischverträgen kommen, bei denen qualitäts- und ein-

\footnotetext{
752 Deutsches Institut für Urbanistik 2005, S.10

753 vgl. Blümel 2004, S.21

754 vgl. Deutsches Institut für Urbanistik 2005, S.28
} 
nahmenorientierte Aspekte in den Vordergrund rücken. ${ }^{755}$ Dieses sind entweder Bruttoanreizverträge, die Anreizsysteme beinhalten oder aber Nettoverträge, die die Möglichkeit der Nachsteuerung aufweisen. So können bei einem Nettovertrag zusätzliche Fahrgastanreize geschaffen werden, worüber das Erlösrisiko für den Ersteller gemindert wird und ein Anreiz für mehr Kundenorientierung erhalten bleibt. Für die Berücksichtigung leistungs- und nachfrageorientierter Parameter - die immer in Abhängigkeit von der Siedlungs- und Verkehrsstruktur zu betrachten sind756 - bedarf es kontinuierlicher Kontrollen wie zum Beispiel Fahrgasterhebungen. ${ }^{757}$ „Voraussetzung für die Anwendung von Anreizverträgen ist [daher] die Entwicklung effizienter Planungs-, Ausschreibungs- und Kontrollkompetenz des Aufgabenträgers“. ${ }^{758}$

\subsubsection{Vergabe von Verkehrsleistung}

\subsubsection{Vergabepraxis}

Die RMV GmbH beabsichtigt, bis zum Jahre 2010 prinzipiell alle Verkehrsverträge im Bereich des regionalen Busverkehrs sowie bis 2014 im Bereich des SPNV im Vergabeverfahren auszuschreiben. ${ }^{759}$ Gemäß den Vorstellungen des HMWVL sollen auch die lokalen Busverkehre ausgeschrieben werden. Ausgenommen von der Vergabe im Wettbewerb sind eigenwirtschaftliche Verkehre, die der Sicherstellung einer ausreichenden Verkehrsversorgung dienen und für die keine konkurrierenden Angebote vorliegen. Bei eigenwirtschaftlichen Anträgen sind generell alle Einnahmen zur Erreichung des Kostendeckungsgrads offen zu legen, wodurch sicher gestellt werden soll, dass es durch unzulässige Beihilfen gemäß der VO (EWG) 1191/69 nicht zur Diskriminierung andere Wettbewerber kommt. Zu diesen Einnahmen gehören auch Ausgleichs-, Sonder- und Subventionszahlungen. Das HMWVL betont hierbei folgendes:

„Insbesondere bei kommunalen Verkehrsunternehmen liegt durch den Ausgleich der jährlichen Unterdeckung im kommunalen Unternehmensverbund eine [...] Finanzierung aus

\footnotetext{
755 vgl. Sparmann, V. 2005 (a), S.6

756 vgl. Becker, T. 2004, S.33f

757 vgl. Sparmann, V. 2005 (a), S.6

758 Deutsches Institut für Urbanistik 2005, S.28

${ }^{759}$ vgl. RMV 2005, S.62 sowie HMWVL 2003, S.2
} 
öffentlichen Mitteln im Sinne des europäischen Beihilferechts vor, so dass eine sorgfältige beihilferechtliche Prüfung durch die Kommunen [als Aufgabenträger] hier ratsam ist". ${ }^{760}$

Denn marktunübliches und nicht erwerbswirtschaftliches Verhalten, das nicht der Sicherstellung der Verkehrsbedienung dient und zu einer unzulässigen Bevorzugung dient, ist nicht erlaubt. Hierzu gehört beispielsweise die Weitergabe von Gewinnen eines Energieunternehmens an ein Verkehrsunternehmen, bei dem die Betriebskosten die Einnahmen kontinuierlich übersteigen, da dies keine unternehmenseignen Interessen erkennen lässt. So wurde die finanzielle Unterdeckung der kommunalen Eigenbetriebe bislang häufig noch aus dem Querverbund mit anderen kommunalen Unternehmen ausgeglichen ${ }^{761}$, d.h. die Kommune als verantwortlicher Aufgabenträger und Betreiber eines Verkehrsunternehmens stellte das eigene Verkehrsunternehmen über kommunale Verlustausgleiche eigenwirtschaftlich.

Das Oberverwaltungsgericht in Magdeburg hat in einem Rechtsspruch aus dem Jahre 1997 entschieden, dass öffentliche Zuschüsse und Subventionen nur dann zulässig sind, wenn sie der Sicherstellung einer ausreichenden Verkehrsbedienung dienen. ${ }^{762}$ Der Europäische Gerichtshof (EuGH) hat in einem Urteil zu den Auslegungsverfahren des Magdeburger Rechtsspruches bestätigt, dass Beihilfen unter bestimmten Voraussetzungen gewährt werden können. Das Bundesverwaltungsgericht hat schließlich in seinem Urteil vom 19.10.2006 endgültig entschieden, dass sowohl gesetzliche Ausgleichszahlungen wie auch Zahlungen der Aufgabenträger an eigene kommunale Verkehrsunternehmen zur Deckung von Defiziten die Eigenwirtschaftlichkeit herangezogen werden können, sofern es sich nicht um eine beihilferechtswidrige Finanzierung handelt. 763

Es bedarf also objektiver Kriterien, anhand derer die Ausgleichshöhe festzumachen ist, damit keine Überkompensation entsteht. ${ }^{764}$ Besteht eine solche Überkompensation, wird der Antrag auf einen eigenwirtschaftlichen Verkehr abgelehnt. Wird ein eigenwirtschaftlicher Verkehr genehmigt, entfällt für diesen die Möglichkeit der Finanzierung über öffentliche Zuschüsse gemäß des Hess. ÖPNVG. Für gemeinwirtschaftliche Verkehre gilt dagegen das in der VO (EWG) 1169/69 vorgesehene Verfahren der Vergabe der Verkehrs-

\footnotetext{
760 HMWVL 2007, S.2

${ }^{761}$ vgl. Riehl 2005, S.1

$762 \mathrm{ebd}$.

763 vgl. HMWVL 2007, S.2

${ }^{764}$ ebd., S.45f
} 
leistung im Wettbewerb. Ausnahmen hiervon soll es allerdings für Busunternehmen geben, die zu 100\% den Aufgabenträgern gehören und ausschließlich in den kommunalen Gebietsgrenzen fahren.765 Für die Möglichkeit dieser sogenannten „Direktvergabe“ („inhouse-Vergabe“) ohne Wettbewerb haben sich insbesondere die größeren Städte und Sonderstatusstädte im Gebiet des Rhein-Main-Verkehrsverbundes „eingesetzt“ ${ }^{766}$ Doch auch diese Sonderstellung bedeutet keineswegs, dass die kommunalen Busunternehmen ihre Leistung zu marktunüblichen Konditionen anbieten dürfen. Sollten die Konditionen übertrieben hoch sein, droht der Verlust der Sonderstellung und damit die Vergabe im Wettbewerb. Insofern geht der hessische Wirtschafts- und Verkehrsminister Riehl auch davon aus, ",dass die Direktvergabe eine seltene Ausnahme bleiben wird“ . ${ }^{767}$

Obwohl das Bundesverfassungsgericht in seinem Urteil vom 6.12.2006 bestätigt hat, dass weder aus nationalen noch europäischen Vorschriften eine Pflicht der Vergabe von eigenwirtschaftlichen Verkehrsleistungen abgeleitet werden kann, impliziert dies nicht, dass auf Wettbewerb verzichtet werden darf. „Dienstleistungsbeziehungen der öffentlichen Hand zu privaten Dritten [müssen] zumindest in einem transparenten und diskriminierungsfreien Wettbewerbsverfahren realisiert werden". ${ }^{768}$

Es liegt letztendlich also in der „öffentlichen Hand“ der Aufgabenträger, die Vorgaben einer wettbewerblichen Vergabe von Verkehrsleistung in ihren Zuständigkeitsgebieten umzusetzen. Inwieweit sich die kommunalen Busunternehmen vor Wettbewerb "geschützt" wägen dürfen, mag dabei von Kommune zu Kommune unterschiedlich ausfallen. Eine Reihe von lokalen und regionalen Verkehrsunternehmen hat sich allerdings bereits auf den Wettbewerb eingestellt ${ }^{769}$ und sich teilweise $\mathrm{zu}$ Bietergemeinschaften zusammengeschlossen. ${ }^{770}$ „Letztlich wird aber der Aufgabenträger entscheiden, ob für ihn die Vorteile aus dem Verzicht auf Ausschreibungen oder die Vorteile des Ausschreibungswettbewerbs überwiegen“.771 Für die Stadt Frankfurt hat ein Gutachten ergeben,

\footnotetext{
765 Diese Korrektur in der Hessischen Verkehrspolitik wird nach dem Hauptabteilungsleiter im HMWVL auch "Güttler-Erlass" genannt; vgl. www.busaktuell.de.

766 Einige Städte drohten gar mit einer Klage, hätte sich das Land mit dem Zwang zur Ausschreibung weiterhin in die Zuständigkeiten und das Eigentum der Kommunen eingemischt; vgl. FR v.19.11.05

767 ebd.

768 Jasper und Pooth 2007, S.42

${ }^{769}$ Beispiele hierfür sind die Darmstädter HEAG, Fuldaer ÜWAG und Stadtwerke Marbrug

770 vgl. Frankfurter Rundschau v. 19.11.2005

771 Umweltbundesamt 2005 (a), S.9
} 
„dass Ausschreibungen unterm Strich pro Jahr um 500.000 bis 2,1 Millionen Euro günstiger sind als eine Direktvergabe“. Voraussetzung sei aber, dass die Kosten für die "Ausschreibungsbehörde" niedrig gehalten werden. ${ }^{772}$

Nach Auffassung des HMWVL und der RMV GmbH wird mit dem EuGH-Urteil aber dennoch „der bisher eingeschlagene hessische Weg bestätigt, der auf Rechtssicherheit und Wettbewerb setzt". ${ }^{\prime 73}$

\subsubsection{Positionierung der Verkehrsunternehmen im Wettbewerb}

Um einen geordneten Übergang in den Wettbewerb zu ermöglichen, werden im RMV drei Phasen unterschieden, während der die Verkehrsunternehmen Zeit haben, sich auf den Wettbewerb einzustellen. ${ }^{774}$ Wurden in der bereits abgeschlossenen Vorlaufphase die alten Verkehrs-Service-Verträge mit den Verkehrsunternehmen noch verlängert, sieht die Übergangsphase bereits die Vergabe von Teilnetzen (im Schienenverkehr) und Linienbündeln (im Busverkehr) im Wettbewerb vor. Vergeben werden Bruttoanreizverträge auf der Basis eines konkreten Leistungsverzeichnisses. Die Vertragsvereinbarung sieht bei guter Leistungserbringung einen Bonus vor, bei Nichterfüllung einen Malus. ${ }^{775}$ Grundlage dieses Bonus-Malus-Systems ist die Prüfbarkeit objektiver (bspw. über Messungen und Erhebungen) und subjektiver (bspw. über Befragungen) Kriterien. In der Wettbewerbsphase schließlich sollen alle Verkehre im Wettbewerb ausgeschrieben werden. ${ }^{776}$

Hieraus ergeht, dass den Verkehrsunternehmen, die sich in Hessen bzw. im RMV um Verkehrsleistungen bewerben möchten, eine Übergangsfrist eingeräumt wird, in der sie sich auf den Wettbewerb einstellen können und z.B. strukturelle Maßnahmen zur betrieblichen Wirtschaftlichkeitssteigerung durchführen können. Denn aus der Sicht eines im Wettbewerb stehenden Verkehrsunternehmens ist die Erreichung einer verbesserten Wirtschaftlichkeit, bei transparenten Kosten und gestiegener Qualität, die Voraussetzung, in einem liberalisierten Verkehrsmarkt bestehen zu können. Trotz der eingeräumten Übergangsfristen trifft der Wettbewerb viele Verkehrsunternehmen aber dennoch unvorbereitet. Dies hat mit dem Umstand zu tun, dass strukturelle Veränderungen nicht aus Ei-

\footnotetext{
772 vgl. Höchster Kreisblatt v. 14.12.2006

773 RMV 2005, S.64

${ }_{774}$ vgl. HMWVL 2002, S.4

775 ebd., S.5

776 vgl. RMV 2005, S.65
} 
geninitiative heraus betrieben werden, sondern erst auf äußeren Druck erfolgen. Die Resistenz gegenüber Erneuerungsmaßnahmen lässt sich aus der Rechtslage heraus ableiten, die Teilbereichsausnahmen von der VO (EWG) 1191/69 zulässt. In diesem Zusammenhang bestärkt die Einräumung einer möglichen Direktvergabe bei rein kommunalen Busunternehmen unter Wahrung des Querverbunds die zögerliche Positionierung im Wettbewerb.

Im Vergleich zu kommunalen Busbetrieben hat sich die DB AG mit ihren DB RegioTochterunternehmen auf den Wettbewerb im SPNV vorbereitet. Selbst wenn die DB AG den Wettbewerb kritisch sieht, nimmt sie „an der Ausschreibung von Streckennetzen seitens der Länder teil, bemüht sich allerdings um langfristige Zehn-Jahres-Verträge. Um sinnvoll und auf tragfähig-verlässlicher Grundlage investieren zu können“. ${ }^{777} \mathrm{Im}$ dritten Themenheft der DB AG aus dem Jahre 2003 wird über den Wettbewerb im Nahverkehr auf der Schiene und der damit verbundenen Entstehung von Privat- und Länderbahnen sowie Aufgabenträgerorganisationen folgendes Urteil gefällt:

„Droht doch mit Gründung der zahlreichen Länderbahnen ein Rückfall in die Zeit der Kleinstaaterei wie zu Beginn des Eisenbahnzeitalters. Auch erfordern die neu geschaffenen administrativen Strukturen einen nicht unerheblichen, sowohl finanziellen als auch personellen Mehraufwand. Zudem sorgen Zahl und Namensgebung sowie mannigfach differierende Regelwerke und Rahmenbedingungen all der neuen Verkehrsinstitutionen für Konfusion unter den Kunden. Von Problemen bei Anschlüssen untereinander oder zum Fernverkehr ganz abgesehen". ${ }^{778}$

Wenngleich in dieser Kritik ein nostalgischer Rückblick auf Bundesbahnzeiten mitschwingt, ist unbenommen, dass die Liberalisierung des Verkehrsmarktes nicht nur interne organisatorische Veränderungen mit sich bringt, sondern die Auswirkungen bis an die Schnittstelle zum Kunden reichen. Insofern legt die DB AG, die sich in der Rolle des Leistungserstellers wiederfindet, Wert darauf, dass die Kunden wissen, dass für „manche Kritik, ob nun an Tarif oder Personalaufwand, an Taktfrequenz oder Streckenführung“, die Aufgabenträgerorganisationen verantwortlich sind. 779

\footnotetext{
777 Deutsche Bahn AG 2003, S.124

778 ebd.

${ }^{779}$ vgl. Deutsche Bahn AG 2003, S.124
} 
Eine hilfreiche organisatorische Veränderung zur verbesserten Positionierung der Verkehrsunternehmen wäre die rechtlich-organisatorische Abkopplung von den kommunalen Versorgungsbetrieben. Hierdurch würde eine institutionelle Trennung von politischer und unternehmerischer Aufgabe erkennbar, wie dies in der prinzipiellen Trennung von Aufgabenträger („,Besteller“) und Verkehrsunternehmen („Ersteller“) gefordert wird. ${ }^{\prime \prime 0}$ Eine Einschätzung der wirtschaftlichen Effizienz eines Unternehmens kann durch die bislang verursachte Intransparenz kaum vorgenommen werden. Denn eine Abgrenzung, „welcher Teil des Wirtschaftsergebnisses auf die unternehmerische Leistung und welcher auf die politischen Vorgaben zurückzuführen ist" ${ }^{\star 781}$, ist nicht möglich. Im Zweifelsfall werden die Verkehrsunternehmen für einen Fehlbetrag stets die Vorgaben der Politik verantwortlich machen. ${ }^{782}$ Von der Abkopplung eines Verkehrsunternehmens von der behördlichen Ebene verspricht sich das HMWVL daher grundsätzlich mehr Transparenz sowie eine aus betriebs- und privatwirtschaftlicher Sicht bessere Betriebsführung, da Fehlentscheidungen und -entwicklungen klarer lokalisiert werden können. ${ }^{783}$

Eine alternative Möglichkeit in der Verbesserung der Konkurrenzfähigkeit besteht im Zusammenschluss zu Bietergemeinschaften oder gar der Expansion durch den Erwerb von Beteiligungen oder Unternehmenszukäufen. Doch vielen, gerade mittelständischen deutschen Unternehmen fehlt es hierzu an finanziellen Mitteln. Für das Gebiet des RMV betrifft dies im wesentlichen nur die VGF, die in der Vergangenheit Geschäftsanteile an der Hanauer Straßenbahn GmbH und den Offenbacher-Verkehrs-Betrieben (OVB) erworben hat. Dagegen haben sich in den europäischen Ländern, in denen die Deregulierung schon früher griff, bereits zahlreiche Großunternehmen herausgebildet, die nun als „Global Player" auch auf den deutschen Verkehrsmarkt drängen. Im Gebiet des RMV ist dies beispielsweise das französische Unternehmen Vivendi bzw. deren Tochterunternehmen Connex, die wiederum an dem Unternehmen Alpina beteiligt ist. Die Kapitalkraft von Connex wird daran deutlich, dass es die Mehrheit an der Deutschen Nahverkehrsgesellschaft mbH erworben hat, einem Zusammenschluss kommunaler Unternehmen der Städte Leipzig, Bonn und Hannover. ${ }^{784}$ Dieses Beispiel macht gleichzeitig deutlich, dass es weitreichenderer Aktivitäten bedarf, die kommunalen Verkehrsunternehmen auf den Wettbewerb vor-

\footnotetext{
780 vgl. Barth 2000, S.157 sowie Püttner 2000, S.51ff

781 Riehl 2005, S.1

782 ebd.

783 vgl. Riehl 2005, S.1

${ }^{784}$ vgl. Becker, T. 2004, S.35
} 
zubereiten, als beispielsweise nur die Gesellschaftsform zu ändern. Der Stand der Vergabe von Verkehrsleistungen im Buslinienverkehr unterstreicht diese Notwendigkeit: Ende 2005 waren 43 Linienbündel (etwa 19\% der Gesamtleistung von über 150 Mio. km) im Buslinienverkehr in Hessen vergeben. Nur 16\% entfielen auf kommunale Verkehrsbetriebe. Private Busunternehmen hatten dagegen bereits 25\% sowie Kooperationen und Bietergemeinschaften 27\% der Ausschreibungen gewonnen. 785

Von daher - wie auch aus wettbewerbsrechtlichen Gründen - sollte hinterfragt werden, ob ein kommunales Verkehrsunternehmen in einem deregulierten Verkehrsmarkt überhaupt zeitgemäß ist. Schließlich würde eine konsequente Umsetzung des BestellerErsteller-Prinzips es den Kommunen ermöglichen, sich auf ihre Aufgabe, Mobilität unter Berücksichtigung finanzieller Rahmenbedingungen sicherzustellen, im erforderlichen Umfang zu konzentrieren, d.h. sich im Rahmen ihrer (wirtschaftlichen) Aktivitäten vorwiegend auf das lokale Gemeinwohl zu beschränken. ${ }^{786}$

\subsubsection{Wettbewerbsverzerrungen durch kommunale Aktivitäten}

Durch die Übertragung der Verantwortung für die Organisation und Ausgestaltung des ÖPNV auf die Kommunen, die eine Aufwertung ihrer Verantwortlichkeiten erfahren, bedeutet "Deregulierung" aus organisatorischer Sicht daher auch "Dezentralisierung". Für die Kommunen bedeutet Deregulierung aber auch weniger Einflussnahme auf den Erstellermarkt, selbst wenn es dabei um die verbesserte wirtschaftliche Position eines kommunalen Eigenbetriebs geht. Denn „echte“ Wirtschaftlichkeit von Verkehrsunternehmen in kommunaler Verantwortung ${ }^{787}$ stellt sich aufgrund der engen Verknüpfung mit der kommunalen Verwaltung häufig problematisch dar. Nach vollzogener Trennung nach dem Besteller-Ersteller-Prinzip kann die Politik dann aber nicht mehr in die Führung des Verkehrsunternehmens hineinregieren, sondern nur noch Verträge mit diesem schließen. 788

\footnotetext{
785 vgl. Riehl 2006, S.10

786 vgl. Barth 2000, S.157f

787 Als öffentliches Unternehmen unterscheidet sich ein kommunales Verkehrsunternehmen deutlich von der Kommunalverwaltung durch die wirtschaftliche Zielstellung, auch wenn es einem öffentlichen Zweck und dem öffentlichen Interesse dient. Das Unternehmen erwirtschaftet Erträge, die Einfluss auf den Kommunalhaushalt haben oder eine marktübliche Verzinsung erzielen sollen. Hieraus wird auch die Trennungslinie zum Regieunternehmen bzw. zum Verkehrsverbund deutlich, der selber Teil der Verwaltung ist; vgl. Wöhe 1990, S.395ff.

${ }^{788}$ vgl. HMWVL 2003 (b)
} 


\section{Grenzen kommunaler Wirtschaftstätigkeit}

Die hessische Gemeindeordnung regelt die kommunalen wirtschaftlichen Aktivitäten auf Gemeindeebene, wonach ein kommunales Wirtschaftsunternehmen nur dann gerechtfertigt ist, wenn es einem öffentlichen Zweck dient. ${ }^{789}$ Hier gibt es allerdings einen Interpretationsfreiraum über die Festlegung, was zweckmäßig ist und was nicht. Aktiv darf eine Kommune beispielsweise in einem Bereich werden und dort auch Gewinne erzielen, der sonst „brach“ liegen würde. Das kommunale Unternehmen darf dabei jedoch nicht mit privatwirtschaftlichen Unternehmen konkurrieren, wenn letzteres die Leistung genauso gut oder besser, d.h. auch günstiger erbringen kann („Subsidaritätsklausel“). Hinsichtlich der Erstellung von ÖPNV-Verkehrsleistung wird die Gemeindeordnung dahingehend ausgelegt, dass alle Aktivitäten, die unmittelbar mit der ÖPNV-Leistungserstellung zu tun haben - also auch Marketing und Vertrieb - einem öffentlichen Zweck dienen und eine Gewinnerzielung legitim ist, sofern ein privates Unternehmen nicht dazu besser geeignet ist.

Allerdings beschränkt die hessische Gemeindeordnung die wirtschaftliche Tätigkeit auf das Gemeindegebiet, auf dem das Verkehrsunternehmen ansässig ist („Territorialprinzip“).790 Im Sinne des unmittelbaren Gemeinwohlzwecks kann dieses Verkehrsgebiet auch auf benachbarte Gemeinden, verkehrlich verflochtene Räume oder einem Verkehrsverbund ausgedehnt werden. „Diese Beschränkung besteht von Verfassungs wegen und steht nicht zur Disposition der Landesgesetzgeber“. ${ }^{791}$ Inwiefern aber eine Verbesserung der Wirtschaftlichkeit unter derart räumlicher Beschränkung erreicht werden kann, ist mehr als fraglich, da von vornherein zahlreiche Synergie- und Masseneffekte ausgeblendet werden. Die wirtschaftliche Aktivität außerhalb des Gemeindegebiets kann sogar existenziell notwendig werden, wenn Konzessionen im eigenen Gebiet an konkurrierende private Unternehmen verloren gehen. ${ }^{792}$

\section{Kommunale Verlustausgleiche}

Trotz Wettbewerb ergeben sich unterschiedliche Ausgangsvoraussetzungen bei kommunalen und privatwirtschaftlichen Verkehrsunternehmen. Diese Unterschiede können dazu

\footnotetext{
${ }^{789} \mathrm{vgl}$. Hessische Staatskanzlei 2005 (b), S.1ff

790 vgl. Barth 2000, S.91ff

791 Barth 2000, S.113

${ }^{792} \mathrm{vgl}$. Umweltbundesamt 2005 (a), S.10
} 
führen, dass sich das öffentliche Unternehmen aufgrund seiner institutionellen und personellen Ausrichtung wettbewerbsverzerrende Marktvorteile erschleicht. Die Vorteile resultieren insbesondere aus Informationsvorsprüngen und (öffentlichen) Kundenkontakten sowie Kommunikationsvorteilen über öffentliche Einrichtungen und Medien. Des weiteren stehen einem öffentlichen Unternehmen auch andere Finanzierungsquellen zur Verfügung. So genießen diese beispielsweise in der Kreditwirtschaft eine andere Einstufung (,Ranking“) als private Unternehmen. Darüber hinaus bietet der Querverbund den Kommunen als Eigentümer die Möglichkeit, die Gewinne durch Kompensation mit Verlusten von der Körperschaftssteuer zu entlasten. Auch hieraus ergab sich eine marktverfälschende und den Wettbewerb behindernde Situation, in der die Verbraucher von Energie, die nicht den ÖPNV nutzen, die Verkehrsleistungen in Form erhöhter Gas- und Strompreise bezahlen. Die Privatisierung des Energiesektors und des ÖPNV trägt allerdings dazu bei, dass die Quersubventionierung des ÖPNV rückläufig ist.

Dennoch bestehen nach wie vor zahlreiche andere Kapitalquellen, die privatwirtschaftlichen Unternehmen in der Form nicht zugänglich sind. Hier ist insbesondere die Umlagefinanzierung zu nennen, mit der die Verluste der öffentlichen Verkehrsunternehmen aus Steuergeldern abgedeckt werden. Insgesamt betrachtet drängen die Kommunen durch ihre eigene Wirtschaftstätigkeit private Verkehrsunternehmen in eine ungünstige Wettbewerbsposition, die sich letztlich wiederum in einer verschlechterten Ertragslage ausdrückt. 793

\subsubsection{Deregulierung als Chance}

Die Erfahrungen der Länder, in denen es bereits Wettbewerb im ÖPNV gibt, sind durchweg positiver Art. Die erzielten Effizienzgewinne ergeben sich aus gestiegenen Fahrgeldeinnahmen sowie Kosteneinsparungen durch die Reduzierung der Wegekosten (Kilometerpreis) und belaufen sich auf durchschnittlich 10-30\%, bei erstmaligen Ausschreibungen sogar noch darüber. ${ }^{794}$ Alleine im RMV wurden nach Aussage des hessischen Ministers für Wirtschaft, Verkehr und Landesentwicklung, Rhiel, in den ersten beiden Jahren 20 Mio. Euro eingespart795, die wiederum für neue S-Bahnen, Niederflurbusse und Klimaan-

\footnotetext{
${ }^{793} \mathrm{vgl}$. Barth 2000, S.98ff

${ }^{794}$ vgl. Werner, J. 2003, S.5 sowie Kahl 2005, S.278

${ }^{795}$ vgl. Riehl 2006, S.10
} 
lagen in Fahrzeugen ausgegeben wurden. ${ }^{796}$ Die Ausschreibung von Verkehrsleistung ist daher ein potentes Instrument, wenn es darum geht, die Verkehrsleistung nicht nur günstiger, sondern auch qualitativ besser zu erbringen. So tragen die eingesparten Gelder einerseits dazu bei, die enger werdenden Finanzspielräume auszugleichen, andererseits könnten die freien Mittel aber auch dazu verwendet werden, zusätzliche Verkehrsleistung zu finanzieren und dadurch Mehreinnahmen erzielt werden. ${ }^{797}$ Bemerkenswert ist, dass alleine schon die Ankündigung des Wettbewerbs dazu geführt hat, dass es zu Preisnachlässen auf der Erstellerseite gekommen ist. Diese liegen vor allem im Personalabbau und in der Reduzierung von Lohnkosten begründet. Ob es allerdings auch schon zu wesentlichen Prozessoptimierungen oder gar verbesserter Kundenorientierung gekommen ist, muss bezweifelt werden. ${ }^{798}$

Im Hinblick auf die kommunalen Verkehrsunternehmen muss resümiert werden, dass je länger diese vor Wettbewerb "geschützt" werden, die Gefahr wächst, dass notwendige Restrukturierungen ausbleiben und die Unternehmen im Wettbewerb nicht bestehen können. Zögerliche oder gar nicht getroffene Unternehmensentscheidungen mit dem Ziel der Marktanpassung bzw. der Kundenorientierung können dazu führen, dass das Unternehmen früher oder später ganz vom Markt verschwindet. Und dies könnte nicht nur einzelne Verkehrsunternehmen betreffen, sondern ganze Stadtwerke. ${ }^{799}$ Kahl beschreibt die Situation der Verkehrsunternehmen im Wettbewerb folgendermaßen:

\footnotetext{
„Denn für ein Verkehrsunternehmen wird es - will es auch zukünftig am Markt vertreten sein - unter den Bedingungen des kontrollierten Wettbewerbs zum einen nur sehr eingeschränkt möglich sein, sich von der Marktgegenseite und von Marktkonkurrenten weitgehend unabhängig zu verhalten, zum anderen schwindet die Macht, tatsächlichen Wettbewerb zu verhindern bzw. potenzielle Wettbewerber fern zu halten". 800
}

Nach Einschätzung des HMWVL ist der Übergang für die Verkehrsunternehmen ein durchaus schwieriger Prozess. „Umso wichtiger ist es, sich intensiv vorzubereiten, um einen Vorsprung zu gewinnen. Diejenigen, die dies getan haben, sind bei den Ausschrei-

\footnotetext{
796 vgl. Frankfurter Rundschau v. 25.11.05, S.32

${ }^{797}$ vgl. Umlandverband 2000, S. 18

798 ebd., S.243

799 vgl. Schöller 2005, S.245

${ }^{800}$ Kahl 2005, S.404
} 
bungen auch erfolgreich“. ${ }^{801}$ Finanziell gesehen konnten im Bereich des RMV im Busverkehr im Fahrplanjahr 2005 bereits etwa 5,7 Mio. Euro eingespart werden. Für den gesamten Bereich des Busverkehrs werden die Einsparpotenziale auf 15 bis 25 Mio. Euro beziffert. Für den Bereich des SPNV liegen die bisherigen Einsparungen zwar nur im „marginalen“ Bereich, dafür konnten hier qualitative Verbesserungen durch den Einsatz neuer Fahrzeuge erreicht werden. 802

Es lohnt also, den Blick nach vorne zu richten und sich nicht darauf zu versteifen, die etablierten Strukturen und Prozesse bewahren zu wollen. Dabei sind aber nicht alleine die Verkehrsunternehmen gefragt, sondern auch die Aufgabenträger als Besteller der Verkehrsleistung. Es obliegt ihnen, die Nachfragestruktur am Verkehrsmarkt richtig einzuschätzen und die Nahverkehrsplanung auf die real existierenden Marktbedürfnisse und -erwartungen auszurichten. Das Beispiel anderer europäischer Länder803, die bereits seit längerer Zeit Wettbewerb im ÖPNV eingeführt haben und ebenfalls die Verantwortung für die ÖPNV-Vermarktung auf die Aufgabenträger verlagert haben, zeigt, dass sich die Aufgabenträger entsprechend auf diese Aufgaben vorbereiten müssen um Fehlentwicklungen entgegen zu wirken. Denn auf Seiten der Aufgabenträger besteht durchaus eine gewisse Marktferne sowie einer Überlagerung der Ziele durch die lokale politische Einflussnahme auf die Regieebene. Dies könnte dazu führen, dass die Verkehrsunternehmen ihr Marketing alleine auf die Behörde und nicht auf den Kunden ausrichten. ${ }^{804}$ Blümel bezeichnet diese Struktur als „Dilemma des geteilten Markts und der geteilten Verantwortlichkeiten im ÖPNV“ (siehe Abbildung 29). Er beanstandet, dass die Art und Weise

\footnotetext{
801 RMV 2005, S.62

802 ebd., S.75

${ }^{803}$ Hier werden u.a. die Beispiele Schweden und Frankreich zitiert, wo es in Folge des Wettbewerbs zu einer Verdrängung zahlreicher kleinerer und mittelständischer Verkehrsunternehmen gekommen ist; vgl. Will 2001, S.29 und Püttner 2000, S.65f. In Großbritannien kam es aufgrund der Deregulierung in Form eines freien Wettbewerbs im Markt zu einem rein nachfrageorientierten ÖPNV-Angebot mit der Konsequenz, dass umsatzschwache Relationen - vor allem im ländlichen Raum - nach wie vor von den Kommunen finanziert werden müssen. Des weiteren lösten sich bereits bestehende Verbundstrukturen mit einheitlichen Preis- und Produktangeboten auf, was zu einem „Bruch“ in der Kundenbedienung führte, d.h. der Fahrgast muss nach Einführung des Wettbewerbs bei jedem Umstieg eine neue Fahrkarte lösen. Daneben entstand - zumindest in der Anfangszeit - auch ein intramodaler Wettbewerb, bei dem Schnellbuslinien mit dem Schienenverkehr konkurrierten; vgl. Püttner 2000, S.63 und Becker, T. 2004, S.9ff. Darüber hinaus wurde teilweise auch ein Wiederanstieg der Kosten nach erfolgter Marktkonsolidierung verzeichnet, die allerdings noch deutlich unter den Preisen vor der Marktöffnung liegen; vgl. Becker, T. 2004, S.9 sowie Werner, J. 2003, S.5.

${ }^{804}$ vgl. Will 2001, S.29 sowie Blümel 2004, S.13
} 
der Finanzierungsstruktur über Ausgleichszahlungen und Zuschüssen zu einer Situation führt, in der die Kunden keine Rolle spielen und die Verkehrsunternehmen gegenüber den Kundenerwartungen immunisiert werden. ${ }^{805}$ Es geht also eher um die Optimierung der Zuschüsse, als um eine optimales Angebot. ${ }^{806}$

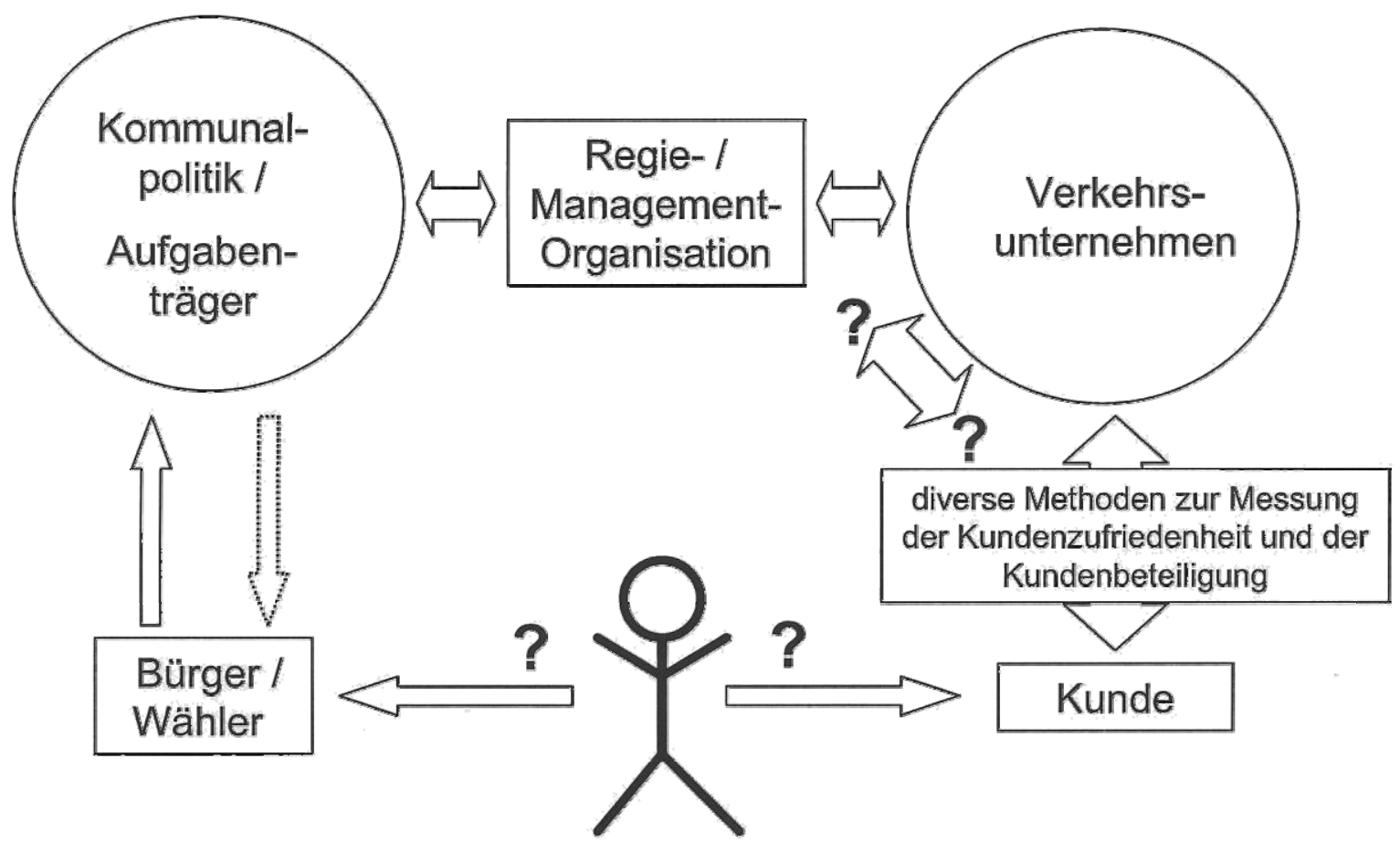

Abbildung 29: Dilemma des geteilten Markts und der geteilten Verantwortlichkeiten im ÖPNV

Quelle: Blümel 2004, S.14

Demnach bedarf es eines kompetenten Aufgabenträgers bzw. seiner Management-/ Bestellerorganisation, um marktgerechte und vertraglich angemessene Vergaben durchzuführen. Grundlage hierfür ist unter anderem das Wissen über die Marktnachfrage (u.a. Marktvolumen, Nachfrage, Kundenzufriedenheit und -erwartungen). Ferner sind aber auch Informationen über den Anbietermarkt (u.a. Unternehmensstruktur und Leistungsvermögen der anbietenden Verkehrsunternehmen, Wettbewerbsintensität) wichtig, die eine Kontrolle und Steuerung des Wettbewerbs ermöglichen. 807 Die alleinige organisatorische Trennung in Aufgabenträger und Leistungsersteller ist also per se kein Garant für mehr Effizienz. Auch dürfen sich die Bestellerorganisationen selbst nicht zu „überdimensionierten Organisationen zur Verteilung der Bundesmittel“ entwickeln, wie dies der e-

\footnotetext{
805 vgl. Blümel 2004, S.14

806 vgl. Umweltbundesamt 2005 (a), S.11

807 vgl. Werner, J. 2003, S.8
} 
meritierte Giessener Verkehrswissenschaftler Aberle in einigen Bundesländern bereits befürchtet. 808

Insgesamt bietet der Wettbewerb jedoch mehr Chancen als Risiken für eine verbesserte Bearbeitung des Verkehrsmarktes. „Der Weg in den Wettbewerb bietet neben der Chance des effizienteren Einsatzes öffentlicher Gelder die Möglichkeit, verkehrs- und umweltpolitische Ziele und eine attraktive kundenorientierte Gestaltung des ÖPNV zu verwirklichen" ${ }^{809}$ So gestattet die Novellierung des Hess. ÖPNVG eine grundlegende Erneuerung der ÖPNV-Vermarktung, über die erstmals eine einheitliche „Bearbeitung“ des Verkehrsmarktes möglich wird, zumal nur die Erstellung der Beförderungsleistung in den Wettbewerb überführt wird. Für eine marktkonforme Anpassung des Leistungsangebotes sowie der eigentlichen Marktbearbeitung bedarf es allerdings immer noch eines Instrumentariums, mit dem die Beziehungen zu den Kunden aufgebaut und verwaltet, Maßnahmen am Markt umgesetzt sowie die Effizienz und Wirtschaftlichkeit dieser Maßnahmen nachvollzogen oder sogar optimiert werden können. Die $R M V G m b H$ sieht daher „einen zentralen Vertrieb über neue Technologien mit individualisierter Erfassung und Abrechnung der Fahrten vor," 810 auf den im weiteren Verlauf der Arbeit (Kapitel 7.3) noch näher eingegangen wird.

\subsection{Organisation des ÖPNV in der Region Frankfurt Rhein-Main}

\subsubsection{Funktionsträger im ÖPNV}

Der ÖPNV in Hessen ist nach dem Prinzip des „3-Ebenen-Modells“811 organisiert. Hier erfolgt eine Trennung in eine gesetzgebende Politikebene, eine Regieebene für die Organisation der regionalen und der lokalen Verkehre sowie in eine operative Unternehmensebene. Die Aufgaben der Politik-Ebene werden durch den Aufsichtsrat der RMV GmbH

${ }^{808}$ vgl. Handelsblatt vom 08.06.2006 sowie Blümel 2004, S.17

809 Umweltbundesamt 2005 (a), S.5

810 RMV 2005, S.93

811 Das Prinzip des „2-Ebenen-Modells“ ist das eines Zweckverbandes. Es orientiert sich am Gesetz über kommunale Gemeinschaftsarbeit (KGG). Im Gegensatz zum „3-Ebenen-Modell“ fehlt die Regieebene, was zu einer engeren Kopplung an die kommunale Verwaltung führt. So sind die Mitglieder der Verbandsversammlung in der Regel Vertreter der Gebietskörperschaften, so dass der Einfluss der Kommunen auf die LNO gewährleistet ist. Insgesamt ergibt sich daraus ein weniger flexibler und freier Handlungsspielraum für unternehmerische Tätigkeiten als im „3-Ebenen-Modell“. 
wahr genommen, in dem die politischen Vertreter der Gebietskörperschaften vertreten sind. Hier werden Entscheidungen über das Angebot und die daraus resultierenden Kosten getroffen. Schließlich entscheidet der Aufsichtsrat, nach welchen Vorgaben die RMV $\mathrm{GmbH}$ auf der Regie-Ebene den Regionalverkehr ausübt. Auf der Unternehmensebene sind die Verkehrsunternehmen für die operative Abwicklung des ÖPNV bzw. die Erbringung der Beförderungsleistung zuständig. Beide Verkehrsverbünde in Hessen sind nach diesem Prinzip organisiert.

\subsubsection{Hessisches Ministerium für Wirtschaft, Verkehr und Landesentwicklung}

In Hessen betreuen zwölf Ämter für Straßen- und Verkehrswesen das Verkehrsnetz vor Ort. Das Hessische Landesamt für Straßen- und Verkehrswesen (HLSV) in Wiesbaden steuert die Prozesse aus übergeordneter Sicht.

\subsubsection{Genehmigungsbehörde}

Das Regierungspräsidium Darmstadt, das für den südlichen Teil Hessens zuständig ist und einen Großteil der Region Frankfurt Rhein-Main abdeckt, ist eine staatliche Mittelinstanz zwischen den Ministerien und den unteren Verwaltungsbehörden. Die Behörde ist Genehmigungsbehörde und Geschäftsstelle der Regionalversammlung Südhessen, die den Regionalplan beschließt, der zukünftig auch den Flächennutzungsplan beinhaltet. Ihre Aufgaben im Bereich des ÖPNV ergeben sich insbesondere aus dem PBefG. In Südhessen genehmigt die Behörde im ÖPNV u.a. Tarife, Konzessionen und Streckenstilllegungen. ${ }^{812}$

\subsubsection{Aufgabenträgerorganisationen}

Die Umsetzung des Regionalisierungsgesetzes in den Bundesländern findet ihre teils sehr unterschiedlichen Ausprägungen in den Landesgesetzen. Das Hess. ÖPNVG definiert den ÖPNV als Aufgabe der Daseinsvorsorge und hat zur Sicherstellung flächendeckend Nahverkehrsverbünde gegründet. Dieses sind:

- Rhein-Main-Verkehrsverbund (RMV) - Mittel- und Südhessen ${ }^{813}$

- Nordhessische Verkehrsverbund (NVV) - Nordhessen

\footnotetext{
812 vgl. http:/ / www.rp-darmstadt.hessen.de

${ }^{813}$ Dr hessische Kreis Bergstraße ist assoziiert mit dem Verkehrsverbund Rhein-Neckar (VRN)
} 


\section{Rhein-Main-Verkehrsverbund}

Der Rhein-Main-Verkehrsverbund ist ein Zusammenschluss von 15 Landkreisen und 11 Städten sowie dem Land Hessen. Alle regionalen Verkehre im RMV werden somit von den öffentlichen Aufgabenträgern Mittel- und Südhessens gemeinsam verantwortet. Der Verbund übernimmt Grundsatzaufgaben und regionale Verkehrsaufgaben:

- Festlegung der Tarifsystematik

- Planung und Gestaltung der regionalen Verkehrslinien und Verkehrsnetze (Verkehrssysteme, Leistungsumfang und Qualität) und deren Umsetzung,

- Bestellungen von Verkehrsleistungen im regionalen Verkehr, Abschluss von Verkehrsverträgen mit den regionalen Verkehrsunternehmen.

- Erstellung von regionalen Nahverkehrsplänen, Mitwirkung bei lokalen Nahverkehrsplänen und bei Investitionsprogrammen. ${ }^{814}$

Der RMV deckt die Region Frankfurt Rhein-Main zu großen Teilen (siehe Kapitel 4.3.2) und den etwas kleiner geschnittenen Ballungsraum Rhein-Main zur Gänze ab. Das Verbundgebiet des RMV erstreckt sich im Nordosten bis in den Vogelsbergkreis, im Norden bis Marburg, im Westen bis nach Limburg und Lorch im Rheingau-Taunus-Kreis, im Süden bis nach Erbach im Odenwald und im Osten bis in den Main-Kinzig-Kreis. Die Stadt Mainz ist kooperiertes Mitglied des Verbundes. Mit ca. $13.500 \mathrm{~km}^{2}$ nimmt das Verbundgebiet den Großteil der Fläche Mittel- und Südhessens ein. Bezogen auf die Wirtschaftsregion Frankfurt Rhein-Main muss allerdings festgestellt werden, dass wichtige Gebiete, die in enger wirtschaftlicher und damit auch verkehrlicher Interaktion mit dem Ballungsraum stehen ${ }^{815}$, nicht abgedeckt werden. Letztendlich waren bei Verbundgründung aber weniger die tatsächlichen Nahverkehrsbeziehungen ausschlaggebend, sondern vielmehr die Kooperationsbereitschaft der gründenden Gebietskörperschaften. 816

Nachdem die RMV GmbH die Aufgaben der Gründungsphase abgeschlossen hat, bei der es im Sinne der Verbundgründung um die Realisierung eines Tarifverbundes ging, sind die vornehmlichen Ziele in der Phase des "Aufgabenträgerverbunds“ nach eigener Aussage:

\footnotetext{
814 vgl. Püttner 2000, S.6

815 Hier ist v.a. der Rhein-Neckar-Raum zu nennen.

${ }^{816}$ vgl. Freund 2002, S.93
} 
- Umsetzung des Aufgabenträgerverbunds,

- Entwicklung neuer Finanzierungs- und Organisationsmodelle,

- Modernisierung der Infrastruktur,

- Neustrukturierung und Ausweitung des Leistungsangebots,

- Steigerung der Fahrgastzahlen,

- Verbesserung des wirtschaftlichen Ergebnisses.817

Lokale Nahverkehrsorganisationen (LNO)

Die Kommunen, also die gesetzlichen ÖPNV-Aufgabenträger, sind für die Organisation des ÖPNV auf lokaler Ebene verantwortlich („dezentrales Prinzip“). Die damit zusammenhängenden Aufgaben werden in der Regel den Lokalen Nahverkehrsorganisationen (LNO) übertragen, die das Bindeglied zwischen den Aufgabenträgern sowie den lokalen Verkehrunternehmen darstellen. Sie übernehmen folgende Aufgaben. ${ }^{818}$

- Planung des lokalen Verkehrs und Aufstellung von Nahverkehrsplänen,

- Bestellung der lokalen Nahverkehrsleistung,

- Aufsicht über die Leistungserstellung,

- Marketing und Kundenbetreuung,

- Finanzierung der lokalen Verkehrsleistung,

- Aufstellung von Investitionsprogrammen.

In der Regel sind die Gesellschafter der LNO der Kreis sowie kreisangehörige Städte und Gemeinden. In einigen Fällen haben vorerst kommunale Verkehrsunternehmen die Aufgabe der LNO übernommen. Dieses ist insofern problematisch, als dass die LNO als Unternehmer auftritt, was eine wettbewerbskonforme Vergabe der Verkehrsleistung erschwert (s.u.). Das Hess. ÖPNVG sieht aber vor, dass alle Aufgabenträger bis 2007 über eine $L N O$ verfügen müssen.

Die Lokale Nahverkehrsorganisation für die Stadt Frankfurt, TraffiQ ist für die lokale ÖPNVPlanung, Vergabe und Vermarktung der Verkehrsleistung zuständig. Nach eigenen An-

817 vgl. RMV 2005, S.7

${ }^{818}$ vgl. Freund 2002, S.8 
gaben hat sie sich die „Erhöhung des ÖPNV-Anteils am ,Modal split’, die Gewährleistung von Qualitätsstandards und die Sicherung einer ausreichenden Mobilität bei gleichzeitiger Reduzierung der Kosten“ zum Ziel gesetzt. Da die U-Bahn- und StraßenbahnKonzessionen aber noch bis zum Jahr 2011 laufen, werden zunächst nur lokale Buslinienbündel ausgeschrieben. In diesem Zusammenhang soll die TraffiQ auch die Qualitätsstandards definieren und kontrollieren. ${ }^{819}$

Im Rahmen des Wettbewerbs und der Trennung nach dem Besteller-Ersteller-Prinzip kommen für die Aufgabenträgerorganisationen also zahlreiche neue Aufgabe zu (vgl. auch Kapitel 6.4.2), was letztlich eine Orientierung weg von Verwaltungsaufgaben hin zu Dienstleistungsaufgaben nach marktwirtschaftlichen Prinzipien nach sich zieht. ${ }^{820}$ Neben der Sicherstellung der ÖPNV-Finanzierung - und den damit verbundenen Problemen wie dem Abbau der Querverbundsvorteile - gilt es insbesondere Bestellkompetenz aufzubauen. $\mathrm{Zu}$ diesen Kompetenzen gehören neben der „handwerklichen“ Durchführung der Konzeption, Organisation und Durchführung der Bestellung vor allem die Koordinierungs- und Finanzierungsverantwortung und eine marktbezogene Ausrichtung der Leistungsbestellung. Hierfür muss umfassendes Wissen über den Nachfragermarkt vorhanden sein bzw. generiert werden. Darüber hinaus müssen nicht nur Vorgaben für die Qualität der Verkehrsleistungserstellung entwickelt werden, sondern auch die Einhaltung entsprechender Qualitätsstandards kontrolliert werden. ${ }^{821} \mathrm{Zu}$ den weiteren Aufgaben gehört die Bereitstellung von Infrastruktur zur Durchführung einer chancengleichen Leistungserstellung. ${ }^{822} \mathrm{Im}$ Bereich der SPNV wird dies bereits durch die RMV GmbH zum Fahrplanwechsel 2006 im ausgeschriebenen Odenwaldnetz durch die Bereitstellung von eigenen Dieseltriebwagen praktiziert. ${ }^{823}$

\subsubsection{Verkehrsunternehmen}

Die überwiegende Anzahl der mehr als 150 Verkehrsunternehmen im Rhein-MainVerkehrsverbund sind kommunale Eigenbetriebe, die ihre Leistung vorwiegend im lokalen Bereich erbringen. ${ }^{824}$ Der zuständige Gemeinderat erlässt in der Regel für das jeweili-

\footnotetext{
${ }^{819} \mathrm{vgl}$. www.traffiq.de (Zugriff am 4.12.2005)

${ }^{820}$ vgl. Deutsches Verkehrsforum 2005, S.143

${ }^{821}$ vgl. Scholz 2006, S.46

822 vgl. Werner, J. 2000, S.16

${ }^{823}$ vgl. RMV 2005, S.73

824 ebd., S.14
} 
ge Verkehrsunternehmen eine Betriebssatzung und trifft auch grundsätzliche Entscheidungen bzgl. Wirtschaftsplanung und Finanzierung. Die Unternehmensführung selbst liegt bei der Betriebsleitung. ${ }^{825}$

Durch die stringente Aufteilung der Verantwortlichkeiten nach Aufgabenträgern und Verkehrsunternehmen verbleibt bei letzteren ausschließlich die Betriebsdurchführung der Verkehre sowie der dezentrale Vertrieb. Hierzu gehören die Bereitstellung der Betriebsanlagen und Betriebsmittel, die Planung der Betriebsdurchführung nach den Vorgaben der Aufgabenträger sowie die Fahrgelderhebung. Je strikter eine Trennung nach dem Besteller-Ersteller-Prinzip erfolgt, beispielsweise durch die Auslagerung des Vertriebs in aufgabenträgereigenen Vertriebsgesellschaften, desto eher werden Anreizmechanismen notwendig sein, die die Verkehrsunternehmen an einer optimierten Kunden- und Erlösorientierung beteiligen. ${ }^{826}$ Hierfür bedarf es allerdings auch auf der Seite der Verkehrsunternehmen gewisser unternehmerischer Spielräume, die in Hessen durch einen „partnerschaftlichen“ Umgang von Aufgabenträgern und Verkehrsunternehmen sichergestellt werden sollen. 827

\subsubsection{Finanzierung des ÖPNV}

Die Finanzierung der notwendigen Investitionen sowie der Betriebskosten im ÖPNV besteht aus einem komplexen, inkonsistenten und intransparenten Fördersystem. ${ }^{828}$ Sichergestellt wird die Finanzierung des ÖPNV alleine durch die Feststellung, dass die öffentlichen Aufgabenträger die Finanzierungsverantwortung tragen und diese die Aufgabe der Sicherstellung einer ausreichenden Verkehrsbedienung haben. ${ }^{829}$ Das heißt, die Kommunen stehen für den Fehlbetrag gerade, den sie in der Vergangenheit - und auch teils heute noch - aus dem Querverbund mit anderen kommunalen Unternehmen gegenfinanzieren.

\footnotetext{
${ }^{825}$ vgl. Wöhe 1990, S.398

${ }^{826}$ vgl. Deutsches Verkehrsforum 2005, S.141

827 vgl. VDV 2005 (b), S.96

828 vgl. Handelsblatt v. 08.06.2006; Umweltbundesamt 2005 (a), S.11 sowie Bölke 2005, S.34

829 Teilweise trifft man auf eine Argumentation, die den ÖPNV als notwendigen Grundversorgungsbestandteil einer Volkswirtschaft betrachtet und in der Konsequenz eine kostenfreie Nutzung einfordert. Dies birgt die Gefahr, dass betriebswirtschaftliche Aspekte völlig aus den Augen verloren gehen. Anders herum ist es so gut wie unmöglich bzw. rein theoretischer Natur, den Produktivitätsbeitrag oder den Nutzen des ÖPNV (wie auch anderer Wirtschaftszweige) zur Volkswirtschaft konkret zu beziffern, insbesondere weil die Erlöse aus der Verkehrsleistung sich immer aus einem Gesamtnetz mit vielfältigen sich gegenseitig beeinflussenden Faktoren ergeben; vgl. Woll 1990, S.121.
} 
Allerdings gibt es die unterschiedlichsten Fördertöpfe für den ÖPNV, aus denen die Zuschüsse aber immer weniger stark sprudeln. So fließen Zuschüsse aus Regionalisierungsmitteln des Bundes ${ }^{830}$ nur noch in sehr begrenztem Umfang, Ausgleichszahlungen für den Schüler- und Schwerbehindertentransport (§45a PBefG bzw. §62 Schwerbehindertengesetz) nur noch pauschalisiert und Gelder nach dem GVFG des Landes gar nicht mehr. Hinzu kommen Infrastrukturfinanzierungen durch die Länder und die Kommunen selbst sowie Fördermittel zur Einnahmesicherung bei Kooperationen (z.B. bei Verbundtarifen), steuerliche Begünstigungen (z.B. bei Linienbussen) und kostenlose Infrastruktursondernutzungen (z.B. Busspuren, Durchfahrtsgenehmigungen). Der SPNV profitiert vom Schienenwegeausbaugesetz (SchWAbG) und der Fahrzeugförderung aus Landesmitteln. Zusammen genommen sind dies jährlich ca. 13 bis 15 Mrd. Euro bundesweit. ${ }^{831}$ Die finanziellen Leistungen der öffentlichen Hand werden etwa zur Hälfte vom Bund getragen, sowie jeweils zu einem Viertel von den Ländern und Kommunen. 832

Empfänger dieser Leistungen sind häufig nicht die Aufgabenträger, die den ÖPNV zu gestalten und zu definieren haben und konsequenterweise auch die Finanzierungskompetenz haben müssten, sondern die Verkehrsunternehmen selbst. Durch dieses Verfahren wird der wenig zielgerichtete Einsatz der Mittel gefördert und ein Nachweis des effizienten Mitteleinsatzes erschwert. 833 „[...] Effizienz kann immer behauptet, jedoch nicht kontrolliert werden". 834

Die Finanzierungsprinzipien im deutschen ÖPNV müssen insbesondere vor dem Hintergrund der EU-Bestrebungen für mehr Wettbewerb im Verkehr kritisch betrachtet werden. Zwar werden durch die EU-Verordnung VO (EWG) Nr.1191/69 sowie VO 1893/91 den Unternehmen Ausgleichszahlungen zugesichert. Die EU-Kommission strebt jedoch an, von der Beihilfeverordnung zu einer klaren Marktzuordnungsverordnung zu kommen. Hieraus leitet sich auch eine klare Trennung der Finanzierungsverantwortlichkeit ab und letztlich auch die Möglichkeit einer verbesserten Kosten-Nutzen-Transparenz: Jeder er-

830 Die Bundesregierung plant, die Regionalisierungsmittel jährlich um eine halbe Milliarde Euro auf rund 6,6 Mrd. Euro zu kürzen, vgl. Handelsblatt vom 08.06.2006, S.20: „Bus und Bahn müssen sparen“. Für den RMV betragen diese Kürzungen für die Jahre 2007 bis 2009 rund 66 Millionen Euro. Hinzu kommen Kürzungen im Bereich investiver Mittel in Höhe von rund 15 Mio. Euro; vgl. Handelsblatt v. 13.07.2006.

831 vgl. Püttner 2000, S.7; Lehmann 2000, S.32 sowie Bölke 2005, S.34

832 vgl. Barth 2000, S.41

833 vgl. Bölke 2005, S.34 sowie Umweltbundesamt 2003 (a), S.14

834 Schöller 2005, S.72 
brachten Leistung stehen konkrete Kosten gegenüber. Dies alleine sollte für die Zukunft schon eine neue und bessere Einschätzung verkehrspolitischer Maßnahmen ermöglichen. Die hessische Landesregierung hat hierauf insofern reagiert, als dass zum Jahre 2004 die investive sowie die konsumtive ${ }^{835}$ Förderung weitgehend reduziert oder gar eingestellt wurde. So erhalten im Bereich der Fahrzeugförderung nur noch Aufgabenträgerorganisationen, beispielsweise in der Form von Fahrzeugvorhaltegesellschaften, Zuwendungen ${ }^{836}$, die oftmals auch pauschalisiert sind. ${ }^{837}$ Eine Arbeitsgruppe des VDV zu nutzerfinanzierten Tarifstrategien hat errechnet, dass „bis zum Jahre 2010 eine jährliche Steigerung der Fahrgelderlöse um vier Prozent am Markt durchgesetzt werden“ müsste, um die verringerten „Fahrgastsurrogate“ zu kompensieren, unter Berücksichtigung der Preiselastizitäten sogar Anpassungen um bis zu sechs Prozent. 838

Vor dem Hintergrund gekürzter ÖPNV-Subventionen und einer sich hieraus ergebenden „Finanzierungslücke“839 in Hessen, stellt sich die Mobilitätssicherung über den umfassenden Ausbau und die Steigerung des Leistungsangebots im ÖPNV zur Lösung von Verkehrsproblemen aussichtslos dar. Ein derartiges Vorgehen wurde noch im Jahre 1993 durch den damaligen deutschen Verkehrsminister Töpfer befürwortet:

"Zur Hebung der Lebens- und Aufenthaltsqualität in unseren Städten muß es in Zukunft darum gehen, sie zunehmend vom motorisierten Individualverkehr wieder zu befreien und die Plätze und Straßen den Menschen zurückzugeben. Dies gelingt umso besser, wenn wir die erwünschte Mobilität durch einen großzügigen Ausbau des öffentlichen Personennahverkehrs erhalten. Das heißt für die Stadtverkehrsplanung: Ausbau des ÖPNV und Rücknahme des motorisierten Individualverkehrs müssen Hand in Hand gehen." 840

Eine Sicherstellung der bisherigen Qualität und Quantität wird kaum ohne eine Veränderung der Finanzierungsgrundlagen des ÖPNV auskommen. Vor allem muss aber ein effizienter Einsatz der bereitgestellten Gelder gewährleistet sein bzw. sollte der Mitteleinsatz an der Effizienz des ÖPNV ausgerichtet sein. Bislang sind aber die durch das ÖPNVAngebot erzielten Wirkungen nicht der Maßstab für die Höhe bereitgestellter öffentlicher

\footnotetext{
835 z.B. in Form der Betriebshofförderung

${ }^{836}$ vgl. VDV 2005 (b), S.96

837 vgl. Umweltbundesamt 2005 (a), S.12

$838 \mathrm{vgl}$. Ackermann und Stammler 2006, S.9ff

839 BUND Hessen 2006, Pressemitteilung v. 3.7.2006

840 Töpfer 1993, S. 3
} 
Gelder. Die Voraussetzung für einen effizienteren und transparenteren Mitteleinsatz ist daher nicht alleine die umfassende Zuweisung der Aufgaben-, sondern auch der Ausgabenverantwortung bei den Aufgabenträgern. Eine klare Trennung in eine Ersteller- und Bestellerseite stellt dabei gleichzeitig die wettbewerbsneutrale Verwendung der Gelder sicher und ist Grundlage für eine substanzielle Effizienzsteigerung des ÖPNV. ${ }^{841}$

Die ÖPNV-Finanzierung und die fortschreitende ÖPNV-Deregulierung sind wichtige Rahmenbedingungen für Veränderungsprozesse im ÖPNV. Ausgehend von diesen Rahmenbedingungen wird die Dringlichkeit der internen Erneuerung in den Verkehrsorganisationen und -unternehmen häufig nur als Druck von Außen wahrgenommen. Die zeitweilig unklare Rechtssprechung zur Vergabe von Verkehrsleistung im Wettbewerb sowie vage verkehrspolitische Zielvorgaben fördern zudem das Festhalten an traditionellen Strukturen. Dabei wird häufig übersehen, dass eigene Reformbestrebungen zur Unternehmensentwicklung mit dem Ziel der Effizienzsteigerung einen wesentlichen Beitrag liefern, lokale Verkehrsprobleme und damit verbundene negative Umwelteinflüsse zu mindern. 842

Der Schlüssel zu einer erfolgreichen und starken Marktpositionierung liegt in der Verbesserung der Eigenfinanzierung. Denn bleibt der notwendige öffentliche Finanzierungsaufwand konstant - oder verschlechtert sich dieser sogar - sind Einbußen im Bedienungsumfang und in der Qualität unabwendbar. Die Verbesserung der Eigenfinanzierung kann nur über die Steigerung der Unternehmenseffizienz erfolgen, d.h. indem Kosten gesenkt und Mehreinnahmen generiert werden (siehe Kapitel 6.2). Denn nur über zusätzliche Einnahmen können neue Angebote geschaffen werden, beispielsweise um auf Anforderungen aus dem Verkehrsmarkt nach flexibler Mobilität oder individuelleren Produkten reagieren zu können, aus denen dann wieder Einnahmen fließen. Auf der anderen Seite müssen die Kostenstrukturen in den Unternehmen angepasst werden. Hierfür ist allerdings eine Kostentransparenz die Voraussetzung, damit Kostentreiber identifiziert und abgebaut werden können.

\footnotetext{
841 vgl. Bölke 2005, S.34 sowie Umweltbundesamt 2003 (a), S.14

842 ebd., S.35
} 


\subsubsection{Kostendeckungsgrad als Indikator}

Seit den 60er Jahren des 20. Jahrhunderts hat sich die finanzielle Situation des ÖPNV stetig verschlechtert. In bezug auf die Einschätzung der allgemeinen Wirtschaftlichkeit des ÖPNV ist festzustellen, dass dieser heute hochgradig defizitär ist. Die unmittelbar erzielten Umsatzerlöse aus Fahrgeldeinnahmen betrugen bei den im VDV zusammengeschlossenen Verkehrsunternehmen 2003 etwa 42\%.843 Im SPNV (im ländlichen Raum) wurden gar Umsatzerlöse von nur 20-30\% erzielt. ${ }^{844}$ Durch zusätzliche gesetzliche Ausgleichszahlungen konnten nach Auskunft des VDV Kostendeckungsgrade von ca. 60\% erreicht werden. 845

Im RMV wurden im Jahr 2005 ca. 1,2 Mrd. Euro für die Erbringung der Verkehrsleistung aufgewendet. Der Anteil der Fahrgeldeinnahmen aus Fahrkartenverkäufen betrug ca. 45\% (Kostendeckungsgrad). Weitere 5\% wurden über Ausgleichszahlungen sowie nochmals $7 \%$ aus einer Kooperationsförderung eingenommen, so dass die RMV GmbH von einem „Preisdeckungsgrad“ von 57\% spricht. Abbildung 30 veranschaulicht, dass es der RMV $\mathrm{GmbH}$ in den letzten Jahren gelungen ist, dieses Ergebnis über schwierige Jahre hinweg in etwa zu halten. Die Abbildung zeigt aber auch eine starke Korrelation von Fahrten und Leistungsangebot einerseits sowie von Fahrgeldeinnahmen und Preisdeckungsgrad andererseits. Die Tarifentwicklung wiederum verläuft auf einem höheren Niveau als die Entwicklung des Leistungsangebots. Inwieweit hierbei Preiselastizitäten ausgeschöpft oder überschritten wurden, lässt sich aus der Abbildung heraus nicht erkennen. Da aber im ÖPNV ein „relativ unelastisches Nachfrageverhalten“ vorliegt, wird allgemein davon ausgegangen, dass übermäßige Preisanhebungen zu Fahrgeldeinbußen führen. ${ }^{846}$

\footnotetext{
${ }^{843}$ vgl. Ackermann und Stammler 2006, S.9

844 vgl. Püttner 2000, S.109

845 vgl. Deutsches Verkehrsforum 2005, S.141

${ }^{846}$ vgl. Sterzenbach 2001, S.177
} 


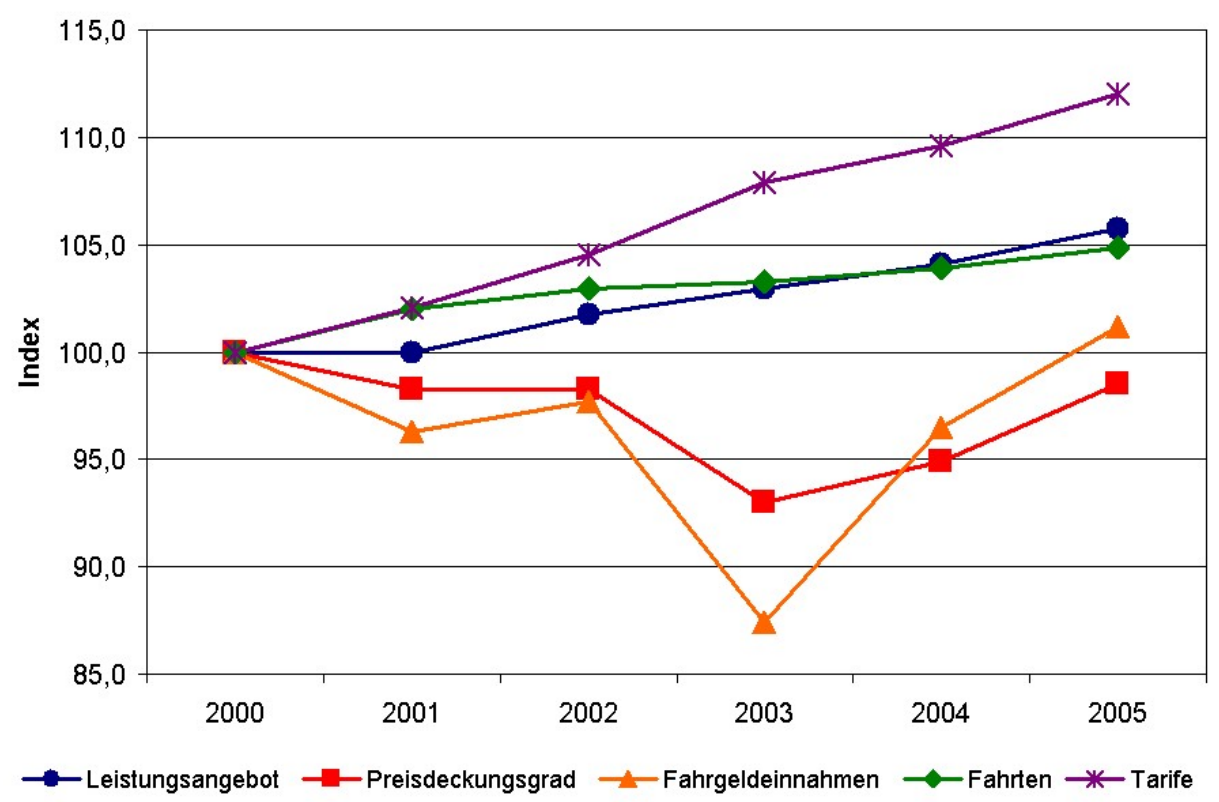

Abbildung 30: $\quad$ Entwicklung von Kennziffern im RMV 2000-2005 (Index-Werte)

Quelle: RMV-Geschäftsberichte 2000-2005 (für Leistungsangebot, Preisdeckungsgrad, Fahrgeldeinnahmen und Fahrgastzahlen) sowie Frankfurter Rundschau v. 5.6.2002, www.wetterau.de/pressestelle2003/themen/dezernat-a/fahrgeld.htm, Marburger News v.7.7.2004, hr-online v.28.5.05 und 24.11.2005.

Die Abbildung verdeutlicht ferner, dass es zusehends schwieriger wird, die Fahrgeldeinnahmen zu halten um somit den „Preisdeckungsgrad“ auf einem hohen Niveau zu stabilisieren, selbst wenn dies dem RMV in den letzten Jahren gelungen ist. Um der Gefahr einer „Kette von Angebotsreduzierung und Preiserhöhung, Attraktivitätsverlust und [...] Fahrgastabwanderung“ $847 \mathrm{zu}$ entgehen, bedarf es zukünftig Strategien, über die der „Preisdeckungsgrad“ über eine Steigerung der Fahrgeldeinnahmen verbessert werden kann. Dass diese Gefahr zusehends größer wird, beweist die RMV-Tariferhöhung zum Fahrplanwechsel im Dezember 2006: Um größere Reduzierungen im Leistungsumfang, insbesondere im ländlichen Regionalverkehr auf der Schiene, durch den Wegfall von Regionalisierungsmitteln auszuschließen, sahen sich die Gesellschafter des RMV gezwungen, die Tarife um 5,9\% anzuheben - die höchste Tarifanpassung seit Bestehen des RMV. 848

Als Ursachen für einen allgemein schlechten Kostendeckungsgrad im ÖPNV werden unter anderem angeführt:

\footnotetext{
847 Stauss 1987, S.145

${ }^{848}$ vgl. Frankfurter Rundschau v. 13.7.2006
} 
- Rückgang der Nachfrage beim ÖPNV, respektive Zunahme des Motorisierungsgrades und Verschiebung des Modal Splits in Richtung MIV,

- Hohes Lohnniveau bei öffentlichen Verkehrsunternehmen (siehe Kapitel 6.1.3),

- Verteuerung bei Personal- und Sachkosten (bspw. im Bereich Wartung und Instandhaltung, Betriebsstoffe) und

- Vorhaltung einer allgemein kostenintensiven Infrastruktur (v. a. im SPNV).

Treber mutmaßt, dass die infrastrukturelle „Förderung des MIV einen hohen Zuschussbedarf für den ÖPNV verbunden mit einer schlechten ÖPNV-Bedienungsqualität nach sich zieht“. Damit wirken sich Fördermaßnahmen des MIV doppelt negativ auf den öffentlichen Haushalt aus: Einerseits durch die Kosten der Maßnahme selbst, andererseits durch den notwendig gewordenen Ausgleich des zusätzlichen Defizits bei den öffentlichen Verkehrsbetrieben. ${ }^{849}$ Die hohen bzw. weiter steigenden fixen wie auch variablen Kosten können durch rückläufige Leistungen der öffentlichen Hand und den Einnahmen aus dem Fahrkartenverkauf immer unzureichender kompensiert werden. Insbesondere die Einnahmen aus dem Fahrkartenverkauf sind in der Vergangenheit sowohl im Verhältnis wie auch absolut gesehen nur geringfügig gestiegen.

\subsubsection{Entwicklung vom Verkäufer- zum Käufermarkt}

Bis zur Deregulierung war der ÖPNV ein Verkäufermarkt mit monopolistischen Zügen und geringer Wettbewerbsintensität, in dem Vertragsbedingungen (z.B. Preise, Rabatte) alleine durch die ÖPNV-Unternehmen bestimmt wurden. Die durch die Verkehrsunternehmen zu erzielenden Einnahmen waren zwar nicht hoch, aber doch konstant und sicher, zumal sie von der öffentlichen Hand kamen. Das Ergebnis war, dass weniger die Kunden im Zentrum des Vermarktungsinteresses der Verkehrsunternehmen und -verbünde standen, sondern vielmehr um Gelder auf der Politikebene gebuhlt wurde (siehe Kapitel 5.3.3). Mit der Deregulierung haben sich diese (Finanzierungs-) Verhältnisse grundsätzlich verändert. Im Zuge einer finanziellen Umorientierung macht nun das Schlagwort der „Nutzerfinanzierung“ die Runde, im Rahmen dessen die ÖPNV-Leistung verstärkt durch „Nutzerentgelte“, sprich Fahrgeldeinnahmen finanziert werden soll. Dies setzt eine Erweiterung der ökonomischen Betrachtungsweise bei den Verkehrsorganisati-

${ }^{849} \mathrm{vgl}$. Treber 1993, S.17 
onen voraus, wie sie bereits durch die Pällmann-Kommission im Jahr 2000 angeregt wurde (siehe Kapitel 3.4). Diese Nutzerfinanzierung sieht einen direkten Bezug zwischen Benutzung und Bezahlung, aber auch der Verwendung der Einnahmen vor. 850 Mit der Nutzerfinanzierung rücken gleichzeitig die Kunden stärker in den Mittelpunkt der wirtschaftlichen Betrachtung. Zwar werden die Kunden im PBefG immer noch als „Beförderungsfälle“ (§8, Abs. 1 PBefG) bezeichnet, doch wird es zukünftig notwendig sein, diese durch geeignete Maßnahmen für den ÖPNV neu zu gewinnen und zu binden. Einerseits gewinnt damit der Einsatz geeigneter Marketinginstrumente im ÖPNV erheblich an Bedeutung, andererseits kann ein beträchtlicher Nachholbedarf in diesem Bereich festgestellt werden ${ }^{851}$, auf den im weiteren Verlauf der Arbeit noch detailliert eingegangen wird.

Mit der veränderten Perspektive auf den Verkehrsmarkt wandelt sich die Wahrnehmung des Verkehrsmarktes von einem „Verkäufermarkt“ zu einem „Käufermarkt”. In diesem Markt müssen sich die ÖPNV-Unternehmen im intermodalen Wettbewerb um die Kunden behaupten, zumal es eine hohe Verfügbarkeit an Mobilitätsangeboten in Form konkurrierender Verkehrsträger (insbesondere dem Pkw) gibt. In diesem Wettbewerb wird der ÖPNV nur bestehen können, wenn das Nachfragedefizit auf der ÖPNV-Seite verringert werden kann. ${ }^{852}$ Allerdings setzen nutzerbasierte Effizienzsteigerungen mehr voraus, als nur einen Perspektivwechsel. Vielmehr bedarf es organisatorischer und struktureller Veränderungen, die über das Maß hinausgehen müssen, das Verkehrsunternehmen bereits heute an Restrukturierung im Rahmen des intramodalen Wettbewerbs durchlaufen.

\subsection{Marktpositionierung der ÖPNV-Unternehmen als Mobilitäts- dienstleister}

Der ÖPNV ist aus rechtlicher Sicht betrachtet eine öffentliche Aufgabe der Daseinsvorsorge und wird zu einem überwiegenden Anteil aus öffentlichen Geldern finanziert. Diese Aufgabe wird zukünftig unter Wettbewerbsbedingungen zu erfüllen sein, wobei die Qualität und die Kosten der Verkehrsleistung gemäß dem EuGH (im sogenannten „Magdeburg-Urteil“) für die Öffentlichkeit transparent sein sollen. Die organisatorischen Grundlagen hierfür sind im Hess. ÖPNVG im Besteller-Ersteller-Prinzip verankert, das eine institutionelle und personelle Trennung in Aufgabenträger und Verkehrsunternehmen vor-

\footnotetext{
850 vgl. Pällmann 2005, S.174

851 vgl. Rumpke 2005, S.11

852 vgl. Homburg und Krohmer 2003, S.5
} 
sieht. Diese Forderung nach Marktöffnung fällt in einen Zeitraum, in dem sich der ÖPNV durch die Haushaltskrise der öffentlichen Hand von Mittelkürzungen konfrontiert sieht. Hieraus erwächst ein Handlungsdruck, dem sich die Verantwortlichen auf den unterschiedlichen Entscheidungs- und Verwaltungsebenen des ÖPNV nicht länger verschließen können, zumal die Erkenntnis reift, dass es sich hierbei um eine generelle Entwicklung handelt, die sich nicht wieder umkehren lässt. Entscheidungen auf Bundesebene, wie beispielsweise das sogenannte „Koch-Steinbrück-Papier“, das in seiner Konsequenz in massiver Weise die Subventionen auch im ÖPNV verringert, manifestieren sowohl die Eindeutigkeit dieser Entwicklung wie auch die Erkenntnis der Unumkehrbarkeit. 853

Neben der Veränderung des wettbewerbs- und finanzrechtlichen Rahmens trägt der gesellschaftliche Wandel ein Übriges dazu bei, dass sich die ÖPNV-Branche grundsätzlich neu positionieren muss - und zwar nicht alleine gegenüber der Politik als Zuwendungsgeber, sondern am Verkehrsmarkt, d.h. gegenüber den Kunden. ${ }^{854}$ Einige Verkehrsunternehmen und -verbünde haben dies erkannt und streben eine marktorientierte Weiterentwicklung an. In diesem Zusammenhang ist im RMV in der weiteren Unternehmensentwicklung von einer strategischen Positionierung als „Mobilitätsverbund“ die Rede. Diese ist dadurch gekennzeichnet, dass es zu einem integrierten Einsatz des gesamten Marketingmixes unter Verwendung neuer Technologien und intelligenter Organisationsmodelle kommen soll, damit über verbesserte Kundenorientierung eine bessere Marktausschöpfung gelingt und hierüber der Deckungsbeitrag verbessert wird.855 Meyer beschreibt dieses Verhalten vom Prinzip her als "offensives Marketing“, welches auf einer „offensiven Einstellung [basiert], Märkte zu gestalten, Verhalten zu ändern, neue Wege zu gehen und Konkurrenten in die Nachahmerposition zu zwingen [...]“.856

Auch die Lokalen Nahverkehrsorganisationen sowie die Verkehrsunternehmen geben sich ihrem Verständnis nach kunden- und dienstleistungsorientiert. Die Zeit des Vorhaltens von Transportkapazitäten für Beförderungsfälle scheint also auch hier vordergründig überwunden. Hintergründig muss allerdings davon ausgegangen werden, dass nicht alle ÖPNV-Akteure bereits ihre Position im Mobilitätsverbund gefunden haben bzw. sich mit der ihnen zugewiesenen Rolle abfinden. Das gilt vor allem für die Verkehrsunternehmen,

\footnotetext{
853 vgl. Koch und Steinbrück 2003 sowie Ackermann und Stammler 2006, S.8

854 vgl. Blümel 2004, S.95

855 vgl. RMV 2005, S.7

856 Meyer 2005, S.7
} 
die sich durch die in Hessen ausgeübte organisatorische Unterteilung in „Besteller“ und „Ersteller“ im Rahmen der wettbewerblichen Vergabe von Verkehrsleistungen zu „Lohnkutschern“ degradiert sehen. Dabei bietet gerade das Hess. ÖPNVG die Chance, dass die bisher unstrukturierte Verantwortlichkeit für die Vermarktung der Verkehrsleistungen durch die ÖPNV-Akteure zukünftig besser, d.h. nachfrage- und kundengerechter ausgeübt wird. So eröffnet beispielsweise die Vergabe von Verkehrsleistungen auf der Basis von Bruttoanreizverträgen eine Möglichkeit, die Verkehrsunternehmen am Markterfolg mittels Bonifizierungen zu beteiligen. Insofern hat also auch die Positionierung der Verkehrsunternehmen als „Mobilitätsdienstleister“ im „Mobilitätsverbund“ durchaus ihre Berechtigung.

Die Idee, Mobilität umfassend zu vermarkten, gibt es nicht nur im ÖPNV. Wie in Kapitel 3.7 dargestellt, wird mit dem Begriff nicht nur von der DB AG oder von Autoherstellern geworben. Auch online-Reisebüros, Autovermieter, Automobilclubs, Autowerkstätten und sogar Reifenhersteller bieten „Mobilitätsdienstleistungen“ in unterschiedlicher Form an. Meffert, Perrey und Schneider definieren Mobilitätsdienstleistungen als

"selbständige marktfähige Leistungen, die mit der Bereitstellung und/oder dem Einsatz von Leistungsfähigkeiten zur Überwindung von räumlichen Distanzen verbunden sind [...], in deren Erstellungsprozess interne und externe Faktoren kombiniert werden [...] und deren Faktorenkombination mit dem Ziel eingesetzt wird, Ortsveränderungen von Personen [...] vorzunehmen". 857

Demnach ergibt sich, dass ein Mobilitätsdienstleister, der ein konkretes Leistungsversprechen über die Beförderung abgibt, das entsprechende Angebot koordiniert, vermarktet und für dessen Erbringung einsteht. Damit wird von der Vorhaltung des schlichten Beförderungsdienstes abgerückt zugunsten einer umfassenden Dienstleistung „am Kunden", die auch die begleitenden Prozesse im Vor- und Nachlauf einer Reise abdeckt (bspw. Information, Buchung, Reservierung, Bezahlung etc.). Die Bewältigung dieser Aufgaben verlangen den Einsatz unterschiedlicher strategischer und operativer Marketinginstrumente zur marktorientierten Ausrichtung des Mobilitätsdienstleisters am Nachfragermarkt, respektive an der Schnittstelle zum Endkunden. 858

\footnotetext{
857 vgl. Meffert, Perrey und Schneider 2000, S.7f

${ }^{858}$ vgl. Rumpke 2005, S.17f
} 
Für eine glaubwürdige Positionierung der Kooperationspartner im Rhein-MainVerkehrsverbund als Mobilitätsverbund bedarf es daher auch eines gemeinsamen Auftritts der Mobilitätsdienstleister am Markt mit einheitlichen Kundenschnittstellen und einer durchgängigen Kundenbetreuung auf der Basis gemeinsamer organisatorischer und technischer Kommunikationsstrukturen. Über letzteres werden nicht nur die Voraussetzungen für verbesserte Kundenorientierung geschaffen, sondern auch die (Infra-) Strukturen für Prozessoptimierungen bereitgestellt, die zu Kosteneinsparungen und letztlich insgesamt höherer Effizienz führen.

Die strategische Marktpositionierung der ÖPNV-Unternehmen als Mobilitätsdienstleister hat zum Ziel, den Marktanteil des ÖPNV zunächst zu halten und dann auszubauen. Im Sinne eines integrierten Gesamtverkehrsmarktes darf sich der ÖPNV dabei aber selbst nicht als Konkurrenten zum Auto begreifen, sondern muss seine eigenen spezifischen Vorteile gegenüber dem privaten $\mathrm{Pkw}$, die es zweifellos gibt, herausstellen und gewinnbringend vermarkten. Nur so wird sich der ÖPNV, wie im Hess. ÖPNVG gefordert, „als Säule des Gesamtverkehrssystems, in das er integriert ist und in dem die Angebote möglichst miteinander verknüpft sind“859, entwickeln können. Andernfalls wird sich der ÖPNV zu einem Nischenprodukt entwickeln, dass - gefördert mit unverhältnismäßig hohen öffentlichen Mitteln - nur noch von Kundengruppen genutzt wird, die keine alternativen Möglichkeiten der Fortbewegung haben. Moderne Vermarktungsstrukturen, Produktinnovationen und Benutzerfreundlichkeit sind daher Aspekte, die zukünftig verstärkt in den Fokus rücken müssen, ohne dass die Kernleistung dabei auf der Strecke bleibt. Hilfreich für diesen äußeren Wandel ist ein innerer Bewusstseinswandel der Branche, der den ÖPNV nicht zuallererst als Arche Noah der sozialen Fürsorge und des Umweltschutzes begreift, sondern den ÖPNV stärker an den Markterfordernissen ausrichtet.

Es bleibt die Feststellung, dass der ÖPNV in Zukunft besser in bezug auf Effizienz, Qualität und Flexibilität werden muss, soll ihm zukünftig verstärkt die Rolle zukommen, auf Basis eines umfassenden Versorgungsanspruches die negativen Effekte der individuellen Mobilität zu dämpfen. Denn auch in der Region Frankfurt Rhein-Main droht der Verkehr ein Ausmaß zu erreichen, durch das eine sozialverträgliche, wirtschaftliche und insbesondere nachhaltige Entwicklung unter ökologischen Gesichtspunkten verhindert wird.

${ }^{859}$ Hessischer Landtag 2005, S.13 


\title{
6 Möglichkeiten der Effizienzsteigerung im ÖPNV
}

\author{
„Man darf den Wandel nicht einfach als etwas präsentieren, das ganz nett wäre. Er muss eine Über- \\ lebensfrage sein." \\ David Swanson, amerikanischer Manager (Procter \& Gamble)
}

In diesem Kapitel wird beleuchtet, welche marketingseitigen, organisatorischen und technischen Instrumentarien und Ansätze im ÖPNV geeignet sind, Mehreinnahmen zu generieren und Kostensenkungen zu erzielen. Zunächst wird aber auf einige Aspekte eingegangen, die häufig als „Besonderheiten des Verkehrsmarktes“ angeführt werden - vor allem mit dem Ziel die bestehenden Verhältnisse im ÖPNV zu bewahren und Veränderungsprozesse herauszuschieben.

\subsection{Merkmale des ÖPNV}

\subsection{1 ÖPNV als Dienstleistung von „Mensch zu Mensch“}

Bei einem Verkehrsbetrieb handelt es sich um einen „persönlichen“ Dienstleitungsbetrieb 860 , da hier - trotz des umfassenden Einsatzes von mobiler und stationärer Infrastruktur - die menschliche Leistung im Erstellungsprozess dominiert. Dies impliziert, dass die Qualität des Angebots wesentlich von der persönlichen und individuellen Leistungsfähigkeit der Mitarbeiter eines Verkehrsunternehmens abhängt. Diese Leistungsfähigkeit kann trotz Schulungsmaßnahmen und definierten Anforderungen nicht standardisiert werden und unterliegt daher starken Schwankungen, je nachdem, welche Erfahrungen und Fertigkeiten die einzelnen Mitarbeiter aufweisen. Darüber hinaus spielen individuelle Komponenten eine Rolle, wie etwa die "Tagesform“ oder die Dienstleistungsbereitschaft bzw. Serviceorientierung des Einzelnen. ${ }^{861}$ Diese menschliche Komponente in der Leistungserstellung wird umso bedeutender, als dass sich das ÖPNV-Angebot direkt an andere Menschen richtet. Das heißt, dass die wahrgenommene Qualität durch den Kunden ganz wesentlich von den Mitarbeitern der Verkehrsunternehmen beeinflusst wird.

\footnotetext{
860 vgl. Korndörfer 1992, S.6

861 vgl. Werner, P.1997, S.316 sowie Kretschmann 2001, S.84
} 
Dies kann sich sowohl negativ (durch Verständigungsschwierigkeiten, Missverständnisse, fehlender Kundenorientierung) wie auch positiv (persönliche Beratung, individuelle Problembehandlung) auswirken und schlägt sich im Image (s.u.) nieder, das der Kunde vom ÖPNV hat. ${ }^{862}$

Homburg und Krohmer schlagen für einen Dienstleistungstyp im Massengeschäft, zu dem ja auch der ÖPNV zählt, beispielhaft vor, die marketingstrategischen Prioritäten (zunächst) auf die effiziente Abwicklung der Geschäftsprozesse im Rahmen des Wachstums, die Gewinnung und Schulung qualifizierter Mitarbeiter im Kundenkontakt, die emotionale Anreicherung der Dienstleistungen sowie die Gestaltung der Dienstleistungsinfrastruktur zur Unterstützung des Qualitätsimages zu legen. 863

\subsubsection{Fehlende Lagerfähigkeit und Vorhaltung von Reservekapazitäten}

Charakteristisch für das ÖPNV-Angebot ist, dass die Lagerfähigkeit fehlt bzw. die räumliche und zeitliche Produktion mit dem Absatz zusammenfallen ${ }^{864}$. Allerdings ist dies eine Eigenschaft, die nicht alleine für den ÖPNV von Bedeutung ist, sondern gemeinhin für den ganzen Dienstleistungssektor gilt. So kann auch die ÖPNV-Dienstleistung nach unternehmerischen und damit marktwirtschaftlichen Grundsätzen erstellt werden. ${ }^{865}$ Dies trifft auch für die Vorhaltung von Reservekapazitäten in den Hauptverkehrszeiten zu. Denn auch in anderen Wirtschaftsbereichen kann nicht von einer konstanten Nachfrage ausgegangen werden. Das Problem ist insoweit sogar der staatlichen Regulierung zuzuordnen, als dass in Zeiten der Spitzennachfrage aus sozialpolitischen Gründen auf eine Umverteilung von Verkehrsleistung über höhere Fahrpreise verzichtet wurde. Die dadurch erst verursachte Vorhaltung von Reservekapazitäten in der Hauptverkehrszeit (und durch unpaarige Verkehrsströme bedingte Leerfahrten) könnte gerade im Rahmen des Wettbewerbs durch Preisdifferenzierung vermindert werden.866 Darüber hinaus gibt es Möglichkeiten, die durch Schülerverkehr verursachten Verkehrsspitzen durch die Staffelung von Schulzeiten zu entzerren. Ferner kann eine Verstätigung von Fahrten im Be-

\footnotetext{
862 Die persönliche Dienstleistung ist von der automatisierten (unpersönlichen) Dienstleistung abzugrenzen.

${ }^{863}$ vgl. Homburg und Krohmer 2003, S.832

864 vgl. Aberle 2003, S.230

865 vgl. HMWVL 2003 (b), S.3

${ }^{866}$ vgl. Kahl 2005, S.114
} 
rufsverkehr durch die zunehmende Flexibilisierung von Arbeitszeiten erwartet werden (siehe Kapitel 3.8.2).

\subsubsection{Hoher Fixkostenanteil}

Die Kostenstruktur von Verkehrsunternehmen im ÖPNV ist durch die Vorhaltung und den Betrieb der Verkehrsinfrastruktur und der Verkehrsmittel gekennzeichnet. Die Bedeutung insbesondere der infrastrukturellen Komponenten des Fahrweges im schienengebundenen ÖPNV ist dabei größer einzustufen als im straßengebundenen Verkehr. Beim Betrieb dagegen spielen die Personal- und Energiekosten die wichtigste Rolle. Hier lohnt insbesondere eine nähere Betrachtung der Personalkosten, die in einem Busbetrieb ca. 60$75 \%$ der Gesamtkosten ausmachen. ${ }^{867}$ Hier entfallen wiederum ca. drei Viertel der Personalkosten auf den Bereich des Fahrdienstes. 868 Bei näherer Betrachtung zeigt sich, dass der hohe Fixkostenanteil im Personalbereich bei kommunalen Verkehrsunternehmen ungleich höher ist als bei privaten Unternehmen. Becker, T. verdeutlicht in einer Untersuchung, dass bei den Personalkosten ein privates Unternehmen um mehr als $40 \%$ günstiger liegt. Betrachtet man alle Aufwendungen, also auch die Kosten für Abschreibungen, Materialaufwand und sonstige Aufwendungen, werden die Verkehrsmittel durch das private Unternehmen fast zu einem Drittel günstiger betrieben. ${ }^{869}$ Bemerkenswert ist, dass die Untersuchung davon ausgeht, dass sowohl das kommunale wie auch das private Unternehmen die volle „Fertigungstiefe“ abdecken und somit die Personale beider Unternehmen beispielsweise auch in den Bereichen Marketing und Planung eingesetzt werden. 870 Demnach besteht also durchaus ein Optimierungspotenzial bei der Reduzierung des Fixkostenanteils.

\subsubsection{Natürliche Monopolstellung und ruinöser Wettbewerb}

Die These des Marktversagens durch natürliche Monopole wurde bereits angesprochen. Sie besagt, dass ein bestimmtes Verkehrsangebot in einem relevanten Nachfragebereich durch einen Anbieter kostengünstiger erstellt werden kann, als es durch mehrere Anbieter im Wettbewerb erfolgen könnte. In der Folge kommt es daher zu einem ruinösen

\footnotetext{
${ }^{867}$ vgl. Aberle 2003, S.273

868 vgl. Becker, T. 2004, S.69

${ }^{869}$ vgl. Becker, T. 2004, S.90ff sowie Barth 2000, S.39

870 vgl. Becker, T. 2004, S.64
} 
Wettbewerb, bei dem auch effizient wirtschaftende Unternehmen vom Markt verdrängt werden. ${ }^{871}$ Dies ist dadurch begründet, dass es aufgrund von unternehmerischen Größenvorteilen (economies of scale) bei der Erstellung dieses Angebotes durch mehrere Unternehmen zu einer Ressourcenverschwendung kommt. ${ }^{872}$ Diese These trifft höchstens für den SPNV insoweit zu, als dass es sich beim Schienennetz um eine sogenannte „essential facility“ handelt, die einer besonderen wettbewerbsrechtliche Berücksichtigung bedarf. Dennoch rechtfertigt dies keinesfalls eine Regulierung, sondern spricht eher dafür, dass das Schienennetz kartellrechtlichen Regelungen unterworfen sein sollte, wie dies im Rahmen der Diskussion um die Trennung von Netzinfrastruktur und Leistungserstellung erörtert wird. Aberle geht daher davon aus, dass sich ein Marktversagen weniger aus Gründen einer natürlichen Monopolstellung ableitet, sondern es sich hier tatsächlich um ein „Staatsversagen“ handelt. ${ }^{873}$

Auch für die hessische Landesregierung ist eine mögliche natürliche Monopolstellung kein Grund für Wettbewerbsbeschränkung. Vielmehr ist es ihr Ziel, über Regelungen und Standards den Mobilitätsmarkt auf ein bestimmtes Ziel hin zu steuern. ${ }^{874}$

\subsubsection{Bild und Selbstbild des ÖPNV}

Die Voraussetzung für Veränderung ist das Erkennen von Defiziten bzw. die Realisierung von Potenzialen und die Bereitschaft, diese Potenziale über einen aktiven Prozess des Wandels zu erschließen. Veränderung setzt also einen Erkenntnisprozess voraus. So ist das Selbstbild des ÖPNV vielerorts von der Auffassung geprägt, dass Leistung und Angebot gut seien, die Öffentlichkeit - also der Kunde - dies jedoch nicht wisse oder einfach nicht anerkenne. ${ }^{875}$ Auch gibt es eine weit verbreitete Einstellung, der Kunde müsse den ÖPNV alleine schon aus rational-ökologischen Beweggründen nutzen. Daraus resultiert eine Außendarstellung, in der der ÖPNV als „ökologisch korrektes Massenverkehrsmittel“ präsentiert wird. ${ }^{876}$ Die Erkenntnis, dass es Optimierungsbedarf im Umgang mit dem Kunden gibt und der hierfür notwendige Wandel von innen heraus eingeleitet werden

\footnotetext{
${ }^{871}$ vgl. Aberle 2003, S.104

872 vgl. Kahl 2005, S.113

873 vgl. Aberle 2003, S.105

874 vgl. Riehl 2005, S.1

875 vgl. Schöller 2005, S.96

${ }^{876}$ vgl. Schliephake 1982, S.133
} 
muss, respektive nicht vom Kunden erwartet werden kann, setzt sich an den verantwortlichen Stellen im ÖPNV (nur) langsam durch.

Ganz allgemein kann davon ausgegangen werden, dass der ÖPNV ein Imageproblem hat. „Unpünktlichkeit, lange Wartezeiten, Verschmutzung, Vandalismus, Gefahr für Leib und Leben, Gedränge und Belästigung“ 877 sind gängige Vorbehalte gegenüber einer Nutzung des ÖPNV. Insbesondere im Vergleich mit der Werbung der Automobilindustrie zum ÖPNV wird dieses Defizit deutlich. Auf der einen Seite findet der Mobilitätskonsument in überaus aufwendigen Werbeproduktionen ein sehr emotionales (bzw. emotionalisiertes) Produkt, welches auf seine speziellen Bedürfnisse mit einem Höchstmaß an Flexibilität, Individualität und „voller Verständnis“ eingeht. 878 Auf der anderen Seite wirbt der VDV mit einer „Vorbildfunktion“ für die gesamte Branche in seinen Anzeigen mit rationalen Appellen an das Bewusstsein der potenziellen Nutzer und fordert zum ökologischen, verantwortungsvollen oder rücksichtnehmenden Verhalten auf. In der Tonalität geben sich diese ÖPNV-Anzeigen als müssten die Nichtnutzer des ÖPNV nur zur Einsicht gebracht werden. ${ }^{879}$ Der ÖPNV wird als umweltfreundlich dargestellt und das Auto als Umweltverschmutzer.

Zweifellos gehen vom MIV erhebliche umweltzerstörende Einflüsse aus. Doch angesichts stagnierender Auslastungszahlen bzw. rückläufiger Modal Split-Anteile muss sich auch der ÖPNV verstärkt dem Vorwurf aussetzen, umweltbelastenden Einfluss zu haben. Die Projektgruppe Mobilität am Wissenschaftszentrum Berlin für Sozialforschung spricht gar von einer „ökologischen Legitimationskrise des ÖPNV“. ${ }^{880}$ So transportiert ein Bus im Stadtverkehr durchschnittlich nur 10 bis 12 Personen, d.h. die Fahrzeuge sind nur zu etwa 15\% ausgelastet. Dagegen ist ein Pkw mit 1 Person schon zu 20\% ausgelastet. Taktverdichtungen des Fahrplans zur gutgemeinten Attraktivitätssteigerung wirken sich hier verschärfend aus, wenn keine neuen Kunden erreicht werden können. Betrachtet man den Schadstoffausstoß eines Dieselbusses pro Kilometer und beförderter Person, zeigt sich, dass ein moderner Pkw mit Katalysatortechnik 10-mal weniger Ausstoß produziert. Problematisch erweist sich im straßengebundenen ÖPNV auch die Tatsache, dass viele Busse oft 18 und

\footnotetext{
877 Pernack 2005, S.30

878 vgl. Klühspies 1999, S.18

${ }^{879}$ vgl. Schöller 2005, S.99

${ }^{880}$ vgl. WZB / Projektgruppe Mobilität 2001, S.15
} 
mehr Dienstjahre hinter sich haben und von daher auch nicht mit neuster Emissionstechnik ausgerüstet sind. 881

Für einen verkehrsreichen Ballungsraum wie die Region Frankfurt Rhein-Main mag sich diese Bilanz relativieren, zumal insbesondere im SPNV moderne und somit umweltfreundliche Regionalzüge, S- und U-Bahnen eingesetzt werden. 882 Doch auch dieses darf nicht dazu führen, dass die ÖPNV-Unternehmen und ihre Interessenvertreter auf dem Standpunkt verharren, der ÖPNV sei per se umweltfreundlich. Unbenommen ist aber, dass der ÖPNV, insbesondere dann, wenn zeitgemäße Technologien zur Anwendung kommen, vom Nutzungscharakteristikum her betrachtet die Kriterien an Nachhaltigkeit viel besser erfüllt als der MIV. Insofern ist zu hoffen, dass es im Rahmen der Deregulierung nicht zu einem "Öko-Dumping“ 883 kommt, bei dem umweltfördernde Aspekte des ÖPNV aus ökonomischen Zwängen heraus außer Acht gelassen werden. Hier sind die Aufgabenträger als Besteller gefordert, entsprechende Qualitätsstandards zu formulieren.

Auch wenn der MIV ohne Zweifel die Gesundheit, Sicherheit und Natur beeinträchtigt und volkswirtschaftlich sinnvoll einzusetzende Zeit in Staus verloren geht, ist doch unstrittig, dass das Auto einen hohen gesellschaftlichen Stellenwert einnimmt; Es gar ein Garant von Mobilität und Flexibilität ist und den Lebens- und Arbeitsalltag erheblich erleichtert. „Nicht die Abschaffung des Autos steht [daher] zur Debatte, sondern die Gestaltung des Umgangs damit. Nicht die Vermeidung jeglichen Verkehrs steht zur Debatte, sondern dessen mensch- und umweltgerechte Gestaltung“ ${ }^{\prime} .84$

Jede verkehrs- und unternehmenspolitische Strategie, die diese Fakten vernachlässigt und sich auf einen Wettbewerb mit dem Auto um Marktanteile einlässt, muss daher zum scheitern verurteilt sein. Gerade vor dem Hintergrund der gewünschten Positionierung als „Mobilitätsdienstleister“, mit dem Anspruch des Abbildens kompletter (intermodaler) Wegeketten, bedarf es eines aufgeschlosseneren Umgangs mit dem Pkw. Anspruch und Erkenntnis sollten sich daher gleichermaßen in den ÖPNV-Produkten und im ÖPNVMarketing widerspiegeln.

\footnotetext{
881 ebd., S.17

882 vgl. RMV 2005, S.8

883 ebd. S.19

${ }^{884}$ vgl. Jentsch 1996, S.129
} 


\subsection{Effizienzsteigerung im ÖPNV zwischen Gewinnmaximierung und Be- sitzstandswahrung}

\subsubsection{Theoretischer Ansatz}

Folgt man allgemein dem ökonomischen (Grund-)Prinzip, mit gegebenen Mitteln einen maximalen Nutzen zu erzielen (Maximalprinzip) bzw. ein bestimmtes Ziel mit möglichst geringem Aufwand zu erzielen (Minimalprinzip), ergeht die allgemeine Aufgabe an den ÖPNV, unter Verwendung möglichst geringer finanzieller Mittel ein „optimales“ Verkehrsangebot bereit zu halten. ${ }^{885}$ Ein wichtiges Element zur Erfüllung dieser Aufgabe stellt der technische Fortschritt in Form von Automatisierung, Rationalisierung und Synergieeffekten dar, über den nicht nur das quantitative „Input-output-Verhältnis“ verbessert werden kann, sondern auch qualitative Verbesserungen erzielt werden können. In der Erfüllung dieser Aufgabe spiegelt sich der wirtschaftliche Erfolg eines Verkehrsunternehmens - wie in jedem anderen Wirtschaftsunternehmen - in der Differenz zwischen Erträgen und Aufwendungen bei mindestens gleichen Qualitätsergebnissen wider. 886

Effizienz im ÖPNV bedeutet aus theoretischer Sicht, dass das ÖPNV-Angebot entweder zu den geringsten Kosten oder unter maximaler Ausschöpfung der eingesetzten Faktoren erstellt wird. Von Relevanz ist insbesondere die produktive Effizienz, die berücksichtigt, ob die Verkehrsleistung zu den geringsten Kosten erbracht wird. So wirken sich beispielsweise die geringe Auslastung (Personenkilometer im Verhältnis zu Sitzplatzkilometern) einerseits sowie die hohen Kosten pro Leistungseinheit andererseits negativ auf den Erfolg aus. ${ }^{887}$

Bei der Betrachtung der rechtlich-organisatorischen Rahmenbedingungen wurde bereits auf die unterschiedlichen Motivationen, Interessen und Verständnisse von Aufgabenträgern und Verkehrsunternehmen hingewiesen, die Verkehrsleistung - im produktivem Sinne - effizient zu erbringen. Die Erreichung eines betriebswirtschaftlichen Optimums (d.h. mit einem positiven Saldo) stellt sich allerdings aus beiderlei Sicht aufgrund begrenzter Möglichkeiten schwierig dar. Auch „massive Kosteneinsparungen“ alleine werden an dieser Situation grundsätzlich nichts ändern. ${ }^{888}$ Denn vor dem Hintergrund der

\footnotetext{
885 vgl. Schierenbeck 1993, S.3

886 vgl. Wöhe 1990, S.491ff

887 vgl. Kretschmann 2001, S.103

${ }^{888}$ vgl. Blümel 2004, S.21
} 
Tendenz, dass der öffentlichen Hand immer weniger Mittel zur Verfügung stehen, um das bisherige ÖPNV-Verkehrsangebot qualitativ und quantitativ aufrecht $\mathrm{zu}$ erhalten, kann "Optimum“ in erster Linie nur Bestandswahrung bedeuten. Denn dass der ÖPNV bei gleichbleibender oder sogar steigender Qualität kostendeckend bzw. „wirklich eigenwirtschaftlich“ betrieben werden kann, ist kaum zu erwarten. 889

Die sich ändernden Rahmenbedingungen bei der Finanzierung des ÖPNV (siehe Kapitel 5.4.2) und bei der Mobilitätsplanung (siehe Kapitel 3.8) müssen letztlich auch Eingang in die Verkehrsplanung finden. Es reicht nicht länger aus, über Modellrechnungen, die in der Regel auf der Basis von statistischen Hochrechnungen mit älterem Datenmaterial stattfinden, den sich wandelnden Bedarf abzuschätzen um dann die produktionsseitigen Parameter anzupassen. ${ }^{890}$

Effizienzsteigerung muss zukünftig mehr umfassen, als nur die produktive Effizienz. So ist auch die allokative Effizienz von Bedeutung, die Auskunft darüber gibt, ob das ÖPNV-Angebot nachfragegerecht erstellt wird. ${ }^{891}$ Hierbei ist auch der Grenznutzen der erbrachten Verkehrsleistung zu berücksichtigen, der unter anderem von der Menge der nachgefragten Verkehrsleistung abhängig ist und dieser wiederum ganz wesentlich vom Preis. Ausdruck dieser Abhängigkeit von Preis und Nachfrage ist die Preiselastizität der Nachfrage. Die Preiselastizität kann für den Kunden durchaus variabel sein, vor allem dann, wenn es sich um wahlfreie Kunden handelt, die vom ÖPNV gewonnen oder an den MIV verloren werden können. ${ }^{892}$

Daneben spielt aber auch die qualitative Effizienz eine Bedeutung, die Auskunft darüber gibt, ob die Qualität der Leistung den Erwartungen und Bedürfnissen der Kunden entspricht. Im ÖPNV, wo das Qualitätsniveau bezogen auf die unterschiedlichen Verkehrsmittel einheitlich sein sollte, bedeutet dies ein über alle Nutzergruppen hinweg gemitteltes Qualitätsniveau.

\footnotetext{
889 vgl. Schöller 2005, S. 62 sowie Püttner 2000, S.118.

${ }^{890}$ vgl. Blümel 2004, S.25

891 ebd., S.102f

892 In Hessen kommt den Verkehrsverbünden die hoheitliche Aufgaben der Tarifgestaltung zu, insofern haben sie maßgeblichen Anteil an der Effizienz des ÖPNV; vgl. Woll 1990, S.106ff.
} 
Dynamische Effizienz schließlich spielt vor allem in bezug auf die Innovationsbereitschaft eine bedeutende Rolle, um qualitative und quantitative Verbesserungen in der Erstellung der Verkehrsleistung nutzbar zu machen. ${ }^{893}$

\subsubsection{Strategische Umsetzung}

Effizienz im ÖPNV bedeutet aus strategischer Sicht die Erreichung eines besseren Kostendeckungsgrades. Da nicht davon ausgegangen werden kann, dass es durch restriktive verkehrspolitische Maßnahmen (push-Faktoren, siehe Kapitel 3.6) zu einer verstärkten Nutzung des ÖPNV kommen wird, muss der ÖPNV selbst besser - also wirtschaftlicher werden. Dieses ist nur zu erreichen, indem die Umsätze erhöht und die Kosten gesenkt werden.

Dieser Ansatz spiegelt sich in der Konsequenz in den Unternehmenszielen der Aufgabenträgerorganisationen in der Region Frankfurt Rhein-Main wider. So ist in der Zielwertvereinbarung der RMV GmbH mit dem Land Hessen, die die Finanzierung des RMV für die Jahre 2005 bis 2009 regelt, die Erreichung konkreter Ziele festgeschrieben, die außerdem einen Bezug zwischen der Steigerung der Fahrgeldeinnahmen und der Verbesserung der Kundenzufriedenheit herstellen:

- Steigerung der Marktreichweite: Die Fahrgeldeinnahmen steigen gemessen an den Einnahmen des Vorjahres; eine Steigerung der Anzahl der Fahrten ist damit notwendigerweise nicht verknüpft.

- Steigerung der Kundenzufriedenheit: Die Kundenzufriedenheit steigt gemessen an den in den Verkehrsverträgen festgeschriebenen Qualitätszielen.

- Effizienzsteigerung: Der „Preisdeckungsgrad“ (siehe Kapitel 5.4.3.1) im Regionalverkehr steigt; ebenfalls soll der Anteil im Wettbewerb vergebener Leistung steigen. 894

Auch die Ziele der Lokalen Nahverkehrsorganisation für die Stadt Frankfurt sehen die Mobilitätssicherung bei gleichzeitiger Reduzierung der Kosten vor. 895

\footnotetext{
${ }^{893} \mathrm{vgl}$. Lehmann 2000, S.38

894 vgl. RMV 2005, S.9

${ }^{895}$ vgl. www.traffiq.de (Zugriff am 4.12.2005)
} 
Die Umsätze erhöhen sich, wenn Kunden öfter den ÖPNV nutzen bzw. Nichtkunden zu Nutzern des ÖPNV werden, ohne dass zumindest in gleicher Höhe ein Mehrangebot (aus öffentlichen Geldern) erbracht werden muss. Im Idealfall erhöhen sich die Umsätze nachhaltig bei einem gleich bleibenden oder nur leicht erhöhten Leistungsangebot. Für leichter umsetzbar wird allerdings häufig die Möglichkeit der Effizienzsteigerung durch ein reduziertes Angebot erachtet. Wenn allerdings zur Erreichung eines besseren Kostendeckungsgrades die Reduzierung des Leistungsangebots zu größeren Einsparungen führt als durch neue Kunden Mehreinnahmen generiert werden, ist die nachhaltige Daseinsvorsorge bedroht. 896

Die stärkere Beteiligung der Kunden an der Finanzierung des ÖPNV („Nutzerfinanzierung“) bedeutet, dass Zahlungsbereitschaften vorhandener Kunden besser abgeschöpft („Marktausschöpfung“) und neue Kunden gewonnen werden („Markterschließung“). "Ausgangspunkt für die Identifikation der entscheidenden Hebel zur Steigerung der Fahrgeldeinnahmen sind die vier P's aus dem Marketing“" (siehe Kapitel 6.5.1). ${ }^{897}$ Damit berührt die Steigerung der Fahrgeldeinnahmen die Marktleistungen eines ÖPNVUnternehmens, also alle Leistungen, die vom Kunden direkt wahrgenommen werden. Die Marktleistungen betreffen die primären Wertschöpfungsprozesse, die vom Kunden erwartet, wahrgenommen und nachgefragt werden. Im Vergleich dazu bleiben die internen Leistungen den Kunden weitgehend verborgen. Hierzu gehören innerbetriebliche Abläufe eines einzelnen ÖPNV-Unternehmens wie auch die organisatorischen Prozesse des Zusammenwirkens mehrerer Unternehmen. ${ }^{898}$

Diese innerbetrieblichen Abläufe stellen die interne Voraussetzung dafür dar, dass eine hochwertige Marktleistung erbracht werden kann. Sind die Voraussetzungen hierfür nicht gegeben, fehlen also die produktionstechnischen (Fahrzeuge, Betriebshöfe, Vertriebs- und Serviceinfrastruktur etc.) oder organisatorischen Voraussetzungen, sind diese zu schaffen oder anzupassen. Gerade im Hinblick auf eine kundenorientierte Unternehmensausrichtung im ÖPNV gilt es dann, die internen bzw. sekundären Wertschöpfungsprozesse neu aufzusetzen. Von daher ist der Einsatz der organisatorischen Instrumente

\footnotetext{
896 vgl. Schäfer-Sparenberg, Bongardt und Dalkmann 2006, S.71

897 Borrmann und Peistrup 2006, S.24

$898 \mathrm{vgl}$. Anreiter und Schaaffkamp 2006, S.27
} 
im Rahmen der Effizienzsteigerung von hoher Relevanz. Hierauf wird in Kapitel 6.4 ausführlicher eingegangen.

\subsubsection{Benchmarking zur Potenzialanalyse}

In bezug auf die Identifizierung von Verbesserungs- oder Rationalisierungspotenzialen bietet sich ein Benchmarking an. Das Benchmarking ist ein Verfahren, bei dem die Leistung anderer Unternehmen (in der eigenen oder auch einer fremden Branche) als Messlatte für die eigene Leistungsfähigkeit dient. Im Ergebnis werden Kennzahlen generiert (siehe Kapitel 6.4.4.5), die es als „Best-Practice-Werte“ selber anzusteuern gilt. Dabei können unterschiedliche Verfahren angewendet werden:

- Internes Benchmarking (Vergleich zwischen den Abteilungen eines Unternehmens)

- Wettbewerber-Benchmarking (Vergleich mit konkurrierenden Unternehmen)

- Branchenweites Benchmarking (Vergleich mit Branchenführern)

- Externes Benchmarking (Vergleich mit Teilfunktionen anderer Unternehmen anderer Branchen)

Insbesondere für kommunale Verkehrsunternehmen erscheint ein Wettbewerber-Benchmarking mit privaten Unternehmen besonders ratsam. Becker, T. schreibt hierzu:

„Um aus dem Vergleich auch Maßnahmen ableiten und umsetzen zu können, bedarf es einerseits einer spezifischen Detailtiefe, die es erlaubt, die entsprechenden ,Stellschrauben' zu entdecken. Andererseits sollten hinsichtlich der methodischen Genauigkeit, insbesondere der Datenharmonisierung, nicht zu hohe Maßstäbe angelegt werden [...]. In diesem Zusammenhang ist [...] auf die 80:20-Regel hinzuweisen, die als ökonomisches Prinzip auch einem Benchmarking zugrunde [liegt] und damit offensiv vertretbar ist". 899

Neben der Ermittlung der Bereiche, in denen Verbesserungs- und Rationalisierungsmaßnahmen durchgeführt werden können, eignet sich das Benchmarking auch zur Festlegung von Zielwerten, die erreicht werden sollen. In der Literatur werden hier vier unterschiedliche Dimensionen genannt: Einnahmen (z.B. Umsatz pro Fahrgast, Linie), Ausgaben (Be-

${ }^{899}$ Becker, T. 2004, S.134f 
triebsausgaben pro Fahrzeug, Vertriebsaufwand pro Fahrkarte oder Fahrt), Beförderungsleistung (z.B. Auslastung, Personenkilometer) und Qualität (z.B. Pünktlichkeit, Störfälle, Kundenzufriedenheit). .900

Da sich eine gute Qualität günstig auf der Einnahmenseite niederschlägt und eine effiziente Erstellung der Beförderungsleistung günstig auf der Ausgabenseite, kann der Abstand zum Wettbewerbsniveau daher durch Mehreinnahmen und Kostenreduzierungen verringert werden.

\subsection{Effizienzpotenziale}

6.3.1 Mehreinnahmen

Es lassen sich im wesentlichen vier unterschiedliche Arten von Mehreinnahmen identifizieren:

- Fahrgeldeinnahmen

Die Einnahmen aus der Beförderungsleistung sind der anteilig größte Ertragsposten. Sie ergeben sich aus der Preis-Absatz-Funktion, die wiederum abhängig ist von der Qualität des ÖPNV-Angebots sowie der angebotenen (Tarif-)Produkte, d.h. also vom für das Angebot verlangten Preis. Darüber hinaus gibt es zahlreiche weitere Faktoren, die die Nachfrageelastizitäten beeinflussen, so etwa die Kundeninformation über das Angebot, das Wissen der Kunden über den Systemzugang zum ÖPNV 901 oder auch Witterungsverläufe. ${ }^{902}$ Aus der Preis-Absatz-Funktion ergibt sich auch, dass der Absatz ganz wesentlich über den Marketing-Mix beeinflusst werden kann.

- Gesetzliche Ausgleichs- und Erstattungszahlungen

Hierzu gehören vor allem die Ausgleichszahlungen, die für reduzierte Tarife im integrierten Schüler- und Auszubildendenverkehr nach §45a PBefG gewährt werden sowie die Zahlungen für reduzierte und freie Fahrten bei der Beförderung von

\footnotetext{
900 vgl. Rother und Vitt 1999, S.161

901 vgl. Becker, T. 2004, S.52

902 zum Beispiel führen lange warme und trockene Sommer zu einer verringerten Nachfrage, hingegen sich lange Schlechtwetterperioden positiv auf die Nachfrage auswirken.
} 
Schwerbehinderten nach $\$ 62$ Schwerbehindertengesetz. ${ }^{903}$ Insbesondere die Ausgleichszahlungen nach §45a PBefG tragen maßgeblich zur Finanzierung des straßengebundenen ÖPNV in ländlichen Räumen bei, wo der Anteil beförderter Schüler oftmals bis zu 80\% erreicht ${ }^{904}$. In Hessen gibt es Bestrebungen, die Ausgleichszahlungen zum Schüler- und Ausbildungsverkehr nur noch pauschalisiert zu gewähren und insgesamt die Aufwendungen hierfür zu kürzen.

- Sonstige Einnahmen

Alle sonstigen Einnahmen stammen aus Geschäften, die nicht der Kernleistung, also der ÖPNV-Beförderungsleistung, zuzuordnen sind. Als gängiges Nebengeschäft ist vor allem die Vermietung von Werbeflächen in und an den Fahrzeugen verbreitet. Darüber hinaus spielt beispielsweise die Nutzung von Überkapazitäten im Werkstattbereich eine Rolle, bei der Wartungs- und Instandhaltungsarbeiten für Dritte angeboten werden oder die Nutzung von Fahrzeugen im Touristikund/oder Chartergeschäft. Eher selten wird das vorhandene Wissen im Verwaltungsbereich als Dienstleistung an Dritte vermarktet.905

\section{- Defizitfinanzierung}

Unter die Defizitfinanzierung fallen alle Finanzmittel, die ein Verkehrsunternehmen im Rahmen des Verlustausgleiches erhält. Hierzu gehören beispielsweise Betriebs-, Investitions- und Aufwandszuschüsse906, Zahlungen aus dem steuerlichen Querverbund, Zuschüsse für besondere Linien, zusätzliche Gesellschaftereinlagen sowie Zuschüsse, die sich aus der Durchtarifierung im Verbund ergeben. Bereits die Art der Zuschüsse macht klar, dass es sich um Finanzierungen handelt, die aufgrund der knappen öffentlichen Haushaltsmittel in der Zukunft von Streichung bedroht sind. ${ }^{907}$

\footnotetext{
${ }^{903}$ vgl. Barth 2000, S.40, Lehmann 2000, S.32 sowie Becker, T. 2004, S.57

904 vgl. Hessischer Landtag 2005 (b), S.87

905 vgl. Becker, T. 2004, S.58

906 ohne Zahlungen aus dem Gemeindeverkehrsfinanzierungsgesetz (GVFG-Mittel)

${ }^{907}$ vgl. VDV 2003 (b), S.53 sowie Becker, T. 2004, S.60
} 


\section{3 .2}

Mobilisierbares Kunden- und Erlöspotenzial

Die Studie MiD 2002 (siehe Kapitel 3.1.2 und 4.4) hat neben dem Verkehrsverhalten in Deutschland auch die subjektive Einschätzung der Erreichbarkeit „üblicher Ziele“ erhoben. Darüber hinaus wurden Faktoren der individuellen Verkehrsmittelwahl wie Image von bzw. Einstellung zu Verkehrsmitteln, die Wirkung sozialer Normen oder die subjektiv empfundenen Vor- und Nachteile von Verkehrsmitteln innerhalb der bestehenden ÖPNV-Kundschaft erfragt. Dabei wurden drei Teilgruppen von heutigen ÖPNV-Nutzern unterschieden:

- gelegentliche ÖPNV-Nutzung mit Einzel-, Gruppen- bzw. Tageskarten,

- regelmäßige Nutzung mit selbsterworbener (Unterschied zur 3. Teilgruppe) Zeitkarte (Wochen-, Monatskarten bzw. Jahresabo),

- gelegentliche oder regelmäßige Nutzung mit Fahrkarten, die von Dritten (z. T. verpflichtend wie beim Semesterticket oder Jobticket) oder als Preisanteil (z.B. Kombiticket bei Veranstaltungen) zur Verfügung gestellt wurden.

Hieraus können potenzielle (positive) Änderungen im Nachfrageverhalten abgeleitet werden, die sich nicht alleine auf bestehende ÖPNV-Stammkunden, sondern auf die Gesamtheit aller potenziellen Nachfrager beziehen.

Bei den Zeitkartennutzern im Gebiet des Planungsverbands gibt es in etwa eine Drittelung in der Verkehrsmittelwahl: Etwa 33\% aller Wege werden zu Fuß und mit dem Fahr$\mathrm{rad}, 30 \%$ mit dem ÖPNV und zu 36\% mit dem Pkw zurückgelegt. Bei gleichzeitiger Verfügbarkeit von Pkw und Fahrrad sowie dem Besitz einer Zeitkarte sinkt dieser Wert zwar auf 20\% im Bereich des Planungsverbands, er liegt aber immer noch deutlich über dem Wert von $8 \%$ ÖPNV-Nutzung bei allen befragten Personen. Dies lässt die Schlussfolgerung $\mathrm{zu}$, dass der ÖPNV auch für die sogenannten „wahlfreien“ Kunden, die jederzeit zwischen Pkw und ÖPNV entscheiden können, eine Alternative darstellt. ${ }^{908}$ Multimodalität ist also keine Utopie, sondern wird von einer relativ großen Bevölkerungsgruppe "gelebt". ${ }^{\prime 99}$

\footnotetext{
908 vgl. Planungsverband Ballungsraum Frankfurt/Rhein-Main u.a. 2005, S.49

${ }^{909}$ vgl. Endemann u.a. 2006, S.43
} 
Im Gebiet des Planungsverbands geben ferner zwei Drittel (66\%) der Befragten an, dass unter den heutigen Angebotsbedingungen im ÖPNV (Bedienungshäufigkeit, ErschlieBungsqualität, Platzangebot, ...) „übliche Alltagsziele“ mit Bussen und Bahnen gut bzw. sehr gut erreicht werden können (siehe Abbildung 31). Immerhin 16\% beurteilen die Erreichbarkeit noch mit „einigermaßen“. Lediglich 15\% schätzen die Erreichbarkeit „schlecht“ oder „sehr schlecht“ ein. In Frankfurt und Offenbach liegen diese Werte aufgrund des guten ÖPNV-Angebots noch darüber (80\% für „sehr gute“ und „gute“ Erreichbarkeit; $10 \%$ „einigermaßen“; $8 \%$ "schlecht“ und „sehr schlecht"). ${ }^{910}$ Auch wenn die Einschätzungen der Erreichbarkeit „üblicher Ziele“ mit dem Pkw noch besser ausfallen, macht dieses Ergebnis angesichts der mehrfach niedriger liegenden ÖPNV-Wege-Anteile das erhebliche Potenziale deutlich, das durch eine verbesserte Vermarktung des ÖPNVAngebots erschlossen werden könnte. ${ }^{911}$

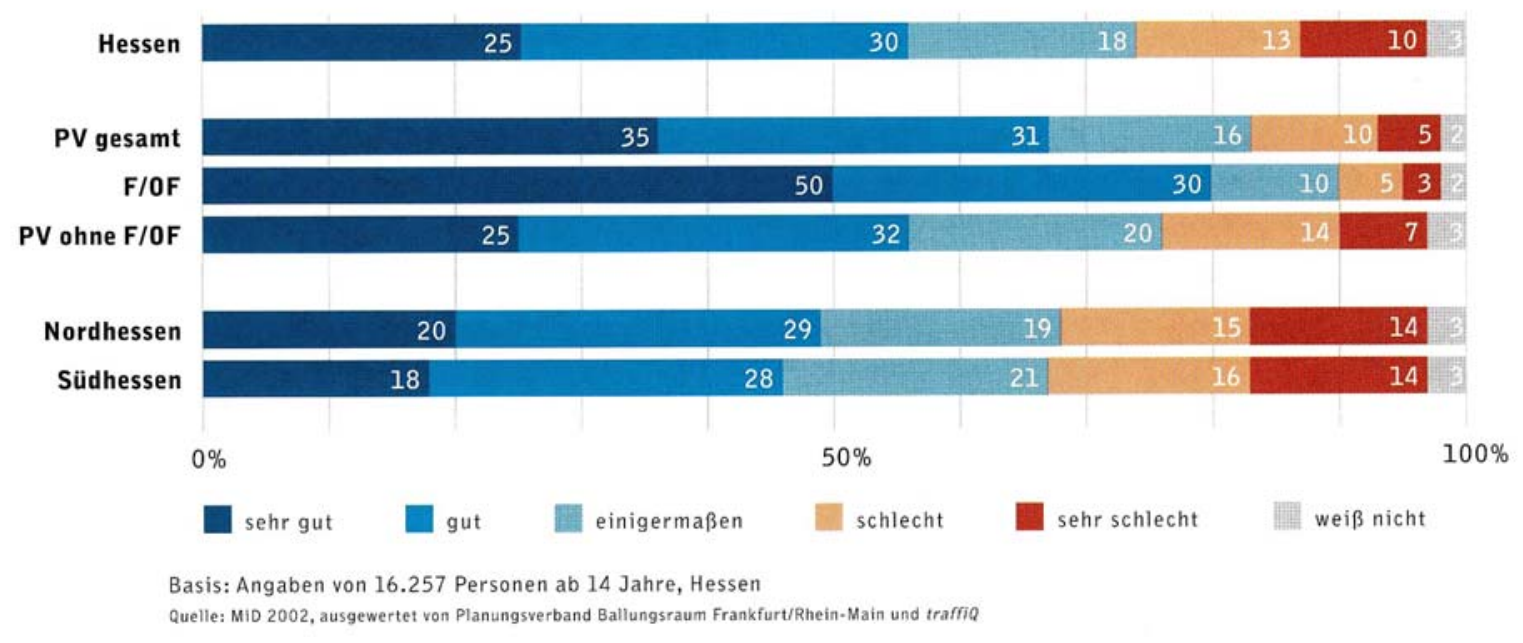

Abbildung 31: Erreichbarkeit „üblicher Alltags-Ziele“ mit dem ÖPNV (in \%)

Quelle: Planungsverband Ballungsraum Frankfurt/Rhein-Main u.a. 2005, S.60

Hochgerechnet auf das RMV-Gebiet gibt es somit etwa 1 Million potenzielle ÖPNVKunden, die heute selten oder nie den ÖPNV nutzen und die die Erreichbarkeit ihrer Alltagsziele mit Bussen und Bahnen aber als gut bzw. sehr gut einschätzen. Dieses legt gleichzeitig die Vermutung nahe, dass unter den heutigen Häufignutzern des ÖPNV vor allem sogenannte „Nicht-Wahlfreie“ sind (ÖPNV-Kunden, ohne Alternative eines ande-

\footnotetext{
${ }^{910}$ vgl. Planungsverband Ballungsraum Frankfurt/Rhein-Main u.a. 2005, S.60

911 Die vergleichsweise guten Ergebnisse dürften zumindest teilweise in wechselseitigem Zusammenhang zu betrachten sein, da "übliche Ziele" häufig auch aufgrund ihrer guten Erreichbarkeit ausgewählt werden; vgl. Endemann u.a. 2006, S.43.
} 
ren Verkehrsmittels). Aufgrund der weiter steigenden Pkw-Verfügbarkeit wird aber auch diese Gruppe zukünftig eine immer kleinere Rolle spielen.

Aus diesen Einschätzungen heraus lässt sich schlussfolgern, dass sich substanzielle Kundenpotenziale für den ÖPNV mobilisieren lassen und dass sich der Anteil von Personen/Haushalten, die über Zeitkarten-Produkte verfügen, deutlich vergrößern lässt. Die positive Einschätzung der Erreichbarkeit üblicher Alltagsziele macht deutlich, dass die Kernleistung des ÖPNV hierfür in der Regel nicht unbedingt verbessert werden muss. Vielmehr müssen die Zugangsbarrieren zum ÖPNV gesenkt werden, deren Überwindung vom Kunden als Aufwand wahrgenommen wird. Hierzu gehören neben den monetären Aufwänden auch Zeitaufwände für beispielsweise Information, Vertragsanbahnung, Kauf, Reklamation. Die Bedeutung dieser Aufwände ${ }^{912}$ für eine Entscheidung für oder gegen den ÖPNV wird im Vergleich zum Auto deutlich, wo der Kunde einen weit geringeren Informations-, Planungs- und Entscheidungsaufwand hat. ${ }^{913}$ Über die Anwendung neuer Informations-, Kommunikations- und Vertriebskanäle lassen sich daher die Aufwände für den Kunden deutlich senken.

\subsubsection{Kosteneinsparungen}

Die Möglichkeit der Generierung von Kosteneinsparungen kann unterteilt werden in die folgende Bereiche: ${ }^{914}$

- Betriebsabläufe und -organisation

Die Art und der Umfang der Betriebsabläufe und -organisation hängen von der Fertigungstiefe in einem Verkehrsunternehmen ab, d.h. davon, ob das Unternehmen lediglich die Verkehrsleistung erstellt oder auch für Marketing, Angebotsplanung, Einnahmenabrechnung etc. zuständig ist. Kosten können dann gespart werden, wenn sich die Verkehrsunternehmen ausschließlich auf die Erbringung der Verkehrsleistung konzentrieren und gleichzeitig ihre Marketingaktivitäten auf ein Mindestmaß reduzieren, also beispielsweise bei einem Busbetrieb auf den Verkauf von Fahrtberechtigungen auf dem Fahrzeug („economies of scope“). Geeignete Ansätze für eine Kooperation bei der Vermarktung von Verkehrsleistung ergeben

\footnotetext{
912 Diese werden auch als „Transaktionskosten“ bezeichnet; vgl. Rumpke 2005, S.107

913 vgl. Blümel 2004, S.27

${ }^{914}$ vgl. Becker, T. 2004, S.64
} 
sich vor allem dort, wo Vertriebsleistungen separat ausgeschrieben und verhandelt sind oder übergeordnete Aufgaben (z.B. Marketing, Angebotsplanung, Einnahmeaufteilung) ausgegliedert sind, beispielsweise in eine Nahverkehrsorganisation oder in einen Verkehrsverbund. Darüber hinaus ergeben sich im Rahmen einer solchen Kooperation weitere Netzwerkvorteile aus der gemeinsamen Vorhaltung von Infrastrukturen und Verwaltungseinrichtungen, die von mehreren Verkehrsunternehmen gleichermaßen genutzt werden können (z.B. Personal für Planung und Management, aber auch Betriebshöfe, „economies of network structu-

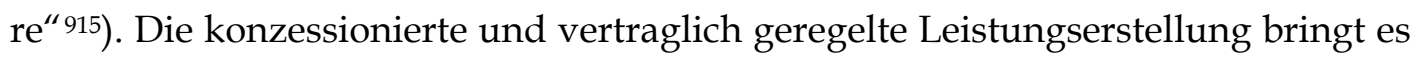
mit sich, dass die Verkehrsleistung nicht beliebig erweiterbar ist und Einsparungen über Masseneffekte („economies of scale“) gerade bei kleinen und mittelständischen Unternehmen nur schwerlich erreicht werden können, bzw. diese Unternehmen Schwankungen am Markt stärker ausgesetzt sind als große Unternehmen mit einem umfassenderen Angebot. Am ehesten werden Skaleneffekte erreicht, wenn das bediente Verkehrsgebiet aus Sicht der Nutzer ein Optimum erreicht.

- Materialaufwand, Abschreibungen und sonstige Aufwendungen

Ein wesentlicher Posten ist hier der Aufwand für Kraftstoffe, bei Busverkehrsunternehmen insbesondere in Form von Dieselkraftstoff und im SPNV vor allem in Form von Strom (hier kommen in der Regel nur auf Nebenstrecken oder in ländlichen Gebieten Dieseltriebwagen zum Einsatz). Die Menge des verbrauchten Diesels/Stroms ist einerseits abhängig von der Fahrzeugflotte (Alter, Art der Fahrzeuge) und andererseits vom Einsatzgebiet (Stadt, ländlicher Raum, Topographie, Abstand der Haltestellen etc.). Vor dem Hintergrund des zuletzt stark gestiegenen Rohölpreises kommt dem Einsatz moderner, energiesparender Fahrzeuge eine entsprechend große Bedeutung zu. Darüber hinaus ist die Einheitlichkeit bzw. Typenvielfalt der Fahrzeugflotte ${ }^{916}$ ausschlaggebend für den Ersatzteilaufwand und die Vorratshaltung. Die Höhe der Abschreibungen und sonstigen Aufwendungen korrespondiert u.a. mit den Intervallen, in denen die Fahrzeugflotte oder feste An-

915 vgl. Lehmann 2000, S.60ff.

916 Welche Effekte hierüber erzielt werden können, lässt sich am Beispiel einiger „Billig-Airlines“, wie etwa Ryanair, verfolgen, deren günstige Angebote auch durch die Einheitlichkeit der Flotte erreicht wird. Hierdurch werden u.a. geringere Wartungskosten und die Aushandlung entsprechend günstiger Rabatte bei den Flugzeugherstellern ermöglicht. 
lagen ersetzt werden. Es ist davon auszugehen, dass mit dem fortschreitenden Technisierungsgrad (EDV-Anlagen, Telekommunikationskosten, RBL, dynamische Fahrgastinformation etc.) dieser Aufwandsposten im Verhältnis ansteigt.917

- Personalaufwand

Bereits in Kapitel 6.1.3 wurde auf die hohen Personalkosten im ÖPNV hingewiesen, die vor allem im Fahrbetrieb anfallen. So machen in einem Busbetrieb die Personalkosten bis zu $60-75 \%$ der Gesamtkosten des Unternehmens aus. ${ }^{918}$ Hier entfallen wiederum ca. drei Viertel der Personalkosten auf den Bereich des Fahrdienstes. ${ }^{919}$ Diese Kosten lassen sich vom Prinzip her nur über strukturelle Anpassungen des Tariflohns reduzieren, beispielsweise durch das "Outsourcing“ von Personalien in Dienstleistergesellschaften. ${ }^{920}$ Ansonsten gibt es die Möglichkeit der Schließung oder Verkürzung von Geschäftszeiten von personalbedienten Verkaufsstellen oder der Verringerung von Fahrkartenkontrollen. Derartige Maßnahmen können sich allerdings nachteilig auf die Angebotsqualität auswirken und das Abwandern von Fahrgästen oder eine Erhöhung von Betrugsfällen („,Schwarzfahrer") zur Folge haben.

- Nachfragegerechte Kapazitätsanpassung

Im Rahmen einer nachfragegerechten Kapazitätsanpassung geht es einerseits um Optimierungen im Liniennetz sowie andererseits um Anpassungen im Bedienungsumfang. Letzteres betrifft auch die Art der eingesetzten Fahrzeuge (z.B. Standardlinienbus oder Gelenkfahrzeug) oder die Fahrzeugbehängung (z.B. Anzahl der Wagons). ${ }^{921}$ Soll die Kapazitätsanpassung nicht dauerhaft sein, beispielsweise zu einem Fahrplanwechsel, sondern flexibel im Betriebsablauf durchgeführt werden, sind hierfür infrastrukturelle und personelle Ressourcen notwendig, die

917 vgl. Becker, T. 2004, S.89

918 vgl. Aberle 2003, S.274

919 vgl. Becker, T. 2004, S.69

${ }^{920}$ Dem HMWVL zufolge soll durch den Wettbewerb nicht „Billig-Anbietern“ der Weg geebnet werden, die zum Beispiel über Lohn-Dumping die Qualität der Leistungserbringung drücken. Die Tarifvertragsparteien sollen hier für eine Anpassung der Löhne bei privaten und kommunalen Busunternehmen Sorge tragen; vgl. HMWVL 2004, S.6.

${ }^{921} \mathrm{Da}$ insbesondere der hohe Anteil des Schülerverkehrs - speziell in ländlichen Gebieten - zu ausgeprägten Nachfragespitzen am Morgen und am frühen Nachmittag führt, bietet sich hier die Staffelung der Schulzeiten an. Dieses liegt aber nicht im alleinigen Kompetenzbereich der ÖPNV-Unternehmen. 
eine Anpassung überhaupt zulassen. Weitere Voraussetzung für die (flexible) nachfragegerechte Kapazitätsanpassung ist das Wissen über die Entwicklung der Nachfrage. Da Fahrgasterhebungen nur ein statisches Bild der Nachfrage liefern und Verkaufsstatistiken nur sehr begrenzt Rückschlüsse auf die Nachfrage zulassen, gibt es häufig keine verlässlichen Grundlagen für nachfragegerechte Kapazitätsanpassungen, abgesehen von planbaren Ereignissen wie Großveranstaltungen. 922

\subsubsection{Erreichbare Kosteneinsparungen}

Kosteneinsparungen können dahingehend unterschieden werden, ob die damit zusammenhängenden Maßnahmen sich auf die Qualität des Leistungsangebotes auswirken oder nicht. Da viele Maßnahmen zu Veränderungen führen, die von den Kunden subjektiv wahrgenommen werden, lässt sich eine Qualitätsreduzierung allerdings nicht immer eindeutig beurteilen. Kommt es allerdings zu für die Kunden spürbaren Qualitätseinbußen, besteht das Risiko eines Nachfragerückgangs und damit von Einnahmeverlusten. ${ }^{923}$ Von daher sind solche Kosteneinsparungsmaßnahmen anzustreben, bei denen die Marktleistung unberührt bleibt. Dieses sind vor allem Maßnahmen, die die internen Wertschöpfungsprozesse (vgl. auch Kapitel 6.2.2) betreffen und vom Kunden nur indirekt oder längerfristig realisiert werden. Hierzu gehören innerbetriebliche Leistungen eines einzelnen ÖPNV-Unternehmens wie auch die organisatorischen Prozesse des Zusammenwirkens mehrerer Unternehmen. 924 Auf die Effekte, die sich aus der Vergabe von Verkehrsleistung im Wettbewerb ergeben (u.a. Reduktion von Wegekosten), wurde bereits in (siehe Kapitel 5.3.3) hingewiesen.

\section{Personalaufwand}

Die größten Kosteneinsparungen im ÖPNV sind potenziell im Bereich des Personalaufwands bei kommunalen Verkehrsunternehmen zu erzielen. Laut T. Becker liegen die Personalkosten eines privaten (Referenz-)Unternehmens um mehr als $40 \%$ unter denen eines öffentlichen Unternehmens. Der größte Kostenblock entfällt hierbei auf die Gruppe des Fahrdienstes. Verursacht wird dieser Kostenunterschied durch die unterschiedlichen

\footnotetext{
922 vgl. von Kretschmann 2001, S.103f

923 vgl. Borrmann und Peistrup 2006, S.22

${ }^{924} \mathrm{vgl}$. Anreiter und Schaaffkamp 2006, S.27
} 
Lohnniveaus.925 „Die größten Gestaltungsspielräume sind bei den verschiedenen tariflichen Auslagerungsmodellen und bei der Verhandlung von Haustarifen vorhanden“. ${ }^{926}$ Am Beispiel der VGF, des größten Busverkehrsunternehmens in der Region Frankfurt Rhein-Main, wird diese Entwicklung deutlich. 2006 übernahm die VGF die In-der-City-Bus $\mathrm{GmbH}$, an der sie bis dahin 51\% der Anteile hielt, vollständig. Als Verkehrsdienstleister sind dort hauptsächlich Busfahrer beschäftigt, die deutlich unter dem Stundensatz von 13 Euro verdienen, der bei der VGF üblich ist. Denn wenn ein Verkehrunternehmen konkurrenzfähig sein möchte, müssen Stundenlöhne von 10 Euro und weniger eingerechnet werden. ${ }^{927}$

Es muss dennoch konstatiert werden, dass sich die Senkung der Personalkosten durch Personalabbau im Bereich des Fahrpersonals aufgrund der systemimmanent personalintensiv zu erbringenden Beförderungsleistung als schwierig darstellt. Dies wird im wesentlichen nur über Verlagerung von Personalen in (outgesourcte) Unternehmen mit günstigeren Tarifstrukturen möglich sein. ${ }^{928}$ Dies wiederum kann sich allerdings durchaus als langwieriger Prozess darstellen. Möglichkeiten der Rationalisierungen durch die Automatisierung von Arbeitsplätzen, wie in der Industrie, lassen sich allenfalls durch die betriebliche Einführung von fahrerlosen Systemen erreichen, wie sie weltweit schon recht häufig zum Einsatz kommen. Die Voraussetzung für diese Systeme ist aber eine vollständige systemische Trennung der Fahrwege von allen anderen Verkehrsmitteln. In Deutschland gibt es bislang nur in Nürnberg Erfahrungen mit dem Betrieb einer führerlosen UBahn auf zwei Strecken. Dort rechnet man mit einem theoretischen Einsparpotenzial von 80 Mitarbeitern in den Bereichen Fahrpersonal, Werkstatt und Leitstelle. Allerdings entstehen gleichzeitig neue Arbeitsplätze in den Bereichen Leitstelle für fahrerlose U-Bahn sowie Kunden- und Systemservice. Dieses Personal ist u.a. notwendig, um das subjektive Sicherheitsgefühl der Fahrgäste zu verbessern, dass sich durch den Wegfall des Fahrpersonals erst mal verschlechtert. 929

\footnotetext{
${ }^{925}$ vgl. Becker, T. 2004, S.90ff

926 Becker, T. 2004, S.116

927 vgl. FAZ v. 25.2.2006

${ }_{928}$ vgl. Kretschmann 2001, S.92f

929 vgl. Trapp 2004, S.15ff
} 


\section{Vertrieb}

Der Endbericht zur Delphi-Studie „ÖPNV-Markt der Zukunft“ kommt zum Ergebnis, dass der „mit der Vertriebspräsenz verbundene Aufwand [...] einer kostengünstigen Distribution entgegen" steht.

"Dieser Zielkonflikt in Verbindung mit neuen Technologien wird dafür sorgen, dass der Vertrieb grundlegend verändert wird. Dabei stehen Entscheidungen zur Festlegung von Standards bei der Vertriebsqualität, über den Technologieeinsatz und über die Nutzung von Vertriebslösungen anderer, verwandter Branchen an".930

Da sich die Kostensituation im Vertriebsbereich als ein Schwachpunkt der Branche darstellt, ist die Verschlankung und Effizienzsteigerung der Vermarktung der ÖPNV-Beförderungsleistung ein vielversprechendes und zentrales Element zur Einsparung von Kosten im ÖPNV.

Eine Arbeitsgruppe auf VDV-Ebene erarbeitete zur Identifizierung von Einsparpotenzialen im Vertrieb eine Benchmarking-Studie ${ }^{931}$, an der sich die Verkehrsunternehmen aus Dresden, Erfurt, Hamburg und München beteiligten. Der VDV geht dabei aus, dass die unterschiedliche Struktur der Verkehrsunternehmen einen Orientierungsrahmen vorgibt, in den auch andere Verkehrunternehmen eingeordnet werden können. Unter anderem wurden die Vertriebskostenintensität und die Kosten pro verkaufter Fahrkarte für die folgenden Vertriebskanalarten herausgearbeitet:

- Verkauf über Fahrpersonal,

- VU/LNO-eigene Vertriebsstellen,

- private Vertriebsstellen,

- Abo-Vertrieb,

- Automatenvertrieb (stationär und mobil) sowie

- Schüler und Semesterticket.

Die Vertriebskostenintensität wird dabei als Kennziffer wiedergegeben, die sich aus dem Aufwand des jeweiligen Vertriebskanals und den hierüber generierten Nettoerlösen dar-

930 Deutsches Verkehrsforum 2005, S.103

${ }^{931}$ vgl. Ackermann, Czurzim und Roch 2004, S.20ff 
stellt. „Diese Kennzahl kann sowohl für den gesamten Vertrieb als auch für jeden einzelnen Vertriebsweg gebildet werden. Die Kennzahl gibt an, welcher Anteil der Erlöse bereits für den Verkaufsprozess verbraucht wird“. ${ }^{932}$ Bezogen auf die einzelnen Vertriebskanäle zeigte sich in der Studie eine große Varianz, wenngleich sich der Verkauf über stationäre Fahrkartenautomaten sowie personalbediente Verkaufsstellen als eher kostenintensiv präsentiert. Eher kostengünstig stellt sich der Verkauf von Fahrkarten im Abonnement (Abo) und im kollektiven Verkauf (z.B. Semesterticket, Schülerticket) dar. Die VDV-Studie kommt zufolgendem Schluss:

"Das Benchmarking hat gezeigt, dass der Vertrieb mit Aufwendungen von zirka sechs bis acht Prozent der Vertriebseinnahmen bei größeren Verkehrsunternehmen und hohem AboAnteil sowie zehn bis fünfzehn Prozent bei kleineren Unternehmen mit geringem AboAnteil zurechtkommen muss". ${ }^{933}$

\begin{tabular}{|l|c|c|c|c|c|c|}
\hline & $\begin{array}{c}\text { Abo/ } \\
\text { Jahres- } \\
\text { karte }\end{array}$ & $\begin{array}{c}\text { Eigene } \\
\text { Verkaufs- } \\
\text { stellen }\end{array}$ & $\begin{array}{c}\text { Private } \\
\text { Verkaufs- } \\
\text { stellen }\end{array}$ & $\begin{array}{c}\text { Fahr- } \\
\text { personale }\end{array}$ & $\begin{array}{c}\text { Automaten } \\
\text { stationär }\end{array}$ & $\begin{array}{c}\text { Semester- } \\
\text { und Schüler- } \\
\text { tickets }\end{array}$ \\
\hline $\begin{array}{l}\text { Vertriebskosten- } \\
\text { intensität }\end{array}$ & $2-5 \%$ & $10-30 \%$ & $2-7 \%$ & $8-40 \%$ & $3-6 \%$ & $0,5-3,2 \%$ \\
\hline $\begin{array}{l}\text { Relative Ver- } \\
\text { triebskostenin- } \\
\text { tensität }\end{array}$ & $0,7-1,5 \%$ & $0,4-5 \%$ & $0,1-2 \%$ & $0-1 \%$ & $1-2,5 \%$ & $0,01-0,3 \%$ \\
\hline $\begin{array}{l}\text { Aufwendungen } \\
\text { je verkaufter } \\
\text { Fahrkarte (EUR) }\end{array}$ & $\begin{array}{l}10,00- \\
16,00^{*}\end{array}$ & $1,00-3,60$ & $0,12-2,00$ & $0,10-0,50$ & $0,20-0,60$ & $0,20-2,00^{*} *$ \\
\hline
\end{tabular}

Quelle: VDV 2004, S.11ff

* Je Vertrag im Kalenderjahr

* * Semesterticket

Tabelle 9: Vertriebskostenintensität für einzelne Vertriebskanäle

Möchte man abschätzen, welche möglichen Vertriebskosteneinsparungen sich im RMV ergeben, kann dies nur auf Basis der Vertriebs- und Strukturdaten abgeschätzt werden: Im RMV gibt es über 150 Verkehrsunternehmen. Darunter existieren mit der VGF und der DB AG nur zwei große Unternehmen in der Region Frankfurt Rhein-Main (jeweils über 2000 Mitarbeiter und über 500 (VGF) bzw. 1000 Fahrzeuge (DB)). Daneben gibt es in den größeren Städten einige mittelgroße Unternehmen (u.a. in Wiesbaden (ca. 600 Mitarbeiter, 190 Fahrzeuge), Darmstadt (180 Mitarbeiter, 77 Fahrzeuge), Offenbach (190 Mitarbeiter, 57

\footnotetext{
932 ebd., S.21

933 ebd., S.24
} 
Fahrzeuge) und Hanau (187 Mitarbeiter, 60 Fahrzeuge). Ansonsten überwiegt die Anzahl kleinerer Unternehmen mit weniger als 100 Mitarbeitern und 50 Fahrzeugen. Ferner ist festzuhalten, dass der Anteil von Jahreskarten an den 587 Mio. Euro ${ }^{934}$ Erträgen in 2005 mit $11 \%$ sehr gering und der Anteil von sogenannten Bartarif-Kunden (Kurzstrecke, Einzelfahrkarte, Tageskarte) mit ca. einem Drittel sehr hoch ist. ${ }^{935}$ Berücksichtigt man zusätzlich, dass es innerhalb der Gruppe der Jahreskartenkunden auch noch Barzahler gibt, liegt der Ertragsanteil von Abo-Kunden deutlich unter 10\%. Im RMV gibt es also nicht nur sehr viele kleine Verkehrsunternehmen, auch der Abo-Anteil ist vergleichsweise niedrig. Überträgt man die Ergebnisse der Benchmarking-Studie nun überschlägig auf die Strukturzahlen des RMV, kann von einer Vertriebskostenintensität ausgegangen werden, die über 10\% liegt. Das heißt, dass ca. 60 Mio. Euro im RMV jährlich für den Verkauf von Fahrkarten aufgewendet werden müssen.936 1\% Einsparung in diesem Bereich, beispielsweise über die Optimierung des Vertriebskanalmixes durch die Verlagerung von Verkaufsprozessen auf günstigere Vertriebskanäle, bedeuten also 600.000 Euro.

Pauschale Aussagen über die Effizienz von Vertriebskanälen sagen allerdings wenig über die Wirtschaftlichkeit einzelner Vertriebsstandorte aus. So ist die Effizienz des Automatenvertriebs einerseits vom angebotenen Fahrkartensortiment abhängig (hoch- oder niedrigpreisig), andererseits aber vom Automatenstandort. Die Effizienz einzelner Vertriebsstandorte stellt sich in Städten aufgrund ihrer relativ hohen Frequentierung besser dar als in ländlichen Räumen, beispielsweise an SPNV-Haltepunkten. ${ }^{937}$ Die Kostentreiber im Automatenvertrieb sind insbesondere die Bargeldentsorgung (bzw. der damit verbundene hohe Personalaufwand), die Störungsanfälligkeit und Vandalismusschäden. Auch im Bereich des personenbedienten Verkaufs ist die Frequentierung ausschlaggebend dafür, ob sich die hohen Personalkosten bei diesem Vertriebskanal rentieren. Allerdings muss bei der Schließung von personalbedienten Vertriebsstellen berücksichtigt werden, dass die Beratungsqualität hierunter leiden kann bzw. müssen gegebenenfalls alternative Beratungsangebote geschaffen werden (z.B. Hotline, Internet). Einsparmöglichkeiten ergeben sich insbesondere durch die Reduzierung der Anzahl externer (nicht unternehmenseigener) Verkaufsstellen durch den Wegfall der Vertriebsprovisionen und des Logis-

\footnotetext{
934 vgl. RMV 2006 (a), S.49

935 vgl. Preuss 2006, S.7

936 Integriert sind dabei Kosten für das Auskunfts- und Beschwerdemanagement sowie für den Prüfdienst.

${ }^{937}$ vgl. VDV 2004 (b), S.21
} 
tikaufwands. Einzelfallbetrachtungen bei der Identifizierung von Vertriebskosteneinsparungen sind daher unerlässlich.

Die Betrachtung der Senkung der Vertriebskosten kann allerdings nicht isoliert erfolgen. Auch hier - wie in anderen Bereichen - sind enge Wechselwirkungen mit Organisationsstrukturen und anderen Marketinginstrumenten zu verzeichnen. So beeinflussen sich die Tarif- und Vertriebspolitik im Hinblick auf die zeitliche und räumliche Verfügbarkeit von Vertriebsstellen für bestimmte Tarifangebote oder verhindern Tarifbestimmungen und komplexe Geschäftsprozesse, dass der Kunde über ein Call-Center oder das Internet eine Fahrtkarte erhält, die zur sofortigen Benutzung berechtigt. 938

\subsection{Organisatorische Instrumentarien}

Die Entwicklung organisatorischer Instrumente im Bereich des Verkehrs ist auf drei Ebenen von Bedeutung: Auf der Ebene der intermodalen Kooperation im Rahmen eines Gesamtverkehrssystems, im Rahmen der intramodalen Kooperation zwischen den ÖPNVAkteuren und auf der Ebene der unternehmensinternen Restrukturierung in den ÖPNVUnternehmen. Alle drei Ebenen sind im Prinzip abhängig voneinander, wobei die unternehmensinterne Organisation als Voraussetzung für die intramodale Kooperation und diese wiederum für die intermodale Zusammenarbeit angesehen werden kann. Da in Kapitel 4.7.2 bereits auf die Bedeutung der spezifischen Stärken der einzelnen Verkehrsträger im Rahmen eines Gesamtverkehrssystems eingegangen wurde, wird im Folgenden auf die Voraussetzungen und Möglichkeiten der Entwicklung der unternehmensinternen und intramodalen Organisation eingegangen. Dies geschieht vor dem Hintergrund der strategischen Unternehmensausrichtung der ÖPNV-Unternehmen als „Mobilitätsdienstleister" und einer damit verbundenen stärkeren Kundenorientierung. Zunächst wird aber auf die Grundprinzipien der Organisationsentwicklung eingegangen, die den engen Zusammenhang von Organisation und Kommunikation erklären. Dieser Zusammenhang ist vor allem vor dem Hintergrund von Interesse, als dass sich die IuK-Technologien in den letzten Jahren rasant weiterentwickelt haben und sich dadurch neue Möglichkeiten der Kommunikation und Organisation ergeben. Darüber hinaus beinhalten diese Grundprin-

938 vgl. Petersen u.a. 2004, S.47 
zipien auch die zentralen Steuerungsprinzipien für Veränderungsprozesse öffentlicher Verwaltungen.939

\subsubsection{Organisationsentwicklung}

\subsubsection{Grundprinzipien}

Henning und Marks lehren an der RWTH Aachen seit vielen Jahre über das Thema „Kommunikations- und Organisationsentwicklung“. Ihr Ziel ist es, „in dem interdisziplinären Feld des Vorlesungsthemas Grundkenntnisse und Ansätze zu vermitteln, die geeignet sind, komplexe, unübersichtliche Organisationen, Unternehmen, Vereine, Produktionsanlage usw. zu diagnostizieren und den Prozeß einer Reorganisation einzuleiten“. ${ }^{940}$ Die hier vorgestellten Grundprinzipien geben in stark zusammengefasster Form einige für die Organisation des ÖPNV wesentliche Aspekte wieder.

Organisation kann als soziales System verstanden werden, in dem Menschen miteinander interagieren und kommunizieren. Das Ziel dieses Systems ist es, „sich leichter Umwelteinflüssen anzupassen mit dem Ergebnis einer höheren Effizienz der Organisation und einer größeren Arbeitszufriedenheit der in der Organisation handelnden Menschen“ ${ }^{941}$ Die Gesellschaft für Organisationsentwicklung (GOE) versteht Organisationen als

„offene soziale Systeme mit eigenen Gesetzmäßigkeiten, Werten, Geschichten und Kulturen. Nachhaltige Veränderungen können nur unter Einbezug und Beachtung aller Faktoren und Zusammenhänge erreicht werden. Organisationsentwicklung orientiert sich daher an einer ganzheitlichen Sichtweise, die Individuum, Organisation, Umwelt und Zeit als Teile eines Ganzen betrachtet". ${ }^{942}$

Bereits in den Anfängen der Organisationsentwicklung in der 1930er Jahren wurde den Wechselwirkungen in der sozialen Interaktion großen Stellenwert eingeräumt. Die sozialen Rückkopplungsprozesse hielten Einzug in die Sozialwissenschaften und wurden wissenschaftlich "getestet", indem in den USA lebende Indianer als korrespondierende Partner in den Integrationsprozess in die US-amerikanische Gesellschaft eingebunden wurden (bis Ende 1945). Wenige Jahre danach entwickelte der Sozialpsychologe Kurt Lewin, der

\footnotetext{
${ }^{939} \mathrm{vgl}$. Schäfer 2005, S.100ff

940 Henning und Marks 2000, Vorwort

941 ebd., S.7

942 GOE o.J., S.1
} 
als der gedankliche Vater der Organisationsentwicklung gilt, ein 3-Phasen-Modell der Organisationsentwicklung:

- "Unfreezing“

Phase des Auftauens und des in Frage stellen, in der die Motivation für Veränderungen geweckt wird,

- "Moving“

Phase der Veränderung, des in Bewegung setzten, in der neue Verhältnisse und Arbeitsabläufe entwickelt werden und

- "Refreezing“

Phase des Einfrierens, in der veränderte Verhaltensweisen und Verhältnisse stabilisiert und integriert werden. ${ }^{943}$

Es ist unschwer zu erkennen, dass sich der ÖPNV (noch) in der ersten „Phase des Auftauens" befindet, in der es gilt, die Turbulenzen des sich verändernden Verkehrsmarktes und seiner Rahmenbedingungen zu erkennen und die Bereitschaft zur Veränderung zu entwickeln. Dabei gilt es einen Paradigmenwechsel zu vollziehen, im Rahmen dessen unzeitgemäße standardisierte Abläufe, Entscheidungsstrukturen, Regeln und Vorschriften einem Veränderungsprozess unterzogen werden müssen. Es gilt die Flexibilität und Unbestimmtheit des Marktes herauszufordern und dessen Wechselwirkungen zu akzeptieren. Auch muss anerkannt werden, dass das eigene Handeln Auswirkungen auf die soziale, ökologische und ökonomische Umwelt hat. Die Entwicklung dieses Bewusstsein ist gleichzeitig eine wichtige Voraussetzung für nachhaltiges Handeln.

Je höher der Grad an Wechselwirkungen in einem System ist, desto eher wird von einem "lebendigen“ System gesprochen. Je komplexer und lebendiger ein System also ist, desto weniger kann es aus mono-kausalen Zusammenhängen erklärt werden, bei der eine Ursache immer eine Wirkung hat. Ein lebendiges System ist demnach durch Offenheit gegenüber Einflüssen gekennzeichnet. Diese Einflüsse können den sozialen Teil betreffen, also die Menschen im System (und deren Erwartungen, Rollen und Bedürfnisse materieller und psychischer Art) - oder aber den technischen Teil, d.h. alle materiellen und räumlichen Gegebenheiten (Arbeitsmaterialien, Produktionsmittel, Gebäude etc.). Ein optimales Gesamtsystem ist daher immer von einem Einklang beider Teilsysteme abhängig bzw.

${ }^{943}$ vgl. Henning und Marks 2000, S.9 
kann ein Teilsystem nicht ohne das andere optimiert werden. ${ }^{944}$ Insofern wird verständlich, dass der Einsatz von Technik immer die Menschen berücksichtigen muss, die die Technik anwenden sollen. Dies gilt beispielsweise auch für den Einsatz von Telematikanwendungen im Verkehr (siehe Kapitel 4.6.3.1).

In einem lebenden System mit vielen Abhängigkeiten und Wechselwirkungen spielt die Kommunikationsstruktur für die Fähigkeit der Interaktion eine entscheidende Rolle. Die „totale Kommunikation“ in einem „vollständigen Netz“ gewährleistet, dass Informationen unverfälscht ausgetauscht und auch kaum zurückgehalten werden können. Es liefert die Voraussetzungen für häufige Kommunikation, aber auch für die meisten Kommunikationsfehler (Missverständnisse, Übertragungsfehler etc.). Eine Kommunikation im „Kreis“ bietet dagegen lediglich mit den direkten Nachbarn die Möglichkeit zum intensiven Informationsaustausch. Dialog und Interaktion bleiben daher stets auf wenige Teilnehmer beschränkt. Der „Stern“ bietet die geringsten Möglichkeiten des Austauschs. Hier besitzt ein Teilnehmer das Informationsmonopol.

Im Aufbau ähnelt die sternförmige Kommunikationsstruktur der vertikalen oder hierarchischen Kommunikation, wie sie beispielsweise in Behörden lange üblich war oder noch ist. Im ÖPNV ist vor allem eine „kreisförmige“ Kommunikation anzutreffen, bei der es nur zwischen wenigen Verkehrsunternehmen zum Austausch kommt - erst recht nicht zum Zwecke der gemeinsamen Marktbearbeitung - oder der Informationsfluss „sternförmig“ über eine zentrale Instanz, z.B. einen Verbund läuft. Von daher beeinflusst die Art und Weise der Kommunikation auch die Organisationsstruktur - und umgekehrt. ${ }^{945}$

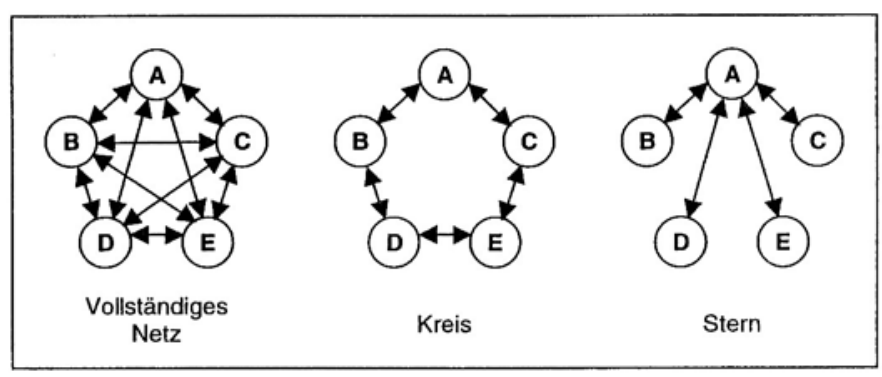

Abbildung 32: Kommunikationsstrukturen in einer Gruppe

Quelle: Bartram, P.: „Die innerbetriebliche Kommunikation“. Berlin 1969, nach Henning und Marks 2000, S.70.

944 ebd., S.83f

945 ebd., S.69ff 
Soll dieser Zustand der Organisation verändert („moving“, s.o.) werden, muss zunächst definiert werden, was eigentlich erreicht werden soll. Aus der Motivation heraus („unfreeze“, s.o.), dass sich überhaupt etwas ändern muss, wurde von den ÖPNVUnternehmen auf einer strategischen Ebene das Ziel der Entwicklung hin zu „Mobilitätsdienstleistern“ formuliert. Auch wurde mit der Verbesserung der Nutzerfinanzierung ansatzweise geklärt, wie dies erreicht werden soll. Weniger konkret können allerdings die Fragen beantwortet werden, wie dazu vorgegangen werden muss oder was konkret zu tun ist. Auch existieren kaum Erkenntnisse, wie der Verkehrsmarkt auf etwaige Maßnahmen reagiert, bzw. wie die Rückkopplungsprozesse im Markt sind. Diese Fragen sind umso schwerer zu beantworten, als dass sich die Rahmenbedingungen kontinuierlich ändern, was dazu führt, dass von den Verkehrsunternehmen eher taktiert als strategisch vorgegangen wird.

Je nachdem, welche Grundlagen und Rahmenbedingungen sich ändern, muss das soziale oder das technische Teilsystem oder die Organisationsstruktur selbst umgestaltet werden. Dies kann die Aufbau- und Ablauforganisation, Funktionen, Hierarchien sowie die räumlichen, zeitlichen und sachlichen Ablaufprozesse betreffen.

Die bisherige statische Betrachtungsweise reicht daher nicht aus, die komplexer werdende Welt zu beschreiben. Der „Ist-Zustand“ als Ausgangsbasis für Veränderungen verschweigt, wie sich bestimmte Probleme entwickelt haben. Das Erfassen der Entwicklung bis zum heutigen Ist-Zustand ist daher mindestens genauso wichtig. Schließlich darf nicht der Fehler begangen werden zu glauben, dass mit der Einführung einer Problemlösung das Problem gelöst sei. Auch die Problemlösung muss sich entsprechend der veränderten Rahmenbedingungen weiterentwickeln und verbessern. Erst damit wird eine Lösung zukunftsfähig und nachhaltig. Da die zukünftige Entwicklung aber weitgehend unvorhersehbar ist, muss es immer auch mehrere Lösungsoptionen geben. Da der Anpassungsprozess kontinuierlich erfolgen sollte, ist auch weniger von Entwicklungsschritten zu sprechen, als vielmehr von Entwicklungsphasen, die einander überdecken können. ${ }^{946}$

Für das soziale Teilsystem des ÖPNV bedeutet dies, über eine aufgabenorientierte Arbeitsgestaltung ein flexibles und leistungsfähiges System zu schaffen. Das technische Teilsystem muss dagegen von hoher Flexibilität sowie Zukunftsfähigkeit gekennzeichnet sein

946 ebd., S87ff 
und ein Höchstmaß an Kommunikation (im Dialog) ermöglichen. Die Organisationsstruktur selbst sollte durch eine sinnvolle Arbeitsteilung geprägt sein, wobei es weniger um die Abgrenzung von Arbeitsbereichen geht, als vielmehr um die Betonung der Beziehung zwischen den einzelnen Bereichen. Das soziale und technische Teilsystem müssen diese Beziehungen abbilden. Die Aufgabe des Gesamtsystems aber leitet sich aus den Bedürfnissen der Kunden ab. Um welche „Kunden“ es sich hierbei handelt und welche Kompetenzen notwendig sind, um deren veränderte Bedürfnisse $\mathrm{zu}$ befriedigen, wird in den folgenden Kapiteln behandelt. ${ }^{947}$

\subsubsection{Corporate Governance im ÖPNV}

Kundenorientierung in der Unternehmensplanung der Verkehrsunternehmen bedeutet, dass der „Markterfolg“ nicht (alleine) auf Politikebene sondern verstärkt im Verkehrsmarkt realisiert werden muss (siehe Kapitel 5.3.3). Hierfür sind die Interessen aller Kunden zu berücksichtigen. Die UITP zählt zu diesen Kunden auch die „Stakeholder“ - und damit alle Personen, die Entscheidungen beeinflussen oder von Entscheidungen betroffen sind: 948

"Die Akteure des ÖPNV, die tagtäglich Kontakt zur Öffentlichkeit haben und eine große Anzahl von Menschen befördern und beschäftigen, werden sich in zunehmenden Maße bewusst, dass sie innovative Wege finden müssen, um die Einstellungen und die Wahrnehmung aller ihrer Stakeholder zu managen und auf sie einzuwirken. Zu diesen Stakeholdern gehören die Kunden, die Beschäftigten und die Zulieferer sowie Investoren politischer und/oder gewerblicher Art. Dies erfordert den Aufbau von Vertrauen und die Entwicklung positiver Beziehungen, so dass hieraus kurz-, mittel- und langfristig Vorteile erwach$\operatorname{sen}^{\prime \prime} .949$

Im Rahmen der hierfür notwendigen Steuerungs- und Handlungskoordination ist seit den 1990er Jahren eine Abkehr von rein staatlich-hierarchischen Regierungsstrukturen (government) zu verzeichnen. Dieses erfolgt zugunsten einer Steuerungsform, die stärker auf Kooperation und Konsens zwischen öffentliche (politischen) und privaten (gesellschaftlichen) Akteuren - eben den "Stakeholdern“ - ausgerichtet ist. Für diese Form der Zusammenarbeit hat sich mittlerweile in der Literatur bzw. Wissenschaft der Begriff "governan-

\footnotetext{
947 ebd., S.91ff

948 UITP 2005, S.27

949 ebd., S.9
} 
ce" herausgebildet. ${ }^{950}$ Gerade bei der Entflechtung ehemals staatlicher Dienste, wie der Energieversorgung, dem Postdienst oder der Telekommunikation, haben sich Koordinationsmechanismen mit Marktcharakter bewährt. Darüber hinaus ist die Netzwerkbildung ein Merkmal von governance-Strukturen, wobei staatliche und privatwirtschaftliche (und auch non-profit-Organisationen wie Interessenverbände) zusammengefasst werden. Corporate governance bezieht sich dagegen vor allem auf die Regelung des Innenverhältnisses eines Unternehmens, also die interne Organisationsstruktur, die Unternehmensführung und -kontrolle. ${ }^{951}$ Im Prinzip beschreibt corporate governance, „wie Unternehmen in der Gesellschaft organisiert und geführt werden und stellt dabei die Rolle und die Aufgabenverteilung der Unternehmensbeteiligten vor". ${ }^{952}$ Berndt formuliert hierzu weiter:

„Wer Bereiche der Corporate Governance regulieren darf (Gesetzgeber oder Selbstregulierungsorganisation), in welchem Umfang (allgemeine Prinzipien oder detaillierte Einzelfallregelungen) und mit welchem Verpflichtungsgrad (zwingende oder freiwillige Normen) dies geschehen soll, hängt maßgeblich davon ab, welche Wahrnehmung man vom Verhalten der Unternehmensführung und der Anspruchsgruppen hat“. 953

Mit governance-Strukturen sind eine Reihe von Merkmalen der Organisationsführung verbunden, die für börsennotierte Unternehmen in Deutschland im Deutschen Corporate Governance Kodex (DCGK) festgehalten sind und zu deren Einhaltung bzw. Nichteinhaltung sich jedes Unternehmen nach Paragraph 161 des Aktiengesetzes im Geschäftsbericht äußern muss. ${ }^{954}$ Der Kodex gibt allerdings nur einen Rahmen vor, der von den Unternehmen selbst auszufüllen ist. Was gute governance („good governance“) auszeichnet, kann also am ehesten über ein Vergleich von "good practice“-Beispielen herausgefunden werden.

Konkrete Handlungsempfehlungen gilt es daher erst abzuleiten. Allgemein kann aber festgehalten werden, dass es um folgende Aspekte geht:

- die Rechenschaftspflicht (z.B. hinsichtlich der Erfüllung von Zielen),

\footnotetext{
${ }^{950}$ vgl. Falger 2001, S.218

951 vgl. Berndt 2006, S.2

952 vgl. Sell 2004, S.2

953 Berndt 2006, S.2

$954 \mathrm{vgl}$. www.corporate-governance-code.de
} 
- der Verantwortlichkeit (z.B. für die wirksame Erfüllung einer übertragenen Aufgabe),

- die Transparenz von Abläufen und Strukturen sowie

- Fairness (Ehrlichkeit).

Aus dem DCGK für börsennotierte Unternehmen können eine Reihe von Regeln abgeleitet werden, die auch für eine nach innen gerichtet corporate governance von ÖPNVUnternehmen von Bedeutung sind, zumal die privatwirtschaftlichen Grundsätze der Unternehmensführung auch für öffentliche Unternehmen gelten. Zwar liegt ein wesentlicher Unterschied zwischen öffentlichen und privatwirtschaftlichen Unternehmen darin, dass die öffentliche Verkehrsleistung zu einem möglichst günstigen Preis erstellt werden soll, hingegen die Privatunternehmen die Gewinnmaximierung anstreben. Da bei öffentlichen Unternehmen die Ergebnisse des Wirtschaftens den Bürgern zukommen müssen, gibt es hier ein großes öffentliches Interesse an einer effizienten Aufgabenerfüllung und der Transparenz der verwendeten Mittel. Dieses Interesse wird noch dadurch genährt, dass es eine große politische Einflussnahme (siehe Kapitel 5.3.3) auf das Management öffentlicher Unternehmen gibt. So sind Aufsichtsräte und Führungsgremien häufig mit Politikern besetzt, die diese Funktionen entweder fachlich nicht ausfüllen können oder aber der ihnen gestellten Aufgabe materiell nicht gerecht werden. ${ }^{955} \mathrm{Im}$ ungünstigsten Fall entsteht aus diesen Ineffizienzen und Intransparenzen Misstrauen bei den Bürgern, das durch die Managementpraktiken noch verstärkt wird. Hierzu gehört(e) u.a. die weit verbreitete Rechnungslegung der Kameralistik in kommunalen Verkehrsunternehmen (siehe Kapitel 6.4.4.6).

Kennzahlensysteme zur quantitativen Erfassung der Leistungsaspekte (z.B. Balanced Scorecard, siehe Kapitel 6.4.4.5) könnten zur Optimierung der Geschäftsabläufe beitragen und auch ein „angemessenes Risikomanagement und Risikocontrolling“ 956, wie im DCGK gefordert, wäre bei öffentlichen Unternehmen möglich. Die Einführung betriebswirtschaftlicher Controllinginstrumente könnte also insgesamt zu mehr Transparenz, Kostenvorteilen und effizienteren Arbeitsweisen führen. Da bei öffentlichen Unternehmen der Sanktionierungseffekt durch den Kapitalmarkt nicht besteht, schlägt u.a. Budhäus vor,

\footnotetext{
955 vgl. Dietrich und Struwe 2005, S.199

956 Regierungskommission Deutscher Corporate Governance Kodex 2006, S.6
} 
einen eigenen Corporate Governance Kodex für öffentliche Unternehmen zu verabschieden, über den gar das Vertrauen der Öffentlichkeit „in die für öffentliche Unternehmen zuständigen Entscheidungsträger gefestigt und dort, wo es nicht (mehr) existiert, wieder hergestellt werden“ 957 könnte. Voraussetzung hierfür wäre aber eine gesetzliche Verankerung der Berücksichtigung eines „Public Corporate Governance Kodex“ im Bundes- oder Landesrecht.

\subsubsection{Neue Kompetenzen zur nachhaltigen Mobilitätssicherung}

Um die Mobilität in nachhaltiger Weise zu sichern, bedarf es eines ausgewogenen Mixes von ordnungspolitischen Maßnahmen. $\mathrm{Zu}$ diesen Maßnahmen gehören beispielsweise steuerliche Einflüsse wie die Einführung der Ökosteuer, siedlungspolitische Maßnahmen, die eine Durchmischung räumlich-funktionaler Strukturen fördern sowie verkehrsverlagernde Maßnahmen, die den Umweltverbund insgesamt stärken.958 Doch auch die im ÖPNV tätigen Unternehmen müssen einen aktiven Beitrag zur Veränderung leisten. Denn die traditionellen Geschäftskonzepte und -muster der Dienstleistungserbringung sind weder förderlich für die eigenen geschäftlichen Interessen der Verkehrsunternehmen im Wettbewerbsumfeld, noch tragen sie zum öffentlichen Wohl im Sinne der Daseinsvorsorge bei. Hunecke empfiehlt hier, das geschäftliche Augenmerk auf die Zukunft zu richten und die Nabelschau der Vergangenheit zu beenden:

„Die bisherigen organisatorischen Leistungen des Güter- und Personenverkehrs haben entscheidend zur Steigerung des gesamtwirtschaftlichen Wohlstandes und zur Unabhängigkeit und Sicherheit in der individuellen Lebensführung beigetragen. Doch mittlerweile rücken die Schattenseiten eines permanent anwachsenden Verkehrsaufkommens immer stärker in den Vordergrund“. 959

Hinsichtlich der Einschätzung der Unternehmenskultur und -führung, stellt Becker, T. für die ÖPNV-Branche fest, dass

„ÖPNV-Unternehmen häufig konservativ angelegt [sind], was sich zum einen in der Unternehmenskultur, zum anderen in der Führungsphilosophie widerspiegelt. Oft gibt es mehrfach hierarchisch ausgebaute Organisationen (im Gegensatz zu flachen Strukturen),

\footnotetext{
957 Budhäus 2005, S.16

$958 \mathrm{vgl}$. Hunecke 1998, S.52

959 Hunecke 1998, S.51
} 
eher wertkonservative Haltungen und Normen, Führungsphilosophien, die eher auf Status und Macht und nicht auf Kompetenz beruhen, und aus letzterem abgeleitet, Führungsverhalten, welches eher anordnend als partizipierend angelegt ist". 960

Der Wandel des Verkehrsmarktes, die weiterhin steigende Nachfrage nach Verkehrsleistungen und die sich ändernden rechtlich-organisatorischen Rahmenbedingungen erfordern von den Verantwortlichen im ÖPNV ein Umdenken und Handeln, damit auf die veränderten Anforderungen unternehmerisch reagiert werden und ein Entwicklungsprozess einsetzen kann. Die UITP unterstreicht die Forderung nach Veränderungen im ÖPNV ausdrücklich:

„Die traditionellen Geschäftsprozesse und Verfahren der Dienstleistungsversorgung müssen sich ändern. Diese Notwendigkeit ergibt sich aus der zunehmenden Liberalisierung, Deregulierung und Privatisierung sowie aus anderen Faktoren [...]. Vielmehr gilt es ein Gleichgewicht zwischen hohem Wettbewerbsdruck, kurzfristigen Gewinne und den längerfristigen Zielen einer nachhaltigen Entwicklung zu erreichen". ${ }^{961}$

$\mathrm{Zu}$ diesen anderen Faktoren gehören auch der Wettbewerb und der zunehmende Einfluss von IuK-Technologien, die zur „Entstehung anderer Wertvorstellungen und Erwartungen“962 auf Kundenseite führen. Nur so wird gewährleistet werden können, dass sich der ÖPNV weiterentwickelt und seinen spezifischen und bedeutsamen Beitrag zur nachhaltigen Mobilitätssicherung in einem Gesamtverkehrssystem leistet.

Wesentliches Merkmal dieser Weiterentwicklung muss sein, dass nicht mehr nur die betriebliche Planung und Erstellung der Beförderungsleistung im unternehmerischen Zentrum steht, die bislang die Kernkompetenz der Verkehrsunternehmen darstellte, sondern die Dienstleistung gegenüber den „Kunden“, welches neue fachliche und organisatorischbetriebliche Kompetenzen erfordert. Die UITP verweist darauf, dass die Entwicklung des öffentlichen Verkehrssektors von einem „technologie- zu einem dienstleistungsorientierten Wirtschaftszweig“, der auch den Anforderungen an Nachhaltigkeit gerecht wird, „auf neuen, oder zumindest anderen Werten als [dem] traditionelle[n] Geschäftsbetrieb“ beru-

\footnotetext{
960 Becker, T. 2004, S.105

961 UITP 2005, S.6

962 ebd.
} 
hen muss. ${ }^{963}$ Die Aneignung dieser Fähigkeiten und Kompetenzen setzt einen Veränderungsprozess bei den Verkehrsorganisationen voraus, der auf der Managementebene beginnen muss. Das erforderliche Kompetenzspektrum ist in Abbildung 33 dargestellt:

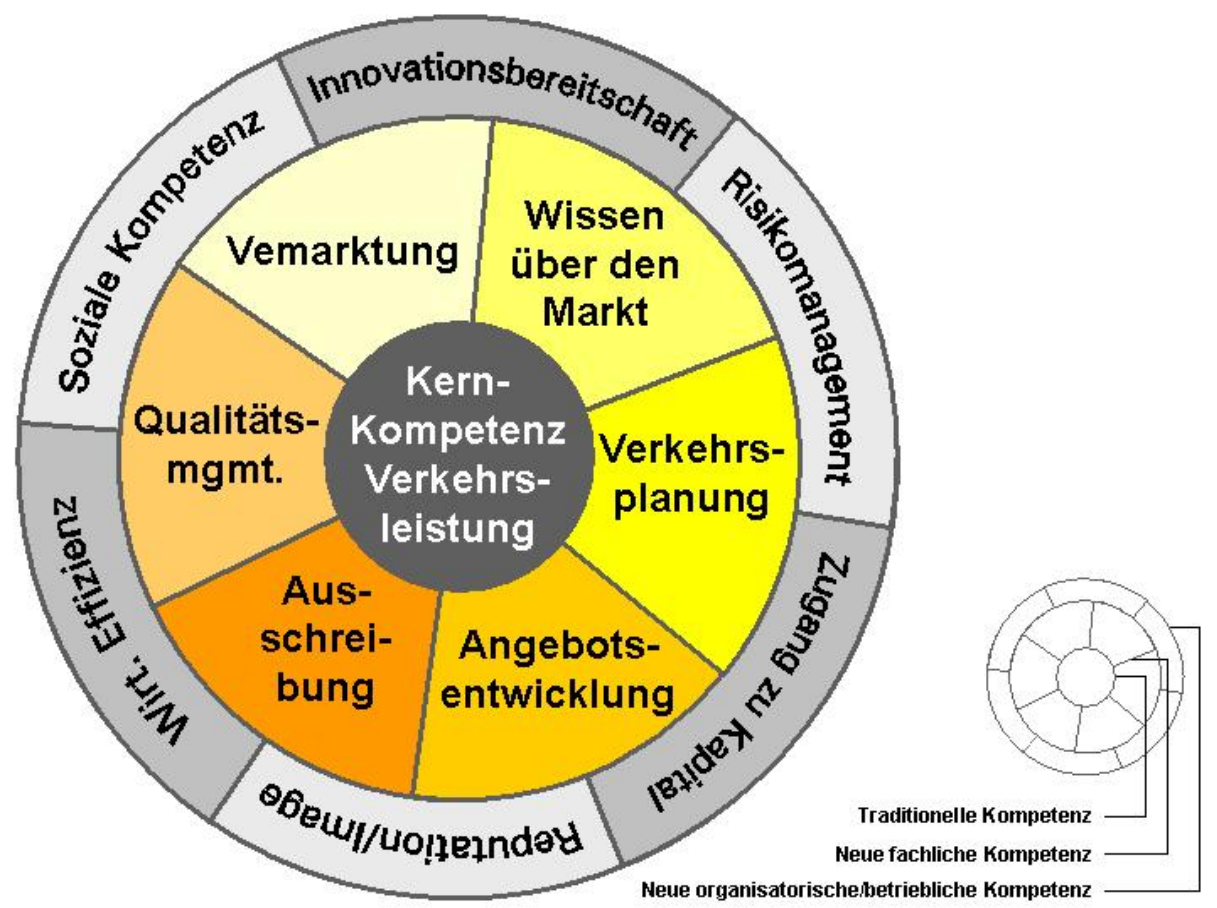

Abbildung 33: Kompetenzspektrum der ÖPNV-Akteure in einem sich verändernden Verkehrsmarkt Quelle: Eigene Darstellung

Die Deregulierung des ÖPNV-Marktes und der Wettbewerb um Verkehrsleistung verlangen sowohl von den Verkehrsunternehmen als auch von den Aufgabenträgern neue fachliche Kompetenzen im Bereich der Ausschreibung von Verkehrsleistung. Für die Verkehrsunternehmen geht es hier zuallererst um die Konkurrenzfähigkeit gegenüber Mitbewerbern und damit um eine effiziente Erstellung der Verkehrsleistung. Die Vergabe dieser Leistung in Form von Anreizverträgen verlangt auf der Seite der Verkehrsunternehmen zusätzlich qualitätssichernde Maßnahmen. Auf der Seite der Aufgabenträger erfordert dies die konsistente und qualitätsorientierte Leistungsbeschreibung sowie die Kontrolle der Einhaltung der in den Verkehrsverträgen vereinbarten Qualitätsstandards (Qualitätsmanagement). Hier bedarf es auch der Fähigkeit, entsprechende Besser- oder Schlechterleistung zu vergüten oder Sanktionen auszusprechen, beispielsweise im Rahmen von Bonus-Malus-Regelungen. ${ }^{964}$

963 UITP 2005, S.10

964 vgl. Anreiter und Schaaffkamp 2006, S.27 
Die Reduzierung öffentlicher Fördermittel führt ferner dazu, dass das ÖPNV-Angebot in größerem Umfang als bisher durch Fahrgeldeinnahmen abgedeckt werden muss („Nutzerfinanzierung“). Insofern also ein verbesserter Kostendeckungsgrad nicht über Kosteneinsparungen und die Erhöhung der Fahrpreise erzielt werden kann, bedarf es der Generierung von Mehrfahrten. Dieses wird nur durch Attraktivitätssteigerung mittels neuer Angebote und Kommunikationsstrategien möglich sein (Angebotsentwicklung). Dabei machen es die Flexibilisierung der Arbeitswelt und die Individualisierung der Gesellschaft notwendig, das bestehende Bedienungskonzept und den Bedienungsumfang auf die geänderten Bedürfnisse des Verkehrsmarktes hin zu überprüfen und ggf. abzuändern (Verkehrsplanung). Hierfür ist bei den Aufgabenträgern nicht nur ein umfassendes Wissen über den Verkehrsmarkt notwendig, sondern muss auch die Kompetenz der Vermarktung der neu geschaffenen Mobilitätsdienstleistungen vorhanden sein.

Neben den neuen fachlichen Kompetenzen haben zukünftig neue organisatorischbetriebliche Kompetenzen - auch im Sinne neuer Managementqualitäten - einen größeren Einfluss auf den Unternehmenserfolg. Die Wichtigkeit der wirtschaftlichen Effizienz setzt hierbei eine stärker betriebswirtschaftliche Denkweise und Unternehmensführung voraus. In diesem Zusammenhang verspricht die Fähigkeit der Bereitschaft zur Nutzung von Innovationen und die Fertigkeit aus ihrer Anwendung zu Lernen ein hohes Erfolgspotenzial. Denn durch den Einsatz neuer Technologien können die Veränderungsprozesse und die geschäftlichen Aktivitäten in den neuen Handlungsfeldern (sprich „Mobilitätsdienstleistungen“) maßgeblich unterstützt werden. Daher ist der gezielte Einsatz von Innovationen eine wichtige Komponente für den Unternehmenserfolg. Gleichzeitig gewährleisten und dokumentieren Innovationen Modernität und stellen darüber hinaus einen wichtigen Imagefaktor dar, der die Attraktivität und die Akzeptanz des ÖPNVAngebots durch den Kunden wesentlich verbessert. Positives Image und gute Reputation sind aber auch für potenzielle Investoren und damit für den Zugang zu neuem Kapital eine wichtige Voraussetzung. Denn vor dem Hintergrund leerer öffentlicher Kassen und einer sich abzeichnenden Veränderung der Finanzierungsgrundlagen des ÖPNV gewinnt die Erschließung neuer Finanz- und Investitionsquellen an Bedeutung. Neues Kapital kann den Investitions- und Betriebsaufwand kompensieren helfen und die Grundlage für die Erschließung von (Kosten-)Vorteilen im Wettbewerb sein. Dies könnte vor allem für die kommunalen Verkehrsunternehmen neue Finanzierungsperspektiven 
eröffnen, zumal sie durch die öffentlichen Haushaltskürzungen besonders betroffen sind. Insofern gewinnen Kooperationen zwischen kommunalen und privaten Unternehmen (sogenannte „Public-Private-Partnerships“), bei denen gemeinschaftlich sowohl Verkehrswie auch erweiterte Mobilitätsdienstleistungen angeboten werden, mehr und mehr an Bedeutung. Den privaten Partnern erschließt sich ein großer Absatzmarkt, den öffentlichen Partnern „erschließen sich durch eine Kooperation mit privaten Unternehmen Kapital, spezialisiertes Technologie-Know-How und die notwendigen Managementkapazitäten". 965

Allerdings ergeben sich durch den Einsatz von Innovationen und neuen Geschäftsmodellen auch Risiken, die es abzuschätzen und zu bewältigen gilt. Die UITP verweist diesbezüglich auf die Bedeutung eines Risikomanagements:

"Das Risikomanagement und das Geschick, Verpflichtungen und potentielle Chancen ins Gleichgewicht zu bringen, sowie die Fähigkeit der Organisation, den gegenwärtigen und künftigen Herausforderungen zu entsprechen, werden von Investoren bewertet und müssen vom Management deutlich aufgezeigt werden". 966

Bevor also externe Geschäftspartner eingebunden und finanzielle Verpflichtungen eingegangen werden, sollten die Verkehrsunternehmen zunächst das eigene unternehmerische Potenzial entwickeln und zu Entfaltung bringen. Das größte Potenzial der Verkehrsunternehmen sind hierbei die eigenen Mitarbeiter. Insofern ist die soziale Kompetenz für die Erhaltung des langfristigen Mitarbeiterbestands des Unternehmens von besonderer Relevanz. Hier spielt vor allem die Fähigkeit der Motivation und der Zufriedenstellung der Mitarbeiter eine Rolle, da diese die qualitativ hochwertige Mobilitätsdienstleistung gegenüber den Kunden erbringen sollen und auch die Schnittstelle zu anderen ÖPNVUnternehmen bilden. „Eine sozial verantwortungsbewusste Unternehmenskultur hilft dabei, sicherzustellen, dass die Beschäftigten ihre Verantwortung ernst nehmen, und fördert zudem das Wohlwollen zwischen den Unternehmen“. ${ }^{967}$

Zusammenfassend betrachtet tragen die neuen Kompetenzen dazu bei, dass die ÖPNVUnternehmen in einem sich verändernden Verkehrsmarkt ihre Aufgaben entsprechend

\footnotetext{
$965 \mathrm{vgl}$. Achenbach 2002, S.276f

966 UITP 2005, S.12

967 ebd., S.32
} 
verantwortlich wahrnehmen können. Die neuen Kompetenzen sind gleichzeitig die notwendige Grundlage für „die Schaffung der sozialen sowie informations- und kommunikationstechnischen Voraussetzungen für eine umweltschonende Organisation von Mobilität im Rahmen einer verbesserten inter- und intramodalen Kooperation der Verkehrsträger“. ${ }^{968}$ Sie sind die Voraussetzung dafür, dass das in Kapitel 5.3.3 beschriebene „Dilemma des geteilten Marktes“ gemindert werden kann. So kann beispielsweise die Marktferne der ÖPNV-Aufgabenträger durch verbessertes Marktwissen reduziert und die lokale politische Einflussnahme durch die Erschließung neuer Finanzquellen verringert werden. Insbesondere ermöglichen die neuen Kompetenzen den Verkehrsunternehmen und Aufgabenträgern nun, dass alle „Kunden“ adressiert werden können.

Die neuen Kompetenzen ermöglichen eine Verlagerung der unternehmerischen Aktivitäten in Richtung des Verkehrsmarktes - und eine Fokussierung auf den Mobilitätskunden als Endverbraucher. Diese Fokussierung kann bereits heute schon in der strategischen Unternehmensausrichtung festgestellt werden (siehe Kapitel 6.4.3). Die Verwendung des Begriffs „Kundenorientierung“ im Rahmen einer strategischen Marktpositionierung hat allerdings - konsequent umgesetzt - weitreichenden Einfluss auf die organisatorische Unternehmensstruktur und die Unternehmensführung.

\subsubsection{Kundenorientierung in der strategischen Unternehmensausrichtung}

Der Begriff „Kundenorientierung“ korrespondiert mit einigen anderen Begriffen wie „Kundennähe“ oder auch „Berücksichtigung von Kundenwünschen“. Kundenorientierung beschreibt die Fähigkeit eines Unternehmens, flexibel und schnell mit guten und individuellen Problemlösungen auf Kundenwünsche und Marktveränderungen reagieren zu können. Wenn allerdings kundenorientiertes unternehmerisches Handeln gemeint ist, geht es weniger um kurzfristige und taktische Maßnahmen, sondern eher um Kundenorientierung als Organisationsform (siehe Kapitel 6.4.4.2) und damit um eine „langfristige und strategische partnerschaftliche Ausrichtung des Unternehmens auf die Bedürfnisse der internen und externen Kunden“. ${ }^{969}$ Darüber hinaus unterscheidet sich die langfristig

\footnotetext{
968 Henning und Schmidt 1998, S.24

${ }^{969} \mathrm{vgl}$. Schnippe 2000, S.25f
} 
ausgelegte strategische Unternehmensplanung von der kurzfristigen, taktischen Planung auch aufgrund ihres stärkeren operativen Bezugs. ${ }^{970}$

Der RMV als „Kooperationsform zwischen Markt und starrer staatlicher Ordnung“ sieht in der verbesserten Kundenorientierung eine Herausforderung (siehe Kapitel 5.5 sowie 7.5.3), der er sich als „Mobilitätsverbund“ stellen möchte. Das strategische Ziel hierbei ist es, das Marktpotenzial besser zu erschließen und auszuschöpfen („Marktreichweite“), effizienter $\mathrm{zu}$ werden und die Kundenzufriedenheit $\mathrm{zu}$ verbessern. ${ }^{971}$ Die $R M V-G m b H$ spricht in diesem Zusammenhang gar von einer „Einheit aller Wege, Verkehrsmittel und Ziele“ mit dem Absicht der
"[...] Entwicklung eines integrierten Gesamtverkehrssystems, das durch die intermodale Vernetzung von motorisiertem Individualverkehr, Fußgänger- und Radverkehr sowie ei- nem leistungsstarken öffentlichen Verkehr die Mobilität der Menschen nachhaltig, um- welt- und sozialverträglich sichert und die Standortqualität Hessens als Wirtschaftsfaktor fördert". ${ }^{972}$

Ähnliche Ziele haben die Lokalen Nahverkehrsorganisationen. Auch sie sehen ihren Auftrag in der Kundenbetreuung und in der kundenorientierten Weiterentwicklung des ÖPNV-Angebots und positionieren sich zum Beispiel als „Dienstleister für alle Nutzer von Bussen und Bahnen“. 973 Die Verkehrunternehmen geben sich ebenfalls kundenorientiert und sehen sich als „Mobilitätsdienstleister“974 oder „Dienstleister“, die ihr Leistungsangebot an den Erwartungen und Anforderungen der Fahrgäste ausrichten.975 Die Kundenperspektive nimmt also bei der Erfüllung zukünftiger - auch hoheitlicher - Aufgaben bei allen ÖPNV-Akteuren an Bedeutung nicht nur zu, es kann sogar festgestellt werden, dass „Kundenorientierung“ zum strategischen Unternehmensziel avanciert. Wohingegen die „Kundenorientierung“ bei den Verkehrsunternehmen als eine unternehmerische Funktionalstrategie neben anderen (z.B. Produktions- oder Beschaffungsstrategie) zu sehen ist, spielt „Kundenorientierung“ bei den Aufgabenträgerorganisationen eine noch

\footnotetext{
$970 \mathrm{vgl}$. Aberle 2003, S.415ff

971 vgl. RMV 2005, S.9

972 ebd., S.7

973 vgl. z.B. hierzu den Internetauftritt der Lokale Nahverkehrsgesellschaft Frankfurt am Main, Traffiq: www.traffiq.de oder der Verkehrsgesellschaft Oberhessen mbH: www.vgo.de.

974 vgl. HEAG 2006, S.2

975 vgl. z.B. hierzu Internetauftritt der Verkehrsgesellschaft Frankfurt: www.vgf-ffm.de
} 
größere Rolle, bis hin zu einer Gleichsetzung von Marketing- und Unternehmensstrategie. 976

Kundenorientierung als Unternehmensstrategie dient letztendlich der Umsatz- und Ergebnisverbesserung des Unternehmens. Meyer und Specht verweisen darauf, dass die positiven ökonomischen Wirkungen bereits mehrfach nachgewiesen sind. Dieses liege vor allem daran, dass begeisterte Kunden

- bei Bedarf immer wiederkehren,

- eine höhere Einkaufsfrequenz und Einkaufsbeträge haben,

- Weiteremfehlungen aussprechen, d.h. ein positives Bild verbreiten (Image),

- gegenüber Preiserhöhungen unempfindlicher sind als unzufriedene Kunden

- $\quad$ und mehr Anbietervorteile kennen. ${ }^{977}$

Ferner betonen Meyer und Specht, dass für eine enge Kundenbindung einfache Kundenzufriedenheit nicht ausreiche, sondern es das Ziel sein müsse, „höchste Kundenzufriedenheitswerte im Sinne von Kundenbegeisterung“" zu erreichen (siehe auch Abbildung 35).978 Jensen und Fürst unterstreichen, dass „hohe Kundenzufriedenheit allein nicht zu wirtschaftlichem Erfolg führt, sondern dass hierfür echte Kundenbindung erforderlich ist“ ${ }^{\prime 979}$

Die Kundenorientierung verdrängt dabei keineswegs die - in den Verkehrsunternehmen bislang vorherrschende - Finanzperspektive, sondern erweitert diese Perspektive. Schließlich ist das Ziel der strategischen Kundenorientierung ebenfalls ein betriebswirtschaftlich optimales Ergebnis zu erzielen - und dieses bemisst sich nun mal am finanziellen Erfolg. Die Erweiterung um die Kundenperspektive berücksichtigt daher eine Reihe von für den Unternehmenserfolg wichtigen Faktoren und Einflüssen. Robert Kaplan und David Norton 980 schlagen im Rahmen des von ihnen entwickelten „Balanced-ScorecardAnsatzes“ (BSC, siehe auch Kapitel 6.4.4.5) insgesamt vier Perspektiven vor, die es bei der

\footnotetext{
976 vgl. Homburg und Krohmer 2003, S.349f

977 vgl. Meyer und Specht 2002, S.377

978 ebd.

979 Jensen und Fürst 2004, S.45

980 Zur vertiefenden Betrachtung siehe u.a.: Kaplan, R. S. und Norton, D. P.: “The Balanced Scorecard. Translating Strategy into Action“. Boston 1996
} 
Strategieumsetzung $\mathrm{zu}$ berücksichtigen gilt und die in einer Ursache-WirkungsBeziehung im Verhältnis zueinander stehen:

- Finanzperspektive (betriebswirtschaftlicher Erfolg)

- Kundenperspektive (Erfüllung der Kundenerwartung)

- (Interne) Prozessperspektive (Qualität und Geschwindigkeit der - erfolgsentscheidenden - Geschäftsprozesse)

- Innovationsperspektive (Potenzial, Prozesse zu optimieren, Produkte und Leistung zu verbessern sowie Mitarbeiter zu motivieren)

Erst die Berücksichtigung aller Perspektiven erlaubt es, „Transparenz zwischen den Beziehungen zwischen Ursache und Wirkung der einzelnen Faktoren zu schaffen und die Komplexität der betrieblichen Abläufe auf die relevanten Teilaspekte zu reduzieren. Außerdem sollte es in einer sich ständig verändernden Welt möglich sein, notwendige Strategieanpassungen vorzunehmen und über ständige Feedback-Schleifen eine kontinuierliche Annäherung an die gesetzten strategischen Ziele zu erreichen“. ${ }^{981}$ Der Ansatz der BSC lässt sich allerdings um beliebig viele Perspektiven erweitern. So können auch Umweltfaktoren, eine Ökobilanz oder branchenspezifische Betrachtungen Eingang finden. Bei zu vielen Perspektiven besteht allerdings die Gefahr, dass die BSC mit zu vielen und zu komplexen Zielen überlastet wird. ${ }^{982}$ Gleichzeitig erfordert der kontinuierliche Abgleich der erreichten Ziele anhand von Messdaten und Erhebungen ein hohes Maß an Unternehmenskommunikation, sowohl horizontal wie auch vertikal. ${ }^{983}$

981 Krüger und Seelmann-Eggebert 2003, S.246

982 vgl. http:/ / de.wikipedia.org/wiki/Balanced_Scorecard (Zugriff am 2.7.2007)

983 vgl. Hemmersbach, Roß und Deckmann 2002, S.63 
Strategisches Ziel: Ergebnisverbesserung durch Nutzerfinanzierung und Effizienz

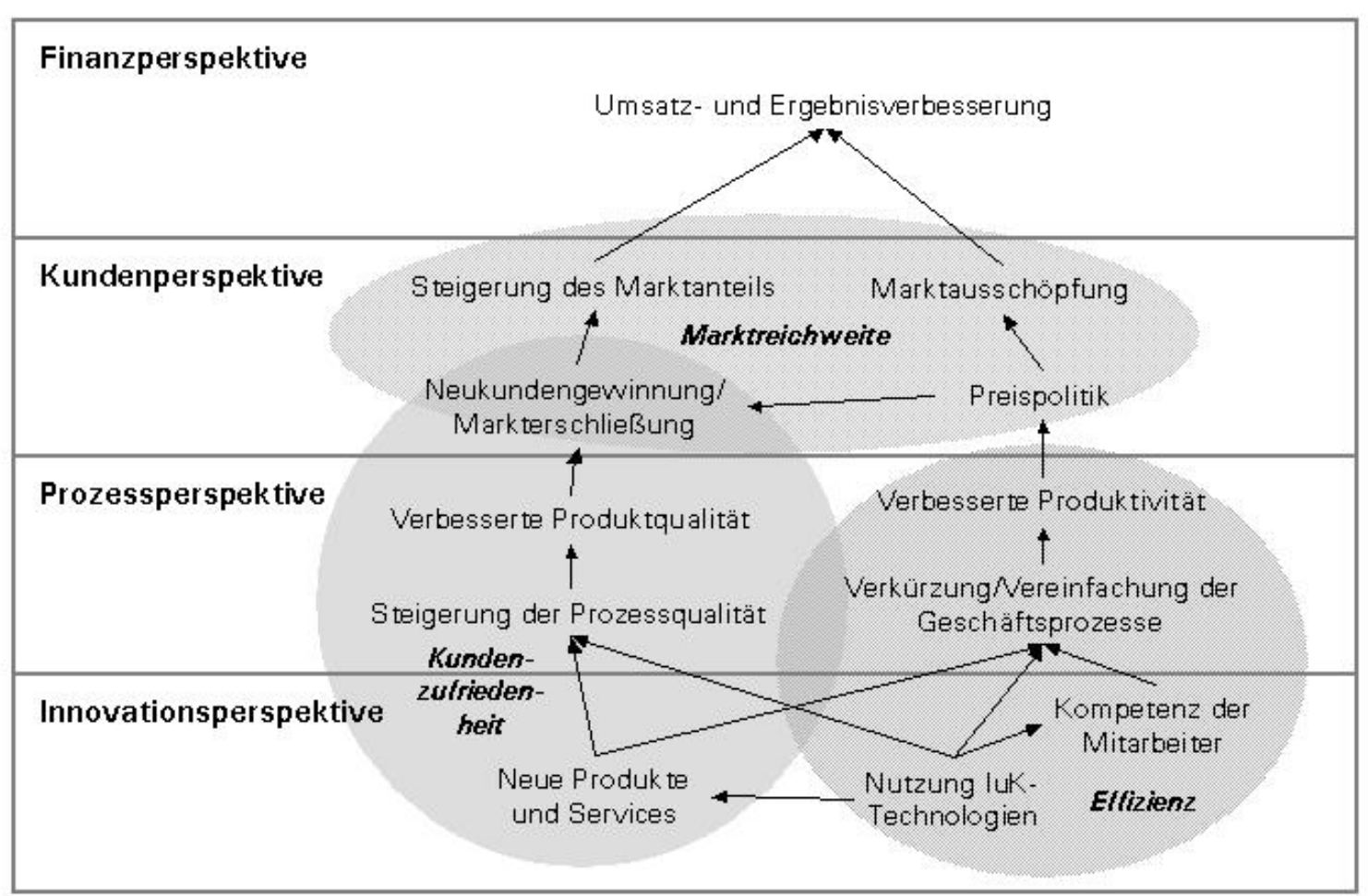

Abbildung 34: Perspektiven der strategischen Unternehmensausrichtung und Ursache-Wirkungs-Beziehung Quelle: eigene Bearbeitung in Anlehnung an Krüger und Seelmann-Eggebert 2003, S.249

Die Offenlegung der Ursache-Wirkungs-Beziehung im Rahmen einer konsequenten Betrachtung der Kundenerwartungen macht deutlich, dass Kundenorientierung nicht erst an der Schnittstelle zum Kunden entsteht, also sozusagen an der „Benutzeroberfläche“, sondern alle Geschäftsprozesse eines Unternehmens berührt. Abbildung 34 verdeutlicht in vereinfachter Weise ${ }^{984}$ den Ursache-Wirkungs-Zusammenhang am Beispiel einer strategischen Unternehmensausrichtung, wie es sie bspw. im RMV geben könnte. Über die Einführung neuer Produkte und Services auf der Basis der Nutzung von IuKTechnologien wird eine höhere Effizienz bei den Geschäftsprozessen und in der Qualität der Produkte erzielt. Insgesamt kann die Kundenzufriedenheit verbessert und Neukunden gewonnen werden. Gleichzeitig ermöglicht die bessere Produktivität eine Anpassung der Preispolitik, über die der Markt besser erschlossen bzw. ausgeschöpft und der Marktanteil vergrößert werden kann.

${ }^{984}$ Auf die Komplexität von Ursache-Wirkungs-Beziehungen wird in Kapitel 6.4.1 hingewiesen. 
Damit aus Kundenorientierung auch tatsächlich ein strategischer Wettbewerbsvorteil erwächst, müssen drei Merkmale - gleichzeitig - erfüllt sein:

- Kundenorientierung wird vom Kunden als wichtig bzw. relevant aufgefasst (z.B. im Verhältnis zu einem Wettbewerber)

- Kundenorientierung ist wahrnehmbar und

- Kundenorientierung ist dauerhaft. 985

\subsubsection{Umsetzung einer kundenorientierten Unternehmensstrategie}

Im folgenden wird dargestellt, welche organisatorischen Instrumente geeignet sind, ÖPNV-Unternehmen auf einer strategischen Ebene stärker an den Bedürfnissen des Marktes auszurichten. Da im Zusammenhang mit der Unternehmensentwicklung die Analyse (Messung) und transparente Darstellung der Unternehmenssituation eine größere Rolle spielen, wird auch auf den Bereich Controlling eingegangen. Dieser Bereich übernimmt bei der Unternehmenssteuerung im Hinblick auf die Ergebnisoptimierung die Koordinationsfunktion.

\subsubsection{Kundenorientierte Organisationsstruktur}

Aberle weist darauf hin, "dass eine strategische Unternehmensplanung in der Verkehrswirtschaft erst seit wenigen Jahren und hier außerdem nur bei einigen Unternehmen besteht“ ${ }^{\prime \prime} 96$ So sei diese insbesondere bei der DB AG zu finden, deren Aufgaben sich im Bereich der strategischen Unternehmensplanung durch den Wettbewerb wesentlich erweitert haben. ${ }^{987}$ Demnach besteht häufig eine Diskrepanz zwischen dem Anspruch und der unternehmerischen Umsetzung von „Kundenorientierung“. Die Gründe hierfür sind darin zu sehen, dass die (kommunalen) Verkehrsunternehmen bislang überwiegend in einer Verwaltungsstruktur geführt wurden, was eben mit ihrer kommunalen Eigentümerschaft und einer damit verbundenen Einbindung in politische Vorgaben zusammenhängt. Der hohe öffentliche Subventionsbedarf und die Finanzierungsstrukturen (z.B. über den Querverbund) trugen ein Übriges dazu bei, dass die Marktorientierung gering und die "qualitative Struktur des Managements" oft nicht hinreichend waren.988

\footnotetext{
985 vgl. Meyer und Specht 2002, S.378

986 Aberle 2003, S.434

987 vgl. Aberle 2003, S.437

988 ebd, S.448
} 
Die Unternehmensausrichtung im ÖPNV ist vom organisatorischen Standpunkt sehr stark funktions- und vom Instrumenteneinsatz sehr stark technikorientiert. Von daher ist die funktionale Ausrichtung der Geschäftseinheiten bei Verkehrsorganisationen die am weitesten verbreitete Organisationsform. In der Regel existieren bei mittleren und größeren Unternehmen unterhalb einer Ebene der Unternehmensleitung die Geschäftseinheiten, die mit den Funktionen Beschaffung, Marketing und Vertrieb, Produktion und Betrieb sowie Finanzen und Personal betraut sind. Bei vielen kleineren Unternehmen verhindert die geringe Personaldecke allerdings eine funktionale Differenzierung bzw. decken einzelne Personen eine oder sogar mehrere Funktionen ab.

Homburg und Krohmer sowie Kretschmann verweisen darauf, dass häufig schon die rein funktional ausgerichtete Organisationsform eines Unternehmens eine verbesserte Kundenorientierung verhindert. Vielmehr seien produktorientierte Geschäftseinheiten einzurichten, die den funktionalen Einheiten übergeordnet oder diesen gleichgestellt sind. $\mathrm{Zu}$ den Vorzügen produktorientierter Geschäftsbereiche äußern sich Homburg und Krohmer wie folgt:

„Die Divisionalisierung im Rahmen der Bildung produktorientierter Geschäftseinheiten ermöglicht einen besseren Fokus auf einzelne Märkte. Folglich ist die Kundenorientierung bei dieser Organisationsform bereits höher als bei der rein funktionalen Organisation". 989

Doch auch produktorientierte Organisationsformen beinhalten Risiken, insbesondere dann, wenn einzelne Unternehmensbereiche eine (zu) hohe Eigendynamik entwickeln, die nicht konform mit dem unternehmerischen Ziel bzw. Ergebnis ist. Als mögliche Nachteile werden u.a. „Egoismen“ einzelner Abteilungen genannt, die zwar „ihre Funktionsinteressen optimieren wollen“, jedoch "das Gesamtinteresse des Unternehmens vernachlässigen“. ${ }^{990}$ Außerdem werden die stark hierarchisierten und bürokratisierten Entscheidungsprozesse bemängelt, die durch einen hohen Koordinationsaufwand zwischen den Abteilungen noch erschwert werden. Diese Strukturen würden keine kurzfristigen Reaktionen auf Markt- und Wettbewerbsveränderungen zulassen, wovon sowohl strategische Entscheidungen wie auch Innovationen betroffen seien. ${ }^{991} \mathrm{Im}$ ungünstigen Fall kann sich diese Organisationsform auch nachteilig auf das Kundenverhältnis auswirken, wenn zum Beispiel verschiedene Unternehmensbereiche individuelle Vertriebsorganisati-

\footnotetext{
989 Homburg und Krohmer 2003, S.962

990 Kretschmann 2001, S.120; siehe auch Jensen und Fürst 2004, S.47

${ }^{991}$ vgl. Kretschmann, S.120f
} 
onen besitzen und der Kunde Produkte mehrerer Geschäftsbereiche bezieht. ${ }^{992}$ Auch die Aufteilung des Vertriebs nach Regionen oder Kundengruppen scheint hierfür nicht unbedingt die Lösung zu sein, zumal viele Kunden unterschiedlich in Erscheinung treten. So ist der Pendler oder Geschäftsreisende in der Woche auf anderen Relationen unterwegs als am Wochenende im Freizeit- oder Besorgungsverkehr.

Kretschmann resümiert, dass die Verkehrsunternehmen eine stärker kundenorientierte Organisationsform entwickeln müssen, sollen aus ihnen „Mobilitätsdienstleister“ werden, zumal dies eine Voraussetzung für eine markt- und kundenorientierte Unternehmensführung ist. ${ }^{993}$ Eine kunden- oder marktorientierte Organisationsform ist damit die Voraussetzung, dass Instrumente einer kundenorientierten Unternehmensführung greifen können.

Die Bedingung für eine derartige (Re-)Organisation ist allerdings, dass das Unternehmen „eine gewisse Größe“ überschreitet, damit organisatorische Differenzierungen bzw. Spezialisierungen überhaupt umgesetzt werden können. Dies gilt insbesondere auch für den Marketingbereich, wo das „Spektrum der möglichen Spezialgebiete“ sehr breit ist. ${ }^{994}$ Die gängigste funktionsorientierte Spezialisierung des Marketingbereichs bei Verkehrsorganisationen ist die Unterteilung in "Marketing" und „Vertrieb“. In der Regel ist damit die Unterscheidung aller Geschäftsprozesse für den Fahrkartenverkauf und Kundendienst sowie „aller übrigen“ Geschäftsprozesse aus dem Marketingbereich gemeint, also vor allem Werbung (auch der Verkauf von Werbeflächen) und Öffentlichkeitsarbeit. ${ }^{995}$ Die Aufgaben können so zwar - funktionsorientiert - routiniert und effizient von Spezialisten durchgeführt werden. Durch die Gefahr der Innenorientierung können allerdings die Belange der Kunden aus den Augen verloren werden, wodurch die Effektivität ${ }^{996}$ der Maßnahmen - also die Marketingeffekte - leiden. 997

Auch hier bietet sich als Steuerungsinstrument die Verwendung einer BSC an, indem einerseits die übergeordneten Unternehmensziele entsprechend der gewählten Perspektiven auf die einzelnen Abteilungen heruntergebrochen werden, andererseits die Wirkun-

\footnotetext{
992 vgl. Homburg und Krohmer 2006, S.964 sowie Kretschmann 2001, S.122

993 vgl. Kretschmann 2001, S.124

994 vgl. Homburg und Krohmer 2003, S.966f

995 vgl. Stauss 1987, S.124

996 Unter Effektivität wird in dieser Arbeit die Wirksamkeit im Verhältnis zu den angewendeten Mitteln verstanden.

997 vgl. Homburg und Krohmer 2003, S.956
} 
gen und die Zielerreichung der Maßnahmen kontinuierlich überprüft werden. Für die Kundenperspektive bietet sich hier das übergeordnete strategische Ziel des einheitlichen Marktauftritts gegenüber dem Kunden an - im englischen auch als „One-face-to-thecustomer" bezeichnet ${ }^{998}$ und im RMV synonym mit dem Begriff des „Mobilitätsverbunds" besetzt. Kennzeichen dieses einheitlichen Marktauftritts ist ein integriertes Marketing, welches alle Interessen und Marketingmaßnahmen bündelt.

Da bei den Verkehrsunternehmen traditionell der Betrieb bzw. die Erbringung der Verkehrsleistung im Vordergrund steht, ist der Verwaltungsbereich in der Regel entsprechend personell klein ausgeprägt. Beim größten lokalen Verkehrsunternehmen in der Region, der VGF, gibt es nur einen Bereich „Kundendienst und Vertrieb“, der sich mit Marketingaufgaben befasst. ${ }^{999}$ Sonstige Marketingbereiche wie Marktforschung, Direktmarketing, Produktplanung, Verkaufsförderung, Werbung oder Informationssysteme sind nicht zu finden. Das mit der Unternehmensgröße auch die Spezialisierung zunimmt, lässt sich an der Lokalen Nahverkehrsorganisation der Stadt Frankfurt, TraffiQ, erkennen. Mit ca. 60 Mitarbeitern besitzt die Gesellschaft neben einem Bereich „Marketing und Kundenbetreuung", in dem die Aufgaben "Werbung, Produktion von Kundeninformationen, Beschwerdemanagement und Info-Hotline“ zusammengefasst sind, auch einen Bereich „Markt- und Verkehrsforschung“ sowie den produktorientierten Bereich „Angebotsplanung“. ${ }^{1000}$

Bei der größten Verkehrsorganisation des ÖPNV, der RMV GmbH, die über 100 Mitarbeiter hat, geht die funktionsorientierte Spezialisierung des Marketingbereichs noch weiter. Im Geschäftsbereich Marketing sind hier zwar nur die Bereiche „Tarif und Vertrieb“ und „Marktforschung“ zu finden. Darüber hinaus gibt es - allerdings eben nicht im Geschäftsbereich „Marketing“ - als Stabsstelle einen Bereich „Werbung und Marktauftritt". Des weiteren sind produktorientierte Bereiche im Geschäftsbereich „Planung“ untergebracht, wobei allerdings erwähnt werden muss, dass unter „Produkt” hier vor allem die klassische Einteilung in die unterschiedlichen Verkehrsmittel zu verstehen ist (Bus, S-Bahn, sonstige Schiene). Der marketingseitig eng mit dem „Produkt“ verknüpfte Aspekt der Sicherung der Qualitätsanforderungen an die Produkte befindet sich wiederum in einem anderen Geschäftsbereich („Bestellmanagement“). Darüber hinaus gibt es mit dem Ge-

\footnotetext{
998 „Ein Gesicht zum Kunden“; vgl. Homburg und Krohmer 2003, S.964

${ }^{999} \mathrm{vgl}$. www.vgf-ffm.de

1000 vgl. Traffiq 2006, S.35ff
} 
schäftsbereich „Innovation“ Ansätze einer vertriebskanalspezifischen Spezialisierung. Damit wird vom Prinzip her nicht nur einer zunehmenden Verbreitung von Mehrkanalsystemen Rechnung getragen, sondern sind gleichzeitig auch erste organisatorische Ansätze einer stärker objektorientierten Spezialisierung erkennbar.

Für die RMV GmbH kann daher einerseits resümiert werden, dass auch hier vom Prinzip her eine klassische funktionsorientierte Organisationsstruktur vorliegt, die eine marktund kundenorientierte Gesamtausrichtung des Unternehmens nur bedingt zulässt. Andererseits ist aber auch deutlich, dass viele wichtige Funktionsbereiche für eine ganzheitliche und übergreifende Vermarktung des ÖPNV vorhanden sind. Für eine verbesserte Kundenorientierung bedürfte es allerdings der organisatorischen Restrukturierung, die sich weniger an der Art der Aufgaben orientiert, sondern vielmehr am „Bezugsobjekt“ also am Markt oder den Kunden, die wiederum bestimmte Produkte (im Sinne von Leistungen) kaufen sollen. Problematisch hierbei ist aber der Umstand, dass die RMV GmbH in erster Instanz Aufgabenträger ist und keine operativen Vertriebsaufgaben hat, also nicht direkt die Kundenschnittstelle besetzt. Dennoch muss anerkannt werden, dass die $R M V$ GmbH nicht nur von ihrer Größe her, sondern auch von ihrem geographischen Zuständigkeitsbereich her die einzige Organisation ist, die für die Koordination oder auch die Durchführung einer übergreifenden Vermarktung des ÖPNV in der Region Frankfurt Rhein-Main in Frage kommt.

\subsubsection{Kundenorientierte Unternehmensführung}

Homburg und Krohmer sehen in der marktorientierten Unternehmensführung - zusammen mit dem Kundenbeziehungsmanagement (siehe Kapitel 6.4.4.4) - eine grundlegende Erweiterung im Verständnis des Marketingbegriffs. ${ }^{1001}$ Die markt- bzw. kundenorientierte Unternehmensführung bezieht sich dabei nicht nur auf den Marketingbereich eines Unternehmens, sondern auf das gesamte Unternehmen bzw. dessen Führungsinstrumente. Insofern betrifft Kundenorientierung alle Wertschöpfungsbereiche eines Unternehmens. ${ }^{1002}$ Auch Meyer betont, dass „Offensives Marketing [...] eine Führungs- und Organisationsaufgabe [ist] - Die Verantwortung und Initiative dafür liegt bei der Unternehmensleistung“. ${ }^{1003}$ Damit gilt es nicht alleine die primären Wertschöpfungsprozesse kundenorientiert auszurichten, die vom Kunden direkt wahrgenommen werden („Marktleistung“),

1001 vgl. Homburg und Krohmer 2003, S.9

1002 vgl. Meyer und Specht 2002, S.379

${ }_{1003}$ Meyer 2005, S.9 
sondern auch die internen Betriebsprozesse eines Unternehmens, die beispielsweise der Organisation oder der Planung dienen, die dem Kunden in der Regel verborgen bleiben. Denn letztendlich profitieren alle Unternehmensbereiche von einem Austausch mit den Kunden. So können auf Basis der generierten Informationen und des gewonnenen Wissens die Qualität und die Wirkungen des eigenen Angebots und Verhaltens am Markt reflektiert und entsprechende Maßnahmen zur Angebots- und Verhaltensverbesserung abgeleitet werden.

Auch die Unternehmenskultur hat einen wesentlichen Einfluss auf die Kundenorientierung. Hierzu zählen die Offenheit in der internen Kommunikation, die vorhandene Qualität und Kompetenz, die abteilungsübergreifende Zusammenarbeit und die Wertschätzung der Mitarbeiter. ${ }^{1004}$ Auf die soziale Kompetenz, die für die Umsetzung dieser Werte bei der Unternehmensführung vorhanden sein muss, wurde bereits in Kapitel 6.4.2 hingewiesen. Meyer und Specht sprechen in diesem Zusammenhang auch von einer „internen Kundenorientierung“, die wesentlich zu Motivation der Mitarbeiter und damit zur Leistungsbereitschaft und Qualität der - für den Kunden - erbrachten Leistung beiträgt. Diese Leistungsbereitschaft wird zusätzlich durch erhöht, „wenn mit einem hohen Niveau der Kundenzufriedenheit Incentives wie Lob und Anerkennung oder Sonderzahlungen verknüpft sind“. ${ }^{1005}$

Da sich die markt- und kundenorientierte Unternehmensführung sehr eng an die Erfüllung der Kundenerwartungen anlehnt, kommt dem Bereich des Qualitätsmanagements (siehe Kapitel 6.4.4.5), und damit zusammenhängend der Messung der Dienstleistungsqualität sowie der Erhebung der Kundenzufriedenheit, eine herausgehobene Bedeutung zu. Die Instrumente einer markt- und kundenorientierten Unternehmensführung können danach unterschieden werden, inwieweit der Kunde in die betrieblichen Prozesse eingebunden ist. Blümel unterteilt diese Maßnahmen auf der anbieterbezogenen Seite in unternehmensbezogene und interpretative Verfahren sowie auf der nachfrageorientierten Seite in integrative und direkt-kontaktive Verfahren. Zu den Einzelinstrumenten gehören unternehmensbezogen u.a. Benchmarking-Methoden (Unternehmensvergleich anhand von Kennzahlen), Qualitätsaudits (Überprüfung unternehmensinterner Abläufe und Qualitätsanforderungen) und das betriebliche Vorschlagswesen. $\mathrm{Zu}$ den interpretativen Verfahren zählen u.a. Expertenbefragungen und Auswertungen von Kundenreklamationen.

${ }^{1004}$ vgl. Homburg und Krohmer 2003, S.1079

${ }^{1005}$ vgl. Meyer und Specht 2002, S.382f 
$\mathrm{Zu}$ den integrativen Verfahren gehören geheime Testkäufe („silent shopping“) und Qualitätstester sowie merkmalsorientierte Verfahren, bei denen unterschiedliche Kundenbewertungen $\mathrm{zu}$ verschiedenen Themen $\mathrm{zu}$ einem Gesamtergebnis verdichtet oder auch Kundeneinstellungen abgefragt werden. ${ }^{1006}$

Letztendlich sollen diese Instrumente dazu führen, dass sich das Unternehmen in seiner Organisation, im Personalmanagement, im Informationsmanagement, in der Unternehmensplanung und in der Kontrolle (Controlling) stärker und besser an den Kundenbedürfnissen ausrichten kann. Um alle hiermit bezogenen Aktionen und Maßnahmen in ausgewogener Weise aufeinander abzustimmen und die Umsetzung und Zielerreichung kontinuierlich zu überprüfen, gibt es wiederum unterschiedliche Managementinstrumente. ${ }^{1007}$

\subsubsection{Erfüllung der Kundenerwartung}

In der Mobilitätsforschung werden bei Untersuchungen zum Verkehrsmittelwahlverhalten, insbesondere im Rahmen der ökonomischen Verhaltenstheorie, häufig individuelle Kosten-Nutzen-Bilanzen zur Erklärung herangezogen. Relevante, die Motivation des Einzelnen beeinflussende Kriterien, sind hier der anfallende Kosten- und Zeitaufwand. Der Theorie des geplanten Verhaltens ${ }^{1008}$ entsprechend ist die individuelle Bewertung dieser Kriterien im Hinblick auf die persönlichen Konsequenzen ausschlaggebend für die Einstellung zu einem Verkehrsmittel. Zusätzlich haben der soziale Erwartungsdruck und die soziale Kontrolle, ein entsprechendes Mobilitätsverhalten auszuführen, Einfluss auf das tatsächliche Nutzerverhalten. Vor allem bei wahlfreien Personen ist das Mobilitätsverhalten daher als das Resultat von sozialen Bewertungsprozessen zu verstehen, die allerdings um zwei weitere Kriterien ergänzt werden müssen. Zum einen sind dies ökologisch motivierte Entscheidungskriterien, die zunehmend an Relevanz gewonnen haben (deren kommunikative Verwendung aber sorgfältig abgewogen sein muss; s.u.), zum anderen und vor allem - sind es auch individuelle emotionale Gründe, die eine Einzelperson bei ihrer Entscheidung ein bestimmtes Verkehrsmittel zu nutzen oder nicht zu nutzen beeinflussen. Hunecke spricht in diesem Zusammenhang von „symbolisch-emotionalen Bewer-

\footnotetext{
1006 vgl. Blümel 2004, S.54ff

${ }^{1007}$ Hierzu gehört bspw. die Balanced Score Card; vgl. Görn und Krug 2002, S.25

1008 Zur vertiefenden Betrachtung siehe: Ajzen, Icek: „The Theory of Planned Behaviour. Some unresolved issues“. In: Organizational Behaviour an Human Decision Processes, 50. o.O. 1991. S.179-211.
} 
tungen der Mobilität“, die in die vier Dimensionen Autonomie, Status, Erlebnis und Privatheit unterteilt werden (vgl. Kapitel 3.8.3).1009 Meyer und Specht weisen darauf hin, dass die „Kunden [...] zunehmend auch „weichere“ Faktoren wie beispielsweise Wertschätzung, Motivation, Flexibilität oder Einfühlungsvermögen der Mitarbeiter“ als qualitätsrelevante Faktoren wahrnehmen. ${ }^{1010}$

Anknüpfungspunkte, über die diese emotionalen Werte vermittelt werden können, spielen im ÖPNV bislang eine untergeordnete Rolle. Die Vermittlung von Beweggründen den ÖPNV zu nutzen, beschränkt sich häufig auf rein rationale Argumente, wie beispielsweise den ökologischen Kriterien. Dies führt dazu, dass der ÖPNV im Vergleich zum Pkw in allen vier oben genannten Dimensionen unterliegt und in der Konsequenz als nachteilig eingeschätzt wird bzw. die Wahl des Verkehrsmittels zugunsten des Pkw ausfällt. Gerade weil "Image“ eine stark emotionale und damit psychologische Komponente hat, ist die Verbesserung auf der Basis rein rationaler Argumente nur schwer zu schaffen. Verkaufsfördernde Maßnahmen und Kommunikationsmaßnahmen, die imagefördernd wirken sollen, müssen daher viel stärker auf der emotionalen bzw. „affektiven“ Ebene der Kundenerwartungen und -ansprüche wirken. ${ }^{1011}$

Realisiert wird Kundenorientierung durch die Erfüllung der Kundenerwartungen auf den unterschiedlichen Anforderungsebenen, die (u.a.) im „Kano-Modell“1012 beleuchtet werden. Demnach hat der Kunde eine Reihe von Basisanforderungen, deren Erfüllung, am Beispiel des ÖPNV etwa durch das Verkehrsunternehmen, vorausgesetzt werden. Ist das Verkehrsmittel also unpünktlich und werden Anschlüsse nicht erreicht, reagiert der Kunde mit extremer Unzufriedenheit. Die Erfüllung bestimmter Leistungsanforderungen werden vom Kunden erwartet. Die Verbesserung der Aufenthaltsqualität an den Haltestellen und in Bahnhöfen, eine freundliche Auskunft des Servicepersonals oder ein angenehmes Klima in den Fahrzeugen erhöhen beispielsweise auch die Zufriedenheit des Kunden. Hinsichtlich der Begeisterungsfaktoren ist die Erwartungshaltung des Kunden sehr gering. Der fehlende Zeitungs- oder Erfrischungsverkauf in den Fahrzeugen führt also zu keiner Verschlechterung des Images. Umgekehrt kann ein derartiges Angebot

\footnotetext{
${ }^{1009}$ vgl. Hunecke und Schweer 2006, S.150

1010 Meyer und Specht 2001, S.388

1011 vgl. Rumpke 2005, S.89

1012 Das Kano-Modell wurde 1978 von Professor Noriaki Kano von der Universität Tokio, Japan, aus Kundenwünschen abgeleitet.
} 
durchaus zu einer Verbesserung der Kundenzufriedenheit führen, weil der Kunde positiv überrascht wird. Hieraus ergibt sich, dass zunächst die Basisanforderungen erfüllt sein müssen, d.h. also die Qualität der Beförderungsleistung - als Kernleistung - vom Kunden zufriedenstellend wahrgenommen wird. Dies betrifft insbesondere die produktseitigen Ausprägungen der Verbindungs- und Erschließungsqualität, aber auch den Preis für diese Leistung. ${ }^{1013}$

Die vom Kunden subjektiv wahrgenommene Produktqualität und der wahrgenommene Preis führen zu einem vom Kunden wahrgenommenen Nutzen. Ist dieser „Netto“-Nutzen größer als der Preis, den der Kunde bereit ist zu zahlen, ist die Kaufwahrscheinlichkeit groß. Nimmt der Kunde aber ein schlechtes Preis-Leistungsverhältnis wahr, bzw. rechtfertigt aus Kundensicht die Produktqualität nicht den Preis, ist auch der wahrgenommene Nutzen zu klein, um zu einer Kaufentscheidung zu führen. ${ }^{1014}$ Entspricht die Kernleistung nicht den Kundenerwartungen, können auch weiterführende Aktivitäten, wie z.B. Vermarktungsanstrengungen, die beim Kunden für Begeisterung sorgen sollen, kaum zum erwünschten Erfolg führen. Die Qualität der Leistung einerseits und die Kundenorientierung andererseits sind daher zwei sich gegenseitig beeinflussende und bedingende Faktoren.

Solide Produktqualität und marktgerechte Preise sind also angebotsseitig die Grundlage für Kundenorientierung. Für „echte“ Kundenorientierung bedarf es darüber hinaus aber auch der Flexibilität und der Fähigkeit der Interaktion mit dem Kunden. Der Grad der Flexibilität wird durch die Fähigkeit des Unternehmens erkennbar, persönlichen Wünschen der Kunden nachzukommen und diese auch in einem weit vorgerückten Produktionsstadium (zum Zeitpunkt der Beförderung) umzusetzen. Dabei muss Kundenorientierung allerdings nicht bedeuten, dass der Wunsch eines einzelnen Kunden in den Fokus des Unternehmens rückt. Als hilfreich wird bereits das Handeln nach Kundenkategorien und deren Erwartungen angesehen oder die Orientierung an der Lösung von kundenseitigen Problemen. Die Fähigkeit der Interaktion bemisst sich in der Möglichkeit zum „Informations- und Anregungsaustausch“ mit den Kunden.1015 Dieses trifft sowohl für die Konsum- und Investitionsgüterindustrie zu wie für den Dienstleistungssektor, da sowohl

\footnotetext{
1013 vgl. Schäfer-Sparenberg, Bongardt und Dalkmann 2006, S.47

1014 vgl. Homburg und Krohmer 2003, S.587

1015 vgl. Blümel 2004, S.53
} 
aus marktnahen und bedürfnisgerechten Produkten wie auch aus Dienstleistungen höhere Preise erzielt werden. Die daraus resultierenden besseren Auslastungsgrade der Ressourcen führen $\mathrm{zu}$ einer Effizienzsteigerung und wirken, gemessen an der einzelnen Transaktion, auch kostenreduzierend. ${ }^{1016}$

Entsprechend des Kano-Modells gilt es also zunächst die Basisansprüche im Bereich der Kernkompetenz eines Mobilitätsdienstleisters zu erfüllen. So werden vom Kunden insbesondere bestimmte Qualitätsstandards als Basisanforderungen bei den Fahrzeugen und infrastrukturellen Einrichtungen vorausgesetzt (z.B. Sauberkeit). Als die vom Kunden ebenfalls vorausgesetzte Leistungsanforderung gilt die Zufriedenheit mit der Verkehrsleistung (z.B. Sicherheit, Pünktlichkeit), zumal dies das „Gut“ ist, wofür der Kunde bezahlt. Darüber hinausgehende Leistungen werden vom Kunden von einem Verkehrsunternehmen nicht unbedingt erwartet. 1017

Werden von einem Mobilitätsdienstleister allerdings Leistungsversprechen im Bereich „Mobilität und Service“ gemacht, müssen diese auch eingehalten werden. Der Begriff „Mobilitätsdienstleister“ darf also keine leere Worthülse bleiben, sondern muss mit konkreten und fassbaren Mobilitätsleistungen - quasi als Beweisführung - untermauert werden. Erst dann wird die Kundenorientierung für den Kunden auch wahrnehmbar. Soll gar Begeisterung beim Kunden für den Mobilitätsdienstleister geweckt werden, bedarf es Leistungen, die über das Erwartete - das erfüllt sein muss - hinausgehen. Hier bedarf es Maßnahmen und Angebote, die den Kunden auf einer emotionalen Ebene ansprechen und die über den ÖPNV hinausgehende Mobilität zum positiven „Erlebnis“ machen. Damit stellt diese Stufe nicht nur den Bereich mit der größten horizontalen und vertikalen Angebotsdifferenzierung dar - quasi als höchste Veredelungsstufe der (ÖPNV-) Kernleistung - sondern wird hier auch die größte Kundenorientierung und die höchste Wertschöpfung erreicht (siehe Abbildung 35).

1016 ebd., S.45

1017 vgl. Topp 2006 (a), S.25f 


\section{Wertschöpfung durch Kundenorientierung}

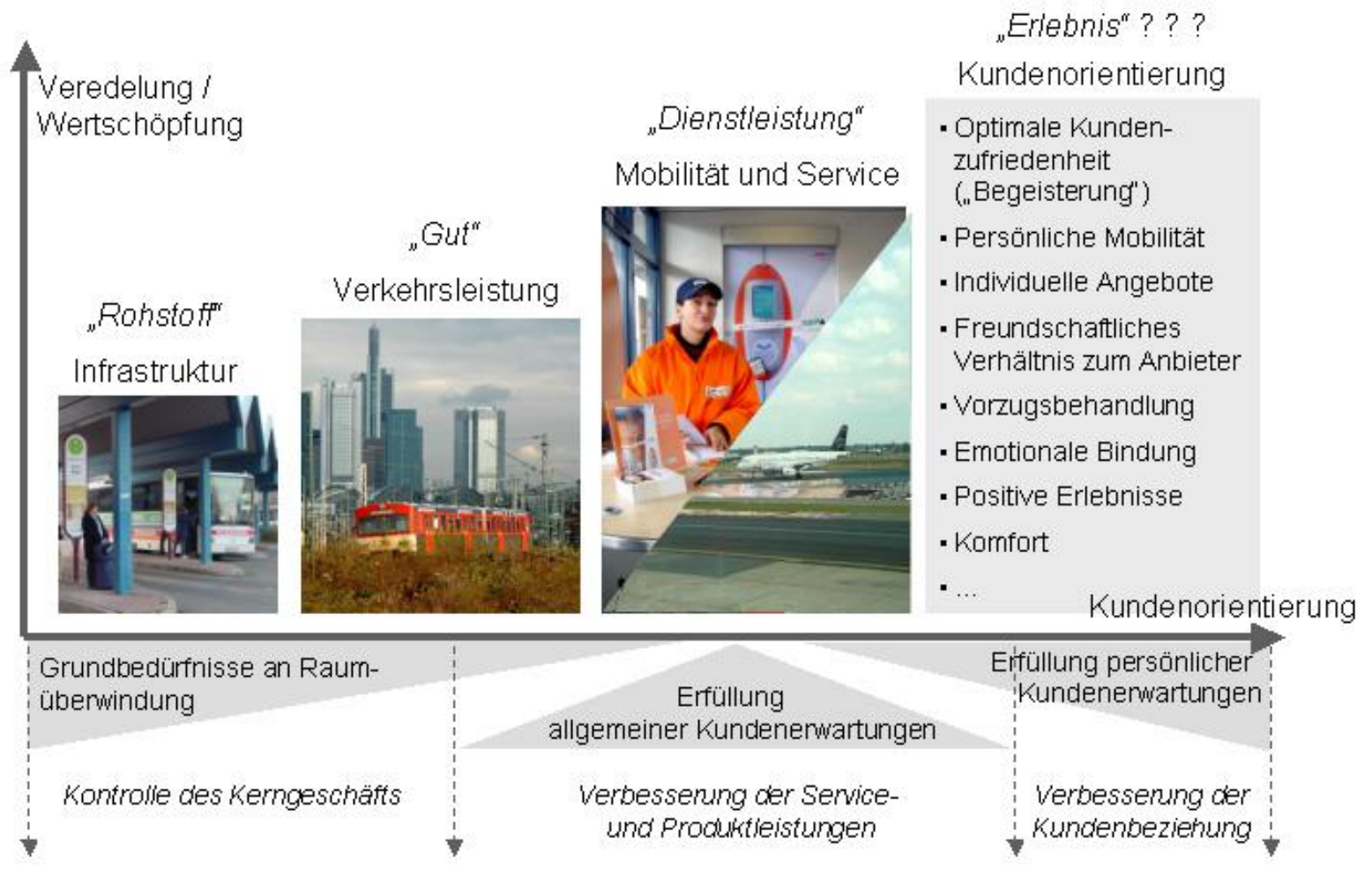

Abbildung 35: Wertschöpfung durch Kundenorientierung im ÖPNV

Quelle: Eigene Bearbeitung, in Anlehnung an Meyer 2005, S.38 und UITP 2003 unter Verwendung eigener Fotos

Laut Delphi-Studie zur Zukunft des ÖPNV stimmen mehr als die Hälfte aller Befragten aus ÖPNV-Unternehmen der These zu, dass das vorherrschende Qualitätsverständnis im ÖPNV eher techniklastig als kundenorientiert sei. Darüber hinaus gestehen fast $90 \%$ der Befragten ein, dass ÖPNV-Unternehmen und Kunden nicht das selbe Qualitätsverständnis haben. ${ }^{1018}$ Durch den Niederschlag dieser - die entscheidungsrelevanten Faktoren des Verkehrsmarktes oftmals vernachlässigenden - Selbsteinschätzung der ÖPNV-Entscheidungsträger in unternehmens- und verbandseigenen Werbekampagnen werden die rein rational verfassten und verhaltensmaßregelnde Botschaften auch in den Markt getragen. In Verbindung mit unflexiblen Angeboten, als zu teuer empfundenen Leistungen und einer geringen Kundenorientierung mit teilweise schlechtem Kundenservice schneidet die öffentliche Verkehrsbranche daher bei Studien und Markterhebungen zur Kundenbewertung regelmäßig als Schlusslicht ab. In einer Marktstudie der Unternehmensberatung

1018 vgl. Deutsches Verkehrsforum 2005, S.59 
Marketing Corporation belegten die öffentlichen Verkehrsmittel nach Schulnoten bewertet mit 3,9 - zusammen mit der Telekommunikation - den letzten Platz. ${ }^{1019}$

Es gibt also einen akuten Handlungsbedarf, über den Ausbau der Kernkompetenz, mit attraktiven Angeboten und emotionaler Kundenansprache die Kundenorientierung und somit das Image des ÖPNV zu steigern. Dabei darf es nicht darum gehen, die Konkurrenz schlecht zu machen (siehe Kapitel 6.1.5.). Vielmehr sollen die spezifischen Vorteile eines jeden Verkehrsmittels hinsichtlich räumlicher und zeitlicher Erfordernisse herausgestellt werden und über zeitgemäße Produkte und Vertriebswege eine Verknüpfung (Stichworte Zusatzleistungen und „cross-selling“) zu zusätzlichen Leistungen und Services aus dem Mobilitätsbereich aufgebaut werden, die auf ein emotional begründetes Wahlverhalten zugunsten des ÖPNV abzielen.

Im günstigsten Fall entsteht so Multimodalität, die ohne Brüche in der Wegekette auskommt. Dies verlangt aus Sicht des ÖPNV eine Unvoreingenommenheit und Objektivität gegenüber dem Verkehrsmittel "Auto“ sowie der selbstkritischen Erkenntnis, dass der ÖPNV eine Reihe von Defiziten aufweist. Hierfür ist allerdings nicht alleine ingenieurswissenschaftliches, sondern auch umfangreiches wirtschafts- und sozialwissenschaftliches Wissen über die Funktionsprinzipien des Verkehrsmarktes notwendig. Insbesondere im psychologischen Bereich, der die emotionalen Faktoren der Verkehrsmittelwahl betrifft, hinkt der ÖPNV hinter der Automobilbranche Jahre hinterher. Schließlich bedarf es zur Erreichung einer verbesserten Kundenorientierung geeigneter Instrumentarien, den Erkenntnisgewinn auch in Form neuer Angebote, Produkte, Kommunikationsstrategien etc. am Markt zu platzieren, offensiv zu vermarkten und messbare, finanzielle Erfolge zu realisieren.

\subsubsection{Kundenbeziehungsmanagement}

Homburg und Krohmer beschreiben die Bedeutung der Kundenbeziehung für das Marketing:

„Parallel zur Betonung der marktorientierten Unternehmensführung rückte die Kundenperspektive als Betrachtungsobjekt stärker in den Mittelpunkt. Kern dieser Perspektive ist

1019 vgl. Marketing Corporation 2005 
das Verständnis, dass der Aufbau und die Erhaltung langfristiger (für den Anbieter profitabler) Kundenbeziehungen eine zentrale Herausforderung des Marketing darstellt“. 1020

Anwendungen aus dem Bereich des Kundenbeziehungsmanagements („Customer Relationship Management“, CRM) haben sich als Bestandteile von betriebswirtschaftlich orientierten Konzepten in den letzten Jahren für viele private Unternehmen zu einem zentralen Geschäfts- und Managementinstrument entwickelt. Generell wird CRM als Ansatz verstanden, durch ein systematisches Management der existierenden Kundenbeziehungen die Kunden langfristig an ein Unternehmen zu binden und Kunden- sowie Unternehmenswert zu steigern. Dabei spielt die Erkenntnis eine wesentliche Rolle, dass es günstiger ist einen Kunden zu halten als einen neuen zu gewinnen.1021 CRM beschreibt dabei nicht nur ein bestimmtes Verfahren, sondern ein Bündel maßnahmenbezogener und nachfrageorientierter Maßnahmen, die es speziell für jedes einzelne Unternehmen zusammenzustellen gilt.

Dieser Ansatz der Strategieentwicklung besteht in der zielgerichteten Festlegung und Steuerung eines markt- und kundenorientierten Geschäftsplanes. Von daher wird CRM auch als unternehmensinternes Marketinginstrument zur Optimierung marktbezogener Aktivitäten verstanden (siehe Kapitel 7.6.4.1). Im Prinzip handelt es sich dabei um einen kontinuierlichen Kreislauf, im Rahmen dessen die Methoden und Modelle der Marktbearbeitung immer weiter verbessert werden. Die Stationen dieses Kreislaufs sind die Analyse des Marktes und die Definition von Zielgruppen bzw. die Marktsegmentierung, die Entwicklung von geeigneten Konzepten und Kampagnen, die Reaktionserfassung und Erfolgsauswertung sowie die erneute Analyse und das Ableiten von Verbesserungen, beispielsweise über die Optimierung der Vertriebsprozesse oder das Management von Marketingkampagnen. Auf Unternehmensebene schafft CRM damit erst die Voraussetzungen, dass der Markt in effektiver und effizienter Weise kundenorientiert bearbeitet werden kann. ${ }^{1022}$

Aufbauend auf einer umfassenden und verlässlichen Datenbank mit allen verfügbaren Kundendaten und relevanten Informationen über die Historie der Kundenbeziehung, insbesondere Bestellungen, Beschwerden und sonstige Kontakte, ist es das Ziel, Wissen über den Nachfragermarkt zu generieren und hieraus Mehrwert zu schöpfen. Da hierfür

\footnotetext{
1020 Homburg und Krohmer 2003, S.9

1021 vgl. Sterzenbach 2001, S.147

1022 vgl. Homburg und Krohmer 2003, S.11
} 
systemtechnische Voraussetzungen vorliegen müssen, wird die Anwendung durch technische und ökonomische Rahmenbedingungen begrenzt. Wesentlich ist, dass technische Möglichkeiten in ökonomisch sinnvolle Handlungen überführt werden bzw. ökonomische Anforderungen in Prozesse übersetzt werden, die technisch und analytisch handhabbar und abbildbar sind. Die Einführung eines CRM-Systems soll unter der Maßgabe der konsequenten gesamtheitlichen Ausrichtung eines Unternehmens auf den Kunden bzw. die Kundenprozesse erfolgen. Die Einführung von CRM - insbesondere im ÖPNV bedeutet gleichzeitig die Initiierung eines strategischen Organisationsentwicklungs- respektive Veränderungsprozesses und steht damit im Kontext eines organisatorischen Managementinstruments.

Da es im ÖPNV, wie im gesamten öffentlichen Bereich, weder „klassische Kunden“ noch „klassische Wettbewerber“ gibt, scheint ein CRM-Konzept auf den ersten Blick nicht relevant zu sein. Bislang wurde die Beziehung zwischen dem ÖPNV-Anbieter und den Kunden häufig zweck- oder sogar zwangsorientiert gesehen, weshalb sich die Frage nach Sinn und Ziel eines Kundenbeziehungsmanagements im öffentlichen Bereich gar nicht oder bestenfalls anders stellte. Dass das Thema CRM im öffentlichen Umfeld (bspw. in der öffentlichen Verwaltung) aber dennoch von hoher praktischer Relevanz ist, zeigt die fortschreitende Veränderung des gesellschaftlichen, politischen und bürgerbezogenen Dienstleistungsumfeldes. ${ }^{1023}$ So hat der gestiegene Kommunikations- und Informationsbedarf der Menschen und die geänderten Kundenpräferenzen auch Auswirkungen auf das Nachfrageverhalten im ÖPNV.

Zusätzlich bringt die Trennung von Aufgaben nach dem Besteller-Ersteller-Prinzip unter veränderten Finanzierungsbedingungen neue Aufgaben und Herausforderungen für ÖPNV-Aufgabenträger und Verkehrsunternehmen mit sich (siehe Kapitel 6.4.2), die es erforderlich machen, dass die Planung, Erbringung und die Vermarktung der Verkehrsleistung in einer strikte(re)n betriebswirtschaftlichen Weise zu erfolgen hat. Eine ganzheitliche CRM-Strategie soll in diesem Zusammenhang eine effektive Prozessabwicklung, besseren Service und bessere Betreuung für die Kunden unterstützen.

${ }^{1023}$ Der sich langsam durchsetzende Dienstleistungsgedanke im öffentlichen Raum wird in angloamerikanischen Ländern, wo dieser Trend bereits weiter vorangeschritten ist, auch als New Public Management (NPM) bezeichnet. 
Zwar wird auch zukünftig den Marketingsegmenten Produkt- und Preispolitik nach wie vor eine hohe Bedeutung zukommen. ${ }^{1024}$ Vor dem Hintergrund der Positionierung von Verkehrsunternehmen und -verbünden als Mobilitätsdienstleister wird aber die Beherrschung von Serviceprozessen bei den angebotenen Vertriebs- und Kommunikationskanälen immer wichtiger. Die Prozesswahrnehmung jedes Kunden ist hierbei unterschiedlich und individuell. Während der ÖPNV-erfahrene Kunde eine schnelle Abwicklung von Routinetätigkeiten erwartet, sucht der traditionell orientierte oder unsichere Kunde relevante Hilfestellungen und Unterstützung. CRM ermöglicht hier eine zielgruppenspezifische Kommunikation die zu einer höheren Kundenzufriedenheit und einem Imagegewinn führen soll.

In der wirtschaftlichen Bewertung ist der langfristig zu erzielende Deckungsbeitrag für die Optimierung der Kundenbeziehung entscheidend. Deshalb muss in erster Linie die Qualität der Kundenbearbeitung erhöht werden, z.B. durch eine konsequente Ausrichtung an kundenorientierten Zielen wie eben die Kundenzufriedenheit oder durch gezielte Informationsversorgung der Vertriebsmitarbeiter. CRM bedeutet daher keine Rationalisierung der Kundenbetreuung, sondern eine Investition in die Kundenbeziehung.

Der Erfolg eines CRM-Konzeptes für den ÖPNV hängt in erster Linie von der Zielformulierung für die Implementierung eines CRM-Systems ab. Damit hängt auch die Ausformulierung von Umfang und Stufen eines CRM-Ansatzes zusammen. Für den RMV bietet sich zunächst die Einführung eines analytischen CRM-Systems an, bei der es um die Generierung von Wissen über das Kundenverhalten geht. Dieses Wissen stellt die Basis für den Einsatz der gewonnenen Information im Kontakt mit dem Kunden dar (operatives CRM) sowie schließlich die darauf abgestimmte Synchronisation der Kommunikationsund Vertriebskanäle (kollaboratives CRM). ${ }^{1025}$

Die notwendige Einbeziehung aller Vertriebsakteure sowie der Vertriebsverantwortlichen macht die organisatorische Herausforderung, die die Einführung von CRM bedeutet, deutlich. Um die durchgängig einheitliche und auf der selben Datenbasis basierenden Kundenbetreuung zu gewährleisten, müssen verbundweit nicht nur alle Partner an einem Informationssystem angeschlossen sein, sondern auch Arbeitsabläufe im Rahmen der Vermarktungsaktivitäten synchronisiert werden. Dieses betrifft Prozesse in allen Abtei-

1024 vgl. Sterzenbach 2001, S.45

1025 vgl. Bretzger und Ebbing 2005, S.8 
lungen eines Unternehmens wie auch die Prozesse in technischen Systemen. ${ }^{1026}$ Aufgrund der gewachsenen Strukturen bei sowohl Aufgabenträgern und Verkehrsunternehmen ist zu bedenken, dass ein erforderliches Änderungs-Management in der Managementebene nicht ohne weiteres wie in der Privatwirtschaft umzusetzen ist, was ein schrittweises Vorgehen rechtfertigt.

\subsubsection{Messung der Kundenorientierung}

Die Qualität der Leistungserbringung spielt aus allgemeiner ÖPNV-Sicht im intermodalen Wettbewerbsverhältnis, insbesondere zum MIV, wie auch aus Unternehmenssicht im Wettbewerb mit anderen Leistungserstellern eine Rolle. Die Aufgabenträger sind vor allem an der Quantität und Qualität des Angebots interessiert, die das Verkehrsunternehmen im Rahmen der vertraglichen Vereinbarungen gegenüber den Kunden zu erbringen hat. Das Wissen über die Qualität der erbrachten Leistung und der Grad der Kundenzufriedenheit sind bei der Überwachung der Einhaltung von Qualitätsvorgaben im Rahmen von Bruttoanreiz- und Nettoverträgen besonders wichtig. Hier bedarf es aufgabenträgerseitig der Aneignung umfassender Kompetenzen im Bereich des Qualitätsmanagements, welches an den Kundenbedürfnissen ausgerichtet ist und die Kundenerwartungen mit den Eigenschaften der angebotenen Produkte vergleicht (siehe Kapitel 6.4.2). ${ }^{1027}$ Hierbei sind nach wie vor betriebswirtschaftliche Aspekte von Relevanz: So ist der Auslastungsgrad beispielsweise ein Indikator für die Kundenakzeptanz eines Angebots oder ist ein optimaler (störungsarmer) Betriebsablauf die Voraussetzung für zufriedene Kunden. ${ }^{1028}$

Damit die Qualität der ÖPNV-Leistung messbar und vergleichbar wird, müssen die Leistungsmerkmale des Angebots quantifizierbar sein. Wie in anderen Branchen auch, können im ÖPNV Kennziffern zu harten und weichen Qualitätsmerkmalen unterschieden werden. Harte Merkmale können objektiv gemessen werden, weiche Merkmale werden dagegen subjektiv bewertet. Das Deutsche Institut für Urbanistik bewertet die Bedeutung harter Qualitätsmerkmale im ÖPNV wie folgt:

„Harte Qualitätsmerkmale sind vor allem Pünktlichkeit, Platzangebot, Fahrtenausfälle und Qualifikation der Fahrer. [...] Harte Qualitätsmerkmale eignen sich daher gut für Bonus- und Malusregelungen bei Anreizverträgen. Sie haben zentrale Bedeutung für die

\footnotetext{
${ }^{1026}$ vgl. Homburg und Krohmer 2006, S.1100f

1027 vgl. Anreiter und Schaaffkamp 2006, S.27ff

1028 vgl. Deutsches Institut für Urbanistik 2005, S.30
} 
Qualität der Leistung, handelt es sich hierbei doch um Basisanforderungen an das ÖPNVAngebot. Nachteil ist, dass ihre Festlegungen oft in abstrakter Form erfolgen und der direkte Bezug zum Kundennutzen nicht immer erkennbar ist“. ${ }^{1029}$

Von daher ist es wünschenswert, harte Merkmale erheben zu können, die zuallererst Auskunft über die Nachfrage geben, insbesondere die Anzahl beförderter Kunden oder die Auslastung. Bislang werden in den Unternehmen „harte“ betriebsleistungsorientierte Daten erfasst (Fahrplankilometer, Wagenkilometer, Platzkilometer, Fahrplanstunden, Wagenstunden). Verkehrsleistungsorientierte Daten (v.a. beförderte Personen), die eine nachfragegerechte Planung und Einnahmeaufteilung ermöglichen, müssen jeweils sehr aufwändig durch umfangreiche (kostenintensive) Stichprobenverfahren (im RMV 1997 und 2004) erhoben werden. Dies geschieht bislang über manuelle und personalintensive Zählverfahren. Die herkömmliche Methode beschränkt sich auf wenige, möglichst repräsentative Stichproben. Die Ergebnisse werden mit Hilfe von statistischen Verfahren auf das Gesamtnetz hochgerechnet. Für die Folgejahre wird die Verkehrsleistung gegebenenfalls in weiteren Hochrechnungen fortgeschrieben, die sich ggf. auf verfügbare Ergänzungsdaten bezieht. Hier sind insbesondere die Verkaufsstatistik und eventuell punktuelle Zählungen von Bedeutung. Da die manuellen Zählverfahren sehr kostenintensiv sind, werden Vollerhebungen nur in sehr großen zeitlichen Abständen durchgeführt, bzw. in vielen Regionen gar nicht. Zudem wird sich bei der Erhebung und Analyse dieser Daten auf die wesentlichen Analysefelder konzentriert. ${ }^{1030}$ Außerdem macht der Einsatz von umfangreichem Zählpersonal und die mehrfachen Hochrechnungsverfahren das manuelle Zählverfahren insgesamt fehleranfällig.

Weiche Qualitätsmerkmale beziehen sich zum Beispiel auf die Freundlichkeit des Serviceund Fahrpersonals, das subjektive Sicherheitsempfinden, die Service- und Aufenthaltsqualität (Sauberkeit) sowie den empfundenen Komfort an Haltestellen und in Fahrzeugen. Da diese Merkmale subjektiver Natur sind, können sie nur schlecht gemessen werden. Geeignete Erhebungsverfahren sind daher Kundenbefragungen, Beobachtungen oder Umfragen unter Mitarbeitern. Weiche Merkmale spiegeln in direkterem Maße die Fahrgastbelange und damit auch die Kundenzufriedenheit wider. ${ }^{1031}$

1029 Deutsches Institut für Urbanistik 2005, S.30f

1030 vgl. Becker, T. 2004, S.117ff

1031 vgl. Deutsches Institut für Urbanistik 2005, S.31 
Seit dem Jahr 2002 gibt es eine Europäische Norm (EN 13816) über die Definition und Festlegung von Leistungszielen sowie zur Messung der Servicequalität im ÖPNV. Einerseits soll mit ihr die Kundenzufriedenheit - als Differenz zwischen der vom Kunden erwarteten und wahrgenommenen Qualität - gemessen werden. Andererseits soll sie Auskunft geben über die Qualität der Dienstleistung - als Differenz zwischen angestrebter und erbrachter Qualität. ${ }^{1032}$ Gemessen wird die Qualität in drei übergeordneten Ebenen: Bedienungsqualität (Verfügbarkeit, Zugänglichkeit), Beförderungsqualität (Information, Zeit, Kundenbetreuung, Komfort, Sicherheit) und Umwelteinflüsse. Damit werden sowohl harte wie auch weiche Kriterien adressiert. Je nach Kriterium kommen unterschiedliche Mess- und Steuerverfahren zum Einsatz. Die Norm sieht Kundenzufriedenheitsmessungen, Testkundenverfahren und direkte Leistungsmessungen vor. „Daneben existieren weitere Messmethoden, in denen in unterschiedlicher Form die Erfahrungen und der Nutzen von Kunden Eingang finden“1033, die allerdings in ihrer Anwendung - außerhalb von Forschungsprojekten - in der ÖPNV-Branche kaum bekannt sind. ${ }^{1034}$ Blümel warnt allerdings davor, dass der Standard nicht dazu verwandt werden darf, einen nach messbaren Kriterien genormten Verkehr zu möglichst geringen Kosten durchzuführen“. Vielmehr sollte es das Unternehmensziel sein, tatsächlich die Kundenwünsche besser zu bedienen. 1035

Für die Messung der für die Kundenzufriedenheit relevanten Faktoren bieten sich Kennzahlensysteme („Scorecards“) an, die betriebswirtschaftliche Einflussgrößen erfassen, in Beziehung zueinander setzen und so Auskunft über die Leistungsfähigkeit eines Unternehmens geben. An dieser Stelle soll die Verwendung der bereits erwähnten „BalancedScorecard“ kurz exemplarisch dargestellt werden. Dabei ist die BSC kein klassisches Kennzahlensystem, sondern ein Steuerungsinstrument, das über Messgrößen Auskunft über die Erreichung von Unternehmenszielen gibt. Hemmersbach, Roß und Deckmann beschreiben die BSC wie folgt:

\footnotetext{
1032 Diese Einteilung orientiert sich am „Dienstleistungsqualitätskreis“, bei der die gemessene Zufriedenheit sowie die gemessene Leistung die angestrebte, erbrachte, wahrgenommene und schließlich erwartete Dienstleistungsqualität beeinflussen; vgl. Blümel 2004, S.34, Deutsches Institut für Urbanistik 2005, S.32f, Umweltbundesamt 2003 (a) S.28 sowie Anreiter und Schaaffkamp 2006, S.31.

1033 vgl. Deutsches Institut für Urbanistik 2005, S.32f

1034 vgl. Blümel 2004, S.35

1035 Blümel 2004, S.38
} 
"Die BSC ist ein strategisches Managementinstrumentarium, das dem Unternehmen hilft, Strategien systematisch zu konkretisieren sowie wirkungsvoll in Aktion zu überführen und somit in die Organisation zu tragen. Die BSC schließt somit die Lücke zwischen Strategiefindung und ihrer operativen Umsetzung und wird damit zum entscheidenden Erfolgsfaktor auf dem Weg zu einer höheren Wettbewerbsfähigkeit und der Erschließung neuer Geschäftsfelder". 1036

Durch die Berücksichtigung anderer Perspektiven (siehe Kapitel 6.4.3) als ausschließlich der Finanzperspektive, wird das Blickfeld der Unternehmensführung dabei auch auf andere relevante Bereiche - des Unternehmens selbst wie auch des Marktes - gelenkt und ein ausgewogenes („,balanced“) Bild vermittelt.

Bezogen auf die Positionierung der Verkehrsunternehmen und Aufgabenträger als Mobilitätsdienstleister können die strategischen Ziele zwar einzelnen Perspektiven zugeordnet werden. Sinn einer BSC ist es jedoch, zu jeder Perspektive konkrete Ziele zu formulieren, die sich wiederum einem übergeordneten Ziel („Dach-Scorecard“) unterordnen. „Konkret“ heißt in diesem Zusammenhang, dass das Ziel messbar und mit Maßnahmen unterlegt sein muss. Gleichzeitig dienen die übergeordneten Ziele auf erster Ebene als spezifische Ziele für die unterschiedlichen Unternehmensbereiche, es entsteht also ein Hierarchiesystem von Zielen. Die zu erreichenden Zielwerte können über ein WettbewerberBenchmarking im Vergleich zu konkurrierenden (privaten) Unternehmen oder über ein externes Benchmarking im Vergleich mit Unternehmen anderer Branchen ermittelt werden (siehe Kapitel 6.2.3), bei denen Kundenorientierung unter Wettbewerbsbedingungen bereits länger von Bedeutung ist. Die Beurteilung durch die Kunden gibt dabei zunächst einmal Auskunft über die wahrgenommenen relativen Stärken und Schwächen eines Unternehmens. Erst der Leistungsvergleich mit anderen Unternehmen macht den tatsächlichen Handlungsbedarf absolut transparent. Schließlich kann überprüft werden, inwieweit Maßnahmen anderer Unternehmen adaptiert werden können. ${ }^{1037}$

Die Dresdner Verkehrsbetriebe (DVB) haben als eines der ersten Verkehrsunternehmen in Deutschland mit der Anwendung der BSC - in Verbindung mit der Dezentralisierung von Verantwortlichkeiten - Erfahrung gesammelt. Die DVB setzte bei ihrer BSC ebenfalls vier

1036 Hemmersbach, Roß und Deckmann 2002, S.62

1037 vgl. Rother und Vitt 1999, S.261ff 
unterschiedliche Perspektiven zugrunde, die vor dem Hintergrund des Markt- und Wettbewerbsumfeldes als relevant eingestuft werden:

- Wirtschaft/ Finanzen

- Kunde/Markt

- Qualität/ Prozesse

- Mitarbeiter

Entsprechend dieser Unterteilung wurden für die einzelnen Unternehmensbereiche Unterziele definiert, Maßnahmen abgeleitet, Messgrößen identifiziert und Zielwerte bestimmt. Bei kontinuierlichem Einsatz stellt die BSC „für die DVB AG ein integratives Navigationssystem dar, das die Aufmerksamkeit auf die wesentlichen Perspektiven lenkt und dadurch die Datenflut auf eine begrenzte Zahl von Mess- und Steuerungsgrößen reduziert" ${ }^{\prime \prime} 1038$ Es geht also keineswegs darum, ein möglichst dichtes Messnetz aufzubauen und möglichst viele Daten zu erheben. Gerade bei ÖPNV-Unternehmen, die noch ein großes Rationalisierungspotenzial aufweisen, genügt anfänglich die Konzentration auf ein vergleichsweise einfaches Kennzahlenset, um das Drehen an den "großen Schrauben“ zu ermöglichen. So ist eine der wichtigsten Kennzahlen der Finanzperspektive die Entwicklung des Kostensatzes pro Kilometer. Mit der Entwicklung des Unternehmens muss das Kennzahlenset dann den veränderten Zielhierarchien angepasst werden ${ }^{1039}$ Bei der DVB hat die „BSC-Erstellung [...] die Auseinandersetzung nicht nur mit der eigenen strategischen Positionierung, sondern auch mit den Interdependenzen zu anderen Bereichen einen wertvollen Beitrag zur Identifikation mit der Unternehmensstrategie der DVB geführt". ${ }^{1040}$

\subsubsection{Controlling und Berichterstattung}

Die Organisation der meisten kommunalen Verkehrsunternehmen orientierte sich bislang an der behördlichen Verwaltung. Die so entstandenen Strukturen genügen im Hinblick auf Effizienz und Effektivität kaum den Wettbewerbsanforderungen des Marktes, insbesondere in bezug auf Kostenwirksamkeit und erreichbare Qualitäten. Restrukturierungsprogramme können dazu führen, dass die Verkehrsunternehmen stärker nach betriebs-

1038 Hemmersbach, Roß und Deckmann 2002, S.63

1039 vgl. Becker, T. 2004, S.131ff

1040 Hemmersbach, Roß und Deckmann 2002, S.63 
wirtschaftlichen Gesichtspunkten organisiert werden und über ein effektives Controlling und Reporting mehr Transparenz über die eigene Leistungsfähigkeit geschaffen wird und ein „den tatsächlichen Verhältnissen entsprechendes Bild der Vermögens-, Finanz- und Ertragslage des Unternehmens“ 1041 geschaffen wird. Wesentlichen Einfluss hat in diesem Zusammenhang auch die Art und Weise der Finanzbuchhaltung im Verkehrsunternehmen. Hierüber sollen notwendige Informationen für die Bereiche Planung, Steuerung und Kontrolle abgeleitet werden, die Auskunft zu Kennziffern der Effizienz geben, wie beispielsweise die Eigenkapitalquote, die Gewinngröße oder den Kapitalfaktor im Verhältnis zur Gewinngröße.

Bislang war in den Eigenbetrieben der öffentlichen Hand die Kameralistik das „Steuerungsinstrument" (Verbuchungsmethode), die nur Einnahmen und Ausgaben aufzeichnete. Sie diente zur Feststellung, inwieweit Haushaltsansätze eingehalten und finanzielle Spielräume („Töpfe“) ausgeschöpft wurden bzw. finanzielle Mittel noch zur Verfügung standen. Kennzeichen dieser traditionellen Finanzbuchhaltung ist es, dass sie vor allem über vergangene Leistungen berichtet und keine Aussagen über die zukünftige finanzielle oder auch ökologische oder soziale Leistungsfähigkeit macht. ${ }^{1042}$

Dieses Ausschöpfen von Mitteln ohne (ganzheitlichen) Ansatz förderte Verhaltensweisen, die über die Jahre wesentlich zur Kostensteigerung beitrugen. Darüber hinaus zeichnet sich die Kameralistik durch ihre systembedingte Vernachlässigung nicht zahlungswirksamer Kosten aus und verhindert realistische Kostenanalysen. So werden im wesentlichen nur Einnahmen und Ausgaben in dokumentarischer Form als getrennte Kostenblöcke verbucht; ein Zusammenhang zwischen Mittelherkunft und -verwendung besteht nicht und kostenträgerbezogene Auswertungen über die Mittelverwendung sind nicht möglich. Insgesamt können damit keine rationalen kostenbasierten Entscheidungen über privatwirtschaftliche Alternativen (Leasing oder Kauf, Eigenfertigung oder Fremdbezug) mit haushaltsentlastenden Effekten getroffen werden. Letztendlich bleibt die Kameralistik auch die Vermögensüberstellung über definierte Zeiträume (Kalenderjahr, Wirtschaftsjahr) schuldig, woraus sich erst ein umfassendes Bild der finanziellen Entwicklung eines Unternehmens im Hinblick auf Vermögens-, Finanz- und Ertragslage ergibt.

1041 Regierungskommission Deutscher Governance Kodex 2006, S.2

1042 vgl. UITP 2005, S.35 
In Hessen wird in den kommunalen Verwaltungen seit 1997 die Ablösung der Kameralistik durch das doppelte Rechnungswesen betrieben. Bis spätestens 2009 müssen alle hessischen Kommunen ihre Buchhaltung auf die „Doppelte Buchführung in Konten Soll und Haben“ (Doppik) umgestellt haben. Die kaufmännische Buchführung berücksichtigt den Ressourcenverbrauch und umfasst eine Bilanz-, Gewinn- und Verlustrechnung, was mehr Transparenz im Hinblick auf Vermögen und Kosten schaffen soll. ${ }^{1043}$ Durch die "Ganzheitliche Betrachtung“ der modernen Betriebsführung sind die sich hieraus ergebenden Kontrollinstrumente des Controllings umfassend anwendbar und können zur effizienten Verwendung von Betriebsmitteln und Vermögen eingesetzt werden. So tauchen Vermögenswerte nicht nur im Jahr ihrer Anschaffung auf, sondern wird der aktuelle Wert über Jahre abgeschrieben. Unabhängig hiervon ist weiterhin eine Haushaltsrechnung möglich und sinnvoll, da hiermit der durch den Haushaltsplan dokumentierte Zuschuss aus Steuermitteln zur Leistungserbringung des Unternehmens im Einzelfall dokumentiert werden kann. Gleichzeitig ist eine sinnvolle, durch die Aufstellung des Haushalts gegebene Budgetierung des folgenden Wirtschaftsjahrs (Kalenderjahr) möglich. Hiermit verbunden ist die Ermächtigung an die Geschäftsführung zur durch das Budget begrenzten Ausgabe und der damit gegebenen Kontrollmöglichkeit der Revision (Rechnungshof, Rechnungsstellen der öffentlichen Hand).

Insgesamt ist zu erwarten, dass vor dem Hintergrund der Wettbewerbssituation (siehe Kapitel 5.3) die Einführung der Doppik auch in den kommunalen Verkehrsunternehmen die Grundlagen für eine stärkere betriebswirtschaftlich ausgerichtete Betrachtung der Mittelverwendung und damit ein effizienter Mitteleinsatz unterstützt werden. Bei der Restrukturierung eines Unternehmens ist - zusätzlich zum Bereich des internen Rechnungswesens - die Einführung eines effektiven Controllings im Unternehmen ein wichtiger Schritt. Als zentrales Planungs- und Kontrollinstrumentarium zur Ergebnisoptimierung hat das Controlling die Funktion eine zielgerichtete Abstimmung zwischen den unterschiedlichen Unternehmensbereichen sicherzustellen. Vor allem berät und unterstützt das Controlling die Führung des Unternehmens, wodurch der (Kommunikations-) Schnittstelle zwischen dem Management und dem Controlling eine wesentliche Bedeutung zukommt. Schließlich gilt es praktikable Umsetzungsmaßnahmen aus den unternehmensstrategischen Zielen abzuleiten und sich nicht mit theoretischen Planspielen zu

${ }^{1043}$ vgl. Wiesbadener Kurier v. 25.1.07, S.15 
beschäftigen. Die Problemlage muss genau erfasst sein und realisierbare Maßnahmen in Richtung eines definierten zukünftigen Zielzustandes aufgezeigt werden. Der momentane Zustand sollte möglichst objektiv erfasst werden und Interventionen zeitnah erfolgen können. Für die Ableitung von Lösungen sind aussagekräftige Kennzahlen die Basis, die nach Möglichkeit fortlaufend generiert werden sollten (beispielsweise über die Anwendung einer BSC, siehe Kapitel 6.4.4.5). Letztlich sind diese Zahlen die Grundlage für eine transparente und glaubwürdige Berichterstattung, die wiederum eine wesentliche Voraussetzung für den Zugang zu neuem Kapital und neuen Finanzierungsmöglichkeiten ist (siehe Kapitel 6.4.2).

\subsection{Marketing-Instrumentarien}

Wie bereits in Kapitel 6.2.2 dargestellt, stellen die Marketing-Instrumentarien die zentralen Hebel zur Verbesserung der Fahrgeldeinnahmen dar. Der Bedeutungszuwachs für Marketingaufgaben geht einher mit der notwendigen Schwerpunktverlagerung der ÖPNV-Finanzierung auf eine höhere Nutzerfinanzierung. Diese Schwerpunktverlagerung ist in der marktorientierten strategischen Positionierung der $R M V G m b H$, der Lokalen Nahverkehrsorganisationen sowie der Verkehrsunternehmen als „Mobilitätsdienstleister für die Region“ nachzuvollziehen. Diese strategische Ausrichtung sieht vor, dass über einen gezielten und ausgewogenen Einsatz der unterschiedlichen Marketinginstrumentarien, zeitnahe marktbezogene Aktivitäten "gegenüber Nachfragern oder potentiellen Nachfragern“ konzipiert und umgesetzt werden. Dieses beinhaltet sowohl die systematische Informationsgewinnung sowie die "Gestaltung des Produktangebots, die Preissetzung, die Kommunikation und den Vertrieb“. ${ }^{1044}$

\subsubsection{Der Marketing-Mix im ÖPNV}

Die grundsätzliche und notwendige Voraussetzung für die Generierung von mehr Fahrgeldeinnahmen ist, dass die wichtigste Marktleistung des ÖPNV, also die Beförderung vom Ausgangsort zum Ziel, den Marktbedürfnissen und Kundenansprüchen voll entspricht. Sie ist die Kernleistung, für die der Kunde in erster Linie sein Geld ausgibt. Alle anderen Leistungen können als Nebenleistungen hierzu begriffen werden. Das bedeutet, dass eine schlechte Beförderungsleistung dazu führt, dass auch alle anderen Marketing-

${ }^{1044}$ vgl. Homburg und Krohmer 2003, S.10f. 
Maßnahmen, beispielsweise image- oder informationsfördernde Aktivitäten, ins Leere laufen bzw. nicht zur Kundenzufriedenheit beitragen und damit auch die Nachfrage nicht steigern. ${ }^{1045}$

Die Höhe der Fahrgeldeinnahmen ergibt sich aus dem Zusammenspiel von Preis und Angebot einerseits sowie Absatz und Nachfrage andererseits. Neben der Qualität und der Verfügbarkeit des Angebots ist das Wissen des Kunden über das Angebot ausschlaggebend. Hieraus ergibt sich, dass die Fahrgeldeinnahmen über Instrumente des Marketingmixes entscheidend beeinflusst werden können. Im Bereich der Dienstleistungen wird in der Regel die klassische betriebswirtschaftliche Einteilung in die vier Marketing-„„P's“ angewendet: 1046

- $\quad$ Product $=$ Produkt

- Price $=$ Preis, Tarif

- $\quad$ Placement $=$ Vertrieb, Distribution

- $\quad$ Promotion $=$ Kommunikation, Positionierung

Aufgrund der Bedeutung, den der Beförderungsprozess auf die Nachfrage hat, wird mit dem Bereich der „Prozesspolitik“ gelegentlich ein fünfter Bereich für den ÖPNV ergänzt. Hierbei handelt es sich um die Prozesse und Abläufe, die direkt mit der Erstellung der Beförderungsleistung als Kernleistung zu tun haben.1047 Die Prozesspolitik ist daher als Auskopplung aus der Produktpolitik zu verstehen. Durch die enge Verknüpfung bzw. Wahrnehmung der Qualität der Leistung (Prozesspolitik) und des Angebots (Produktpolitik) durch den Kunden scheint eine weitere Untergliederung in ÖPNV- oder dienstleistungsspezifische Segmente ${ }^{1048}$ im Rahmen dieser Arbeit nicht notwendig.

Einzig die Personalpolitik ist vor dem Hintergrund der Entstehung von „Mobilitätsdienstleistern“ und einer damit verbundenen stärkeren Kundenorientierung von Interes-

\footnotetext{
$1045 \mathrm{vgl}$. Anreiter und Schaaffkamp 2006, S.28

1046 vgl. Rumpke 2005, S.47

1047 vgl. Sterzenbach 2001, S.43

1048 zur Diskussion um weitere Marketingsegmente siehe u.a. Booms, Bernard H. und Bitner, Mary J.: „Marketing strategies and organization structures for service firms". In: Donnelly, James und George, William R. (Hrsg.): „Marketing of services”. Orlando, Fl 1982 oder Stauss 1987, Bernd: „Grundlagen des Marketing öffentlicher Unternehmen“. Baden-Baden 1987.
} 
se, ${ }^{1049}$ zumal die Marketing- und Vertriebsstrategie direkte Auswirkung auf den Personalbedarf hat. ${ }^{1050}$ So können Personalentwicklungsprogramme helfen, die Akzeptanz von Veränderungsmaßnahmen im Betriebsablauf bei Produktinnovationen zu steigern oder freigesetzte Mitarbeiter für den Einsatz in einem anderen Bereich vorzubereiten. Soweit es sich aber um reine Schulungsmaßnahmen handelt, sind auch diese der internen Kommunikation und damit dem Bereich der Kommunikationspolitik zuzuordnen. Vor dem Hintergrund einer angestrebten Effizienzsteigerung ist ferner von Bedeutung, dass personalbediente Vertriebskanäle gleichzeitig zu den kostenintensivsten gehören.

Bezogen auf den ÖPNV kann festgestellt werden, dass es weder zu einem ausgeglichenen Einsatz der vier klassischen Instrumente kommt ${ }^{1051}$, noch die Marketingaktivitäten in gesamtheitlichen Marketingstrategien eingebettet sind. Kotler geht allgemein von „zwei Fehlannahmen über Marketing“ aus, die daher rühren, dass „Unternehmensführungen [...] vielleicht falsche Vorstellungen davon [haben], was Marketing bewirkt oder bewirken kann“. ${ }^{1052}$ Diese Fehlannahmen, die auch in der ÖPNV-Branche vorhanden sind, sind zum einen die falsche Meinung, dass Marketing gleich Verkauf ist. Richtig ist vielmehr, dass der Verkauf ein Teil des Marketings ist, da Marketingmaßnahmen bereits einsetzen, bevor das Produkt vom Kunden am Markt überhaupt zu erwerben ist. Damit geht die Auffassung einher, Marketingausgaben nicht als Investition, sondern als Kosten zu betrachten. Zum anderen wird Marketing als Aufgabe einer Unternehmensabteilung begriffen. ${ }^{1053}$ Richtig ist jedoch, dass auch die Arbeit anderer Abteilungen wesentlich auf die Kundenakzeptanz einwirkt. Dies betrifft zum Beispiel die Planungsabteilung, wo falsche Abfahrtszeiten oder nicht ausreichende Sitzplatzkapazitäten schnell zur Unzufriedenheit der Kunden führen können. Es ist also nicht alleine Aufgabe der Marketingabteilung Kunden zu gewinnen und zufrieden zu stellen, sondern eine Aufgabe für das gesamte Unternehmen. ${ }^{1054}$ So ist es nicht weiter verwunderlich, dass im ÖPNV die als obligatorisch betrachteten Bereiche Produkt- und Preispolitik dominieren 1055, woraus sich ergibt,

\footnotetext{
1049 vgl. Rumpke 2005, S.47

1050 vgl. Homburg und Krohmer 2003, S.1038

1051 vgl. Sterzenbach 2001, S.52

1052 Kotler 2003, S.35

${ }^{1053}$ Dies trifft auch für den RMV zu, wo der Geschäftsbereich „Marketing“ für die Vertriebs- und Preispolitik zuständig ist. Die Aufgaben Kommunikation und Marktauftritt werden dagegen organisatorisch als Stabsfunktionen behandelt.

1054 vgl. Kotler, S.35ff

1055 vgl. Sterzenbach 2001, S.45
} 
dass hier die Optimierungspotenziale zwar geringer sind als in den Bereichen Vertriebsund Kommunikationspolitik, aber keineswegs schon ausgeschöpft sind.

Zur Einschätzung des Optimierungspotenzials im Marketingbereich bietet es sich an, den Einsatz des Marketingmanagements als Teil des unternehmerischen Konzepts in den Aufgabenträgerorganisationen und Verkehrsunternehmen zu überprüfen. Hierfür kommen grundsätzlich

- ergebnisbezogene,

- einsatzbezogene,

- managementbezogene und

- instrumentenbezogene

Indikatoren in Frage. 1056

Aufgrund des Defizits sowie des eher abträglichen Bildes des ÖPNV in der Öffentlichkeit eignen sich aber ergebnis- wie auch managementbezogene Indikatoren nur bedingt zur Überprüfung. Zumal dem ÖPNV nach wie vor die Aufgabe der Daseinsvorsorge zukommt und sich das Angebot nicht alleine nach Marktbedingungen erstellen lässt. So hängt der erreichbare Kostendeckungsgrad beispielsweise stark von den Raum- und Siedlungsstrukturen und damit von der potenziellen Konkurrenzfähigkeit zum MIV ab. Auch ist die stagnierende Nachfrageentwicklung im starken Maße von externen Faktoren abhängig, wie beispielsweise dem Motorisierungsgrad der Bevölkerung, der allgemeinen Wirtschaftslage oder tariflichen sowie politischen Rahmenvorgaben. Hinsichtlich der Betrachtung der einsatz- und managementbezogenen Verwendung von Marketinginstrumenten, die sich „auf den Mitteleinsatz und die Organisationsstruktur beziehen“ stellt Rumpke fest, dass diese „verhältnismäßig wenig Aussagekraft für die Beurteilung des Marketingverhaltens haben“, da die „Information über Marketingbudgets oder über das Vorhandensein von Marketingabteilungen bei der Beurteilung des Marketingverhaltens nicht weiter[helfen“. ${ }^{1057}$ Als ergebnisbezogenes Maß wäre am ehesten die Kundenzufriedenheit dienlich, würde sich diese ausschließlich auf das Leistungsangebot beziehen. Tatsächlich richtet sich die heutige Unzufriedenheit - auch potenzieller Kunden - vor allem

1056 vgl. Stauss 1987, S.114f

1057 Rumpke 2005, S.17 
gegen pauschale Preiserhöhungen sowie intransparente Tarife und Produkte. ${ }^{1058}$ Eine unmittelbare Bezugnahme auf ergebnisbezogene Indikatoren ist daher nur schwerlich möglich.

Im folgenden wird daher der instrumentenbezogene Einsatz von Mitteln des Marketings im RMV exemplarisch beleuchtet.

\subsubsection{Produktpolitik}

Die Raumüberwindung, d.h. die Beförderungsleistung von "A nach B“, ist das Produkt bzw. das Angebot der ÖPNV-Unternehmen und stellt die Basis ihrer (Kern-)Leistung dar. ${ }^{1059}$ Die Einzelinstrumente der Produktpolitik im ÖPNV sind typische Werkzeuge der Verkehrsplanung. Hierbei geht es vor allem um die Angebotsgestaltung der Beförderungsleistung als Kernkompetenz der Verkehrsunternehmen. Aus Marketingsicht geht es darum, über die Verbindungs- und Erschließungsqualität sowie den angebotenen Komfort ein Maximum an Kunden zu gewinnen.

\subsubsection{Verbindungsqualität}

Unter der Verbindungsqualität wird die Bedienungshäufigkeit, die Bedienungsgeschwindigkeit und die räumliche Verknüpfung (Umsteigehäufigkeit, Luftliniengeschwindigkeit) des Liniennetzes verstanden. Im lokalen Verkehr sind dies vor allem die Verbindungen zum Kernrandbereich, im regionalen Verkehr die Verbindungen der Kernbereiche der Städte zu den benachbarten Ober-, Mittel- und Grundzentren sowie zu sonstigen ausgewählten Zentren (bspw. Flughafen).

\subsection{Bedienungshäufigkeit}

Die Bedienungshäufigkeit bemisst sich nach dem Fahrgastaufkommen, dem Mindestbedienungsstandard sowie den betrieblichen Randbedingungen. Der sich aus der Bedienungshäufigkeit von Haltestellen und Stationen ergebende Fahrplan kann regelmäßig, also im Takt, oder flexibel sein. ${ }^{1060}$ Die Dichte des Fahrplans hat unter anderem Auswirkungen auf den Personal- und Fahrzeugbedarf, woraus sich ergibt, dass Optimierungspotenziale in der Ausdünnung des Fahrplans bestehen. Derartige Veränderungen im Ange-

\footnotetext{
1058 vgl. Stauss 1987, S.116f

1059 vgl. Kotler 2003, S.127

${ }^{1060}$ vgl. Fiedler 1994, S.4-23
} 
bot sollten sich an der Nachfrage orientieren. Zu berücksichtigen ist, dass bestimmte Umläufe (bspw. zur Bereitstellung) für einen reibungslosen und nachfragegerechten Betriebsablauf notwendig sind. Darüber hinaus sind Taktfahrpläne vom Kunden leichter zu behalten als flexible Pläne, d.h. dass die Informationsnotwendigkeit bei unregelmäßiger Bedienung steigt, was sich wiederum negativ auf die Nachfrage auswirken kann. Im Gegensatz neigen Fahrgäste bei Taktzeiten unterhalb von 10 Minuten dazu, auf einen Fahrplan ganz zu verzichten, was wiederum verkaufsfördernd ist. ${ }^{1061}$

Im RMV wurde in den vergangenen Jahren ein integraler Taktfahrplan ${ }^{1062}$ eingeführt. Im regionalen SPNV bedeutet dies, dass Züge unterschiedlicher Linien sich „immer am gleichen Ort und zur gleichen Zeit" treffen und Umsteigemöglichkeiten in unterschiedliche Richtungen bestehen. Dieses soll unter der Einhaltung eines angemessenen UmsteigeZeitfensters geschehen. ${ }^{1063}$ So stellte beispielsweise die Verdichtung des Taktes auf der SBahn an Wochenenden auf 30 Minuten im Jahr 2003 eine wichtige qualitätsfördernde Maßnahme dar, wie sie bereits in anderen Verbünden existierte. ${ }^{1064}$

\subsection{Beförderungsgeschwindigkeit}

Die Beförderungsgeschwindigkeit ist für die Gesamtreisezeit und damit für die Attraktivität aus Kundensicht von größter Bedeutung, da in der Regel ihr zeitlicher Anteil am größten ist. Die Geschwindigkeit wird u.a. von der Leistung des Fahrzeuges in bezug auf Beschleunigung und Verzögerung, der Fahrtstrecke und -beschaffenheit sowie der Haltestellenabstände beeinflusst. ${ }^{1065}$ Des weiteren haben Siedlungsstruktur und -dichte einen unmittelbaren Einfluss auf die Beförderungsgeschwindigkeit.

Um die Beschleunigung des ÖPNV weiter voranzutreiben, sind vor allem (schnellere) Schienenverbindungen wünschenswert. Die damit zusammenhängenden Probleme zeigen sich im Rhein-Main-Gebiet beispielsweise an den - bislang vergeblichen - Versuchen der Einführung von Stadtbahnen in Wiesbaden und Hanau. Dennoch konnten im RMV durch die Modernisierung von Schienenstrecken auf zahlreichen Verbindungen Zeiter-

\footnotetext{
1061 ebd.

1062 Hiermit ist die Abstimmung der Taktzeiten aller öffentlichen Verkehrsmittel an relevanten Netzknoten gemeint; vgl. RMV 2005, S.15

1063 vgl. RMV 2005, S.15 sowie LEP Hessen 2000, S.33

1064 vgl. RMV 2005, S.22

1065 vgl. Sterzenbach 2001, S.70
} 
sparnisse bei der Reisezeit realisiert werden. So wurde beispielsweise die Leistungsfähigkeit der S-Bahn-Tunnelstammstrecke in Frankfurt weiter erhöht. 1066

Beschleunigungsprogramme im straßengebundenen ÖPNV weisen die Problematik auf, dass sich ÖPNV und MIV häufig die Fahrwege teilen müssen und sich hierüber auch gegenseitig beeinflussen. Geeignete Ansatzpunkte zur Optimierung liegen daher in der Separierung der ÖPNV-Fahrwege vom MIV in Form eigener Fahrspuren und Vorrangschaltungen an Lichtsignalanlagen und vor Weichen und/oder Bahnübergängen. Bei der Umsetzung solcher Maßnahmen sollte allerdings darauf geachtet werden, dass hierdurch nicht die Beförderungsgeschwindigkeit zu Lasten anderer Verkehrsmittel (auch der des MIV) optimiert wird, da dieses kaum einer nachhaltigen Mobilitätssicherung in der Region entsprechen würde. Gerade durch die Einrichtung von Busspuren in Innenstädten, wo die Grundgeschwindigkeit sowieso schon am geringsten ist, wird der für den MIV zur Verfügung stehende Verkehrsraum eingeengt, wodurch die Staubildung gefördert wird.

Die Effektivität von Beschleunigungsprogrammen sollte daher gezielt erfolgen. Insbesondere ergeben sich Möglichkeiten zur Verkürzung der Zugfolgezeiten (z.B. in der „Tunnelstammstrecke“ der S-Bahn zwischen Frankfurt Hbf und Ostendstraße) und zur Zeitersparnis bei der Abfertigungszeit der Fahrgäste. Dies trifft vor allem auf den fahrerbedienten Verkauf von Fahrausweisen im straßengebundenen ÖPNV zu.

\subsection{Umstiege}

Für das Erreichen des Fahrtziels ist es häufig unumgänglich, dass der Fahrgast ein oder mehrere Male von einem Verkehrsmittel in ein anderes umsteigen muss. Dieser Umsteigeprozess ist mit einem zeitlichen Aufwand zu bemessen, der sich aus der Fußwegezeit zur nächsten Haltestelle sowie der Wartezeit auf die Anschlusslinie zusammensetzt. Letztere ist von der Abstimmung der Fahrpläne aufeinander abhängig, wie sie beispielsweise durch die Einführung des integralen Taktfahrplans im RMV erreicht werden konnte. Optimierungspotenziale ergeben sich hier über Anschlusssicherungsprogramme, die voraussetzen, dass die Ist-Information über das Eintreffen einer Zubringerlinie in einem Fahrzeug der Anschlusslinie vorhanden ist. Hierfür sind neben einem ITCS/RBL in Verbindung mit einem geographischen Ortungssystem auch die funktionierende Kommunikation zwischen Fahrzeugen bzw. der Betriebsleitung notwendig, damit alle notwendigen

${ }^{1066}$ vgl. RMV 2005, S.20ff 
Daten über den Fahrtverlauf bei Erstellern und Bestellern vorliegen. Die Schaffung der technischen Voraussetzungen in Verbindung mit einer Bonus-Malus-Regelung im Rahmen der Ausschreibung von Verkehrsleistung soll maßgeblich zur Qualitätssteigerung in diesem Bereich beitragen. ${ }^{1067}$

Aus Kundensicht bedeutet ein mehrfaches Umsteigen die Verlängerung der Reisezeit und den Verlust an Bequemlichkeit. Das Ziel der Angebotsgestaltung sollte es daher sein, möglichst viele Direktverbindungen mit entsprechenden Kapazitäten anzubieten. Es ist damit die Aufgabe des Bestellers, in regelmäßigen Abständen die Marktkonformität des Angebots zu überprüfen. Je dynamischer sich eine Region jedoch entwickelt, desto schneller kann das ÖPNV-Angebot „veralten“. So können beispielsweise Neuansiedlungen von Gewerbe- und Wohngebieten oder der Bau von Umgehungsstraßen eine Veränderung im Angebot notwendig machen. Nachfragestarke Relationen ergeben sich einerseits aus einer die Raum- und Siedlungsstrukturen berücksichtigenden fundierten Planung, andererseits aus regelmäßig durchgeführten Marktforschungen (bspw. über Haushalts- oder Fahrgastbefragungen). Letztere können jedoch bezogen auf das Gesamtnetz nur als Stichproben durchgeführt werden. Reine Fahrgasterhebungen, die nur die Querschnittsbelastung auf bestimmten Linien erheben, lassen zwar Rückschlüsse auf die Nachfrage zu, doch ergeben sich hieraus keine Indizien für eine Angebotsverbesserung. Insgesamt spiegeln die Daten über Quelle-Ziel-Relationen also immer nur einen Status-quo wider.

\subsubsection{Erschließungsqualität}

Unter der Erschließungsqualität versteht man den räumlichen Einzugsbereich der Haltestellen sowie die Netzdichte1068. Diese sind maßgeblich für die fußläufigen Entfernungen zu den Zugangspunkten und haben damit ebenfalls Einfluss auf die Gesamtreisezeit. Insofern ist die Erschließungsqualität im starken Maße von der Siedlungsstruktur eines Raumes abhängig. Faktoren wie Siedlungsdichte oder Zentralität der Versorgungsschwerpunkte beeinflussen diese Qualität. In der Regel ist eine funktionsgerechte und gleichzeitig attraktive Erschließungsqualität nur mittels Kombination verschiedener Betriebsformen zu erreichen, die entsprechend ihrer Stärken differenziert eingesetzt werden. Zudem wird eine attraktive und flächendeckende Erschließung aus einer sinnvollen Verknüpfung lokaler und regionaler Netze mit entsprechend kurzen Umstiegszeiten erreicht.

1067 vgl. RMV 2005, S.80

1068 vgl. Kreiswerke Heinsberg 1997, S.56 
Die Optimierungspotenziale hinsichtlich der räumlichen Erschließung beziehen sich auf die Verlegung sowie auf die Neueinrichtung von Haltestellen. In einem bestehenden Netz können vorhandene Haltestellen aufgrund infrastruktureller Einrichtungen (Bus-,,caps“, Wartebereiche etc.) aber nur bedingt verlegt werden. Zusätzliche Haltestellen führen in der Regel dazu, dass sich durch Umwege oder zusätzliche Haltezeiten die Fahrtzeiten insgesamt verlängern, was sich wiederum negativ auf die Verbindungsqualität auswirkt.

In den Jahren seit Bestehen des RMV wurde die Erschließungsqualität insbesondere durch den Bau neuer S-Bahn-Linien sowie die Modernisierung bestehender Linien verbessert. Derartige kostenintensive Infrastrukturmaßnahmen werden in Zukunft eher die Ausnahme bleiben, zumal die hessische Landesregierung die Priorität bei Lückenschlüssen im Angebot sieht (s.o.). Substanzielle weitere Optimierungspotenziale, wie sie bspw. der teilweise Neubau der „Regionaltangente West“ 1069 darstellen, bestehen daher in diesem Bereich kaum. ${ }^{1070}$

\subsubsection{Komfort}

Die Beförderungsqualität wird im wesentlichen definiert durch die Ausstattung der Haltestellen und Stationen sowie die Ausrüstung der Fahrzeuge, aber auch durch die Serviceorientierung von ÖPNV-Mitarbeitern. Vor dem Hintergrund einer einfachen komfortablen Nutzung ist ein barrierefreier Zugang zu den Haltestellen, Stationen und Fahrzeugen die Voraussetzung für die ÖPNV-Nutzung von mobilitätsbehinderten Menschen, eine Erleichterung für mobilitätseingeschränkte Personen und ein Komfortgewinn für alle übrigen Kunden. ${ }^{1071}$ In direktem Zusammenhang mit dem Komfort steht die Sauberkeit von Haltestellen, Stationen und Fahrzeugen.

\subsection{Bahnhöfe und Haltestellen}

Bahnhöfe und Haltestelle dienen dem Kunden als Zugang zum ÖPNV und können als Aushängeschilder des ÖPNV betrachtet werden. Ihnen kommt in einem Verkehrsnetz auch die Funktion von Verkehrsknoten $\mathrm{zu}$, an denen unterschiedliche Verkehrsträger möglichst abgestimmt und kleinräumig miteinander verknüpft sein sollten. ${ }^{1072}$ Durch die

1069 Die „Regionaltangente West" soll den Vordertaunus direkt mit dem Flughafen und NeuIsenburg verbinden und dabei den Knotenpunkt Frankfurt entlasten; vgl. RMV 2005, S.39

1070 vgl. RMV 2005, S.38f

1071 vgl. Topp 2006 (b)

1072 vgl. LEP Hessen 2000, S.38 
Lage, die Zugänglichkeit, dem Verkehrsangebot und dem gebotenen Komfort sowie das Erscheinungsbild wird die Entscheidung der Kunden, den ÖPNV zu nutzen oder nicht, maßgeblich beeinflusst. Die Ausstattung von Haltestellen und Bahnhöfen muss in erster Linie den Bedürfnissen der Kunden entsprechen. Sie sollte von diesem als Teil der Gesamtleistung des ÖPNV wahrgenommen werden. In der Gestaltung sollte sie unverwechselbar sein und der Bevölkerung gegenüber ein positives Image vermitteln. ${ }^{1073}$

Im RMV gibt es bereits seit dem Jahr 1996 ein Stationsentwicklungs-Programm (STEP), im Rahmen dessen die über 400 Bahnhöfe und Haltepunkte im SPNV sukzessive verbessert werden sollen. Antrieb für dieses Programm war u.a. die Tatsache, dass die DB AG, die immer noch den größten Anteil im SPNV bedient, in der Vergangenheit viele Bahnhofsgebäude im ländlichen Raum und entlang von Nebenstrecken geschlossen und verkauft hat, mindestens aber den personenbedienten Fahrkartenschalter abgeschafft hat. Somit verloren viele Bahnhofsgebäude einen ihrer wichtigsten Berechtigungsgründe: Den Verkauf von Fahrausweisen. Heute wird dies in der Regel über den automatenbedienten Verkauf realisiert. In der Konsequenz können viele Bahnhöfe heute nicht einmal mehr betreten werden und wurden seit Jahren nicht mehr renoviert. Hinzu kommt, dass Bahnhöfe insbesondere in größeren Städten auch häufig soziale „Brennpunkte“ darstellen und „Probleme unserer Gesellschaft offen zu Tage treten“. ${ }^{1074}$ Eingeleitet wird die Verwahrlosung von Bahnhöfen und Stationen häufig von "Graffiti-Schmierereien", die nicht nur von der Bevölkerung als „Symbol für den Zerfall der Ordnung angesehen werden“, sondern im schlimmeren Fall sogar als Bedrohung empfunden werden.1075 Derartige negative emotionale Erfahrungen führen dazu, dass der Zugang zum ÖPNV gemieden wird. Die Funktion des Empfangsgebäudes, welches der Bahnhof zur Gründerzeit hatte und Ausdruck bürgerlichen Stolzes war, ist oftmals verschwunden. Mit Hilfe des Stationsentwicklungsplanes sollen die Bahnhöfe im RMV wieder an Bedeutung gewinnen und ihre ursprüngliche Funktion wieder erlangen sowie neue Funktionen dazugewinnen.

Darüber hinaus gibt es auch bei der DB AG seit einigen Jahren Bestrebungen, ausgewählze städtische Bahnhöfe zu urbanen Zentren mit erweiterten Dienstleistungsfunktionen zu entwickeln. Geschäfte, Kinos und Gastronomiebetriebe sollen dazu beitragen, den Bahn-

\footnotetext{
1073 vgl. Kreiswerke Heinsberg 1997, S.21

1074 vgl. RMV 1996 (a), S.6

1075 vgl. www.anti-graffiti-rheinmain.de
} 
höfen ihre ursprüngliche Bedeutung zurückzugeben. ${ }^{1076}$ Herausragendes Beispiel hierfür in der Region Frankfurt Rhein-Main ist die für 117 Mio. Euro teure und aufwendige Sanierung des Frankfurter Hauptbahnhofes, der seit 1972 unter Denkmalschutz steht und wieder in seinen ursprünglichen Zustand von 1888 bzw. 1924 gebracht wurde. Unter anderem wurde das riesige Glashallendach wieder hergestellt. Auch im betrieblichen Bereich werden technische Verbesserungsmaßnahmen durchgeführt, die direkte Auswirkung auf die Bedienungsqualität haben (z.B. Elektronisches Stellwerk zur Kapazitätssteigerung, Erhöhung der Ein- und Ausfahrgeschwindigkeit auf $60 \mathrm{~km} / \mathrm{h}$, Verlängerung zahlreicher Bahnsteige). Heute finden die Kunden auf ca. $9.000 \mathrm{~m}^{2}$ Verkaufsfläche ein vielfältiges Angebot von Gastronomie über Dienstleistungsgewerbe bis Einzelhandel, was den Hauptbahnhof nicht nur für Reisende, sondern auch für Besucher attraktiv macht. Für Service, Sicherheit und Sauberkeit auf den Bahnsteigen und im gesamten Bahnhof sorgt eine so genannte "3-S-Zentrale“, die rund um die Uhr besetzt ist. Zudem sind alle Bereiche räumlich barrierefrei erschlossen. Weitere Beispiele sind die Bahnhöfe in Mainz und Wiesbaden. Im letzteren Bahnhof, der für 25 Millionen Euro saniert und umgebaut wurde, halten zwar nur 21 Fernverkehrszüge am Tag, dennoch präsentiert der Wiesbadener Hauptbahnhof sich heute als Aushängeschild für die Landeshauptstadt. Die Renaissance der Bahnhöfe drückt sich aber auch in Bahnhofsneubauten aus, wie etwa in Rüsselsheim. ${ }^{1077}$

Die Maßnahmen, die attraktivitätssteigernd in einem Bahnhof wirken, sind vielfältig:

- Bahnsteigüberdachung, geschützter, angenehmer Wartebereich,

- (überdachte) Abstellmöglichkeiten für Pkw, abschließbare Fahrradboxen,

- verglaste Fahrstühle, hell ausgeleuchtete Gleisunterführungen,

- kundenfreundliche Wegeleit- und Informationssysteme,

- Sicherheit über Kameraüberwachung,

- Attraktive Einkaufs-/Versorgungsmöglichkeiten,

- Sauberkeit.

1076 vgl. Nuhn und Hesse 2006, S.76f

1077 vgl. Rhein-Main-Presse v. 19.8.2006 
Um die Infrastruktureinrichtungen, aber auch die eingesetzten Fahrzeuge vor Vandalismusschäden zu schützen, besteht seit Februar 2003 die Arbeitsgruppe „Anti-Graffiti Frankfurt RheinMain“. Die Beteiligten (u.a. die Stadt Frankfurt, die RMV GmbH, die in Frankfurt tätigen Verkehrsunternehmen sowie die Polizeibehörden) möchten durch Aufklärungsarbeit, strikte Verfolgung der Täter und schnelle Schadensbeseitigung die Vandalismusschäden reduzieren. Zu den gemeinsam ausgetragenen Projekten zählen Plakataktionen, die Gestaltung einer U-Bahnstation durch Schüler, Reinigungsaktionen, gezielte Überwachungsmaßnahmen und Pressearbeit. ${ }^{1078}$

Neben der Attraktivität der Bahnhöfe ist auch entscheidend, ob die infrastrukturellen Einrichtungen der Bahnhöfe das aktuelle und zu erwartende Verkehrsaufkommen auch von der Kapazität her bewältigen können. Der Regionale Nahverkehrsplan für den RMV (RNVP) sieht für insgesamt 10 Bahnhöfe Maßnahmen vor, die dazu dienen, die zukünftig erwarteten Fahrgäste fahrplankonform abzufertigen. Die Maßnahmen für diese 10 Bahnhöfe wurden auf ca. 5,4 Millionen Euro beziffert. Dem gegenüber steht ein gesamtwirtschaftlicher Nutzen, der mit ca. 4 Millionen Euro bewertet wurde. ${ }^{1079}$ Insgesamt betrachtet werden die Optimierungspotenziale in diesem Bereich im RMV konsequent angegangen.

\subsection{Fahrzeuge}

Der Qualität der Fahrzeuge kommt eine besondere Bedeutung zu, da sich die Kunden gemessen an der Gesamtreisezeit hier (in der Regel) am längsten aufhalten. Auch hier ist mit fortschreitender Ausschreibung von Netz- und Linienbündeln eine Qualitätssteigerung im RMV festzustellen, so etwa am Beispiel der SPNV-Teilnetze im „Westerwaldnetz" und auf der „Odenwaldbahn“, wo mit Konzessionswechsel völlig neue Fahrzeuge zum Einsatz kamen. Entsprechende Leistungsstandards, wie sie im RMV im Rahmen von Ausschreibungen hinsichtlich Höchstgeschwindigkeit, Beschleunigung und Antriebsleistung formuliert wurden, tragen maßgeblich dazu bei, dass die Reisezeiten minimiert werden können. ${ }^{1080}$ Komfortkriterien wie Niederflurigkeit, niedrige Geräuschentwicklung sowie Fahrgastinformationen „on-board“ tragen zum Reisekomfort bei. Videoüberwachung, Einsehbarkeit des Fahrgastraums und Notrufeinrichtrungen sollen die Sicherheit in den Fahrzeugen erhöhen.

\footnotetext{
1078 vgl. www.anti-graffiti-rheinmain.de

1079 vgl. RMV 2004 (a), S.18

1080 vgl. RMV 2005, S.37
} 
Mit der Gründung der ersten Fahrzeugvorhaltegesellschaft in der Hand der Aufgabenträger, der fahma GmbH, wird einerseits eine wettbewerbsneutrale Fahrzeugförderung ermöglicht, andererseits sollen insbesondere die Chancen von mittelständischen Unternehmen gestärkt und der Wettbewerb insgesamt belebt werden. Gefördert werden demnach nicht mehr die Verkehrsunternehmen, sondern die Aufgabenträger, die damit die volle Finanzierungsverantwortung tragen. Eine ähnliche Lösung wird auch für die Fahrzeugwartung angestrebt, da sich letztlich auch aus der kostenintensiven Vorhaltung von Betriebshöfen und Abstellanlagen Wettbewerbsverzerrungen ergeben können. ${ }^{1081}$

Generell gilt im Fahrzeugbereich, dass Wagenmaterial eingesetzt werden sollte, welches die spezifischen Kundenerwartungen erfüllt. Leider werden gerade bei Verstärkerfahrten im Bereich des Schülerverkehrs alte und wenig komfortable Busse eingesetzt, was im Sinne einer frühzeitigen Kundengewinnung als negativ zu bewerten ist. Die vermeintliche Tatsache, dass insbesondere von dieser Kundengruppe Vandalismusschäden verursacht werden, mag letztlich auch mit der geringen Wertschätzung bzw. Achtung gegenüber ausgedientem Wagenmaterial zusammenhängen.

\subsubsection{Sicherheit}

Sicherheit vor Belästigung und Übergriffen bei der Benutzung von Bussen und Bahnen ist ein relevantes Qualitätsmerkmal, bei dem die Verkehrsunternehmen aus Kundensicht einen hohen Verbesserungsbedarf aufweisen. „Im Personenverkehr trifft der Einzelne immer auf eine sehr große Anzahl fremder Menschen, die er nicht einordnen kann. ,Sich sicher fühlen’ ist mit dem Gefühl verbunden, alles unter Kontrolle zu haben“. ${ }^{1082}$ Das vom Meinungsforschungsinstitut EMNID jährlich erhobene Kundenbarometer ÖPNV1083 ergab für die Stadt Frankfurt für das Jahr 2004 eine „sehr schlechte“ Beurteilung $(3,54)$ der „Sicherheit abends an Haltestellen“ sowie eine "schlechte“ Beurteilung $(3,32)$ der "Sicherheit abends in Fahrzeugen“. Dagegen wird die Sicherheit tagsüber "eher gut" eingestuft $(2,81$ bzw. 2,70). ${ }^{1084}$

Auch wenn objektiv betrachtet Übergriffe vergleichsweise selten sind, kann das subjektive Sicherheitsempfinden bei ÖPNV-Nutzern bzw. das negative Image des ÖPNV im Be-

\footnotetext{
1081 vgl. HMWVL 2002, S.6f

1082 vgl. Pernack 2005, S.31

1083 Befragt wurden nur Kunden, die den ÖPNV mindestens einmal im Quartal nutzen.

$1084 \mathrm{vgl}$. ÖPNV-Kundenbarometer 2004, veröffentlicht u.a. in www.forum.nahverkehr-ffm.de
} 
reich "Sicherheit" bei Nicht-Nutzern als möglicher Grund identifiziert werden, warum Menschen den ÖPNV entweder gar nicht oder nicht häufiger nutzen. So ergab eine vergleichende Studie zum Thema Sicherheit im ÖPNV für die Städte Mannheim und Hanau, dass Sicherheitsbedenken bei ca. 10\% der Fahrgäste bei der Verkehrsmittelwahl eine Rolle spielen. Fast 40\% der Männer und sogar fast 50\% der Frauen gaben an, bei einem konkreten Unsicherheitsgefühl den Pkw zu nutzen. ${ }^{1085}$ Die Verbesserung des subjektiven Sicherheitsempfindens sowie der objektiven Sicherheit steht daher seit mehreren Jahren im Fokus der RMV GmbH, der lokalen Aufgabenträger sowie der Verkehrsunternehmen. Zu den Maßnahmen in diesem Bereich gehören u.a.:

- Einsatz von Sicherheitskräften in S-Bahnen in den Abendzeiten Bereits seit einigen Jahren werden S-Bahnzüge in den Abendstunden nach 20 Uhr von Sicherheitskräften in den vorderen Wagen begleitet. Im Rahmen des „3-SKonzeptes“ der DB AG, dass insgesamt für mehr Service, Sicherheit und Sauberkeit sorgen soll, werden außerdem kombinierte Auskunfts- und Notrufsäulen auf Bahnsteigen aufgestellt. ${ }^{1086}$

- Ausbildung von Buslotsen, „die auf dem Schulweg in Bussen und Bahnen für eine friedlichere Atmosphäre sorgen sollen“. ${ }^{1087}$

Dieses Konzept, das zuerst im Verkehrsverbund Rhein-Ruhr eingesetzt wurde, wird seit einigen Jahren auch vom RMV gefördert und bei vielen Verkehrsunternehmen eingesetzt.

- Einsatz von Videoüberwachung in Bussen und auf Bahnstationen.

Verschiedene Verkehrsunternehmen im RMV haben mit der Videoüberwachung bereits Erfahrungen gesammelt. Im Rahmen eines Testprojektes der Offenbacher Verkehrs-Betriebe gaben fast $90 \%$ der befragten Fahrgäste an, sich in videoüberwachten Bussen deutlich sicherer zu fühlen und meinten, dass durch Videokameras der Vandalismus eingeschränkt würde. Dies sei nach Aussage der Verantwortlichen allerdings nicht alleine auf die Überwachung zurückzuführen, sondern auch auf die Kopplung an Fernsehbildschirme, über die Informationen (wie bspw.

\footnotetext{
1085 vgl. Cohrs u.a. 2005, S.17ff

1086 vgl. RMV 1999, S.28ff

1087 vgl. RMV 2004 (b), S.50 sowie Georgi und Wüst-Rocktäschel 2005, S.60
} 
die Haltestellenanzeige) und Werbespots laufen. Alleine aus den Werbeeinnahmen können solche Anlagen bereits refinanziert werden. ${ }^{1088}$ Auch die ESWE in Wiesbaden zog nach einjähriger Praxiserfahrung ein positives Resumé: Vandalismus und Gewalt seien auch hier merklich zurückgegangen, so dass sich die „nicht unerhebliche Investition [...] durch die Einsparungen infolge des Rückgangs der Vandalismusschäden zügig rentieren wird“. ${ }^{1089}$

Eine weitere sicherheitsrelevante Maßnahme, die im Zusammenhang mit der Einführung von elektronischen Fahrgeldmanagementsystemen gelegentlich thematisiert wird, ist der Aufbau von Zugangssperren (gates) im Bereich des SPNV. Durch die Installation von Zugangssperren (z.B. Drehkreuzen) sollen ausschließlich Personen mit gültigem Fahrausweis auf die Bahnsteige gelangen. Ziel ist die Erhöhung des Sicherheitsempfinden der Fahrgäste, indem der öffentliche Raum, von dem eine subjektive „Bedrohung“ ausgeht, quasi ausgesperrt wird. Voraussetzung für den Aufbau von Zugangssperren sind Fahrausweise, die maschinell lesbar sind (z.B. Magnetstreifenkarten, kontaktbehaftete oder kontaktlose Speicher-/Chipkarten; siehe Kapitel 7.6.1.3). Im Vergleich zu den meisten ausländischen Nahverkehrssystemen handelt es sich bei den deutschen Nahverkehrssystemen im Bereich des schienengebundenen Nahverkehrs um räumlich offene Systeme. Inwieweit die Einführung von Zugangssperren in Deutschland realistisch bzw. zielführend ist, kann kaum abgeschätzt werden.

\subsubsection{Preispolitik}

Die Preispolitik umfasst alle Instrumente, die auf das zu entrichtende Entgelt für das Produkt sowie die Preisbereitschaft der Kunden und deren Preiswahrnehmung als potenzialbezogene Zielgröße abzielen. ${ }^{1090}$ Der Preis für die Beförderungsleistung im ÖPNV ist gleichbedeutend mit dem Fahrpreis. Der Tarif dagegen umfasst neben den Fahrpreisen auch alle allgemeinen Beförderungsbedingungen. Durch die Auswirkung des Preises auf die Nachfrage beeinflusst dieser direkt auch die Einnahmeseite. Gleichermaßen werden an die Fahrpreise im ÖPNV die Anforderungen gestellt, dass diese wirtschaftlich ergiebig und sozial gerecht sowie überschaubar sein sollen. ${ }^{1091}$ Vor dem Hintergrund einer verbes-

\footnotetext{
1088 vgl. Georgi und Wüst-Rocktäschel 2005, S.61f

1089 vgl. ESWE 2006, S.10

1090 vgl. Homburg und Krohmer 2003, S.551

${ }^{1091}$ vgl. Rumpke 2005, S.62
} 
serten Nutzerfinanzierung ist es die Herausforderung einer marktorientierten Preispolitik, in diesem Spannungsfeld, die Effizienz des ÖPNV entscheidend zu verbessern.

\subsubsection{Preisbildung und Tarifsystematik}

Für die Region Frankfurt Rhein-Main liegt die Tarifhoheit fast flächendeckend beim RMV, der mit Gründung einen einheitlichen Verbundtarif eingeführt hat. Aufgrund der polyzentrischen Struktur kam ein Flächen-Zonen-Tarif mit zwei Kernzonen (Frankfurt sowie Mainz/Wiesbaden) zur Anwendung, der auf 7 Preisstufen aufbaut und unterschiedliche Zeit- und Einzelfahrkarten kennt. Allerdings gibt es eine fast unüberschaubare Anzahl von Sonderfahrausweisen, die das Fahrkartensortiment ergänzen und die Tarifstrukturen im RMV äußerst komplex machen. Das RMV-Tarifsystem ist das Ergebnis einer Vereinheitlichung von mehreren hundert historisch bestehenden Fahrkartenangeboten und Tarifsystemen. ${ }^{1092}$ Das Ziel des RMV-Tarifs ist es, einen möglichen hohen Erlös bei der Vermarktung der Betriebsleistung zu erwirtschaften. Dieses System hat aus Kundensicht die folgenden Nachteile:

- Es werden dem Kunden bei kurzen Strecken zu grobe Absatzquanten (z.B. beim Flächen-Zonen-Tarif) und damit ein zu hoher Zugangspreis vorgegeben bzw. dem Fahrgast Leistungsquanten angeboten, die dieser nicht in Anspruch nehmen möchte.

- Stark differenzierte Angebote werden vom Kunden als zu kompliziert erachtet und wirken damit als Zugangsbarriere.

- Eine differenzierte und schwer durchschaubare Zonierung sowie ein weit gefächertes Angebot ist im Massengeschäft schwer praktikabel. Zu groß gefasste Tarifzonen erschweren eine ausreichende Differenzierung der Fahrpreise. 1093

Das System ist allerdings nicht alleine für den Kunden nachteilig, der ein solches Angebot als nicht preis-/leistungsgerecht ansieht, sondern auch für die Verkehrsunternehmen, die bestimmte Teilmärkte nur ökonomisch unvollständig erschließen und ausschöpfen können. Von Aufgabenträgerseite her wurden unterschiedliche Instrumente zur Lösung dieser Probleme entwickelt. Der Erfolg von Kurzstreckentarifen zur Senkung des Einstiegspreises oder Pauschalangebote mit niedrigeren Preisen stellt aber nur ansatzweise eine

1092 vgl. RMV 2005, S.86

1093 vgl. Sterzenbach 2001, S.166 
Problemlösung dar. Denn diese Angebote können die Übersichtlichkeit der Tarifsysteme noch erschweren und darüber sogar zu Erlösminderungen führen. Vor dem Hintergrund der Erlössicherung sind auch jene Angebote kritisch zu betrachten, die zwar zu einem Kundengewinn geführt haben, gleichzeitig aber mit sinkenden Durchschnittserlösen pro Fahrt einhergingen - und dies meist bei gestiegenem Bedienungsaufwand. Dieses gilt auch für zu niedrige Fahrpreise, die aufgrund sozialpolitischer Forderungen eingeführt wurden. ${ }^{1094}$

Das am häufigsten angewandte Instrument zur Generierung von mehr Fahrgeldeinnahmen ist nach wie vor die Anhebung der Fahrpreise. Diese orientiert sich in der Regel am allgemeinen Preisanstieg. Laut \$39, PBefG, bedürfen Beförderungsentgelte und deren Veränderung jedoch der Genehmigung, die im RMV das Regierungspräsidium erteilt (siehe auch Kapitel 5.4.1.2). ${ }^{1095}$

Da es im ÖPNV jedoch kaum Instrumenten gibt, über die nachgewiesen werden kann, wie die Nachfrage auf die Preisveränderung reagiert („Nachfrageelastizität“), ist das Instrument der Tariferhöhung nur bedingt geeignet, die wirtschaftliche Situation der ÖPNV-Unternehmen insgesamt und dauerhaft zu verbessern oder sogar kostendeckende Preise einzuführen. Eine derartige Verbesserung setzt überproportionale Tariferhöhungen voraus, die erfahrungsgemäß am Markt nicht durchzusetzen sind. ${ }^{1096}$ Überproportionale Tariferhöhungen führen wie spürbare Angebotseinschränkungen bei wahlfreien Kunden zu deutlichen Nachfragerückgängen und bei gebundenen Kunden zu deutlicher Verärgerung. Jedoch muss auch ein Ausbleiben von Protesten in der Öffentlichkeit nicht gleichbedeutend mit der Durchsetzbarkeit von Preisen am Markt sein. ${ }^{1097}$ Dies trifft umso mehr für die hochpreisige Tarifstruktur des Rhein-Main-Verkehrsverbundes zu. Eine Anhebung der RMV-Fahrpreise um fast 6\% im Dezember 20061098 birgt daher die Gefahr, dass die Nachfrage „elastisch“ wirkt; der Umsatz also deutlich hinter der Nachfrage zurück bleibt und sich die Anhebung der Fahrpreise kontraproduktiv auf die Abschöpfung der Konsumentenrente auswirkt.

\footnotetext{
1094 vgl. Stauss 1987, S.142

1095 vgl. Sterzenbach 2001, S.153f

1096 vgl. ebd., S.177

1097 vgl. Stauss 1987, S.144

1098 vgl. Frankfurter Rundschau v. 13.07.2006
} 


\subsubsection{Preisdifferenzierung}

Gemäß Aberle geht es bei der Preisdifferenzierung darum,

„im Vergleich zum Einheitspreis für eine Leistung weitere Teile der Konsumentenrente in Erlöse zu transformieren. Damit unterschiedliche Zahlungsbereitschaften der Nachfrager marktwirksam werden, sind unterschiedliche Qualitäten anzubieten [...]". 1099

Dass eine preisliche Differenzierung bezogen auf bestimmte Nutzergruppen auch im ÖPNV von Relevanz ist und sich am Markt durchsetzen lässt, ist am Beispiel der 1. Klasse deutlich, wo es Preisunterschiede gegenüber der 2. Klasse von bis zu 50\% gibt.

Pauschale Fahrpreiserhöhungen betreffen alle Fahrgäste gleichermaßen, egal wie ihre Zahlungsbereitschaft im einzelnen aussieht. Bei gebundenen Kunden („,captives“), wie auch bei wahlfreien zahlungsbereiten Kunden, führt eine Preisanhebung zur verbesserten Abschöpfung der Konsumentenrente. Die wahlfreien Kunden, die ihre Nachfrage nach Mobilität mit einem anderen Verkehrsmittel, in der Regel dem privaten Pkw, befriedigen können, drohen jedoch abzuspringen. Gerade im RMV ist das Niveau der Fahrpreise, auch gemessen an der regionalen Kaufkraft, sehr hoch.1100 Daraus lässt einerseits schlussfolgern, dass die Preiselastizitäten bereits gut ausgenutzt werden, andererseits besteht hierdurch die Gefahr bei weiteren Preisanhebungen Kunden zu verlieren. Dieser Absprungbereitschaft kann entgegengewirkt werden, wenn dem Kunden innerhalb des Fahrkartensortiments alternative Angebote gemacht werden, wofür allerdings eine weitere preisliche Differenzierung im Tarifangebot notwendig wäre.

Der RMV-Tarif bzw. das angebotene Fahrkartensortiment ist nach räumlichen (Distanz und Örtlichkeit) und zeitlichen (Einzelfahrausweise, Tag, Woche, Monat, Jahr) Kriterien differenziert. Für Kinder einschließlich bis 14 Jahren gibt es einen ermäßigten Tarif, allerdings nur für Einzelfahrkarten und Tageskarten. Seit einiger Zeit gibt es für Monats- und Jahreskarten das preislich ermäßigte "9-Uhr-Ticket“, das zur Benutzung des ÖPNV nach 9 Uhr berechtigt. Sondertarife existieren für Schüler und Auszubildende sowie für Studenten und größere Firmen („Jobticket“). Außerdem gibt es Gruppentageskarten bis 5 Personen ${ }^{1101}$ sowie eine 1. Klasse im Schienenregionalverkehr und in der S-Bahn. Ansonsten

1099 Aberle 2003, S.336

1100 vgl. Achenbach 2002, S.229

1101 vgl. RMV 2006 (b), S.10ff 
findet kaum eine Differenzierung nach Art des Verkehrsmittels (Bus, Straßenbahn, SBahn, Regionaler Schienenverkehr) oder sozialen Gruppen (bspw. „Senioren“) statt, was allerdings in der ÖPNV-Branche verbreitet ist. ${ }^{1102}$ Auch wird ein Bindung des Kunden an das Verkehrsunternehmen in Form eines Abonnements nicht monetär vergütet. Eine Jahreskarte, die im Voraus - auch anonym bezahlt wird - ist sogar etwas günstiger als eine Jahreskarte im Abonnement, deren Monatsbeiträge zehnmal abgebucht werden. ${ }^{1103}$

Vor dem Hintergrund des ehedem schon sehr komplexen RMV-Tarifs muss konstatiert werden, dass eine weitere preisliche Differenzierung des Angebots, etwa anhand von leistungs- und stärker differenzierten entfernungsabhängigen Parametern, auf Basis der vorhandenen Vertriebs- und Kommunikationsmedien dem Kunden nicht zugemutet werden kann. Für eine Wertsteigerungsstrategie im Rahmen der Marketingkonzeption, die dem Kunden einerseits einen möglichst hohen Nutzen bietet und andererseits das Angebot so gestaltet, dass es bestehende Zahlungsbereitschaften weitgehend ausschöpft, bedarf es sowohl des Einsatzes von Elektronischen Fahrpreisfindungssystemen als auch der Nutzung neuer Informationstechnologien. Nur so können dem Kunden Fahrpreise angeboten werden, die von diesem als preis-leistungsgerecht empfunden werden und er gleichzeitig den Überblick über die komplexe Ermittlung des Fahrpreise erhält.

\subsubsection{Kommunikationspolitik}

\subsubsection{Information}

\subsection{Informationsnotwendigkeit}

Im ÖPNV stellt sich generell das Problem der Informationsnotwendigkeit dar. Wenn ein Kunde Busse und Bahnen nutzen möchte, muss er eine Vielzahl von Information nicht nur kennen, sondern richtig interpretieren (Haltepunkt, Erreichbarkeit, Fahrplan, Tarif/Preis, Bezahlmöglichkeiten, Transportmöglichkeiten am Zielort, Rückfahrmöglichkeiten, etc.). Die Komplexität der Tarife und der Tarifbestimmungen, die Vielfalt des Fahrkartenangebots und die damit verbundenen Schwierigkeiten sowie der monetäre und zeitliche Aufwand („Transaktionskosten“) des Fahrkartenerwerbs stellen nach wie vor das größte Hindernis für die Benutzung des ÖPNV dar. Schließlich ist in einer Marktwirt-

\footnotetext{
1102 vgl. Stauss 1987, S.145

${ }^{1103}$ vgl. RMV 2006 (b), S.28f
} 
schaft der "Preis“ die entscheidende Information schlechthin. ${ }^{1104}$ Die Bereitstellung aller notwendigen Informationen an den unterschiedlichen Informationsorten entlang der Wegekette ist ein kritischer Erfolgsfaktor für die Vermarktung des ÖPNV. Es muss daher das Ziel sein, den Zugang zur Information zu vereinfachen bzw. die Informationsnotwendigkeit $\mathrm{zu}$ reduzieren. ${ }^{1105}$

Die Vermittlung der „Verkehrs“-Information ist aber nur ein Teilbereich eines gesamtheitlichen Marketings im ÖPNV. Information ist Teil der Kommunikation ${ }^{1106}$ und ergänzt sämtliche Maßnahmen, die Auswirkung auf den Erfolg des Produkts am Markt haben. Heute stellt sich bereits der Zugang zur Information im ÖPNV als Hindernis dar. ${ }^{1107} \mathrm{Zu}$ mal die Information - üblicherweise - einfach nur „bereitgestellt“ wird und die Entscheidung, wie mit dieser Information umzugehen ist, dem Verkehrsteilnehmer überlassen bleibt. Insofern bedarf es einer Informationsstrategie mit einer den individuellen Kundenbedürfnissen angemessenen marketingseitigen Handlungsumsetzung. Diese Umsetzung muss sich in vermarktungsfähigen Angeboten niederschlagen, im Rahmen derer die notwendigen Einzelprozesse zusammengefasst werden und automatisch ablaufen, ohne vom Kunden notwendigerweise stets neu angestoßen werden zu müssen. Generalisiert kann hier von einer Zusammenführung der (Ober-) Prozesse „Informieren“ und „Kaufen“ (im Sinne von „Buchen“ und „Bezahlen“) gesprochen werden. Idealerweise bezieht sich dies auf die gesamte Nutzung. Dies muss nicht unbedingt nur die komplette Wegekette sein, sondern kann auch den Reiseanlass miteinbeziehen.

Insgesamt werden zwar die Möglichkeiten der Information durch die Diversifizierung der Informations- bzw. Kommunikationskanäle verbessert (s.u.). Nach wie vor bleibt für den Kunden aber die grundsätzliche Notwendigkeit der Information bestehen bzw. schafften es die Verkehrsunternehmen und -verbünde bislang nicht, den Informationsvorgang mit dem Verkaufsvorgang prozessual zu verknüpfen. Der Kunde muss nach wie vor alle Informationen über das Fahrplanangebot und das Fahrkartensortiment zusammentragen, um für sich selbst den Entschluss zu fassen, welche Kombination aus Tarif und Produkt für ihn geeignet ist. Diese Transferleistung wird ihm ausschließlich durch eine persönliche Auskunft abgenommen, die sich aber aus Sicht der bereitstellenden Verkehrsunter-

\footnotetext{
1104 vgl. Becker, U. 2007, S.5

1105 vgl. Müller und Rau 1997, S.31 sowie VDV 2001, S.198ff

1106 vgl. Werner, P. 1997, S.314

${ }^{1107}$ vgl. Müller und Rau 1997, S.28
} 
nehmen und Aufgabenträger in Form der Hotline oder der Mobilitätszentrale bzw. personalbedienten Verkaufsstelle als sehr teuer darstellen. Aus Sicht des Kunden wirken einerseits die räumliche Distanz zur beratenden Stelle sowie andererseits die entstehenden Telefongebühren als Widerstände. Laut VDV muss es daher das Ziel sein,

"die Fahrgastinformation in allen Phasen der Wegekette erheblich zu verbessern. Das herausragende Merkmal aller Bemühungen ist es, möglichst aktuelle Informationen über den tatsächlichen Betriebszustand und den voraussichtlichen Ablauf einer Fahrt zu liefern, die es dem Fahrgast ermöglichen, seine Reise auf verlässlicher Basis zu planen und durchzuführen". 1108

\subsection{Informationskanäle}

Für die persönliche Kundeninformation im RMV gibt es die personenbedienten Verkaufsstellen der Verkehrsunternehmen sowie die Mobilitätszentralen, die teilweise auch in der Verantwortung der lokalen Aufgabenträger geführt werden. Insbesondere in den Mobilitätszentralen ist die ausführliche Information möglich, die bei der Vermittlung von Dienstleistungen gerade für die Neukundengewinnung besonders geeignet ist. ${ }^{1109}$ Daneben spielt natürlich immer noch das Fahrpersonal als Ansprechpartner für Auskünfte eine große Rolle bzw. führt wenig qualifiziertes Personal schnell zu einer schlechten Kundenzufriedenheit. Da eine Tendenz zu verzeichnen ist, dass bei vielen Verkehrsunternehmen häufig Fahrpersonal eingesetzt wird, dass der deutschen Sprache kaum mehr mächtig ist, werden in Ausschreibungen, beispielsweise in der Stadt Frankfurt am Main, mittlerweile Deutschkenntnisse, Kenntnisse über Tarife und Beförderungsbestimmungen sowie Ortskenntnisse als Qualitätskriterien vorgeschrieben. ${ }^{1110}$

Daneben ist vor allem die zentrale telefonische Auskunft des RMV von Bedeutung. Die Nummer wird verbundweit beworben. Neben dieser zentralen telefonischen Auskunft gibt es noch die Hotline der LNO Frankfurt (TraffiQ), die eigenständig beworben wird. Sowohl RMV- wie auch TraffiQ-hotline werden vom gleichen Dienstleister betreut. Darüber hinaus nutzen viele Kunden die bestehenden Möglichkeiten, mit dem lokalen VU oder der LNO vor Ort direkt Kontakt aufzunehmen. Dies resultiert auch aus einer Unsicherheit des Kunden heraus, wer eigentlich der zuständige Ansprechpartner für ihn ist.

1108 VDV 2001, S.198

1109 vgl. Rumpke 2005, S.94

1110 vgl. Schäfer-Sparenberg, Bongardt und Dalkmann 2006, S.45ff 
Die uneinheitliche Markierung (branding) vieler Fahrzeuge, bei denen die Logos des jeweiligen Verkehrsunternehmens, des lokalen Aufgabenträgers oder des RMV scheinbar beliebig aufgebracht sind, führen zu einer Irritation, wer eigentlich der Verantwortliche für die Leistungserstellung ist.

Neben der Kundenzeitschrift „RMVmobil“, die dreimal im Jahr mit einem Lokalteil als Beileger zur Tagespresse sowie als Ausleger erscheint, gibt es ein breites Angebot an Printmedien zur Information. Hier sind zuallererst die Fahrplanbücher von Bedeutung. Daneben gibt es eine Vielzahl von lokalen Broschüren, Flyern etc., die über die lokalen Angebote informieren und die an unterschiedlichen Stellen ausliegen. Für die Information unmittelbar vor Reiseantritt hängen an allen Haltestellen und Bahnhöfe Aushangfahrpläne aus. Derartige Information ist allerdings für Uninformierte unzureichend und führt dazu, dass der ÖPNV häufig erst gar nicht in die Verkehrsmittelwahl einbezogen wird.1111

Zukünftig geht es also darum, die Information über das ÖPNV-Angebot dort bereitzustellen, wo der Kunde die Entscheidung über das zu nutzende Verkehrsmittel trifft, idealerweise bereits zielgruppenspezifisch oder individualisiert aufbereitet. ${ }^{1112}$ An dieser Stelle können IuK-Technologien einen - vielleicht den entscheidenden - Beitrag liefern, die Akzeptanz und damit die ÖPNV-Nutzung signifikant zu vereinfachen und in der Konsequenz erhöhen. Insbesondere das Internet gewinnt hier mehr und mehr an Bedeutung. Die Internetseite des RMV (www.rmv.de) ist der einzige Web-Auftritt mit regionalem Anspruch und gleichzeitig die Informationsplattform für die Mobilitätszentralen und die zentrale telefonische Auskunft (RMV-Hotline). Daneben halten aber auch noch die lokalen Anbieter Kundeninformationen auf ihren Internetseiten parat. Als besonders kundenfreundlich stellt sich die Fahrplanauskunft dar, bei der die Kunden nicht ihre Start- und Zielhaltestelle eingeben müssen, sondern lediglich die Start- und Zieladressen. Der RMVInternet-Auftritt wird auch über Info-Terminals, die sich u.a. in Bürgerbüros und Sparkassen befinden, erreicht. ${ }^{1113}$ Via Internet ist es ferner möglich, an den RMV eine E-Mail $\mathrm{zu}$ verschicken (ebenfalls über einen Antwort-Zettels im RMVmobil) und so aktuelle Informationen rund um den RMV in Form eines kostenlosen Newsletters bzw. der Kundenzeitschrift RMVmobil (z.B. mit lokalen Besonderheiten) zu erhalten. Hierzu kann der

\footnotetext{
1111 vgl. Sterzenbach 2001, S.98

1112 vgl. Müller und Rau 1997, S.32

1113 vgl. RMV 2005, S.97ff
} 
Kunde das für ihn relevante Fahrplangebiet auswählen, über das er besonders informiert werden möchte. Auf der RMV-Intenetseite gibt es zudem Ansätze einer individualisierten Information (siehe Kapitel 6.5.4.5).

Seit einiger Zeit wird auch das Mobilfunktelefon als Informationskanal genutzt. So kann sich der Kunde einen persönlichen Fahrplan via GPRS auf sein Mobilfunktelefon herunterladen.

\subsubsection{Werbung und Marktauftritt}

Es ist die Absicht der RMV GmbH, den Begriff „Rhein-Main-Verkehrsverbund“ als (Mobilitäts-) Dienstleistungs-Marke zu positionieren. ${ }^{1114}$ Ziel ist ein integriertes Kommunikationskonzept, das sowohl die "Marke RMV“ als auch die Partner innerhalb des Verbundes als Dienstleister im Mobilitätsmarkt positioniert. Die Kommunikationsstrategie und die Gestaltungsrichtlinien des RMV geben den Lokalen Nahverkehrsorganisationen den konzeptionellen Rahmen für (Werbe-) Kampagnen vor. ${ }^{1115}$ In einem einmal jährlich stattfindenden „Round Table“, den die RMV-GmbH durchführt, wird den lokalen Nahverkehrsorganisationen der aktuelle „Look“ des RMVmobil (siehe Kapitel 6.5.4.4) sowie die Anzahl der im laufenden Jahr erscheinenden Ausgaben und erste Themeninhalte vorgestellt. Bei der Gestaltung einer Kampagne sollten sich die LNOs an die Vorgaben des RMV halten. Im Gegenzug finanziert die RMV GmbH die LNO-Maßnahmen mit. Allerdings ist nicht festgelegt, wie häufig oder in welcher Anzahl eine LNO eine Kampagne durchführen muss. Dieses wird individuell von der LNO entschieden. Das bedeutet, dass insgesamt betrachtet, kein abgestimmtes Vorgehen zum Kampagnenmanagement vorliegt.

Aufgrund der Unterschiedlichkeit der Marktauftritte der verschiedenen Organisationen existiert bislang im RMV kein einheitlicher ÖPNV-Marktauftritt. So gibt es zwar ein definiertes "Corporate Design“ der RMV GmbH,1116 dieses wird aber von den zahlreichen Mobilitätsdienstleistern nicht als "Corporate Identity“ wahrgenommen bzw. genutzt. So spiegelt sich beispielsweise das Erscheinungsbild des ÖPNV in der Stadt Frankfurt in den unterschiedlichen Farben und Logos des RMV, der LNO Frankfurt, TraffiQ sowie der VGF als das größte lokale Verkehrsunternehmen im Bus- und Straßenbahnverkehr und der DB

\footnotetext{
1114 vgl. RMV 2005, S.96

1115 ebd., S.97

1116 ebd., S.96
} 
AG als S-Bahn-Betreiber wider. Einzig das Logo des RMV wurde als kleinster gemeinsamer Nenner von allen Partnern übernommen.

Inwieweit hieraus eine Verunsicherung für den potenziellen Kunden abgeleitet werden kann, ist schwer abschätzbar. Der Endbericht zur Delphi-Studie „ÖPNV-Markt der Zukunft" hebt hervor, dass "die Signalisierung verschiedener Produkteigenschaften zur Gewährleistung einer einheitlichen Benutzeroberfläche durchaus sinnvoll“ ist. ${ }^{1117}$ Als hinderlich im Prozess der Markenbildung werden jedoch die unterschiedlichen Auffassungen der ÖPNV-Akteure erachtet, was eigentlich zu „markieren“ ist. Das mögliche Spektrum umfasst sowohl Bedienungsformen und bestimmte Angebote wie auch Unternehmens- und Verbundnamen, Tarife, Linien und Regionen. Diese unterschiedlichen Auffassungen wie auch die Tatsache, dass fast zwei Drittel der in der Studie befragten ÖPNVExperten keine Notwendigkeit einer einheitlichen Markenherausbildung im ÖPNV sehen, machen deutlich, dass nicht zu erwarten ist, dass der ÖPNV zukünftig als einheitliche Marke zu vermarkten ist. Vielmehr werden Unternehmen versuchen, sich über eine Markierungsstrategie von der - vermeintlichen - Konkurrenz abzugrenzen. Dennoch wird die Möglichkeit gesehen, dass die Aufgabenträger, insbesondere die Verbünde aufgrund ihres Bedeutungszuwachses im Rahmen des Wettbewerbs, bei der Markierung von Produkten eine Markenführerschaft übernehmen. ${ }^{1118}$ So strebte auch die $R M V G m b H$ bislang eher danach ihren Firmennamen als Dachmarke zu etablieren, anstatt bestimmte Produkte, also Angebote, als Marken am Markt zu positionieren. ${ }^{1119}$

\subsubsection{Verkaufsförderung}

In der Regel werden im ÖPNV unter verkaufsfördernden Maßnahmen vor allem die zeitlich befristete Verteilung von Angebotsinformation, beispielsweise von Linienfahrplänen oder Kundenzeitschriften über Promotion-Teams gezählt. Bei der Eröffnung neuer Haltestellen und Linien zählen „Events“ zu den verkaufsfördernden Maßnahmen, die die Aufmerksamkeit von Öffentlichkeit und Presse auf das neue Angebot lenken sollen. Des weiteren zählen hierzu Schulungsmaßnahmen des Verkaufs- und Fahrpersonals, die das Personal in die Lage versetzen sollen, über neue Angebote Auskunft erteilen zu können. Als Dienstleistung von „Mensch-zu-Mensch“ kann sich auch die Mitarbeitermotivation

\footnotetext{
1117 Deutsches Verkehrsforum 2005, S.114

1118 vgl. Deutsches Verkehrsforum 2005, S.115f

${ }^{1119}$ vgl. Rumpke 2005, S.129f
} 
verkaufsfördernd auswirken. Im RMV werden verkaufsfördernde Maßnahmen insbesondere im Zusammenhang mit dem jährlichen Fahrplanwechsel durchgeführt (z.B. der „RMV-MitarbeiterExpress“), zu dem die jeweils neuen Fahrpläne erscheinen. Gerade die Mitarbeiter von Verkehrsunternehmen sind für die Kundenzufriedenheit von besonderer Bedeutung, weswegen Schulungs- und Fortbildungsmaßnahmen zu aktuellen Produkten sowie zu den Tarif- und Beförderungsbedingungen, aber auch in den Bereichen Beschwerde- und Konfliktmanagement, von großer Bedeutung für die Kundenzufriedenheit sind. 1120

„In Zeiten der stärkeren Individualisierung, in der sich differenzierte Kundenbedürfnisse und Werthaltungen in der Bevölkerung herausbilden, haben es undifferenzierte Lösungsansätze [„Gießkannenprinzip“], die auf die höhere Auslastung des ÖPNV als ,Massenverkehrsmittel' abzielen - und damit auf (Verkaufs-)Förderung“ - schwer. ${ }^{1121}$ Umgedreht wirkt sich die Heterogenität des Vermarktungsansatzes auf die Verkaufsförderung negativ aus, da die Eingängigkeit der kommunizierten Botschaften unter der Vielzahl der Absender leidet.

\subsubsection{4 Öffentlichkeitsarbeit}

„Die Öffentlichkeitsarbeit umfasst die Gesamtheit aller absatzpolitischen Maßnahmen, die nicht unmittelbar auf einen Absatzerfolg, sondern auf die Imageverbesserung des ÖPNV insgesamt und der einzelnen ÖPNV-Unternehmung, ausgerichtet sind“. ${ }^{1122}$ Wie in Kapitel 6.4.4.3 dargelegt, hängt die Verbesserung des Images maßgeblich von der Vermittlung emotionaler Werte ab. Im RMV - wie auch in anderen Verkehrsorganisationen - fällt dem Unternehmensbereich Öffentlichkeitsarbeit die Aufgabe zu, mit sachlichen und rational nachvollziehbaren Argumenten Unternehmensentscheidungen nach außen zu tragen. Die Adressaten dieser Information können dabei durchaus unterschiedliche Anforderungen besitzen. Hier geht es also um Objektivität und um die Vermittlung von Vertrauen, das sich auf die Übereinstimmung von Handeln und Information stützt. Transparenz wird u.a. dadurch erreicht, dass im Internet die Presseberichte archiviert werden oder sogar die Geschäftsberichte der letzten Jahre eingesehen werden können. Obwohl die RMV GmbH

\footnotetext{
1120 vgl. Schäfer-Sparenberg, Bongardt und Dalkmann 2006, S.48

1121 vgl. Henning und Schmid 1998, S.27

1122 Sterzenbach 2001, S.139
} 
selbst „Transparenz [...] zur Maxime gemacht hat" ${ }^{\prime 1123, ~ f i n d e n ~ s i c h ~ d i e ~ G e s c h a ̈ f t s b e r i c h t e ~}$ allerdings nicht im Internet.

Eine kontinuierliche und aktive Medien- bzw. Pressearbeit sowie ansprechend gestaltete und professionell durchgeführte Presseveranstaltungen können ferner dazu beigetragen, dass sich in erster Instanz in den Medien ein positives Bild des ÖPNV festsetzt. Allerdings sind die Medien durchaus meinungsbildend im Hinblick auf die Bewertung von ÖPNVUnternehmensentscheidungen, so dass unternehmensseitig nicht darauf gebaut werden kann, dass sich die Kunden auf der Basis objektiv gehaltener Fakten eine vollständig eigene Meinung bilden können. Insofern hat der RMV eine eigene Berichterstattung, über die eine positive Stimmung vermittelt werden soll: Mit der RMV-eigenen Zeitschrift „RMVmobil“ werden dreimal im Jahr sämtliche Haushalte im RMV über aktuelle Neuerungen im ÖPNV informiert. Dabei besteht die Möglichkeit, in einem regionalen Teil auf Neuigkeiten aus den jeweiligen Zuständigkeitsbereichen der lokalen Aufgabenträger hinzuweisen. Somit wird die potenzielle Relevanz der vermittelten Information für die anonym angesprochenen Personen erhöht. Dennoch besteht nach wie vor das Defizit, dass nur wenige Kunden direkt angesprochen werden können.

Eine weitere Form der Öffentlichkeitsarbeit besteht in der Einberufung von Fahrgastbeiräten, die in der Regel periodisch gewählt werden. Sie sollen dafür Sorge tragen, dass die Bedürfnisse der Kunden in die Arbeit und Konzepte der Aufgabenträger und Verkehrsunternehmen einfließen. Der Fahrgastbeirat des RMV tagt viermal pro Jahr in wechselnden Städten im Verbundgebiet. Daneben haben neun weitere Aufgabenträger und Verkehrsunternehmen einen Fahrgastbeirat eingerichtet.1124 Blümel vom Wissenschaftszentrum Berlin für Sozialforschung kritisiert, dass Kundenforen und Fahrgastbeiräte vor allem von „verkehrspolitischen Akteuren“ besetzt seien, die „dem Unternehmen jedoch keine Rückmeldungen über die Bewertung der Dienstleistung aus Kundensicht geben“ ${ }^{1125}$

\subsubsection{Direktkommunikation}

Wie in Kapitel 3.8.2 dargestellt, entsteht durch die Fragmentierung bzw. die Individualisierung der Märkte eine Vielzahl von Zielgruppen mit geringer Homogenität, respektive

\footnotetext{
${ }^{1123}$ vgl. RMV 2005, S.100

1124 vgl. ww.rmv.de/coremedia/generator/RMV/WirUeberUns/StrukturDesRMV/Fahrgastbeirat (Zugriff am 7.1.2007)

1125 Blümel 2004, S.31
} 
mit vielen verschiedenen Bedürfnissen. Hierdurch wird eine gezielte Ansprache - und in der Konsequenz auch die dauerhafte Bindung des Kunden an ein Unternehmen - immer schwieriger. Denn je differenzierter die Wünsche der Kunden sind, desto anspruchsvoller ist die Ermittlung und Befriedigung der Kundenerwartungen. Im angebotsorientierten ÖPNV hat die Kundenerwartungen bislang eine nachrangige Bedeutung, mit dem Ergebnis, dass die Kunden „zweckorientiert“ behandelt werden. Unter „Kundenbeziehung“ wird heute weniger Kommunikation oder Dialog mit den Kunden verstanden, sondern der periodisch wiederkehrende Verkaufsvorgang. Eine Unterscheidung in Kundengruppen gibt es dabei allenfalls bei Abo-Kunden, deren Anzahl jedoch im RMV vergleichsweise gering ist (siehe Kapitel 6.3.4) und deren Betreuungsqualität und -umfang sich nach dem verkaufenden Verkehrsunternehmen richtet.

Die aktive Ansprache von bekannten ÖPNV-Kunden wie auch von potenziellen Nutzern, kann im Rahmen des Direktmarketings zur Gewinnung von Kunden sowie zur nachhaltigen Kundenbindung - und damit zur Einnahmensteigerung - maßgeblich beitragen. Zwar werden über eine anonyme Breitenwerbung mit Anzeigen und Plakaten mehr Kunden erreicht, doch liegt die Wirksamkeit dieser Werbemaßnahmen deutlich unterhalb derer von Maßnahmen mit persönlichem Kundenkontakt, deren Erfolg sich an der Dauerhaftigkeit der Kundenbeziehung bemisst. Dieses hängt wesentlich vom Aufbau der Maßnahmen ab: Einmalige Werbebriefe an Stammkunden (v.a. Abonnementen) ohne begleitende Aktivitäten (z.B. nochmaliges Nachfassen) haben sich als wenig zielführend herausgestellt. Vielmehr führen mehrstufige Kampagnen, die aus einer Abfolge schriftlicher und persönlicher Kommunikation bestehen dazu, dass Verhaltensroutinen aufgebrochen werden können. Wesentliches Merkmal der direkten Kommunikation ist dabei die direkte Antwort-Möglichkeit des Kunden („response“), beispielsweise über Rückantwortkarten oder eine Telefonnummer. ${ }^{1126}$ Gleichzeitig liefern die Stufen der Kampagnen in jeder Phase des Kundenlebenszyklus' aufschlussreiches Wissen für die Bildung und vertiefende Differenzierung von Zielgruppen, das in späteren Phasen der Kampagne wieder eingesetzt werden kann.

Zu den Direktmarketingmaßnahmen gehören u.a.:

${ }^{1126}$ vgl. Homburg und Krohmer 2003, S.666 
- Schriftliche Kommunikation (personalisierte Werbebriefe, Informationsbroschüren etc.),

- telefonische Kommunikation,

- Kundenclubs (inklusive Kundenzeitschriften),

- E-Mail-Newsletter.

Die Voraussetzung für direkte Kundenkommunikation aber ist das Kennen der Kundenadressen, die heute entweder nur von Stammkunden vorliegen oder im Rahmen von Promotions, Werbesendungen (unpersonalisierte Postwurfsendungen mit Antwortmöglichkeit) etc. mühsam gesammelt werden müssen. ${ }^{1127}$ Dass die gezielte und direkte Ansprache von Zielgruppen aber an Bedeutung zunimmt, glauben immerhin 84\% der in der „Delphi-Studie zum ÖPNV-Markt der Zukunft“ befragten ÖPNV-Experten. ${ }^{1128}$

Auf ihrer Internetseite www.rmv.de bietet die $R M V-G m b H$ seit einiger Zeit „personalisierte Dienste“ an, über die der Kunde u.a. eine Verbindungsauskunft, An- und Abfahrtszeiten am Frankfurter Flughafen, einen deutschlandweiten Routenplaner und einen Aktivitätenplaner nutzen kann. Grundsätzlich sind dies jedoch Dienste, die auch anonym genutzt werden könnten. Die Personalisierung erfolgt, damit die Nutzer ihre „ermittelten Routen ${ }^{1129}$ in der Ablage abspeichern“ können. Außerdem kann der Nutzer seine „Mobilitätsvorgaben und Orte [...] im Profil abspeichern und bei neuen Abfragen wieder aufrufen“. ${ }^{1130}$ Die Nutzung dieser Daten im Rahmen von Direktmarketingmaßnahmen bleibt allerdings - auch aus Kundensicht - unklar.

\subsubsection{Vertriebspolitik}

\subsubsection{Vertriebsorganisation}

Die Aufgabenträger (lokal die LNO bzw. Städte/Landkreise, regional der RMV) haben als Besteller der Verkehrsleistung und der damit zusammenhängenden Einnahmeverantwortung ein großes Interesse an einer umfassenden und qualitativ hochwertigen Kundenbetreuung, wozu der Verkauf von Fahrtberechtigungen und die Kundeninformation ge-

\footnotetext{
${ }^{1127}$ vgl. Heller 2003, S.4

${ }^{1128}$ vgl. Deutsches Verkehrsforum, S.117

1129 Möglich ist auch die Ablage von Haltestellen.

${ }^{1130}$ vgl. www.rmvplus.de (Zugriff am 16.7.2006)
} 
hören. Die Durchführung des Vertriebs und die Auswahl der Vertriebs- und Informationskanäle liegt aber in der Verantwortlichkeit eines Verkehrsunternehmens selbst. Diese Vertriebsleistung stellt(e) bislang einen integralen Bestandteil der Erbringung der Verkehrsleistung durch die Verkehrsunternehmen dar. Allerdings gibt es etliche Aufgabenträgerorganisationen, die aufgrund ihrer Entstehung aus einem kommunalen Verkehrsunternehmen noch über Linienkonzessionen verfügen und ebenfalls Vertriebseinrichtungen vorhalten. Letztlich verkauft also jedes kommunale Verkehrsunternehmen - wie im PBefG als gewerberechtliches Regelwerk festgehalten - Fahrkarten in seinem Gebiet bzw. auf „seiner Linie“. Eine Ausnahme hiervon stellt allerdings die DB AG dar, die aufgrund ihrer regionalen Präsenz in den Verkaufsgebieten der kommunalen Verkehrsunternehmen oftmals als Vertriebskonkurrent wahrgenommen wird. Der gesamte Vertrieb im ÖPNV ist also von ausgesprochener Heterogenität gekennzeichnet, mit stark redundanten und konkurrierenden Strukturen sowie althergebrachten Verfahren. Es gibt keine einheitliche Vermarktung des ÖPNV-Angebots, sondern lediglich einen Verkauf von Fahrkarten über die unterschiedlichen und vom Verkehrsunternehmen selbst bestimmten Vertriebskanäle. Übergeordnete Richtlinien gibt es im RMV für Merkmale von Papierfahrkarten (z.B. Sicherheitsanforderungen) sowie das Aufstellen von Verkaufsgeräten oder für technische Anforderungen an die Verkaufsinfrastruktur. ${ }^{1131}$

\subsubsection{Vertriebskanäle}

Da bei der ÖPNV-Beförderungsleistung die räumliche und zeitliche Produktion mit dem Absatz zusammenfallen (vgl. Kapitel 6.1.2), spielen physisch-logistische Verteilungs- und Lagerungsprozesse eine nur untergeordnete Rolle. ${ }^{1132}$ Die Vertriebs- (oder auch Absatz-) kanäle sind daher das wichtigste Instrument der Vertriebspolitik. Sie wird unterschieden in Kanäle des direkten (verkehrsunternehmenseigene Kanäle) und des indirekten (verkehrsunternehmensfremde Kanäle) Vertriebs. Die direkten Vertriebskanäle können nochmals differenziert werden nach zentralen/dezentralen sowie selbstbedienten/personalbedienten Verkaufskanälen (siehe Abbildung 36).

${ }^{1131}$ vgl. RMV 2005, S.93

1132 Zwar gibt es im Rahmen der Wartung von z.B. Fahrkartenautomaten die Notwendigkeit der Bereitstellung von Fahrkartenpapier sowie der Entsorgung des Bargeldes, was ebenfalls logistische Prozesse nach sich zieht. Diese Aspekte spielen hier jedoch nur eine untergeordnete Rolle. 


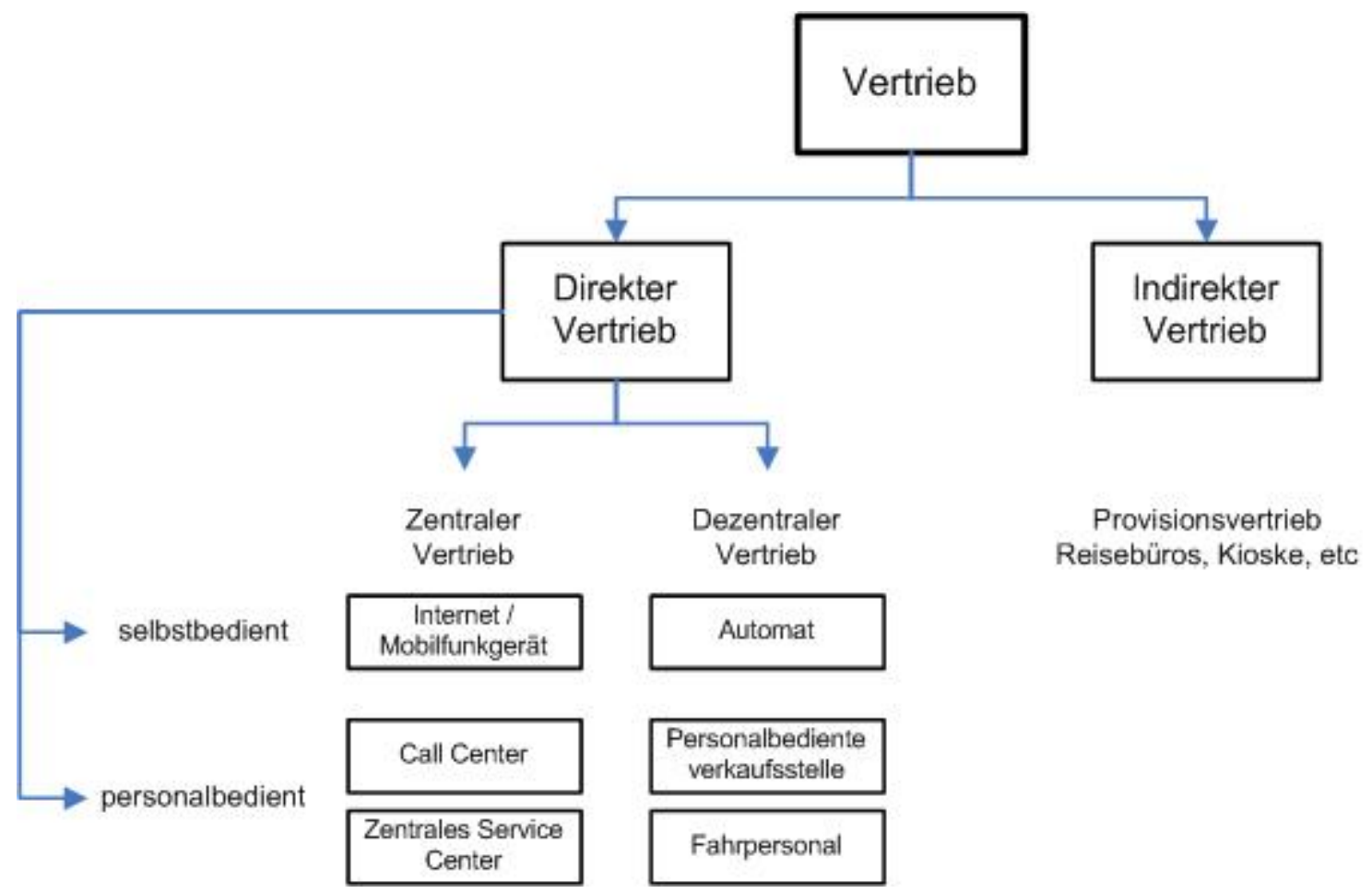

Abbildung 36: Differenzierung von Vertriebskanälen

Quelle: Eigene Darstellung

Im Hinblick auf die Verfügbarkeit von Vertriebsstellen stellt sich dem Kunden heute folgendes Bild dar: Bezogen auf die einzelnen Verkehrsmittel besteht ein durchgängiges Grundangebot. In den Bussen gibt es einen Verkauf durch die Busfahrer (allerdings auch hier mit Ausnahmen, bspw. die Stadt Mainz oder die Stadt Darmstadt, in der es mobile Fahrkartenautomaten in den Fahrzeugen gibt). Im Schienenverkehr erfolgt der Verkauf über Fahrkartenautomaten, die grundsätzlich an den $\mathrm{Zu}$ - und Abgängen positioniert sein sollen, gelegentlich aber auch auf den Bahnsteigen stehen oder sogar in den Fahrzeugen. Im Busverkehr wird der Verkauf an besonders stark frequentierten Haltestellen, etwa Omnibusbahnhöfen, ebenfalls durch stationäre Fahrkartenautomaten unterstützt.1133

Dieses Grundangebot im Vertrieb wird manchenorts durch personenbediente Verkaufsstellen ergänzt. Hier muss wiederum in bezug auf die dargebotene Dienstleistung differenziert werden: Verkaufsstellen auf Provisionsbasis (Kioske, Zeitungsläden, Reisebüros etc.) bieten nur den Verkauf von Fahrkarten an; Verkaufsstellen der Verkehrsunternehmen bieten auch Information wie Fahrplanauskünfte an; Mobilitätszentralen beraten die

1133 vgl. RMV 2006 (b), S.37 
Kunden umfassend. Der Fahrkartenverkauf sollte hier nur ein Bestandteil einer umfassenden Mobilitätsberatung sein. ${ }^{1134}$

Je nach Vertriebskanal sowie Örtlichkeit gibt es Unterschiede im Fahrkartenangebot: Verbundweit werden über die Busdrucker in den Bussen alle Einzelfahrkarten, Tageskarten sowie Gruppentickets (einschließlich Hessenticket) vertrieben. Insbesondere in ländlichen Bereichen werden aber auch Zeitkarten - bis hin zur Monatskarte - durch das Fahrpersonal verkauft. Das selbe Sortiment wird in der Regel auch über die Fahrkartenautomaten angeboten. Zeitkarten (Wochen- und Monatskarten sowie Jahreskarten) werden in den Verkaufsstellen vertrieben. Darüber hinaus gibt es in größeren Städten sowie bei der DB AG auch Fahrkartenautomaten, an denen Zeitkarten (bis hin zur Monatskarte) erhältlich sind.

\begin{tabular}{|l|l|}
\hline Autorisierte Vertriebspartner & mehr als 150 \\
\hline Personalbediente Verkaufsstellen & ca. 900 \\
\hline Fahrkartenautomaten & ca. 1.700 \\
\hline Card-o-maten & 38 \\
\hline Webshops (mit Verkauf von Fahrkarten) & $\begin{array}{l}4^{*}: \text { ESWE-Wiesbaden, } \\
\text { Main-Taunus-Verkehrsgesellschaft, } \\
\text { Offenbacher-Verkehrsbetriebe, Verkehrsge- } \\
\text { sellschaft Frankfurt }\end{array}$ \\
\hline & $*$ Stand: April 2007
\end{tabular}

Tabelle 10: Kennzahlen zum Vertrieb im RMV

Quelle: RMV 2005 (a), S. 93

Der Vertrieb von Fahrkarten über das Internet (per Post) - obwohl räumlich nicht auf ein bestimmtes Gebiet begrenzt - geschieht ebenfalls durch mehrere Anbieter (siehe Tabelle 10). Als selbstbediente dezentrale Verkaufsautomaten existieren außerdem noch die sog. "Card-o-maten", die ausschließlich in geschützten halböffentlichen Räumen (bspw. in Bankenfoyers) aufgestellt sind. Hier ist auch der (ausschließlich bargeldlose) Erwerb von Jahreskarten möglich. ${ }^{1135}$ Diese können sonst nur an personenbedienten Verkaufsstellen (anonym oder im Abonnement) erworben werden.

Der Vertrieb von Jobtickets wird über die $R M V G m b H$ zentral angebahnt, die Einnahmen hieraus aber sämtlich den Verkehrsunternehmen zugeordnet. Ebenfalls werden die Tarif-

${ }^{1134}$ vgl. www.rmv.de/coremedia/generator/RMV/Service/Infos/MobiZ (Zugriff am 7.1.2007) ${ }^{1135}$ vgl. RMV 2006 (b), S.37 
verhandlungen mit den Allgemeinen Studentenvertretungen (Asten) der Universitäten und Fachhochschulen durch die RMV GmbH geführt. Die Einnahmen hieraus werden den lokalen Aufgabenträgerorganisationen zugeschieden, in deren Gebieten sich die Universitäten und Fachhochschulen jeweils befinden. Hierbei handelt es sich also um eine zentrale Vertriebsform. ${ }^{1136}$

Zentrale Vertriebsformen sind damit im RMV weitgehend unterrepräsentiert. Das CallCenter des RMV erteilt lediglich Auskünfte bei eingehenden Anrufen und ist zentrales Element im Rahmen des Beschwerdemanagements. Bei einigen Angeboten (Semesterticket, Jobticket) übernimmt die RMV GmbH Funktionen eines Zentralen Service Centers. Gerade im Segment der Abo-Kunden, wo eine zentrale Abwicklung besonders geeignet wäre, gibt es keine Kooperation zwischen den einzelnen Verkehrsorganisationen. Gleiches gilt für den Internetvertrieb, der von den vier betreibenden Unternehmen ohne Bündelung von Vertriebsprozesse durchgeführt wird. Die wohl bekannteste Internet-Präsenz unter den Verkehrsorganisationen, die des RMV, bietet bislang (noch) keine Kaufoption an. Seit April 2006 ist es aber möglich, für die Tarifzone Frankfurt eine (oder auch mehrere) Einzelfahrkarten (auch Kurzstrecke), Tageskarten sowie Gruppentageskarten über das Mobilfunkgerät zu kaufen. Voraussetzung ist die Anmeldung über Internet. Abgerechnet wird über Lastschrifteinzug oder Kreditkartenbelastung. ${ }^{1137}$

Durch die weitgehend unabgestimmte Vorgehensweise im Bereich der Vertriebskanalentwicklung muss konstatiert werden, dass es kaum Möglichkeiten gibt den Vertriebskanalmix zu optimieren. Obwohl es mit dem Vertrieb von Fahrkarten über das Internet und das Mobilfunkgerät erste, gute Ansätze der Vertriebsmodernisierung gibt, blieb die Anwendungen technologischer Neuerungen in anderen Vertriebskanälen bislang aus. Abbildung 37 veranschaulicht an einem Informationsblatt der Hanauer Straßenbahn AG aus dem Jahre 1965, dass sich im Prinzip in den letzten 40 Jahren, seit Einführung des fahrerbedienten Verkaufs in Bussen, am Verkaufsvorgang „auf dem Fahrzeug“ grundsätzlich nichts verändert hat. Dies trifft prinzipiell auch auf andere personalbediente Vertriebskanäle zu.

\footnotetext{
1136 vgl. RMV 2005, S.91

1137 vgl. gemeinsame Presseerklärung von RMV, Traffiq und VGF v. 26.04.2006: „Ab sofort kann man für Frankfurt RMV-Fahrkarten per Handy kaufen“.
} 


\title{
"Sie fragen- \\ wir antwarten!"
}

\author{
Fahrgast: "Was ist denn ein Einmannbus?" \\ Verkehrsbetrieb: "In einem Einmannbus gibt es keinen \\ Schaffner. Der Fahrer muß fahren, kassie- \\ ren und die Fahrscheine ausgeben." \\ Fahrgast: "Kann das der Fahrer alles schaffen?" \\ Verkehrsbetrieb: "Ja, da das Kassiergeschäft sich an den \\ Haltestellen abwickelt, wie es bereits auch \\ bei anderen Verkehrsbetrieben durchge- \\ führt wird." \\ Fahrgast: „Werden dabei die Aufenthalte an den \\ Haltestellen nicht sehr lang?" \\ Verkehrsbetrieb: "Das wird im allgemeinen schnell vor sich \\ gehen, wenn jeder Fahrgast das Fahrgeld \\ oder seinen Fahrtausweis bereit hält. \\ Außerdem ist der Fahrer mit einem Fahr- \\ scheindrucker und einer Wechselkasse \\ ausgerüstet." \\ Fahrgast: Ist das alles, was Sie für den Fahrer tun?" \\ Verkehrsbetrieb: "Nein, die neven Einmannwagen haben \\ ein automatisches Getriebe. Dadurch wird \\ sein Dienst am Steuer wesentlich erleich- \\ tert."
}

\section{Hanauer Straßenbahn AG}

Abbildung 37: Informationsblatt zur Einführung der "Einmannbusse“ von Oktober 1965.

Quelle: Hanauer Straßenbahn AG

\subsubsection{Fahrausweiskontrollen}

Fahrausweiskontrollen dienen vornehmlich der Reduzierung der Fahrgeldhinterziehung und damit der Einnahmensicherung, d.h. sie sollen die Effizienz des Verkehrsunternehmens verbessern. Problematisch ist hierbei, dass die Prüfkosten selbst - v.a. in Form von Personalkosten - beträchtlich sind und sich am ehesten rechnen (durch die Erhebung von erhöhten Beförderungsentgelten, EBE), wenn die Kontrolldichte und die Aufdeckung hinterzogener Fahrgelder in einem optimalen Verhältnis zueinander stehen. Tatsächlich 
ist die Kontrolldichte aber gering und der Verlust durch entgangene Einnahmen entsprechend hoch. Grote, Himmelmann und Prim zufolgen, entgehen

"Jährlich [...] den Verkehrsunternehmen in Deutschland mehrere hundert Millionen Euro durch Fahrgäste ohne Fahrschein. Vielerorts wird versucht, eine Balance der Prüfdienstkosten mit den erzielten Einnahmen aus dem erhöhten Beförderungsentgelt zu erreichen". ${ }^{1138}$

Die Fahrausweiskontrollen werden vornehmlich in der Verantwortung der Verkehrsunternehmen in Form von Stichproben durchgeführt. In der Stadt Frankfurt am Main werden Fahrausweiskontrollen aber in Ausschreibungen im Busverkehr vorgeschrieben.1139 Im Regionalverkehr auf der Schiene erfolgte die Fahrausweiskontrolle bislang durch die Kundenberater im Nahverkehr (KIN). Durch die praktizierte automatisierte Zugabfertigung (z.B. bei Doppelstockwagen neuerer Bauart) wird dieses Personal nun aber vermehrt eingespart, was sich ebenfalls negativ auf die Kontrolldichte im Regionalverkehr auf der Schiene auswirkt. Seit einiger Zeit setzt sich vor allem bei Busverkehrsunternehmen der Einstieg beim Busfahrer durch. Im ländlichen Bereich und im Regionalverkehr geschieht dies durchgängig, im Ballungsraum oft in den Abendstunden (z.B. in Wiesbaden nach 20 Uhr). Dabei müssen die Fahrausweise dem Fahrpersonal bei Einstieg vorgezeigt werden, das die Gültigkeit überprüft. Bei den Berliner Verkehrsbetrieben geht man davon aus, dass es durch die Einführung des kontrollierten Einstiegs zu einer Einnahmesteigerung von über $6 \% \mathrm{kam} .{ }^{1140}$

Allerdings ist nicht nur die Produktivität der Kontrolle ausschlaggebend, sondern auch die Qualität, d.h. die Prüfgenauigkeit. Schlecht ausgebildetes und motiviertes Prüfpersonal, das mit der Tarif- und Produktvielfalt überfordert ist oder Fälschungen und Verfälschungen nicht identifizieren kann sowie Fehler bei der Kontrolle selbst sind für den Erfolg der Fahrausweiskontrolle abträglich. Diese Unsicherheit bei der Fahrkartenkontrolle sowie unklare Kulanzregeln können auch auf der Kundenseite zu ausgeprägtem Missmut führen. Schließlich führt der hohe Aufwand in der Nachbearbeitung - inklusive der Bearbeitung der Kundenreklamationen - zu einer Erhöhung der Ineffizienz der Kontrollen. ${ }^{1141}$

\footnotetext{
1138 Grote, Himmelmann und Prim 2002, S.61

1139 vgl. Schäfer-Sparenberg, Bongardt und Dalkmann 2006, S.45

1140 vgl. Reinhold 2006, S.15

${ }^{1141}$ vgl. Grote, Himmelmann und Prim 2002, S.63
} 


\subsection{Technische Instrumentarien}

6.6.1 Technische Innovationen im Verkehr

In der neueren innovationstheoretischen Forschung wird betont, dass Innovationen stets als erfolgreiche Kombination von Ausrüstung (hardware) und Ideen (software) unter bestimmten gesellschaftlichen und institutionellen Bedingungen angesehen werden. Demnach geht es nur auf den ersten Blick um technische Aspekte. Dies trifft auch auf die marktgerechte Nutzung und den Nutzen von IuK-Technologien (respektive Telematikanwendungen) im Verkehrsbereich zu. Zu den gesellschaftlichen und institutionellen Voraussetzungen für die erfolgreiche Einführung von technischen Maßnahmen zählen sowohl die staatliche Förderung von technologischen Forschungsvorhaben, die Bereitstellung notwendiger Infrastrukturen sowie die Schaffung günstiger rechtlicher Rahmenbedingungen. Schließlich spielt auch das gesellschaftliche Interesse bei der erfolgreichen Akzeptanz von technischen Innovationen eine entscheidende Rolle. Dabei trifft man häufig auf polarisierende und starre Meinungsbilder, die technologische Neuerungen entweder grundsätzlich positiv einschätzen, auch im Hinblick auf die Nachhaltigkeit ihres Einsatzes, oder aber grundsätzlich ablehnend sind und technische Innovationen vornehmlich zur Effizienzsteigerung von technischen Systemen selbst wahrnehmen. Beide Meinungsbilder vernachlässigen allerdings, dass Technik zunächst einmal neue Gestaltungsräume eröffnen soll. ${ }^{1142}$ So kann beispielsweise der gesteigerte Wirkungsgrad eines Automotors dazu genutzt werden, den Wagen mit mehr Leistung auszustatten oder aber den Verbrauch und damit den Schadstoffausstoß zu reduzieren. Insofern gilt es, die Möglichkeiten, aber auch die Folgen des Einsatzes neuer Technologien bereits im vorhinein abzuschätzen und schließlich im Rahmen eines Gesamtsystems zu erschließen. Halbritter u.a. äußern sich diesbezüglich wie folgt:

„Erst die Integration verschiedener Einzeltechniken stellt somit sicher, dass die Systemvorteile neuer Technikkonzepte insgesamt realisiert werden können. Diese Integration kann nur dann erfolgreich sein, wenn Organisationsstrukturen vorliegen, die die Konzeptentwicklung, die Koordinierung und die praktische Durchführung des Aufbaus und Betriebs der Dienste leisten". ${ }^{1143}$

\footnotetext{
1142 vgl. Halbritter u.a. 2005, S.28

${ }^{1143}$ Halbritter u.a. 2005, S.32
} 
Die technologischen Neuerungen im ÖPNV beschränkten sich in der Regel auf die ingenieurs-affinen Bereiche der Fahrzeugtechnik, der Betriebssteuerung oder der Infrastruktureinrichtungen. Gerade die Komplexität und der Koordinationsaufwand der Integration der unterschiedlichen Entwicklungsstadien der einzelnen Techniken behindern häufig die Einführung einheitlicher technologischer Neuerungen bei mehreren Verkehrsunternehmen gleichzeitig. Auch dauert die Entwicklung konkreter Anwendungen bis zur praxisreifen Einführung häufig länger, als die Innovationszyklen der zugrunde liegenden Techniken selbst. „Für den Erfolg der Telematik ist es [daher] unverzichtbar, erfolgversprechende Techniken auch dann in der Praxis einzuführen, wenn sich neue Weiterentwicklungen für die Einzeltechniken bereits abzeichnen“. ${ }^{1144}$ Anderenfalls wird die Vision des „high-tech“-Prozesses, die von der Vorstellung genährt wird, dass demnächst noch höherentwickelte Technologien mit erweitertem Nutzungsspektrum vorliegen, jegliche Innovation verhindern. ${ }^{1145}$ Insofern sollte die Praxis der Vergabe von ÖPNVVerkehrsleistungen im Ausschreibungswettbewerb auch dazu genutzt werden, Innovationen nicht nur zeitnah, sondern vergleichsweise kostengünstig umzusetzen.

\subsubsection{Entwicklung der Telematik im ÖPNV}

Bezogen auf den ÖPNV kann festgestellt werden, dass die Nutzbarmachung innovativer technologischer Entwicklungen der vergangenen Jahre an diesem keineswegs spurlos vorbei gegangen ist. Allerdings betrafen die Neuerungen vor allem Bereiche, die ohnehin schon "technikgeprägt“ waren, also beispielsweise die Fahrzeug- oder Verkehrsleittechnik (inklusive der Fahrzeugortung), die Beeinflussung von Lichtsignalanlagen oder die Einführung von Rechnergestützten Betriebsleitsystemen (siehe Kapitel 4.6). So gut wie ausgespart von der technologischen Entwicklung blieb das gesamte Marketing des ÖPNV, also die Schnittstelle zum (potenziellen) Kunden. ${ }^{1146}$ Die Ausnahme bildet hier die Einführung von elektronischen Fahrgastinformationssystemen in Form von Fahrplanauskünften im Internet und über das Mobilfunkgerät sowie (dynamische) Fahrplananzeiger an Haltestellen. Auch der VDV kommt zur Einschätzung, dass viele dieser Neuerungen in der Vergangenheit „Einzellösungen“ darstellten und Telematiklösungen „deshalb heute stets übergreifend angelegt sein“ müssen. Die Herausforderung bestünde nun darin, „[...]

\footnotetext{
1144 ebd., S.33

1145 vgl. Halbritter u.a. 2005, S.33

1146 vgl. Sparmann, V. 2005, S.74
} 
die Integration der bereits bestehenden konventionellen Technik in die neusten Informations- und Kommunikationstechnologien“ zu ermöglichen, „damit ein optimal funktionierendes Gesamtsystem entsteht “. ${ }^{1147}$

Der Einsatz von technischen Instrumentarien (auf Basis von IuK-Technologie) ist also stets als Mittel zum Zweck zu betrachten und nicht als Problemlösung an sich. Die eindimensionale Anwendung von Verkehrstelematik dient eher der Fortschreibung bisheriger Entwicklungstrends. ${ }^{1148}$ Das heißt, dass technische Maßnahmen immer in einer Gesamtstrategie eingebunden sein müssen, in der jeder Verkehrsträger entsprechend seiner spezifischen Stärken zum Einsatz kommt und hierüber die vorhandenen Ressourcen voll ausschöpft.

\subsection{Fazit: Schaffung einer technisch-organisatorischen Plattform für die Vermarktung von Mobilitätsdienstleistungen}

In bezug auf den Einsatz der Marketinginstrumente kommt es bei den unterschiedlichen Akteuren im RMV-Verbundgebiet nicht nur aufgrund ihrer oftmals unklaren Zuständigkeiten zu einem sehr unterschiedlichen Einsatz. Die $R M V G m b H$ selbst - als regionaler Aufgabenträger - versteht es, die klassischen Marketinginstrumentarien in ihrem Zuständigkeitsbereich stetig zu optimieren. Dies gilt insbesondere für die Instrumente der Produktpolitik, wenngleich der Grad an Marktorientierung im Sinne einer innovativen und flexiblen Anpassung des Angebots an veränderte Kundenwünsche verbessert werden könnte. Im Bereich der Preispolitik sind jedoch die vorhandenen Instrumentarien in der angewandten Weise ausgereizt. Da das Tarifniveau die obere Grenze der Marktverträglichkeit erreicht hat und von einer fortschreitenden Kürzung öffentlicher Mittel ausgegangen werden muss - mit einhergehenden Angebotsverknappungen - droht zukünftig eine verschlechterte Marktausschöpfung bzw. eine verringerte Kostendeckung.

Für eine Kompensation wird es daher wesentlich auf den verbesserten Einsatz der Marketinginstrumentarien aus den Bereichen der Kommunikations- und Vertriebspolitik ankommen. Diese Bereiche sind bislang hauptsächlich das originäre Geschäft der im Kundenkontakt stehenden Verkehrsunternehmen. Diese gehen aber größtenteils unabgestimmt am Markt vor, nicht zuletzt aufgrund ihres Konkurrenzverhältnisses zueinander.

\footnotetext{
1147 vgl. VDV 2001, S.22

1148 vgl. Henning und Schmidt 1998, S.23
} 
Ansätze der Verbesserung der Kommunikationspolitik durch den Einsatz neuer Medien (z.B. Fahrplanauskunft über das Mobilfunkgerät und Internet) sind hauptsächlich von der RMV GmbH initiiert. Eine aktive Ansprache und Betreuung von Zielgruppen oder Einzelindividuen zur Kundenbindung findet nicht statt, zumal hierfür zentrale Strukturen notwendig wären, die bislang nicht existieren.

Als besonders unterentwickelt präsentieren sich vor allem die Instrumente der Vertriebspolitik. Zwar gibt es - ebenfalls initiiert durch die $R M V G m b H$ - vielversprechende Ansätze in der Erprobung neuer Technologien (Elektronisches Fahrgeldmanagement und Vertrieb über Mobilfunkgeräte), aber macht auch hier die organisatorische Zersplitterung der Vertriebslandschaft die Optimierungsbestrebungen schwierig. Dies könnte sich mit den oben beschriebenen organisatorischen Veränderungen der Aufgabenzuständigkeiten allerdings ändern. Denn die eindeutige Zuteilung von Verantwortlichkeiten - im Sinne von verteilten Zuständigkeiten sowie Rollen und nicht Hierarchien - dient nicht nur der Zielbildung im jeweiligen Unternehmen, sondern auch der Strukturierung der Interaktionsmöglichkeiten. Hierfür ist die kommunikationstechnischen Vernetzung aller ÖPNVAkteure (und anderer Verkehrsträger) notwendig. Diese Vernetzung ist gleichzeitig die Basis für eine kunden- und marktorientierte Ausrichtung des ÖPNV und einen optimalen Einsatz der Marketinginstrumente, die es erlaubt, dort zu handeln, wo es Marktveränderungen und Kundenwünsche erforderlich machen. Damit würde auch die Grundlage für die Herausbildung einer einheitlichen (Marketing-) Strategie gelegt, die unterschiedliche Lösungsansätze als Maßnahmenmix integriert und auf einen Bereich konzentriert.

Ohne eine solche Gesamtstrategie werden auch telematikgestützte Lösungsansätze in Zukunft nicht oder nur selten zu den gewünschten Effekten führen. Bei der Entwicklung telematikgestützter Lösungsstrategien müssen zudem gesellschaftliche Trends und Funktionsprinzipien von sozialer und geographischer Mobilität in stärkerem Maße Berücksichtigung finden. So kann Telematik viel dazu beitragen, auch die Akzeptanz des ÖPNV zu stärken, indem der höhere Informationsbedarf gegenüber dem MIV (zumindest teilweise) kompensiert wird und das jeweilige Verkehrsmittel entsprechend seiner systembedingten Stärke ökologisch wie ökonomisch sinnvoll eingesetzt wird. Voraussetzung ist aber auch hier das organisatorische Zusammenspiel aller Akteure im Verkehrsmarkt. Insgesamt sind Informations- und Kommunikationstechnologien also immer „Mittel zum Zweck“. 
Neben der engen und abgestimmten Kooperation zwischen Unternehmen ist des weiteren die unternehmensinterne Positionierung im wettbewerblichen Markt von Bedeutung. Neben der Einführung moderner und zeitgemäßer Steuerungs- und Controllingwerkzeuge ist hier die Ausrichtung aller Prozesse auf den Kunden von Relevanz. Die Befähigung der offensiven Marktbearbeitung ist demnach nicht Aufgabe der Marketingabteilung. ${ }^{1149}$ Sie setzt vielmehr ein organisatorisches Zusammenwirken aller Beteiligten auf den unterschiedlichsten Unternehmensebenen voraus: Von der Angebotsplanung über die Produktentwicklung und der innerbetrieblichen und externen Vermarktung über unterschiedliche Kommunikations- und Vertriebskanäle bis hin zur dauerhaften Qualitätssicherung. Aus dem Anspruch der Entwicklung hin zu einem „Mobilitätsdienstleister“ oder der Konzentration auf die effiziente Erbringung der Beförderungsleistung lassen sich konkrete Zieldefinition ableiten. Diese sind nicht alleine bestimmend für die Herausbildung einer geeigneten Organisationsstruktur. Hierüber können auch technische Maßnahmen und Instrumente identifiziert werden, die geeignet sind, diese Ziele zu erreichen.

Hinderlich für einen ganzheitlichen Lösungsansatz ist, dass technikorientierte Ansätze nach wie vor noch sehr stark im Vordergrund stehen. Dies hängt aber nur teilweise mit der rasanten Entwicklung bei den Informations- und Telekommunikationstechnologien zusammen. Insbesondere die Industrieseite propagiert, dass alleine durch den Einsatz neuer (Informations-) Technologien Verkehrsprobleme gelöst werden können. Entsprechende Signale werden vor allem in Richtung der Entscheidungsträger gesendet, die häufig in den Verwaltungen sitzen. Und dort existiert eine traditionell stärker auf Investition ausgerichtete Denkweise bei der Lösung von Problemen. Infrastrukturmaßnahmen, deren - wenn auch bescheidene - Erfolge sich vielleicht schneller einstellen, stehen in der Gunst insofern vor Organisationsstrukturmaßnahmen, die auf langfristige Verbesserung ausgelegt sind - und deren Erfolg sich oft erst nach Ablauf von Legislaturperioden einstellt. Dennoch ist festzustellen, dass immer mehr Entscheidungsträger in den verantwortlichen hoheitlichen Genehmigungs-, Entscheidungs- und Planungsinstanzen (Verkehrsbehörden, Ministerien, Verbund) die Notwendigkeit des Handelns vom Grundsatz her erkannt und sogar erste Initiativen zur Sicherung der Mobilität in der Region eingeleitet haben. Die angepassten administrativen und gesetzlichen Rahmenbedingungen (EUVerordnung, Hess. ÖPNV-Gesetz) ergeben für die notwendigen organisatorisch-

${ }^{1149}$ vgl. Meyer 2005, S.9 
strukturellen Veränderungen bei der Vermarktung der ÖPNV-Leistung den erforderlichen Freiraum. Für eine verbesserte gesamtheitliche Vermarktung der teuer erstellten ÖPNV-Leistung und einer daraus resultierenden Verlagerung von Fahrten auf Busse und Bahnen mit der Verbesserung der Wirtschaftlichkeit des ÖPNV, fehlt allerdings bislang noch eine technisch-organisatorische Plattform. 


\title{
$7 \quad$ Erschließung der Effizienzpotenziale über E-Ticketing
}

\author{
„Die Technik entwickelt sich vom Primitiven über das Komplizierte zum Einfachen." \\ Antoine de Saint-Exupéry
}

\subsection{Strategischer Ansatz}

Entscheidend für das wirtschaftliche Bestehen vieler kommunaler, aber auch mittelständisch privater ÖPNV-Unternehmen, ist die Weiterentwicklung vom öffentlichen Transportunternehmen zum unternehmerisch handelnden Dienstleister. ${ }^{1150}$ Der Erfolg des hierfür notwendigen Transformationsprozesses ist allerdings an Voraussetzungen geknüpft. Zuallererst muss bei den Entscheidungsträgern in den Unternehmen sowie bei den Eigentümern die Erkenntnis reifen, dass Veränderungen notwendig sind, um den veränderten Bedürfnissen des Verkehrsmarktes gerecht zu werden. Diese Erkenntnis muss sich in der strategischen Ausrichtung und in der Organisationsstruktur und Unternehmensführung der Verkehrsunternehmen niederschlagen. Soll die Marktpositionierung als innovativer Mobilitätsdienstleister vom Kunden als gerechtfertigt wahrgenommen werden, bedarf es ferner der Verbreiterung der Angebotsbasis - auch über die ausgeschriebene Verkehrsleistung hinaus. Der Erfolg der angebotenen Mobilitätsdienstleistungen wird wiederum entscheidend davon abhängen, inwieweit dem Prinzip der sogenannten Multimodalität zum Durchbruch verholfen werden kann. Voraussetzung für die Erschließung von Vermarktungspotenzialen ist ferner eine Unvoreingenommenheit gegenüber dem „Konkurrenten“ Auto sowie solides Wissen über die Kundenbedürfnisse und deren Nachfrageverhalten. Schließlich werden Marketingstrategien benötigt, die den Einsatz aller Marketinginstrumente vorsehen und deren Potenziale für den ÖPNV ausschöpfen.

Ziel der Umsetzung der Marketingstrategie muss es sein, die Kunden nicht nur argumentativ, sondern auch gefühlsmäßig zu überzeugen. Dabei soll der Kunde möglichst direkt und bedürfnisorientiert angesprochen werden, wozu Angebote notwendig sind, die nicht nur einen Teil der Wegekette abdecken, sondern von „Haustür zu Haustür“ reichen. Es

${ }^{1150}$ vgl. Deutsches Verkehrsforum 2005, S.99 
gilt Preisstrategien zu entwickeln, die die oft gegensätzlichen Prinzipien wie Einfachheit, Differenzierung und Preisanreize zusammenführen. Schließlich soll die Verkehrsmittelwahl für den Kunden so einfach wie möglich gestaltet sein. Nur so wird die meist starre und extrem routinemäßige (habitualisierte) Wahl eines Verkehrsmittels (egal ob Pkw oder Bus bzw. Bahn) durch eine echte Auswahl zwischen den bestehenden Alternativen überwunden werden können. Dieser Auswahlvorgang muss im Idealfall genauso einfach, unkompliziert, bequem und schnell vom Kunden zu bewältigen sein, wie heute der Griff zum Autoschlüssel.

In dieser Hinsicht befinden sich einige Vorreiter der ÖPNV-Branche bereits auf einem richtigen Weg, wie Beispiele (Haus-zu-Haus-Fahrplanauskünfte, Mobilitätspakete mit periodischer Mobilitätsrechung) eindrucksvoll zeigen. Vor dem Hintergrund einer sich ausweitenden Zersiedlung sowie räumlich verteilten Wirtschaftsstandorten stellt diese Aufgabe aber für den straßengebundenen ÖPNV außerhalb der Ballungszentren eine immense Herausforderung dar. Für den schienengebundenen ÖPNV (SPNV) mit seinen festen Trassen ist dies insbesondere im ländlichen Raum sogar ein ernstes Problem, denn auf die sich verändernden Raumstrukturen können die Verkehrsunternehmen mit kostenintensiven Infrastrukturen nur beschränkt reagieren (aufgrund der zurückgehenden Nachfrage werden Schieneninfrastrukturen sogar zurückgebaut). An das ÖPNVLeistungsangebot werden in der Zukunft daher neue Anforderungen in bezug auf Flexibilität gestellt werden, sei es für die Bedienformen oder für die Tarifangebote.

Ein Instrument zur Modernisierung des ÖPNV ist das „Electronic Ticketing“ (ETicketing), das im Deutschen häufig mit „Elektronischem Fahrgeldmanagement“ (EFM) bezeichnet wird. Dabei geht es nur vordergründig um die Weiterentwicklung der bestehenden Fahrgeldmanagementsysteme, weshalb die Gleichsetzung von E-TicketingSystemen mit Elektronischem Fahrgeldmanagement auch zu kurz greift. Kossak zufolge geht es beim E-Ticketing um folgendes:

"Es geht aber eben nicht nur um die Verbesserung der Wirtschaftlichkeit des Fahrgeldmanagements, sondern um Modernisierung, Attraktivitäts- und Effizienzsteigerung des öffentlichen Personenverkehrs insgesamt; es geht um die Vertriebs-, Marketing-, Management-, Planungs-, Informations- und Kommunikationssysteme“. ${ }^{1151}$

${ }^{1151}$ Kossak 2005, S.14 
Durch E-Ticketing können interne Restrukturierungsmaßnahmen zur marketingseitigen, organisatorischen und technologischen Prozessoptimierung unterstützt werden, weswegen es sich als Instrument im Rahmen der Umsetzung einer ganzheitlichen Unternehmensstrategie anbietet.

Kossak und Pällmann sehen den ÖPNV durch die Einführung und Nutzung des ETicketing gar an der Schwelle zu einer Innovationsphase, im Rahmen derer genau diese Potenziale erschlossen werden können:

„Der ÖPNV steht am Beginn einer weiteren Innovationsphase. Mit der Einführung des elektronischen Ticketing [...] wird nicht nur der Vertrieb grundlegend modernisiert; darüber hinaus eröffnen sich vielfältige Möglichkeiten im Bereich der Management-, Planungs- und Informationsinstrumente sowie der besseren Einbindung des ÖPNV in den Mobilitätsverbund, in dem m- und e-commerce“. 1152

E-Ticketing wird also als “enabler“ betrachtet, den ÖPNV „nicht nur moderner und attraktiver, sondern auch wirtschaftlicher" zu gestalten. Gleichzeitig verweisen sie auf die Verantwortung der Aufgabenträger, mittels einer Anschubfinanzierung das E-Ticketing auf ein wirtschaftlich tragfähiges Fundament zu stellen. ${ }^{1153}$

Mit dem Begriff „Electronic Ticketing“ werden sehr unterschiedliche Ziele, Erwartungen und Hoffnungen verbunden, so dass die möglichen, umfassenden Wirkungen gleichzeitig Grund für den teilweise zögerlichen Umgang mit dem Thema darstellen.1154 Von daher soll zunächst eine Erklärung des Begriffs erfolgen, bevor im weiteren Verlauf die möglichen Wirkungen erläutert werden.

\subsection{Einordnung des E-Ticketing im Electronic Business}

\subsubsection{Neue Möglichkeiten im Internetzeitalter}

Im Zuge des oben angesprochenen gesellschaftlichen Wandels hin zu einer Informationsund Dienstleistungsgesellschaft hat sich die Quantität und Qualität der verfügbaren Information rasant entwickelt. Die technologischen Entwicklungen im Bereich der IuK-

\footnotetext{
1152 Kossak und Pällmann 2006, S.26

1153 ebd., S.27

${ }^{1154}$ vgl. Kossak 2005, S.14
} 
Technologien haben dazu geführt, dass Information in nie zuvor vorhandenen Dichte und Umfang verfügbar ist. Das Internet als „Kristallisationspunkt dieser Entwicklung“ ermöglicht den Zugriff auf zuvor weltweit verteiltes Wissen. ${ }^{1155}$ Die Entwicklungsdynamik der IuK-Technologien ist zugleich die Grundlage für die Entstehung zahlreicher neuartiger Güter und Dienstleistungen in der Computer-, Multimedia- und Telekommunikationsbranche und hat $\mathrm{zu}$ einer eigenen Internetökonomie geführt (e-commerce, e-business). Kennzeichen dieser Güter und Dienstleistungen ist häufig die Digitalisierung wesentlicher Bestandteile und die interaktive Nutzung. ${ }^{1156}$ Nach der ersten Euphoriephase ist mittlerweile eine Konsolidierung der Internetökonomie zu verzeichnen, aus der zahlreiche internetbasierte Geschäftsmodelle und Firmen ${ }^{1157}$ gestärkt hervorgegangen sind. Darüber hinaus ist ein Verschwimmen der Grenzen zwischen Medien-, Computer- und Telekommunikationsprodukten zu verzeichnen bzw. das Zusammenwachsen der Bereiche Medien, Informationstechnologie und Telekommunikation. Die Konvergenz dieser Bereiche wird u.a. durch die Herausbildung von Netzwerkstrukturen oder die Funktionsintegration von Internetservices auf Mobilfunkgeräten untermauert. ${ }^{1158}$ Außerdem sind Veränderungen in den Nutzerpräferenzen festzustellen, so vor allem im Bereich der Information und Kommunikation, die eng mit der Personalisierung und Individualisierung der eingesetzten Medien zusammenhängen.

\subsubsection{Bargeldlose Bezahlung als Basis für E-Ticketing}

Einhergehend mit der Etablierung des „Electronic Business“ über das Internet entwickelt sich der Trend zur bargeldlosen Geschäftsabwicklung. Dabei muss die Bezahlung nicht unbedingt auch auf elektronischem Wege über das Internet abgewickelt werden. Oftmals fungieren elektronische Medien nur als „Bestellkanal“ und die Bezahlung erfolgt auf klassischem, dennoch ebenfalls bargeldlosem Wege, etwa über Lastschrifteinzug oder Rechnung. Die Zahlungssysteme im Electronic Business dagegen funktionieren rein elektronisch, weswegen sie besondere Anforderungen an die Sicherheit, Verfügbarkeit und Benutzerfreundlichkeit erfüllen müssen. Mittlerweile gibt es unterschiedliche elektronische Zahlungssysteme, von denen die Kreditkartenzahlung, eCash, die Geldkarte sowie soge-

\footnotetext{
1155 vgl. Wirtz 2001, S.5

1156 ebd., S.2

1157 Hierzu gehören bspw. Freenet sowie United Internet; vgl. http:/ / boerse.ard.de/: „We survived the Neuer Markt" (Meldung v. 9.3.2007).

${ }^{1158}$ vgl. Wirtz 2001, S.136f
} 
nannte Micropayments wie „Paypal“ die wichtigsten sind.1159 Seit Frühjahr 2006 bieten die Sparkassen mit Giropay ein Internetbezahlverfahren an, dass auf den Sicherheitsmerkmalen des Online-Bankings (z.B. Verschlüsselungsverfahren, PIN- und TANEingabe, persönliches Nutzungsprofil) beruht. 1160

Gerade die Abfrage von Sicherheitsmerkmalen stellt im bargeldlosen Zahlungsverkehr eine kritische Zeitgröße dar. Ist dies bei Bezahlung über das Internet noch relativ unkritisch, stellt sich eine Verzögerung des Bezahlvorgangs - beispielsweise durch das Zustandekommen einer Onlineverbindung zwischen Händlerterminal und Hintergrundsystem an Orten mit hohem Kundenaufkommen problematisch bzw. akzeptanzmindernd dar. Hier zeichnet sich eine Entwicklung ab, bei kleineren Beträgen den Datenaustausch nicht mehr kontaktgeführt, d.h. über Magnetstreifen oder Kontakt, sondern kontaktlos zu realisieren. So planen Kreditkartenunternehmen wie VISA zukünftig ihre Karten mit einer kontaktlosen Schnittstelle auszustatten, über die Beträge unterhalb von 15 Euro schnell und kontaktlos abgebucht werden können. Eine aktive Eingabe von Sicherheitsmerkmalen durch den Kunden ist dabei nicht erforderlich. Die Sicherheitsmerkmale werden zwischen Karte und Akzeptanzterminal innerhalb weniger Millisekunden auf einer Distanz von bis zu $10 \mathrm{~cm}$ gesichert ausgetauscht. ${ }^{1161}$ Auch die Sparkassen sowie Volks- und Raiffeisenbanken sehen zukünftig einen kontaktlosen Zugriff auf den Chip der Geldkarte vor. Zwar ist nicht vorgesehen, über die Luftschnittstelle auch Geld zu transferieren, doch sollen mit der Geldkarte erworbene Nutzungsberechtigungen (sprich „Tickets“) kontaktlos validiert werden können und eine Verknüpfung zwischen dem Buchungs- und Bezahlvorgang herbeigeführt werden. ${ }^{1162}$

\subsubsection{Zusammenführung der Prozesse Informieren, Bezahlen und Buchen}

Der Begriff „Electronic Ticketing“ bezeichnet im Bereich des Electronic Business, dass in der Regel nicht nur die Bezahlung elektronisch erfolgt, sondern auch die Nutzungsberechtigung (in Form eines „Tickets“) auf elektronischem Wege bereit gestellt wird. Im Bereich des Luftverkehrs bezieht sich dies insbesondere auch auf die Reservierungs- und die Check-in-Systeme. Bereits vor über 10 Jahren hat die Deutsche Lufthansa AG das soge-

\footnotetext{
1159 vgl. Wirtz 2001, S. 421f

1160 vgl. Sparkassen-Finanzportal

1161 vgl. Handelsblatt v. 24.10 .2005

1162 vgl. EURO-Kartensysteme
} 
nannte „E-Tix“ eingeführt, bei der die Flugbuchung in einem Hintergrundsystem elektronisch hinterlegt wird und der Kunde, nach Authentifizierung, den Flugschein beim Check-In ausgedruckt bekommt. 1163

Für den ÖPNV hat der VDV einen dreistufigen Ansatz entwickelt, in dem E-Ticketing in die Bereiche

- Zahlungsfunktion (Stufe 1)

- Fahrkartenfunktion (Stufe 2)

- Tariffunktion (Stufe 3)

unterteilt wird.1164 Beiden Ansätzen ist gleich, dass mit der Einführung von E-Ticketing Standards für die unternehmensübergreifende Anwendung entwickelt werden. So strebt die International Air Transport Association (IATA) für ihre Fluggesellschaften an, bis 2007 das E-Ticketing zum globalen Standard zu erheben. Der VDV entwickelte mit der Kernapplikation eine Softwarelösung, die die Interoperabilität unterschiedlicher E-TicketingSysteme in bezug auf die gegenseitige Nutzbarkeit des Kundenmediums sicherstellen soll und ebenfalls mit anderen europäischen und sogar weltweiten Lösungen abgestimmt ist.

\section{Exkurs: Prozessoptimierung im Güterverkehr}

Im Güterverkehr, insbesondere im Bereich des Transports von Lebensmitteln, gibt es Ansätze zur Effizienzsteigerung, die vom Prinzip her der Idee des E-Ticketing nahe kommen. So sieht das Supply Chain Management die Optimierung der Wertschöpfungskette in einem Netzwerk von Herstellern, Handel und Dienstleistern vor. Eine wichtige Voraussetzung hierbei ist eine durchgängige Informationsinfrastruktur über Electronic Data Exchange, die nachvollziehen lässt, wo sich die Güter befinden. Hierzu sind die Güter entweder mit Barcodes oder mit "Tags" (Chips) zur Identifizierung versehen. Die Datenbestände werden dann in einem zentralen Data-Warehouse für alle Beteiligten der Logistikkette zugänglich gemacht. Auch wenn diese Entwicklung mit einer Erhöhung der Anforderungen an die Logistikunternehmen einhergeht, schätzt man europaweit die Einsparpotenziale auf ca. $8-10 \%$ ein. ${ }^{1165}$

\footnotetext{
1163 vgl. Lufthansa Systems Group 2004

1164 vgl. VDV 2001, S.261f

1165 vgl. Aberle 2003, S.514
} 
Auch im Warentransport soll zukünftig e-commerce zu weiteren Kosteneinsparungen führen. Dabei ist weniger das direkte Kundengeschäft von Interesse, was dem traditionellen Versandhandel entspricht, sondern vielmehr der business-to-business-Bereich (B2B). Aufgrund der Umstrukturierung von Geschäftsprozessen insbesondere im Einkaufsbereich über elektronische Marktplätze oder Auktionsplattformen wird hier mit einer Reduzierung der Beschaffungskosten gerechnet. Gleichzeitig werden die Bezahlvorgänge, auch auf internationaler Ebene, stark vereinfacht.

Insofern kann hier von einer Vereinfachung und Zusammenführung der drei traditionellen Handelsfunktionen Informieren, Kaufen/Verkaufen, Bezahlen gesprochen werden, die auch für den ÖPNV erstrebenswert ist. 1166

\subsection{Entwicklung und Standardisierung von E-Ticketing-Systemen}

\subsubsection{Technisch-funktionale Darstellung}

In Kapitel 7.2 wurde bereits die Untergliederung des E-Ticketing nach den drei Stufen des VDV dargelegt. Die Erschließung aller Nutzenpotenziale und die Erreichung der über ETicketing angestrebten Ziele wird jedoch vor allem mit der Umsetzung der VDV-Stufe 3, also der Automatisierten Fahrpreisfindung, verbunden. Wesentliches Merkmal dieser Realisierungsstufe ist die Erfassung der Fahrdaten. Hier werden die Fahrten der Kunden (-medien) über Datenerfassungsgeräte aufgezeichnet und im Hintergrundsystem verarbeitet. Zum besseren Verständnis der Funktionsweise eines E-Ticketing-Systems und den sich ergebenden Möglichkeiten, werden im folgenden kurz die allgemeinen Anforderungen und Funktionsweisen der notwendigen Systemkomponenten sowie der ITArchitektur dargestellt.

\subsubsection{Kundenmedium}

Als Kundenmedien kommen im E-Ticketing vor allem kontaktlos funktionierende Chipkarten zum Einsatz, die auf Basis der Radiofrequenz-Identifikationstechnik (RFID) arbeiten. RFID ist die Übertragung von Information über elektromagnetische Wellen zwischen dem Lesegerät (Erfassungsgerät) und dem Transponder (Chip). Der Transponder auf dem Kundenmedium ist sowohl Kommunikationseinheit wie auch Datenträger. Er wird ent-

1166 ebd. S.515 
weder über die elektromagnetische Strahlung mit Energie versorgt oder aber durch eine eigene Energiequelle, z.B. in Form einer Batterie oder eines Akkus. Da die meisten ÖPNVAnwendungen chipkartenbasiert sind und auf diesen Medien keine Stromquelle vorhanden ist, ist der Transponder passiv. Erst durch das elektromagnetische Feld des Lesegerätes wird ein Ladekondensator im Chip aufgeladen um selbst ein schwaches Magnetfeld zu erzeugen und automatisch antworten zu können. Dies geschieht in der Regel in einer Distanz von weniger als $10 \mathrm{~cm}$. Dieses Verfahren wird als "proximity-Verfahren“ bezeichnet, dass nach ISO 14443 standardisiert ist. ${ }^{1167}$ Für dieses Verfahren sind unterschiedliche Frequenzbereiche definiert, was bedeutet, dass nicht alle RFID-Systeme dieses Standards auch miteinander kommunizieren können. Der RFID-Chip kann aber auch über größere Distanzen identifiziert werden, wobei dann allerdings die notwendigen Feldstärken ein Beschreiben des Kundenmediums nicht mehr zulassen. ${ }^{1168}$ Darüber hinaus gibt es je nach Anwendung unterschiedliche Sicherheitsanforderungen. Die wichtigsten sind die Verschlüsselung von Daten sowie die Authentifizierung, bei der zunächst kontrolliert wird, ob Transponder und Lesegerät überhaupt miteinander kommunizieren dürfen. Schließlich ist die Speicherkapazität eines Transponders für seine Leistungsfähigkeit ausschlaggebend. In Systemen, wo der Chip ausschließlich zur Identifikation genutzt wird, benötigt man einen eher kleineren Speicher. In Anwendungen im Rahmen von Geldtransaktionen, bei denen komplizierte Verschlüsselungsalgorithmen ablaufen, werden Prozessorchips mit hoher Speicherkapazität benötigt. ${ }^{1169}$ Maßgebend beim Einsatz von Transpondern in Anwendungen des ÖPNV ist, dass die Transaktionszeiten zwischen Transponder und Lesegerät möglichst kurz sind, d.h. in der Regel kleiner als 300 ms. ${ }^{1170}$

${ }^{1167}$ Im Gegensatz dazu gibt es das vincinity-Verfahren gemäß ISO 15693, das in einem Entfernungsbereich zwischen 10 und 100cm funktioniert sowie das Wide-Range-Verfahren bei Leseentfernungen über 100cm; vgl. VDV 2001, S.296.

1168 In Malaysia sollen Neufahrzeuge zukünftig über RFID-Chips verfügen, die fest am Fahrzeug angebracht (,verplombt") sind. Diese RFID-Chips können über eine Distanz von 100 Metern gescannt werden. So sollen Autodiebstähle reduziert werden. Über ähnliche Verfahren, bei denen sich die RFID-Chips bspw. in Auto-Nummernschildern befinden, könnte auch eine Identifizierung von Fahrzeugen zum Zwecke der Erhebung von Straßenbenutzungsgebühren erfolgen; vgl. Omnicard-Newsletter, Januar 2007.

${ }^{1169}$ vgl. Finkenzeller 2002, S.11ff

1170 vgl. VDV 2001, S.292ff 


\section{Exkurs: Internet der Dinge}

RFID-tags werden insbesondere im Bereich des Warenverkehrs eingesetzt. Dort sollen sie in Zukunft den Barcode ablösen, der zum Auslesen Sichtkontakt zum Lesegerät haben muss und viel weniger Daten beinhaltet. Bei den Barcodes wurden Herkunftsland, Hersteller und Artikelgruppe in den schwarzen und weißen Balken codiert. Bei den RFID-tags kommt noch eine Artikelnummer des einzelnen Produktes hinzu (Elektronischer Produktcode, EPC). Wird diese Nummer in das Internet eingegeben, entsteht eine Verknüpfung, über die der entsprechende Artikel in einer Datenbank verwaltet werden kann. Jedes Objekt enthält also eine eigene Identität. Korrespondiert dieses Objekt mit Lesegeräten, können automatisiert Informationen abgeleitet werden, die bspw. Auskunft über Zustellort und Haltbarkeit geben. Hinter jedem "Ding" steckt damit ein Stück potenzieller Intelligenz. Bevor aber jedes Produkt einen RFID-Label erhält, müssen vor allem die Preise noch deutlich sinken. ${ }^{1171}$

\subsubsection{Erfassungsgeräte}

Die Datenerfassungsgeräte werden entsprechend der betrieblichen Anforderungen an definierten Standorten (auf Bahnsteigen, im Straßenraum, in den Fahrzeugen) aufgestellt. Sie sammeln die Leistungsdaten und übermitteln diese an das Hintergrundsystem zur weiteren Verarbeitung (Fahrtenbildung, Bepreisung, etc.). In umgekehrter Richtung werden Systemparameter, Infrastruktur- und Tarifdaten sowie die aktuellen Sperrlisten oder Aufträge an die Chip-Lese-/Schreibgeräte übertragen.

Für die Bepreisung der in Anspruch genommenen Beförderungsleistung im Rahmen der VDV-Stufe 3 ist es notwendig, dass die Fahrdaten des Kunden (bzw. des Kundenmediums) erfasst werden. ${ }^{1172}$ Die Identifizierung des Kundenmediums kann sowohl durch einen aktiven Prozess des Kunden angestoßen werden, bei dem dieser sich bei Fahrtantritt und Fahrtende an Akzeptanzterminals an- bzw. abmeldet (check-in/check-out = CICO), wie auch passiv geschehen, wobei der Kunde dann lediglich ein Medium mit sich trägt, dessen Anwesenheit automatisch erfasst wird („Raumerfassung“ oder be-in/be-out $=\mathrm{BIBO})$ ). Darüber hinaus sind auch Mischvarianten denkbar, bei denen sich der Kunde

1171 vgl. Rosol 2006, S.44ff

1172 vgl. Kossak 2005, S.27 
bspw. nur aktiv anmeldet ${ }^{1173}$ oder aktiv anmeldet und der Ausstieg des Kunden automatisch erfasst wird (CIBO). Aufgrund der Erfassung der Fahrdaten liefert die VDV-Stufe 3 die Voraussetzung für die Entwicklung und Nutzbarmachung neuer, leistungsabhängiger Tarife, wie sie im Bereich der Telekommunikation bereits seit längerer Zeit angewandt werden.

Folgende Technologien der Datenerfassung sind möglich:

- Datenerfassung auf Basis von check-in- bzw. check-out-Daten (CICO) im Bereich der Proximity-Technologie

Der Kunde checkt sich mittels einer Chipkarte oder eines NFC-fähigen Mobilfunkgeräts (Mobilfunkgerät mit kontaktloser Schnittstelle, Near Field CommunicationSchnittstelle, siehe auch Kapitel 7.6.2.4.1) an Chipkartenlesegeräten (im straßengebundenen Verkehr im Fahrzeug; im Schienenbereich i.d.R. auf den Bahnsteigen) ein und aus. Die Chipkarte wird dabei unmittelbar an das Chipkartenlesegerät herangeführt und gelesen sowie beschrieben. Die Daten werden in einem Bordoder Stationsrechner gesammelt und von dort in das Hintergrundsystem weitergeleitet. ${ }^{1174}$

- Datenerfassung auf Basis von walk-in- bzw. walk-out-Daten (WIWO) im Bereich der Vincinity-Technologie

Der Kunde trägt ein aktives Kundenmedium (Chipkarte mit Batterieversorgung oder NFC-fähiges Mobilfunkgerät) bei sich, dass bei Einstieg und bei Verlassen des Fahrzeuges erfasst wird. Hierzu sind in den Einstiegsbereichen RFIDLesegeräte („Schranken“) angebracht, die auf einer Distanz von ca. 1 Meter das Medium lesen und beschreiben. Die Daten werden in einem Bordrechner gesammelt und von dort in das Hintergrundsystem weitergeleitet.

- Datenerfassung auf Basis von be-in- bzw. be-out-Daten (BIBO) im Bereich der Wide-Range-Technologie

Der Kunde trägt ein aktives Kundenmedium (Chipkarte mit Batterieversorgung oder NFC-fähiges Mobilfunkgerät) bei sich, das bei Einstieg in ein Fahrzeug durch

1173 Vom Prinzip her wird dann die Fahrtberechtigung bei Fahrtantritt elektronisch validiert.

$1174 \mathrm{vgl}$. Boldt und Ordon 2004, S.51 
RFID-Antennen "geweckt" wird, d.h. aus einem Stromsparmodus in einen aktiven und empfangsbereiten Zustand versetzt wird. Während der Fahrt wird das Medium durch eine weitere Antenne im Fahrzeug über eine mehrere Meter betragende Distanz gelesen und beschrieben. Steigt der Kunde aus, verlässt er den Empfangsbereich, was durch das System erkannt wird. Der Kunde ist damit "abgemeldet". Die Daten werden in einem Bordrechner gesammelt und von dort in das Hintergrundsystem weitergeleitet. ${ }^{1175}$

- Datenerfassung auf Basis einer Mischung von check-in und be-out (CIBO)

Der Kunde trägt ein aktives Kundenmedium (Chipkarte mit Batterieversorgung oder NFC-fähiges Mobilfunkgerät) bei sich, mit dem er sich bei Einstieg in das Fahrzeug an einem Chipkartenlesegerät anmeldet. Dadurch wird das Medium gleichzeitig "geweckt", d.h. aus einem Stromsparmodus in einen aktiven und empfangsbereiten Zustand versetzt und gelesen sowie beschrieben. Steigt der Kunde aus, verlässt er den Empfangsbereich, was durch das System erkannt wird. Der Kunde ist damit „abgemeldet“. Die Daten werden in einem Bordrechner gesammelt und von dort in das Hintergrundsystem weitergeleitet.

- Datenerfassung über Mobilfunktelefone mit NFC-Schnittstelle

Die Voraussetzung hierfür ist ein Mobilfunktelefon mit kontaktloser Schnittstelle (NFC-Schnittstelle). Bei der Datenerfassung über Mobilfunktelefone übernehmen diese entweder die Funktion des Kundenmediums oder aber des Kundenmediums und des Erfassungsgerätes. Im letzteren Fall erfolgt die Erfassung der Standortdaten entweder über die Identifizierung an einem RFID-Chip vor Ort (auf dem die entsprechenden Standortdaten hinterlegt sind und diese dann über das Mobilfunknetz geschickt werden) oder aber durch die Ortung über die Mobilfunkzelle, in dem sich das Mobilfunkgerät bzw. der Kunde befindet (siehe Kapitel 7.7.2.1, Exkurs Mobilfunk-Ortung). In beiden Fällen werden die erfassten Daten über das Mobilfunknetz in das Hintergrundsystem übermittelt und dort weiterverarbeitet. ${ }^{1176}$

\footnotetext{
1175 vgl. Megger und Vorgang 2000, S.4

1176 vgl. Ackermann 2007, S.16
} 


\subsubsection{Hintergrundsystem}

Die erfassten Fahrdaten werden im Hintergrundsystem gesammelt, einer Vollständigkeitsprüfung unterzogen und gegebenenfalls komplettiert. Die An- und Abmeldedatensätze werden dann zu kompletten Einzelfahrten und schließlich zu zusammenhängenden Reisen zusammengeführt. Bei fehlenden Meldungen wird die Fahrt, soweit möglich, rekonstruiert. Falls keine Rekonstruktion möglich ist, werden entweder komplette Linienverläufe als Grundlage der Leistungsverrechnung oder eine regelmäßig vom Kunden genutzte Relation angenommen. Die Fahrtenbildung und Fahrtenrekonstruktion sind äußerst rechenintensive Prozesse, die entsprechende Performanzen des Hintergrundsystems notwendig machen. Auf Basis der gebildeten Reisen erfolgt dann die Zuordnung zu Tarifen. Je nach Kundenvertrag und gültigem Tarif werden Fahrpreisoptimierungen (BestPreis-Option, Rabatte) durchgeführt. Schließlich werden die Abrechnungsdatensätze erzeugt und die so verarbeiteten Fahrdaten zum Zwecke der Abrechnung mit den Kundendaten zusammengeführt. Die Buchungen werden angestoßen und an die Kunden die Rechnungen verschickt (per Post oder E-Mail). Des weiteren können ebenfalls die Clearing- und Inkassoprozesse sowie Auswertungen (Statistiken, z.B. linien-, haltestellen- oder verkaufsstellenspezifische Auswertungen) über das Hintergrundsystem laufen. ${ }^{1177}$

Neben der Verwaltung der Kunden- (Vertrags- und Stammdaten) und Fahrdaten wird auch der Systembetrieb über das Hintergrundsystem gesteuert. Hierzu gehören die Leistungsdaten der Komponenten aus dem Feldsystem, die Auskunft über die Verfügbarkeit bzw. Ausfallzeiten geben. Ferner werden auch die Tarifparameter gepflegt, wie etwa gültige Umstiegszeiten. Im Rahmen des Kartenmanagements kann über das Hintergrundsystem nachvollzogen werden, welche Karten sich im Umlauf befinden bzw. ausgegeben und zurückgenommen wurden und wie der Lagerbestand aussieht. Außerdem werden im Hintergrundsystem die zentralen Sperrlisten gepflegt, auf der zu sperrende Karten und Komponenten gelistet sind (evtl. aufgrund von Diebstahl, Verlust oder nicht bezahlter Rechnungen) und die täglich aktualisiert und in die Kontrolleurs- sowie Datenerfassungsgeräte übertragen werden.

Im Hintergrundsystem sind die unterschiedlichen Funktionalitäten in Funktionsmodulen zusammengefasst. Die technische - oder auch räumliche - Trennung der Module erlaubt

1177 vgl. Boldt und Ordon 2004, S.51f 
die flexible Abbildung unterschiedlicher Organisations- bzw. Betreibermodelle, bei denen die Geschäftsprozesse bestimmten Rollen eindeutig zugeordnet sind. Je nach Komplexität oder der Anzahl von Akteuren können auch mehrere Rollen auf eine Organisation entfallen.1178 Wichtig ist, dass alle Partner auf die selbe Datengrundlage zurückgreifen, denn nur so kann eine einheitlich und qualitativ hochwertige Kundenbetreuung gewährleistet werden.

\subsubsection{IT-Architektur}

Die IT-Architektur stellt im Prinzip die technologische Infrastruktur dar, um Daten und Applikationen verarbeiten zu können. Allerdings wird die Struktur der eingesetzten Technologie grundlegend von der Organisation (eines Unternehmens oder eines Unternehmensverbundes) beeinflusst. Schließlich werden durch die IT-Architektur die Geschäftsprozesse abgebildet bzw. unterstützt und im besten Fall auch optimiert. „Die ITArchitektur eines Unternehmens stellt die Gesamtheit aller Komponenten, Technologien und organisatorischen Maßnahmen dar, die die im Unternehmen vorkommenden Funktionen, Prozesse und Daten abbilden und deren Zusammenspiel ermöglichen".1179 Entsprechend der strategischen Anforderungen, kann die IT-Architektur also unterschiedliche Züge haben. Sie ist u.a. abhängig von

- den Fachanforderungen und Rahmenbedingungen,

- zukünftigen geplanten Entwicklungen,

- ausgewählten Applikationen und Softwarekomponenten und der

- Verwendung von Standards.

Da es, wie bereits in Kapitel 7.1 geschildert, bei E-Ticketing nicht alleine um die Einführung von Elektronischem Fahrgeldmanagement oder eines neuen Vertriebskanals geht, sondern um die umfassende Modernisierung sowie Attraktivitäts- und Effizienzsteigerung des ÖPNV, ist die Betrachtung aller relevanten Funktionszusammenhänge des Systems „ÖPNV“ notwendig. Im günstigsten Fall ist die IT-Architektur nicht nur in der Lage die augenblickliche Aufgabenverteilung abzubilden, sondern können auch verschiedene, sich entwickelnde Organisationsformen abgebildet werden. In der Fachwelt spricht man

\footnotetext{
1178 vgl. Fleischhauer und Ordon 2003, S.12

1179 Krüger und Seelmann-Eggebert 2003, S.29
} 
gar von „Unternehmensökosystemen“, wodurch die Wechselbeziehungen und Zusammenhänge von Unternehmen oder Teilen von Unternehmen beschrieben werden. Es gilt daher nicht alleine nur Daten, Applikationen und Prozesse abzubilden, sondern auch die Organisation. Grundlegender Gedanke ist dabei die Abbildung der Wertschöpfung im Unternehmen. Letztendlich muss das Zusammenspiel dieser Teile aber genügend Flexibilität aufweisen, die verfolgte Unternehmensstrategie abzubilden bzw. diese Wertschöpfung - auch zukünftig in einem sich weiter verändernden Verkehrsmarkt - zu generieren (siehe Abbildung 38). So werden etwa sukzessiv neue Prozesse abzubilden sein oder die sich weiter verändernden Rahmenbedingungen zwingen zu Anpassungen in den organisatorischen Ablaufprozessen. ${ }^{1180}$

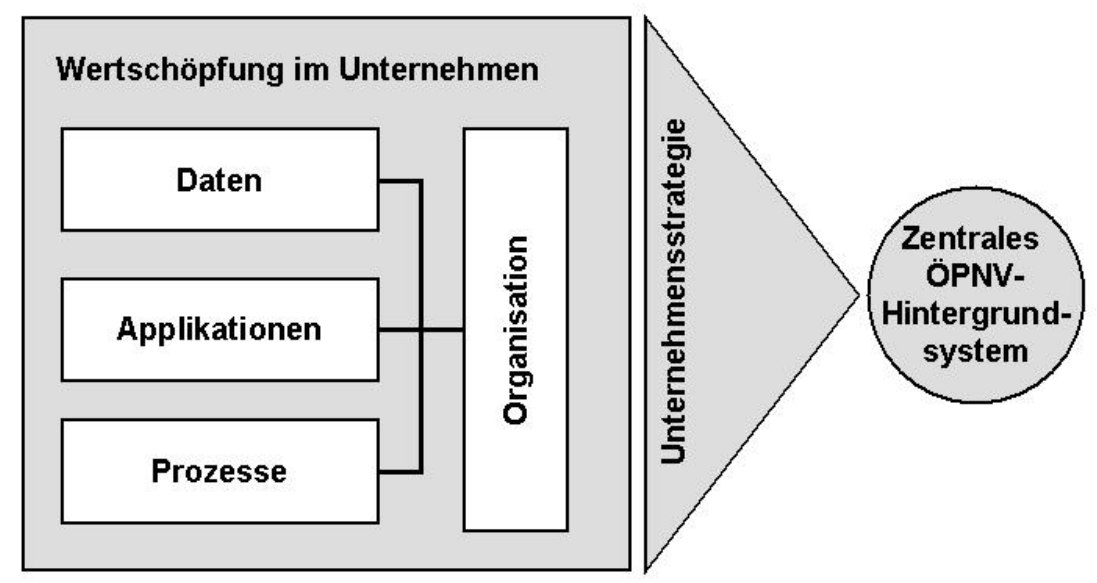

Abbildung 38: Aspekte der IT-Architektur

Quelle: Krüger und Seelmann-Eggebert 2003, S.39, eigene Bearbeitung

Vor dem Hintergrund des Zielkorridors einer einheitlichen und partnerschaftlichen Vermarktung des ÖPNV muss die IT-Architektur in der Lage sein, die Geschäftsprozesse zu vereinheitlichen und zu bündeln, die Schnittstellen der unterschiedlichen Partner zu managen und Daten in einer durchgängig konsistenten Aktualität vorzuhalten. Von der Systemarchitektur ist die Anlage der Hintergrundverarbeitung eines E-Ticketing-Systems gleich welcher Ausbaustufe - als zentrales System sinnvoll. ${ }^{1181}$ So bietet beispielsweise die zentrale Architektur Effizienzvorteile im Hinblick auf eine zentrale Datenpflege und Ad-

1180 vgl. Krüger und Seelmann-Eggebert 2003, S.37f

${ }^{1181}$ vgl. Fleischhauer und Ordon 2003, S.12 
ministration. Dabei spielt es keine Rolle, ob das Hintergrundsystem als zentrale Plattform oder Netzwerk angelegt ist.

Da mehrere Partner über die unterschiedlichsten (Kommunikations-, Informations-, Vertriebs-) Kanäle auf das selbe System zugreifen können, ist nicht nur eine extrem hohe Verfügbarkeit zu gewährleisten, sondern stellen sich auch höchste Ansprüche an die Sicherheit des Systems. Durch entsprechende organisatorische und technische Maßnahmen muss auch sichergestellt sein, dass die geltenden Datenschutzbestimmungen gewährleistet sind. Hierzu gehört auch, dass die Datenhoheit der jeweiligen Partner (auch des Kunden) respektiert wird, also jede Organisation nur die Daten sieht, die auf dem zentralen System gespeichert sind, zu der es berechtigt ist. Diese als „Mandantenfähigkeit“ bezeichnete Eigenschaft des zentralen HGS ist daher, neben der technischen Skalierbarkeit und Flexibilität, eine der wichtigsten Anforderungen, zumal über sie gewährleistet wird, dass das angestrebte Machtgefüge im ÖPNV etabliert wird.

\subsection{2 Übertragbarkeit bestehender Lösungen und Standards}

Weltweit gibt es mittlerweile mehr als 100 Metropolen und Regionen, in denen der ÖPNV-Vertrieb über E-Ticketing-Systeme organisiert wird. Unter ihnen gibt es etliche Systeme, die bereits technologische Weiterentwicklungen hinter sich haben. So wurden einige Systeme von der Magnetstreifentechnik auf Chipkarten umgestellt (New York, Paris) oder wurden in räumlich offenen Systemen Zugangskontrollen („gates“) eingeführt (Niederlande, London). Dies belegt unter anderem, dass es weder einen „richtigen“ Zeitpunkt noch „die richtige Ausprägung“ für einen Einstieg in das E-Ticketing gibt. Der richtige Zeitpunkt wird alleine dadurch definiert, ob Mehreinnahmen generiert und Kosteneinsparungen vorgenommen werden können und müssen. ${ }^{1182}$

Obwohl es eine Vielzahl von existierenden Lösungen für den ÖPNV weltweit gibt, können vorhandene technische Lösungen aus dem Ausland in den seltensten Fällen „1:1“ übertragen werden. Dies liegt nur teilweise an dem Umstand, dass es sich in der Regel bei ausländischen Systemen um räumlich geschlossene Systeme - also mit Zugangssperren handelt. ${ }^{1183}$ Zwar ließen sich auch deren technische Komponenten entsprechend der hiesigen Anforderungen anpassen („,customizen“), doch müssen bestehende Lösungsansätze

\footnotetext{
1182 vgl. Kossak 2005, S.15

1183 vgl. Ordon 2004, S.27
} 
auch an die hiesigen strukturellen und organisatorisch-rechtlichen Rahmenbedingungen angepasst werden. Dass diese organisatorischen Rahmenbedingungen nicht nur national, sondern auch regional unterschiedlich ausgelegt und gelebt werden können, zeigt das hessische Beispiel des „Besteller-Ersteller-Prinzips“. Darüber hinaus gilt es insbesondere auch die spezifischen Kundenerwartungen zu berücksichtigen. Denn natürlich zeigen sich zwischen den einzelnen Ländern teilweise deutliche Mentalitätsunterschiede in der Einstellung beispielsweise hinsichtlich Datenschutz, akzeptierter Bezahlverfahren, Nutzungserfassung und -verarbeitung oder Aufgeschlossenheit gegenüber technologischen Neuerungen und Verfahren.1184

\subsubsection{Standard für E-Ticketing in Deutschland}

Der VDV strebt an, die unterschiedlichen Ansätze der Entwicklung von E-TicketingSystemen in Deutschland durch die Bereitstellung einer Standardapplikation zueinander kompatibel bzw. „interoperabel“ zu gestalten. Da eine einheitliche und abgestimmte Einführung von E-Ticketing in Deutschland unwahrscheinlich ist, soll diese Interoperabilität über die landesweite bzw. regionale Akzeptanz der jeweiligen Kundenmedien erfolgen. Dabei spielt nicht nur die Kontrollfähigkeit eines Kundenmediums eine Rolle, sondern auch die Möglichkeit für den Kunden, mit seinem Medium in einer anderen Region eine Fahrtberechtigung kaufen zu können. Dies soll unabhängig davon möglich sein, ob bzw. zu welchem Zeitpunkt oder auf welche Art die Bezahlung erfolgt oder Nutzungsdaten erfasst werden. ${ }^{1185}$ „Diese durchgängige Nutzbarkeit soll technisch durch eine VDVKernapplikation realisiert werden“"1186, die alle möglichen Funktionen berücksichtigt. Diese reichen von der bargeldlosen Bezahlung (Stufe 1) über die elektronische Abbildung des Fahrscheins (Stufe 2) bis hin zur Automatisierten Fahrpreisfindung (Stufe 3), bei der die Kunden von der Notwendigkeit entbunden werden, vor Fahrtantritt den jeweils adäquaten Tarif $\mathrm{zu}$ wählen. Gleichzeitig sollen über das Sicherheitsmanagement der VDVKernapplikation alle Produktions- und Geschäftsprozesse dahingehend geschützt werden, dass „Manipulationen von außen und von innen verhindert“ werden und „mit allen Partnern abrechnungswirksame Daten“ ausgetauscht werden können. ${ }^{1187}$

\footnotetext{
$1184 \mathrm{ebd}$.

1185 vgl. Fischer 2006, S.8

1186 vgl. VDV 2006

1187 Ackermann 2007, S.17
} 
Die sich ergebende Anzahl möglicher technischer Ausprägungen von E-TicketingSystemen spiegelt gleichzeitig auch das Spektrum verfolgter Ansätze in Deutschland wider, die auch innerhalb der einzelnen Stufen durchaus unterschiedlich sind. Während man in Niedersachsen die VDV-Stufe 2 mit kontaktbehafteten Chipkarten favorisiert, setzt man im Verkehrsverbund Rhein-Ruhr auf rein kontaktlose Abläufe und Medien. In Sachsen wird langfristig die VDV-Stufe 3 mittels Raumerfassung angestrebt. Der RMV hatte als erster Verkehrsverbund in Deutschland ein produktives System der VDV-Stufe 3 auf Basis von CICO begrenzt auf die Stadt Hanau eingeführt. Dieses Projekt sollte als Pilotprojekt die zukünftige Richtung im E-Ticketing dokumentieren. Mittlerweile gibt es aber im RMV, wie auch in einigen anderen Verbünden (z.B. Verkehrsverbund BerlinBrandenburg sowie Verkehrsverbund Oberelbe), die Absicht, die verbundweite Einführung von E-Ticketing über die VDV-Stufe 2 zu realisieren. ${ }^{1188}$ Damit sollen finanzielle und technisch-organisatorische Risiken minimiert und gleichzeitig die weitere technologische Entwicklung im Bereich der Raumerfassung abgewartet werden.

Für die technisch-organisatorische Interoperabilität von Systemen ist es allerdings unwichtig, ob und wie Fahrdaten erfasst werden. Wichtig ist die standardisierte Form der Weitergabe von Fahrtberechtigungsdaten zwischen definierten Rollen, also die Standardisierung von Prozessen und Schnittstellen. Insofern gibt die Kernapplikation auch nicht vor, welche technischen Datenerfassungssysteme zu verwenden sind. Vorgaben gibt es insofern für die Datenstruktur auf den Kundenmedien und für die Sicherheit bei den Datenaustauschprozessen. Die Kernapplikation spezifiziert hier das Sicherheitsmodul, welches die sichere Kommunikation zwischen den eingesetzten Komponenten regelt, sowie die Applikation selbst. Allerdings ist es für die Kunden wichtig, dass sie wissen, in welchem System sie sich wie zu verhalten haben bzw. wie sie ihr Kundenmedium einzusetzen haben. Hier geht es also um die Eindeutigkeit der Benutzerführung, also die einheitliche Gestaltung der Benutzeroberflächen und die Abstimmung von Geschäftsregeln, u.a. aus dem Tarifbereich. Dies hat auch der VDV erkannt und mit zwei - sich an das Projekt „Kernapplikation“ anschließenden - Projekten zur Vereinheitlichung der Kundenschnittstelle sowie der Geschäftsprozesse und Tarifbestimmungen die Standardisierungsbestrebungen auf ein ganzheitliches Ziel ausgerichtet.

${ }^{1188}$ vgl. Wiesbadener Kurier v. 16.01.2006 
Vor dem Hintergrund der Standardisierungsbestrebungen hat der VDV zusammen mit einigen Verkehrsunternehmen und Verkehrsverbünden - darunter auch der VGF und der RMV GmbH - die VDV-Kernapplikations GmbH \& Co KG gegründet, die zukünftig unter anderem die Zertifizierung von Systemkomponenten sowie das Sicherheitsmanagement einschließlich der Bereitstellung der Sicherheitsmodule koordinieren soll. ${ }^{1189}$

Die VDV-Kernapplikation gewährleistet gleichzeitig die organisatorische Interoperabilität zukünftiger E-Ticketing-Systeme, aus der vertraglich-rechtliche Regelungen abgeleitet werden (wozu z.B. auch Datenschutzbestimmungen gehören). Das Rollenmodell der VDV-Kernapplikation benennt alle Akteure und wesentlichen Aufgaben in einem ETicketing-System und beschreibt das Zusammenspiel über die Zuordnung von Funktionen und Geschäftsprozessen. ${ }^{1190}$ Die eindeutige Zuordnung von Aufgaben zu logischen Rollen sowie deren vertraglich definierte Rechtsbeziehungen (z.B. über Ausgabe von Medien, Branding, Akzeptanz, Datenverarbeitung) regelt die Beziehung der am E-Ticketing beteiligten Unternehmen im operativen Betrieb. Dabei können unterschiedliche reale Organisationsmodelle abgebildet werden bzw. können sich die Aufgaben und Funktionen der Beteiligten auch ändern. ${ }^{1191}$

Die VDV-Kernapplikation kennt mindestens 6 definierte Rollen (siehe Abbildung 39). Der „ÖPV-Dienstleister“ ist ein Verkehrsunternehmen, das die Verkehrsleistung erstellt und Kundenmedien kontrolliert. Der „Produktverantwortliche“ spezifiziert die Produkte und Tarifregeln. Der „Kundenvertragspartner“ vertreibt Fahrtberechtigungen und ist Vertragspartner gegenüber dem Kunden und kassiert dadurch (zunächst) die Fahrgeldeinnahmen. Der "Applikationsherausgeber" garantiert die Sicherheit des Datenaustauschs und der Sicherheitsschlüssel und zertifiziert die Systemkomponenten. Der „Kontrollservice“ pflegt und verteilt die Sperrlisten. Der "Nutzer“ schließlich nutzt die Applikation bzw. die darauf abgelegte elektronische Fahrtberechtigung. ${ }^{1192}$ Darüber hinaus gibt es weitere, nicht durch die KA spezifizierte Rollen, die ausgefüllt sein müssen, die aber keinen Einfluss auf die Sicherstellung der interoperablen Zusammenarbeit haben. Hierzu gehören u.a. Aufgaben des Kartenmanagements und der Hintergrundverarbeitung.

\footnotetext{
1189 vgl. KompetenzCenter EFM NRW 2005, S.9

1190 ebd., S.8

1191 vgl. Fischer 2006, S.16

1192 vgl. Kompetenzcenter EFM NRW 2005, S.8f
} 


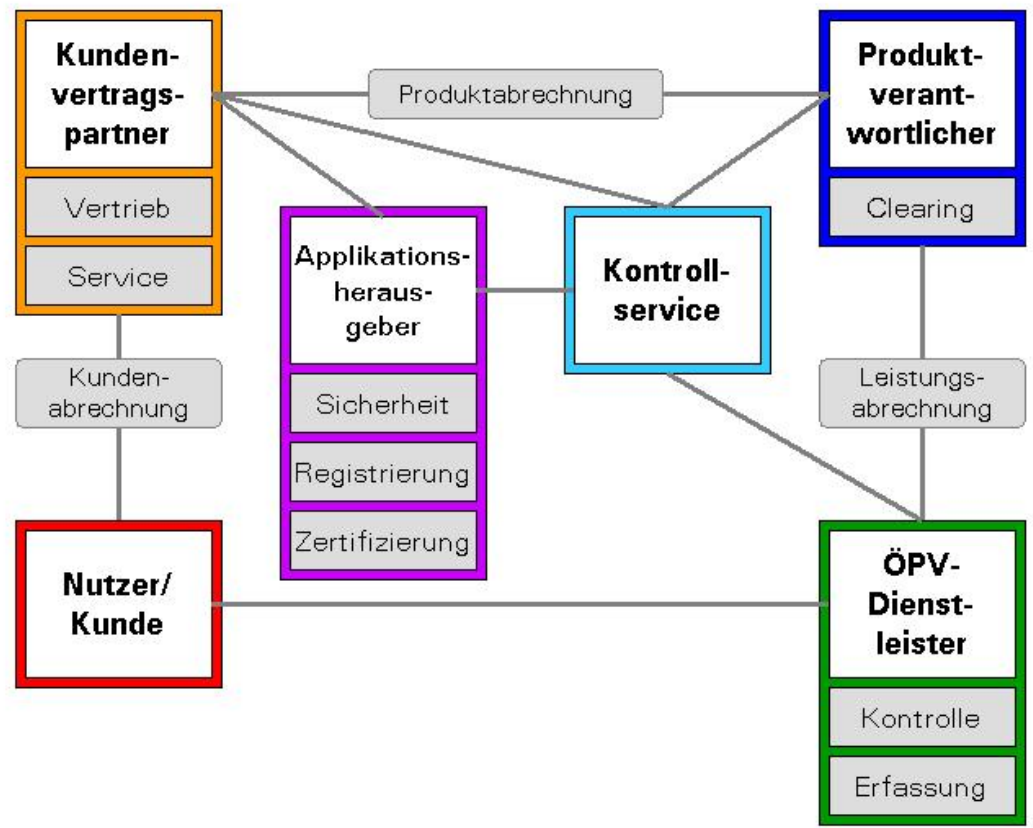

Abbildung 39: Rollenmodell der VDV-Kernapplikation

Quelle: Kompetenzcenter EFM NRW 2005, S.8 sowie Fischer 2006, S.12

Hierin zeigt sich, dass die alleinige Spezifikation von technischen Anforderungen nicht zu strukturellen Qualitätsverbesserungen führt. Vielmehr ist das einheitliche Sicherheitskonzept und die technische Interoperabilität der organisatorischen Interoperabilität untergeordnet. Es bedarf also zunächst einer konkreten Festlegung eines organisatorischstrukturellen Zielzustandes sowie der damit im Zusammenhang stehenden Geschäftsabläufe, die dann durch die Technik effizienter als bisher abgebildet bzw. unterstützt werden sollen.

Auch wenn man in Deutschland auf einem guten Weg ist, die ÖPNV-Applikation auf den „Nutzermedien“ sowie die organisatorischen, rechtlichen und administrativen Spielregeln $\mathrm{zu}$ vereinheitlichen, so wird das E-Ticketing auch in Zukunft von einer Vielzahl technologischer Varianten und Alternativen gekennzeichnet sein. Die VDV-Kernapplikation wird sich daher an den Nutzenpotenzialen dieser Neuerungen messen lassen und genug Flexibilität aufweisen müssen, geeignete Ansätze zu integrieren. Bereits heute zeichnet sich ab, dass bestimmte Entwicklungen im Telekommunikationsbereich, wie etwa die bereits erwähnte NFC-Technologie, ein auf RFID-Technologie basierender drahtlo- 
ser Datenaustausch, der vom Kunden einfach und intuitiv zu handhaben ist, einen nicht unwesentlichen Einfluss auf die zukünftigen Produktentwicklungen haben werden. ${ }^{1193}$

In einer Befragung des Unternehmens trend-research aus dem Jahr 2004 gaben immerhin fast die Hälfte der befragten ÖPNV-Unternehmen an, im Rahmen ihrer „mittel- bzw. langfristigen Strategie in Bezug auf E-Ticketing" die Fertigstellung der VDVKernapplikation abzuwarten. ${ }^{1194}$ Wie bedeutsam Standardisierung auch im Hinblick auf eine eventuelle finanzielle Unterstützung durch das Land Hessen ist, wird bei einem Blick in das hessische Haushaltsgesetz 2005 deutlich. Dort heißt es unter §5: "Mittel für Zwecke der Informationstechnik sind gesperrt, soweit sie für nicht den erlassenen Standards entsprechende Maßnahmen eingesetzt werden sollen".1195 Auf diese Weise soll ein standardkonformer Einsatz von IuK-Technologien im Land Hessen sichergestellt werden.

\subsubsection{Bisherige Erfahrungen mit E-Ticketing im RMV}

Die RMV GmbH befasst sich seit einem Feldversuch in Marburg im Jahre 1996, bei der die technische Erprobung der kontaktlosen Chipkartentechnologie im Vordergrund stand, mit der Einführung von E-Ticketing-Systemen. ${ }^{1196}$ Seit 1999 erarbeitete eine RMVProjektgruppe unter der Bezeichnung „Viatec“ ein Handbuch, welches wesentliche Grundsätze bei der Einführung von E-Ticketing-Systemen festhielt. Die dort beschriebenen Ausprägungen beruhen auf intensiven Marktforschungen, Gesprächen mit Verkehrsunternehmen und Lokalen Nahverkehrsorganisationen, Austausch mit der Industrie, Mitwirkungen in nationalen und internationalen Arbeitskreisen, Studienreisen und RMVeigenen konzeptionellen Arbeiten. ${ }^{1197}$

Diese Arbeiten führten schließlich zur Realisierung eines ersten Pilotprojektes in Hanau. Dort wurde mit der get»in-Chipkarte ${ }^{1198}$ erstmalig eine E-Ticketing-Anwendung auf den lokalen Markt (nur Binnenverkehre der Städte Hanau und Bruchköbel) gebracht, die vollständig die VDV-Stufe 3 der automatisierten Fahrpreisfindung umsetzt, sowie den Kunden eine nachträgliche Abrechung auf Basis des Best-Preises anbietet. Das Projekt get»in

\footnotetext{
${ }^{1193}$ vgl. Ackermann 2007, S.16

1194 vgl. trend-research 2004

${ }_{1195}$ Hessischer Landtag 2004, S.540

1196 vgl. RMV 2005, S.93

1197 vgl. Sparmann und Ordon 1999, S.18ff

1198 vgl. www.rmv-get-in.de
} 
brachte vor allem im Bereich der Kundenakzeptanz umfassende Erkenntnisse, die u.a. auch in die Erstellung der VDV-Kernapplikation einflossen. ${ }^{1199}$

Auf Basis dieser Erfahrungen wurde im Rahmen einer Machbarkeitsstudie mit der DB AG (Zeitraum: September 2002 bis April 2003) die Übertragung der Ansätze, die in Hanau auf den lokalen Busbereich beschränkt waren, auf den regionalen Schienenverkehr der DB AG überprüft. Insbesondere sollte die Studie klären, ob mit E-Ticketing - als modernem Marketing- und Vertriebsinstrument - neue Marktpotenziale im Bereich der S-Bahn und Regionalbahn Rhein-Main erschlossen werden können. Es galt daher ein Konzept zu entwerfen, welches zu einem Qualitätssprung an der Kundenschnittstelle führt und in den Bereichen Kundenmanagement und Vertrieb von nachhaltigem Nutzen ist.

Es wurde ein Geschäftsmodell entworfen, das die Rollen der RMV GmbH und der DB AG in den relevanten Bereichen skizziert. Ferner wurde der Ausrüstungsumfang identifiziert und das nötige Investitionsvolumen kalkuliert. Insbesondere wurden die Besonderheiten einer zeitgleichen Einführung auf der S-Bahn sowie den parallel laufenden Regionalverkehren herausgestellt. Den Abschluss dieser Machbarkeitsstudie bildeten mögliche Einführungsszenarien für die Einführung von E-Ticketing. ${ }^{1200}$ Letztlich blieb aber eine Realisierung im Bereich des S-Bahn-Netzes aus.

Schließlich gründete die $R M V G m b H$ zusammen mit zehn Gebietskörperschaften bzw. deren Lokalen Nahverkehrsorganisationen eine gemeinsame Planungsgesellschaft (cosmobil Projektmanagementgesellschaft $\mathrm{mbH}$ ), die die fundierten Planungen für das ETicketing innerhalb der nächsten drei Jahre abschließen sollte. Die letztlich politisch getragene Entscheidung für die Einführung des E-Ticketing obliegt aber weiterhin den Gesellschaftern der $R M V-G m b H$, wodurch diesem die organisatorische Verantwortung zukommt. ${ }^{1201}$ Für die Einführung des E-Ticketing im Verbundgebiet ist u.a. aus finanziellen Gründen eine stufenweise Umsetzung geplant. So sollen zunächst „alle Zeitkarten, beginnend mit den Jahreskarten, auf Chipkartentechnologie umgeswicht" werden. ${ }^{1202}$ Danach sollen dann zusätzlich Wochen- und Monatskarten sowie eventuell auch Tageskarten auf der Basis von Chipkarten angeboten werden, die der Kunde dann „an Verkaufsstellen,

\footnotetext{
1199 vgl. Göbel 2002, S.19f; Ordon 2002, S.11ff sowie RMV 2005, S.93

$1200 \mathrm{vgl}$. Fleischhauer und Ordon 2003, S.10ff

1201 vgl. Ordon 2004, S.27

1202 vgl. RMV-Pressemitteilung v. 18.11.2005
} 
Automaten und im Internet aufladen kann“. Die Einführung von elektronischen Einzelfahrkarten auf Basis der Chipkarte ist - zunächst - nicht geplant. ${ }^{1203}$ In diesem Fahrkartensegment entwickelt der RMV Angebote über das Mobilfunktelefon. ${ }^{1204}$

\subsection{Voraussetzungen für eine zielgerichtete Umsetzung des E-Ticketing}

\subsubsection{Von der Notwendigkeit der Zieldefinition}

Generell wird mit der Einführung von E-Ticketing das Ziel der wirtschaftlichen Effizienzsteigerung über eine verbesserte und optimierte ÖPNV-Vermarktung verfolgt. Wie in Kapitel 6.2 dargestellt, wird zwischen den beiden Oberzielen „Umsätze steigern“ und „Kosten einsparen“ unterschieden. Alle weiteren (Unter-) Ziele, die mit der Einführung von E-Ticketing verfolgt werden, lassen sich diesen Oberzielen zuordnen. Die Maßnahmen, die zu diesen Zielen führen sollen, zielen ertragsseitig insbesondere auf den Abbau von Zugangshemmnissen, die Attraktivitätssteigerung des ÖPNV sowie die verbesserte Kundenbindung ab. Aufwandsseitig werden vor allem Maßnahmen zur Kosteneinsparung über Prozessoptimierung und -bündelung sowie erhöhter Sicherheit von Kundenmedien zitiert. ${ }^{1205}$ Vor dem Hintergrund der heutigen Strukturen im ÖPNV geht es also um mehr als „nur“ Wirtschaftlichkeitssteigerung.

Die Bandbreite der zur Diskussion stehenden Veränderungen im ÖPNV ist gleichzeitig mit ein Grund für die bislang fehlende Umsetzung von E-Ticketing in Deutschland. Denn es ist kaum zu erwarten, dass ein Verbund oder ein Verkehrsunternehmen ein ETicketing-System einführt, dass alle Ziele und Erwartungen gleichermaßen und zum gleichen Zeitpunkt adressiert. Eine pauschale Debatte über das Für und Wider einer Einführung von E-Ticketing führt dazu, dass die Ziele diffus werden und diejenigen, die eigentlich hätten überzeugt werden sollen, in Zweifel über die Umsetzbarkeit geraten. ${ }^{1206}$ Hinzu kommt, dass die Diskussion von technischen und betrieblichen Aspekten überlagert wird und die Chancen und Möglichkeiten leichtfertig abgetan werden. ${ }^{1207}$

\footnotetext{
${ }^{1203}$ vgl. Wiesbadener Kurier v. 16.1.2005

1204 vgl. RMV-Pressemitteilung v. 28.9.2006

1205 vgl. RMV 2005, S.93

1206 vgl. Kossak 2005, S.14

1207 vgl. Rüffer 2004, S.46
} 
Für eine zielgerichtete Diskussion über die Einführung von E-Ticketing ist daher zunächst eine Analyse des aktuellen Ist-Zustands vor Ort sinnvoll sowie die Klärung der Frage, wie es zu diesem Zusatnd kam (vgl. Kapitel 6.4.1.1). Ausgehend hiervon kann entschieden werden, welche konkreten Bedürfnisse existieren und welche Maßnahmen geeignet sind, diese Probleme zu beheben. Da die Einführung von E-Ticketing zweifellos kostenintensiv ist, liegt es auf der Hand nicht nur Einzelprobleme zu adressieren, sondern die Ausgangssituation ganzheitlich zu analysieren und Maßnahmenbündel zu identifizieren sowie nach Möglichkeit auch zu priorisieren. Die Identifizierung und Bewertung dieser Maßnahmen ist ausschlaggebend, ob ein E-Ticketing-System primär als Kooperationsplattform, neuer Vertriebskanal, Fahrgeldmanagementsystem, Planungswerkzeug, Controllingtool, Betriebsabwicklung etc. angeschafft wird. Ein E-Ticketing-System in der Region A kann also einen anderen Zweck verfolgen und damit ein anderes Ziel adressieren, als ein E-Ticketing-System in der Region B. Alle Wirkungsbereiche des E-Ticketing sind dennoch primär dem Marketingbereich zuzuordnen, wenngleich zweifellos auch positive Wirkungen für eine verbesserte organisatorische Zusammenarbeit von einem E-TicketingSystem ausgehen. Doch können diese organisatorischen Aspekte nicht Selbstzweck sein, sondern müssen schließlich zu einer messbaren - monetären - Verbesserung des Geschäftsergebnisses aus der Kundenbeziehung führen. So unterstützen E-TicketingSysteme aufgrund ihrer Vernetzung die regionale Zusammenarbeit, wodurch letztlich das endogene Entwicklungspotenzial des ÖPNV in der Region mobilisiert werden kann. Insbesondere dort, wo es heute an finanziellen Mittel fehlt, können durch die Zusammenarbeit bei der zentralen Beschaffung von Hard- und Software oder die gemeinsame Nutzung eines mandantenfähigen Hintergrundsystems Investitions- und Betriebskosten gesenkt werden. ${ }^{1208}$ Das Ziel der verbesserten Nutzerfinanzierung wird aber vorrangig durch die Einnahmesteigerung über die verbesserte Marktausschöpfung und -erschließung erreicht und erst an zweiter Stelle durch die Erschließung von Kosteneinsparungen. Denn nur wer Geld hat, kann auch welches einsparen. Die Erfahrungen aus der Einführung des E-Ticketing im Verkehrsverbund Rhein-Ruhr (VRR) belegen, dass die „Einführung des EFM [...] insgesamt wirtschaftlich machbar"1209 ist - und dies schon mit der VDV-Stufe 2.

\footnotetext{
1208 vgl. Zühlke 2005, S.278

${ }^{1209}$ Zühlke 2005, S.278
} 


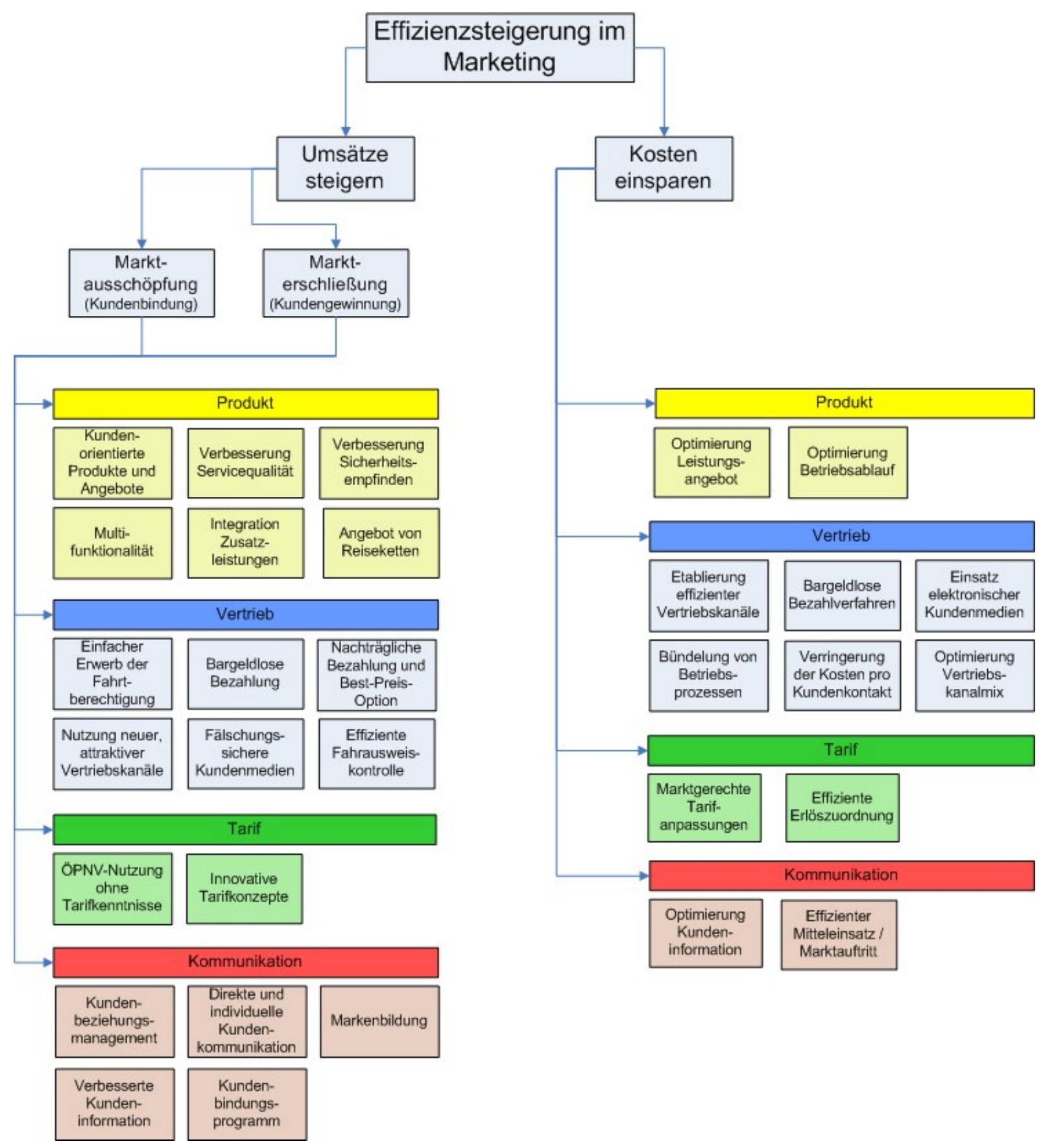

Abbildung 40: Wirkungsbereiche des E-Ticketing im Marketingbereich

Quelle: Eigene Darstellung

Das Spektrum der primären Wirkungsbereiche eines E-Ticketing-Systems ist in Abbildung 40 dargestellt. Die Wirkungsbereiche sind in Kapitel 7.6 (ertragsseitige Optimierungsansätze) und 7.7 (aufwandsseitige Optimierungsansätze) näher beschrieben.

Zahlreiche der adressierten Ziele werden erst mit einer vollständigen technischen Einführung von E-Ticketing erreicht. Dies wird an einem Beispiel aus Kundensicht deutlich: Nur 
auf der Basis einer durchgängigen Datenerfassung, für die eine umfangreiche Infrastruktur im Feld aufgebaut werden muss, sowie einer zentralen Hintergrundverarbeitung, in der die Daten aller Verkehrsunternehmen zusammenlaufen, kann dem Kunden eine Automatisierte Fahrpreisfindung mit einer Best-Preis-Option angeboten werden. Denn die Berechnungslage hierfür ist eine Fahrtenhistorie, die entsprechend geltender Tarifbestimmungen preislich optimiert werden kann. Die Erschließung und Ausschöpfung des ÖPNV-Marktpotenzials im RMV, die auf langfristige Verhaltensänderungen im Verkehr abzielen, bedürfen daher des Einsatzes eines umfassenden Maßnahmenspektrums bzw. eines differenzierten Marketingmixes. Alleine aufgrund starker Wechselwirkungen zwischen den einzelnen Marketingsegmenten ist hier eine ganzheitliche Lösungsentwicklung notwendig. So gibt es etwa direkte Interdependenzen zwischen den Vertriebseinrichtungen/-strukturen, die großen Einfluss auf die Kaufentscheidung haben, mit dem bestehenden Tarifsystem, dem Fahrkartensortiment und den Tarif. Zudem geht die Etablierung moderner Marketinginstrumentarien einher mit der (teilweisen) Restrukturierung bestehender Kooperationsformen im Marketing, die bislang nur auf Teilmärkte ausgerichtet sind sowie der Einführung und Nutzung verbundweiter und einheitlicher Kommunikationsnetze. Das Nutzenpotenzial, das von der Anwendung eines derart integrierten Marketingkonzeptes ausgeht, kann kaum unterschätzt werden.

Die Einführung eines E-Ticketing-Systems, auch wenn sie letztendlich aus wirtschaftlichen Erwägungen getroffen wird, sollte eben nicht als reine Investition (siehe Kapitel 6.5.1) betrachtet werden, bei der die heutigen Einnahmeverhältnisse gegengerechnet werden, sondern muss selbstverständlich „zukünftige Entwicklungen und Chancen einbeziehen". 1210

\subsubsection{Räumliche Aspekte der Umsetzung}

Vor dem Hintergrund der Vielzahl unterschiedlicher möglicher System-Lösungsansätze stellt sich die Frage, wie ein E-Ticketing-System konfiguriert sein muss, damit es den spezifischen Anforderungen des Verkehrsmarktes in der Region Frankfurt Rhein-Main bzw. im RMV im Hinblick auf eine Förderung des ÖPNV Rechnung trägt. Die Potenziabschätzung (siehe Kapitel 6.3.2 und 6.3.4) sowie die Erörterung der Besonderheiten des ÖPNVVerkehrsmarktes zeigen, dass eine auf Markterschließung und -abschöpfung ausgerichte-

1210 vgl. Sparmann, V. 2005, S.71 
te Marktstrategie mit dem Ziel der Erhöhung der Nutzerfinanzierung mehr Erfolg verspricht, als die Senkung von Kosten. Auch sind heute die Fahrgeldeinnahmen beförderter Personen immer noch die Haupteinnahmequelle des ÖPNV. Andererseits scheint aufgrund der Unterdeckung die Realisierung jeder Maßnahme gerechtfertigt, die dazu beiträgt den ÖPNV effizienter zu machen. Wie viel Vertriebs- und Controllingsystem, Marketing- und Planungsinstrumentarium bedarf es, um - im Verhältnis zu den Kosten - geeignete Effekte zu erzielen? Daneben stellt sich die Frage der räumlichen Ausdehnung und damit der technisch-organisatorischen Einbindung aller RMV-Gesellschafter.

Bislang ist es erklärtes Ziel der RMV GmbH, E-Ticketing verbundweit, d.h. flächendeckend einzuführen.1211 Es steht jedoch außer Zweifel, dass die Wirtschaftlichkeit eines ETicketing-Systems im Agglomerationsraum deutlich größer ist, als in einem ländlichen bzw. strukturschwachen Gebiet, bzw. die Nutzerfinanzierung im ländlichen Raum an ihre Grenzen stößt. ${ }^{1212}$ In Kapitel 4.1.3 wurde bereits darauf verwiesen, dass die metropolitane Region Frankfurt Rhein-Main, mit ihrer polyzentrischen Struktur, von einer (neuen) Einheit von Stadt und Umland gekennzeichnet ist. Die Verflechtungen nehmen in der Region zwar vom Ballungsraum hin zum Umland ab, dennoch besteht zwischen den Räumen eine Funktionsteilung, die die Region als Ganzes erst charakterisiert und letztlich wettbewerbsfähig macht. Diese Pluralität, die in einem engen Kontext mit einer nachhaltigen Entwicklung steht, geht also über die Wertschöpfung lokaler Wirtschaftsstandorte hinaus. Von daher bedürfen geeignete Lösungsansätze, nicht nur ausschließlich im Bereich der Mobilität, einer regionalen Sicht.

Hieraus ergibt sich die Forderung, dass ein E-Ticketing-System grundsätzlich im gesamten RMV-Verbundraum eingeführt werden sollte. Denn auch im ländlichen Raum wird heute immer noch ein Verkehrsangebot aufrecht erhalten, dass über die Ansprüche der Schülerbeförderung hinausgeht. Warum sollte also nicht versucht werden, die hier existierenden freien Kapazitäten besser zu vermarkten bzw. auszulasten? Voraussetzung hierfür sind allerdings Maßstabskriterien im Marketing und in der Planung, die sich aufgrund der andersartigen Nachfrage von denen im Ballungsraum deutlich absetzen. Insofern hat die verbundweite Einführung von E-Ticketing das Ziel, die pauschalisierende ÖPNVVermarktung, die die unterschiedlichen Anforderungen der Räume weitgehend ignoriert,

\footnotetext{
1211 vgl. RMV 2005, S.93

1212 vgl. Ackermann und Stammler 2006, S.14
} 
zugunsten einer ÖPNV-Vermarktung unter lokalspezifischen Gesichtspunkten abzulösen. Dieser Ansatz wird durch die dezentralen organisatorischen Zuständigkeiten der Lokalen Nahverkehrsorganisationen für die Ausgestaltung des ÖPNV auf lokaler Ebene unterstützt. Ob es allerdings zur Attraktivitätssteigerung auch im ländlichen Raum notwendigerweise einer durchgehenden Erfassung der Fahrdaten bedarf, muss im Rahmen eines detaillierten Einführungskonzeptes geklärt werden. Einhergehend mit Maßnahmen der Kommunikations- (z.B. verbesserte Information) und Produktpolitik (z.B. Anschlusssicherung) sowie der Erleichterung des Fahrkartenerwerbs durch den Einsatz neuer Vertriebskanäle, könnte sich die Einführung von Elektronischen Tickets (VDV-Stufe 2) durchaus als sinnvolle Endausbaustufe erweisen. Insofern es also - ausgehend von den Unterschieden in der Nachfragestruktur - zu unterschiedlichen VDV-Stufen im Ballungsraum sowie im ländlichen Raum käme, müsste die Sicherstellung der Interoperabilität dann über die Vereinheitlichung der Kundenschnittstelle (Bedienoberfläche) sowie klar verständlicher Geschäftsregeln erzielt werden.

Bezüglich des Einführungszeitpunktes ist festzustellen, dass es keinen richtigen Zeitpunkt gibt. „Der richtige Zeitpunkt wird alleine dadurch definiert, ob Mehreinnahmen generiert und Kosteneinsparungen vorgenommen werden können und müssen“.1213 Die unterschiedlichen E-Ticketing-Systeme in der ganzen Welt, von denen etliche bereits weiterentwickelt wurden, beweisen, dass mit unterschiedlichen technischen Systemausprägungen wirtschaftliche Erfolge erzielt werden können. ${ }^{1214}$

\subsection{Organisatorische Umsetzung}

\subsubsection{Vernetzung als Leitgedanke der intermodalen Zusammenarbeit}

In Kapitel 4 (siehe vor allem Kapitel 4.1.3) wurde dargestellt, dass es eine Diskrepanz zwischen dem Raum gibt, dem starke wirtschaftliche Interdependenzen zueigen sind und den übergeordneten politischen und administrativen Strukturen, die sich wiederum nicht mit den Grenzen der Region Frankfurt Rhein-Main decken. Trotz der herausragenden Bedeutung, die der Verkehr für die Region hat, gibt es somit keine über alle Verkehrsträger übergreifende koordinierende Einheit, die den Verkehr in der Region ganzheitlich

1213 Sparmann, V. 2005, S.72

1214 ebd. 
„managet". In Kapitel 4.7 wurde erläutert, dass die unterschiedlichen Verkehrsakteure zwar ein integriertes Gesamtverkehrssystem als Zielzustand anstreben, es jedoch nach wie vor eine geradezu „klassische“ Konkurrenzsituation zwischen den unterschiedlichen Verkehrsträgern gibt. Ein integriertes Gesamtverkehrskonzept ist aber gerade durch die physische, informatorische und organisatorische Vernetzung der Verkehrssysteme charakterisiert, die erst intermodale Wegeketten ermöglicht (siehe Kapitel 4.7.2.1).

Die Umsetzungsbestrebungen des integrierten Gesamtverkehrssystems spiegeln sich ansatzweise in der Gründung der IVM und im Rahmen Initiative „Staufreies Hessen 2015“ wider. In diesen Ansätzen dient die Technik vornehmlich der Daten- und Informationsübermittlung (informatorische Vernetzung) an die Verkehrsteilnehmer und weniger der Förderung der organisatorischen Vernetzung bzw. Kooperation zwischen den Verkehrsakteuren. Damit tragen die Telematikanwendungen in bezug auf die Schaffung einer einheitlichen Datengrundlage zu einer engeren Abstimmung bei, aber kaum zur Herausbildung neuer Organisationsmodelle. Vielmehr sollte die Telekommunikation stärker genutzt werden, um die unterschiedlichen dezentralen Organisationseinheiten in der Region Frankfurt Rhein-Main zu vernetzen, ohne dass diese dabei ihre Selbständigkeit aufgeben müssten. Ein solches Organisationsmodell verspricht aufgrund der Integration lokalörtlicher Kompetenzen außerdem die größte Marktnähe. So wird über die Technik, bzw. Telekommunikation, ein „Akteursnetzwerk“ bereitgestellt, über das multimodale Angebote - als wesentliche Merkmale eines integrierten Gesamtnetzwerkes - erst ermöglicht werden. Von daher kommt nicht nur der Intermodalität des Angebots, sondern auch der Multifunktionalität - im Sinne von Multioptionalität - eine große Bedeutung zu. ${ }^{1215}$ Hunecke kommt hier zur Erkenntnis, dass eine

„konkrete Option zur Umsetzung der Multimodalität [...] eine Mobilitätskarte“ dar[stellt], mit der je nach Bedarf unterschiedliche Verkehrsträger genutzt werden können. So wird nicht mehr gewohnheitsmäßig das Auto für alle Wege und Aktivitäten genutzt, sondern die Buchung von adäquaten Mobilitätsdienstleistungen (z. B. Car-Sharing, ÖV-Tickets) beim Mobilitätsberater wird ihrerseits zu einer Routinehandlung". ${ }^{1216}$

Derartige intermodale Angebote eignen sich vor allem in Ballungsräumen, wo aufgrund des hohen Verkehrsaufkommens der private Pkw an Attraktivität gegenüber dem ÖPNV

\footnotetext{
1215 vgl. Maertins 2006, S.2

1216 Hunecke 1998, S.94
} 
verliert. Gleichzeitig muss aber konstatiert werden, dass aufgrund der fehlenden organisatorischen und technischen Netzwerke sich ein derartiges intermodales Modell eher noch als ideales Leitbild darstellt1217, zumal auch die einzelnen Akteure im intramodalen Bereich divergierende Interessen haben.

\subsubsection{Intramodale Kooperation und Koordination im Mobilitätsverbund}

Für eine erfolgreiche Positionierung in einem integrierten Gesamtverkehrssystem ist es unerlässlich, dass sich der ÖPNV einheitlich am Markt aufstellt („One-face-to-thecustomer", siehe Kapitel 6.4.4.1). Die hierfür notwendige Abstimmung zwischen den ÖPNV-Akteuren, sprich die intramodale Kooperation, ist eine wesentliche Voraussetzung für ein wirkungsvolles und erfolgreiches Zusammenarbeiten in einem Netzwerk von Mobilitätsdienstleistern. ${ }^{1218}$ Voraussetzung ist allerdings, dass Informationen zwischen allen Mobilitätsdienstleistern ungehindert fließen können, es sich also vom Prinzip her um ein „vollständiges Netz“ (siehe Kapitel 6.4.1) handelt. Der Handlungsspielraum für die rechtlich-organisatorische Umsetzung eines ÖPNV-Netzwerkes mit klar definierten Aufgaben und Rollen wird durch das im Hess. ÖPNVG verankerte Besteller-Ersteller-Prinzips vorgegeben. Daraus wird deutlich, dass es sich innerhalb dieses Organisationsmodells nicht um ein Netzwerk von Gleichberechtigten handelt, sondern um ein Kooperationsmodell, welches über die Zuordnung von Rollen einer gewissen hierarchischen Struktur bedarf; Allerdings nicht in Form einer „sternförmigen Struktur“ (siehe Kapitel 6.4.1), bei der Entscheidungen an einer „Spitze“ getroffen und „Unten“ umgesetzt werden, sondern im Sinne von verteilten Zuständigkeiten und Rollen mit definierten Eigenverantwortlichkeiten. Insbesondere dort, wo Organisationsmodelle dazu beitragen sollen ein Unternehmen oder am Beispiel des ÖPNV eine ganze Branche - kunden- bzw. marktorientiert auszurichten, sollte bzw. darf nicht mehr hierarchisch entschieden werden. Vielmehr muss dort gehandelt werden, wo der Kunde nachfragt. Dieses ist nicht alleine räumlich gemeint, sondern auch in bezug auf Kontakt- und Vertriebskanäle. Nur so kann sicher gestellt werden, dass auf Marktveränderungen und sich wandelnde Kundenbedürfnisse flexibel reagiert werden kann. ${ }^{1219}$

\footnotetext{
1217 vgl. Hunecke 1998, S.95

1218 vgl. Henning und Schmidt 1998, S.49

1219 vgl. Lehmann 2000, S.55
} 
Dieses Netzwerk kann vom Prinzip her der von der RMV GmbH angestrebte „Mobilitätsverbund“ sein. In diesem Netzwerk behalten die zusammengeschlossenen Unternehmen ihre Eigenständigkeit - auch im Hinblick auf die Anpassungsfähigkeit an den Markt. Der Mobilitätsverbund koordiniert aber die Mobilitätsdienstleister und stellt Dienste zentral bereit. Nun gilt es diesen Spielraum auszuschöpfen, das Netzwerk formal umzusetzen und die ÖPNV-Akteure technisch einheitlich instrumentell auszustatten. Denn inwieweit „diese Möglichkeiten der Kooperation ausgeschöpft werden können, hängt [...] ganz wesentlich von der Herausbildung einheitlicher Kommunikations- und Kooperationsstandards zwischen den Mitgliedern des Netzwerkes $a b{ }{ }^{1220}$

Partner in diesem intramodalen Netzwerk sind in erster Instanz die ÖPNV-Aufgabenträger und Verkehrunternehmen, deren vorrangiges Ziel es sein muss, ihr (bisheriges) Kerngeschäft über dieses Netzwerk zu vermarkten. Erst in zweiter Instanz geht es auf mittel- bis langfristiger Sicht um die Einbindung von Partnern aus der Wirtschaft und der Industrie - und damit um die Bildung von neuen multifunktionalen und multimodalen Angeboten, die die Positionierung der ÖPNV-Akteure als Mobilitätsdienstleister am Markt glaubhaft macht.

Kapitel 6 hat gezeigt, dass die ÖPNV-Akteure auf breiter Front die Notwendigkeit für eine kundenorientierte Neupositionierung ihrer Unternehmen realisiert haben. Hierfür stehen den Unternehmen vom Prinzip her die unterschiedlichsten Marketinginstrumentarien zur Verfügung. Bislang muss allerdings resümiert werden, dass neben den klassischen Instrumenten der Produkt- und Preispolitik eine Vielzahl von Marketinginstrumenten nicht oder nur ansatzweise zum Einsatz kommen. Auch organisatorisch-strukturelle Veränderungen, die eine verbesserte Kundenorientierung einzelner Unternehmen oder sogar der gesamten ÖPNV-Branche unterstützen, sind nicht mit der notwendigen Konsequenz umgesetzt worden. Rumpke sieht vor allem

„sich überschneidende Zuständigkeiten zwischen den Akteuren, falsche Anreize oder öffentliche/politische Einflussnahme; fehlende Wirksamkeitsnachweise, mangelnde Inhalte oder technische Probleme bei der Umsetzung der Marketinginstrumente sowie geringe Finanzmittel, wenig qualifizierte Mitarbeiter oder innerorganisatorische Hürden"1221

1220 ebd.

${ }^{1221}$ Rumpke 2005, S.199 
als Gründe für die Tatsache, dass die ÖPNV-Unternehmen die Marketinginstrumente nicht oder nur selten anwenden. Als Ursache wird allerdings die "mangelhafte Akteursorganisation“ genannt. Das Resultat ist, dass Marketinginstrumente nur partiell zum Einsatz kommen, dann allerdings unabgestimmt und mit wenig Erfolg. ${ }^{1222}$ Es fehlt den ÖPNV-Akteuren bislang also eine gemeinsame operationelle Kooperationsplattform und eine übergeordnete Koordination.

\subsubsection{Der RMV als ÖPNV-Kooperationsplattform}

Die zwingende Voraussetzung für eine Kooperation im ÖPNV, die auf die Verbesserung der Kundenorientierung abzielt, ist das Selbstverständnis der Akteure, dass es zwischen ihnen keinen unmittelbaren Wettbewerb um Fahrgäste gibt. Nur so ist eine Positionierung gegenüber dem MIV erreichbar, die auch vom Kunden als durchgängig echte Alternative wahrgenommen wird. Sichtbares Resultat dieser Kooperation muss daher eine einheitliche Benutzeroberfläche sein, „unterhalb“ derer es zu einem abgestimmten Einsatz aller Marketinginstrumente kommt. Dieses setzt voraus, dass alle Mobilitätsdienstleister ihre Aktivitäten im Marketingbereich in einer zentralen Einheit zusammenführen, die für Planung, Umsetzung und Kontrolle zuständig ist. Dies ermöglicht gleichermaßen erst den effizienten Mitteleinsatz wie auch eine höchstmögliche Effektivität der Maßnahmen. ${ }^{1223}$ Rumpke unterstreicht, dass sich die Arbeit dieser zentralen Instanz nicht alleine auf Koordinations- und Moderationsaufgaben beschränken darf, sondern diese im operativen Geschäft tätig sein soll. Anderenfalls bestehe die Gefahr der „Institutionalisierung der Verantwortungslosigkeit“. ${ }^{1224}$ Eine verbundweit operierende Instanz gewährleistet zudem, dass der Fokus der Marktbearbeitung auf die Region gerichtet ist und nicht alleine auf lokale Teilmärkte und dass hierüber Synergie- und Rationalisierungseffekte an alle ÖPNV-Akteure weitergegeben werden.

Für die Region Frankfurt Rhein-Main gibt es mit der RMV GmbH bereits eine solche zentrale Instanz, zumal die Instrumente der Preispolitik sowie der regional bedeutsamen Bestandteile der Produktpolitik hier hoheitlich zugewiesen sind. Der RMV stellt als Regieebene (siehe Kapitel 5.4) bereits eine Kooperationsform zwischen Markt und starrer staat-

\footnotetext{
1222 vgl. Rumpke 2005, S.199

1223 ebd., S.203f

1224 Rumpke 2005, S.204
} 
licher Ordnung bzw. Hierarchie dar. Die Zusammenarbeit der rechtlich selbständigen Gesellschafter ist vertraglich geregelt und hat langfristigen Charakter. ${ }^{1225}$ Der RMV ist „Aufgabenträgerverbund“, in dem alle Träger öffentlicher Belange des ÖPNV zusammengeschlossen sind und die ÖPNV-Verkehrsleistung planen, organisieren, ausschreiben und vergeben sowie finanzieren. Dabei ist im Rahmen des "dezentralen Prinzips“ die lokale und regionale Verantwortung voneinander getrennt, welches die Abstimmung und Kooperation (bspw. über verbindliche Qualitätsstandards) notwendig macht. ${ }^{1226}$ Diese Dezentralität bringt es mit sich, dass unterschiedliche politische Belange, insbesondere bei Landkreisen mit schlechter ÖPNV-Anbindung sowie den Städten und Kreisen im Ballungsraum, Kompromisse notwendig machen. Dennoch besteht grundsätzlich das gemeinsame Ziel, möglichst viele Fahrgäste für den ÖPNV zu gewinnen und dabei gleichzeitig ein betriebswirtschaftlich zufriedenstellendes Ergebnis zu erzielen. ${ }^{1227}$ Mittlerweile wurde bei einer Tochtergesellschaft der RMV GmbH ein „Kompetenzcenter Mobilität” $(\mathrm{kcm})$ eingerichtet, das als offenes Netzwerk von Beratungsunternehmen im Verkehrsumfeld Ideen und Erfahrungen bündeln sowie weitervermitteln soll. ${ }^{1228}$

Wie bereits in Kapitel 5.5 erwähnt, möchte sich der RMV von einem „Aufgabenträgerverbund“ zu einem „Mobilitätsverbund“ weiterentwickeln. Wichtigste Weiterentwicklungen sind hierbei:

- Verwirklichung eines einheitlichen integrierten Marketings mit Markenbildung und -führung,

- integrierte Verkehrsangebote,

- Kundenbindung und -loyalisierung,

- innovative Vertriebs- und Informationssysteme,

- Abbau von Zugangsbarrieren und

- intelligente Organisationsmodelle. ${ }^{1229}$

1225 vgl. Knieps 2004, S.187

1226 vgl. RMV 2005, S.7

1227 vgl. Knieps 2004, S.187

1228 vgl. www.kompetenzcenter-mobilitaet.de

${ }^{1229}$ vgl. RMV 2005, S.7 
„Das große Ziel Mobilitätsverbund“1230 ist nach eigenen RMV-Aussagen eng mit dem Ziel verknüpft, für alle Akteure umfassende Information, Kommunikation und Dienstleitung bereitzustellen. Als Grundvoraussetzung wird ein integriertes Gesamtverkehrssystem erachtet, in dem die unterschiedlichen Verkehrsträger miteinander vernetzt sind. Diese intermodale Vernetzung sowie ein leistungsstarker ÖPNV werden als substanziell angesehen, „die Mobilität der Menschen nachhaltig, umwelt- und sozialverträglich“ zu sichern und „die Standortqualität Hessens als Wirtschaftsfaktor“ zu fördern. Als Instrumente der Umsetzung werden vor allem eine weitere Vernetzung der Aktivitäten und Partner sowie ein zielgerichteter Technologieeinsatz gesehen. Der Zusammenführung der drei Prozessbereiche „Informieren, Buchen und Zahlen“ wird dabei eine Schlüsselrolle eingeräumt. ${ }^{1231}$

Die Rolle des „Mobilitätsverbundes“ ist insofern also als organisatorische Klammer um die lokalen und regionalen Verkehrsunternehmen, die als „Mobilitätsdienstleister“ am Markt agieren, zu verstehen. Gleichzeitig vertritt die $R M V G m b H$ die Interessen aller ÖPNV-Akteure im Gesamtverkehrssystem. Um dieser Aufgabe gerecht zu werden, muss der „Mobilitätsverbund“ über die heutigen Aufgaben hinaus weitere koordinierende und zentrale Funktionen wahrnehmen, womit die Aneignung neuer Kompetenzen verbunden ist (siehe Kapitel 6.4.2). Neben der traditionellen Verkehrsplanung gehören hierzu Aufgaben wie Marktforschung und -beobachtung sowie die Messung von Dienstleistungsqualitäten und Nachfragegrößen. Wenn darüber hinaus selber Mobilitätsdienstleistungen vom RMV angeboten werden sollen, sind weitere Marketingkompetenzen notwendig. ${ }^{1232}$ Dies scheint vor dem Hintergrund der Notwendigkeit einer verbundweit übergreifenden Vermarktung auch sinnvoll.

Rumpke zweifelt an, dass eine kommunal geführte Marketinggesellschaft diese Aufgabe zufriedenstellend bewerkstelligen kann. Er kritisiert vor allem die Kundenferne der Aufgabenträger und die Zuordnung des Erlösrisikos, das im Rahmen der Deregulierung und der damit verbundenen Vergabe von Verkehrsleistung über Nettoverträge mehr und mehr auf der Verkehrsunternehmensseite zu finden ist. Demnach müssten den Verkehrsunternehmen unternehmerische Freiheiten eingeräumt werden, die Marketinginstrumente marktnah einzusetzen. Bei der Vergabe von Verkehrsleistungen im Rahmen von Brut-

\footnotetext{
1230 ebd.

1231 ebd.

1232 vgl. Blümel 2004, S.96
} 
to- oder Bruttoanreizsystemen sieht Rumpke allerdings die Verantwortung für die Marketinginstrumente in den Händen der Aufgabenträger, wobei er einschränkend sagt, dass diese in der Praxis kaum anzutreffend sind und „vermutlich auch in Zukunft nur selten“ sein werden. ${ }^{1233}$

Dies trifft allerdings in dieser Form nicht für den RMV zu, zumal es hier nicht zu einer völlig freien Entfaltung der Marktkräfte kommen soll:

"Ausschreibungsgegenstand ist ein Bruttoanreizvertrag in Verbindung mit einem Leistungsverzeichnis, in dem die Leistungsprofile für die Vergabe der Verkehrsdienstleistungen mit konstruktiven und funktionalen Elementen beschrieben sind. [...] Im Hinblick auf das Anreizsystem wird die betriebliche Qualität bei der Leistungserbringung über objektive Kriterien (Messungen und Erhebungen, beispielsweise zur Pünktlichkeit) sowie subjektive Kriterien (Kundenbefragungen, beispielsweise zur Sauberkeit der Züge) überprüft. Bei guter Qualität in der Leistungserbringung wird ein Bonus gezahlt, während bei Schlechtleistung empfindlich sanktioniert wird (Bonus-Malus-System)“. ${ }^{1234}$

Durch die konsequente Anwendung dieser Vertragsmechanismen auf der Basis konstruktiver, also möglichst konkreter Vorgaben, gewährleisten Bruttoanreizverträge am ehesten die Umsetzung von verkehrs-, sozial- und umweltpolitischen Zielen. ${ }^{1235}$ Auch ist bei einer Marketinggesellschaft in kommunaler Führerschaft die Kontinuität der Marktbearbeitung gewährleistet. Denn gerade durch den Wettbewerb wird es regelmäßig zu Abgängen und Neuzugängen bei einer verkehrsunternehmenseigenen Trägerschaft der Marketinggesellschaft kommen. Damit sind nicht nur divergierende Interessen und Vorstellungen über die Art und Weise der Marktbearbeitung vorprogrammiert, es besteht auch ein hoher organisatorischer Aufwand im Hinblick auf den Interessensausgleich der in teilweise völlig unterschiedlichen Räumen operierenden Verkehrsunternehmen. Nicht zuletzt könnten sich auch - wie Rumpke selbst einräumt - rechtliche Probleme bei einer dann notwendigen Zwangsmitgliedschaft der Verkehrsunternehmen in einer zentralen Marketinggesellschaft ergeben. ${ }^{1236}$ Auch Lehmann verweist auf die Instabilität von Kooperationen im ÖPNV, insbesondere dann, „wenn die Unternehmen sehr unterschiedliche Größe aufweisen.

\footnotetext{
${ }^{1233}$ vgl. Rumpke 2005, S.206ff

1234 RMV 2005, S.65

1235 vgl. Deutsches Institut für Urbanistik 2005, S.42

1236 vgl. Rumpke 2005, S.206
} 
Denn große Unternehmen könnten der Versuchung erliegen, die Kooperation zu verlassen, um in einen Verdrängungswettbewerb gegen kleine Unternehmen einzutreten“ ${ }^{1237}$ Umgekehrt wird durch eine koordinierende kommunale Instanz sichergestellt, dass die bereitgestellten Mehrwertdienste, z.B. in Form des E-Ticketing, auch von neuen Unternehmen am Markt genutzt werden können. Der Gefahr einer destabilisierenden Wirkung, die durch neue Marktzutritte entsteht, weil die „Alt-Koalitionäre“ Einbußen befürchten, wird damit entgegengewirkt. ${ }^{1238}$

Das Deutsche Institut für Urbanistik kommt zum Schluss, dass die Aufgabenträger sich zwischen einem Entwicklungspfad als Mobilitätsdienstleister oder als Koordinator entscheiden müssen. ${ }^{1239}$ Der RMV hat sich in dieser Frage klar positioniert, indem er selbst gestalterisch als Mobilitätsverbund tätig sein möchte. „Dazu nimmt er gezielt alle wichtigen Regie- und Managementfunktionen wahr und bedient sich der Verkehrsunternehmen als ausführende Akteure, die er über Vertragssteuerung und Controlling eng an sich bin$\operatorname{det}^{\prime \prime} .{ }^{1240}$ Die Etablierung einer zentralen Marketinggesellschaft in kommunaler Führerschaft bedeutet aber nicht, dass die Verkehrsunternehmen aus ihrer Vertriebsverantwortung entlassen werden. Nach wie vor wird der Verkauf von Fahrtberechtigungen und die Beratung vor Ort eine wichtige Schnittstelle zum Kunden darstellen, was über Vertriebsprovisionen oder entsprechende Anreizsysteme auch entsprechend honoriert werden kann. Das Thema „Kundenorientierung“ wird also für die Verkehrsunternehmen in einem deregulierten Markt durch die Berücksichtigung subjektiver Parameter in den Bruttoanreizverträgen an Bedeutung zunehmen. Insofern bedarf es auch auf der Ebene der Verkehrsunternehmen einer Weiterentwicklung vom „Beförderungsdienstleister“ zum „Mobilitätsdienstleister“, sprich der Erhöhung der Kundenorientierung. ${ }^{1241}$

Darüber hinaus ist auch nicht ausgeschlossen, dass privatwirtschaftlich geführte Unternehmen - entweder als Unterauftragnehmer oder sogar in der Form beteiligter Partner im Rahmen einer Public-Private-Partnership - ihre Erfahrung in die Vermarktung von Mobilitätsdienstleistungen einfließen lassen können und sollen (siehe Kapitel 6.4.1.2). Auf-

\footnotetext{
1237 Lehmann 2000, S.134

1238 vgl. Lehmann 2000, S.135

${ }^{1239} \mathrm{vgl}$. Deutsches Institut für Urbanistik 2005, S.40

1240 ebd.

1241 Vorbildfunktion hinsichtlich des Produktangebots kommt hier der Deutschen Bahn AG zu, die in Ergänzung zu ihrer Kernleistung „Beförderung auf der Schiene“ Zusatzleistungen wie CarSharing, Leihfahrräder und eine intermodale Reiseauskunft bereit hält.
} 
grund der hohen Involvierung öffentlicher Infrastrukturen sollte es aber zu einer hoheitlichen bzw. kommunalen Führerschaft kommen. Ansonsten besteht die Gefahr, dass bedingt durch kurzfristige Gewinnerwartungen der Instandhaltung und Weiterentwicklung der benötigten Infrastrukturen zu wenig Beachtung geschenkt wird. Dieses ist insbesondere auch vor dem Hintergrund einer auf Nachhaltigkeit ausgelegten Gesamtlösung von Bedeutung. ${ }^{1242}$

Berücksichtigt man zusätzlich die Unternehmensgrößen der unterschiedlichen Aufgabenträgerorganisationen, die ausschlaggebend für eine Aufgabenspezialisierung sind (siehe Kapitel 6.4.4.1), bleibt unterm Strich die Erkenntnis, dass die RMV GmbH nicht nur unter den gegebenen organisatorischen Rahmenbedingungen die einzige Institution ist, die sich als zentrale Instanz einer verbundweit übergreifenden Kooperation zur Vermarktung des ÖPNV anbietet, sondern auch vor dem Hintergrund der weiteren Umsetzung des „Hessischen Wegs“ eine wichtige Rolle an der Schnittstelle von Aufgabenträgern und Verkehrsunternehmen einnimmt. Die selbstformulierten Ziele der RMV GmbH machen einerseits das vorhandene Problembewusstsein für den notwendigen Handlungsbedarf deutlich, andererseits zeigt sich die Komplexität der Aufgabenstellung in der Mehrdimensionalität des Ansatzes, der die Aneignung neuer Kompetenzen sowie die organisatorische und unternehmerische Weiterentwicklung erforderlich macht. Insbesondere bedarf es eines Instrumentariums, mit dem die $R M V G m b H$ die Vermarktung gleichermaßen umsetzen als auch kontrollieren kann. Insoweit scheint auch die Frage geklärt zu sein, ob die RMV $\mathrm{GmbH}$ auch Verantwortung für operative Aufgaben eines logischen „Kundenvertragspartners" nach dem VDV-KA-Rollenmodell übernehmen sollte und es nicht nur bei koordinierenden Aufgaben belässt. Die Rollen des „Produktverantwortlichen“, des „Kontrollservices“ und des „Kartenherausgebers“ sind ebenfalls durch die RMV GmbH zu besetzen und in Zusammenarbeit mit den lokalen Aufgabenträgern auszufüllen. Letztere übernehmen auf lokaler Ebene die Aufgabe von „Mobilitätsagenturen“ im Mobilitätsverbund bzw. sind für die lokale Vermarktung der ÖPNV-Leistung verantwortlich.

Ein E-Ticketing-System kann hier einen wertvollen Beitrag liefern, das Kompetenzspektrum des RMV als Mobilitätsverbund deutlich zu erweitern. So ist ein E-Ticketing-System ein technisches Instrument, mit dem der RMV den Verkehrsmarkt gezielt bearbeitet kann um Marktpotenziale zu erschließen und Zahlungsbereitschaften abzuschöpfen, da es die

${ }^{1242}$ vgl. Halbritter u.a. 2005, S.37f 
umfassende Anwendung des gesamten Marketingmixes ermöglicht (Vermarktungskompetenz). Gleichzeitig können hierüber Qualitätsstandards im Marketing neu definiert, eingeführt und kontrolliert werden (Qualitätsmanagementkompetenz), was insbesondere für die Vergabe von Verkehrsleistungen im Rahmen von Bruttoanreizverträgen von Bedeutung ist (Ausbau der Bestell- und Ausschreibungskompetenz). Zudem liefert das System wichtige und zeitnahe Daten der Verkehrsnachfrage, die für die marktgerechte Verkehrsplanung von hoher Bedeutung sind (Verkehrsplanungskompetenz). Insgesamt wird das Verhältnis zum Kunden intensiviert, bzw. das Unternehmen überhaupt erst in die Lage versetzt, mit seinen Kunden in Kontakt zu treten und auszutauschen. Das hieraus generierte Wissen über den Markt kann wiederum in die kundenorientierte Angebotsentwicklung einfließen. Nicht zuletzt aufgrund der Bündelung von Prozessen bei einer zentralen Instanz können auch unterschiedliche Einspareffekte erzielt werden.

\subsubsection{Voraussetzungen für eine kommunale Marketinggesellschaft}

Bei der Vermarktung von Fahrtberechtigungen durch eine kommunal geführte Marketinggesellschaft ist zu berücksichtigen, dass laut PBefG ein Verkehrsunternehmen die Transportleistung auf eigenen Namen und auf eigene Rechnung betreibt - mit allen umsatzsteuerrechtlichen Konsequenzen. Für den Kunden bedeutet dies bislang, dass er eine vertragliche Rechtsbeziehung bei Einstieg in ein Fahrzeug mit dem befördernden Verkehrsunternehmen eingeht. Dieses verpflichtet sich zur Beförderung des Kunden, der seinerseits für diese Leistung einen entsprechenden Fahrpreis zu entrichten hat. In §5, Abs. 1 der "Gemeinsamen Beförderungsbedingungen“ des RMV wird hierauf hingewiesen. ${ }^{1243}$ Demnach besteht also eine Vertragsbeziehung immer nur zwischen Kunde und Verkehrsunternehmen.

Es gibt allerdings Ausnahmen von dieser Regelung. So tritt der die RMV GmbH bereits heute als Vermittler (also quasi als "Agentur“) zugunsten von Verkehrsunternehmen beim Vertrieb von Kombi- oder Jobtickets in Erscheinung. Prinzipiell können derartige Ausnahmen von der Regelung, dass der Fahrkartenverkauf über die Verkehrsunternehmen erfolgt, aber auch im Rahmen von Verkehrsverträgen vereinbart werden, zumal das Hess. ÖPNVG ausdrücklich vorsieht, dass „Serviceleistungen“ - und hierzu wird auch der Vertrieb von Fahrtberechtigungen gezählt - im Besteller-Ersteller-Verhältnis vertrag-

${ }^{1243}$ vgl. RMV 2006 (b), S.36 
lich zu regeln sind. ${ }^{1244}$ Es bestünde damit durchaus die Möglichkeit, dass die Verkehrsunternehmen Teile ihrer Vertriebsaufgaben an die Aufgabenträger - und damit an eine zentrale Vermarktungsinstanz - abtreten. Eine ähnliche Abtretungspflicht gibt es bereits heute im RMV im Bereich der Tarifplanung. Gemäß §2, Abs. 2 des Hess. ÖPNVG obliegt es dem Verkehrsverbund den Verbundtarif festzulegen. ${ }^{1245}$

Eine andere Möglichkeit besteht in der vergaberechtlichen Trennung von Verkehrs- und Vertriebsleistung, bei der alleine der Betrieb bzw. die Bedienung einer Relation ausgeschrieben wird. Aufgrund der betrieblichen Verknüpfung von Betrieb und Vertrieb durch den Fahrerkauf in Bussen eignet sich eine derartige Aufspaltung v.a. im SPNV. Auch hier wurden bei der RMV GmbH bereits Erfahrungen gesammelt: im Zuge der Ausschreibung der Odenwaldbahn wurde nur der Betrieb des Netzes vergeben und gleichzeitig auch die hierfür notwendigen Dieselfahrzeuge von der fahma GmbH (siehe Kapitel 6.5.2.3.2) bereitgestellt. ${ }^{246}$ Der Vertrieb entlang der Strecke wird weiterhin von der DB AG bewerkstelligt.

Diese Beispiele machen deutlich, dass es zahlreiche rechtliche Ansatzpunkte gibt, Vertriebsaufgaben zu zentralisieren und eine zentrale kommunale Marketinggesellschaft im RMV zu etablieren. In Abhängigkeit von vertraglichen Vereinbarungen zwischen den Aufgabenträgern und den Verkehrsunternehmen könnte diese zentrale Marketinggesellschaft als „Agentur“ im Namen der Aufgabenträger bzw. der Verkehrsunternehmen am Markt auftreten und somit die Rolle eines „logischen“ Kundenvertragspartners einnehmen (siehe Kapitel 7.3.3). Für eine umfassende Kundenbetreuung, die auch die - treuhänderische - Abrechnung der Kunden vorsieht, bedürfte es allerdings weitreichenderer vertraglicher Vereinbarungen, beispielsweise zu Datenüberlassungen.

\footnotetext{
${ }^{1244}$ vgl. Hessischer Landtag 2005, S.789

1245 ebd., S.788

${ }^{1246}$ vgl. o.V. 2006, S.7ff
} 


\subsection{Ertragsseitige Optimierungsansätze}

\subsubsection{Produkt}

\subsubsection{Kundenorientierte Produkte und Angebote}

Aufgrund der sich weiter differenzierenden individuellen Mobilitätsansprüche in der Bevölkerung sowie der unterschiedlich strukturierten Räumen mit heterogenen Bedienungsanforderungen wird es für die ÖPNV-Unternehmen zusehendst schwerer, marktgerechte Angebote - mit den zur Verfügung stehenden Mitteln und Methoden des Marketingmanagements - zu entwickeln (Markterschließung durch Produktinnovation) oder zu verbessern (Marktausschöpfung durch Produktdifferenzierung) und entsprechend zu vermarkten. Den Anspruch eines Mobilitätsdienstleisters wird man aber kaum gerecht ausfüllen können, wenn es auf die formulierten Ansprüche der (potenziellen) Kunden keine passenden Angebote gibt. Ein modernes und kundenorientiertes Produktmanagement ${ }^{1247}$, dass marktgerechte Produkte entwickelt, muss vor allem flexibel auf die Bedürfnisse der Kunden eingehen bzw. auf veränderte Marktsituationen nicht nur reagieren können, sondern im Idealfall den Markt aktiv beeinflussen. Der ÖPNV befindet sich hier allerdings noch in einem Stadium, in dem sich die Investitions- und Konsumgüterindustrie in den 1950er Jahren befand, als die Produktqualität von den Herstellern vorgegeben wurde. 1248

Die Voraussetzung für die Entwicklung kundenorientierter Produkte ist die Kenntnis der Kundewünsche. Dieser Kenntnisstand korreliert mit der Fähigkeit, mit dem Kunden in Kontakt zu treten und sich mit diesen auszutauschen. ${ }^{1249}$ Im ÖPNV werden regelmäßig angebotsabhängige Informationen erhoben, die auf die Erhebung quantitativer Merkmale ausgerichtet sind. Diese dienen aber weniger der Produktoptimierung, als vielmehr der Schaffung einer Datengrundlage für das Controlling bzw. die Einnahmenaufteilung. Daten über die nachgefragte ÖPNV-Leistung werden periodisch alle paar Jahre über aufwendige Verkehrszählungen bzw. Kundenbefragungen durchgeführt. Der Stichprobenumfang liegt in der Regel zwischen 1,5 und 2,5\%. Um das Bild der Nachfrage zu verbessern, werden die Erhebungen zu verschiedenen Jahreszeiten durchgeführt, normalerweise

\footnotetext{
1247 Im Rahmen des Produktmanagements werden der Leistungsumfang, die Qualitätsanforderungen an das Produkt, der Preis sowie die Vertragsbedingungen definiert.

1248 vgl. Blümel 2004, S.46

1249 ebd., S.53
} 
zu Verkehrszeiten, in denen keinen Schulferien liegen. Dennoch kann auch dieses Verfahren nicht verhindern, dass die Erhebungen eine Momentaufnahme darstellen, die das Risiko größerer Ungenauigkeiten beinhalten.

Die genaue Kenntnis über die nachgefragte Leistung ist zwar wichtig (s.u.), lässt jedoch nur sehr ungenaue Rückschlüsse auf die Erfüllung der Kundenerwartungen zu. Hierfür bedarf es qualitativer Informationen, zu deren Erhebung der Kunde notwendigerweise integriert werden muss. Zu den im ÖPNV gängigsten Instrumenten der Erhebung qualitativer Merkmale gehören die interpretative Auswertung der Meldungen aus dem Beschwerdemanagement (sofern sie aufgezeichnet werden), Kundenbefragungen im Rahmen von Marktforschungsaktivitäten sowie der Informationsaustausch im Rahmen eines Fahrgastbeirats. ${ }^{1250}$ Letztlich sind Häufigkeit und Umfang der durchgeführten Maßnahmen ausschlaggebend für die Aussagekraft der Ergebnisse.

In einem E-Ticketing-System der VDV-Stufe 3, in dem die in Anspruch genommene Beförderungsleistung kontinuierlich quantitativ genau ermittelt wird, können weitreichende Rückschlüsse gezogen werden, inwieweit die angebotene ÖPNV-Verkehrsleistung bedarfsgerecht angeboten und vermarktet wird. ${ }^{1251}$ Über die Quelle-Ziel-Beziehungen lassen sich beispielsweise die Umsteigebeziehungen und damit die räumliche Verflechtung der Verkehrsnachfrage nachvollziehen. Auf Relationen mit häufigen Umsteigevorgängen können über Veränderungen in der Linienführung oder der verbesserten Abstimmung der Linienfahrpläne die Verbindungs- oder Umstiegszeiten optimiert und die Verbindungsqualität insgesamt verbessert werden. Über die so erreichte Reduzierung der Umstiegsbeziehungen können dann auch verlässlichere Mobilitätsgarantien an die Kunden gegeben werden.

Hierfür ist aber mindestens ein Check-In des Kunden bei Fahrtantritt sowie beim Fahrzeugwechsel notwendig. Für eine exakte Erfassung der leistungsrelevanten Daten ist die Erfassung über Check-In/Check-Out bzw. Be-In/Be-Out notwendig. Theoretisch lassen sich auf Basis dieser Information auch für kleine Kundensegmente maßgeschneiderte Tarif- bzw. Mobilitätsangebote entwickeln und so vorhandene Zahlungsbereitschaften bes-

\footnotetext{
1250 ebd., S.55f

1251 vgl. Megger und Vorgang 2000, S.4
} 
ser ausschöpfen. ${ }^{1252}$ Selbst in einem E-Ticketing-System, in dem nur ein Teil der Fahrten elektronisch erfasst wird, können die Daten über gewohnte statistische Hochrechnungsverfahren ein vollständiges und repräsentatives Bild der quantitativen Nachfrage ergeben. Es ist also keineswegs eine flächendeckende Erfassung aller Nutzergruppen notwendig. ${ }^{1253}$

In bezug auf die Generierung von qualitativen Informationen bietet ein E-TicketingSystem über das zentral organisierte Kundenmanagement einen geeigneten Ansatzpunkt. Hier ist insbesondere das Beschwerdemanagement zu nennen, dass Kundeninformationen aus dem gesamten Verbundgebiet zusammenführt und so repräsentative Aussagen und Rückschlüsse zulässt. Darüber hinaus kann sich durch die Integration moderner Kommunikationskanäle zum Kunden das bislang reaktive Beschwerdemanagement, das vor allem beschwichtigen soll, zu einem serviceorientierten aktiven Verbesserungsmanagement weiterentwickeln. Es ist dadurch gekennzeichnet, dass es die Kundenzufriedenheit nicht nur wieder herstellt, sondern auf „Unternehmensseite Leistungsdefizite analysiert und darüber hinaus Anregungen für Verbesserungen sowie Innovationen der angebotenen Leistung“ liefert. ${ }^{1254}$ Das zentral organisierte Kundenmanagement ist des weiteren die Basis für die Nutzung der Intensivierung des direkten kommunikativen Austauschs zwischen Unternehmen und Kunden (siehe Kapitel 7.6.4). Das zentral organisierte Kundenmanagement liefert aber nicht nur Erkenntnisse für die Produktentwicklung und -verbesserung, sondern trägt auch ganz wesentlich zur Verbesserung eines weiteren Produktmerkmals bei: Der Servicequalität.

\subsubsection{Verbesserung der Servicequalität}

Service wird als Dienstleistung von Mensch zu Mensch wahrgenommen (siehe Kapitel 6.1.1). Der Begriff „Qualität“ verdeutlicht, dass es sich hierbei um einen Bereich handelt, der mit harten Parametern wie eingesetztes Personal, Personalaufwand, Anzahl angebotener Kommunikationskanäle u.s.w. zwar grundsätzlich beschrieben werden kann, der aber zu einem nicht unerheblichen Teil von der Ausbildung und Befähigung des ÖPNVPersonals abhängt. ${ }^{1255}$ Die Serviceorientierung von Mitarbeitern im ÖPNV spielt daher

\footnotetext{
$1252 \mathrm{vgl}$. Achenbach 2002, S.231

1253 vgl. Keppeler, Kröpel, Sinisalo und Sirikiä 2005, S.57

1254 vgl. Blümel 2004, S.61

1255 vgl. Werner, P. 1997, S.316
} 
eine große Rolle bei der Kundenzufriedenheit. Doch auch die beste Schulungsmaßnahme wird fehlschlagen bzw. wird der am besten ausgebildete Mitarbeiter dort an die Grenzen seiner Hilfsbereitschaft stoßen, wo das System ihn nicht befähigt, Hilfe zu leisten. Dies hat insbesondere damit zu tun, dass aufgrund der abgegrenzten räumlichen (bezogen auf eine Linie oder ein Bedienungsgebiet) oder administrativen (bezogen auf ein bestimmtes Verkehrsmittel) Zuständigkeiten von Verkehrsunternehmen, das Servicepersonal in vielen Fällen - insbesondere bei Beschwerden, die häufig zu negativen emotionalen Zuständen bei den Kunden führen - nur für das Bedienungsgebiet Auskunft erteilen können, für das sie zuständig sind. Die ist für den Kunden, der auf seiner Fahrt häufig die Leistung mehrerer Anbieter in Anspruch nimmt, schwer verständlich. Auch einem übergeordneten Verbund ist es aufgrund fehlender Kommunikationsnetze und damit einhergehender fehlender Informationen im Rahmen einer Kundenreklamation nicht möglich, diese Kundenanliegen übergreifend zu bearbeiten.

Durch den Aufbau einer verbundweit einheitlichen Informations- und Vertriebsplattform mit einer gemeinsamen Datengrundlage sowie der Diversifizierung der Kommunikationskanäle über die Nutzung neuer (Kunden-) Medien (v.a. Internet) ist in einem ETicketing-System sichergestellt, dass der Kunde über jeden Vertriebs- bzw. Kommunikationskanal die selbe Information erhält und in Konsequenz die gleiche Auskunft erfährt. Damit können Kundenanfragen und -beschwerden nicht nur viel schneller bearbeitet und beantwortet werden, sondern auch auf einem einheitlich hohen Qualitätsniveau. Eine so verwaltete Kundenbeziehung ermöglicht die Behandlung des Kunden als „ÖPNVKunden" und nicht mehr als Kunden eines bestimmten Verkehrsunternehmens. Ein Verweis auf die Verantwortlichkeit einer anderen Stelle, wie es heute häufig der Fall ist, entfällt. Dieses ist eine wichtige Voraussetzung, sich dem Kunden gegenüber als Mobilitätsdienstleister zu positionieren und das Bild eines Transportunternehmens abzuschütteln.

Des weiteren wird durch die Verlagerung von Verkaufsvorgängen auf kundenbediente Vertriebskanäle (siehe Kapitel 7.6.2.4) eine Reduzierung von Fahrscheinverkäufen in den Fahrzeugen erreicht und das Fahrpersonal entlastet. Bei unveränderten zeitlichen Fahrplanabläufen kann die hierüber frei werdende Zeit für die Betreuung der Fahrgäste eingesetzt werden. ${ }^{1256}$

${ }^{1256}$ vgl. Achenbach 2002, S.213 


\subsubsection{Verbesserung des Sicherheitsempfindens}

In Kapitel 6.5.2.4 wurde bereits auf die schlechte Bewertung des subjektiven Sicherheitsempfindens im ÖPNV bzw. im öffentlichen Raum hingewiesen. Über die Einführung eines E-Ticketing-Systems lassen sich in allen Ausbaustufen Verbesserungen bezüglich der Sicherheit erreichen. Bereits in der VDV-Stufe 1 wird der Kunde von der Mitführung von Bargeld entbunden. Gerade das Herausnehmen einer Geldbörse in der Öffentlichkeit, wo die eigenkontrollierten Räume (siehe Kapitel 3.8.2) ohnehin geschrumpft sind, verursacht bei vielen Menschen ein Unsicherheitsgefühl. In einem E-Ticketing-System der VDV-Stufe 2 wird der Bezahlprozess mit dem Erwerb einer elektronischen Fahrtberechtigung zusammengeführt. Dieses führt für den Kunden nicht nur zu einer weiteren Vereinfachung des Ticketerwerbs, sondern es „wird durch den beschleunigten Einstiegsvorgang das Risiko von Unfällen und Verletzungen verringert" ${ }^{\prime \prime} 1257$ da er - z.B. in einem anfahrenden Bus - schneller einen sicheren Sitzplatz einnehmen kann. Ein elektronisches Ticket ${ }^{1258}$ kann außerdem, sofern ein Kundenbezug hergestellt werden kann, gesperrt und ein Ersatz hierfür ausgestellt werden. Dies erhöht das Sicherheitsempfinden hinsichtlich Verlust oder Diebstahl. ${ }^{1259}$

Ein Höchstmaß an verbesserter Sicherheit wird in einem räumlich geschlossenes ETicketing-System erreicht. Dafür werden die Zugänge zu den Verkehrsmitteln, die sonst ohne Sperren zu erreichen sind (vor allem Bahnhöfe und Stationen) mit Zugangssperren versehen. In den Niederlanden war die Verbesserung der Sicherheitslage im SPNVBereich sogar einer der „Business-Treiber“ zur Einführung eines E-Ticketing-Systems mit Zugangssperren. ${ }^{1260}$ Darüber hinaus erwartet man dort von einem kontrollierten Zugang zum System auch einen Rückgang der Schwarzfahrerquote und somit eine Steigerung der Fahrgeldeinnahmen, zumal ein direkter Zusammenhang zwischen „Schwarzfahrern“ und Sicherheitsgefährdung gesehen wird:

"Most cases involving aggression with regard to public transport are due to fare evasion. It will be very difficult to travel without a valid ticket because the OV-chipkaart operates with

\footnotetext{
${ }^{1257}$ Achenbach 2002, S.218

1258 bzw. die Applikation auf dem Kundenmedium

$1259 \mathrm{vgl}$. Zühlke 2005, S.276

${ }^{1260}$ vgl. Jansen 2006, S.6 sowie Amling u.a. 2004, S.215
} 
gates and card readers. This will contribute to the general safety and security of the public transport system". ${ }^{261}$

Auch aus anderen Ländern werden positive Erfahrung im Bereich Sicherheit bei der Verwendung von räumlich geschlossenen Systemen im SPNV berichtet. Diese sind u.a. darauf zurückzuführen, dass die Sperren „zu einer Kanalisierung und damit Entzerrung von Fahrgastströmen“ beitragen.1262 „Systeme mit Zugangskontrollen (,gating') durch Drehkreuze oder Ähnliches wurden bei den Betrachtungen im RMV-Gebiet zunächst zurückgestellt. Bei einem Großteil anderenorts existierender System bilden sie aber die Grundlage“ ${ }^{\prime 263}$ Hierbei handelt es sich in der Regel um Schienenverkehre in Großstädten (UBahn, S-Bahn), bei denen der Zugang zu den Bahnsteigen räumlich eingegrenzt ist (unterirdische Stationen, Hochstationen). Insofern verwundert es nicht, dass sich der Verkehrsverbund Berlin-Brandenburg mittlerweile für die Einführung von Zugangssperren in Berlin als der Stadt mit dem größten S- und U-Bahn-System ausgesprochen hat. ${ }^{1264}$

\subsubsection{Multifunktionalität und Integration Zusatzleistungen}

Die Produktentwicklung und -verbesserung muss sich aber nicht ausschließlich auf die Kernleistung der ÖPNV-Beförderung beziehen. Denn nicht nur aus technischer Sicht, sondern auch aus marketingseitiger und organisatorischer Sicht kann die Verknüpfung mehrerer Funktionen auf einer Chipkarte für Kunden und Unternehmen sinnvoll sein. Der Begriff „Multifunktionalität“ umschreibt dabei die Möglichkeit, dass die Applikation „ÖPNV-Beförderung“ sowohl auf einer verkehrsunternehmenseigenen Karte wie auch auf der Karte eines Dritten untergebracht sein kann, vorausgesetzt, die technischen und organisatorischen Spielregeln werden eingehalten. Unternehmensseitig können so Medien und Vertriebswege anderer genutzt werden, beispielsweise gegen ein Entgelt für den Speicherplatz, wodurch die Kosten hierfür im eigenen Unternehmen gespart werden.

Bei der Nutzung von Karten Dritter ist allerdings zu berücksichtigen, dass die "Marke" ÖPNV als zusätzliche Funktion bzw. Leistung aus Kundensicht in den Hintergrund tritt

\footnotetext{
${ }^{1261}$ www.translink.nl/content.asp?languageID=UK\&pageID=22 (Zugriff am 23.11.2006)

1262 Fischer, Könnecke und Ordon 2001, S.35

1263 Boldt und Ordon 2004, S.31

${ }^{1264}$ vgl. Potsdamer Neueste Nachrichten v. 01.12.2006: „VBB will Sperren für Bahnsteige“. Bislang wird dieser Vorschlag aber von den Berliner Verkehrsbetrieben und der Berliner S-Bahn mit dem Argument abgelehnt, dass für die Überwachung und für Hilfeleistungen weiteres Personal erforderlich sei.
} 
und sich eventuelle Effekte in bezug auf Kundenbindung nicht ergeben. Dennoch kann sich der Vertrieb von Einzelfahrtberechtigungen über die Trägermedien- und Vertriebsplattform Dritter als sinnvoll erweisen, wenn hier vor allem Seltennutzer angesprochen werden, deren Bindungspotenzial für den ÖPNV eher gering ist. ${ }^{1265}$ Für die originäre ÖPNV-Kundenbindung eignen sich dagegen verkehrsunternehmenseigene Karten, auf denen dann Zusatzleistungen Dritter untergebracht sein können, bei denen aber die Beförderung durch den ÖPNV im Vordergrund steht. Der ÖPNV stellt damit nach wie vor die Kernleistung des angebotenen Produktes dar, die zusätzlichen Leistungen sind als vertikale Produkterweiterung zu verstehen. ${ }^{1266}$

Diese Zusatzleistungen können sowohl kostenfrei wie auch kostenpflichtig sein. Im Rahmen eines E-Ticketing-Systems können diese Leistungen mit dem Erwerb eines bestimmten Produktes auf der Chipkarte oder mit der Chipkarte alleine verbunden sein. Die Nutzung dieser Leistungen kann an einen Kundenstatus gebunden sein (bspw. „Vielfahrerstatus") oder generell allen Kunden angeboten werden, vergleichbar mit dem Eintritt in einen Kundenclub (siehe Kapitel 7.6.4.3). Die Zusatzleistungen können folgendes beinhalten:

- Privilegierung; der Kunde erhält Leistungen kostenfrei, beispielsweise gegen Vorlage der Chipkarte, einer Identifizierungsnummer o.ä.

- Zutrittsfunktion: der Kunde erhält gegen die Vorlage der Chipkarte, einer Identifizierungsnummer o.ä., Eintritt in einen kostenpflichtigen Bereich und rechnet die damit zusammenhängende Nutzungsgebühr über seine Chipkarte ab.

- Information: der Kunde erhält gegen Vorlage der Chipkarte, einer Identifizierungsnummer o.ä., weitergehende Informationen (z.B. persönliche leistungsbezogene Daten zur Chipkartennutzung, detaillierte Mobilitätsauskünfte u.s.w.) beispielsweise über das Internet, Infoterminal oder Mobilfunkgerät.

Die Leistungen können dem Mobilitätsbereich (sogenannte „Intraservices“) zugeordnet sein (z.B. die Bezahlung von Straßenbenutzungsentgelten ${ }^{1267}$, der Zugang zu kostenlosen

\footnotetext{
$1265 \mathrm{vgl}$. Achenbach 2002, S.219f

1266 vgl. Deutsches Verkehrsforum 2005, S.99f

1267 Im Rahmen des Europäischen Forschungsprojektes „TransPrice“ wurde die Akzeptanz von Straßenbenutzungsentgelten in fünf verschiedenen Großstädten in Europa untersucht. Bezüglich der Bezahlung wurde eine vorausbezahlte elektronische Karte vor allen anderen Bezahlva-
} 
Park-and-Ride-Plätzen, die Nutzung abschließbarer Fahrradboxen mit der Chipkarte (siehe Kapitel 4.3.7)), aber auch aus branchenfremden Bereichen (sogenannte „Interservices“) stammen, z.B. dem Freizeit-/Tourismusbereich, Kultur- und Sportbereich oder dem Einzelhandel. ${ }^{1268}$ Je nach Ausprägung und Zusammensetzung lassen sich so zielgruppenspezifische Angebotspakete zusammenfügen, die auch entsprechend zielgerichtet vermarktet werden können. Ziel ist es einerseits aus Kundensicht einen Mehrwert zu stiften, andererseits aus Unternehmenssicht den Kunden $\mathrm{zu}$ einer vermehrten Nutzung seines ETicketing-Mediums anzuregen. Die Kundenbeziehung wird also durch die - mit vergleichsweise geringem Aufwand betriebene - Vermarktung und den Verkauf passender, ergänzender Produkte und Dienstleistungen zum ÖPNV optimal ausgeschöpft (sogenannte cross-selling-Potenziale). Bei der zielgruppengenauen Offerte von Zusatzleistungen liefert der Einsatz einer Wissensdatenbank wertvolle Dienste - vorausgesetzt der Kunde hat hierzu zugestimmt („permission marketing“). Meyer und Specht liefern hierfür folgendes Beispiel:

„Weiß man beispielsweise, dass ein 42jähriger Berufspendler aus München Vater zweier Kinder ist und Vorliebe für den bayrischen Wald hat, können neben der regelmäßigen Erneuerung des Jahrestickets maßgeschneiderte Angebote für Wochenendausflüge und Kurztrips angeboten werden". 1269

Insgesamt betrachtet entsprechen Zusatzleistungen also voll und ganz dem Ansatz einer emotionalen Kundenbindung und der Erweiterung der Wertschöpfungskette.

\subsubsection{Angebot von Wegeketten / Produktintegration}

Die Ausdehnung der Produktpalette auf die gesamte Wegekette ist nicht nur grundlegender Anspruch an einen Mobilitätsdienstleister, sondern wird als Voraussetzung für diese Bezeichnung verstanden - schließlich enden die Mobilitätsansprüche der Kunden nicht an einer Haltestelle, sondern am Reiseziel. Im Gegensatz zu den Zusatzleistungen, die eine vertikale Produkterweiterung darstellen, geht es bei der Integration der gesamten Wegekette, also den Vor- und Nachlauf betreffend, um eine horizontale Produkterweiterung mit dem Ziel, die Wertschöpfung auf die gesamte Wegekette auszudehnen. Die

rianten bevorzugt. Die geringste Zustimmung erhielten Barzahlung und elektronische Kreditkarten; vgl. Schade und Schlag 2001, S.76.

${ }^{1268}$ vgl. Ordon und Fleischhauer 2003, S.11 sowie Megger und Vorgang 2000, S.5

${ }^{1269}$ Meyer und Specht 2002, S.386 
Kernleistung wird also auf andere Verkehrsmittel ausgeweitet, bzw. deren Dienstleistungen und Produkte integriert. Beispielhaft hierfür ist etwa eine Flugreise, bei der die Anreise zum Flughafen mit der Bahn inklusive ist und auch der Hoteltransfer und der Gepäcktransport gewährleistet ist. ${ }^{1270}$ Einige Verkehrunternehmen und -verbünde (so auch der RMV) bieten im Rahmen ihrer Fahrplan- bzw. Verbindungsauskünfte ein adressgenaues Routing an, das die Grundlage für Haus-zu-Haus-Angebote ist. Die DB AG integriert hierbei bereits die Produkte des Fern- und Nahverkehrs, letztere im Vor- und Nachlauf.

Für die Abbildung einer intermodalen Wegekette, die den ÖPNV integriert, bietet sich eine Chipkarte als multifunktionale Integrationsplattform an. So können Fahrtberechtigungen und Buchungen elektronisch auf der Chipkarte abgelegt werden, die dann beispielsweise in Car-Sharing-Fahrzeugen (im Bordrechner) oder in den elektronischen Buchungssystemen von Fluggesellschaften (z.B. E-Tix) und Mietwagenfirmen abgerufen werden können. Denkbar ist auch die Integration der Mitfahrbörse „Pendlernetz RheinMain", wo bereits unterschiedliche Reiseprofile mit Zwischenstationen abgespeichert werden, an denen Personen aufgenommen werden können.1271 Derartige Zwischenstationen können auch ÖPNV-Haltepunkte sein. So kann eine intermodale Wegekette, bestehend aus der Beförderung durch unterschiedliche Verkehrsmittel, als ein Produkt vermarktet werden. In der Wahrnehmung durch den Kunden dokumentiert sich dies durch den Gebrauch eines Mediums als Zugangs- und Nutzungsberechtigung zu allen Mobilitätsdienstleistern.

\subsubsection{Vertrieb}

\subsubsection{Einfacher Erwerb der Fahrberechtigung}

Neben der Informationsbereitstellung über das Leistungsangebot und der Tarifauswahl stellt der Kaufprozess der ÖPNV-Fahrtberechtigung eine der wesentlichen Widerstände bei der Benutzung von Bussen und Bahnen dar. Im Rahmen der Einführung eines elektronischen Tickets (VDV-Stufe 2) wird der Bezahlprozess mit dem Erwerb der Fahrtberechtigung - bei gleichzeitiger Speicherung des Tickets auf einem Kundenmedium - zusammengeführt. Die Tarif- und Produktauswahl sind als gesonderte Prozesse vom Kunden jedoch separat auszuführen. Damit wird der Gesamtvorgang aus Kundensicht jedoch

\footnotetext{
$1270 \mathrm{vgl}$. Fakiner und Scherz 2003, S.618ff

${ }^{1271}$ vgl. www.rheinmain.pendlernetz.de
} 
nicht vereinfacht, denn der Erwerb der Fahrtberechtigung stellt prinzipiell die gleichen Anforderungen an den Kunden, wie dies in einem papierbasierten Vertriebssystem der Fall ist. Erst bei der Automatisierten Fahrpreisfindung (VDV-Stufe 3) können die aufwändigen Prozesse der Tarif- und Produktauswahl sowie des Bezahlens - als vom Kunden auszuführen - automatisiert werden. Dieses wird dadurch erreicht, dass die Tarif- und Produktauswahl auf einen Zeitpunkt nach der Beförderung erfolgt und auf Basis des Beförderungsumfangs automatisch im Hintergrundsystem abläuft. Dieses führt letztlich zu einer signifikanten Erleichterung und Verkürzung der Prozessschritte - und damit der Transaktionskosten - aus Kundensicht. Besondere Komfort-Vorzüge genießt der Kunde, wenn nicht nur die Tarif- und Produktauswahl nachträglich erfolgen, sondern auch die Bezahlung. Das damit verbundene einfache „Einsteigen und Losfahren“ bedeutet eine wesentliche Vereinfachung des Kundenaufwands, was für alle Kundengruppen ein Komfortgewinn bedeutet und insbesondere für mobilitätsbehinderte und mobilitätseingeschränkte Personen - auch im Sinne einer Barrierefreiheit - eine Vereinfachung des ÖPNV-Zugangs mit sich bringt.

\subsubsection{Nachträgliche Bezahlung und Best-Preis-Option}

Die nachträgliche Bezahlung der in Anspruch genommenen ÖPNV-Beförderungsleistung im Rahmen der Automatisierten Fahrpreisfindung (VDV-Stufe 3) bedeutet für den Kunden, dass er sich im Vorfeld der Inanspruchnahme weder auf eine bestimmte Relation noch ein bestimmtes Tarifprodukt (z.B. Wochen- oder Monatskarte) festlegen muss.1272 Somit ist der Kunde in der Nutzung flexibel. Voraussetzung hierfür ist, dass er dennoch eine gültige Fahrtberechtigung in Form eines Kundenmediums erhält, mit der er sich bei Kontrollen ausweist und über das er sich im System (z.B. in Fahrzeugen und an Haltestellen) an- und abmeldet, damit die Nutzungsdaten für die spätere Bepreisung erfasst werden.

Die nachträgliche Bezahlung der in Anspruch genommenen ÖPNV-Beförderungsleistung setzt in der Regel eine Registrierung des Kunden im Vorfeld der ÖPNV-Nutzung voraus. Diese Registrierung kann dabei durch eine Personalisierung des Kundenmediums, d.h. durch die Zuordnung zu einem Vertragspartner erfolgen, bei der auch der Bezahlzeitpunkt und das Bezahlverfahren festgelegt werden. Die Festsetzung des Bezahlzeitpunktes

1272 vgl. Sparmann, V. 2005, S.69 
nach Inanspruchnahme ermöglicht gleichzeitig die Bepreisung von Leistungskontingenten über einen längeren Zeitraum, d.h. von beliebig vielen Fahrten in einem Zeitraum. Die so erfolgte „automatisierte Fahrpreisfindung“ ist logisch eng mit der (unter ÖPNVFachleuten) häufig kontrovers diskutierten „Best-Preis-Option“ verbunden (siehe 7.6.3.1), die dem Kunden die Garantie bietet, stets mit dem für ihn günstigsten Tarif unterwegs zu sein. Voraussetzung hierfür ist eine Kontobindung mit einer Lastschriftabrechnung oder ein vorausbezahltes Guthaben auf einem ÖPNV-Kundenkonto, auf das bei Unterschreiten eines Mindestbetrages ggf. auch automatisch Beträge aufgebucht werden können (sog. „Auto-load“-Verfahren). ${ }^{1273}$

Soll die Automatisierte Fahrpreisfindung dem Kunden als anonymes Verfahren angeboten werden, muss zum Zeitpunkt der Freischaltung des Kundenmediums vom Kunden ein Betrag auf ein anonymes ÖPNV-Kundenkonto bezahlt werden, welches dem jeweiligen Kundenmedium zugeordnet ist und im Hintergrundsystem geführt sowie gegen die aktuelle Inanspruchnahme geprüft wird. Die erneute Aufladung des Kontos muss dann vom Kunden selbst veranlasst werden. Voraussetzung ist, dass dem Kunden der jeweils aktuelle Status bzw. Ladebetrag seines Kontos kommuniziert wird, beispielsweise durch akustische oder optische Signale beim An- oder Abmeldevorgang. Mit dieser anonymen Variante liegt der eigentliche Bezahlzeitpunkt zwar vor der ÖPNV-Nutzung (pre-paid), jedoch können dem Kunden die selben tariflichen Vorteile gewährt werden, wie dies bei der persönlichen Variante der Fall ist. Das Auto-Load-Verfahren entfällt hierbei, da hierfür eine vertragliche Beziehung zwischen Kunde und ÖPNV-Unternehmen die Voraussetzung ist. Als alternative anonyme Bezahlvariante kommt die Bezahlung aus einer elektronischen Börse in Betracht (vgl. Kapitel 7.6.2.3.2). ${ }^{1274}$

Prinzipiell ist es auch möglich, unter der Berücksichtigung einer Fahrtenhistorie Rabatte auf Einzelfahrkarten zu gewähren. Werden in einem bestimmten Zeitraum also Einzelfahrkarten (i.d.R. derselben Tarifzone) erworben, verringert sich jeweils der Preis der weiteren Einzelfahrkarte. Voraussetzung hierfür ist die Erfassung der Nutzungsdaten sowie die Zuordnung dieser Daten zu einem Nutzer. Dieses Verfahren wird mittlerweile in ei-

\footnotetext{
1273 vgl. Ackermann 2007, S.15 $1274 \mathrm{ebd}$.
} 
nigen deutschen Städten (Hamburg, Köln, Bonn, Gera) im Rahmen des Verkaufs elektronischer Einzeltickets über das Mobilfunkgerät angeboten. ${ }^{1275}$

Im Rahmen der Diskussion zu den wirtschaftlichen Effekten der „Best-Preis-Option“ wird einerseits argumentiert, dass die gewonnene Flexibilität in der ÖPNV-Nutzung zu Mehrfahrten und damit Mehreinnahmen führt. Dies liegt u.a. darin begründet, dass es außerordentlich umständlicher und kaum zu kommunizierender Prozesse bedarf, um einen Anschlussfahrschein zu erwerben, der dem Kunden die Fahrt über den Gültigkeitsbereich seiner üblich genutzten Relation hinaus erlaubt. Andererseits werden durch die Einführung der „Best-Preis-Option“ Einnahmeverluste befürchtet, da die Kunden nur noch für tatsächlich genutzte Leistungen bezahlen - die bezahlten Kontingente also voll ausschöpfen. Aus Kundensicht ist allerdings festzuhalten, dass mit der nachträglichen Bezahlung und der damit verbundenen „Best-Preis-Option“ eine neue Flexibilität in der ÖPNVNutzung sowie fairer und gerechter Leistungsberechnung realisiert wird, die sich insgesamt zu einer Verbesserung der Einstellung zum ÖPNV niederschlagen dürfte, was grundsätzlich als umsatzsteigernd eingeschätzt werden kann. Dort, wo E-TicketingSysteme mit einer Best-Preis-Option eingeführt wurden (Hanau, ${ }^{1276}$ Wels und Steyr in Oberösterreich) wird die Einführung von Kundenseite positiv bewertet.

\subsubsection{Einfache, bargeldlose Bezahlung}

\subsection{Relevanz aus Kundensicht}

Wie bereits erwähnt, ist der zunehmende Trend der bargeldlosen Geschäftsabwicklung ein Kernelement des „Electronic Business“. Insbesondere bei nachträglicher Bezahlung im Rahmen der Automatisierten Fahrpreisfindung können die klassischen Bezahlverfahren des Lastschrifteinzugs und der Rechnungsstellung aus Kundensicht erheblich zur Vereinfachung beitragen. Gerade aber bei Selten- und Gelegenheitsnutzern, die ihre ÖPNVFahrtberechtigung im vorhinein begleichen (müssen), stellt die Bezahlung mit Bargeld häufig eine nicht zu unterschätzende Zugangsbarriere zum ÖPNV dar. Insbesondere im selbstbedienten Fahrkartenverkauf an Automaten setzt die Barzahlung voraus, dass die Kunden den zu bezahlenden Betrag in der geforderten Höhe oder sogar - bei fehlendem Wechselgeld im Automaten - passend parat haben. Im RMV können die Preise für am

${ }^{1275} \mathrm{vgl}$. www.myhandyticket.de (Zugriff am 25.6.2006)

1276 vgl. Göbel 2002, S.19f sowie Ordon 2002, S.11f 
Automaten verkaufte Fahrkarten, aufgrund des großen Einzugsgebietes des Verbundes, beträchtliche Summen aufweisen. So kann der Preis für eine Einzelfahrt bis zu $€ 11,90$ und für eine Tageskarte bis zu $€ 23,80$ betragen. Für eine Wochenkarte muss der Kunde in der höchsten Preisstufe schon $€ 58,80$ und für eine Monatskarte gar über $€ 150$ bezahlen. ${ }^{1277}$ Damit erreichen die Fahrkartenpreise Summen, die viele Kunden nicht bar mit sich führen.

Die Wechselgeldproblematik stellt sich auch in anderen Vertriebskanälen. Gerade beim Verkauf von Fahrkarten durch das Fahrpersonal "auf den Fahrzeugen“ versetzt die Handhabung von Bargeld und Fahrkarte (gerade bei älteren Leuten in einem fahrenden Fahrzeug) sowie die eventuelle gleichzeitige Beaufsichtigung von Mitreisenden, etwa Kindern, oder Gepäck die Kunden in eine Stresssituation, die durchweg negativ empfunden wird. Zudem ist die Verzögerung durch den gesamten Verkaufsprozess (Tarifinformation, Bezahlung, Wechselgeldrückgabe etc.) auch für mitreisende Kunden lästig, insbesondere wenn sich hierdurch Verspätungen einstellen. Neben Komfortaspekten sprechen aber auch Sicherheitsaspekte für eine bargeldlose Abwicklung des Fahrkartenerwerbs, insbesondere - aber nicht nur - bei Kindern. Aus technischer Sicht kann erwartet werden, dass die Ausfallzeiten von Fahrkartenautomaten reduziert werden können, was aus Kundensicht ebenfalls ein Komfortgewinn verspricht. Der Einsatz elektronischer Zahlungssysteme und neuer Bezahlmethoden (siehe Kapitel 7.6.2.3.3) besitzt daher im ÖPNV hohe Relevanz.

\subsection{Erfahrungen mit der Geldkarte}

Die Geldkarte ist eine elektronische Börse, die - da vorausbezahlt, also pre-paid - keine Bonitätsanforderungen an den Kunden stellt. Die Geldkarte wird sowohl in Verbindung mit Kundenkarten der Kreditwirtschaft wie auch kontoungebunden, beispielsweise in Form von lokalen Kundenbindungsprogrammen, ausgegeben. Obwohl diese Voraussetzungen günstig für eine hohe Marktdurchdringung sind, hat sie im bargeldlosen Zahlungsverkehr keine Bedeutung. Nur etwa 0,09\% aller bargeldlosen Transaktionsgeschäfte werden über sie abgewickelt; verglichen mit Kreditkartenbezahlung und electronic cash erreicht die Geldkarte nur einen Anteil von etwa 3\%. ${ }^{1278}$

\footnotetext{
1277 vgl. RMV 2006 (b), S.28f

1278 vgl. Bretzger und Ebbing 2005, S.9
} 
So ist auch die Erfahrung fast aller Verkehrsunternehmen, die in den letzten Jahren in die Aufrüstung ihrer Vertriebsinfrastruktur zur Akzeptanz der Geldkarte investiert haben, durchweg schlecht. Dies hat vor allem mit den umständlichen Aufladeprozessen zu tun, die keinen wirklichen Mehrwert für den Kunden darstellen; im Gegenteil kommen Prozesse hinzu. Hieraus ergibt sich, dass „die Durchschaubarkeit eines neuen Zahlungsmediums eine zentrale Rolle in der Kundenakzeptanz spielt. Außerdem scheint der direkt zuerkennende Kundennutzen von großer Bedeutung zu sein“. ${ }^{1279}$ Des weiteren spielt die schlechte Marktdurchdringung insgesamt eine Rolle. So gibt es bislang keine „Killerapplikation“1280, die der Geldkarte bundesweit zum Durchbruch verholfen hat.

Die vielversprechendste Anwendung ist der Einsatz der Geldkarte in Parkhäusern, wo vergleichsweise hohe Akzeptanzraten erzielt werden. Der Grund liegt im klar ersichtlichen Kundennutzen, da der Parkhausbenutzer nun nicht mehr an den Kassenautomaten muss. Zwar bedarf es nach wie vor der Aufladung der Geldkarte durch den Kunden im vorhinein, doch wird dieser Umstand durch die erhebliche Vereinfachung des Bezahlprozesses und den damit verbundenen Komfortgewinn mehr als ausgeglichen.

Höhere Akzeptanzraten könnten zukünftig auch durch den kontaktlosen Einsatz der Geldkarte erzielt werden. Denn seit kurzem werden nun auch von der Kreditwirtschaft Chipkarten mit kontaktloser Schnittstelle angeboten. Damit können diese Karten prinzipiell auch in einem E-Ticketing-System Verwendung finden, in dem sich die Kunden mittels ihrer Karte im System an- und abmelden und die Bezahlung im nachhinein stattfindet. In Verbindung mit der Geldkarte - also als pre-paid-Anwendung - können über die Luftschnittstelle allerdings nur geldwerte Kontingente aus einem anwenderspezifischen Bereich der Geldkarte, wie beispielsweise ÖPNV-Fahrtberechtigungen, verbucht werden sowie aufgebuchte elektronische Tickets kontaktlos kontrolliert werden. ${ }^{1281}$ Damit handelt es sich de facto nicht mehr um eine offene elektronische Geldbörse, sondern um eine geschlossene Börse, die vom Kunden für eine bestimmte Nutzung vorher geladen werden muss. Dieses setzt wiederum einen Kaufprozess voraus, der die Möglichkeit zur sponta-

\footnotetext{
1279 ebd. S.16

1280 „Killerapplikation“ im dem Sinne, als dass eine Anwendung der bereits schon länger exisitierenden Technologie der Geldkarte zum Durchbruch verhilft und hierbei andere, evtl. sogar jüngere Technologien verdrängt; vgl. www.wikipedia.org/wiki/killerapplikation (Zugriff am 6.1.2007).

${ }^{1281}$ vgl. www.geldkarte.de/ww/de/pub/aktuelles/cebit_2005_print.htm: Messerückblick 2005 v. 24.3.2005
} 
nen Nutzung deutlich mindert. Der Zentrale Kreditausschuss erlaubt nach wie vor nicht die Transferierung von „echtem“ Geld über die kontaktlose Schnittstelle. Es kann vermutet werden, dass diese Einschränkung dazu führt, dass sich die Akzeptanz der Geldkarte nicht verbessern wird bzw. es erst gar nicht zum Einsatz einer kontaktlosen Geldkarte im ÖPNV oder in der Parkraumbewirtschaftung kommen wird.

\subsection{Sonstige bargeldlose Bezahlverfahren}

Es bleibt daher abzuwarten, wie sich andere elektronische Bezahlsysteme in Zukunft weiterentwickeln. Im Bereich der Kreditkarten wird die Magnetstreifentechnologie mittelfristig durch den von Europay, MasterCard und Visa unterstützten Standard (EMVStandard) abgelöst. Interessant dürfte hier vor allem der mögliche Einsatz von chipkartenbasierten, kontaktlosen Kreditkarten sein, bei denen der Autorisierungsprozesse für die Abbuchung kleinerer Beträge, bis beispielsweise 15 Euro, durch das bewusste Heranführen der Karte an ein Akzeptanzterminal ausgelöst werden.

Der Einsatz des Mobilfunktelefons eröffnet zukünftig weitere Möglichkeiten im bargeldlosen „electronic business“ bzw. „mobile commerce“ (m-commerce). Stand die Bezahlung von Leistungen (bis € 4,99) über eine Premium-SMS im unmittelbaren Zusammenhang mit dem Herunterladen von beispielsweise Klingeltönen, Logos oder der Teilnahme an "Votings", ist die Bezahlung über Premium-WAP losgelöst von der Versendung oder dem Erhalt einer SMS. Auf dieser Basis ist es möglich, dass dem Kunden eine Fahrtberechtigung beispielsweise via GPRS oder UMTS auf sein Mobilfunkgerät übermittelt wird und die Bezahlung über die Mobilfunkrechnung erfolgt. Der Kaufvorgang kann dabei über die Menüführung des Mobilfunkgerätes unterstützt werden. Damit ist das Mobilfunktelefon nicht nur Bezahlmedium, sondern wird zum Vertriebskanal (siehe Kapitel 7.6.2.4.1).

\subsection{Relevanz aus Unternehmenssicht}

In bezug auf die Generierung höherer Einnahmen, hat die Nutzung bargeldloser Bezahlverfahren vor allem Relevanz im Hinblick auf die Reduzierung des Betrugs durch Mitarbeiter der Verkehrsunternehmen. Obwohl dies ein heikles Thema ist, kann nicht verschwiegen werden, dass der Umlauf großer Bargeldmengen zu einer Veruntreuung von Fahrgeldern verleitet. Ein Problem ist insbesondere die „persönliche Vereinnahmung von 
Fahrgeldern bei Barverkäufen ohne Aushändigung des Fahrscheins an den Kunden“.1282 Dies ist ein Phänomen, was insbesondere beim Verkauf von Einzelfahrkarten im Bus und auch hier bei niedrigen Preisstufen - besteht und in der Schadenssumme nicht unterschätzt werden darf.

\subsubsection{Nutzung neuer, attraktiver Vertriebskanäle}

\subsection{Mobilfunktelefone}

Die Mobilfunktechnologie entwickelt sich mehr und mehr zu einer Basistechnologie des innovativen Vertriebs. Durch sie werden Interaktionen und Transaktionen zeit- und ortsunabhängig, wodurch insbesondere die spontane Nutzung des ÖPNV verbessert wird. Denn durch den Einsatz des Mobilfunktelefons wird der Zeitpunkt der Informationsbeschaffung und des Fahrkartenerwerbs von "pre-trip“ in Richtung "on-trip“ verlagert.1283 Der Vertriebs- und Informationskanal „Handy“ kann jederzeit bequem von zu Hause, am Ausbildungs- oder Arbeitsplatz aber eben auch von unterwegs genutzt werden. Da die ÖPNV-Nutzung in der Regel mit der Informationsbeschaffung verknüpft ist (Tarife, Haltestellen, Abfahrtszeiten, Fahrtzeiten etc...) liegt ein wesentlicher Vorteil in der Verknüpfung des Vertriebs von Fahrtberechtigungen mit Auskunfts- und Informationsdiensten, die ebenfalls über das Mobilfunknetz bereitgestellt werden können. Mit der zunehmenden Verbreitung und der Senkung der Datentransportkosten durch GPRS und UMTS ist davon auszugehen, dass auch hochwertigere Verkehrsinformationsdienste eine breitere Akzeptanz finden werden. Durch die Möglichkeit der Verknüpfung von Ist-Daten aus einem RBL kann auch die Datenlage soweit verbessert werden, dass kundenseitig Unsicherheit reduziert werden, die sich bislang als Barriere für den Erwerb von Fahrtberechtigungen erwiesen. ${ }^{1284}$

In bezug auf den Erwerb einer elektronischen Fahrtberechtigung bietet das Mobilfunkgerät unterschiedliche technische Möglichkeiten, die bundesweit auch im Betrieb oder in der Erprobung waren oder noch sind. Dabei sind die verschiedenen Möglichkeiten weniger als eigenständige Lösungen zu begreifen, sondern vielmehr als Entwicklungsstufen, die mehr oder weniger aufeinander aufbauen. In Osnabrück und Bonn wählt der - vorher registrierte Kunde - eine kostenlose Telefonnummer, an die sich der Code einer ge-

\footnotetext{
1282 vgl. Achenbach 2002, S.227

1283 vgl. Dziekan 2004, S.10

${ }^{1284}$ vgl. Beckers u.a. 2001, S.9
} 
wünschten Preisstufe anschließt. Das Ticket wird dann per SMS zugestellt, die Bezahlung erfolgt über die Telefonrechnung. Nicht registrierte Kunden können den Service nutzen, wenn sie vorher einen Betrag auf ein mobilfunkbetreiberspezifisches (Schatten-) Konto überwiesen haben. In Berlin erfolgt dagegen auch die Ticketbestellung per SMS. Je nach eingegebenem Code erhält der Kunde entweder eine Einzel- oder Tageskarte. Hier erfolgt die Abrechnung über die Telefonrechnung. Eine vorherige Registrierung ist nicht notwendig, der Dienst ist aber auch hier an einen bestimmten Mobilfunkbetreiber gebunden. Im Vogtland wird der Ticketkauf per Mobilfunkgerät über eine JAVA-Applikation unterstützt, die eine onlinegestützte und menügeführte Auswahl des Tickets ermöglicht. Die eigentliche Berechtigung wird im Hintergrundsystem abgelegt, zu der nur der Kontrolleur Zugang hat. Die Nutzung dieses Angebots ist von der JAVA-Fähigkeit des Mobilfunkgerätes abhängig. ${ }^{1285} \mathrm{Im}$ „Handy-Ticketing des RMV werden dagegen die Sicherheitsmerkmale im Display des Mobilfunkgerätes angezeigt, d.h. die Prüfbarkeit orientiert sich an den heutigen visuellen Prüfprozessen. Die DB AG bietet ab September 2006 den Kauf von Fernverkehrstickets an. Nutzungsvoraussetzung ist ein internetfähiges (UMTSoder GPRS) Mobilfunkgerät. Die Fahrtberechtigung wird per MMS als 2D-Barcode auf dem Handy abgelegt. Die elektronische Kontrolle erfolgt optisch über die bei der DB AG eingesetzten Kontrollgeräte. ${ }^{1286}$

Das Mobilfunkgerät übernimmt also nicht alleine die Funktion eines Vertriebskanals, sondern auch die Rolle des Kundenmediums, auf der die Fahrtberechtigung abgelegt wird. Des weiteren kann auch die in Anspruch genommene ÖPNV-Beförderungsleistung über die Mobilfunkrechnung beglichen werden.

Der Einsatz dieser neuen Technologien trägt zum Imagegewinn eines Unternehmens bei ${ }^{1287}$ und unterstützt somit letztlich Kundengewinnung und Kundenbindung. Durch die Selbstbedienung der Kunden am eigenen Gerät (Handy) werden Vertriebsprozesse, die heute häufig als kritisch für die ÖPNV-Nutzung angesehen werden, auf ein Medium verlagert, zu dem weitaus weniger Berührungsängste bestehen als beispielsweise zu einem ÖPNV-Fahrkartenautomaten. Es ist davon auszugehen, dass es mit der zunehmenden Verbreitung von mobilfunkgestützten Diensten zu einer kundenseitigen Gewöhnung

\footnotetext{
1285 vgl. Murtz 2004, S.7f

${ }^{1286}$ vgl. www.bahn.de/p/view/planen/reiseplanung/mobileservices/handy_ticket.shtml

(Zugrtiff am 30.4.2007)

1287 vgl. Zühlke 2005, S.276
} 
kommt, wodurch die Kundenakzeptanz für Informations- und Vertriebsangebote auch im ÖPNV weiter steigt. ${ }^{2288}$

Dieses mag auch für die NFC-Technologie zutreffen, zumal sich einige Mobilfunkanbieter hiervon den endgültigen Durchbruch mobiler Dienste versprechen. Begrifflich betrachtet stellt NFC - eine Entwicklung von Philips und Sony in Kooperation mit Nokia - die Verbindung zwischen RFID und Mobilfunk her. Andere drahtlose Verbindungen (z.B. Bluetooth, Infrarot) werden durch NFC also nicht ersetzt, sondern ergänzt. Technisch betrachtet bedeutet NFC die drahtlose Datenübertragung kleinerer Datenpakete mittels eines RFID-Chips über eine kurze Entfernung $(<10 \mathrm{~cm})$. Die Datenübertragung erfolgt im selben Frequenzbereich von 13,56 MHz., wie sie bereits im E-Ticketing zur Anwendung kommt. ${ }^{1289}$ Durch die Integration eines RFID-Chips in ein Mobilfunktelefon werden aber neue Nutzungsmöglichkeiten eröffnet, deren Anwendung über die intuitive Nutzerführung denkbar einfach ist. Das Mobilfunkgerät muss einfach vor einen RFID-Chip („tag“) gehalten werden um die Übertragung von Daten anzustoßen. Auch können hierüber weitere Prozesse (Information, Kauf etc.) angestoßen werden, beispielsweise der Datenabruf aus dem UMTS- oder GPRS-Netz sowie der Ticketkauf. ${ }^{1290}$ Der RMV erprobt seit 2005 erfolgreich den Einsatz von NFC-fähigen Mobilfunkgeräten im Hanauer get»in-System, wo sie die Chipkarte als Kundenmedium ergänzen. ${ }^{1291}$

Die Anwendung dieser Technologie ermöglicht es auch, - zumindest technisch gesehen das Mobilfunkgerät selber als Datenerfassungsgerät in einem E-Ticketing-System einzusetzen. Hierzu müsste jede Haltestelle mit einem RFID-Chip ausgestattet werden, der die einzulesenden Haltestelleninformationen beinhaltet. Da das Mobilfunkgerät den aktiven, stromliefernden Part der Datenerfassung und auch -übertragung übernimmt, bräuchte es hierfür keine Stromversorgung an der Haltestelle. ${ }^{1292}$ Der Kunde muss sein Mobilfunkgerät einfach an den "tag“ heranführen („Touch \& go“) ${ }^{1293}$ und hat die Informationen über den Ein- bzw. Ausstiegsort auf seinem Medium. Gleichzeitig wird eine Applikation ange-

\footnotetext{
1288 vgl. Dziekan 2004, S.10

1289 vgl. Keutling 2006, S. 2 ff

1290 vgl. Connect 5/2005, S.18

${ }^{1291}$ vgl. www.rmvplus.de/coremedia/getininfo.jsp?seite=/RMVPlus/de/Artikel-Get-in/Get-inInfo/,templateId=render.jsp (Zugriff am 7.1.2007)

1292 Aufgrund der Umkehr des Datenflusses bei der Datenerfassung und -übertragung gegenüber den VDV-Verfahren, wird dieses Verfahren auch als passives NFC bezeichnet; vgl. www.nfcforum.org bzw. Near Field Communication Interface and Protocol (NFCIP-1), S.43.

1293 vgl. Keutling 2006, S.6
} 
stoßen, die die notwendigen (Fahr-)Daten für die Generierung einer Fahrtberechtigung und deren Abrechnung über das Mobilfunknetz in das Hintergrundsystem übermittelt. Dieses Verfahren wird von der DB AG und Vodafone mit lokalen Kooperationspartnern ab 2008 in einem Korridor zwischen Berlin und Hannover getestet. Eingeschlossen sind neben dem Fernverkehr auch der Regional- und Stadtverkehr in Potsdam sowie ausgewählte Regional- und S-/U-Bahnstrecken in Berlin. ${ }^{1294}$

Die Investitionskosten für ein E-Ticketing-System der VDV-Stufe 3, insbesondere im Hinblick auf die fahrzeug- und haltestellenseitige Ausrüstung mit Datenerfassungsgeräten sowie den Aufbau einer entsprechenden Kommunikationsinfrastruktur, würden sich herüber gegebenenfalls drastisch reduzieren lassen. Allerdings sind die Busse und Bahnen sowie Bahnhöfe / Haltepunkte bereits heute mit diversen elektronischen Geräten ausgerüstet (IBIS-Bordrechner, RBL, Haltestellenanzeige und -ansage, Videoüberwachung, Verkaufsgeräte etc.), die häufig schon über die entsprechenden technischen Schnittstellen für die Anbindung von Erfassungsgeräten verfügen. Auch müssten die RFID-Chips an der Haltestelle in einer physisch sicheren Umgebung angebracht sein, um diese vor Manipulation jeglicher Art zu schützen. Durch die fehlende Möglichkeit der online-Kontrolle bedürfte es außerdem einer umfänglichen Wartung. Zu prüfen wäre daher, ob im Busverkehr eine fahrzeugseitige Installation von RFID-tags in Frage käme, die über den Bordrechner die jeweils aktuelle Haltestelle ausgespielt bekämen - ansonsten aber über keine weiteren Funktionalitäten verfügen. Hinsichtlich der Entwicklung auf einen angestrebten Endzustand würde die NFC-Technologie zwar nicht die Ausgabe von Chipkarten ersetzen können, aber zu einer deutlichen Reduzierung der Ausgabe von Chipkarten führen, die für diejenigen Nutzer vorgehalten werden müssten, die entweder über kein Mobilfunkgerät oder keines mit entsprechender NFC-Schnittstelle verfügen.

Aber auch ohne den Einsatz der NFC-Technologie für die passive Datenerfassung könnte sich diese Technik für das einfache und bargeldlose Bezahlen auch im ÖPNV durchsetzen und die Kundenprozesse weiter vereinfachen. „Der Anwender erhält mit NFC eine für ihn jederzeit greif- und erlebbare Schnittstelle zur digitalen Welt", 1295 also dem allgegenwärtigen Computer („,ubiquitous computing“), der als unsichtbarer Assistenz im Hintergrund agiert.

${ }^{1294}$ vgl. Berliner Zeitung v. 17.3.2007

1295 Keutling 2006, S.7 
Insgesamt betrachtet, sollte Mobile-Ticketing 1296 basierend auf SMS oder MMS sowie unterstützt durch Java immer als Ergänzung bzw. Bestandteil einer ganzheitlichen ETicketing-Lösung im Rahmen eines VDV-Stufe 2-Systems betrachtet werden. Murtz zufolge erreicht man mit einem ausschließlichen Mobile-Ticketing-System :

"nicht diejenigen Fahrgäste, die kein Handy besitzen oder es einfach nur zu Hause gelassen haben. Für sich allein ist Handy-Ticketing also noch keine Ideallösung. Und je komplexer die Tarifstrukturen werden, desto weiter entfernt sich das mobile Ticketing davon". ${ }^{1297}$

Erst ausgehend von der NFC-Technologie bieten sich neue Perspektiven für die Nutzung von Mobilfunktelefonen, ja für die gesamte Systemarchitektur eines Systems der VDVStufe 3. Dieser Ansatz hat dann allerdings nur noch das Mobilfunktelefon als Kundemedium mit den heute betriebenen Anwendungen gemein.

\subsection{Internet}

Genau wie beim Vertrieb über das Mobilfunktelefon sind im Internetvertrieb der Imagegewinn und die damit verbundenen Potenziale der Kundengewinnung und -bindung von hoher Relevanz. Zühlke beschreibt die Vorteile des Internets (und des Mobilfunktelefons) als innovativen Vertriebskanal folgendermaßen: „Mit bequemen, barrierefreien, zeitund ortunabhängigen Zugangswegen zu Fahrscheinangebot, Fahrplan- und Tarifinformationen sollen mehr Fahrgäste für den öffentlichen Personennahverkehr gewonnen werden“. ${ }^{1298}$ Identisch zum Mobile-Ticketing ist auch hier die Unabhängigkeit in bezug auf die Öffnungszeiten gegeben und können Informationen und Auskünfte mit dem Erwerb der Fahrtberechtigung zusammengeführt werden. Somit wird dem Kunden insbesondere bei den Vertriebskanälen Internet und Mobile-Ticketing ein hohes Maß an Einfachheit und Flexibilität gewährt. Die DB AG verkauft mittlerweile jeden sechsten Fahrschein über das Internet und hat den Umsatz in nur vier Jahren von 40 auf 590 Mio. Euro gesteigert. 1299

Eine wichtige Voraussetzung für einen "echten“ Internetvertrieb, der die Prozesse aus Kundensicht vereinfacht - und bei dem entsprechende Kostenvorteile generiert werden

\footnotetext{
1296 Der Begriff „Mobile-Ticketing“ wird in dieser Arbeit synonym mit dem Begriff „Handy-Ticketing verwandt.

1297 Murtz 2004, S.9

1298 Zühlke 2005, S.278

1299 vgl. Frankfurter Rundschau v. 5.5.2007
} 
können -, ist neben der elektronischen Bezahlung (siehe Kapitel 7.2.2), die elektronische Zustellung von Tickets. Denn nur dieses „virtuelle“ Verfahren gewährleistet, dass der Kunde sein Medium nicht notwendigerweise beim Kauf "physisch“ vorlegen und den Weg zu einer Verkaufsstelle antreten muss. Nur hierüber können personal- und kostenintensive Geschäftsprozesse optimiert werden.

Die elektronische Zustellung von Tickets kann auf mindestens drei unterschiedliche Arten erfolgen:

- Die Kunde kauft über Internet ein Ticket. Die Ticketdaten werden im Hintergrundsystem gehalten und das Kundenmedium dient ausschließlich der Identifizierung von Verkaufsdaten (Prinzip „Identifikation“).

- Der Kunde kauft über Internet ein Ticket. Die Ticketdaten gelangen über das Hintergrundsystem in die Kontroll- oder Erfassungsgeräte vor Ort. Sobald das Kundenmedium dort registriert wird, werden die aktuellen Daten übertragen (Prinzip "Auto-Load“).

- Der Kunde kauft über Internet ein Ticket und beschreibt das Kundenmedium mittels einer kontaktlosen Lese- und Schreibeinheit bzw. Schnittstelle selbst (Prinzip "online-Kauf").

Gegen die ausschließliche Datenhaltung im Hintergrundsystem sprechen bislang die VDV-Kernapplikation, die aus organisatorischen Gründen die Speicherung der Tarifdaten auf dem Kundenmedium vorsieht. Ähnlich kritisch könnte sich dies beim online-Kauf herausstellen. Auch hier müssten die zu aktualisierenden Daten bzw. Berechtigungslisten in möglichst kurzem Zeitabstand in die Validierungs- und Kontrollgeräte übertragen werden, was bei einer hohen Anzahl von Internetkäufen zu technisch anspruchsvollen Prozessen führt. Aus diesen Gründen scheint die Option des online-Kaufs, bei dem der Kunde über ein eigenes Lese-/Schreibgerät verfügt, besonders reizvoll. In dem Maße, wie kontaktlose Schnittstellen wie die NFC-Technologie marktfähig werden und in Mobilfunktelefonen und Heimcomputern Anwendung finden und dem Kunden es ermöglichen, (Ticket-)Daten auf ein eigenes Medium zu laden, sollten sich die Möglichkeiten des Internetvertriebs und damit der Kosteneinsparung jedoch stetig verbessern. Das einzige Problem, was es hierbei aus technisch-organisatorischer - und damit auch aus Kostensicht - zu lösen gilt, ist die Einhaltung der Sicherheitsanforderungen entsprechend der KA- 
Vorgaben, die vorsehen, dass sich in jedem Verkaufsgerät ein eigenes Sicherheitsmodul (SAM) befindet.

In Verbindung mit leistungsfähigen Mobilfunknetzen mit hohen Datenübertragungsraten rückt die Möglichkeit des mobilen Zugriffs auf Internetdienste über internetfähige Endgeräte (,smartphones“) in den Blickpunkt. Technische Grundlagen hierfür sind die Verbesserung der bestehenden Mobilfunktechnologie, beispielsweise die Einführung von UMTS, Breitband-Technologie oder die Verbesserung der "Übergabe von Endgeräten“ von einer Funkzelle zur nächsten (,hand-over“), ohne dass es zu einem Zusammenbruch der Verbindung kommt. So verschwimmen hier durch die bereits angesprochene Konvergenz der Bereiche Informations- und Telekommunikationstechnologie (siehe Kapitel 7.2.1) die Grenzen der nutzbaren Kanäle, bzw. entstehen durch diese Konvergenz neue, für Kunden nutzbare Mehrwerte. ${ }^{1300}$

Auch wenn bislang keine gesicherten empirischen Erkenntnisse darüber vorliegen, dass sich das Kundenverhalten aufgrund der Bereitstellung von Internetdiensten im ÖPNV ändert, verweisen doch die steigenden Zahlen von Aufrufen von Internetseiten darauf, dass diese Dienste akzeptiert werden und aus Kundensicht sinnvoll sind. Von daher entlastet das Internet nicht alleine kostenintensivere Informationskanäle, sondern trägt auch zu einem höheren Sicherheitsempfinden in bezug auf die Verlässlichkeit der bereit gestellten Informationen bei. ${ }^{1301}$

\subsection{Zentrales Service Center}

Die Zusammenführung der Nutzungs- und Kundendaten im zentral organisierten Hintergrundsystem ermöglicht die Bereitstellung qualitativ konsistenter und gleichzeitig aktueller Kundendaten. Vom Prinzip her "schauen“ alle am E-Ticketing Beteiligten auf die selben Daten, auch wenn die jeweilige Sicht entsprechend der verschiedenen Nutzungsberechtigungen (Mandantenfähigkeit) unterschiedlich ist. Jede Vertriebsstelle ist somit Kundenschnittstelle zur zentral organisierten Informations- und Vertriebsplattform. Ganz gleich, ob es sich also um einen automatisierten oder personalbedienten Vertriebskanal handelt, die Vertriebsdienste werden letztlich von einer zentralen Instanz, dem Zentralem Service Center (ZSC) für die Vertriebspartner, die für die Vermarktung von Fahrtberech-

${ }^{1300} \mathrm{vgl}$. Wirtz 2001, S.136f

${ }^{1301}$ vgl. Dziekan 2004, S.15 
tigungen verantwortlich sind, bereitgestellt. Insofern übernimmt das ZSC ServiceFunktionen im Front-Office-Bereich und agiert dort als „Customer Care Center“. ${ }^{1302}$ Die zentrale und kompetente Betreuung sämtlicher Kundenanliegen sowie die hohe oder gar durchgängige Erreichbarkeit soll wesentlich zur Kundenzufriedenheit und damit zur Kundenbindung beitragen.

Das ZSC stellt über die direkte Erreichbarkeit über die Kontaktkanäle Telefon, E-Mail und Fax im Prinzip einen eigenständigen zentralen Vertriebskanal dar, über den Fahrtberechtigungen vermarktet werden. Gleichzeitig fungiert das ZSC als „Helpdesk“ für übergreifende Auskünfte und Beschwerdeanfragen. Von daher ist die Verknüpfung des ZSC mit einem Call-Center sinnvoll. Neben der Vertriebstätigkeit steht daher auch die Kundenberatung im Vordergrund, zumal die Mitarbeiter des Call-Centers schnell die Bedürfnisse des Kunden erfragen und über die zentrale Datenbank kundenrelevante Informationen abfragen und Empfehlungen (bspw. hinsichtlich Probleme mit Kundenmedien, Rechnungen, Bonusprogramm, Produkten und Tarifen etc) aussprechen sowie gegebenenfalls an die richtige lokale Vertriebsstelle vor Ort weiterdelegieren können. Um das ZSC allerdings wirtschaftlich betreiben $\mathrm{zu}$ können, und zum Beispiel auch einen 24-StundenBetrieb effizient anbieten zu können, ist es wichtig, eine entsprechende Größe, d.h. in der Regel auch Einzugsgebiet zu erreichen. Von daher ist es sinnvoll, möglichst viele Prozesse dort zentral zusammenzufassen bzw. aus den entsprechenden Fachbereichen der Aufgabenträger und Verkehrsunternehmen auszusiedeln. ${ }^{1303}$

\subsubsection{Fälschungssichere elektronische Kundenmedien}

Die Höhe gefälschter oder auch manipulierter Papierfahrkarten kann in der Regel nur geschätzt werden. Laut DB AG sind ca. 3 bis 5\% aller Papierfahrkarten im Nahverkehr gefälscht. Der VDV berichtet, dass „,die Anzahl der gefälschten Tickets und der Schwarzfahrer [...]alarmierend gestiegen“" sei. ${ }^{1304}$ Problematisch - weil nur schwer zu erkennen sind solche Fälschungen vor allem dann, wenn sie auf echtem Fahrkartenpapier gedruckt sind, das beispielsweise aus Verkaufsautomaten entwendet wurde. Denn die Sicherheitsmerkmale befinden sich bei Papierfahrkarten auf dem Papier selbst. Neben Einzelfahrscheinen werden auch Zeitkarten und Semestertickets gefälscht, die häufig weniger Si-

\footnotetext{
1302 vgl. Arbach 2004, S.49

1303 vgl. Arbach 2004, S.49

${ }^{1304}$ vgl. Kölnische Rundschau v. 12.03.2006
} 
cherheitsmerkmale aufweisen und in unterschiedlichen Designs daherkommen. Aus Unternehmenssicht bedeutet die Einführung fälschungssicherer Kundenmedium also den Schutz vor Manipulation und Betrug. Auch wenn nicht angenommen werden kann, dass es zu einer Einnahmensteigerung in Höhe der Fälschungen kommen wird, gibt es in diesem Bereich ein deutliches Potenzial der Einnahmensicherung. Denn der Aufwand, der betrieben werden muss, um eine Chipkarte zu fälschen, steht kaum im Verhältnis zum geldwerten Nutzen, der hieraus gezogen werden kann. ${ }^{1305}$ Voraussetzung ist allerdings ein Sicherheitssystem, welches "state-of-the-art" ist und sich an den Sicherheitsanforderungen der Kreditwirtschaft orientiert. Dieses ist bei der VDV-Kernappliaktion der Fall.

Aus Kundensicht bietet der Einsatz einer fälschungssicheren Chipkarte ebenfalls eine Erhöhung der Sicherheit. Bedeutet der Verlust - beispielsweise durch Diebstahl - einer heutigen Papierfahrkarte den Verlust des äquivalenten Geldwertes, ist zukünftig die Sperrung der Chipkarte möglich, so dass ein nicht autorisierter Gebrauch der Karte ausgeschlossen ist. 1306 Gleichzeitig kann der Kunde, eventuell gegen Zahlung einer Bearbeitungsgebühr oder den Preis für die Ersatzchipkarte, ein neues Medium mit seiner nach wie vor gültigen Fahrtberechtigung erhalten. Dies bedeutet eine deutliche Verbesserung in der Kundenorientierung.

Die Fälschungssicherheit der Kundenmedien trägt auch zur Reduzierung des bereits angesprochenen Betrugspotenzials durch verkehrsunternehmenseigene Mitarbeiter bei, da der Verkauf von verfälschten oder liegengebliebenen, aber bereits bezahlten Fahrscheinen verhindert wird. ${ }^{1307}$

\subsubsection{Effektive und effiziente Fahrausweiskontrolle}

Die Effizienz der Fahrscheinkontrolle hängt heute ganz wesentlich von der Genauigkeit der Prüfung ab. Obwohl genaue Vorgaben existieren, wie eine Prüfung durchzuführen ist und welche Prüfmerkmale zu kontrollieren sind, gibt es doch qualitative Unterschiede in der Ausführung durch das Prüfpersonal. Es gibt ein weites Spektrum zwischen einem gültigen Fahrschein und gar keinem Fahrschein. In der Abgrenzung zu einem „Schwarzfahrer", der ohne gültige Fahrtberechtigung fährt (bzw. gar keinen physischen Fahrschein

\footnotetext{
${ }^{1305} \mathrm{vgl}$. Achenbach 2002, S.226

1306 Vorausgesetzt, es kann ein Bezug zum Kunden hergestellt werden.

1307 vgl. Achenbach 2002, S.227
} 
besitzt), wird dieser Bereich auch "Graubereich" genannt. Dies trifft beispielsweise auf Fahrgäste zu, die über den Geltungsbereich hinaus fahren oder aber in der 1. Wagenklasse sitzen, obwohl ihr Fahrschein nur für Fahrten in der 2. Wagenklasse berechtigt. Oftmals ist es Ermessenssache des Kontrolleurs, wie mit diesen Fällen umgegangen wird. Das bedeutet, dass (zwischen)menschliche Einflüsse das Prüfergebnis beeinflussen können. Des weiteren fehlt es aber auch häufig an der Genauigkeit der Prüfung durch den Prüfer ${ }^{1308}$ („menschliches Versagen“). So kann das Fahrpersonal oftmals nur erkennen, ob der einsteigende Kunde einen Fahrausweis vorzeigt oder nicht. Genaue Tarifangaben sowie Prüf- und Sicherheitsmerkmale lassen sich in der Kürze der Zeit kaum erfassen. Von daher spricht man in diesen Fällen auch eher von einer "sozialen Kontrolle“, die darauf aufbaut, dass der „täuschende“ Kunde Gefahr läuft entdeckt zu werden.

Durch die elektronische Kontrolle in einem E-Ticketing-System wird dieser Unsicherheitsund Graubereich ausgeblendet, da ein Kontrollgerät das elektronische Ticket automatisch auf Gültigkeit überprüft und es als Prüfergebnis nur noch ein „digitales“ gültig oder nicht gültig gibt. Der Kontrolleur muss also nicht mehr auf Basis des eigenen Wissens oder Ermessens über die Gültigkeit der Fahrtberechtigung entscheiden. Es wird daher eine Verringerung der Grau- und Schwarzfahreranteile erwartet. ${ }^{1309}$ Die Verwendung eines elektronischen Kontrollgerätes legt außerdem die Einführung einer elektronischen und einheitlichen EBE-Erfassung und -Verwaltung nahe, bei der alle erfassten Daten im zentralen Hintergrundsystem abgelegt und verarbeitet werden. Zum Zwecke der Optimierung des Kontrollgrads bietet es sich außerdem an, im Hintergrundsystem ein Planungsprogramm für Kontrollpläne zu verwenden, über die die Einsätze der Personalressourcen im Prüfdienst optimal organisiert werden können.

Die Einführung der Automatisierten Fahrpreisfindung führt aufgrund der erfassten Anund Abmeldevorgänge grundsätzlich zu einer effektiveren, im Idealfall sogar lückenlosen automatisierten Kontrolldichte - vorausgesetzt der Kunde verfügt über ein lesbares Medium. Denn auch in einem räumlich offenen System werden potenzielle "Schwarzfahrer“ nicht vom Einstieg in die Busse und Bahnen abgehalten. Insofern ist am ehesten ein check-in/check-out-System, in dem sich alle Kunden gleichermaßen aktiv an- und abmelden müssen, dazu geeignet den Schwarzfahreranteil über eine soziale Kontrolle zu redu-

1308 vgl. Grote , Himmelmann und Prim 2002, S.63

${ }^{1309}$ vgl. Amling, Kunneman und Rumpke 2004, S.215 
zieren.

Durch den in jüngerer Zeit von vielen Busverkehrsunternehmen vermehrt praktizierten „kontrollierten Einstieg“, bei dem der Einstieg in die Busse ausschließlich über die vordere Fahrzeugtür abgewickelt wird, soll zusätzlich eine psychologische Barriere aufgebaut werden, ohne gültigen Fahrausweis das Fahrzeug zu betreten. Übertragen auf das ETicketing könnte bereits in einem System der VDV-Stufe 2 eine durchgängige Prüfung der elektronischen Fahrscheine erreicht werden. Gleichzeitig könnte ein kontrollierter Einstieg als „ceck-in-only“ bereits als erster Schritt in Richtung VDV-Stufe 3 gelten.

\subsubsection{Einheitliche EBE-Verwaltung}

Durch die zentrale Bereitstellung von Diensten über das Hintergrundsystem wird erstmalig auch eine zentrale und einheitliche Verwaltung der „Erhöhten Beförderungsentgelte“ (EBE) möglich. Diese Prozessoptimierung wirkt sich nicht alleine aufwandsmindernd aus, sondern führt auch zur Verringerung der Einnahmeverluste durch sogenannte „Schwarzfahrer". Insbesondere im ÖPNV ist die Bereitschaft zur nicht ordnungsgemäßen Bezahlung der in Anspruch genommenen Leistung besonders hoch bzw. die Priorität die Zahlung fortzuführen, beispielsweise bei Verschuldung, besonders niedrig (siehe Abbildung 42). 1310 "Schwarzfahren“ wird oft nicht als Betrug - also als Straftat - angesehen, sondern eher als „Kavaliersdelikt“. ${ }^{1311}$ Denn bislang kann ein Kunde, der bei einem Unternehmen zahlungssäumig geworden ist, einfach zum nächsten Verkehrsunternehmen wechseln, ohne dass das vorherige Unternehmen von diesem Vorgang erfährt. Durch ein zentrales Sperrlistenmanagement liegen nun Daten über alle säumigen Kunden im Verbund bei allen Verkehrsunternehmen vor. ${ }^{1312}$ Damit verhindert ein räumlich nicht geschlossenes ETicketing-System zwar nicht das Schwarzfahren. Es wird aber durch die einheitliche EBEVerwaltung eine bessere Verfolgung der bereits auffällig gewordenen Kunden ermöglicht und damit die Hemmschwelle für erneutes Fahren ohne gültige Fahrtberechtigung heraufgesetzt. Vor dem Hintergrund, dass durch Schwarzfahren alleine bei der VGF jährlich ein Schaden von 12 bis 15 Mio. Euro verursacht wird ${ }^{1313}$, stellt die verbundweite Verwal-

\footnotetext{
${ }^{1310}$ vgl. Infoscore 2005, S. 23

1311 vgl. Pressemitteilung der MVG v. 28.05.2004

1312 Bei der Verwendung dieser Informationen müssen allerdings die Datenschutzaspekte unbedingt beachtet werden.

${ }^{1313}$ vgl. www.vgf-ffm.de/vgf/621.jsp (Zugriff vom 24.9.2006)
} 
tung von EBE-Fällen eine Maßnahme dar, die sich auch bei einer anteilsmäßigen Reduzierung schon auszahlen sollte.

\subsubsection{Tarif}

\subsubsection{1 ÖPNV-Nutzung ohne Tarifkenntnisse}

„Das gesamte RMV-Gebiet ist in 60 A-Tarifgebiete untergliedert, die jeweils mit zwei Ziffern gekennzeichnet sind. Diese bilden die Basis der tariflichen Einteilung des Verbundraumes. Um den Interessen der Fahrgäste [...] gerecht zu werden, sind die meisten ATarifgebiete in A0-Tarifgebiete unterteilt.

Um den jeweiligen Fahrpreis ermitteln zu können, ist es für Sie notwendig zu wissen, welche Tarifgebiete Sie befahren. Grundsätzlich ergibt sich der Fahrpreis nach Art und Anzahl der befahrenen Tarifgebiete". 1314

Diese Passage aus den „Tarifbestimmungen“ des RMV verdeutlicht die Problematik der Vorauswahl der richtigen Fahrkarte für den Kunden: Ohne Kenntnisse über Tarifgebiete und Streckenverläufe ist eine aus Kundensicht richtige oder optimale Wahl der Fahrkarte nur schwer zu treffen. Dies führt insbesondere bei ÖPNV-ungeübten, sprich gelegentlichen Kunden zu einer Verunsicherung bei der Nutzung öffentlicher Verkehrsmittel. Hinzu kommt die hohe Komplexität des RMV-Tarifs: Im RMV gibt es - v.a. aufgrund der polyzentrischen Raumstruktur - einen Flächen-Zonen-Tarif mit 7 verschiedenen Preisstufen. Je nach Örtlichkeit existieren allerdings unterschiedliche Grundpreise.

Aber auch für regelmäßige Nutzer kann die adäquate Tarifauswahl schwierig sein, vor allem dann, wenn es um Fahrten außerhalb des Geltungsbereichs einer bereits im Besitz des Kunden befindlichen Fahrkarte geht. Für den dann notwendigen Erwerb einer „Anschlussfahrkarte" muss der Kunde genau wissen, wie viele Tarifgebiete von ihm durchfahren werden und eine entsprechende Anzahl Einzelzuschläge gekauft werden. Dies schränkt die Spontanität und Flexibilität der ÖPNV-Nutzung auch bei Stammkunden stark ein. ${ }^{1315}$

1314 RMV 2006 (b), S.22

${ }^{1315}$ vgl. RMV 2006 (b), S.15f 
Die bereits oben beschriebene "Automatisierte Fahrpreisfindung" entbindet den Kunden von der Notwendigkeit über die Tarife, Fahrpreise und sogar Fahrkartenarten vor Antritt der Fahrt genau Bescheid zu wissen. ${ }^{1316}$ Auch wenn hierdurch nicht die Bereitstellung der Tarifinformationen entfällt, wird die Nutzung jedoch extrem vereinfacht.

\subsubsection{Innovative Tarifkonzepte}

Aufgrund der vorab beschriebenen Komplexität des Tarifangebots und dem Umstand, dass über pauschale Tariferhöhungen die bestehenden (von den Kunden empfundenen) Ungerechtigkeiten weiter verschärft werden, gewinnt die Entwicklung neuer, differenzierter Tarifangebote an Bedeutung. ${ }^{1317}$ Diese neuen Tarifangebote sollen einerseits attraktivitätssteigernd wirken, andererseits - und von den ÖPNV-Experten sogar als noch bedeutsamer eingeschätzt - sollen durch sie die Kundenrendite besser abgeschöpft werden und so maßgeblich zu einer verbesserten Nutzerfinanzierung beitragen. ${ }^{1318}$

Auf Basis der gewonnenen Daten aus dem E-Ticketing-System lassen sich viel differenziertere Tarifkonzepte entwickeln, über die, durch die genauere Adressierung von zielgruppenspezifischen Bedürfnissen, bestehende Zahlungsbereitschaften abgeschöpft werden und so zu Einnahmesteigerungen führen. So können beispielsweise auf der Basis der gewonnenen Erkenntnisse aus den Fahrdaten die unterschiedlichen Rabattmodelle1319 im ÖPNV auf ihre Berechtigung überprüft und entsprechend angepasst werden. Das Ziel der tariflichen Entwicklung sind leistungsabhängige Tarife, die auf der Basis der tatsächlich in Anspruch genommenen Leistung bepreisen. „Das E-Ticket ist die Grundlage für eine tragfähige leistungsabhängige Abrechnung. Damit beeinflusst die künftige Entwicklung des E-Tickets die Einführung und Verbreitung der leistungsabhängigen Abrechnung“.1320 Besonderheit dieser neuen Tarifkonzepte ist, dass sie mehrere Leistungsmerkmale integ-

\footnotetext{
1316 vgl. Sparmann, V. 2005, S.69

1317 Da diese neuen Tarifkonzepte in der Regel auf komplexen Tarifalgorithmen basieren, die auf zuvor elektronisch erfasste Fahrten angewendet werden, ist in diesem Zusammenhang auch von „Elektronischen Tarife“ die Rede.

${ }^{1318} \mathrm{vgl}$. Ackermann und Stammler 2006, S.8f

1319 Hier sind vor allem die verschiedenen Zeitkarten-Fahrscheine von Interesse, die zu unbeschränkten Fahrten innerhalb eines Anspruchsgebietes berechtigen. Noch größere Rabatte werden bei Jobtickets gewährt, deren Nutzungshäufigkeit ebenfalls nur schwer nachzuvollziehen ist.

${ }^{1320}$ vgl. Deutsches Verkehrsforum 2005, S.122
} 
rieren können. So lassen sich Preismodelle entwickeln, die beispielsweise im stärkeren Maße die folgende Parameter ${ }^{1321}$ berücksichtigen:

- Räumlich:

o Entfernung1322,

o Raumtyp (Ballungsraum, ländlicher Raum),

o Richtung (Lastrichtung),

- Zeitlich:

o Tageszeit, Wochentag,

o Häufigkeit der Nutzung pro Zeiteinheit (ähnlich einer Mehrfahrtenkarte bzw. Wochen- oder Monatskarte),

- Personenbezogen:

o Erwachsener, Kind

o Sozialer Status (Schüler, Auszubildender, Rentner, Familie etc.),

- Produktbezogen:

o Gewähltes Verkehrsmittel (Bus, S-Bahn, Regionalzug o.ä.) und damit zusammenhängend die Reisegeschwindigkeit),

o Qualität (z.B. Bedienungshäufigkeit einer Haltestelle),

o Übertragbarkeit; Mitnahmeregelung,

- Vertriebsbezogen:

o Gewählter Vertriebskanal (personenbedient, selbstbedient),

o Zahlungsmittel,

- Konkurrenzsituation mit anderen Verkehrsmitteln (z.B. Erreichbarkeit mit Pkw),

- Unterschiedliche Differenzierung zwischen Basis- und Leistungspreis.

${ }^{1321}$ vgl. Petersen u.a. 2004, S.8

1322 Bei der Einführung des elektronischen Tickets in den Niederlanden wurde bereits von Beginn an ein entfernungsabhängiger Tarif eingeführt, der aus einem grund- und einem leistungsabhängigen Teil besteht. Der Grundpreis, der bei Check-In zu bezahlen ist, beträgt im Busverkehr (in Rotterdam) $€ 0,67$. Pro gefahrenen Kilometer werden weitere $€ 0,11$ berechnet. 
Vor dem Hintergrund der Anlastung der externen Kosten an die Verursacher wäre es sogar denkbar, dass umweltbezogene Parameter Berücksichtigung bei der Tarifierung finden (z.B. $\mathrm{CO}_{2}$-Ausstoß je Fahrt). ${ }^{1323}$

Allerdings darf bei der Preisbildung nicht unberücksichtigt bleiben, dass die Tarife im Wesen für den Kunden nachvollziehbar sein müssen und von diesen als relevante Parameter akzeptiert werden. Das Parkplatzangebot am Zielort etwa als relevanter Tarifparameter mag bei vielen Kunden, die keine andere Wahlmöglichkeit haben, sicherlich auf Unverständnis stoßen. Daneben sind die Parameter Sicherheit, Sauberkeit und Pünktlichkeit als Basisleistung des Kerngeschäfts aufzufassen. Diese Leistung wird vom Kunden erwartet. Vorstellbar ist jedoch, dass bei Nichterfüllung dem Kunden ein Rabatt gewährt werden könnte.

Gleichzeitig sind über die kurzen Verteilungszeiten einfache Tarifanpassungen gewährleistet, so, dass es bei Fehlentwicklungen - beispielsweise der Überschreitung von Preiselastizitäten - nicht zu Einnahmeverlusten kommt. Solche innovativen Tarifkonzepte sind vor dem Hintergrund der Diversifizierung der Gesellschaft und neuer Arbeitszeitmodelle adäquate Marketingansätze, um den ÖPNV bedarfsorientierter zu gestalten und damit attraktiver zu machen. Insofern können über leistungsgerechte Tarife Kundengruppen erschlossen werden, für die bislang keine gesonderten Angebote vorgehalten wurden aber dennoch Wachstumspotenzial beinhalten. Hier sind vor allem Kunden im Freizeitbereich oder "Senioren“ zu nennen. ${ }^{1324}$

Der von der Beratungsfirma BSL Management Consultants initiierte Benchmarkingkreis zum Ertragsmanagement weist zurecht darauf hin, dass sich das Tarifkonzept in den gesamten Marketingmix einfügen muss. So können die wirtschaftlichen Effekte einer Kundenbindungsstrategie ausbleiben, wenn das Preisniveau des Zeitkartensegments zu hoch angesetzt wird. Liegen die Preise für Zeitkarten dagegen zu niedrig, „kannibalisieren die Zugewinne im Dauerkartensegment ergiebigere Tickets“. ${ }^{1325}$ In diesem Fall läuft die Vermarktung von Einzeltickets ins Leere.

\footnotetext{
${ }^{1323}$ Preisbildungen, die die externen Kosten berücksichtigen, sind allerdings nur dann sinnvoll, wenn die Internalisierung bei allen Verkehrsträgern gleichermaßen durchgeführt wird und die Kunden überall „nicht lügende Preise“ vorfinden; vgl. Becker, U. 2007, S.5.

$1324 \mathrm{vgl}$. Ackermann und Stammler 2006, S.12

1325 vgl. Petersen u.a. 2004, S.46ff
} 


\subsubsection{Kommunikation}

\subsubsection{Kundenbeziehungsmanagement}

Durch die Einführung und Nutzung neuer Medien im Rahmen des E-Ticketing nehmen auch im ÖPNV, wo Information eine große Rolle spielt („Informationsnotwendigkeit“), die Interaktionen zwischen Kunden und Unternehmen zu. Mit der Einführung einer zentralen Datenhaltung sowie einer engeren organisatorischen Kooperation ${ }^{1326}$ und der Nutzung neuer Medien bietet das E-Ticketing eine gute Möglichkeit des Einstiegs in eine moderne Kommunikation und ein modernes Management der Kundenbeziehung (Kundenbeziehungsmanagement; Customer Relationship Management (CRM)) im ÖPNV. Für die glaubhafte Positionierung als Mobilitätsdienstleister bedeutet die Einführung eines ganzheitlichen Kundenbeziehungsmanagements die konsequente unternehmensinterne Ausrichtung aller Unternehmensbereiche auf den Kunden. Damit rücken einzelne Marketinginstrumente in den Hintergrund ${ }^{1327}$ und gewinnt die Entwicklung und zielgerichtete Vermarktung von stärker nachfrage- und weniger angebotsorientierten Leistungen an Bedeutung. Hierfür sind Daten über die Kunden und das Kundenverhalten notwendig, die durch das E-Ticketing-System generiert werden.

Kundenbeziehungsmanagement ist ein Konzept, welches die Kundenbedürfnisse in den Fokus der Unternehmensaktivitäten stellt, Produkte und Leistungen an diesen Bedürfnissen ausrichtet ${ }^{1328}$ sowie die Beziehung zwischen Kunde und Unternehmen aktiv gestaltet. Gerade die aktive Gestaltung der Kundenbeziehung ist es, die die Mobilitätsdienstleistung von der „low-involvement-Dienstleistung“"1329, die dem Kunden bislang präsentiert wird, unterscheidet. Charakteristikum dieser Beziehung ist, dass sie in viel stärkerem Maße von Individualität und Emotionalität geprägt ist als bisher. ${ }^{1330}$ Im Gegensatz zum MIV baut eine Positionierung im ÖPNV heute hauptsächlich auf rationalen Argumenten auf. Kunden, die aber nur auf einer solch rationalen Basis entscheiden, können schnell vom MIV abgeworben werden, wo die Emotionalität eine extrem wichtige Rolle spielt.

\footnotetext{
1326 Dies bedeutet, dass alle relevanten Arbeitsabläufe und Schnittstellen bei den verschiedenen Unternehmen in das Kundenbeziehungsmanagement miteinbezogen werden müssen.

1327 vgl. Homburg und Krohmer 2003, S.710

1328 vgl. Schrameyer und Burggraf 2003, S.28

1329 vgl. Hauschildt und Heger-Mehnert 2004, S.63

1330 vgl. Schrameyer und Burggraf 2003, S.29
} 
Zentraler Punkt für den Aufbau einer individuellen Kundenbeziehung ist das Wissen über den Kunden. Bislang kennen die Verkehrsunternehmen ihre Kunden kaum, weswegen die verantwortlichen Entscheidungsträger im ÖPNV häufig nur auf die Entwicklung der Fahrgastzahlen als einzigen Werttreiber schauen. Umgekehrt nehmen aber auch die Kunden selbst den ÖPNV als anonymes Massenverkehrsmittel war, zumal dieser Eindruck durch die anonyme Ansprache in der Breitenwerbung zurückgespiegelt wird (siehe Kapitel 6.1.5). Existiert bei Abonnementen von Jahreskarten bei den Verkehrsunternehmen zumindest noch der Name und die Adresse sowie die Bankverbindung des Kunden, bleibt die nachgefragte Leistung meist völlig im Dunkeln. Insofern können auch keine Rückschlüsse gezogen werden, wie der Wert eines einzelnen Kunden zu beurteilen ist. Es fehlen also die Grundlagen des Beziehungsaufbaus zum Kunden, die sich an dessen Wünschen, Bedürfnissen und Problemen orientieren. Die vom Kunden wahrgenommene Qualität und die daraus resultierende Zufriedenheit sind aber Schlüsselindikatoren für die Nachhaltigkeit der Beziehung und somit die Basis für den Unternehmenserfolg.

Probst und Consorten weisen zurecht darauf hin, dass es auch bei vermeintlich geringen Veränderungen in den Fahrgastzahlen zu beträchtlichen dynamischen Kundenfluktuationen insgesamt kommt. „Weil gleichzeitig viele alte Fahrgäste abgesprungen sind [müssen] in Wahrheit [...] erheblich mehr neue Fahrgäste gewonnen werden“. ${ }^{1331}$ Genau hier sehen Probst und Consorten die werttreibenden Ansätze des Kundenbeziehungsmanagements, indem über intelligentere Kundengewinnung neue Fahrgäste geworben, die Erlöse bei bestehenden Kunden optimiert und absprungbereite Kunden gebunden oder zurück geholt werden. Die Informationen aus dem E-Ticketing-System können dazu genutzt werden, Kundensegmente mit unterschiedlichem Kundenwert zu bilden. Dafür werden die vorhandenen Kundeninformationen in einer Wissensdatenbank gespeichert. Im Zusammenspiel von Stammdaten (Name, Anschrift, Bankverbindung, sonstige persönliche Präferenzen), Vertriebsdaten (z.B. Kaufhäufigkeit, genutzte Produkte, bevorzugter Vertriebs- und Kommunikationskanal, Reklamationen) und Nutzungsdaten (z.B. Nutzungsdauer, genutzte Relationen, bevorzugte Verkehrsmittel) ergibt sich so ein Kundenbild und eine Kundenhistorie, die gleichzeitig Anhaltspunkte der Kundenzufriedenheit und Bindungsintensität liefert. Je nach Kundenlebenszyklus, Erfolgspotenzial und Kundenwert können dann gezielte „proaktive“ Maßnahmen (z.B. Kommunikationsmaßnahmen, Bin-

1331 Probst und Consorten 2006, S.10 
dungsanreize, Verbesserung der individuellen vertraglichen Konditionen, Erhöhung des Vertriebsdrucks) der Kundenwertsteigerung durchgeführt werden. Probst und Consorten haben so am Beispiel des Schülertickets im Verkehrsverbund Rhein-Ruhr die spätere Stammnutzung von Schülern prognostiziert. ${ }^{1332}$

\subsubsection{Direkte und individualisierte Kundenkommunikation}

Mit der Einführung eines E-Ticketing-Systems entsteht eine verbundweit einheitliche Informations- und Vertriebsplattform, die ein umfassendes Kundenbeziehungsmanagement auf der Basis einer einheitlichen Datengrundlage ermöglicht. Da dies wesentlich mehr Kunden sind, als nur die heutigen Jahreskartenkunden, ist die Gesamtheit bekannter Kunden in einem E-Ticketing-System erheblich größer als in einem „klassischen“ Vertriebssystem. Außerdem werden über die Nutzung neuer Informations- und Kommunikationskanäle effizientere Wege der Kundenkommunikation eröffnet, insbesondere über E-Mail. Von daher sollte beim Abschluss eines Nutzungsvertrages immer auch die EMail-Adresse des Kunden erhoben werden. ${ }^{1333}$

Die Aktivitäten im Rahmen des Direktmarketings können idealerweise über das ZSC abgewickelt werden, da hier auf alle Kundendaten zentral zugegriffen werden kann. In Verbindung mit einem Beschwerde- und Kontaktmanagement als Teil eines ganzheitlichen Kundenbeziehungsmanagements ergeben sich hier bereits in einer frühen Ausbaustufe sinnvolle Synergien. Je differenzierter die Wünsche der Kunden allerdings sind, desto anspruchsvoller ist die Ermittlung und Befriedigung der Kundenerwartungen. Insoweit sich die hieraus ergebenden Anforderungen also (noch) nicht im Produkt- oder Tarifangebot niederschlagen können, ist eine Beschränkung auf den Abbau von Informationsdefiziten sinnvoll (siehe Kapitel 7.6.4.4). Der Kunde wird so beispielsweise auf Wunsch und entsprechend seiner Bedürfnisse (beispielsweise Informationen zu seiner Stammstrecke) über Veränderungen im Angebot über einen Kommunikationskanal seiner Wahl (SMS, MMS, Fax, E-Mail) informiert, wodurch die Kundenzufriedenheit erhöht werden kann. Auch ist über die Bündelung von Marketingkampagnen an zentraler Stelle eher gewährleistet, dass die Direktmarketingmaßnahmen professionell durchgeführt werden. Denn: „Unprofessionell durchgeführte Kampagnen wirken kontraproduktiv beim Kunden“. ${ }^{1334}$

\footnotetext{
1332 vgl. Probst und Consorten 2006, S.13ff

1333 vgl. Heller 2003, S.6

1334 Heller 2003, S.10
} 
Im späteren Stadium ist dann die Realisierung eines eigenen Kampagnenmanagementsystems sinnvoll. Dieses soll die Umsetzung individueller Werbekampagnen in jeder Phase des Kundenlebenszyklus' ermöglichen.

\subsubsection{Kundenbindungsprogramm}

In Kapitel 6.4.4.3 wurden die Probleme der abträglichen symbolisch-emotionalen Bewertung der ÖPNV-Mobilität aus Kundensicht und die fehlenden Anknüpfungspunkte einer auf emotionalen Werten ausgerichteten Vermarktung aus Unternehmenssicht dargestellt. Die sich dadurch ergebende Kluft zwischen Kunde und Unternehmen kann zum Teil durch ein Kundenbindungsprogramm überbrückt werden, im Rahmen dessen die Kundenbeziehung aktive und koordiniert gestaltet wird.

Die im Rahmen eines E-Ticketing-Systems notwendige Hard- und Software für die Kundenverwaltung, sowie die Nutzung elektronischer Kundenmedien, liefern eine geeignete Ausgangsbasis für die Etablierung eines Kundenbindungsprogramms, welches auf eine emotionale Bindung des Kunden an den ÖPNV ausgerichtet ist. Zwar gibt es mittlerweile zahlreiche kartenbasierte Kundenbindungsprogramme, doch besitzt ein chipkartenbasiertes Programm im ÖPNV einen systemimmanenten Vorteil: Die Karte als Fahrkarte ist von Relevanz, d.h. der Nutzen muss nicht erst (künstlich) konstruiert werden, sondern liegt klar auf der Hand. ${ }^{1335}$

Das Ziel eines ÖPNV-Kundenbindungsprogramms, etwa in Form eines Rabatt-, Bonussystems oder Loyalitätsprogramms, ist es, gewonnene ÖPNV-Kunden stärker zu binden bzw. zur vermehrten Nutzung anzuregen. Dieses Ziel ist vor allem vor dem Hintergrund von Bedeutung, dass die Gewinnung von Neukunden sieben- bis zehnmal teurer ist als das Halten bestehender Kunden. ${ }^{1336}$ Um einer Abwanderungsbereitschaft entgegenzuwirken bedarf es Anreize, die die (potenziellen) Kunden dazu bewegen, sich im Konkurrenzverhältnis zum Individualverkehr möglichst häufig für die Alternative ÖPNV zu entscheiden.

Eine Möglichkeit der - emotional basierten - Kundenbindung, von der heute schon Gebrauch gemacht wird, bietet die Etablierung eines Kundenclubs. Der Kundenclub zielt darauf ab, mit den Kunden in einen regelmäßigen und direkten Kontakt zu treten und

\footnotetext{
1335 vgl. Ordon 2004, S.26f

1336 vgl. Schrameyer und Burggraf 2003, S.28
} 
ihnen über die Clubmitgliedschaft zusätzliche Leistungen mit wahrnehmbarem Nutzen anzubieten. ${ }^{1337}$

Soweit sich die Vorteile aus Kundensicht aber nur auf den Bezug einer Kundenzeitschrift beschränken, ist der Nutzen - und damit der Erfolg - nur sehr gering. Die Kunden erwarten zunächst einmal Leistungen, die sich direkt auf die Kernleistung beziehen - und das bedeutet in der Regel vergünstigte Fahrten (also einen ökonomischen Nutzen). Eine infasStudie zur Akzeptanz einer „Kleinen Kundenbindungskarte“ im Nahverkehr nach dem Vorbild der BahnCard 25 (also einen 25\%igen Rabatt pro Fahrt bei einer längerfristigen Vertragsbeziehung) ergab für ein solches Produkt ein Marktpotenzial innerhalb der ÖPNV-Kundschaft, das zwischen 21 und 31\% liegt. Hierbei handelt es sich um Gelegenheitsfahrer, die an 3 bis 4 Tagen in der Woche den ÖPNV benutzen. Die infas-Studie, an der sich 6 große deutsche Verkehrsverbünde bzw. Verkehrsunternehmen beteiligten, verdeutlichte aber auch, dass es größerer Anreize bedarf die Potenziale tatsächlich zu aktivieren, als einfach nur einen Preisnachlass zu gewähren. ${ }^{1338}$

Soll also nicht alleine ein ökonomischer Kundennutzen vom Kundenbindungsprogramm ausgehen, sondern auch ein emotionaler Mehrwert, sind weiterführende Anreize und zusätzliche Nutzen mit der Kundenbindungskarte zu verknüpfen. Eine derartige Verknüpfung ermöglicht ein integriertes Bonusprogramm, dass die Treue des Kunden bonifiziert, beispielsweise in Form von Punkten, die der Kunde - je nach Ausprägung des Programms - gegen zusätzliche Leistungen eintauschen kann. ${ }^{1339}$

Kundenbindungsprogramme als systematische Preis- oder Wertwerbung sind grundsätzlich zulässig, seit der Gesetzgeber das Rabattgesetz und die Zugabeverordnung aufgehoben hat. Es ist allerdings zu berücksichtigen, dass Kunden, die ihre persönlichen Daten nicht preisgeben wollen, nicht benachteiligt werden. Der Zugang zum Programm muss daher prinzipiell allen Kunden gewährt werden und die Art und der Umfang der gewählten Vorteile erkennbar bleiben.

Ein ÖPNV-Bonusprogramm kann auch dazu genutzt werden, die Kundenprozesse zu beeinflussen. So ist es beispielsweise möglich, das korrekte An- und Abmelden im E-

\footnotetext{
1337 vgl. Blümel 2004, S.70 sowie Homburg und Krohmer 2003, S.784

1338 vgl. Follmer 2007

1339 vgl. Homburg und Krohmer 2003, S.785
} 
Ticketing-System zu honorieren ${ }^{1340}$ oder die Nutzung günstiger (aus Unternehmenssicht), vom Kunden selbst bedienter Vertriebswege (z.B. Internet) zu fördern und so Vertriebskosteneinsparungen zu erreichen. Außerdem ist eine differenzierte Beeinflussung der Nachfrage möglich, indem etwa Fahrten zu Schwachlastzeiten stärker bonifiziert werden, als Fahrten in der Hauptverkehrszeit. Schrameyer und Burggraf vertreten hier folgende Auffassung:

"Mittelfristig werden sich mit der sukzessiven landes- und bundesweiten Einführung des E-Ticketing weitere Chancen zur Durchsetzung bedarfsspezifischer Kundenbindungsprogramme ergeben, die gegebenenfalls Schnittstellen zu den bereits etablierten Bonussystemen bilden". 1341

Die Einführung eines Bonusprogramms muss nicht bedeuten, dass dem Kunden unbedingt ein monetärer Vorteil geboten wird. ${ }^{1342}$ Denn mit der Gewährung von Rabatten auf die Beförderungsleistung (Kernleistung) riskiert das Verkehrsunternehmen eine Unterlaufung des geltenden Tarifs, also Einnahmeverluste. ${ }^{1343}$ Auch das Bonusprogramm der DB AG für den Fernverkehr kommt ohne diesen geldlichen Vorteil aus. ${ }^{1344}$ Hierfür ist aber wichtig, dass dem Kunden ein klar erkennbarer und zusätzlicher Nutzen angeboten wird. Dazu gehören vor allem zusätzliche Leistungen und besserer Service, die zwar außerhalb der Produktschiene angesiedelt sein können, doch den logischen Zusammenhang und Zusammenhalt zwischen der Kern- und Zusatzleistungen gewährleisten sollen. Anderenfalls besteht die Gefahr, dass das Programm für die Kunden nicht mehr "griffig“ ist (Stichwort „Bauchladen“) und kein homogenes Bild ergibt.

\footnotetext{
${ }^{1340}$ vgl. www.rmvplus.de: Electronic Ticketing

1341 Schrameyer und Burggraf 2003, S.29

1342 vgl. van Bocxlaer 2003, S.24

${ }^{1343}$ Diese Gefahr stellt sich anders dar, wenn das Bonusprogramm integraler Bestandteil des neuen Tarifs ist.

${ }^{1344}$ vgl. Arbach 2004, S.49
} 


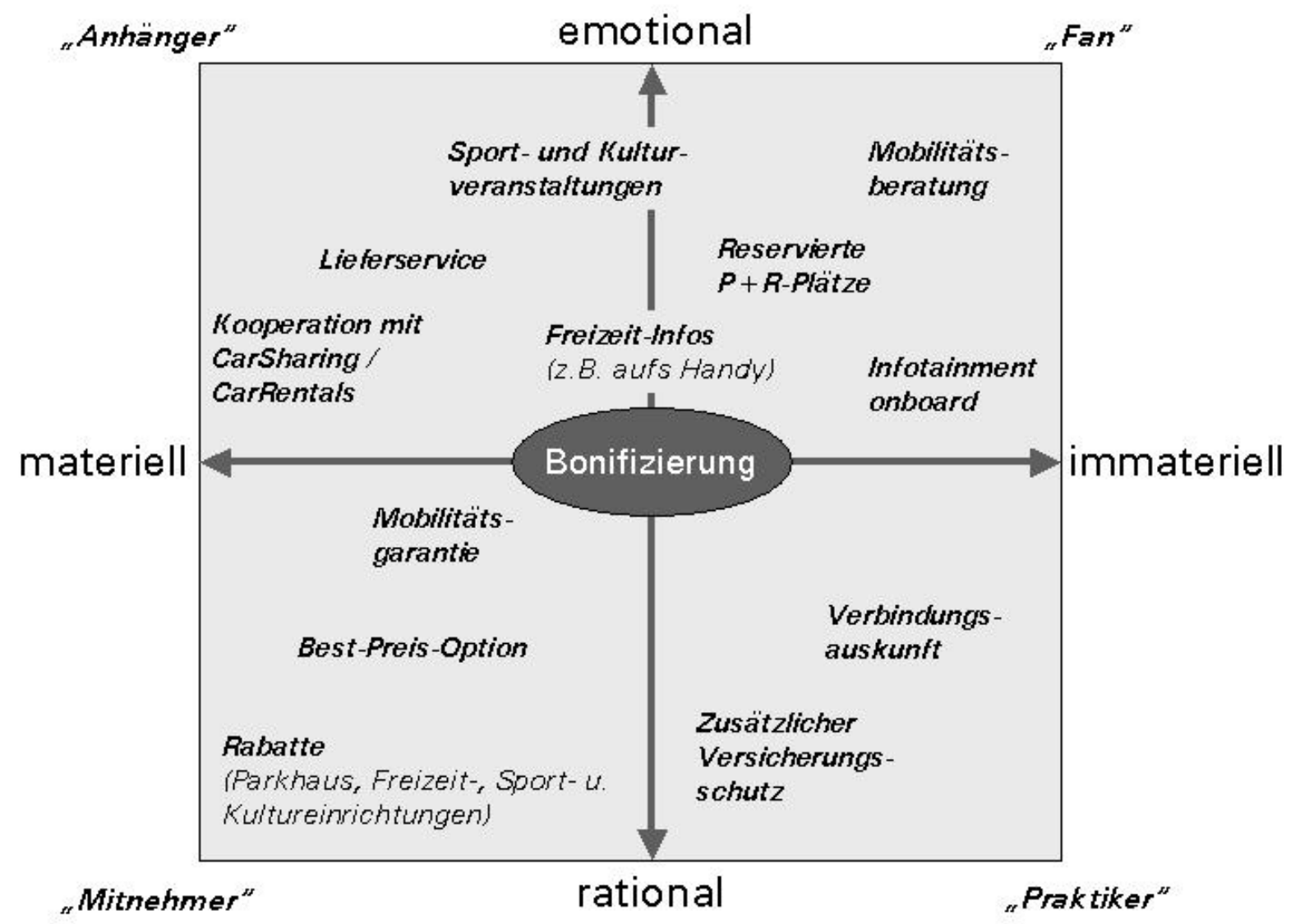

Abbildung 41: Mögliche Dimension eines Kundenbindungsprogramms

Quelle: Eigene Darstellung

Abbildung 41 zeigt exemplarisch die Einbindung möglicher Zusatzleistungen in einen ÖPNV-Kundenclub bzw. in ein ÖPNV-Bonusprogramm. Deutlich ist, dass die Leistungen sowohl hinsichtlich ihrer Emotionalität bzw. Rationalität wie auch bezogen auf ihre Wertigkeit ausgewogen sein müssen. Einerseits ist es das Ziel gute Kunden „aufzubauen“, d.h. sie über rationale und materielle Anreize zu gewinnen und schließlich zu ÖPNV"Anhängern“ oder sogar ÖPNV-„Fans“ zu entwickeln. Andererseits sollen Mitnahmeeffekte, wie sie durch die Gewährung von Rabatten oder einer Best-Preis-Option entstehen, vermieden werden. Insofern ist bei der Einbindung eines Bonusprogramms in das Kundenbindungsprogramm zu beachten, dass sich das Bonusprogramm - aus finanzieller Sicht - selbst trägt, da es ansonsten aus dem Marketingbudget bestritten werden muss. Von den Bonuspunkten bzw. den Prämien sollte ein hoher emotionaler Reiz ausgehen. Andererseits sollten gewährte Bonuspunkte nicht unbegrenzt gültig sein (was zur Bildung von hohen Rücklagen führen würde) oder die Bonuspunkte von den Kunden nicht vollständig eingelöst werden. Dies kann z.B. dadurch erreicht werden, dass von den 
Kunden ein Eigenanteil („Zuzahlung“) erhoben wird, der als Hürde bei der Einlösung von Prämien erachtet wird. Damit wird gleichzeitig erreicht, dass rein rational handelnde Kunden Prämien einfach „mitnehmen“.

Darüber kann ein Bonusprogramm als kommunikatives Element im Rahmen des Beziehungsmanagements eingesetzt werden. Ein aktueller Bonuspunktestand, Neuerungen im Programm oder ein erreichter Status sind geeignet Kommunikationsanlässe, um sich um den Kunden zu „kümmern“, also mit dem Kunden in Kontakt zu treten und zur ÖPNVNutzung anzuregen.

\subsubsection{Kundeninformation}

Die Notwendigkeit der Kundeninformation im ÖPNV wurde bereits an verschiedenen Stellen erwähnt. Die Verbesserung der Kundeninformation durch die Einführung von ETicketing wird im wesentlichen durch die Verbesserung der Servicequalität (siehe Kapitel 7.6.1.2) sowie der Nutzung neuer Kundenmedien erreicht. Hierbei spielt vor allem die Integration des Mobilfunktelefons eine große Bedeutung. Bereits heute, ohne ein ETicketing-System flächendeckend eingeführt zu haben, bietet der RMV seinen Kunden die Fahrplanauskunft und den Ticketerwerb in der Stadt Frankfurt über das Mobilfunktelefon an. Zukünftig könnte über die Integration der Auskunftsfunktion in den verbundweiten Ticketverkauf auf dem Mobilfunktelefon die ÖPNV-Nutzung weiter vereinfacht werden. Über die Nutzung einer NFC-Schnittstelle (siehe Kapitel 7.6.2.4.1) wäre es auch möglich, dass sich der Kunde mit seinem Mobilfunktelefon auch in einem E-Ticketing-System der VDV-Stufe 3 im System an- und abmeldet. Dieses Verfahren wird von der RMV $\mathrm{GmbH}$ und der Hanauer Straßenbahn GmbH bereits im Pilotprojekt in Hanau nach einem Feldversuch seit dem Jahre 2006 erfolgreich eingesetzt. ${ }^{1345}$

Die Möglichkeit der Online-Verbindung in Kombination mit hohen Datenübertragungsraten sowie einer vergleichsweise hohen Bildauflösung erlauben nutzerseitig auf dem Mobilfunkgerät eine qualitativ gute Informationsdarstellung. Anbieterseitig kommt es allerdings auf die Bereitstellung eines entsprechenden Inhalts ("contents“) an. Ideal ist die Verknüpfung mit der Fahrplan- und Tarifauskunft für Soll-Informationen sowie mit einem Intermodalem Transport Control System (ITCS)/RBL, aus dem dynamische (Ist-) Fahrplaninformationen online über das Mobilfunknetz bereitgestellt werden. Hierauf

${ }^{1345}$ vgl. RMV-Pressemitteilung v. 19.4.2007 
aufbauend sind standortabhängige Dienste (sogenannte „location-based-services“) denkbar, die die jeweilige Information entlang der gesamten Wegekette übermitteln, beispielsweise per SMS auf das Mobilfunkgerät. ${ }^{1346}$ Derartige Dienste können auch als sogenannte "push-Dienste“ eingerichtet werden, zu denen sich der Kunde einmalig anmelden muss. Bei seiner Anmeldung gibt er neben seiner Mobilfunkrufnummer dann an, für welche Zeitabschnitte und welche Relationen, Linien oder Haltestellen er Informationen (bspw. Störmeldungen) erhalten möchte. Bei Bedarf wird ihm dann eine SMS auf sein Mobilfunkgerät zugesendet. 1347

\subsubsection{Markenbildung}

Eine Marke im Bereich der Konsumgüterindustrie dient vor allem dazu, ein Produkt von der Konkurrenz abzugrenzen bzw. unterscheidbar zu machen. Der Kunde soll mit einer Marke etwas Einprägsames und Unverwechselbares verbinden („USP=Unique Selling Position“). Eine etablierte Marke ist gleichsam ein Leistungsversprechen, das u.a. auf einem kontinuierlichen Qualitätsniveau aufbaut oder sich vom Image her ableiten lässt. Über die Verbesserung des Images sollen schließlich die Umsätze gesteigert und damit der gesamte Wert des Unternehmens verbessert werden. Das Image eines Unternehmens trägt ganz wesentlich zu den immateriellen Vermögenswerten eines Unternehmens bei, die sich schließlich in der Reputation und im Markenwert widerspiegeln. ${ }^{1348}$ Diese Prinzipien der Markenbildung sind auch auf den ÖPNV übertragbar, wenngleich die jahrzehntelange Monopolstellung in der Vergangenheit eine Markenbildung im ÖPNV verhindert hat und auch die zukünftige Entwicklung eines Markenbilds im ÖPNV mit Problemen behaftet ist. Dies bezieht sich u.a. auf die Vermittlung von Charaktereigenschaften, die von Marken ausgehen. Stehen bestimmte Marken für beispielsweise beruflichen Erfolg und erhöht die Verwendung dieser Marken das soziale Ansehen, muss man kritisch hinterfragen, wie der ÖPNV - dem ein sozial anrüchiges Image anhaftet - es schaffen soll, ein positives und kundengerechtes Markenbild zu entwickeln - vor allem vor dem Hintergrund, dass die bisherigen Zielgruppen sehr groß und homogen gefasst waren. ${ }^{1349}$

\footnotetext{
1346 vgl. Reinsch 2004, S.60ff für das Beispiel der Berliner Verkehrsbetriebe.

1347 vgl. Flach u.a. 2005, S.26 sowie Hoyer und Preil 2004, S.72ff

1348 Es wird bspw. davon ausgegangen, dass der Unternehmenswert von Coca Cola zu über 90\% und der von American Express zu über $80 \%$ aus immateriellen Vermögenswerten bestehen; vgl. UITP 2005, S.12.

${ }^{1349}$ vgl. Mager und Raif 2004, S.30
} 
Ausgehend von der Nutzung neuer Kommunikations- und Vertriebskanälen sowie der Anwendung eines verbundweit einheitlichen Kundenmanagements können in einem ETicketing-System nun gezielt (Werbe-)Botschaften platziert werden, die für die Markenbildung von Bedeutung sind. Im Rahmen der zielgruppenorientierten Ansprache ist die Chance bei einem Kunden auf höheres Interesse zu stoßen („high involvement“) viel gröBer als in der Breitenwerbung, wo die Botschaften nicht ankommen weil kein Interesse (,low interest“) besteht. Dabei kommt es nicht alleine darauf an, die richtigen Zielgruppen mit den richtigen Botschaften (z.B. die Wertvorstellungen betreffend) zu konfrontieren, sondern auch in der richtigen Weise (Tonalität) und über den gewünschten bzw. präferierten Kanal. Vor allem aber ist durch die vernetzte Informations- und Vertriebsplattform sichergestellt, dass der ÖPNV verbundweit mit den identischen Inhalten auf allen „Kanälen“ wirbt. „Auf diese Weise nimmt der Umworbene immer und überall das gleiche Bild der Marke wahr" ${ }^{1350}$ Darüber ist eine hohe Wiederholung der identischen Inhalte über das gesamte Verbundgebiet gewährleistet.

Eine partnerschaftliche markenorientierte Identitätsbildung dient einer klaren Positionierung gegenüber dem „Konkurrenten Auto“ und fördert damit die Wettbewerbsfähigkeit des ÖPNV an sich. Damit wird eine neue Qualität in der Außendarstellung erreicht, bei der Werbung nicht primär dafür eingesetzt wird, die unternehmerische Identitätskrise in den Zeiten der Marktderegulierung zu überwinden. Lokal isolierte und ohne regionalen Bezug durchgeführte Ansätze, wie beispielsweise von der LNO Frankfurt, TraffiQ, mit dem Ziel eine „Marke ÖPNV“ für Frankfurt zu entwickeln1351, können sich leicht kontraproduktiv auswirken, da aus Kundensicht nicht unbedingt eine Differenzierung zwischen den verschiedenen Verkehrsorganisationen stattfindet bzw. es die Kunden nicht wesentlich interessiert wie die rechtlich-organisatorischen Verhältnisse zwischen Besteller und Ersteller geregelt sind. ${ }^{1352}$ Vielmehr bedarf es einer zwischen allen regional Beteiligten (Verbund, Lokale Nahverkehrsorganisationen, Verkehrsunternehmen) abgestimmten Markenstrategie, in der u.a. festgelegt wird, welcher Absender als Dachmarke fungiert,

\footnotetext{
1350 Mager und Raif 2004, S.32

1351 vgl. Traffiq 2003, S.10

1352 Dieses Beispiel macht gleichzeitig die Unsicherheit deutlich, mit der der Begriff „Marke“ im ÖPNV gehandhabt wird. Während die TraffiQ vom "ÖPNV als Marke" spricht und die lokale Nahverkehrsorganisation als Absender sieht, ist es das Ziel des RMV die "Marke RMV“ zu bewerben; vgl. RMV 2005, S.96. In Baden-Würtemberg dagegen positioniert man den „3Löwen-Takt" als Marke; vgl. www.3-loewen-takt.de.
} 
welche Produkte unter diesem Dach vermarktet werden und wie ein einheitliches Erscheinungsbild (",corporate indentity“) - bis hin zu einer einheitlichen Benutzeroberfläche - für den ÖPNV aussieht. Naheliegend ist sicherlich die Positionierung einer Dachmarke „RMV“ mit regionalen Produkten, für die Markenbezeichnungen verwendet werden und den Verkehrunternehmen als Mobilitätsdienstleistern vor Ort.

\title{
7.7 Aufwandsseitige Optimierungsansätze
}

7.7.1 Produkt

\subsubsection{Optimierung des Leistungsangebots}

Die Einführung neuer Produkte am Verkehrsmarkt ist aus Sicht eines Mobilitätsverbundes bzw. -dienstleisters notwendig, um den sich verändernden Anforderungen an Mobilität gerecht zu werden. Eine hinreichend flexible Produktpolitik bzw. -management ist daher für die Erreichung der Unternehmensziele unablässig, sowohl im Hinblick auf das Kerngeschäft wie auch auf mögliche ergänzende Zusatzleistungen. Das Produktmanagement findet seinen Ausdruck in der nachfragegerechten Anpassung des Angebotes und, damit zusammenhängend, in der Vorhaltung von Beförderungskapazitäten. Diese führen im ÖPNV aufgrund der Notwendigkeit der Vorhaltung hoher Reservekapazitäten zu hohen nutzenunabhängigen Kosten („Fixkosten“, siehe Kapitel 6.1.2). ${ }^{1353}$ Kretschmann führt zur nachfragegerechten Anpassung des Leistungsangebotes an:

\begin{abstract}
"Eine Liniennetzoptimierung eröffnet somit, neben einer positiven Auswirkung auf die Erlösseite durch eine Attraktivitätssteigerung, erhebliche Kostensenkungspotentiale durch eine erhöhte Auslastung der Fahrzeuge und die Reduktion von Leerfahrten. [...] Eine Einschränkung der Kapazitätsvorhaltung kann zu Einbussen bei der Qualität der Verkehrsversorgung (zeitlicher Anfall der Verkehrsleistung) und somit zu Umverteilungen des Verkehrsflusses beziehungsweise zur Verschlechterung von Standort- und Marktvorteilen führen". ${ }^{1354}$
\end{abstract}

Um negative Effekte auf die Kundennachfrage minimieren zu können sind aber genaue Kenntnisse der Auslastungsgrade sowie der kundenseitigen Reaktionen auf eine veränderte Angebotsgestaltung notwendig. Kretschmann merkt daher zu recht in einer Fußnote

\footnotetext{
1353 vgl. Aberle 2003, S.233

1354 Kretschmann 2001, S.104
} 
an, dass im Rahmen des Produktmanagements ein elektronisches Ticketing wertvolle Dienste leisten würde. ${ }^{1355}$

Voraussetzung und Grundlage für eine nachfragegerechte Angebots- und Kapazitätsplanung bzw. -anpassung sind genaue Daten über die bestehende Nachfrage, die Stauss zufolge ohne Aussage bleiben, wenn sie nicht im Kontext des Unternehmensumfeldes betrachtet werden:

„Ohne Berücksichtigung situativer Faktoren, wie Veränderungen in Konsumstruktur und -verhalten, Konjunkturlage, Aktivitäten von Substitutionskonkurrenten, politischer Zielvorgaben und ohne Bezug auf die vom Unternehmen angestrebten Absatzziele sind Daten als Indikatoren für Marktorientierung ungeeignet". ${ }^{1356}$

In einem E-Ticketing-System der Automatisierten Fahrpreisfindung werden sowohl Daten über nachgefragten Relationen wie auch Linienauslastungen generiert. ${ }^{1357}$ Mittels dieser Daten kann u.a. nachvollzogen werden, zwischen welchen Relationen im Liniennetz verstärkt Beziehungen bestehen und welche Verbindungen nur sehr gering oder gar nicht nachgefragt werden. Somit können gerechtfertigte Kapazitätsanpassungen vorgenommen werden, ohne - zumindest auf breiter Front - negative Kundenreaktionen hervorzurufen. 1358 Darüber hinaus können über die Einrichtung von direkten Linienverläufen respektive der Reduktion von Umstiegsbeziehungen die Reisegeschwindigkeit auf wichtigen, d.h. von vielen Kunden genutzten Relationen verbessert oder sogar durch frei gewordene Kapazitäten der Bedienungsumfang erhöht werden. Neben der Beschleunigung der Fahrgastabfertigung ist dies eine wichtige Maßnahme die Reisegeschwindigkeit insgesamt zu erhöhen, was sich wiederum auf die Kundenzufriedenheit positiv auswirkt. 1359

\subsubsection{Optimierung des Betriebsablaufs}

In bezug auf die Verbindungsqualität kommt insbesondere der Reisegeschwindigkeit eine große Bedeutung zu, zumal sie häufig als objektiver Bewertungsmaßstab im Vergleich zur Beförderung mit dem MIV herangezogen wird. Aber auch in der subjektiven Wahrnehmung durch den Kunden spielt die Reisezeit eine wichtige Rolle, weil sie starken Einfluss

\footnotetext{
1355 vgl. Kretschmann 2001, S.104

1356 Stauss 1987, S.116f

1357 vgl. Keppeler u.a. 2005, S.57 sowie Achenbach 2002, S.231

1358 vgl. Ordon 2004, S.27

1359 vgl. Blümel 2004, S.86
} 
auf die Kundenzufriedenheit hat. Als negativ auf diese Zufriedenheit wirken sich unter anderem Umwege in der Linienführung zwischen Quell- und Zielorten aus, lange Wartezeiten zwischen den Anschlüssen (Umstiegszeiten) sowie lange Abfertigungszeiten beim Fahrkartenverkauf im Fahrzeug. Die durch den Fahrkartenverkauf im Fahrzeug verursachten Aufenthaltszeiten an den Haltestellen lassen sich kaum planen und können bei Verzögerungen zu Verspätungen und verpassten Anschlüssen führen. Insgesamt führen lange Aufenthaltszeiten und Fahrzeugumläufe zu einer schlechten Produktivität der Fahrzeuge. ${ }^{1360}$

In einem E-Ticketing-System werden die Verkaufsvorgänge durch den Einsatz moderner Vertriebskanäle aus den Fahrzeugen verlagert (VDV-Stufe 2) bzw. erfolgt der Erwerb einer Berechtigung durch den Anmeldeprozess des Kunden im E-Ticketing-System (VDVStufe 3). Damit wird eine exaktere Planung der Fahrtzeiten und die Einsparung von Pufferzeiten ermöglicht. Im Idealfall können so Umläufe und Fahrzeuge eingespart werden, wodurch die teuren Reservekapazitäten gesenkt werden können. Daneben können Personalkosten für die Reduzierung des Bargeldhandlings sowie für Auf- und Abrüstzeiten eingespart werden (siehe Kapitel 7.7.2.2). Nicht zu unterschätzen ist auch das psychologische Stresspotenzial, das von ausgelösten Verspätungen, beispielsweise bei hohem Fahrgastaufkommen, auf das Fahrpersonal einwirkt und krankheitsauslösend wirken kann. So wird durch E-Ticketing nicht nur das Fahrpersonal von zeitintensiven Verkaufsvorgängen entlastet, sondern auch die Verantwortung für das Bargeld und die damit zusammenhängenden Sicherheitsrisiken. ${ }^{1361}$

\subsubsection{Vertrieb}

\subsubsection{Etablierung innovativer Vertriebskanäle}

\section{Mobilfunktelefon}

Die Kosten für den Vertrieb von elektronischen Fahrtberechtigungen fallen für diesen Vertriebskanal im Rahmen eines VDV-Stufe 2-Systems vergleichsweise gering aus, da die Vorgänge zum Erwerb von Nutzungsberechtigungen und deren Bezahlung fast alle automatisiert ablaufen (können) und die Vertriebsgeräte an der Kundenschnittstelle in Form der Mobilfunkgeräte durch den Kunden bereit gestellt werden. Es müssen nur geringe

\footnotetext{
${ }^{1360} \mathrm{vgl}$. Achenbach 2002, S.187

1361 ebd., S.197
} 
Personalressourcen für diesen Vertriebskanal bereitgestellt werden. Voraussetzung für diesen Vertriebsweg ist die einmalige Bereitstellung der hierzu notwendigen technischen Infrastruktur. Laufende Vertriebskosten fallen in Abhängigkeit der eingesetzten Technologie an. So kann je nach ausgehandelten Konditionen mit dem Mobilfunkanbieter eine Übermittlung der Fahrberechtigung per SMS oder MMS vergleichsweise teurer (auch aus Kundensicht) sein, als über GPRS oder UMTS, wo nur die „airtime“ berechnet wird.

Auch Vertriebskostenbestandteile, die nicht mit dem direkten Verkaufsprozess in Zusammenhang stehen (z. B. Wartungsarbeiten), liegen niedriger, da diese an einer zentralen Stelle stattfinden und somit im Gegensatz zu den Vertriebskanälen ,Automat' und ,Fahrpersonal' keinen (kostenintensiven) Fahrtaufwand erforderlich machen. Provisionszahlungen, die sich etwa an der Anzahl von Verkaufstransaktionen orientieren, fallen in der Regel für die Abrechnung und das Inkasso der in Anspruch genommenen Leistung an.

Im Hinblick auf die Attraktivität (aus Kostengründen und Nutzerfreundlichkeit) und die Potenziale dieses Vertriebskanals sollte versucht werden, eine möglichst große Zielgruppe über diesen Vertriebskanal zu erreichen. Für ein E-Ticketing-System der VDV-Stufe 2 gibt es bereits heute verschiedene Anbieter, die den Erwerb von vorausbezahlten Tickets im niedrigpreisigen Segment anbieten. ${ }^{1362}$ In einem System der Automatisierten Fahrpreisfindung kann das Mobilfunkgerät, vorausgesetzt es besitzt eine NFC-Schnittstelle, auch als Medium für die An- und Abmeldung eingesetzt werden (s.o.).

\section{Exkurs: Mobilfunk-Ortung}

Eine besondere Form des MobilE-Ticketing wird seit August 2005 u.a. von der Technischen Universität Braunschweig (Institut für Verkehr und Stadtbauwesen), der Deutschen Bahn AG, der Braunschweiger Verkehrs-AG, der Deutschen Telekom, dem RMV und den Berliner Verkehrsbetrieben mit Förderung durch das Bundesministerium für Wirtschaft und Technologie im Rahmen des Projektes "RingERide" "erforscht". Ziele sind auch hier der Abbau von Zugangshemmnissen und die Reduktion von Vertriebskosten im ÖV-und

\footnotetext{
1362 vgl. hierzu bspw. das Angebot der Firma xsmart AG, Bad Rappenau, für den Bereich des Nahverkehrs oder der Deutschen Bahn AG für den Bereich des Fernverkehrs, das am 1.9.2006 den Betrieb aufgenommen hat.
} 
zwar für den gesamten ÖV. Es integriert also Nah- und Fernverkehr. ${ }^{1363}$ "Das Mobiltelefon übernimmt dabei eine zentrale Funktion. Es ermöglicht dem Kunden nicht nur den Abruf von Informationen zur Reiseplanung, sondern auch das bargeldlose Erwerben und Bezahlen der Beförderungsleistung. Dabei geht es weit über die Möglichkeiten bisher erprobter Bezahlsysteme hinaus: Durch intelligente Ausnutzung der Verortbarkeit eines Mobiltelefons (so genannte Mobilfunk-Ortung bzw. GSM-Ortung) wird es erstmals möglich, Start- und Zielpunkt automatisch zu erfassen und auf dieser Basis eine automatische Abrechnung der Fahrt durchzuführen. Eine automatisierte Fahrpreisfindung im HandyTicketing, ggf. auf Basis einer Best-Preis-Abrechnung, ist damit realisierbar". ${ }^{1364}$

Scheint diese Lösung für den Bereich des Fernverkehrs durchaus denkbar, bleibt abzuwarten, inwieweit sich eine derartige Lösung auch auf den Nahverkehr übertragen lässt. Von daher wird im RingERide-Projekt neben der Ortung der Fernverkehrsleistung der DB AG auch die Ortung von Nahverkehrsleistungen erprobt. Kritisch stellt sich hierbei vor allem die Genauigkeit der Ortung dar, die in städtischen Bereichen auf wenige Meter genau funktionieren muss, soll die Zuordnung zu einer Haltestelle, einem Verkehrsmittel oder einem Verkehrsunternehmen zweifelsfrei geschehen. Darüber hinaus findet die Kommunikation zwischen Kunden und Hintergrundsystem über das Mobilfunknetz statt, wodurch Kosten entstehen. Außerdem verursacht die Ortung Kosten beim Mobilfunkprovider. Diese Kosten müssen letztlich in einem akzeptablen Verhältnis zum Fahrpreis stehen. Projektende soll 2008 sein. 1365

Internet

Das Internet stellt eine Basistechnologie für den elektronischen Vertrieb dar. Denn durch das Internet können kosteneffiziente Interaktionen und Transaktionen verbundweit und partnerübergreifend realisiert werden. ${ }^{366}$ Dabei können Aufgabenträger, Verkehrsunternehmen und Kunden gleichermaßen auf die Vorteile des Internets zurückgreifen. Im Rahmen der verbundweit einheitlichen Informations- und Vertriebsplattform bietet sich das Internet als Kommunikationsnetzwerk sowie zur Bereitstellung von Diensten und Information an. Die dezentrale Organisation der ÖPNV-Struktur im RMV wird dabei als Subnetzwerk abgebildet, d.h. der organisatorische Reorganisationsaufwand ist relativ

${ }^{1363} \mathrm{vgl}$. Sommer 2006, S.5

1364 Nittinger und Kuchenbecker 2005, S.30ff

$1365 \mathrm{vgl}$. Sommer 2006, S.5

${ }^{1366}$ vgl. Wirtz 2001, S.602ff 
gering. Die subsidiären Netze der ÖPNV-Vertriebspartner können neben der gemeinsamen Informations- und Vertriebsplattform autonom weiterlaufen.

Im Verbundgebiet des RMV gibt es (z.T. seit mehreren Jahren) erste Ansätze des Internetvertriebs. Bei den Verbundpartnern Main-Taunus-Verkehrsgesellschaft (MTV), OVB, VGF und der DB AG können per Internet (ausgewählte - d. h. in der Regel Zeit-) Fahrkarten des RMV-Tarifs bestellt werden. Die Zustellung der Tickets erfolgt dann mit der Post.1367 Damit fungieren diese Webshops als reine Bestellkanäle.

Auch dem Internetvertrieb wird in Zukunft als neuem, automatisiertem - und damit vergleichsweise kostengünstigem - Vertriebsweg große Bedeutung beigemessen. Die Vertriebskosten dürften ähnlich wie beim Mobile-Ticketing gering ausfallen, da nach der Einrichtung der notwendigen technischen Infrastruktur viele Schritte automatisiert erfolgen und kaum Personal eingesetzt werden muss. Auch die Wartungs- und Instandhaltungskosten fallen im Gegensatz zum Automatenvertrieb sehr gering aus. Provisionszahlungen fallen gar nicht an. Unterstützt durch die Schließung von personenbedienten Verkaufsstellen und die Kürzung von Provisionszahlungen im Agenturvertrieb konnte so die DB AG ihren Gewinn über den Internetvertrieb im Vergleich zum stationären Vertrieb in den letzten Jahren deutlich steigern. ${ }^{1368}$

\section{Zentrales Service Center}

Neben den bereits oben dargestellten Aufgaben im Front-Office-Bereich werden vom ZSC alle Geschäftsprozesse im Backoffice-Bereich ausgeführt, die nicht automatisiert bzw. elektronisch ausgeführt werden können (bspw. Versendung von Chipkarten oder InfoMaterial, Call-Center). Im ZSC können so Prozesse, die für alle Vertriebspartner im Rahmen des E-Ticketing-Betriebs anfallen, kosteneffizient gebündelt werden. Hierbei handelt es sich um die Rechnungsstellung, Auswertung von statistischen Daten, Vorbereitung und Durchführung von Marketingkampagnen etc.

ÖPNV-Experten (vgl. z. B. Delphi-Studie) prognostizieren auch hierfür, dass der personenbediente Verkauf vor Ort - aus Kostengründen - zurückgehen wird. ${ }^{1369}$ Ähnlich wie bei den Vertriebswege Internet und Mobilfunkgerät, kann das ZSC durch den zentralen

\footnotetext{
${ }^{1367}$ vgl. hierzu bspw. Georgi und Wüst-Rocktäschel 2004, S.46

1368 vgl. Frankfurter Rundschau v. 5.5.2007

1369 vgl. Deutsches Verkehrsforum 2005, S.105
} 
und effizienten Personaleinsatz über entsprechend lange "Öffnungszeiten“ verfügen und fast immer erreichbar sein. Hinzu kommt, dass ein ZSC neben dem eigentlichen Vertrieb auch Ansprechpartner für andere Anliegen ist (Anfragen, zum Produkt, zur Beförderungsleistung, zum ÖPNV-Angebot/Fahrplan, zur Abrechnung, für Beschwerden/ Anregungen) und hier der Kunde ortsunabhängig (von überall erreichbar) agieren kann.

Durch den personenbedienten Betrieb liegen die Vertriebskosten beim ZSC höher als beispielsweise beim Internetvertrieb oder dem Mobile-Ticketing. Nicht zu verkennen ist aber der Zusatznutzen eines ZSC, bei dem ein direkter persönlicher Kontakt zum Kunden hergestellt werden kann und die ZSC-Mitarbeiter (im Call-Center) Ansprechpartner für alle Anliegen sindund in erhöhtem Maße zur Kundenbindung (Kundenbindungsaktionen, Beschwerde-Handling,...) beitragen. Hinzu kommt, dass der Mitarbeiter im Call-Center schnell die Bedürfnisse des Kunden erfragen kann und eine Empfehlung hinsichtlich des passenden Produkts aussprechen kann. Die beratende Tätigkeit steht hier aber im Vordergrund.

\subsubsection{Bargeldlose Bezahlverfahren}

Das bargeldlose Bezahlen stellte als VDV-Stufe 1 im Prinzip den Eingang in die Nutzung des E-Ticketing dar. Zunächst standen die „Bartarifkunden“ im Blickfeld des bargeldlosen Bezahlens; Kunden also, die mit Einzel-, Tages- und Mehrfahrtenkarten unterwegs sind. Diese Fahrgäste machen zwar nur rund ein Drittel der Erträge und ca. 20\% der Fahrten bundesweit aus, doch entfallen auf sie über $80 \%$ aller Verkaufsvorgänge. ${ }^{1370}$ In den 1990er Jahren wurden daher im großen Umfang, auch im RMV gefördert durch das Land Hessen, Fahrscheindrucker in den Bussen sowie Fahrkartenautomaten mit GeldkartenAkzeptoren ausgerüstet. Die Euro-Umstellung im Jahr 2002 führte zu einem weiteren Schub bei der Umrüstung. Die an die Einführung des bargeldlosen Bezahlens geknüpften Erwartungen haben sich bislang allerdings nicht erfüllt. Auch heute besitzt die Geldkarte mit 3\% Anteil an den Bezahltransaktionen und knapp 1\% Anteil am Umsatz am kartengestützten bargeldlosen Zahlungsverkehr nur eine geringe Bedeutung. ${ }^{1371}$ Die enttäuschende Akzeptanz der Geldkarte (vgl. auch Kapitel 7.6.2.3.2) führte ferner dazu, dass etliche Verkehrsunternehmen in der Folge Neuerungen im Zahlungsverkehr zunächst skeptisch gegenüber standen, worunter auch die E-Ticketing-Diskussion litt. Bargeldlose Bezahlver-

1370 vgl. VDV 2001, S.258

1371 vgl. Bretzger und Ebbing 2005, S.9 
fahren werden daher nach wie vor insbesondere im Zeitkartensegment in Form der Kreditkarten- und ec-Kartenbezahlung angeboten sowie speziell für die Abonnementen das Lastschriftverfahren.

Mit der Einführung eines E-Ticketing-Systems und der Etablierung neuer, innovativer Vertriebskanäle, wird das Spektrum bargeldloser Bezahlverfahren deutlich ausgeweitet (vgl. Kapitel 7.2.2). Die Vorteile im Hinblick auf eine Kostenreduzierung ergeben sich unternehmensseitig vor allem aus der Reduzierung des Bargeldvolumens in den lokalen Vertriebsstellen und den damit zusammenhängenden Kosten. Hier sind u.a. die Kosten für die Leerung und Bestückung der Fahrkartenautomaten bzw. Verkaufsstellen zu nennen. „Für die ÖPNV-Unternehmen entsteht durch den Bargeldverkehr sowohl ein großer Bedarf an eigenen Mitarbeitern sowie ein nicht unerheblicher Aufwand für die Beauftragung von Subunternehmen, wie z. B. Werttransporteure“.1372 Des weiteren fallen Gebühren bei der Bargeldanlieferung bei der Kreditwirtschaft an. Ferner sind die Bezahlvorgänge im Fahrzeug sowie das Geldzählen durch das Fahrpersonal am Schichtende zeitaufwendig. Ersteres kann sich zudem negativ auf die Umlaufzeiten und damit die Pünktlichkeit auswirken (siehe Kapitel 7.7.1.2).

Gleichzeitig muss beachtet werden, dass mit der Einführung bargeldloser Bezahlverfahren neue Risiken verbunden sind, die sich ebenfalls monetär auswirken können. Bei den nachträglichen Bezahlerfahren ist hier vor allem das Risiko von Rücklastschriften zu nennen, das im ÖPNV höher ist, als in jeder anderen Branche (siehe Abbildung 42). Dieses ist zwar durch eine vorherige Bonitätsprüfung einzugrenzen, doch müssen die Kosten hierfür vor dem Hintergrund der Wertschöpfung eines einzelnen Kunden abgewogen werden. Die Herausforderung der elektronischen Geschäftsabwicklung bei Bezahlung von niedrigen Beträgen („Micropayment“), wie sie beim Kauf einer Einzelfahrkarte anfallen, stellt sich dagegen eher im Bereich der Transaktionskostenminimierung dar. Die anteiligen Kosten müssen hier deutlich unter den heutigen Aufwendungen pro verkaufter Fahrkarte liegen (vgl. Taballe 9: Vertriebskostenintensität für einzelne Vertriebskanäle).

1372 vgl. Achenbach 2002, S.189f 


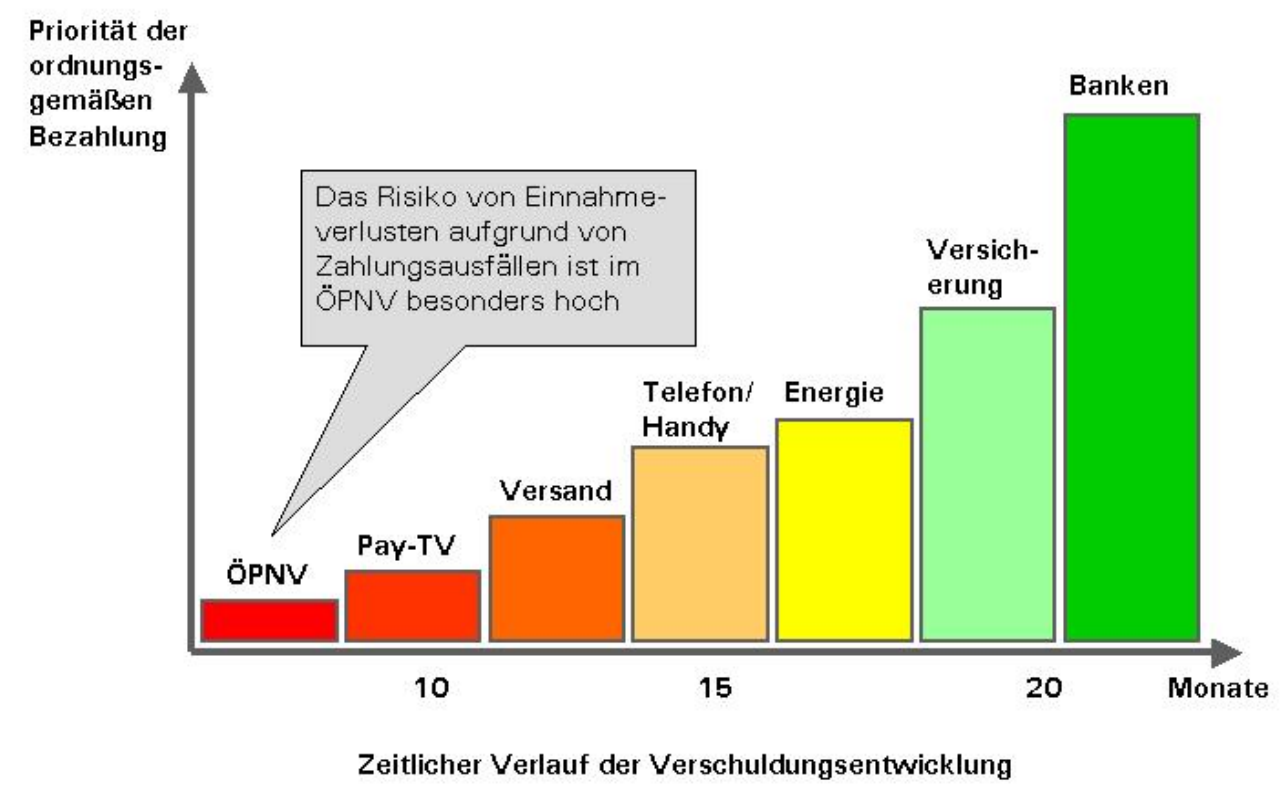

Abbildung 42: $\quad$ Risiko von Zahlungsausfällen in ausgewählten Branchen

Quelle: Infoscore, S.23, eigene Bearbeitung

\subsubsection{Einsatz elektronischer Kundenmedien}

Die Vorteile des Einsatzes langlebiger Kundenmedien im Unterschied zu Papierfahrkarten ergibt sich bereits in der VDV-Stufe 2. Durch die Einführung von Chipkarten werden Kosten für spezielles Sicherheitspapier gespart sowie die Kosten für Druck, Beschaffung und Logistik. ${ }^{1373}$ So benötigt der Kunde nach der Erstausstattung mit einem Kundenmedium nur noch eine elektronische Fahrtberechtigung. Zwar müssen die lokalen Verkaufsstellen nach wie vor mit Medien versorgt werden, doch aufgrund der Wiederverwendbarkeit in einem deutlich reduzierten Umfang (insbesondere nach der Erstausstattung der Kunden mit Trägermedien). Dies kompensiert die höheren Anschaffungskosten für die Chipkarten. ${ }^{1374}$ Durch die flächendeckende Erstausstattung der Kunden mit Trägermedien in Verbindung mit einem elektronischen Vertrieb von Fahrtberechtigungen kann schließlich die Anzahl von Vertriebsstellen reduziert werden. Dieser Vorteil ist insbesondere bei länger genutzten Fahrkartenarten relevant. Außerdem kann bei Jahreskartenkunden auf den periodischen Versand von Wertmarken verzichtet werden, ${ }^{1375}$ was zu

\footnotetext{
1373 vgl. Baumgärtner 2004, S.11

1374 vgl. Achenbach 2002, S.192

1375 vgl. Megger und Vorgang 2000, S.5 sowie Zühlke 2005, S.276
} 
Einsparungen bei den Prozess- bzw. Versandkosten führt. Gleichzeitig ist das Risiko einer Rücklastschrift minimiert, da die Chipkarte bei nicht erfolgter Bezahlung gesperrt und dann bei einer Kontrolle eingezogen werden kann. Gleichzeitig sind die elektronischen Kundenmedien die Voraussetzung für eine effiziente Kontrolle. Dies trifft im Hinblick auf die Beschleunigung des Kontrollprozesses zu, der außerdem mit einer höheren Genauigkeit durchgeführt werden kann.

\subsubsection{Verringerung der Kosten pro Kundenkontakt}

Das Ziel eines umfassenden - elektronischen - Kundenbeziehungsmanagements (siehe Kapitel 6.4.4.4) ist nicht alleine die Verbesserung der Kundenbindung, sondern auch die effiziente Abwicklung der Kundenkontakte. Die heutige Kundenbeziehung ist von sich periodisch wiederholenden Kontakt-, Auftragsgewinnungs- und Kaufprozessen mit der abschließenden Nutzung gekennzeichnet. Zukünftig soll diese Kette um den „Neuauftragsgewinnungsprozess“ erweitert werden, wodurch der teure und aufwendige "Auftragsgewinnungsprozess“ für neue Kunden entfällt (siehe Abbildung 43). ${ }^{1376}$ Denn - wie bereits in Kapitel 7.6.4.3 erwähnt - ist die Gewinnung von Neukunden sieben- bis zehnmal teurer als das Halten bestehender Kunden. ${ }^{1377}$

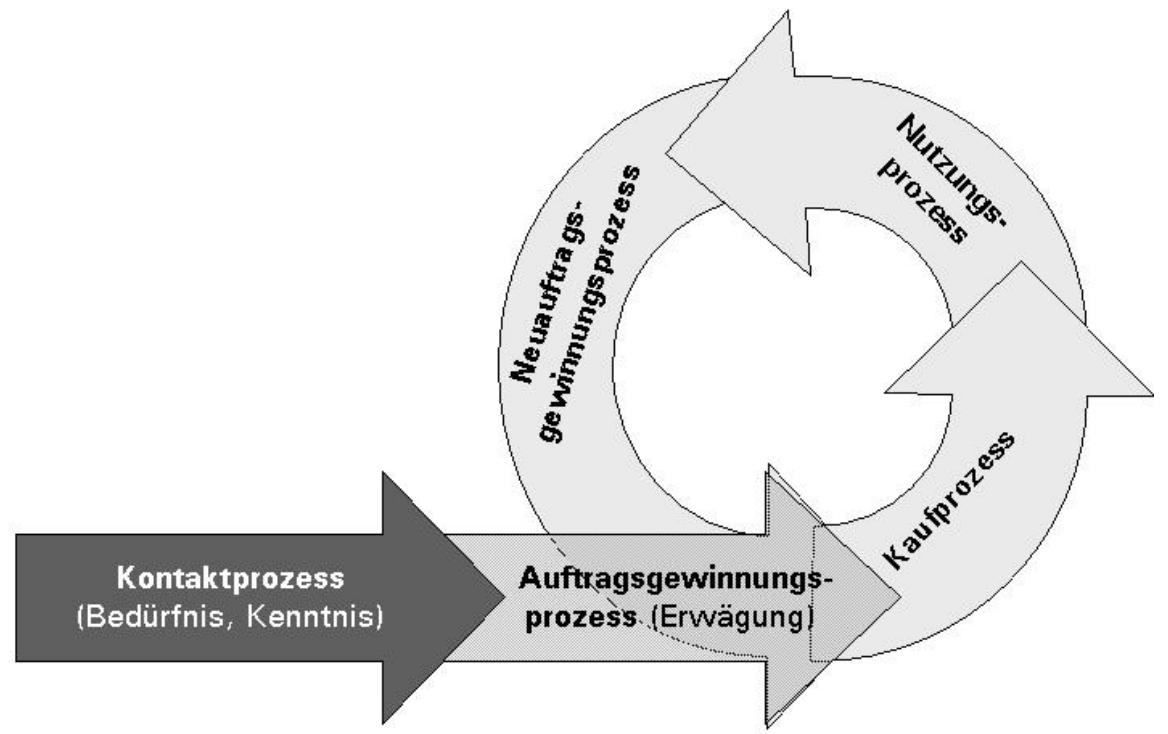

Abbildung 43: Der Kundenbeziehungsprozess im CRM

Quelle: nach Wirtz 2003, S.509, eigene Bearbeitung

1376 vgl. Wirtz 2001, S.508ff

1377 vgl. Schrameyer und Burggraf 2003, S.28 
Voraussetzung hierfür ist die Kenntnis über den Kunden sowie dessen individualisierte und bedürfnisorientierte Ansprache zum richtigen (Kauf-)Zeitpunkt (siehe Kapitel 7.6.4.2), die im Idealfall auch elektronisch erfolgt. Auf diese Weise können nicht nur die Kosten für Akquisition (z.B. Werbung) und Betreuung reduziert werden, sondern über die verbesserte Kundenbindung auch die Transaktionskosten je Kunde deutlich minimiert und in der Konsequenz die Wertschöpfung je Kunde erhöht werden.1378

\subsubsection{Bündelung von Vertriebsprozessen}

Unterschiede in der räumlichen Struktur, im Angebot sowie bei den Unternehmensphilosophien führen zu lokal unterschiedlich ausgeprägten Vertriebsstrategien, im Rahmen derer die Verkehrsunternehmen den Vertrieb in eigener Verantwortung durchführen. In dieser Eigenverantwortung sind sie auch für die Vertriebsprozesse zuständig. Das führt dazu, dass bei jedem Verkehrsunternehmen vom Prinzip her die selben Geschäftsprozesse redundant ablaufen. In einem E-Ticketing-System werden die für den Vertrieb notwendigen Daten und Dienste jedoch zentral und damit nur einmal vorgehalten. Hierdurch kommt es zu einer effizienteren Abbildung der Geschäftsprozesse bzw. werden diese (Vertriebs-)Prozesse teilweise auch neu strukturiert und definiert. ${ }^{1379}$

Neben der technisch-funktionalen Bündelung von Funktionen und Prozessen wird über die organisatorische Zusammenführung - und die kommunikative Vernetzung - eine partnerschaftliche Vermarktung ermöglicht, im Rahmen derer weitere organisatorische Prozesse verschlankt werden können. Durch die Mandantenfähigkeit des Hintergrundsystems ist dabei gewährleistet, dass unternehmensinterne bzw. unternehmenszugehörige Daten nur dem jeweils berechtigten Unternehmen zur Verfügung stehen.

Die Bündelung von Prozesse umfasst insbesondere alle Geschäftsprozesse zur Aufnahme, Pflege und Bereitstellung von Kundenstammdaten, die im übrigen auch für das Beschwerde- und Änderungsmanagement notwendig sind. Die sich hieraus ergebenden qualitätssteigernden Effekte in bezug auf die Kundenbetreuung sind in Kapitel 7.6.1.2 dargestellt. Außerdem können sämtliche Abrechnungs-, Mahn- und Inkassoprozesse zusammengeführt werden. Des weiteren werden über das zentrale Bestellmanagement die logistischen Prozesse bei der Bestellung, Verteilung, Einzug und Vernichtung von Trä-

1378 vgl. Wirtz 2003, S.523 sowie Zühlke 2005, S.276

${ }^{1379}$ vgl. Achenbach 2002, S.188f 
germedien an zentraler Stelle zusammengeführt. Darüber hinaus werden durch den Einsatz von selbstbedienten Kommunikations- und Vertriebskanälen Prozesse automatisiert bzw. auf den Kunden verlagert. Dies führt zur „Verringerung des technischen, administrativen und personellen Aufwands an Verkaufsschaltern“. 1380

Durch die gemeinsame Nutzung der über die E-Ticketing-Plattform bereitgestellten Dienste und Daten, sowie der kommunikativen Vernetzung, ergibt sich somit eine engere organisatorische Zusammenarbeit, die zur effizienteren Abwicklung der Geschäftsprozesse insgesamt genutzt werden kann. Dies ist nicht nur für den gesamten Marketingbereich erstrebenswert, sondern auch für die Abbildung der Geschäftsprozesse im sonstigen Betriebsablauf.

\subsubsection{Optimierung des Vertriebskanalmixes}

Der heutige Vertriebskanalmix im RMV wird durch den Automatenvertrieb, den Verkauf über das Fahrpersonal sowie den personalbedienten Verkauf bestimmt. Wie in Kapitel 6.3.4 dargestellt, gehören diese drei Vertriebsarten zu den kostenintensivsten Vertriebskanälen überhaupt. Um mögliche Einsparungen gegenüber der heutigen Situation zu erzielen, ist daher die Verlagerung von Vertriebsvorgängen auf kostengünstigere Kanäle notwendig. Hierbei darf es allerdings nicht zu einer Erhöhung der Transaktionskosten auf Nachfragerseite kommen, da sich dies nachteilig auf die Einnahmen auswirkt. ${ }^{1381}$

Das Ziel der Nutzung der „neuen“ Vertriebskanäle Internet, Mobilfunkgerät und Zentrales Service Center ist langfristig gesehen die Reduzierung der Vertriebskosten durch den Rückbau der kostenintensiven Vertriebskanäle. In einem Einführungszeitraum wird es allerdings durch das parallele Vorhalten neuer und konventioneller Vertriebskanäle zu einer Vertriebsdiversifizierung kommen, die insgesamt betrachtet die Vertriebskosten erhöht. Dies ist jedoch legitim, wenn hierdurch die Transaktionskosten auf Kundenseite sinken. ${ }^{1382}$ Der "optimale Vertriebskanalmix“ beschreibt daher einen Zustand, bei dem der Vertriebsaufwand auf Unternehmensseite zu den Transaktionskosten auf Nachfragerseite - und damit der Nachfrage selbst - am günstigsten ist. „Günstig“ bedeutet hierbei also ein Zusammenspiel einheitlicher und überschaubarer Strukturen, Aufwandsreduzierung durch Zentralität, lokale Marktausschöpfung und Kundennähe durch dezentrale

\footnotetext{
1380 Achenbach 2002, S.189

1381 vgl. Rumpke 2005, S.107

1382 ebd., S.108
} 
Präsenz. Die Erreichung dieses idealen Zustandes sollte prinzipiell das Ziel der Vertriebskanalentwicklung sein.

Ein E-Ticketing-System kann diese Entwicklung maßgeblich und positiv beeinflussen. Hier ist zunächst einmal die Bereitstellung der technischen Grundlagen zu nennen, denn der Aufbau einer zentralen Informations- und Vertriebsplattform, über die elektronische Tickets vertrieben werden können, ist die notwendige Voraussetzung der Nutzung moderner Vertriebsformen wie Internet, Mobilfunkgerät und Zentrales Service Center. Sie bilden die Grundlage für die Bündelung und/ oder die Verlagerung von Vertriebsprozessen (siehe Kapitel 7.7.2.5).

Im Rahmen innovativer Tarifkonzepte bzw. der Einführung eines elektronischen Tarifs (siehe Kapitel 7.6.3.2) können zudem die Vertriebskanäle unterschiedlich bepreist werden und damit steuernd in die Vertriebskanalwahl des Kunden eingegriffen werden. Unterschiedliche Preise lassen sich in der Kundenkommunikation dadurch rechtfertigen, dass Vertriebskosteneinsparungen an die Nutzer weitergegeben werden. Ein Instrument der Vertriebskanalsteuerung ist auch das Kundenbindungs- oder Bonusprogramms (siehe Kapitel 7.6.4.3), über das Anreize vermittelt werden, beispielsweise kundenbediente und kostengünstigere Vertriebskanäle zu nutzen. In diesem Zusammenhang spielt auch die direkte Kundenkommunikation (siehe Kapitel 7.6.4.2) eine Rolle, über die entsprechende Angebote und damit zusammenhängende Vorteile dem Kunden überhaupt erst vermittelt werden können.

\subsubsection{Tarif}

\subsubsection{Marktgerechte Tarifanpassungen}

In Kapitel 7.6.3.2 wurde bereits die Möglichkeit der Entwicklung und Nutzung innovativer Tarifkonzepte auf Basis eines E-Ticketing-Systems thematisiert. Merkmal und Voraussetzung dieser Tarifinnovation ist die Möglichkeit, Änderungen im Tarifsystem verbundweit einzuspielen und - für den Fall, dass sich Tarifanpassungen als kontraproduktiv erweisen - vom Markt zurückzunehmen. Selbst wenn letzteres eine unpopuläre Maßnahme darstellt, so hat doch das Beispiel des vom Markt genommenen bzw. stark überarbeiteten Deutsche-Bahn-Tarifs „PEP“ im Jahre 2003 und den hierdurch verursachten Ein- 
nahmerückgang die Tragweite einer tariflichen Fehlentscheidung deutlich vor Augen geführt. 1383

Bislang gibt es im RMV einmal im Jahr einen „Fahrplan- und Tarifwechsel“. Dieses ist ein Stichtag, an dem Änderungen im Fahrplan und im Tarif ihre Gültigkeit erhalten und alle Tarifinformationen in den Vertriebsstellen und Verkaufsgeräten, respektive in den Fahrscheindruckern, vorliegen müssen. Dieses ist ein vergleichsweise aufwendiger organisatorischer Prozess, der zeitgleich an den unterschiedlichen Verkaufsgeräten durchgeführt werden muss. Da die Einspielung der neuen Tarifdaten außerdem vor Ort bei den Verkehrsunternehmen manuell angestoßen werden muss, besteht ein gewisses Fehlerrisiko. Gleichzeitig werden neue Fahrpläne und Tarifauskünfte veröffentlicht, die dann ab Stichtag für ein weiteres Jahr - bis zum nächsten Fahrplan- und Tarifwechsel - gültig sind.

Über die online-Anbindung der Verkaufssysteme in einem E-Ticketing-System lassen sich die Tarifanpassungen in einem viel kürzeren Zeitraum und automatisiert sowie zentral angestoßen durchführen. Je mehr Vertriebskanäle angeschlossen sind, desto höher ist der Effizienzgrad bei den Anpassungen bzw. wird der Aufwand verringert sowie das Fehlerrisiko beim Einspielen neuer Tarifdaten reduziert. Damit eröffnet sich zugleich die Möglichkeit Tarifanpassungen nach Bedarf einzuspielen und nicht nur zu einem einzigen Datum im Jahr. So können Anlässe für eine Tarifänderung viel schneller im System - und damit marktgerecht - umgesetzt werden.

\subsubsection{Transparente Erlöszuordnung}

Die aus dem E-Ticketing-System generierten Daten (transparente Leistungs- und Verkaufsdaten) können als Grundlage für eine tragfähige verkehrsleistungs- und qualitätsabhängige Einnahmeaufteilung im RMV herangezogen werden. ${ }^{1384}$ Dies setzt allerdings die Vergabe von Konzessionen im Rahmen von Bruttoanreizverträgen voraus bzw. die Anwendung von Bonus-Malus-Regelungen. Auf Basis dieser Daten könnte auch die Einhaltung von Qualitätslevels nachvollzogen werden, die u.a. die Grundlage von Mobilitätsgarantien sind. Derartige Garantien könnten sich für die Positionierung der Verkehrsunter-

${ }^{1383}$ Noch 2001 ging der Vorstand der Deutschen Bahn AG von einer durch die Tarifreform begünstigten Fernverkehrsleistung von knapp 40 Mrd. Personenkilometern (Pkm) im Jahre 2003 aus. Letztlich wurden es nur gut $31 \mathrm{Mrd}$. Pkm. Nach aktueller Planung wird das Niveau aus dem Jahre 1994 erst wieder 2007/2008 erreicht; vgl. BDI und DIHK 2006, S.89.

1384 vgl. Wissenschaftlicher Beirat beim Bundesminister für Verkehr, Bau- und Wohnungswesen 2003, S.603 
nehmen als Mobilitätsdienstleister zukünftig als besonders wichtig herausstellen und von den Kunden besonders aufmerksam verfolgt werden.

Durch eine linienbezogene Erlösermittlung können die Aufgabenträger des ÖPNV im Wege der wettbewerbsfreien Direktvergabe oder der wettbewerblichen Ausschreibung die Erfüllung der Dienstleistungskonzessionen und den wirtschaftlichen Erfolg besser nachvollziehen. Außerdem wird erstmals eine reale und leistungsgerechte Einnahmenaufteilung der Fahrgeldeinnahmen möglich. Durch die höhere betriebswirtschaftliche Transparenz werden im Rahmen einer wettbewerblichen Bestellung auch die Marktzutrittsmöglichkeiten von neuen Verkehrsunternehmen („,newcomer“) erhöht, welches zu sinkenden Bestellerkosten der Aufgabenträger führen kann.

\subsubsection{Kommunikation}

\subsubsection{Optimierung der Kundeninformation}

In dem Maße, wie die in Anspruch genommene Transportleistung (in einem System der Automatisierten Fahrpreisfindung) leistungsbasiert und genau abgerechnet wird, wird eine vorab getätigte und verlässliche Aussage über den entstehenden Fahrpreis schwierig, insbesondere dann, wenn die Leistung über einen längeren Zeitraum erfasst wird. Dennoch möchte der Kunde wissen, mit welchen Kosten er kalkulieren muss bzw. möchte er die Sicherheit haben, dass ein bestimmtes Kostenniveau nicht überschritten wird (also die Kosten nicht höher als der Nutzen sind). Spätestens mit der Einführung eines leistungsabhängigen innovativen Tarifkonzepts (siehe Kapitel 7.6.3.2) wird deutlich, dass die konventionelle Tarifmatrix, die nach Preisstufen differenziert, die Kundenerwartungen nicht mehr erfüllen kann. Allenfalls können dann noch Basis- oder Einstiegspreise sowie Entfernungspreise (bspw. pro Kilometer) kommuniziert werden, die eine kundenseitige Abschätzung ermöglichen. ${ }^{1385}$ Ein individualisierter Tarif bedarf daher auch einer individualisierten Tarifauskunft. Und diese wird, genau wie der innovative Tarif auch, nicht ohne die Zuhilfenahme elektronischer Medien möglich sein.

Die verstärkte Einbindung von internetbasierten (online-)Auskunftssystemen in einem ETicketing-System bietet einen geeigneten Ansatz, dem Informationsbedarf zum Tarif -

${ }^{1385}$ Dieses Prinzip kennen die Kunden von Telekommunikation, wo leistungsbasiert minuten- oder sekundengenau abgerechnet wird und die Einheiten feste Preise haben. 
aber auch generell, beispielsweise zu Fahrplaninformationen (siehe Kapitel 7.6.4.4) - individualisiert zur Verfügung zu stellen. Die notwendige Basis für die Tarifauskunft ist im Hintergrundsystem in einem Kundenkonto abgelegt (z.B. Kundenstatus, Rabattmodell). Ähnlich wie bei Telekommunikationsanbietern kann der Kunde auf das Hintergrundsystem als Mandant zugreifen, um beispielsweise seine Rechnung online einzusehen. Wird diese Rechnung konform der Fahrtenhistorie gepflegt, besteht die Möglichkeit den aktuellen Stand abzufragen. Denkbar sind in diesem Zusammenhang auch "push-Dienste", die den (anonymen) Kunden informieren, wenn sein Konto (etwa ein vorausbezahltes prepaid-Konto) einen bestimmten Betrag überschritten hat.

In dem Maße, wie diese internetbasierten Informationsdienste angeboten und genutzt werden, kann auf die Herstellung und den Vertrieb von Printmedien zur Fahrplan- und Tarifauskunft verzichtet werden.

\subsubsection{Effizienter Werbemitteleinsatz und gemeinsamer Marktauftritt}

"Nicht selten ist, das was übrig bleibt' oder, das was man glaubt sich leisten zu können' der wahre Maßstab für die Budgets der Verkehrsunternehmen, die für Kommunikation eingesetzt werden. Denn die optimale Höhe eines Werbebudgets kann von vorne herein nicht bewiesen werden - also, so viele Verkehrsunternehmen, kann es auch ruhig niedriger sein". 1386

Diese Einschätzung Mager und Raifs kann dazu führen, dass Werbung im ÖPNV nur als Kostenfaktor wahrgenommen wird und aufgrund fehlender Planung und letztendlicher Ineffektivität auch tatsächlich zu einem wirkungslosen Rechnungsposten wird. Die höchste Effektivität wird dagegen erzielt, wenn Werbeinhalte einfach und verständlich kommuniziert und immer wieder - am besten auf unterschiedlichen Wegen - wiederholt werden. Nur so wird sichergestellt, dass der Kunde nicht nur die Botschaft realisiert, sondern diese auch verinnerlicht und eine Verhaltensreaktion ausgelöst wird (z.B. Informationsbeschaffung über Prospektanforderung und schließlich Nutzung eines Produktes). Wie bereits in Kapitel 7.6.4.5 geschildert, ergeben sich aus einer partnerschaftlichen und verbundweit einheitlichen Werbestrategie die größten Erfolgsaussichten. Diese schlagen sich nicht nur auf der Einnahmenseite nieder, sondern führen auch dazu, dass die Mittel effizient eingesetzt werden.

1386 Mager und Raif 2004, S.33 
Wichtige Voraussetzung für einen effizienten Werbemitteleinsatz ist eine verbundweit zwischen allen Partnern abgestimmte Marketingstrategie, die Inhalte (z.B. Botschaften, relevante Produkte) und Ziele (z.B. Information, Markteinführung) von Werbemaßnahmen definiert. Die Umsetzung kann dann beispielsweise entlang eines Mediaplanes erfolgen. Richten sich die Maßnahmen an bekannte Kunden, können ausgehend vom Kampagnenmanagementsystem die Zielgruppe(n), Zielgebiet(e) und Kommunikationskanäle ausgewählt werden, über die die Kunden angesprochen werden sollen.

Die neuen Kommunikations- und Vertriebskanäle, die im Rahmen von E-Ticketing erschlossen werden, bieten aufgrund ihrer zentralen Verwaltungsstruktur eine gute Möglichkeit einen gemeinsamen Marktauftritt zu etablieren. Als Beispiel sei hier ein einheitlicher Internetauftritt erwähnt, bei dem sich alle Verkehrsunternehmen in einem (ÖPNV-) Mobilitätsportal wiederfinden und ihre aufeinander abgestimmten Leistungen auch abgestimmt vermarkten. Somit würde der „Verbundeffekt Ein Tarif-Eine Fahrkarte - Ein Fahrplan als Integrationsleistung für fünf Millionen Menschen in der Region Frankfurt RheinMain“1387, der zum RMV-Start 1995 realisiert wurde, um weitere wichtige Komponenten erweitert: „Ein Ansprechpartner - Ein Marktauftritt“:

Die Kommunikationsstrategie und die Gestaltungsrichtlinien des RMV geben den lokalen Nahverkehrsorganisationen den konzeptionellen Rahmen für ihre (Werbe-) Kampagnen vor.

\subsection{Datenschutzrechtliche Einschätzung}

Grundlage aller datenschutzrechtlichen Einschätzungen ist die Tatsache, dass erst bei einer Zuordnung zu einer Person oder Personengruppe der Datenschutz relevant wird. Nach Experteneinschätzung sind sämtliche Varianten der RFID-Technologie durch das geltende Datenschutzrecht erfasst. Innerhalb der Datenschutzgesetze (Bundesdatenschutzgesetz, Telekommunikationsgesetz, EU-Richtlinien) bestehen damit keine Gesetzeslücken im Hinblick auf bestimmte Ausprägungen der Technologie (z.B. RFID-tags, Speicherkarten, Prozessorkarten, NFC etc.). So gelten für das E-Ticketing die gleichen Anforderungen hinsichtlich Datenhaltung und -verarbeitung für die Telekommunikationsbranche. Darüber hinaus kam es im Rahmen der Erarbeitung der VDV-Kernapplikation au-

1387 Lunkenheimer 2005, S.679 
ßerdem zu einer begleitenden Empfehlung von Datenschutzbeauftragten unterschiedlicher Bundesländer zum Umgang mit Daten aus einem E-Ticketing-System. ${ }^{1388}$

Aufgrund des beträchtlichen Umfangs von individuellen Leistungsdaten und deren kontaktloser Erfassung, sowie der Verarbeitung von persönlichen Daten zum Zwecke der Abrechnung und der Kommunikation, darf das Thema Datenschutz allerdings in der AuBenwirkung nicht unterschätzt werden. Zumal in der Öffentlichkeit der Datenschutz zumeist als etwas wahrgenommen wird, was allem Anschein nach häufig keine Beachtung findet. Das Unabhängige Landeszentrum für Datenschutz Schleswig-Holstein verweist darauf, dass das „selbstbewusste Einfordern von Datenschutzstandards durch die Kunden [...] zum Lifestyle der Zukunft [gehört]“. ${ }^{1389}$

Das Datenschutzkonzept in einem E-Ticketing-System sollte daher darauf ausgerichtet sein, Kundenvorteile zu generieren. Der Datenschutz soll sich von einem vermeintlichen Wettbewerbsnachteil zu einem Wettbewerbsvorteil entwickeln, zumal davon auszugehen ist, dass die allgemeine Relevanz von Datenschutz zunimmt. Datenschutz muss zu einer selbstverständlichen Leistung in einer serviceorientierten Dienstleistungsgesellschaft werden und darf nicht länger etwas behördlich Verordnetes sein.1390 In einem ETicketing-System muss daher klar und transparent kommuniziert werden, welche personenbezogenen Daten erhoben und (automatisch) verarbeitet werden, wo und wie lange diese Daten gespeichert werden, zu welchem Zweck die Daten verwendet werden, wer Zugriff auf diese Daten hat, ob ausreichende Sicherheitsmechanismen bei Datenübertragungen gewährleistet sind und welches organisatorische Konzept hinter der Datenschutzkontrolle steht. Darüber hinaus ist auch ein Mindestmaß an technischer Aufklärung relevant, um insbesondere Bedenken gegenüber der Art und Weise der Leistungserfassung auszuräumen. Gerade im Rahmen der Verwendung von kontaktlosen Schnittstellen ist es aus Kundensicht wichtig, den RFID-Chip ggf. deaktivieren zu können. In einer „Gemeinsamen Stellungnahme zu der Entschließung der 72. Konferenz der Datenschutzbeauftragten des Bundes und der Länder" wird daher gefordert, dass die Möglichkeit bestehen muss, den RFID-tag „dauerhaft zu aktivieren bzw. die darauf enthaltenen Daten

\footnotetext{
1388 vgl. Ordon 2004, S.27

1389 Unabhängiges Landeszentrum für Datenschutz Schleswig-Holstein, Pressemitteilung v. 20.2.2002

1390 vgl. Unabhängiges Landeszentrum für Datenschutz Schleswig-Holstein, Pressemitteilung v. 20.2.2002
} 
dauerhaft zu löschen, insbesondere dann, wenn Daten für die Zwecke nicht mehr erforderlich sind, für die sie auf dem RFID-tag gespeichert wurden“. ${ }^{1391}$

Da der RFID-Chip in einem E-Ticketing-System vor allem einen sicheren Datenaustausch garantiert und die Chipkarte selbst der Erfassung der in Anspruch genommenen Beförderungsleistung dient, bei der eine Verknüpfung mit personenbezogenen Daten erst im Hintergrundsystem geschieht, müssen sich keine personenbezogenen Daten auf dem Chip befinden. Sollten bestimmte personengebundene Produkte eine Personalisierung, d.h. ein nicht übertragbares Sicherheitsmerkmal erfordern, könnte beispielsweise der Name oder ein Foto auf die Chipkarte aufgedruckt werden, die i.d.R. nicht elektronisch kontrolliert werden können.

${ }^{1391}$ Informationsforum RFID u.a. 2006, S.6 


\subsection{Zusammenfassung}

Im Rahmen einer fachlichen Themenabgrenzung wird in Kapitel 1 zunächst beschrieben, welche disziplinären Gemeinsamkeiten es zwischen der Wirtschaftsgeographie und den Wirtschaftswissenschaften gibt, um raumwirtschaftliche Fragestellungen im Verkehrsbereich zu erörtern. Es werden die unterschiedlichen Aufgabengebiete verkehrsbezogener Disziplinen vorgestellt, die letztlich auch die Verkehrsgeographie als eigene Disziplin rechtfertigen. Der Verkehrsplanung kommt hierbei eine Schnittstellenfunktion zu.

Ausgehend von einer erläuternden Fußnote zum Hess. ÖPNVG wird in Kapitel 2 die Notwendigkeit für Veränderungsprozesse im ÖPNV dargestellt, die insbesondere die Vermarktung der ÖPNV-Leistung betreffen. Damit dem Kunden bereits an der „Benutzeroberfläche“ ein homogenes Bild des ÖPNV präsentiert wird, sind allerdings organisatorische Anpassungen notwendig, die sowohl betriebliche Abläufe berühren wie auch die Kooperation der ÖPNV-Akteure untereinander. Diese Veränderungen sind die notwendige Voraussetzung dafür, dass der ÖPNV wirtschaftlich effizienter wird. Dieser Herausforderung müssen sich die ÖPNV-Akteure stellen, soll auch zukünftig ein qualitativ hochwertiges ÖPNV-Angebot bereitgestellt werden, welches die Grundlage für eine Steigerung der Verkehrsanteile in einem integrierten Gesamtverkehrskonzept zur nachhaltigen Mobilitätssicherung darstellt.

Kapitel 3 behandelt den Einfluss verkehrsrelevanter Standortfaktoren auf die Regionalentwicklung und beschreibt, welche Bedeutung die Mobilität für die nachhaltige Regionalentwicklung hat. Die Grundlage für eine vollständige und flexible Mobilität bildet ein qualitativ hochwertiges Verkehrsangebot und eine leistungsfähige und moderne Verkehrsinfrastruktur. Sie stellen die "harten“, verkehrsbezogenen Standortfaktoren einer Region dar. Darüber gibt es zahlreiche weitere Standortfaktoren, deren Qualität wesentlich von der verkehrlichen Erreichbarkeit beeinflusst wird bzw. deren Erreichbarkeit mitbestimmend für die Beurteilung der regionalen Mobilität ist. Der ÖPNV trägt seinerseits maßgeblich zur Erreichbarkeit von Orten des Wirtschafts- und Alltagslebens bei und da- 
mit zur Stärkung einzelner Standortfaktoren bzw. kann der ÖPNV selbst über den Zweck der Sicherstellung der Mobilität als Standortfaktor gelten. Insbesondere vor dem Hintergrund einer weiterhin wachsenden Verkehrsnachfrage können über eine Stärkung des Standortfaktors „ÖPNV“ andere mobilitätsabhängige Standortfaktoren gestärkt werden. In seiner Funktion als Standortfaktor wurde der ÖPNV bei der Vermarktung einer Region im bundesweiten und internationalen Wettbewerb bislang nicht gebührend beachtet. In den verkehrspolitischen Leitbildern besitzt der ÖPNV dagegen einen hohen Stellenwert. Seit der UN-Konferenz 1992 in Rio, spätestens aber seit der allgemeinen Thematisierung des Klimawandels, werden nachhaltige Mobilität und damit einhergehend ein hoher ÖPNV-Anteil am Modal Split in den Leitbildern durchgängig eingefordert. Ein charakteristisches Merkmal dieser Leitbilder ist die Herbeiführung einer "Verkehrswende“, bei der es zu einer dauerhaften Veränderung des Verkehrsmittelwahlverhaltens kommen soll und zu einer Entkopplung von Verkehrs- und Wirtschaftswachstum.

Obwohl der Begriff der „nachhaltigen Mobilität“ mittlerweile in der Verkehrsbranche weithin Verwendung findet, lässt der Kontext der Verwendung eher einen unverbindlichen Gebrauch vermuten. Offenkundig ist alleine, dass die mit der nachhaltigen Mobilität verbundene „Verkehrswende“ bis heute nicht eingetreten ist. Auch restriktive steuerliche und verkehrspolitische Maßnahmen führten bislang zu keinem nachhaltigen Erfolg. Vor dem Hintergrund des gesellschaftlichen Wandels und der negativen Umweltauswirkungen des Verkehrs wird daher die erlebbare und vermarktungsfähige Entwicklung von „echten“ Mobilitätsdienstleitungen zur Unterstützung von Veränderungen im Verkehrsverhalten immer dringlicher. Dies gilt insbesondere für den ÖPNV mit seinen starren Angebotsformen, soll er in Zukunft eine Alternative zum MIV darstellen und zur nachhaltigen Mobilitätssicherung beisteuern. Denn weder die alleinige Bereitstellung einer leistungsfähigen Verkehrsinfrastruktur noch die Vorhaltung eines Grundangebots im ÖPNV wird dem Leitbild einer nachhaltigen Mobilität vor dem Hintergrund der Ressourcenknappheit und des Ressourcenverzehrs gerecht. Vielmehr bedarf es integrativer Strategien der Mobilitätsplanung, die die gesellschaftlichen Veränderungen berücksichtigen. Nur so wird der Verkehr - mit all seinen positiven Einflüssen und negativen Auswirkungen - in sinnvolle Bahnen gelenkt werden können. Informations- und Kommunikationstechnologien können hier einen entscheidenden Beitrag liefern, der wachsenden Bedeutung von Information und Wissen bei der Angebotsentwicklung und -vermarktung zu 
entsprechen und gleichzeitig die Kommunikation und Kooperation zwischen den Anbietern $\mathrm{zu}$ intensivieren.

In Kapitel 4 wird zunächst die Region Frankfurt Rhein-Main in ihren naturräumlichen und administrativen Grenzen vorgestellt, aus deren unterschiedlichen Zuschnitten sich teils überlappende sowie parallele räumliche Verantwortlichkeiten ergeben. Aus der Darstellung der nationalen und internationalen Wettbewerbssituation wird deutlich, dass die regionale Wirtschaftskraft, als Determinante für Entwicklung und Wohlstand, in der Rhein-Main-Region nach wie vor auf einem sehr hohen Niveau ist. Die leistungsfähige Verkehrsinfrastruktur und das gute Verkehrsangebot tragen hierzu wesentlich bei. Der gesamte Mobilitätsbereich hat sich in der Vergangenheit sehr dynamisch entwickelt und wird auch in näherer Zukunft - vor allem im Ballungsraum - von einer starken Verkehrsnachfrage geprägt sein. Bislang wurde das stetig wachsende Verkehrsaufkommen allerdings fast ausschließlich vom MIV getragen. Der ÖPNV konnte hingegen vom Verkehrswachstum nicht im vergleichbaren Maße „profitieren“. Da die Wachstumsraten des Straßenverkehrs erheblich über den Kapazitätsausweitungen der Verkehrsinfrastruktur liegen, werden insbesondere die Hauptverkehrsstraßen rund um die Kernstadt Frankfurt am Main stellen- und zeitweise weit über die Kapazitätsgrenzen hinaus belastet. Gleichzeitig bestehen nur noch beschränkte finanzielle und räumliche Erweiterungsreserven.

Um die negativen Folgen des Gesamtverkehrsaufkommens für Umwelt, Menschen und Wirtschaft abzuwenden - und die Mobilität in der Region nachhaltig zu sichern - sind daher intensive Bemühungen auf lokaler und regionaler Ebene notwendig, für die die ordnungspolitischen Vorgaben der EU und der Bundesregierung einen allgemeinen Rahmen vorgeben. Die hessische Landesregierung setzt langfristig auf Verkehrsvermeidung und Verkehrsverlagerung von Fahrten des MIV auf umweltfreundliche Verkehrsträger. Kurz- und mittelfristig konzentrieren sich die Aktivitäten auf die Bereiche Verkehrsinfrastruktur und Verkehrsmanagement. Im Bereich Verkehrsinfrastruktur handelt es sich zunehmend um bestandserhaltende Maßnahmen, im Bereich des Verkehrsmanagements sind es hauptsächlich technisch-betriebliche Maßnahmen zur Verbesserung des Verkehrsflusses auf den Hauptverkehrsstraßen. Die größte Aufmerksamkeit erfahren dabei zur Zeit Telematikanwendungen, deren Einsatz in einer von der hessischen Landesregierung angestoßenen Initiative „Staufreies Hessen 2015“ zusammengefasst sind. Der Beitrag dieser stark technik-getriebenen Anwendungen zur nachhaltigen Mobilitätssiche- 
rung wird jedoch aufgrund ihrer eindimensionalen Ausrichtung auf den MIV und fehlender verkehrsträgerübergreifender Konzepte in Frage gestellt.

Die hessische Landesregierung sieht abseits der Aktivitäten zur Initiative „Staufreies Hessen 2015“ zwei Handlungsschwerpunkte, in denen es intensiver Anstrengungen zur nachhaltigen Mobilitätssicherung bedarf: Die Entwicklung eines integrierten Gesamtverkehrskonzeptes, im Rahmen dessen die spezifischen Stärken der einzelnen Verkehrsträger besser zur Geltung kommen sollen, und die Stärkung des ÖPNV, bei dem nicht genutzte Effizienzpotenziale erst noch zu entfalten sind.

In Kapitel 5 werden die rechtlich-organisatorischen Rahmenbedingungen für Veränderungsprozesse im ÖPNV in Hessen dargestellt. Einen maßgeblichen Einfluss auf die administrativen Strukturen haben die wirtschaftspolitischen Vorgaben der EU-Kommission zur Verwirklichung eines einheitlichen europäischen Binnenmarktes, in dessen Folge der bislang stark regulierte und monopolistische ÖPNV-Markt für Wettbewerb und Konkurrenz geöffnet werden soll. Diese Vorgaben finden ihre Ausprägung auch im Hess. ÖPNVG und in der damit verbundenen Aufgabentrennung nach dem Besteller-ErstellerPrinzip. Aus der daraus resultierenden Praxis der wettbewerblichen Ausschreibung von Verkehrsleistungen ergibt sich für die ÖPNV-Akteure die Notwendigkeit der Neuausrichtung. Die konsequente Umsetzung der EU-Vorgaben in Hessen eröffnet gleichzeitig Möglichkeiten, die etablierten Strukturen im ÖPNV aufzulösen. So soll die Bevorzugung kommunaler Eigenbetriebe, die zu Wettbewerbsverzerrungen bei der Vergabe von Verkehrsleistungen führt, nur noch in besonderen Fällen möglich sein. Damit kann das Instrument der Ausschreibung zur Qualitätsverbesserung und Effizienzsteigerung im ÖPNV beitragen.

Insbesondere die angespannte finanzielle Situation der öffentlichen Hand stellt eine große Herausforderung bei der Lösung von verkehrsbezogenen Problemen dar. Aus der Tendenz, dass immer weniger Mittel für den ÖPNV bereitgestellt werden können, erwächst die Notwendigkeit, dass der ÖPNV in Zukunft wirtschaftlich effizienter werden muss, wenn dieser im Rahmen einer integrativen Gesamtlösung eine einflussreiche Größe darstellen soll. Anderenfalls besteht die Gefahr, dass das ÖPNV-Verkehrsangebot in Qualität und Umfang reduziert werden muss, was letztlich dem Ziel widerspricht, die Mobilität in der Region zu stärken. Im Rahmen der - beabsichtigten - Effizienzsteigerung spielt vor 
allen das Thema der „Nutzerfinanzierung“, also die Erhöhung der Fahrgeldeinnahmen, eine große Rolle. Dies setzt gleichzeitig eine größere Marktnähe und Kundenorientierung der ÖPNV-Unternehmen voraus, die über die Positionierung als „Mobilitätsdienstleister“ zwar in den Markt transportiert wird, aber letztlich mit konkreten und wirkungsvollen Maßnahmen zu untermauern ist.

Kapitel 6 stellt die unterschiedlichen organisatorischen und marketingseitigen Möglichkeiten der Effizienzsteigerung im ÖPNV dar und betrachtet das technische Innovationspotenzial im ÖPNV. Zunächst werden die branchenspezifischen Merkmale des ÖPNV beschrieben, denen ein Einfluss auf das betriebswirtschaftliche Ergebnis zugeschrieben wird. Es wird dargestellt, dass es im Rahmen einer umfassenden und nachhaltigen Effizienzsteigerung nicht nur um Optimierungen im produktiven Bereich gehen kann. Vielmehr bedarf es der Verbesserung der Nachfragegestaltung und der Qualität des Angebots sowie des Einsatzes von Innovationen - also des Einsatzes aller Hebel zur Erschließung ertrags- und aufwandsseitiger Potenziale.

Die veränderten ordnungspolitischen Rahmenbedingungen und der Wandel des Verkehrsmarktes stellen die ÖPNV-Akteure vor neue betriebliche Herausforderungen, die weit über die angestammte Kernkompetenz der Bereitstellung von Verkehrsleistung hinausreichen. Um diesen Herausforderungen begegnen zu können, bedarf es einer stärkeren betriebswirtschaftlichen Orientierung und der Generierung neuer Wertschöpfungsfelder. Hierfür sind neue fachliche, organisatorische und betriebliche Kompetenzen notwendig, über die neues Kapital erschlossen, Innovationen genutzt und die eigene Reputation gestärkt werden können. Im Sinne der Einbindung der „Stakeholder“ geht es nicht nur um die Beachtung der behördlichen Zuwendungsgeber, sondern auch um die Motivation der eigenen Mitarbeiter, denen eine tragende Funktion in der Dienstleistungsorientierung gegenüber den Kunden zukommt. Die Fokussierung auf die Kundenwünsche soll schließlich zu einer verbesserten Nutzerfinanzierung führen.

Unternehmensseitig schlägt sich die beabsichtigte verbesserte Nutzerfinanzierung in einer unternehmensstrategischen Kundenorientierung nieder, die über die Positionierung als „Mobilitätsdienstleister" transportiert wird, auf unternehmensinterner organisatorischer Ebene aber auch entsprechend umgesetzt werden muss. Nach außen messbar wird der Grad an Kundenorientierung an der Erfüllung der Kundenerwartungen. Die Grundlagen 
hierfür sind die Beherrschung des Kerngeschäfts und die Erfüllung der allgemeinen Kundenerwartungen an Produkte und Services. Eine höherwertige "echte“ Kundenorientierung wird aber erst erreicht, wenn die individuellen Kundenerwartungen erfüllt werden. Diese wird u.a. durch neue Produkte und Tarife sowie durch die Interaktion mit dem einzelnen Kunden gefördert.

Intern wird die kundenorientierte Unternehmensplanung durch eine angepasste Unternehmensstruktur unterstützt, die den Unternehmenserfolg vor allem im Verkehrsmarkt realisiert - und weniger auf Politikebene anstrebt. Darüber hinaus muss sich Kundenorientierung auch in der Unternehmensführung, im Kundenbeziehungsmanagement und im Controlling widerspiegeln. Aus der Fülle der hieraus erwachsenden Aufgaben wird deutlich, dass die Personalausstattung vieler kleinerer und mittelständischer Verkehrsunternehmen eine für die fundierte Kundenorientierung notwendige Differenzierung in den Geschäftseinheiten nicht zulässt. Für diese Unternehmen bietet sich für die Bereiche Vertrieb und Marketing ein Outsourcing bzw. eine externe Bündelung von Kompetenzen und Diensten an. Über eine zentrale Marketinggesellschaft kann das Spektrum der Marketinginstrumente im ÖPNV zielorientiert und offensiv eingesetzt werden.

Bereits heute kommen im RMV die unterschiedlichsten Marketinginstrumente zum Einsatz, um die Verkehrsleistung am Markt zu verkaufen. Eine Betrachtung des instrumentenbezogenen Einsatzes verdeutlicht jedoch, dass die ÖPNV-Akteure hinter ihren Möglichkeiten zurückbleiben, da die vorhandenen technischen Mittel und organisatorischen Möglichkeiten bereits ausgeschöpft sind. So reduziert sich der Begriff „Marketing“ vor allem auf den "Verkauf von Fahrtberechtigungen" und stellt sich weniger als Aufgabe des gesamten Unternehmens dar, sondern höchstens einer Abteilung im Unternehmen. In der Konsequenz bleibt der Marketingbereich, im Gegensatz zu den stärker betriebs- und technikorientierten Unternehmensbereichen, von Innovationen vielfach ausgespart. Eine verbesserte gesamtheitliche Vermarktung der ÖPNV-Leistung wurde bislang zudem durch die unklare Zuordnung von Zuständigkeiten zwischen Verkehrsunternehmen und Aufgabenträgern erschwert. Nicht zuletzt fehlt aber auch eine gemeinsame technischorganisatorische Plattform, über die Mobilitätsdienstleistungen erfolgreich vermarktet werden könnten. 
In Kapitel 7 wird beschrieben, wie mittels E-Ticketing die Attraktivität des ÖPNV verbessert und Optimierungs- sowie Einsparpotenziale erschlossen werden können und „Kundenorientierung“ für die Nutzer von Bussen und Bahnen zur konsequenten Realität wird. Dabei geht es im Prinzip um die Nutzbarmachung der sich durch die IuK-Technologien bietenden Möglichkeiten im Internetzeitalter für die Vermarktung des ÖPNV. Hier bieten sich durch E-Ticketing vielfältige Ansätze der Optimierung des Einsatzes von Marketinginstrumenten bzw. werden bestimmte Instrumente überhaupt erst nutzbar.

Obwohl das Thema E-Ticketing in Deutschland relative neu ist, handelt es sich keineswegs um technisches Neuland. Dies wird alleine schon durch die Anzahl von weltweiten E-Ticketing-Systemen dokumentiert, aber auch durch die weit fortgeschrittene Standardisierung von E-Ticketing-Systemen hierzulande, die eine technologisch verlässliche Umsetzung erlaubt. Auch der RMV hat zu dieser Entwicklung beigetragen und umfangreiche Erfahrungen im Rahmen von Pilotprojekten gesammelt. Nichtsdestotrotz besteht vor der Planung und Einführung die Notwendigkeit einer Zieldefinition, zumal es E-TicketingSysteme in unterschiedlichen Ausprägungen und Funktionalitäten gibt, durch die unterschiedliche Wirkungsbereiche adressiert werden. Ebenfalls ist die Berücksichtigung - und gegebenenfalls Schaffung entsprechender - organisatorischer Rahmenbedingungen notwendig, die zu einem nicht unwesentlichen Teil die Entfaltung der Potenziale unterstützen. Hier ist wiederum die eindeutige Zuordnung von Kompetenzen und Rollen auf die verschiedenen, am E-Ticketing Beteiligten von Relevanz sowie der Aufbau eines Kommunikationsnetzwerkes als gemeinsame technisch-organisatorische Plattform für eine partnerschaftliche Zusammenarbeit im Bereich der Vermarktung von Mobilitätsdienstleistungen.

Diese Zusammenarbeit erfordert die Koordinierung durch eine "zentrale Instanz", die nicht alleine nur Verantwortung und Aufgaben bündelt, sondern idealerweise selbst operativ tätig wird. Geeignet ist beispielsweise der Bereich der neuen, innovativen Vertriebswege über Internet und Mobilfunkgerät, die eher regionalen, d.h. räumlich übergreifenden Charakter haben, hingegen die lokalen operierenden Partner weiterhin für die Vermarktung vor Ort verantwortlich sind. Eine verbundweit operierende Instanz gewährleistet so, dass der Fokus der Marktbearbeitung auf die Region gerichtet ist und nicht alleine auf lokale Teilmärkte. Außerdem können hierüber Synergie- und Rationalisierungseffekte an alle ÖPNV-Akteure weitergegeben werden. 
Da es mit der RMV GmbH bereits Ansätze einer solchen zentralen Instanz in der Region gibt und auch das Erlösrisiko durch das Besteller-Ersteller-Prinzip auf Seiten der Aufgabenträger liegt, bietet sich die Etablierung einer zentralen Vermarktungsorganisation hier an - allerdings unter der Voraussetzung der Aneignung zahlreicher weiterer Kompetenzen, die in Kapitel 6 beschrieben wurden. Die hierüber entstehende neue Qualität der Zusammenarbeit der ÖPNV-Akteure ist durch Aufgabenteilung - und nicht wie bisher durch redundante Abläufe - unter Koordinierung der RMV GmbH als „Mobilitätsverbund“ gekennzeichnet. Die RMV GmbH gewährleistet zukünftig den abgestimmten Einsatz aller Marketinginstrumente und somit eine einheitliche Benutzeroberfläche und einen effizienten Mitteleinsatz und höchstmögliche Effektivität der Maßnahmen. Die Erschließung dieser Effizienzpotenziale wird unterteilt nach erlössteigernden und aufwandsmindernden Maßnahmen im Kapitel im einzelnen dargestellt. Abschließend wird auf die für die Kundenakzeptanz relevanten datenschutzrechtliche Aspekte des ETicketing eingegangen.

\subsection{Fazit}

In Zeiten der Globalisierung einerseits und sich verschärfender Verkehrsprobleme andererseits, kommt einem funktionierenden Verkehrssystem zur Sicherstellung der Mobilität als Standortfaktor eine große Bedeutung zu. Der Grad an „Mobilität“ in einer Region ist ausschlaggebend für die räumliche Erreichbarkeit von beispielsweise Wohn-, Arbeits-, Produktions-, Freizeit- und Konsumorten und besitzt sowohl Einfluss bei der Wahl des Niederlassungsortes für Menschen wie für Unternehmen. Die Möglichkeiten des ungehinderten Ortswechsels von Personen sowie eines freien Austauschs von Waren, Gütern und Dienstleistungen innerhalb der Region und darüber hinaus sind wiederum Voraussetzung für die nationale und internationale Wettbewerbsfähigkeit eines Wirtschaftsstandortes und damit die Grundlage für regionale Entwicklung und Wohlstand. Eine nachhaltige Mobilitätssicherung, die die ökologischen, ökonomischen und sozialen Belange berücksichtigt, trägt daher wesentlich zur Regionalentwicklung bei.

Auch die Region Frankfurt Rhein-Main profitiert von einer störungsfreien nachhaltigen Mobilität. Die Verkehrssysteme in der Region sind von einer leistungsfähigen Verkehrsinfrastruktur geprägt, welche die Basis für die Kernstadt Frankfurt am Main als europäische und nationale Verkehrsdrehscheibe ist. Insofern wurde dem Ausbau der Verkehrs- 
infrastruktur in der Region in den letzten Jahren große Bedeutung beigemessen, wodurch der steigenden Nachfrage nach Mobilität verkehrspolitisch aber nur bedingt entsprochen wurde. Die wachsende Mobilität in der Region ist aber nicht mehr nur noch ein sichtbares Zeichen prosperierender Wirtschaftskraft, sondern stellt sich zunehmend als kritischer Standortfaktor für die Region selbst dar, den es zu bewahren gilt. Insbesondere das Verkehraufkommen auf dem Verkehrsträger "Straße“ - verursacht von privaten Pkw - weist hohe Wachstumsraten auf und birgt nicht nur die Gefahr, dass die regionale Mobilität beeinträchtigt wird, sondern auch, dass Menschen und Umwelt geschädigt werden. Dieses wiederum hätte negative Folgen für die Region Frankfurt Rhein-Main als Wirtschaftsstandort und lebenswerte Region. Dem ÖPNV kam bei der Erhaltung der regionalen Standortfaktoren in der Vergangenheit keine ausreichende Aufmerksamkeit zu, obwohl man auch hier die infrastrukturellen Voraussetzungen sukzessive verbesserte, beispielsweise im Bereich des SPNV.

Eine leistungsfähige Verkehrsinfrastruktur stellt aber lediglich die Voraussetzung für eine nachhaltige Mobilitätssicherung dar. Erst die Abstimmung der einzelnen Verkehrsträger und Verkehrsmittel in einem integrierten Gesamtverkehrskonzept ermöglicht die ökonomisch, ökologisch und sozial ausgewogene Verkehrsabwicklung. In diesem integrierten Gesamtverkehrskonzept kommt dem ÖPNV aufgrund seiner komparativen Vorteile gegenüber dem MIV bei der nachhaltigen Mobilitätssicherung eine wichtige Funktion zu. Eine verbesserte regionale intermodale Kooperation und damit die Integration des ÖPNV in das Gesamtverkehrssystem, wird jedoch durch strukturelle sowie administrative Gegebenheiten bislang erschwert.

Verbesserungsansätze im Verkehrsbereich konzentrieren sich in der Region bislang entweder auf infrastrukturelle Maßnahmen oder adressieren die betriebliche Optimierung des Straßenverkehrs. In dem Maße, wie öffentliche Gelder knapper werden, wird bei der Lösung von Verkehrsproblemen zunehmend auf Telematikanwendungen gesetzt, die in der Initiative der hessischen Landesregierung „Staufreies Hessen 2015“ gebündelt werden. Diese Anwendungen zielen vor allem auf die kurz- und mittelfristige Verbesserung des Verkehrsflusses ab. Hierdurch kommt es jedoch weder zu einer Veränderung des Verkehrsverhaltens der Verkehrsteilnehmer noch zu einer Vermeidung von Fahrten oder einer Verlagerung von Fahrten des MIV auf umweltfreundlichere Verkehrsmittel, respektive den ÖPNV. Von daher führen diese Maßnahmen auch nicht zu einer Verringerung 
des Gesamtverkehrsaufkommens und einer Minderung negativer Umwelteinflüsse. Um die Mobilität langfristig - und nachhaltig - zu sichern, setzt die hessische Landesregierung daher auf die Einbindung des ÖPNV in ein Gesamtverkehrskonzept, in dem die Verkehrsträger entsprechend ihrer spezifischen Stärken zum Einsatz kommen. Hierbei muss allerdings konstatiert werden, dass auch der ÖPNV seine spezifischen Stärken weiterentwickeln muss, soll er zukünftig einen substanziellen Beitrag zur nachhaltigen Sicherung der Mobilität in der Region Frankfurt Rhein-Main liefern.

Die relative Bedeutung des ÖPNV ist in den vergangenen Jahren allerdings gegenüber dem MIV gesunken, obwohl im RMV kontinuierlich Fahrgäste hinzugewonnen werden konnten. Neben der überproportionalen Zunahme des MIV, die die Fahrgaststeigerung im ÖPNV überkompensiert hat, liegen die Ursachen hierfür einerseits in den gesellschaftlichen und demographischen Entwicklungen begründet, andererseits gibt es aber auch endogene Gründe dafür, dass der ÖPNV Verkehrsmarktanteile verloren hat. So entsprechen die heutigen ÖPNV-Angebote eher starren fordistischen Vorstellungen der Industriegesellschaft, die von immer wiederkehrenden und gleichförmigen Abläufen geprägt waren. Ein zukunftsgewandter ÖPNV muss aber die zunehmende Flexibilisierung, Pluralisierung und Individualisierung einer (Informations-)Gesellschaft reflektieren, für die ein hohes Maß an Mobilität nicht alleine notwendige Voraussetzung zur Teilnahme am gesellschaftlichen und wirtschaftlichen Leben ist, sondern auch Ausdruck der individuellen Selbstverwirklichung ist.

Restriktive verkehrspolitische („push“-) Maßnahmen werden daher - wenn überhaupt nur bedingt und allenfalls kurzfristig zu einer Veränderung der Verkehrsnachfrage führen. Erfolgversprechender ist eine Attraktivitätssteigerung des Gesamtverkehrssystems, das gekennzeichnet ist von neuen Mobilitätsangeboten (als „pull“-Maßnahmen), die den gestiegenen Bedürfnissen an flexibler, individueller und angepasster Mobilität entsprechen: Flexible und intermodale Mobilität. Das dahinter stehende Marktpotenzial haben bereits viele Verkehrsakteure im RMV erkannt und sich das unternehmensstrategische Ziel der Entwicklung zum „Mobilitätsdienstleister“ gesetzt. Wesentliches Kennzeichen ist ein verkehrsträgerübergreifendes Denken und die Bereitstellung von Mobilitätsangeboten und -services entlang der gesamten Wegekette. 
Diese Angebote setzen die abgestimmte und partnerschaftliche Bereitstellung von Diensten voraus und - vor allem - ein hohes Maß an Kundenorientierung. Damit eine höhere Marktausschöpfung erreicht werden kann, ist daher nicht nur der Einsatz des gesamten Marketingmixes unerlässlich, sondern sind auch interne organisatorische Maßnahmen notwendig, die die interne Wertschöpfungskette des gesamten Unternehmens auf die Kundenerwartungen und -wünsche ausrichten und eine kooperative intramodale $\mathrm{Zu}$ sammenarbeit der ÖPNV-Partner ermöglichen. Eine verbesserte Kundenorientierung, als zentrales Merkmal eines „Mobilitätsdienstleisters“, soll schließlich zu einer höheren Nutzerfinanzierung des ÖPNV-Systems führen. Dies stellt die Grundlage dar, auch zukünftig ein qualitativ hochwertiges ÖPNV-Angebot im Rahmen eines Gesamtverkehrssystems garantieren zu können. Mit der Optimierung des „Teilsystems ÖPNV“ unterstützt der RMV - als Mobilitätsverbund und die darin zusammengeschlossenen Verkehrsunternehmen als Mobilitätsdienstleister - maßgeblich die Entwicklung des auf landespolitischer Ebene angestrebten integrierten Gesamtverkehrssystems und liefert einen wichtigen Beitrag zur Mobilitätssicherung in der Region.

Die gegenwärtige Deregulierung des Verkehrsmarktes kommt der Positionierung der RMV GmbH und der Aufgabenträger, aber auch der Verkehrsunternehmen bei der Herausbildung neuer Kooperationsstrukturen und der Zuordnung von Aufgaben zugute. Insbesondere die klare Aufteilung in Besteller und Ersteller von Verkehrsleistung bietet die Chance, die Erstellung von Verkehrsleistungen über den Wettbewerb zu geringeren Kosten zu erreichen. Darüber hinaus lässt sich auch die Vermarktung der ÖPNV-Leistung in den Verkehrsverträgen neu definieren und insgesamt reorganisieren. Dies führt aber dazu, dass Kompetenzen nicht nur neu vergeben werden, sondern neue Kompetenzen bei den Partnern aufgebaut werden müssen. Diese Reorganisation ist daher als Veränderungsprozess zu verstehen, den Aufgabenträger und Verkehrsunternehmen gleichermaßen zu durchlaufen haben. Die neuen Kompetenzen, die in diesem Prozess angeeignet werden müssen, sind auch erforderlich, um das volle Spektrum an organisatorischen, marketingseitigen und technischen Maßnahmen zur modernen und kundenorientierten Marktbearbeitung nutzen zu können.

Die zwingende Voraussetzung für eine glaubhafte Marktpositionierung der ÖPNVAkteure als Mobilitätsdienstleister ist zunächst eine enge intramodale Kooperation, durch die eine kundenorientierte, ganzheitliche Vermarktung der Mobilitätsdienstleistung - mit 
der Beförderung im ÖPNV als Kernleistung - erst möglich wird. Die Kundenwahrnehmung des ÖPNV als echte Alternative zum MIV muss sich in einer einheitlichen Benutzeroberfläche widerspiegeln, „unterhalb“ derer es zu einem abgestimmten Einsatz aller Marketinginstrumente kommt. Daher ist es erforderlich, dass alle Mobilitätsdienstleister ihre Aktivitäten im Marketingbereich zusammenführen. Am Beispiel des RMV wird deutlich, dass sich ein effizienter Mitteleinsatz und die Effektivität von Maßnahmen in den einzelnen Marketingbereichen im ÖPNV weiter verbessern ließe. Dies kann durch eine zentrale Instanz geschehen, die einerseits die Planung, die Umsetzung und den Erfolg der Marketingmaßnahmen organisatorisch koordiniert und andererseits die technischen Voraussetzungen für eine moderne und zeitgemäße Marktbearbeitung bereitstellt.

Mit der RMV GmbH gibt es in der Region Frankfurt Rhein-Main bereits eine zentrale Instanz, die nicht nur von allen Kommunen der Region (auf hessischem Gebiet) sowie dem Land Hessen getragen wird und der bereits zentrale Marketingaufgaben zugeordnet wurden, sondern die auch für das gemeinsame Ziel der Gewinnung neuer ÖPNV-Kunden eintritt. Durch die Bündelung von Aufgaben bei der RMV GmbH als verbundweit operierende Marketinggesellschaft (,zentrale Instanz“) werden keineswegs die im Rahmen der Regionalisierung neugewonnenen Kompetenzen lokaler Aufgabenträger beschnitten. Vielmehr wird erst ermöglicht, dass diese lokal operierenden Einheiten als lokale „Mobilitätsagenturen“ über ihre administrativen Zuständigkeitsgebiete hinaus unternehmensund verkehrsmittelübergreifende Mobilitätsdienstleistungen anbieten können. Dies ist ein wichtiger Baustein für die Untermauerung der Glaubwürdigkeit der Marktpositionierung des gesamten Mobilitätsverbundes und der einzelnen Mobilitätsdienstleister. Darüber hinaus ist der Mobilitätsverbund die organisatorische Klammer, die durch den Zusammenschluss der Verkehrsunternehmen als Mobilitätsdienstleiter die notwendige einheitliche Benutzeroberfläche ermöglicht.

Die Eigentümerschaft der Marketinggesellschaft in kommunaler Hand entspricht dabei der Zuordnung des Erlösrisikos auf die Aufgabenträger, die wiederum die Verantwortung über die Marketinginstrumente durch die praktizierte Vergabe von Verkehrsleistungen im Rahmen von Bruttoanreizverträgen bei sich behalten. Diese organisatorische Trennung in Betriebs- und Vertriebsleistung wird durch das im Hess. ÖPNVG verankerte Besteller-Ersteller-Prinzip zwar nicht explizit ausgedrückt, doch zumindest inhaltlich un- 
terstützt. Eine öffentlich-rechtlich geführte Marketinggesellschaft gewährleistet außerdem die Kontinuität der Marktbearbeitung, die in einem deregulierten und von Wettbewerb geprägtem Markt mit wechselnden Erstellern erforderlich ist.

Ein technisches Mittel, das einerseits die Zusammenarbeit der Partner im Mobilitätsverbund fördert und andererseits die ÖPNV-Akteure in die Lage versetzt, ihre Kompetenzen im Marketingbereich auszufüllen, ist das E-Ticketing. Im E-Ticketing spiegelt sich die Anwendung der IuK-Technologien im ÖPNV-Marketing wider. Das E-Ticketing-System stellt hier zunächst einmal nur die technische Infrastruktur dar, durch die die Abbildung und auch die Reorganisation von Geschäftsprozessen ermöglicht wird. Zur Erschließung von Effizienzpotenzialen ist aber eine übergeordnete Organisation notwendig, die im Rahmen eines Geschäftsprozessmanagements definiert, welche Aufgaben von wem und wann in welcher Weise im E-Ticketing auszuführen sind und die das gemeinsam genutzte technische Equipment vorhält.

Je nachdem, in welchem organisatorischen Rahmen das E-Ticketing eingebunden wird, unterstützt es im ÖPNV beispielsweise die Prozesse des elektronischen Bezahlens, des elektronischen Fahrgeldmanagements, des Controllings oder der elektronischen Erfassung von Fahrdaten. Als Marketinginstrument ermöglicht das E-Ticketing die Verknüpfung von neuen Diensten und neuen Medien zu Mobilitätsdienstleistungen. Die neue Qualität der angebotenen Dienstleistungen besteht nicht zuletzt in der Verfügbarkeit von Diensten und Information über die neuen Medien - quasi zu jeder Zeit und an jedem Ort. Ihr Einsatz hat mittlerweile alle Bereiche der Produktions- und Wertschöpfungsketten sowie des privaten Alltags durchdrungen und findet über das E-Ticketing nun auch im ÖPNV Anwendung.

Aufgrund der komplexen organisatorischen Abhängigkeiten, der vielschichtigen Möglichkeiten und diversen technischen Ausprägungen bedarf es für eine Entscheidung für ETicketing überzeugend formulierter Konzepte mit klaren Zielstellungen. Ansonsten ist die Gefahr groß, dass die „Stakeholder“ auf dem Umsetzungsweg verloren werden. Die Realisierung und Markteinführung wird durch den modularen technischen Aufbau des ETicketing Systems gefördert. Dieser Aufbau ermöglicht es bereits in einer frühen Ausbauphase Nutzenpotenziale zu erschließen. So können beispielsweise bereits durch den Austausch der Trägermedien von Nutzungsberechtigungen (z.B. Papier gegen Prozessorchip- 
karte) sicherheitsrelevante Aspekte verbessert werden. Gleichzeitig setzen die unterschiedlichen Ausbauphasen unterschiedliche technische und organisatorische Voraussetzungen voraus. Hieraus ergibt sich, dass die Einführung des E-Ticketing konform zur strukturellen Reorganisation erfolgen kann.

Letztlich hängt es von der zielgerichteten Ausgestaltung und stringenten Umsetzung des E-Ticketing-Gesamtsystems ab, welche marketingseitigen Effekte erzielt werden und wie sich diese auf der Seite der Einnahmenverbesserung oder Kosteneinsparung niederschlagen. Hinzu kommt, dass die Höhe der Gesamtinvestition in ein E-Ticketing-System die Streckung der Mittel über einen längeren Zeitraum rechtfertigt.

So ist E-Ticketing nicht nur ein System, das langfristig die Kommunikation und den Austausch zwischen Verkehrunternehmen und Verkehrsteilnehmern ermöglicht, sondern zunächst einmal den Dialog zwischen den ÖPNV-Akteuren über gemeinsame Ziele voraussetzt. Die „Delphi-Studie“ über den „ÖPNV-Markt der Zukunft" kommt in ihrer Zusammenfassung zum Schluss, dass zur Erreichung einer verbesserten Wirtschaftlichkeit im ÖPNV, die auf einer „Orientierung an den Bedürfnissen und Erwartungen der Kunden“ basiert, die „Verbesserung der Koordination zwischen den Akteuren“ notwendig ist. ${ }^{1392}$ Dies dürfte in der Region Frankfurt Rhein-Main nicht anders sein. Daher ist auch hier der Dialog der ÖPNV-Akteure der ausschlaggebende Faktor bei der Positionierung des ÖPNV im Verkehrsmarkt der Zukunft, deren wichtigstes Merkmal eine gesteigerte Kundenorientierung ist. Dies haben die ÖPNV-Akteure und Verantwortlichen im RMV erkannt. Nun gilt es, gemeinsame Wege der verbesserten Koordination zu ermitteln und umzusetzen. Die Anwendung von E-Ticketing ist dabei immer Mittel zum Zweck und nicht schon die Lösung selbst. Unternehmensbezogene Alleingänge, die nicht an den Interessen aller "Stakeholder“ ausgerichtet sind, haben dabei wenig Aussicht auf Erfolg.

1392 Deutsches Verkehrsforum 2005, S.169 
Aberle, Gerd:

- „Transportwirtschaft - Einzelwirtschaftliche und gesamtwirtschaftliche Grundlagen“. München 2003.

- „Was bringen Verkehrsinfrastrukturinvestitionen für die regionale Wirtschaft“. Vortrag vor der IHK Darmstadt am 26.09.2006 in Darmstadt.

ACE, Auto Club Europa (Hrsg.): "Verkehrspreise überdurchschnittlich gestiegen". Pressemitteilung vom 15.02.2007. Stuttgart 2007.

Achenbach, Anne: „Wirtschaftlichkeitssteigerung im ÖPNV durch elektronisches Fahrgeldmanagement - Entwicklung eines Analyseschemas zur Identifikation der Aufwandsund Ertragspotenziale automatisierter Fahrpreiserhebung im Öffentlichen Personennahverkehr. Berlin 2002.

Ackermann, Till: „Die VDV-Kernapplikation - Der Standard für das interoperable elektronische Fahrgeldmanagement (EFM) in Deutschland steht bereit zur Umsetzung": In: Nahverkehrs-praxis 3/2007. Dortmund 2007. S. 14-17.

Ackermann, Till; Czurzim, Alexander und Roch, Robert: „Benchmarking im Vertrieb“. In: Der Nahverkehr 11/2004. Düsseldorf 2004. S. 20-24.

Ackermann, Till und Stammler, Horst: „Nutzerfinanzierte Tarifstrategien - Fahrpreise zwischen Förderung und Forderung“" In: Der Nahverkehr 1-2/2006. Düsseldorf 2006, S.815.

ADAC, Allgemeiner Deutscher Automobil-Club e.V. (Hrsg.): "Autofahrer als Staatssanierer: Jetzt reicht's!“. In: ADAC-Motorwelt, Heft 5, Mai 2006. S. 36-40.

Adam Opel GmbH und Hessische Staatskanzlei: Dokumentation zur Pressekonferenz am 16.02.2006. Wiesbaden 2006.

Albrecht, Achim: „Höhere Wirtschaftlichkeit dank elektronischem Fahrgeldmanagement - Kundenverhalten, Vertrieb und Kommunikation im Zeichen der Chipkarte": In: Der Nahverkehr 12/2000. Düsseldorf 2000. S. 34-38.

Allekotte, Dorothee: „RBL als ÖV-Baustein im VMS - Teil1, IGLZ-Integrierte Gesamtverkehrs-Leitzentrale der Stadt Frankfurt am Main. Vortrag im Rahmen der Tagung des VDV-Unterausschusses ITCS III „RBL im Restrukturierungsprozess“ am 3. und 4.11.2004 in Hannover. Hannover 2004.

Amling, Stephan; Kunneman, Peter und Rumpke, Christian: „Smartcard statt Strippenkaart“. In: Internationales Verkehrswesen 5/2004. Hamburg 2004. S. 215-216.

Anreiter, Wilfried und Schaaffkamp, Christoph: „Systematische Qualitätsmessung - Voraussetzungen für die anreizorientierte und justiziable Vergabe von verkehrsverträgen“. In: Der Nahverkehr 11/2006. Düsseldorf 2006. S. 27-33.

Arbach, Souha: „Kundenbeziehungen pflegen - Fehlentwicklungen und Chance des CRM im ÖPNV-Markt. In: Der Nahverkehr 3/2004. Düsseldorf 2004. S. 49-50. 
Barth, Sybille: „Nahverkehr in kommunaler Verantwortung - Der öffentliche Personenverkehr nach der Regionalisierung“. Schriftenreihe für Verkehr und Technik, Band 90. Bielefeld 2000.

Bärnthaler, Andreas: „Visualisierung von Nachhaltigkeit (Sichtbar-Machen)“. Seminararbeit im Rahmen des Geographischen Seminars „Kommunikation und Partizipation in der nachhaltigen (Stadt- und Regional-) Entwicklung an der Universität Graz. Graz 2004.

Baum, Herbert: „Thesen zur Pkw-Maut“. Thesenpapier des Instituts für Verkehrswissenschaft an der Universität zu Köln. Köln 2005.

Baumgärtner, Mario: „E-Ticketing im Verkehrsverbund Bremen/Niedersachsen - Ein erfolgreiches System mit Zukunft". In: Nahverkehrspraxis, Nr. 3/2004, S.11-12. Dortmund 2004.

BDI, Bundesverband der Deutschen Industrie und DHIK, Deutscher Industrie- und Handelskammertag (Hrsg.): „Privatisierung der integrierten Deutschen Bahn AG - Auswirkungen und Alternativen“. BDI-Drucksache Nr. 380. Berlin 2006.

Becker, Thomas: „Restrukturierung von öffentlichen Nahverkehrsunternehmen - Konzepte zur Kostensenkung und Produktivitätssteigerung vor dem Hintergrund der anstehenden Marktöffnung“. Wirtschaftswissenschaften Bd. 8. Münster 2004.

Becker, Udo J.:

- „Nachhaltige Verkehrsentwicklung - Mehr als nur eine Phase in der verkehrspolitischen Diskussion?". In: Der Nahverkehr 1-2/2002. Düsseldorf 2002. S. 12-16.

- „Nutzerfinanzierung des Verkehrs bzw. Verursacherprinzip: Wann hilft Kostenwahrheit dem ÖPNV?“. Vortrag im Rahmen des Beka-Tarif- und Vertriebsworkshops am 27./28.03.2007 in Köln. Köln 2007.

Becker, U. und Gerike, R.: „Mehr Kostenwahrheit im Verkehr - Wem nützt die Internalisierung?". Dresden 2007.

Beckers, Thorsten; Zwick, Daniel; Walf, Fabian; Dressler, Florian; Pape, Henning und von Hirschhausen, Christian: „Potenziale, Wirkungen und ökonomische Bewertung von hochwertigen Verkehrsinformationsdiensten“. Diskussionspapier 2001/14 der Wirtschaftswissenschaftlichen Dokumentation der Technischen Universität Berlin, Fakultät VIII (Wirtschaft \& Management). Berlin 2001.

Beckmann, Klaus J.: „Integrierte Verkehrsentwicklungsplanung - Potenziale zur Verbesserung der Wirksamkeit verkehrsplanerischer Maßnahmen“. Vortrag im Rahmen der 18. Verkehrswissenschaftlichen Tage am 17./18.09.2001. Dresden 2001.

Berger, Dieter: „Duden: Geographische Namen in Deutschland - Herkunft und Bedeutung der Namen von Ländern, Städten, Bergen und Gewässern“. Mannheim, Paderborn, Wien, Zürich 1993.

Berliner Zeitung vom 17.03.2007: Touch in, touch out - Die Bahn testet ein neuartiges Handy-Ticket - unter anderem in Berlin“. Berlin 2007. 
Berndt, Thomas: „Zur Zukunft der Corporate Governance - Regulierung der Unternehmensführung auf dem Prüfstand“. In: ZCG - Zeitschrift für Corporate Governance Juni/2006. Hamburg 2006. S. 2-7.

Bertelsmann Stiftung (Hrsg.): „Wegweiser Demographischer Wandel 2020 - Analysen und Handlungskonzepte für Städte und Gemeinden. 1. Auflage 2006

Beyer, Jürgen; „Die Managementlogik von effizienten Transportprozessen“. In: Für eine neue deutsche Verkehrspolitik - Mobilität braucht Kommunikation. Hrsg.: Stopka, Ulrike und Pällmann, Wilhelm. Hamburg 2005. S.108-123.

Blümel, Hermann: „Mobilitätsdienstleister ohne Kunden - Kundenorientierung im öffentlichen Nahverkehr". Discussion Paper SP III 2004-109, Wissenschaftszentrum Berlin für Sozialforschung. Berlin 2004.

BMW AG (Hrsg.): „Abschätzung der volkswirtschaftlichen Kosten durch behinderten Verkehr“. München 1997.

Bocxlaer, Anja van: „Noch läuft das Fass nicht über! - Marktübersicht mit vielen neuen Gesichtern - Single-Karten-Konzepte“. In: card-Forum, 4/2003. Lüneburg 2003. S. 24-32.

Boldt, Linnart und Ordon, Christian: „Offen für neue Wege - E-Ticketing-System get»in vereinfacht ÖPNV-Nutzung in Hanau“. In: RFID-Forum Nr. 06/2004. Lüneburg 2004. S. 30-33.

Bölke, Michael: „Innovationspotenziale des ÖPNVs“. In: Internationales Verkehrswesen 1+2/2005. Hamburg 2005. S. 33-36.

Borrmann, Matthias und Peistrup, Matthias: „Leere öffentliche Kassen - Wie geht es weiter mit dem ÖPNV?“. In: Der Nahverkehr 11/2006. Düsseldorf 2006. S. 19-26.

Bratzel, Stefan: „Innovationsprozesse umweltorientierter Verkehrspolitik im Städtevergleich“. In: Internationales Verkehrswesen 3/2000. Hamburg 2000. S. 90-94.

Bretzger, Frank und Ebbing, Georg: „Kundenbindung von Gelegenheitsnutzern im ÖPNV - Analysen mit Daten des bargeldlosen Fahrscheinerwerbs“. o. O. 2005.

Brüderl, Josef: „Die Pluralisierung partnerschaftlicher Lebensformen in Westdeutschland und Europa. In: Aus Politik und Zeitgeschichte (Beilage zur Wochenzeitschrift „Das Parlament $\left.{ }^{\prime \prime}\right)$, B 19/2004. Berlin 2004. S. 3-10.

Büch, Frank; Heine, Wolf-Dietrich und Kissinger, Stefan: „Elektronisches Ticketing - Berlin bereitet Feldversuch vor“: In: Der Nahverkehr 5/1999. Düsseldorf 1999. S. 16-22.

Budhäus, Dietrich.: „Public Corporate Governance Kodex - Ein Beitrag zur Bildung von Vertrauen in Politik und Management?“. In: Ruter, R.X; Sahr, K. und Waldersee, G.: Public Corporate Governance. Wiesbaden 2005

Bund für Natur- und Umweltschutz BUND: „Verkehrspolitische Bilanz der rot-grünen Bundesregierung". Auszug aus der umweltpolitischen Bilanz des BUND: Vier Jahre RotGrün). Berlin o. J.

Bund für Natur- und Umweltschutz Hessen: „Sparen beim Schienenverkehr eine glatte Fehlkalkulation - BUND Hessen analysiert Kürzung der Mittel für ÖPNV“: Pressemitteilung vom 03.07.2007 
Bund für Natur- und Umweltschutz BUND und Allgemeiner Deutscher Fahrradclub ADFC:

- „Ergebnisse des Fahrradklimatest 2005: Münster bleibt fahrradfreundlichste Großstadt Deutschlands!“. www.bund.net/verkehr (Zugriff am 27.11.2005).

- „Ergebnis des Fahrradklimatest 2003: Münster ist die fahrradfreundlichste Stadt Deutschlands“. http://www.bund.net/verkehr/ (Zugriff am 27.11.2005).

Bundesamt für Bauwesen und Raumordnung (Hrsg.): „Raumordnungsbericht 2000“. Bonn 2001.

Bundesanstalt für Straßenwesen (Hrsg.): „Jahresbericht 2002“. Berichte der Bundesanstalt für Straßenwesen Heft A26. Bergisch-Gladbach 2003.

Bundesministerium für Verkehr, Bau und Stadtentwicklung (Hrsg.):

- „Kommission Verkehrsstrukturfinanzierung - Schlussbericht 5. September 2000“. Berlin 2000.

- Mobilitätsoffensive - Handlungsempfehlungen für die Mobilität der Zukunft“. Berlin 2005.

Bundesministerium für Verkehr, Bauwesen und Raumordnung (Hrsg.): „Öffentliche Daseinsvorsorge und demographischer Wandel - Erprobung von Anpassungs- und Entwicklungsstrategien in Modellvorhaben der Raumordnung“. Berlin/Bonn 2005.

Bundesregierung (Hrsg.): „Perspektiven für Deutschland - Unsere Strategie für eine nachhaltige Entwicklung“. Berlin 2002

Busch, Fritz; Keller, Hartmut und Kessler, Dirk: „Es gibt noch viel zu tun - Rahmenkonzept für ein Verkehrsmanagement für München und sein Umland“. In: Internationales Verkehrswesen 10/2004. Hamburg 2004. S. 457-460.

Canzler, Weert und Knie, Andreas:

- „New Mobility? Mobilität und Verkehr als soziale Praxis“. In: Aus Politik und Zeitgeschehen (Beilage zur Wochenzeitschrift „Das Parlament“), B 45-46/2000. Berlin 2000.

- „Demografische und wirtschaftsstrukturelle Auswirkungen auf die künftige Mobilität: Neue Argumente für eine neue Wettbewerbsordnung im Öffentlichen Verkehr": Discussion Paper SP III 2005-106, Wissenschaftszentrum Berlin für Sozialforschung. Berlin 2005.

Caspar, Jürgen; Krömmelbein, Silvia und Schmid, Alfons: „Neue Kommunikationstechnologien und Flexibilisierung der Arbeitsverhältnisse“: In: Esser, Josef und Schamp, Eike W. (Hrsg.): „Metrolpolitane Region in der Vernetzung - Der Fall Frankfurt am Main“. Frankfurt am Main 2001. S. 75-102.

Cohrs, Rainer; Rölle, Daniel; Czech, Thomas und Seegmüller, Karl: „Wie sicher fühlen sich Fahrgäste in öffentlichen Verkehrsmitteln?“. In: Der Nahverkehr 9/2005. Düsseldorf 2005. S. 14-19. 
de Jong, G.M.: „Die verkehrspolitische Lage in den Niederlanden - Mobilität in den Niederlanden“. Vortrag im Rahmen der 26. kontiki-Konferenz am 22. u. 23.06.2006 in Rotterdam, NL. Rotterdam 2006.

Deutsche Bahn AG, Flughafen Frankfurt/Main AG, Rhein-Main-Verkehrsverbund GmbH und Stadt Frankfurt am Main (Hrsg.): „Für die Zukunft der Region Rhein-Main“. Ergebnisse der Studie ,Nutzungs- und Erschließungskonzept Bahnhof Flughafen Frankfurt Main in Wechselwirkung zum Hauptbahnhof Frankfurt 21'. Frankfurt am Main 1998.

Deutsche Bahn AG (Hrsg.): „Die Bahn in Bewegung“. Berlin 2003.

Deutsche Bank Research (Hrsg.): „Informations- \& Kommunikationstechnologien - Allheilmittel gegen den Verkehrsinfarkt?“, In: Economics - Internet-Revolution und "New Economy“", Nr. 34 vom 11.12.2002. Frankfurt am Main 2002.

Deutscher Bundestag (Hrsg.): "Demographischer Wandel - Herausforderungen unserer älter werdenden Gesellschaft an den Einzelnen und die Politik". Dokumentation in Auszügen aus dem Schlussbericht der Enquete-Kommission des Deutschen Bundestages. In: Aus Politik und Zeitgeschichte (Beilage zur Wochenzeitschrift "Das Parlament"), B 20/2003. Berlin 2003. S. 43-54.

Deutscher Industrie- und Handelskammertag (Hrsg.): „PKW-Maut - der neue WegeSoli?“. DIHK-Newsletter Nr. 46 v. 18.11.2005.

Deutsches Institut für Urbanistik (Hrsg.): „Umweltfreundlicher, attraktiver und leistungsfähiger ÖPNV - ein Handbuch (Kurzfassung)“. Forschungsvorhaben im Auftrag des Umweltbundesamtes. Berlin 2005.

Deutsches Institut für Wirtschaftsforschung (DIW) und infas-Institut für angewandte Sozialwissenschaft: Mobilität in Deutschland 2002 - Endbericht. Bonn/Berlin 2003.

Deutsches Institut für Wirtschaftsforschung (DIW) (Hrsg.): „Demographischer Wandel und räumliche Mobilität - Einstellung der Bevölkerung, Urteile von Experten“. Wochenbericht Nr. 51-52/2005, 72. Jg., Berlin 2005. S. 769-775.

Deutsches Verkehrsforum (Hrsg.): „Endbericht zur Delphi-Studie - ÖPNV-Markt der Zukunft“. Berlin 2005.

Dienel, Hans-Liudger und Schmucki, Barbara: „Aufstieg und Fall des öffentlichen Personennahverkehrs in Deutschland bis heute". In: Mobilität für alle - Geschichte des öffentlichen Personennahverkehrs in der Stadt zwischen technischem Fortschritt und sozialer Pflicht. Vierteljahrschrift für Sozial- und Wirtschaftsgeschichte, Beiheft 129. Stuttgart 1997. S. 7-19.

Diez, Willi: „Das Auto als Produzent von Verkehrssicherheit und Verkehrsmanagement". In: Für eine neue deutsche Verkehrspolitik - Mobilität braucht Kommunikation. Hrsg.: Stopka, Ulrike und Pällmann, Wilhelm. Hamburg 2005. S. 86-96.

Dietrich, Mike und Struwe, Jochen: „Public Corporate Governance - Effizientere Unternehmensführung in der kommunalen Daseinsvorsorge“. In: Verwaltung und Management 04/2005. Baden-Baden 2005. S. 199-203. 
Dziekan, Katrin: „Customer perceptions and behavioural responses to IT-based public transport information“. Stockholm 2004.

Ellwanger, Gunther: „Externe Kosten internalisieren“. In: Der Nahverkehr 1-2/2001. Düsseldorf 2001. S. 34-36.

Esser, Josef und Schamp, Eike W.: „Metropolitane Region in der Vernetzung - Der Fall Frankfurt / Rhein-Main“. Frankfurt am Main 2001.

ESWE Verkehrsgesellschaft mbH (Hrsg.): „Videoaufzeichnung wird Standard“. In: Infomobil 2/2006. Wiesbaden 2006. S.10.

EURO-Kartensysteme GmbH (Hrsg.): „Messerückblick CeBIT 2005“. http://www.geldkarte.de/ww/de/pub/aktuelles/cebit_2005.htm. Zugriff am 18.2.2006.

Fakiner, Hans und Scherz, Susanne: „Intermodalität am Flughafen Frankfurt - Auf dem Weg zu einem integrierten Gesamtverkehrssystem Schiene/Luft“. In: Internationales Verkehrswesen 12/2003. Hamburg 2001. S. 618-624.

Falger, Monica: „Regionalreform - zwischen Hierarchie und Netzwerk“. In: Esser, Josef und Schamp, Eike W.: „Metrolpolitane Region in der Vernetzung - Der Fall Frankfurt am Main“. Frankfurt am Main 2001. S.215-244.

Faltlhauser, Oliver und Schreiner, Martin: „München auf dem Weg zu einem integrierten Mobilitätsmanagement - Kommunikation als Fundament zukunftsorientierter Verkehrspolitik“. In: Internationales Verkehrswesen 9/2001. Hamburg 2001. S. 418-421.

Fiedler, Joachim: “ÖPNV-Planung und Betrieb". Vorlesungsmanuskript an der Bergischen Universität - Gesamthochschule Wuppertal. Wuppertal 1994.

Finke, Timo; Krug, Stephan und Meinhard, Dirk: „Erfolgsfaktoren für das Mobilitätsmanagement - Erkenntnisse, Empfehlungen und Hilfen für die Praxis aus dem Forschungsprojekt MOSAIC“. In: Der Nahverkehr 9/99. Düsseldorf 1999. S. 7-11.

Finkenzeller, Klaus: „RFID-Handbuch“. München 2002.

Fischer, Elke: „Einordnung der Forschungsansätze in die VDV-Kernapplikation“. Vortrag im Rahmen des BEKA-Seminars „Aktueller Sachstand des elektronischen Fahrgeldmanagements" am 25. und 26.10.2006 in Schwäbisch Hall.

Fischer, Hans-Joachim; Könnecke, Rainer und Ordon, Christian: „ET: Neue Zugangsbarrieren durch Chipkartenlesegeräte?“. In: Der Nachverkehr 6/2001. Düsseldorf 2001. S. 3439.

Flach, Christine; Grunow, Volker; Hoyer, Robert; Pitz, Merlin und Rössig, Fritz: „Fahrgastinformation in der Fläche beschreitet künftig neue Wege“. In: Der Nahverkehr 12/2005. Düsseldorf 2005. S. 24-29.

Fleischhauer, Marc A. und Ordon, Christian: „Machbarkeitsstudie zum E-Ticketing - Die Ergebnisse der gemeinsamen Analyse von RMV und DB AG“. In: Der Nahverkehr 6/2003. Düsseldorf 2003. S. 10-14. 
Follmer, Robert: „Die kleine Kundenbindungskarte - Ergebnisse einer bundesweiten Befragung“. Vortrag im Rahmen des Beka-Tarif- und Vertriebsworkshops am 27./28.03.2007 in Köln. Köln 2007.

Franken, Verena und Lenz, Barbara: „Nutzeranforderungen an Verkehrsinformationsdienste als Grundlage für technische Entwicklungen“. Berlin 2004.

Frankfurter Allgemeine Zeitung vom 16.6.2005: „Die Mainmetropole ist die Verkehrsdrehscheibe Europas “". S. B2.

Frankfurter Allgemeine Zeitung (FAZ) vom:

- 04.03.2005: „Die 100 größten Unternehmen in Hessen“.

- 25.02.2006: „Rolle rückwärts“.

- 28.10.2006: „Sperrgebiet in der Innenstadt“. (FAZ.NET - Rhein-Main-Zeitung)

- 24.04.2007: „Grün und kühn“.

Frankfurter Rundschau:

- 04.03.2004: „Wir wollen keinen neuen Wegezoll“.

- 24./25.03.2005: „Runder Tisch nun auf Touren“.

- 19.11.2005: „Hessen befreit Stadtbusse vom Wettbewerb“.

- 25.11.2005: „Land will Wettbewerb bei Bus und Bahn fördern“.

- 13.07.2006: „Fahrgäste zahlen mehr Geld für weniger Züge“.

- 27.09.2006: „Politiker bremsen bei City.Maut“.

- 15.02.2007: „Die Bahn hat ein Umweltproblem“.

- 24.04.2007: „Autofahrer sollen Straßen bezahlen“.

- 05.05.2007: „Deutsche Bahn zwingt mehr Kunden an die Automaten“.

Fraport AG (Hrsg.):“ Fraport weiter auf Erfolgskurs“. Pressemitteilung vom 06.03.2007, Frankfurt am Main 2007.

Freund, Bodo: „Hessen“. Gotha 2002.

Georgi, Anja und Christine, Wüst-Rocktäschel:

- „Videoaufzeichnung und Fahrgast-TV in der Vandalismusprävention - Erfahrungsbericht über ein Projekt der Offenbacher Verkehrs-Betriebe“. In: Der Nahverkehr 1-2/2005. Düsseldorf 2005. S. 60-63.

- „Neue Wege im Marketing - Die Nutzung klassischer und moderner Vertriebsmodule auf dem Weg eines Nahverkehrs-Unternehmens in die Zukunft“. In: Der Nahverkehr 3/2004. Düsseldorf 2004. S. 46-48.

Gesellschaft für Organisationsentwicklung GOE: „Leitlinien der GOE“. Köln und Weimar O.J. 
Göbel, Stefan: "get-in: Hanau führt die elektronische Fahrkarte ein". In: Stadtverkehr 3/2002. Freiburg 2002. S. 19-20.

Görn, Matthias und Krug, Hennig: „BSC auch für Aufgabenträger - Modernes Managementinstrument erhöht Effizienz und führt zu zielgenauem Mitteleinsatz". In: Der Nahverkehr 11/2002. Düsseldorf 2002. S. 25-29.

Götz, Eva: „Die Organisation des regionalisierten öffentlichen Personennahverkehrs Organisationsprofile und Gestaltungsmöglichkeiten für Aufgabenträger, Genehmigungsbehörden und Nahverkehrsunternehmen". Schriftenreihe Studien zur Stadt- und Verkehrsplanung, Band 3. Hamburg 2002.

Grote, Uwe; Himmelmann, Nils und Prim, Stefan: „Effizientere Fahrausweisprüfung Ertragssituation der Verkehrsunternehmen lässt sich nachhaltig verbessern“. In: Der Nahverkehr 10/2002. Düsseldorf 2002. S.61-66.

Halbritter, G; Fleischer, T.; Kupsch, C.; Kloas, J. und Voigt, U.: „Nationale Innovationsstrategien für neue Techniken und Dienste zur Erreichung einer ,nachhaltigen Entwicklung' im Verkehr". Wissenschaftliche Berichte des Forschungszentrum Karlsruhe in der Helmholtz-Gemeinschaft, FZKA 7157. Karlsruhe 2005.

Hammer, Antje und Scheiner, Joachim: „Lebensstile, Wohnmilieus, Raum und Mobilität Der Untersuchungsansatz von StadtLeben“. In: Beckmann, Klaus, J; Hesse, Markus; HolzRau und Unecke, Marcel (Hrsg.): „StadtLeben - Wohnen, Mobilität und Lebensstil“. Wiesbaden 2006. S. 15-30.

Handelsblatt

- vom 16.06.2005: „Die Mainmetropole ist die Verkehrsdrehscheibe Europas“. Düsseldorf 2005.

- vom 24.10.2005: „Kreditkarten-Anbieter suchen Systeme für den Einkauf der Zukunft". Düsseldorf 2005.

- $\quad$ vom 08.06.2006; Bus und Bahn müssen sparen“. S. 20. Düsseldorf 2006.

Harbich, Ronny; Kausch, Steffen; Guth, Dennis; Lanzendorf, Martin und Siedentorp, Stefan: „Mobilität im suburbanen Raum. Neue verkehrliche und raumordnerische Implikationen des räumlichen Strukturwandels - Teil B: Quantitative Analysen zur Mobilität in suburbanen Räumen“. Abschlussbericht des Forschungsvorhaben „Mobilität im suburbanen Raum“ des Bundesministeriums für Verkehr, bau- und Wohnungswesen. Dresden, Berlin/Erkner, Leipzig 2005.

Harbou, von, Joachim: „Hessen - hier schlagen das Herz der Wirtschaft und der Puls der Zeit": In: Wirtschaftsstandort Hessen - Chancen und Perspektiven eines Landes. Darmstadt 2006.

Hauff, Volker: „Zukunftsverträgliche Mobilität? - Mehr Fragen als Antworten“. In: Nachhaltigkeit und Gesellschaft - Vorträge aus dem Rat für Nachhaltigkeit, Entwicklung 2001 bis 2003. Texte Nr.3, Hrsg.: Hauff, Volker und Bachmann, Günther. Berlin 2003. S.177-184. 
Hauschildt, Heinz und Heger-Mehnert, Coco: „Kundenbindung an Rhein und Ruhr Aktive Fahrgastbetreuung statt passiver Fahrgastverwaltung". In: Der Nahverkehr 10/2004. Düsseldorf 2004. S. 63-66.

HEAG mobilo Gmbh: „Geschäftsbericht 2005“. Darmstadt 2006.

Heinrich, Caroline: „Außenwirtschaft und regionale Spezialisierung - Das Beispiel Hessen“. In: Esser, Josef und Schamp, Eike W. (Hrsg.): „Metrolpolitane Region in der Vernetzung - Der Fall Frankfurt am Main“. Frankfurt am Main 2001. S. 27-74.

Heinze, G. Wolfgang: „Rentabilität in der Fläche?“. Beitrag zum Arbeitsbericht „Streitfragen im Verkehrswesen: Verkehr im Spannungsfeld zwischen Fortschritt und öffentlicher Alimentierung". Ergebnisses des Workshop XIII im Themenfeld Verkehr und Raumstruktur der Akademie für Technologiefolgenabschätzung in Baden-Württemberg. Stuttgart 2001. S. 53-74.

Heller, Jochen: „Gewinnen und Binden von Fahrgästen durch Direktmarketing". In: Handbuch der kommunalen Verkehrsplanung, Teil 3.4.10.3. Bonn 2003.

Hemmersbach, Andreas, Roß, Andreas und Deckmann, Andreas: „Gerüstet für den Wettbewerb - Einführung der Centersteuerung und der Balanced Scorecard bei den Dresdner Verkehrsbetrieben“. In: Der Nahverkehr 11/2002. Düsseldorf 2002. S. 60-63.

Henning, Klaus und Marks, Siegfried: „Kommunikations- und Organisationsentwicklung“. Aachener Reihe Mensch und Technik, Band 1. Aachen 2000.

Henning, Klaus und Olbertz, Ellen (Hrsg.): „Mobilität und Telekommunikation“ . Aachener Reihe Mensch und Technik, Band 22. Aachen 1997.

Henning, Klaus und Schmidt, Silvia (Hrsg.): „Verbundprojekt Mobilität“. Aachener Reihe Mensch und Technik, Band 25. Aachen 1998.

Henning, Klaus: „Mobilität - Ethische Verantwortung angesichts neuer Möglichkeiten von Verkehr und Kommunikation". Aachener Reihe Mensch und Technik, Band 17. Aachen 1996.

Hertel, Günter: „Künftige Chancen einer nachhaltigen Mobilität“. In: Internationales Verkehrswesen 4/2000. Hamburg 2000. S. 132-135.

Hessischer Landtag (Hrsg.):

- Antwort der Landesregierung auf die Große Anfrage der Fraktion der SPD betreffend Verkehrswege in Hessen, Drucksache 15/3947 vom 7.11.2002. Wiesbaden 2002.

- Gesetz über die Feststellung des Haushaltsplans des Landes Hessen für das Haushaltsjahr 2005 (Haushaltsgesetz 2005) und zur Änderung der Hessischen Landeshaushaltordnung. In: Gesetz und Verordnungsblatt für das Land Hessen, Teil 1, Nr. 25 vom 20. Dezember 2004. Wiesbaden 2004.

- Gesetz über den öffentlichen Personennahverkehr in Hessen (ÖPNVG), Wiesbaden 2005.

- „21. Sitzung der Enquetekommission „Demographischer Wandel - Herausforderung an die Landespolitik“". Stenografischer Bericht der öffentlichen Anhörung 
vom 9. November 2005. http://www.hessischer-landtag.de/Dokumente/Plenarsitzungen/EKW-KB-21-oe.pdf. Zugriff am 5.2.2006.

Hessische Staatskanzlei (Hrsg.):

- „Hessen im Dialog - Staufreies Hessen 2015“. Begleitbroschüre zum Öffentlichen Kongress, o. S., Wiesbaden 2005 (a).

- „Hessische Gemeindeordnung (HGO) vom 25. Februar 1952 in der Fassung vom 1. April 2005; Quelle: http://www.hessenrecht.hessen.de/gesetze/33_kommunalwesen/331-1-hgo/hgo.htm. Zugriff am 20.11.2005 (b)

- „Modellprojekt Staufreies Hessen 2015“. Pressekonferenz vom 20.01.2005 (c).

Hessische Straßen- und Verkehrsverwaltung, HSVV (Hrsg.):

- „Mobilitätsdienstleister für Hessen“. Wiesbaden 2005.

- „Handbuch für Verkehrssicherheit und Verkehrstechnik“. Wiesbaden 2006 (a).

- „Leistungsbericht 2004/2005. Wiesbaden 2006 (b).

- „Die Rolle der Verkehrszentrale Hessen im Rahmen der Mobilitätssicherung“. Wiesbaden o. J.

Hessisches Landesamt für Umwelt (Hrsg.):

- „Emissionskataster in Hessen - Sachstand 1999“. Wiesbaden 1999.

- „Umweltatlas“. http://atlas.umwelt.hessen.de/atlas/index-ie.html. Wiesbaden 2006

Hessisches Ministerium für Umwelt, ländlichen Raum und Verbraucherschutz:

- „Luftreinhalteplan für den Ballungsraum Rhein-Main“. Wiesbaden 2002.

- „Aktionsplan Frankfurt am Main 2005“. Wiesbaden 2005.

- "Lokale Agenda 21 - Umsetzung in Hessen“. www.hmulv.hessen.de/irj/HMULV_Internet. Zugriff am 2.4.2006.

Hessisches Ministerium für Wirtschaft, Verkehr und Landesentwicklung:

- „Landesentwicklungsplan 2000“. Wiesbaden 2000.

- „Eckpunkte für den Wettbewerb - Öffentlicher Personennahverkehr in Hessen“. Wiesbaden 2002.

- Presseinformation vom 2.7.2003: „Dr. Riehl: Wettbewerb im ÖPNV wird Kosten senken und Effizienz steigern". Wiesbaden 2003 (a).

- Rede des Ministers Dr. Alois Rhiel zur 2. Veranstaltung der Reihe „Vorrang für Markt und Wettbewerb“" am 2.7.2003 in Kassel. Quelle: www.perspektive-wettbewerb.de/files/referat_minister.pdf. Zugriff am 20.11.2005. Wiesbaden 2003 (b).

- „Wettbewerb im Öffentlichen Personennahverkehr aus Sicht des Landes Hessen“. Wiesbaden 2004. 
Hinricher, Martina und Schüller, Ulrich: „Integrierte Verkehrspolitik - Ein Lösungskonzept für die Mobilität der Zukunft“. In: Internationales Verkehrswesen 12/2002. Hamburg 2002. S. 589-592.

Höchster Kreisblatt vom 14.12.2006: „Stadt spart bis zu 2 Mio. € $€^{\prime \prime}$

Höfler, L; Malinsky, A. H. und Priewasseer, R.: „Verkehrsverlagerung durch Beeinflussung der Verkehrsmittelwahl - Systematische, verkehrsplanerische und verhaltenswissenschaftliche Ansätze am Beispiel des o.ö. Zentralraumes“. Schriftenreihe für Umwelt und Gesellschaft, Reihe B, Band 4. Linz 2000.

Homburg, Christian und Krohmer, Harley: „Marketingmanagement“. Wiesbaden 2003.

Hoyer, Robert und Preil, Herbert: „Fahrgäste individuell informieren“. In: Der Nahverkehr 9/2004. Düsseldorf 2004. S. 72-76.

Huber, Felix; „Demografischer Wandel: Konsequenzen für den Nahverkehr“: Vortrag im Rahmen der 9. Kasseler Nahverkehrstage am 28./29.11.2005 in Kassel.

Hübler, Karl-Hermann und Kaether, Johann (Hrsg.): „Nachhaltige Raum- und Regionalentwicklung - wo bleibt sie? - Befunde, Perspektiven und Vorschläge“. Berlin 1999.

Hunecke, Marcel: „Chancen und Barrieren der Umsetzbarkeit von Leitbildern zur ökologischen Nachhaltigkeit im Bereich personenbezogener Mobilität“. In: Henning, Klaus und Schmid, Silvia (Hrsg.): Verbundprojekt „Mobilität“. Aachener Reihe Mensch und Technik, Bd. 25. Aachen 1998. S. 51-98.

Hunecke, Marcel und Schweer, Indra R.: „Einflussfaktoren der Alltagsmobilität - Das Zusammenwirken von Raum, Verkehrsinfrastruktur, Lebensstil und Mobilitätseinstellungen“. In: Beckmann, Klaus, J; Hesse, Markus; Holz-Rau und Hunecke, Marcel (Hrsg.): „StadtLeben - Wohnen, Mobilität und Lebensstil“. Wiesbaden 2006. S. 148-166.

Hunecke, Marcel; Schubert, Steffi; Zinn, Frank: „Mobilitätsbedürfnisse und Verkehrsmittelwahl im Nahverkehr". Internationales Verkehrswesen, 57. Jahrgang, Heft 1+2. Hamburg 2005. S. 26-33.

IHK-Arbeitsgemeinschaft Hessen (Hrsg.): „Verkehrsinfrastruktur Hessen - Forderungen der hessischen IHKs an funktionierende Verkehrswege“. Frankfurt am Main 2004.

IHK-Forum Rhein-Main (Hrsg.): „Rhein-Main-Region in Zahlen 2005“. Hanau 2005.

IHK Frankfurt am Main (Hrsg.): „Wirtschaftsstandort Frankfurt am Main“. Frankfurt am Main 2004.

IHK München und Münchener Zeitungsverlag (Hrsg.): „Wirtschaftsraum München - Oberbayern 2004“. München 2004.

IFMO (Institut für Mobilitätsforschung, unter Beteiligung der BMW Group, Deutsche Bahn AG, Lufthansa, MAN und Bundesministerium für Bildung und Forschung): „Zukunft der Mobilität - Szenarien für das Jahr 2025“. Erste Fortschreibung. München, Berlin 2005.

Informationsforum RFID, BITKOM, BDI (Bundesverband der Deutschen Industrie e.V.), GS1 Germany, HDE (Hauptverband des Deutschen Einzelhandels): „Gemeinsame Stel- 
lungnahme zu der Entschließung der 72. Konferenz der Datenschutzbeauftragten des Bundes und der Länder - Verbindliche Regelungen für den Einstz von RFIDTechnologien“. O.O. 2006.

Infoscore und Global Group: „Ertragssteigerung beim Kundenmanagement im Retailbanking“. Vortrag im Rahmen der „BankingWorld 2005“ vom 24.-26.01.2005 in Frankfurt am Main.

INFRAS und IWW, Institut für Wirtschaftspolitik und Wirtschaftsforschung an der Universität Karlsruhe (Hrsg.):“ Externe Kosten des Verkehrs - Aktualisierungsstudie“. Zürich, Karlsruhe 2004.

Infraserv (Hrsg.): „Feier für ein 13 Millionen-Euro-Projekt - Trimodalport im Industriepark Höchst fertiggestellt“. Pressemeldung vom 19.05.2004. Frankfurt am Main 2004.

Jansen, Lars: „Einführung der Chipkarte aus Sicher der Aufgabenträger“. Vortrag im Rahmen der 26. kontiki-Konferenz am 22. u. 23.06.06 in Rotterdam. Rotterdam 2006.

Jasper, Ute und Pooth, Stefan: „Rechtsticker Nahverkehr“. In: Nahverkehrs-praxis 3/2007. Dortmund 2007. S. 42.

Jensen, Ove und Fürst, Andreas: „In Search of Excellence: Das Fazit einer 20 Jahre währenden Suche“. In: Absatzwirtschaft 1/2004. Düsseldorf 2004. S. 44-47.

Jentsch, Volker: „Wider den Dilettantismus der Meinungsmacher!“: In: Mobilität - Ethische Verantwortung angesichts neuer Möglichkeiten von Verkehr und Kommunikation“. Aachener Reihe Mensch und Technik, Band 17, Aachen 1996. S. 127-132.

Kagermeier, Andreas: „Verkehrssystem- und Mobilitätsmanagement unter den Bedingungen des ländlichen Raums“. In: IMAGO - Berichte aus einem Projekt im BMBFFörderschwerpunkt „Personennahverkehr für die Region“. Paderborn 2004. S. 19-26.

Kahl, Arno: „Der öffentliche Personenverkehr auf dem Weg zum Wettbewerb“. Wien 2005.

Kanton Zürich, Amt für Verkehr: „Gesamtverkehrskonzept des Kantons Zürich“. Zürich 2006.

Kanzlerski, Dieter und Würdemann, Gerd: „Bewegen wir uns auf einem nachhaltigen (Fahr-) Weg?“. In: Informationen zur Raumentwicklung, Heft 1/2 2002. Bonn 2002. S. 4757.

Keppeler, Bernhard; Kröpel, Stefan; Sinisalo, Kimmo und Sirkiä, Ari: „Nutzung des ETicketings für die Analyse der Verkehrsnachfrage“. In: Sonderdruck der Zeitschrift „Der Nahverkehr" 6/2005. Düsseldorf 2005.

Keutling, Ulrich T.: „NFC und Mobilfunk als Enabler für RFID“. Präsentation zu einem vodafone-Vortrag im Rahmen des Cebit Forum RFID auf der Cebit 2006.

Klühspies, Johannes: „Stadt - Mobilität - Psyche: Mit gefühlsbetonten Verkehrskonzepten die Zukunft urbaner Mobilität gestalten?“. In: Stadtforschung aktuell, Band 71. Basel 1999. 
Klumpp, Dieter: „Wissensmanagement: Rolle der Information und Kommunikation für nachhaltige Mobilitätskonzepte“. In: Für eine neue deutsche Verkehrspolitik - Mobilität braucht Kommunikation. Hrsg.: Stopka, Ulrike und Pällmann, Wilhelm. Hamburg 2005. S. $150-160$.

Knieps, Manfred: „Aufgabenträger oder Verkehrsunternehmen als Gesellschafter von Verkehrsverbünden ? - eine Analyse bestehender Verbundstrukturen und eine Bewertung unterschiedlicher Organisationsmodelle unter institutionenökonomischen Gesichtspunkten“. Dissertation. Gießen 2004.

Koch, Roland und Steinbrück, Peer: „Subventionsabbau im Konsens“. 115-seitiges Vorschlagspapier der Ministerpräsidenten Roland Koch und Peer Steinbrück zum Subventionsabbau in Deutschland. O.O. 2003.

Kölnische Rundschau vom 12.03.2006: „Immer mehr gefälschte Fahrkarten“.

KompetenzCenter Elektronisches FahrgeldManagement des Landes NRW (Hrsg.): „Neuer Standard, mehr Qualität - Die VDV-Kernapplikation und ihre Bedeutung für den Nahverkehr in Nordrhein-Westfalen“. Gelsenkirchen 2005.

Korndörfer, Wolfgang: „Allgemeine Betriebswirtschaftslehre“. Wiesbaden 1992.

Kossak, Andreas:

- "City-Maut: Thema für Deutschland?“. In: Der Nahverkehr 4/2004. Düsseldorf 2004. S. 10-12.

- "Quo vadis, elektronisches Ticketing?“. In: Der Nahverkehr 7-8/2005. Düsseldorf 2005. S. 14-20.

Kossak, Andreas und Pällmann, Wilhelm: „Vier Phasen der ÖPNV-Modernisierung” Die Innovationen des Nahverkehrs in Deutschland seit 1945“. In: Der Nahverkehr 10/2006. Düsseldorf 2006. S. 23-27.

Kotler, Philip: „Marketing - Märkte schaffen, erobern und beherrschen“. München 2003.

Kreiswerke Heinsberg GmbH (Hrsg.): „Nahverkehrsplan für den Kreis Heinsberg“. Heinsberg 1997.

Kretschmann, Caroline: „Produktmanagement im Öffentlichen Personennahverkehr". Schriftenreihe des Instituts für Öffentliche Dienstleistungen und Tourismus. Bern, Stuttgart, Wien 2001.

Krüger, Sascha und Seelmann-Eggebert, Jörg: „IT-Architekur Engineering“. Bonn 2003.

Landtag Nordrhein-Westfalen: „Teilbericht der Enquête-Kommission Zukunft der Mobilität - Integrierte Gesamtverkehrsplanung in NRW: Möglichkeiten, Grundsätze und Empfehlungen“. Drucksache 12/3246 vom 22.10.1998. Düsseldorf 1998.

Lehmann, Carsten: „Effiziente Koordination von Verkehrsleistungen im Öffentlichen Personennahverkehr - Eine mikroökonomische Analyse“. Beiträge aus dem Institut für Verkehrswissenschaft an der Universität Münster, Heft 150; Hrsg.: Karl-Hans Hartwig. Göttingen 2000. 
Lehr, Ursula: „Die Jugend von gestern und die Senioren von morgen“. In: Aus Politik und Zeitgeschichte (Beilage zur Wochenzeitschrift „Das Parlament”), B 20/2003. Berlin 2003. S. 3-5.

Lo, Vivien: „Zwischen regionalen und globalen Beziehungen - Wissensbasierte Netzwerke im Finanzsektor“. In: Esser, Josef und Schamp, Eike W. (Hrsg.): „Metrolpolitane Region in der Vernetzung - Der Fall Frankfurt am Main“. Frankfurt am Main 2001. S. 131-153.

Lotter, Wolf: „Stoffwechsel“. In: brandeins, Heft 04/2005. Hamburg 2005. S. 50-59.

Lucas, Rainer: „Von der regionalisierten Strukturpolitik zur nachhaltigen Regionalentwicklung - Regionale Politikkonzepte im Zeitalter der Globalisierung“" Wuppertal papers 101 der Wuppertal Institut für Klima, Umwelt, Energie GmbH, April 2000. Wuppertal 2000.

Lufthansa Systems Group (Hrsg.): “ Lufthansa Systems realisiert e-Ticket Interlining zwischen Air Canada und Lufthansa“. Pressemeldung vom 07.12.2004.

Lunkenheimer, Jörg: „Der Rhein-Main-Verkehrsverbund - 10 Jahre Mobilität für die Region“. In: Eisenbahntechnische Rundschau, Heft 11/2005. Hamburg 2005. S. 679-688.

Maertins, Christian: „Die Intermodalen Dienste der Bahn: Mehr Mobilität und weniger Verkehr?“. WZB - discussion paper SP III 2006-101. Berlin 2006.

Maier, Jörg und Beck, Rainer: „Allgemeine Industriegeographie“. Gotha 2001.

Mager, Thomas J. und Raif, Stephan K. H.: "Werbung im ÖPNV - aber bitte richtig!". In: Nahverkehrspraxis, Heft 7-8/2004. Dortmund 2004. S. 30-33.

Marketing Corporation: „Mangelhafte Servicekultur in Deutschland - König Kunde entthront". www.innovations-report.de/html/berichte/studien/bericht-28233.html (Zugriff am 9.10.2005)

Meffert, Heribert; Perrey, Jesko; Schneider, Helmut:" Grundlagen marktorientierter Unternehmensführung im Verkehrsdienstleistungsbereich“. In. Meffert, Heribert (Hrsg.): Verkehrsdienstleistungsmarketing. Marktorientierte Unternehmensführung bei der Deutschen Bahn AG. Wiesbaden 2000. S. 1-55.

Megger, Lothar und Vorgang, Klaus: „VRR: Innovatives Ticketingsystem baut Zugangsbarrieren ab“. In: Der Nahverkehr 11/2000 (Sonderdruck). Düsseldorf 2000.

Mehdorn, Hartmut: „Die Deutsche Bahn auf dem Weg zum globalen Mobilitäts- und Logistikkonzern“. Witten 2006.

Meyer, Anton: „Offensives Marketing - Unverzichtbarer Bestandteil für die Zukunftsgestaltung des ÖPNV“. Vortrag im Rahmen des 1. VDV-Marketingkongresses in Dresden am 11.04.2005.

Meyer, Anton und Specht, Mark: „Rigorose Kundenorientierung im Schienenverkehr“. In: Eisenbahn Ingenieur Kalender 2001. Hamburg 2002. S. 375-392.

Mietsch, Fritjof: „Mobilität und Kommunikation - Eine verkehrspolitische Agenda für Deutschland“. In: Für eine neue deutsche Verkehrspolitik - Mobilität braucht Kommunikation. Hrsg.: Stopka, Ulrike und Pällmann, Wilhelm. Hamburg 2005. S. 8-47. 
Müller, Guido. „Mobilität organisieren - Rahmenbedingungen für ein effektives Mobilitätsmanagement“. In: Internationales Verkehrswesen 9/2004. Hamburg 2004. S. 371-378.

Müller, Sascha und Rau, Andrea: Qualitäten und Standards für den ÖPNV in Städten. In: Der Nahverkehr 4/1997. Düsseldorf 1997. S. 28-33.

MVG Münchner Verkehrsgesellschaft mbH und DB Regio AG S-Bahn München (Hrsg.): „Schlechte Zeiten für Schwarzfahrer“. Pressemitteilung vom 28.05.2004. München 2004.

Murtz, Bernhard. „Ticketing per Handy - Ein Steinchen im Mosaik der Vertriebskanäle”. In: Nahverkehrspraxis, Nr. 3/2004. Dortmund 2004. S. 7-9.

Nassauische Neue Presse vom 17. Februar 2005: „Ziel: Täglich 3000 ICE-Fahrgäste“.

Nennen, Heinz-Ulrich: „Daseinsvorsorge: Zwischen Staat und Gesellschaft”. Beitrag zum Arbeitsbericht "Streitfragen im Verkehrswesen: Verkehr im Spannungsfeld zwischen Fortschritt und öffentlicher Alimentierung“. Ergebnisses des Workshop XIII im Themenfeld Verkehr und Raumstruktur der Akademie für Technologiefolgenabschätzung in Baden-Württemberg. Stuttgart 2001. S. 31-52.

Nittinger, Klaus und Kuchenbecker, Michael: „Sicher unterwegs, gut informiert, besser vernetzt - Zwischenbilanz eines Arbeitsjahres“. Informationsbroschüre des Impulskreis Mobilität und Logistik in der Initiative „Partner für Innovation“. Stuttgart 2005. S. 30-32

Nolte, Roland: „Chancen und Risiken des Einsatzes von Telematiksystemen im Verkehr“. In: Henning, Klaus und Olbertz, Ellen (Hrsg.): „Mobilität und Telekommunikation“, Aachener Reihe Mensch und Technik, Band 22. Aachen 1997. S. 79-89.

Nuhn, Helmut und Hesse, Markus: „Verkehrsgeographie“. Paderborn 2006.

o. V.: „Runder Tisch Fahrradverkehr in Frankfurt/Main“. In: Verkehrszeichen, Heft 3/2004. Mühlheim an der Ruhr 2004. S. 30.

o. V.: „Future Touch“. In: connect, Heft 5/2005. Stuttgart 2005. S. 16-21

o.V.: „Betreiberwechsel auf der Odenwaldbahn - ,Sardino’ für Pendler“. In: Der Fahrgast 4/2006, S. 7-15. Berlin 2006.

Ordon, Christian:

- „get»in - Der Einstieg des Rhein-Main-Verkehrsverbundes in das Elektronische Fahrgeldmanagement". In: Nahverkehrspraxis Nr. 3/2002. Dortmund 2002 S. 1113.

- „Datenschutz contra Kundenbindung im E-Ticketing?“. In: Stadtverkehr 3/2004. Freiburg 2004. S. 26-27.

Pällmann, Wilhelm: „Zehn Thesen zur künftigen Verkehrspolitik“. In: Für eine neue deutsche Verkehrspolitik - Mobilität braucht Kommunikation. Hrsg.: Stopka, Ulrike und Pällmann, Wilhelm. Hamburg 2005. S. 173-179. 
Pauli, Bernhard und Schindler, Thilo: „Telematikdienste - Ein Ausweg aus dem drohenden Verkehrschaos?“. München 2001.

Pernack, Roman: „Öffentlicher Raum und Verkehr - Eine sozialtheoretische Annäherung“. Discussion Paper SP III 2005-104, Wissenschaftszentrum Berlin für Sozialforschung. Berlin 2005.

Petersen, Knut; Weigele, Stefan; Colberg, Tilmann und Wagner-Davidsmeyer, Almuth: „Systematisches Ertragsmanagement im ÖPNV - Benchmarkingkreis ermittelt Einnahmepotenziale im ÖPNV“. In: Der Nahverkehr 10/2004. Düsseldorf 2004. S. 46-51.

Planungsverband Ballungsraum Frankfurt/Rhein-Main, TraffiQ Lokale Nahverkehrsgesellschaft Frankfurt am Main und Nordhessischer Verkehrsverbund (Hrsg.): Mobilität in Stadt und Region - Verkehrsverhalten der Bevölkerung in Rhein-Main und Hessen. Frankfurt am Main, Kassel 2005.

Planungsverband Ballungsraum Frankfurt/Rhein-Main (Hrsg.):

- „Mobilität in Ballungsräumen - Herausforderungen und Lösungsansätze“. Dokumentation einer Fachtagung in Frankfurt am Main am 11.11.2003, Frankfurt am Main 2003.

- „Regionales Monitoring 2005“. Frankfurt am Main 2005(a).

- „Frankfurt/Rhein-Main 2020 - die europäische Metropolregion“. Frankfurt am Main 2005 (b).

Potsdamer Neueste Nachrichten vom 02.12.2006: „VBB will Sperren für Bahnsteige“.

Preuss, Peter: „RFID Smart Cards und NFC Mobiltelefone im ÖPNV“. Vortrag im Rahmen des BITKOM-Forums RFID am 12.03.2006 in Hannover.

Prognos AG: "Zukunftsatlas 2004 - Deutschlands Regionen im Zukunftswettbewerb". www.prognos.de/zukunftsatlas.

ProgTrans AG und HSW Luzern (Hrsg.): „Bedeutung des ÖPNV“ Studie im Auftrag des Verband Deutscher Verkehrsunternehmen im Rahmen der VDV-Kampagne „Damit Deutschland mobil bleibt“. Basel 2005.

Puls, Thomas; „Verkehrsinfrastruktur in Deutschland“. Köln 2004.

Püttner, Günter (Hrsg.): „ÖPNV in Bewegung - Konzepte, Probleme, Chancen“. Schriftenreihe der Gesellschaft für öffentliche Wirtschaft, Heft 46. Baden-Baden 2000.

Rat für Nachhaltige Entwicklung (Hrsg.): „Ideale, Ideen, Impulse - Der Rat für Nachhaltige Entwicklung stellt sich vor“. Neuauflage Mai 2006. Berlin 2006.

Rauschenberg, Rainer H.: „Potentiale für die Verringerung der externen Effekte des Verkehrssektors durch einen dezentralisierten und automatisierten Gütertransport der Bahn". Dissertation am Fachbereich Wirtschaftswissenschaften der Universität Frankfurt am Main. Frankfurt am Main 1999.

Regierungskommission Deutscher Governance Kodex (Hrsg.): „Deutscher Corporate Governance Kodex“. Fassung vom 12.06.2006. O.O. 2006. 
Reinhold, Tom: „Wie sich mit den richtigen Marketingkonzepten Ertragssteigerungen erreichen lassen“. Vortrag im Rahmen der CITOP 2006 am 24.10.2006

Reinsch, Carlos: „Fahrgastinformation via SMS“. In: Der Nahverkehr 10/2004. Düsseldorf 2004. S. 60-62.

Rhein-Main-Verkehrsverbund GmbH (Hrsg.):

- „Stationsentwicklungsplan“, RMV-Heft Nr. 5, Hofheim am Taunus 1996 (a).

- „Neue finanzielle Grundlagen für den lokalen Nahverkehr“, RMV-Heft Nr. 7, Hofheim am Taunus 1996 (b).

- „Verbundbericht 1997“. Hofheim am Taunus 1998.

- „Verbundbericht 1998“. Hofheim am Taunus 1999.

- „Bike+Ride im Umweltverbund“, RMV-Heft Nr. 10. Hofheim am Taunus 2000.

- „Regionaler Nahverkehrsplan des Rhein-Main-Verkehrsverbundes 2004-2009“. Hofheim am Taunus 2004 (a).

- "Verbundbericht 2003“. Hofheim am Taunus 2004 (b)

- „Der Rhein-Main-Verkehrsverbund - Eine Erfolgsstory der Region“. Hofheim am Taunus 2005.

- RMV-Pressemitteilung vom 18.11.2005: „Mit der neuen RMV-Fahrkarte die Region erleben".

- „10 Jahre RMV: Eine Region feiert Mobiläum - Verbundbericht 2005“. Hofheim am Taunus 2006 (a).

- „Tarifinformationen 2007“. Hofheim am Taunus 2006 (b).

- RMV-Pressemitteilung vom 19.04.2007: „Handy-Ticketing für alle Hanauer“.

- RMV-Pressemitteilung vom 28.09.2006: „HandyTicket erfolgreich gestartet“.

- RMV-Pressemitteilung vom 14.11.2006: „Region bekennt sich zur Regionaltangente".

Riehl, Alois:

- „Das Besteller-Ersteller-Prinzip - Ein Kernstück des neuen Hessischen ÖPNVGesetzes“. In: Nahverkehrspraxis, 53. Jg., Heft Nr. 9/2005. Dortmund 2005. S. 1.

- „Herausforderungen für den Wirtschaftsstandort Hessen“. Marburger Volkswirtschaftliche Beiträge Nr. 03/2006. Marburg 2006.

Ring, Peter: „Gutachten Wirtschaftsstandort Frankfurt am Main“. Studie im Auftrag der Industrie- und Handelskammer Frankfurt am Main, Frankfurt am Main 2004.

Rosol, Christoph: „Wanzen für die Welt”. In: brandeins 10/06. Hamburg 2006. S. 42-51.

Rother, Frank und Vitt, Jan: „Benchmarking im ÖPNV“. In: Internationales Verkehrswesen 6/1999. Hamburg 1999. S. 261-263. 
Rüffer, Peter: „Nutzwert im Visier - E-Ticketing-Konzepte müssen sich mausern“. In: Card-Foum 09/2004. Lüneburg 2004. S. 45-47.

Rumpke, Christian A.:" Marketinginstrumente bei Mobilitätsdienstleistungen im Öffentlichen Personennahverkehr (ÖPNV) in Deutschland - Wirkungen, Hindernisse und Konsequenzen“. Berlin 2005.

Sachverständigenrat für Umweltfragen: „Umwelt und Straßenverkehr - Hohe MobilitätUmweltverträglicher Verkehr“. Eckpunkte des Sondergutachtens. Berlin 2005.

Schad, Helmut; Riedle, Hubert; Höffken, Michael und Bihn, Friedhelm: „Oft unterschätzt: Der ÖPNV als Standortfaktor“. In: Der Nahverkehr 6/2000. Düsseldorf 2000. S. 21-25.

Schade, Jens und Schlag, Bernhard: „Akzeptierbarkeit von Nachfragemanagement- und Preismaßnahmen in europäischen Städten“. In: Internationales Verkehrswesen, Heft 3/2001. Hamburg 2001. S. 72-77.

Schäfer, Frank: „Change Management für den öffentlichen Dienst“: Hamburg 2005.

Schäfer-Sparenberg, Carolin; Bongardt, Daniel und Dalkmann, Holger: „Steuerung nachhaltiger Daseinsvorsorge im öffentlichen Nahverkehr - Politische Handlungsperspektiven“. Wuppertal Paper Nr. 161 der Wuppertal Institut für Klima, Umwelt, Energie GmbH. Wuppertal 2006.

Schätzl, Ludwig: „Wirtschaftsgeographie 1 - Theorie“. Paderborn 2003.

Schiener, Joachim: „Standortbewegungen und Wohnmobilität“. In: Beckmann, Klaus, J; Hesse, Markus; Holz-Rau und Unecke, Marcel (Hrsg.): „StadtLeben - Wohnen, Mobilität und Lebensstil“. Wiesbaden 2006. S. 67-92.

Schierenbeck, Henner: „Grundzüge der Betriebswirtschaftslehre“. München 1993.

Schliephake, Konrad: „Verkehrsgeographie“. In: Sozial- und Wirtschaftsgeographie 2. München 1982. S. 39-159.

Schnippe, Christian: „Psychologische Aspekte der Kundenorientierung. Die Kundenzufriedenheit mit der Qualität von Dienstleistungsinteraktionen am Beispiel des ÖPNV. Frankfurt am Main 2000.

Schnüll, Robert: „Zielorientierte Mobilitätsplanung als Beitrag zur Nachhaltigkeit im Verkehrswesen“. In: Aus Politik und Zeitgeschichte (Beilage zur Wochenzeitschrift „Das Parlament"), B 45-46/2000. Berlin 2000.

Schöller, Oliver (Hrsg.): „Öffentliche Mobilität - Perspektiven für eine nachhaltige Verkehrsentwicklung“. Wiesbaden 2005.

Scholz, Ralf: „Lokale Regieorganisation im Jahr 2010“. In: Der Nahverkehr 6/2006. Düsseldorf 2006. S. 45-48.

Schrameyer, Eberhard und Burggraf, Peter. „Managementstrategien zur Kundenbindung bei den KVB“. In: Der Nahverkehr 4/2003. Düsseldorf 2003. S. 27-30.

Schuster, Bernd: „Möglichkeiten und Grenzen, Projektbeispiele aus Hessen“. Beitrag zum Arbeitsbericht „Streitfragen im Verkehrswesen: Verkehr im Spannungsfeld zwischen 
Fortschritt und öffentlicher Alimentierung“. Ergebnisses des Workshop XIII im Themenfeld Verkehr und Raumstruktur der Akademie für Technologiefolgenabschätzung in Baden-Württemberg. Stuttgart 2001. S. 13-20.

Sell, Axel: „Die Genesis von Corporate Governance“. In: Knorr/ Lemper/ Sell/ Wohlmuth (Hrsg.): „Berichte aus dem Weltwirtschaftlichen Colloquium der Universität Bremen“. Nr. 94/2004. Bremen 2004.

Siebert, Horst.:

- „Regionales Wirtschaftswachstum und interregionale Mobilität“. Tübingen 1970.

- „Internationale Migration aus wirtschaftswissenschaftlicher Sicht. In: Geographische Rundschau. 1995, 47. S. 405-409.

Sinus Sociovision (Hrsg.): „Zielgruppen, die es wirklich gibt“. Heidelberg 2006.

Socialdata (Hrsg.):"München setzt auf den Umweltverbund. Chancen für Verhaltensänderungen“. Broschüre der Stadt Landeshauptstadt München, Stadtwerke München, Referat Stadtplanung und Bauordnung. München 1993.

Sommer, Carsten:

- "Gehen dem ÖPNV die Gäste aus?“. In: Der Nahverkehr 5/2005. Düsseldorf 2005. S. 7-11

- „Ring and Ride - multifunktionales, mobilfunkgestütztes Handy-Ticketing“. Vortrag im Rahmen der 27. kontiki-Konferenz in Frankfurt a.M. am 28. und 29.09.2006.

Sparkassen-Finanzportal GmbH (Hrsg.): „Online zahlt man giropay - Das neue Bezahlverfahren im Internet“. http://www.sparkasse.de/privatkunden/Konten_und_Karten/ giropay_pk.html. Zugriff am 18.2.2006.

Sparmann, Jürg:

- Integriertes Verkehrsmanagement Region Frankfurt RheinMain“. Vortrag im Rahmen der 9. Kasseler Nahverkehrstage am 28./29.11.2005.

- „Strategien und Maßnahmen zur Mobilitätssicherung - dargestellt am Beispiel der Region Frankfurt RheinMain“. Vortrag im Rahmen des Verkehrswissenschaftlichen Kolloquiums an der Universität Karlsruhe am 23.6.2006. Karlsruhe 2006.

Sparmann, Volker:

- "Gemeinsam den ÖPNV voranbringen“. In: Der Nahverkehr 11/2005. Düsseldorf 2005. S. 6.

- „Mit ,E-Ticketing' in die Mobilität des 21. Jahrhunderts“. In: Für eine neue deutsche Verkehrspolitik - Mobilität braucht Kommunikation. Hrsg.: Stopka, Ulrike und Pällmann, Wilhelm. Hamburg 2005. S. 66-75.

Sparmann, Volker und Ordon, Christian: „VIAtec - Electronic Ticketing - Stärkere Kundenorientierung und höhere Wirtschaftlichkeit im RMV“. In: Der Nahverkehr 7-8/1999. Düsseldorf 1999. S. 18-22. 
Stadt Frankfurt am Main, Bürgeramt, Statistik und Wahlen (Hrsg.): "Frankfurt Statistik aktuell“"

- „Einpendlerzentrum Frankfurt am Main am 30. Juni 2002“. Nr. 3/2004. Frankfurt am Main 2004.

- „Anhaltender Beschäftigungsabbau in Frankfurt am Main zwischen März 2003 und 2004“. Nr. 13/2005. Frankfurt am Main 2005.

- „Frankfurt am Main im Städtevergleich: Erwerbstätige und Arbeitsplatzdichte 2003“. Nr. 14/2005, Frankfurt am Main 2005.

- „Familienstrukturen in Frankfurt am Main 2001 bis 2004“. Nr. 24/2005. Frankfurt am Main 2005.

- „Die größten Stadtprobleme aus Sicht der Frankfurterinnen und Frankfurter - Ergebnisse der Bürgerbefragung vom Dezember 2005“. Nr. 14/2006. Frankfurt am Main 2006.

- „Statistisches Jahrbuch Frankfurt am Main 2006“. Frankfurt am Main 2006.

Stadt Frankfurt am Main, Dezernat Planung und Sicherheit, Stadtplanungsamt (Hrsg.): „Entwicklung der Mobilität in Frankfurt am Main 1998-2003“. Frankfurt am Main 2004.

Stadt Frankfurt am Main, Umweltamt; Hessisches Ministerium für Umwelt, ländlichen Raum und Verbraucherschutz und Hessisches Ministerium für Wirtschaft, Verkehr und Landesentwicklung: „Luftreinhalteplan für den Ballungsraum Rhein-Main - Rechtliche und medizinische Maßnahmen, Quellen der Verschmutzung, Maßnahmenplanung“. Tagungsband einer Veranstaltung vom 7.7.2004 in Frankfurt am Main. Frankfurt am Main 2004.

Statistisches Bundesamt (Hrsg.): „Verkehr in Deutschland 2006“. Wiesbaden 2006.

Stauss, Bernd: "Grundlagen des Marketing öffentlicher Unternehmen“. Baden Baden 1987.

Stein, Axel und Wolf, Ulrike: „Mobilität im suburbanen Raum. Neue verkehrliche und raumordnerische Implikationen des räumlichen Strukturwandels - Teil C: Regionale Fallstudien". Abschlussbericht des Forschungsvorhaben "Mobilität im suburbanen Raum" des Bundesministeriums für Verkehr, bau- und Wohnungswesen. Dresden, Berlin/Erkner, Leipzig 2005.

Sterzenbach, Rüdiger: „ÖPNV-Marketing - Ein Lehr- und Handbuch“. 2. überarbeitete Auflage. München 2001

Storchmann, Karl-Heinz: „Das Defizit im öffentlichen Personennahverkehr in Theorie und Empirie“. Essen 1999. 
Tiefensee, Wolfgang: „Mobilität als Standortfaktor“. Rede des Bundesministers anlässlich der Mobilitätsoffensive am 11.04.2006 in Berlin. Hrsg.: Bundesministerium für Verkehr, Bau und Stadtentwicklung. Berlin 2006

Töpfer, Klaus. „Was alle angeht, können nur alle lösen. Deutsche Umweltpolitik auf dem Prüfstand“. O.O. 1993.

Topp, Hartmut:

- „Stadtverkehr im nächsten Jahrzehnt und die Chancen des Fahrrads“. In: Internationales Verkehrswesen 5/2002. Hamburg 2002. S. 216-220.

- „Perspektiven des Nahverkehrs in einer wachsenden Metropolregion“. In: Der Nahverkehr 1-2/2006. Düsseldorf 2006 (a). S. 21-26.

- „Mobil \& barrierefrei in Stadt und Verkehr“. Vortrag im Rahmen der Tagung "Mehr Wert für @alle“ des Instituts für Technologie und Arbeit der Technischen Universität Kaiserslautern am 10.05.2006. Kaiserslautern 2006 (b).

TraffiQ Lokale Nahverkehrsgesellschaft Frankfurt am Main mbH (Hrsg.):

- „Geschäftsbericht 2002. Frankfurt am Main 2003.

- „Geschäftsbericht 2005. Frankfurt am Main 2006.

Trapp, Oliver: „Die betriebliche Einführung eines fahrerlosen U-Bahn-Systems“. In: Der Nahverkehr 11/2004. Düsseldorf 2004. S.15-18.

Treber, Manfred: „Verkehr in deutschen Städten - wichtiges Handlungsfeld bei der Umsetzung der Rio-Beschlüsse“. Bonn 1993

Treiber, Martin: „Verkehr verstehen und beherrschen“. In: Für eine neue deutsche Verkehrspolitik - Mobilität braucht Kommunikation. Hrsg.: Stopka, Ulrike und Pällmann, Wilhelm. Hamburg 2005. S. 76-85.

Trend-Research (Hrsg.): “E-Ticketing - Trendstudie”. Bremen 2004.

Tutt, Cordula: „Das große Schrumpfen - Von Wohlstandsinseln und Verliererregionen in Deutschland“. In: WZB-Mitteilungen Heft 112, 06/2006. Berlin 2006. S. 19-22.

Ude, Christian: „Städte und ÖPNV“. In: Der Nahverkehr 7-8/2002. Düsseldorf 2002. S. 813.

UIC - Internationaler Eisenbahverband: „Der Weg zur Nachhaltigen Mobilität. Die externen Kosten des Verkehrsreduzieren“. Paris, Brüssel 2000.

UITP - Internationaler Verband für öffentliches Verkehrswesen: „Für mehr Lebensqualität“. Brüssel 2005.

Umlandverband Frankfurt (Hrsg.):

- „Verkehrsströme in der Region Frankfurt RheinMain“. Frankfurt am Main 1999.

- „Generalverkehrsplan 2000“. Frankfurt am Main 2000. 
Umwelt- und Prognose-Institut e.V., UPI (Hrsg.): „Scheinlösungen im Verkehr“ . 4. erweiterte Auflage. Heidelberg 1993.

Umweltbundesamt (Hrsg.):

- „Technischer Fortschritt und Bewußtseinswandel sind die Schlüssel für eine dauerhafte umweltgerechte Entwicklung“. Pressemitteilung vom 18.06.1997. Berlin/Bonn 1997.

- „Fluglärmwirkungen“. Berlin 2000.

- „Modellierung von Feinstaubemissionen in Europa“. Forschungsbericht 29943 249 des Internationalen Instituts für angewandte Systemanalyse, Laxenburg, Österreich. Berlin 2002 (a).

- Möglichkeiten der Umweltentlastung und Kostenreduzierung im Verkehr durch Verkehrsplanung - mit Leitfaden für die LCTP-Anwendung in Kommunen“. Kurzfassung des Schlussberichts. Texte 23/2002. Berlin 2002 (b).

- „Konzeption zur Finanzierung eines umweltverträglichen öffentlichen Personennahverkehrs (ÖPNV) - Diskussionspapier“. Berlin 2003 (a).

- " „CO $\mathrm{CO}_{2}$-Minderung im Verkehr“. Berlin 2003 (b).

- "Qualitätsziele und Indikatoren für eine nachhaltige Mobilität - Anwenderleitfaden“. Dessau 2005 (a).

- „Lokal handeln: Nachhaltige Mobilitätsentwicklung als kommunale Aufgabe Entwurf für ein Gemeindeverkehrsplanungsgesetz (E-GVPlG)“. Kurzfassung eines Forschungsberichts der Forschungsgruppe Kommunale Verkehrsplanung an der Universität Hamburg, Fachbereich Rechtswissenschaften, zur „Entwicklung des rechtlichen Rahmens für eine verbindliche Verkehrsimmissionsschutzplanung in Städten und Regionen als Beitrag zur Kommunalen Agenda 21“. Hamburg 2005 (b).

- " $\mathrm{CO}_{2}$-Emissionsminderung im Verkehr“. O.O. 2006 (Internetpräsens des Umweltbundesamtes).

Umweltfairbund Südhessen (Hrsg.): „Feinstaub - nur weniger Verkehr verringert die Belastung". Ausgabe 2/2005. Darmstadt 2005.

Unabhängiges Landeszentrum für Datenschutz Schleswig-Holstein: „Wettbewerbsvorteile durch Datenschutz". Pressemitteilung vom 20.02.2002. Kiel 2002.

Verband Deutscher Verkehrunternehmen (VDV) (Hrsg.):

- „Telematik im ÖPNV in Deutschland“. Düsseldorf 2001.

- „Klimaschutz im Verkehr“. Köln 2003 (a).

- „VDV-Jahresbericht 2002/03“. Köln 2003 (b).

- „Mit uns kommen alle weiter“, Köln 2004 (a).

- „Benchmarking im Vertrieb“. VDV-Mitteilung Nr. 9713. Köln 2004 (b). 
- „Der Standard für das elektronische Fahrgeldmanagement in Deutschland: Die VDV-Kernappliaktion“. www.vdv.de/wir_ueber_uns/vdv_projekte/vdvkernapplikation_efm. Zugriff am 5.2.2006.

Verkehrsinfrastrukturfinanzierungsgesellschaft (Hrsg.): „Die Rolle der VIFG und von PPP in Deutschland“. Vortrag auf dem Workshop „Finanzierung von Fernstraßen in der Schweiz und in Deutschland“ am 23.05.06 in Berlin. Berlin 2006.

WCED World Commission on Environment and Development: "Our Common Future Brundtland-Bericht". Oxford/New York 1987.

Weizsäcker, Ernst Ulrich von; Young, Oran R. und Finger, Matthias: „Limits to Privatization - A Report to the Club of Rome“. London 2004.

Wagner, Horst-Günter: „Wirtschaftsgeographie“. Braunschweig 1998.

Werner, Jan: „Die derzeitige Marktsituation im ÖPNV - Entwicklungen in Deutschland und Europa“. Vortrag anlässlich der 2. Veranstaltung der Reihe "Vorrang für Markt und Wettbewerb“ am 2.7.2003 in Kassel. Wiesbaden 2003.

Werner, Patrick: „Marketing: Eine Aufgabe für das gesamte Unternehmen“. In: Verkehr und Technik 7/1997. Berlin 1997. S.314-317.

Wiesbadener Kurier (Rhein-Main-Presse):

- vom 16.01.2006: „Elektronischer Fahrschein kommt später“.

- vom 19.08.2006: „Großer Bahnhof für die Industriekultur“.

- vom 07.09.2006: „Eschborn ist Hessens Krösus“.

- vom 25.01.2007: „Thema des Tages - Die Doppik“.

- vom 14.02.2007: „Nachtflugverbot als Zankapfel“.

- Vom 07.03.2007: „Thema des Tages - Sperrzonen für Staubschleudern“.

Will, Wolfgang: „Neuer Ordnungsrahmen für den ÖPNV“. In: Der Nahverkehr 1-2/2001. Düsseldorf 2001. S. 28-33.

Wirtz, Bernd W.: „Electronic Business“. Wiesbaden 2001.

Wissenschaftlicher Beirat beim Bundesministerium für Verkehr, Bau- und Wohnungswesen: „Möglichkeiten und Grenzen des Einsatzes von Telematik im Verkehr - Stellungnahme vom Juli 2003“. In: Internationales Verkehrswesen 12/2003. Hamburg 2003. S. 599607.

Wissenschaftszentrum Berlin für Sozialforschung (WZB), Projektgruppe Mobilität (Hrsg.): „Kurswechsel im ÖPNV - mit automobilen Angeboten in den Wettbewerb“. Berlin 2001.

Wöhe, Günter: „Einführung in die allgemeine Betriebswirtschaftslehre“. München 1990.

Woitschützke, Claus P.: „Verkehrsgeographie“. Troisdorf 2002.

World Commission on Environment and Development, WECD (Hrsg.): „Our Common Future". Brundland-Bericht. New York 1987. 
Woll, Artur: „Allgemeine Volkswirtschaftslehre“. München 1990.

ZDF, Zweites Deutsches Fernsehen (Verantw.): „Viel Dreck, schlechte Beschilderung Qualität von Park-and-Ride-Parkplätzen im Test“. Bericht auch im Wirtschaftsmagazin WISO am 27.03.2006. Mainz 2006.

Zeus $\mathrm{GmbH}$ und Hörzentrum Oldenburg GmbH: „Belästigung durch Fluglärm im Umfeld des Frankfurter Flughafens". Kurzfassung des Endberichts. Gutachten im Auftrag der IFOK GmbH-Institut für Organisationskommunikation im Rahmen des Regionalen Dialogforums. Bochum und Oldenburg 2006.

Zühlke, Karl-Heinz: „Nahverkehr in NRW - Vorreiter in Sachen Innovation“: In: Internationales Verkehrswesen 6/2005. Hamburg 2005. S. 276-278. 


\section{Sachregister}

A

Antriebstechnik 27, 149f

Attraktivität (des ÖPNV) 39, 47f, 52, 108, 133, 135, 140, 151, 171f, 180, 188f, 216, 226, 236, 266, 284, 300, 302, 305f, 336f, 347, 356, 361, 388, 400, $402,413,416,438$

Aufgabenträger 136, 139f, 154, 175, 183 , $188,192,199 \mathrm{ff}, 217 \mathrm{ff}, 228,237 \mathrm{ff}$, 265ff, 277, 286ff, 307ff, 315, 323ff, 337ff, 364ff, 395, 417, 427

Ausbildungsverkehr 100, 244

Ausreichende Verkehrsbedienung 190, $195 \mathrm{ff}$

Ausschreibung 187, 198ff, 265, 302, 306, $315,328 f, 368,427$

\section{B}

Bahnstrukturreform 192

Barrierefreiheit 48, 172, 303, 305, 382, 392

Bedienungshäufigkeit 48, 299ff, 401

Beförderungsgeschwindigkeit $300 \mathrm{f}$

Benutzeroberfläche 5, 6, 17, 143, 272, 318, $351,365,413,432,439,443$

Berufsverkehr 105,129f,171,233

Besteller 184, 209ff, 220, 350, 237, 302, 322, $350,412,439$

Besteller-Ersteller-Prinzip 199f, 220ff, 286, $302,363,371,435,439$

Bevölkerungsentwicklung 56, 181

Bezahlverfahren 339, 350, 382ff, 419ff

Bonus-Malus-System 207, 265, 302, 368, 426

Bruttoanreizvertrag 207, 230, 265, 288f, 368f, 371, 426, 443

C

Chipkarte 164, 341-344, 351, 354f, 378f, $381,386,390 f, 396,406,418,421 f$, 431f, 444

$\mathrm{CO}_{2}$ 119ff, 181, 402
Controlling 262, 273, 279, 292ff, 333, 357, $360,369,373,437,444$

Corporate Governance 260ff

CRM (Customer Relationship Management) 285ff, 403, 422

\section{D}

Deregulierung 134, 191ff, 198, 203, 209, 212ff, 237, 264f, 367, 412

Dienstleistung 16, 40, 65, 71, 77f, 147, 152, $164,186,206,220,244,290,296$, 304f, 315, 320, 324, 338, 375, 381

- Mobilitäts 63ff, 163, 182, 230, 266f, 331, $335,362,367 \mathrm{ff}, 403$

- ÖPNV- 7, 188, 198, 232, 264, 368

Dienstleistungsgesellschaft 19f, 33, 337, 430

Dienstleistungsunternehmen 2, 33ff, 77

Dienstleistungssektor 60, 77, 233, 281

Doppik 294ff

E

E-Business 338

E-Commerce 29f, 337f, 341

Effizienz (allg.) 18, 22, 42, 46f, 148, 152f, 178, 187, 194, 198ff, 209, 212, 215f, 222, 231f, 238, 254ff, 266, 272, 292, $310,327,348,426,435$

- allokative $\sim 239$

- dynamische $\sim 240$

- produktive $\sim 238$

- qualitative $\sim 239$

Effizienzpotenzial 189f, 243ff, 335

Effizienzsteigerung 20, 23, 201, 212ff, 232, 240ff, 282, 297, 329, 336, 347, 356

Emissionshandel 120f

Elektronisches Ticket 377, 414, 335ff, 377, 381, 386ff, 397, 425 
Energieeffizienz 67, 120, 178f

Energieverbrauch 22, 42, 180

Erschließungsqualität 281, 299, 302f

Ersteller 184, 202, 204, 209, 213, 215, 230, 288,412

Europäischer Binnenmarkt 134, 175, 191, 435

EU-Verordnung 222, 333

Externe Kosten 116ff, 126, 129, 133, 158, 159,402

\section{F}

Fahrkartenerwerb 313, 361, 377, 385, 388, 393, 418

Fahrrad 18, 26, 52, 96-101, 105ff, 118, 132, $154,156,166,177 f, 180,245$

Feinstaub 121ff, 135, 144,149,158f

Fixkosten 234, 413

Flächenverbrauch 20, 81, 134

Flexibilisierung 53, 59f, 234, 266, 441

Flughafen Frankfurt 81, 87f, 92ff, 101, 114, $122,127 \mathrm{ff}, 140,152,155,164,299$, 322

Fluglärm 127ff

Flugverkehr 94, 120, 143, 152, 179

Frankfurt am Main, Stadt 53, 61, 70ff, 100, $111 \mathrm{f}, 123,143,145,159,315,328$, 434,439

Freizeitverkehr 12, 17, 106, 115, 171, 176

G

Geldkarte 338f, 385ff, 419

Genehmigungsbehörde 199, 217

Gesamtverkehrssystem 47, 66ff, 142, 153, $163,169,172,185,189 \mathrm{ff}, 231,255$, 264, 269, 362f, 367f, 440ff

Globalisierung 14ff, 21, 23, 25, 33, 175, 439

\section{$\mathbf{H}$}

Hessische Landesregierung 8, 35, 45, 49f, $82,135 f, 142,146 f, 165,200 f, 218$, $223,235,240,354,419,434 f, 440 f f$
Hessen, Land 5, 35f, 49f, 55, 70, 84ff, 96, 102f, 105ff, 111f, 120, 123, 127, 132, 136ff, 139, 143, 153, 164, 167, 170f, 183, 199f, 207, 210, 216ff, 230, 244, 269, 294, 435,

I

Individualisierung 53, 59ff, 266, 319f, 338, 441

Individualverkehr, motorisierter: siehe MIV

Informationsnotwendigkeit 300, 313, 403

Informations- und Vertriebsplattform $376,394,405,412,417 f, 425$

Innovation 2, 10, 22, 27, 42ff, 51, 69, 73, 77, 79, 151, 165, 173, 186ff, 231, 240, 266f, 271, 274, 277, 297, 329f, 337, $373,375,436 f$

Intermodale Kooperation 141, 153, 185, 255,440

Intermodale Mobilität 22, 67, 163, 168, 441

Intermodale (gesamte) Wegekette 66, 99, 173, 237, 269, 284, 314f, 335, 362, $380,411,441$

Intermodaler Wettbewerb 46, 187, 228, $237,288,412$

Internalisierung 117

IuK-Technologien 7, 13, 25ff, 29ff, 133, $163,176,186,189,255,264,272,316$, $329,337,354,438,444$

K

Kano-Modell 280f

Klimawandel 20, 42, 119, 162, 433

Knotenpunkte 32, 85ff, $99 \mathrm{ff}$

Kommunikationskanäle 11, 189, 287f, 314, $333,349,375 f, 404 f, 412,424,429 f$

Kommunikationsnetze 68, 148, 186, 258, $332,359,376,417,438$

Kommunikationspolitik 296ff, 313, 331, 361

Kommunikationsstruktur 231, 258ff

Kostendeckungsgrad 198, 203f, 225, 226, 240f, 266, 298 
Kundenbeziehungsmanagement 277, 284f, 403ff, 422, 437

Kundenerwartung 64, 188, 215, 271, 272, 279ff, 288, 307, 321, 350, 374, 405, 427, 436f, 442

Kundenkommunikation 48, 63, 151, 287, $320 \mathrm{ff}, 405 \mathrm{f}, 425$,

Kundenorientierung 188, 204, 213, 229, 231, 233, 255, 260, 268ff, 280ff, 288, 291, 296, 364f, 369, 396, 436ff

Kundenschnittstelle 7, 188, 202, 231, 277, $351,355,361,394,415$

L

Lärm 18, 46, 98, 118, $126 f$

Lokale Nahverkehrsorganisation (LNO) $165,192,219,229,240,248,269,276$, 295, 317, 354f, 361, 412, 429

Luftverschmutzung 46, 118ff, 123, 180

M

Marketingausgaben 297

Marketinggesellschaft 367ff, 371f, 437, 443

Marketinginstrument 228, 230, 255, 285, 295, 298, 331f, 335, 359, 364f, 367f, $403,437 \mathrm{ff}, 443 \mathrm{f}$

Marketingmix 229, 296, 359, 371, 402, 442

Marketingstrategie 297, 335, 429

Marktausschöpfung 229, 241, 331, 357, $373,424,442$

Marktbearbeitung 216, 258, 285, 333, 365, $368,438,442 \mathrm{f}$

Markterschließung 241, 359, 373

Maut 29, 37, 47, 135, 157ff

M-Commerce 387

Metropolregion 73ff, 113, 178, 187

Migration 10

Motorisierter Individualverkehr (MIV) 6, 18f, 22f, 38, 41, 48, 50, 52, 55, 66, 89, 94, 96, 99, 101, 103, 106f, 110, 113, 115ff, 126, 133, 137, 140, 143-149, 159, 163, 166ff, 176, 178, 180f, 185, 187ff, 196, 227, 236ff, 288, 298, 301,
332, 365, 403 414, 433ff, $440 \mathrm{ff}$

Mobilfunk 13, 28f, 144, 149, 151, 317, 326, $330,332,338,344 \mathrm{ff}, 356,379,384$, 387-394, 410f, 415ff, 424, 438

Mobilitätsbedürfnis 9, 18, 22, 51, 54, 109, $153,156,167$

Mobilitätsdienstleister 53, 63, 68, 189, 228ff, 237, 255, 269, 282f, 287, 291, 295, 296, 333, 335, 363f, 367, 369, $373,376,380 f, 403,413,427,436$, $441 \mathrm{ff}$

Mobilitätskosten 39, 110f, 160

Mobilitätsmanagement 157, 162ff, 167ff, 176,187

Mobilitätsnachfrage $17,54,66,102,156$, $168,172,181,312,440$

Mobilitätsoffensive 44

Mobilitätssicherung 8f, 19, 23, 35, 41, 44, $46,146,172,175,178,181 \mathrm{f}, 188,203$, 223, 240, 263f, 301, 433f, 439f, 442

Mobilitätsverbund 7, 187, 229ff, 269, 276, 337, 363f, 366f, 369f, 413, 439, 442ff

Mobilitätsverhalten 33, 54f, 60, 62, 63, $135,166,174,279$

Modal Split 50, 96, 102ff, 106, 170f, 182, $220,227,236,433$

Motorisierung 5, 10, 12, 41, 89, 115, 137, 227, 298

\section{$\mathbf{N}$}

Nachhaltigkeit 3, 8f, 17f, 20-23, 26, 30ff, 38 , 41f, 44-53, 64ff, 68, 80, 82, 98, 117f, 135, 138, 146f, 165, 172-182, 185, 187ff, 193f, 196, 203, 231, 237, 241, 256f, 259, 263f, 269, 301, 329, $360,367,370,432-435$, 439ff

Nahverkehrsplan 192, 197, 201, 214, 306

Nutzerfinanzierung 227, 241, 259, 266, $295,310,357,360 f, 400,436,442$

O

Öffentlicher Personennahverkehr (ÖPNV) 4-8, 12, 17, 22, 26, 30, 38-41, 47f, 52-55, 58f, 62-67, 92ff, 98-108, 109f, 114-117, 126, 133-136, 140f, 
143, 145, 148-151, 156f, 160f, 164, 168-174, 176f, 180-203, 210-217, 220 252, 255-262, 263-269, 273f, 276f, 280-290, 292, 295-304, 307f, 311-314, 316-323, 330, 332-337, 340ff, 347ff, 354-357, 359f, 362-368, 370, 373f, 376, 378, 381-384, 386-390, 391, 394, 398ff, 402-407, 409-413, 417f, 420, $427,429,432-445$

Ökologie 3, 19f, 22, 42, 48, 51, 64f, 119, 137f, 141, 157, 158, 173, 175, 182, 184, 187, 191, 231, 235f, 257, 279, $293,332,439 f$

\section{$\mathbf{P}$}

Park-and-Ride 99f, 148, 157, 161, 164, 380

Pendler 10, 71, 80, 94, 103f, 111-115, 134, $160,275,380$

Pkw-Verfügbarkeit 90f, 101, 107, 109, 115, 247

Pluralisierung 54, 61f, 441

Produkt (Mobilitäts ) 51f, 164, 188f, 224, 231, 236, 243, 271-276, 281f, 284f, 287f, 295-299, 309, 314, 318f, 328, $331,333,352,361,364 f, 373,375$, 378- 382, 395, 401, 403ff, 407f, 413f, $415,419 f, 428,431,437$

Produktionsfaktor 3, 15f, 25

\section{Q}

Qualitätsmanagement 265, 278, 288, 371

Querverbund 205, 208, 212, 220f, 244, 273

\section{$\mathbf{R}$}

Region Frankfurt Rhein-Main 7ff, 56, 58, 70, 73f, 76f, 79-84, 87ff, 91, 93, 95ff, 100f, 103, 105, 110, 113, 115, 119, $127,130,134,136,141,153,158,165$ 168f, 172, 176, 183, 186, 216ff, 231, $237,240,253,277,305,310,359-362$, $365,429,434,439 f f, 443,445$

Regionalentwicklung 13, 16f, 19-23, 32, $38,81,118,156,187,189,432,439$

Regionalisierung 6, 190, 192, 195, 198f, $217,222,443$

\section{S}

Schienenpersonennahverkehr (SPNV) 92, 192, 199, 201, 204, 208, 214, 220, 222, $225,227,235,237,248,254,300,304$, $306,336,372,378,440$

Siedlungsentwicklung 71, 73, 85, 135, 141, 176,182

Siedlungsstruktur 14, 32, 79, 87, 104, 134, $141,298,300,302$

Standard 5, 7, 17, 42, 135, 148f, 179, 182ff, 201, 220, 232, 235, 237, 252, 257, 265, $282,290,299,306,340 \mathrm{ff}, 347,349$ $352,354,364,366,371,387,430,438$

Standortfaktor 9, 11, 23-27, 35f, 38ff, 81f, $95,116,138,432 \mathrm{f}, 439 \mathrm{f}$

Stau 129-132, 138, 145, 147, 165, 237, 301

Staufreies Hessen 2015 (Initiative) 147f, $154,362,434 f, 440$

Straßenverkehr 17, 31, 45, 90, 96, 117f, $120,122,127,129,132 \mathrm{ff}, 137 \mathrm{f}, 144 \mathrm{ff}$, $149,180,190,434,440$

T

Tarif 7, 17, 47, 63, 94, 157, 164, 199, 201, 208, 217ff, 222f, 225f, 243f, 254f, 276, 296, 298f, 309-315, 318f, 325f, 328, $331,336,340,343,344,350 f, 352$, $359,372,374,381-385,388,392 f, 395$, 397, 399-402, 405, 408, 410, 418f, 425429,437

Telekommunikation 36, 81, 143, 147, 186, $249,261,284,333,338,344,353,362$, $394,428,429$

Telematik 27-31, 44, 67f, 137, 143, 146f, 150f, 154, 168f, 258, 329-332, 362, 434,440

Tertiärer Sektor 71, 77

Transaktionskosten 121, 313, 382, 420, 423,424

Transportkosten 12f, 15, 17, 20f, 24, 47, 388

Trennwirkung 118, 134 
$\mathbf{U}$

Umwelt 4, 18, 20, 22, 30f, 38, 40f, 43-48, $52,66,68,96,98,102,108,116,134 \mathrm{ff}$, 148, 152f, 155f, 158, 160, 168, 174, 175f, 178, 180ff, 184, 191, 195f, 203, 216, 224, 231, 236f, 256f, 268, 269, $271,290,367 \mathrm{f}, 402$, 433f, 440

Umweltverbund 18, 47, 49, 103, 106, 169, $178,180,263$

Unfälle 31f, 118, 130-133, 145, 147f, 165, 377

Unternehmensstrategie 35, 51, 270, 273, $292,337,348$

V

Vergabe 188, 194, 198-201, 203f, 205ff, $210,215,219,230,250,265,330$, $367 f, 371 f, 426,435,443$

Verkehrsinfrastruktur 16, 24ff, 28, 32-37, 40, 43f, 65, 68, 117, 133, 137f, 156, $158,168,174 \mathrm{ff}, 177,187,234,432 \mathrm{ff}$, $439 \mathrm{f}$

Verkehrsmanagement (allg.) 28, 31, 133, 136f, 141ff, 145, 152ff, 163, 164ff, 177,434

Verkehrsmittelwahl 49, 63, 66, 102, 103, 107f, 117f, 157, 174, 180, 245, 279, $284,308,316,336,433$

Verkehrsplanung 1, 4, 42, 76, 134ff, 141, $155,168,172,179,183,184,214,223$, $239,266,299,367,371,432$

Verkehrspolitik 30, 37, 41-44, 48ff, 97, 135, 158, 162f, 165, 173ff, 181, 185f, 191, 197, 223f, 240, 320, 433, 440f

Verkehrsträger 19, 22, 32, 36, 42ff, 52f, 66, 68, 99, 102, 117, 149f, 151-154, 156, 162, 165f, 168f, 176ff, 182, 185, 188, 190, 228, 255, 301, 303, 324, 331f, 361f, 367, 434f, 440f

Verkehrswachstum 43, 49f, 137, 434

Verkehrswende 49, 114, 433

Vertrieb (allg.) 183, 201f, 211, 216, 221, 241, 248, 252-255, 274-276, 284, 285ff, 295ff, 313, 322-326, 331f, 336f, 349, 355f, 359, 366, 369, 371f, 379, 381, 386, 388f, 392-394, 401, 404f, 412f, 415-419, 423ff, 428, 437, 443

Vertriebskanal /-weg 202, 252, 254, 277, 325f, 347, 357, 378, 387f, 394f, 401, $408,415 f, 418,424 f, 438$

Vertriebskosten /-aufwand 243, 252ff, 408, 416f, 418f, 420, 424f

W

Wasserstraßen /-wege 14, 32, 37, 86, 95, $102,118,121$

Wettbewerb

$\sim$ von Regionen 16, 73, 77, 81-84, 433f,

$\sim$ von Standorten in der Region 72, 83, 439

von Unternehmen (allg.) 16, 34ff, 51, 95, 186

von Verkehrsunternehmen 188, 191, 193f, 197f, 200-216, 219, 222f, 227, 228f, 233ff, 240, 250, 263-266, 273ff, 288, 291-294, 307, 318, 330, 333, 368f, $427,435,442,444$

Wirtschaftsbereich 16, 23, 88, 233

Wirtschaftsverkehr 23, 106, 170f

Wirtschaftswachstum 1f, 19, 44, 50, 433

$\mathbf{Z}$

Zugangsbarriere (zum ÖPNV) 8, 173, 188, $247,310,366,384$ 
Lebenslauf

Name: $\quad$ Christian Ordon

Geboren: $\quad$ 16.10.1965 in Großburgwedel, Landkreis Hannover

Familienstand: $\quad$ verheiratet, 2 Kinder

Nationalität deutsch

Schulbildung

1972-1976

Besuch der Städtischen Grundschule in Mettmann

1976-1986

Besuch des Konrad-Heresbach-Gymnasiums in Mettmann

13.06.1986

Erwerb der Allgemeinen Hochschulreife

\section{Studium}

1986-1992

Magisterstudium an der Philosophischen Fakultät der Rheinisch-Westfälisch Technischen Hochschule Aachen

Hauptfach: Geographie

Nebenfach: Wirtschaftsgeographie

Nebenfach: Internationale Technische und Wirtschaftliche Zusammenarbeit

17.02.1992

Abschluss der Magisterprüfung mit der Gesamtnote „sehr gut“

2006-2007

Promotionsstudiengang an der Georg-August-Universität zu Göttingen im Fachbereich Geographie 

